
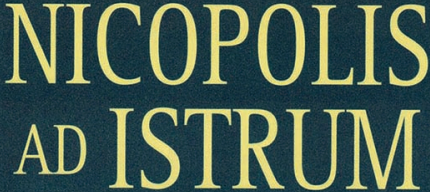

A ROMAN TO EARLY BYZANTINE CITY The Pottery and Glass

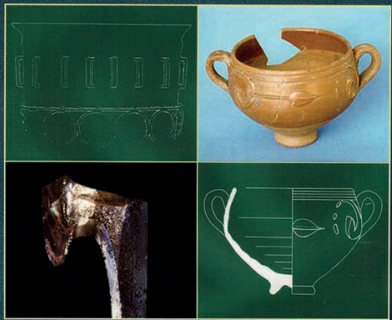

A. G. Poulter 
REPORTS OF THE RESEARCH COMMITTEE OF THE

SOCIETY OF ANTIQUARIES OF LONDON, NO. 57

\section{Nicopolis ad Istrum}





\title{
Nicopolis ad Istrum: A Roman to Early Byzantine City The Pottery and Glass
}

\author{
A.G. Poulter
}

With R.K. Falkner on the pottery and J.D. Shepherd on the glass

LEICESTER UNIVERSITY PRESS

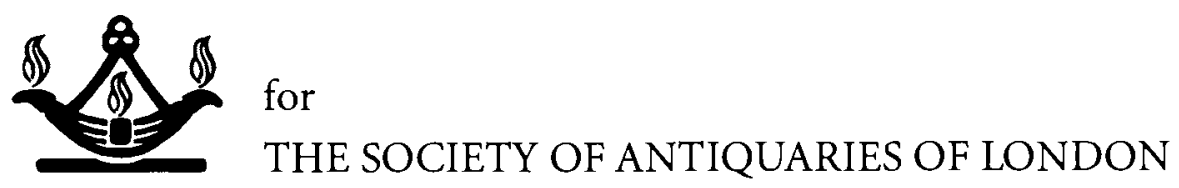


Leicester University Press

A Cassell Imprint

Wellington House, 125 Strand, London WC2R OBB

370 Lexington Avenue, New York, NY 10017-6550

The Society of Antiquaries of London

Burlington House

Piccadilly

London WIV OHS

First published 1999

(c) The Society of Antiquaries of London 1999

The right of A.G. Poulter, R.K. Faulkner and J.D. Shepherd to be identified as authors of this work has been asserted by them in accordance with the Copyright, Designs and Patents Act 1988.

Apart from any fair dealing for the purposes of research or private study or criticism or review, as permitted under the Copyright, Designs and Patents Act 1988, this publication may not be reproduced, stored or transmitted, in any form or by any means or process, without the prior permission in writing of the copyright holders or their agents. Except for reproduction in accordance with the terms of licences issued by the Copyright Licensing Agency, photocopying of whole or part of this publication without the prior written permission of the copyright holders or their agents in single or multiple copies whether for gain or not is illegal and expressly forbidden. Please direct all enquiries concerning copyright to Leicester University Press at the address in London above.

British Library Cataloguing-in-Publication Data

A catalogue record for this book is available from the British Library.

ISBN 0718501683

Library of Congress Cataloging-in-Publication Data

Poulter, A.G.

Nicopolis ad Istrum: the finds/A.G. Poulter; with R.K. Falkner

on the pottery and J.D. Shepherd on the glass.

v. $<1>\mathrm{cm}$.- (Reports of the Research Committee of the Society

of Antiquaries of London: no. 57-)

Includes bibliographical references and index.

ISBN 0-7185-0168-3

1. Nicopolis ad Istrum (Extinct city) 2. Excavations

(Archeology)-Bulgaria-Nicopolis ad Istrum (Extinct city)

I. Falkner, R.K. (Robin Kenneth) II. Shepherd, J.D. (John David)

III. Title. IV Series.

DR98.N48P68. 1998

939'.8-dc21 97-47439 CIP

Typeset by Ben Cracknell Studios

Printed and bound in Great Britain by Bookcraft (Bath) Ltd. 


\section{CONTENTS}

Plates vi vi

Figures vii

Tables $\quad$ ix

Acknowledgements $\quad$ x

Abbreviations $\quad$ xii

Section One The Excavations and the Social

And ECONOMic Context by A. G. Poulter 1

1 The aims of the programme and the excavations 3

2 The results of the excavations and the history of the site 14

3 The economic and social implications of the pottery and glass 28

Section Two The Pottery by R. K. Falkner $\quad 55$

4 The ceramic analysis: methodology 57

$5 \quad$ Wares and their associated types $\quad 63$

6 The problem of residuality and typical assemblages by period 94

7 Pottery production and influences 108

8 Conclusions and future research on ceramics 113

9 The pottery catalogue $\quad 119$

$\begin{array}{ll}\text { Appendix } 1 \text { The wares } & 274\end{array}$

Appendix 2 Relative frequency of types by dated phase $\quad 281$

Appendix 3 Relative frequency of wares

(total body sherds) by dated phase 295

Section Three The Glass by J.D. Shepherd 297

10 The glass: methodology and site assemblages 299

11 The glass catalogue $\quad 312$

12 The glass catalogue: discussion 356

Bibliography $\quad 379$

Index $\quad 387$ 


\section{PLATES}

I Local red-slipped fine ware cup with appliqué decoration, cat. no. 764, SF. 5303

II Local red-slipped fine ware crater with appliqué decoration, cat. no. 710

III Fragments of diatretum (cat. nos 41-63); 1, SF. 14145a, 14145b, 14167; 2, SF. 14639; 3 and 4, SF. 14145a; 5 and 6, SF. 14167.

IV Fragments of diatretum (cat. nos 41-63); 1, SF. 14622; 2, SF. 14145b; 3 and 4, SF. 14630. Fragments of diatretum (cat. no. 64); 5, SF. 13034 and 13036. Fragment from the side of a glass bowl, 6, cat. no. 310 .
$\mathrm{V}$ Aerial view of the central southern part of the Roman/late Roman city and the north- western corner of the early Byzantine defences (bottom), taken with a radio-controlled kite, 1986

VI Reconstruction painting of the early Byzantine city, c. 500

VII The complete Slav pots from the grubenhaus in area $\mathrm{F}$

VIII Maker's mark on the base of a Slav pot, cat. no. 1123, SF. 8041 


\section{FIGURES}

1.1 Plan of the Roman city

1.2 Location plan of the Roman and early Byzantine sites

1.3 Map of the lower Danube in the late Roman period

1.4 Site plan

2.1 Reconstruction drawing of the site, c. 150

2.2 Reconstruction drawing of the site, c. 200

2.3 Reconstruction drawing of the site, c. 350

3.1 The city and its territory

6.1 Pottery in use c. 100-130

6.2 Pottery in use c. 130-250

6.3 Pottery in use $c .130-250$

6.4 Pottery in use c. $250-350$

6.5 Pottery in use c. $350-450$

6.6 Pottery in use c. $350-450$

6.7 Pottery from the period of the early Byzantine city (c. 450-600)

7.1 Stamped local red-slipped ware sherds

8.1 Graph showing the percentage by which ware 8 exceeds ware 1 in given periods (by sherd count)

8.2 Graph showing amphorae as a percentage of total amphorae in given periods (by sherd count)

8.3 Graph showing numbers of different amphorae types present in any given period (by sherd count)

8.4 Graph showing the relative frequency of certain amphorae wares as a percentage of all amphorae in that period (by sherd count)

9.1 Coarse wares: ware $25(1-10)$ and 30/31 (11-14)

9.2 Coarse wares: ware 30/31

9.3 Grey coarse wares: ware 1

9.4 Grey coarse wares: ware 1

9.5 Grey coarse wares: ware 1
9.6 Grey coarse wares: ware 1

9.7 Grey coarse wares: ware 1

9.8 Grey coarse wares: ware 1

9.9 Grey coarse wares: ware 1

9.10 Grey coarse wares: ware 1

9.11 Grey coarse wares: ware 1

9.12 Grey coarse wares: ware 1

9.13 Grey coarse wares: ware 1

9.14 Grey coarse wares: ware 1

9.15 Buff coarse wares: ware 24 .

9.16 Grey micaceous coarse wares: ware 14

9.17 Grey micaceous coarse wares: ware 14

9.18 Red-slipped fine wares: ware 8

9.19 Red-slipped fine wares: ware 8

9.20 Red-slipped fine wares: ware 8

$9.21 \mathrm{Red}$-slipped fine wares: ware 8

9.22 Red-slipped fine wares: ware 8

9.23 Red-slipped fine wares: ware 8

9.24 Red-slipped fine wares: ware 8

9.25 Red-slipped fine wares: ware 8

9.26 Red-slipped fine wares: ware 8

9.27 Red-slipped fine wares: ware 8

9.28 Red-slipped fine wares: ware 8

9.29 Red-slipped fine wares: ware 8

$9.30 \mathrm{Red}$-slipped fine wares: ware 8

9.31 Red-slipped fine wares: ware 8

9.32 Red-slipped fine wares: ware 8

9.33 Red-slipped fine wares: ware 8

9.34 Red-slipped fine wares: ware 8

9.35 Red-slipped fine wares: ware 8

9.36 Red-slipped fine wares: ware 8

9.37 Red-slipped fine wares: ware 8

9.38 Red-slipped fine wares: ware 8

9.39 Red-slipped fine wares: ware 8

9.40 Red-slipped fine wares: ware 8

9.41 Red-slipped fine wares: ware 8

9.42 Red-slipped fine wares: ware 8

9.43 Red-slipped fine wares: ware 8 
9.44 Red-slipped fine wares: ware 8

9.45 Red-slipped fine wares: ware 8

9.46 Fine wares: ware 4, white-slipped censers

9.47 Fine wares: ware 4

9.48 Black-slipped fine wares: ware 78

9.49 Industrial wares: ware 44 and a mortarium

9.50 Miscellaneous wares

9.51 Imported fine wares

9.52 Eastern Mediterranean amphorae

9.53 Eastern Mediterranean, African and miscellaneous amphorae

9.54 Miscellaneous amphorae

9.55 Slav pottery: ware 43

9.56 Slav pottery: ware 43

9.57 Post-medieval pottery

9.58 Post-medieval pottery

9.59 Post-medieval pottery

9.60 Post-medieval pottery

9.61 Post-medieval pottery

11.1 Decorated colourless, ground, polished and wheel-cut vessels, late first to fourth century

11.2 Decorated colourless, ground, polished and wheel-cut vessels, late first to fourth century

11.3 Decorated colourless and blue (no. 64), ground and polished wheel-cut vessels, late first to fourth century

11.4 Jugs, flagons, bottles and phials, first to fourth century

11.5 Jugs, flagons, bottles and phials, first to fourth century
11.6 Beakers, bowls and jars, first to fourth century

11.7 Beakers, bowls and jars, first to fourth century

11.8 Beakers and bowls, first to fourth century

11.9 Beakers and bowls, first to fourth century

11.10 Beakers and bowls, first to fourth century

11.11 Bowls, beakers and jars (bases), first to fourth century, funnels and mould-blown beakers and bowls

11.12 Stemmed goblets and lamps, fourth to sixth century

11.13 Wheel-cut decorated vessels, flanged jar (313), beakers and bowls, fourth to sixth century

11.14 Beakers or bowls, fourth to sixth century

11.15 Jars and beakers, fourth to sixth century

11.16 Beakers, bowls and jars (bases), fourth to sixth century

11.17 Beakers, bowls and jars (bases), jugs, flasks and bottles, fifth to sixth century

12.1 A. Approximate position of diatretum fragments. B. Tentative reconstruction of the diatretum

12.2 Reconstruction of lamp types a-d (after Olczak 1995) 


\section{TABLES}

5.1 The composition of dated assemblages by ware

8.1 Table showing both the more common amphorae, and the rarer types where their origin was identified
10.1 The total number of glass fragments expressed as percentages of the assemblage 10.2 Identifiable, indeterminate and window glass fragments expressed as percentages of the area total and overall site total 


\section{ACKNOWLEDGEMENTS}

Without the help and encouragement of many individuals and organizations, the excavations at Nicopolis could never have been undertaken, the post-excavation completed, nor the results published. Mr R. Falkner and Mr J. Shepherd, the contributors to this volume, have been committed to the programme for a decade and have played a central role in the success of the project and not just because of their efforts in researching the pottery and the glass. Both were involved from the first year of excavation in 1985. Mr Falkner returned annually to participate in the field programme, supervising volunteers and masterminding the pottery analysis. He also regularly stayed on in Bulgaria or returned during the winter months to study the ceramic finds. As a Leverhulme Research Fellow (1992-3) he was able to complete the pottery report for publication. His involvement in the excavations will be remembered by all who worked in Bulgaria. Not only did he assist in fieldwork, both excavation and geophysical survey, he also played an important part, as a senior member of the team, in maintaining morale: when it came to organizing barbecues on a grand scale, he had no equal. Mr John Shepherd carried out the recording and analysis of the glass but, as Vice-Director, he was also responsible for encouraging supervisors and personally directing important excavations in areas $\mathrm{B}$ and $\mathrm{P}$. His tact and enthusiasm endeared him to all members of the team and his skill as a field archaeologist was recognized by all who had the privilege to work with him.

The late Professor Velizar Velkov, the former Director of the Institute of Archaeology, Sofia and Vice-President of the Bulgarian Academy of Sciences, welcomed the British proposal to excavate at Nicopolis. He actively supported all aspects of the programme. His premature death is an incalculable loss to Bulgarian archaeology and it is regrettable that he did not live to see the results published. I am especially indebted to our Bulgarian colleagues and friends in the Institute of Archaeology, Sofia and the Veliko Turnovo Historical Museum; in particular, Professor Ludmila Slokoska, Dr Petko Georgiev, Dr Krasimira Vacheva, Dr Rumen Ivanov, Ms P. Vladkova and Ivan Tsurov. Their help and concern for the welfare of the British members of the team was indispensable.

I am also grateful to those who read sections of the text and provided valuable comments which have improved the content and presentation, including Professor 
J.H.W.G. Liebeschuetz, Ruth S. Leary and Graham C. Guilbert. However, I remain wholly to blame for any errors the reader may detect. David Taylor, the draughtsman in the Department of Archaeology (University of Nottingham), carried out the herculean task of remounting the illustrations and preparing new drawings with his usual calm efficiency which never ceases to astonish me.

The funding of the ceramic programme and the analysis would not have been possible without the support of the Leverhulme Trust. Contributions from the following academic bodies and trusts were essential to the funding of the excavations and the completion of the research: the British Academy, the Foreign and Commonwealth Office, the Trustees of the British Museum, the University of Nottingham, the Craven Fund (University of Oxford), the Robert Kiln Trust and the Society for the Promotion of Roman Studies. In addition to private donations in support of the excavations, a crucial role was played by commercial and industrial sponsors who contributed to the costs, some of whom also provided equipment: APV, British Gas Exploration, Cadbury Schweppes, Courtaulds, EMI, Enterprise Oil, ICI, ICL, Rank Xerox, Rothschild and Sons, Shell and Wimpey.

Above all, I am grateful to the Society of Antiquaries of London for supporting this publication and I would especially like to record my thanks to Kenneth Painter and Janet Clayton for their unswerving support and encouragement.

A.G. Poulter

Nottingham

2 December 1996

I would like to express my gratitude to all of our Bulgarian colleagues, especially those whose comments and ideas on the pottery were of great value, in particular Gergana Kabakchieva, Professor L. Slokoska, Vesselina Nacheva, Pavlina Vladkova, Sonia Soultova and Zlatka Genova. I would also like to thank Dr P. Georgiev and Ivan Tsurov for all their help. For the duration of the excavations, I was fortunate to have working with me several assistants who are deserving of special thanks: Sarah Buckingham, Karen Griffiths, Pamela Guest, Noelle Kite, Adrian Powell, Scott Martin and David Best. Most of the original drawings are by Isabelle Rubens and myself, with additional material supplied by Derek Kennet and Bob Alvey. The drawings of the local trays and Samian wares are by Nigel Harriss, and I am indebted to Professor A. Milcheva and John Shepherd for comments on the Samian wares.

The research and final analysis for this report were funded by the Leverhulme Trust and the University of Nottingham, to whom I am most grateful. I would also like to thank Andrew Poulter and Professor M. Fulford for comments on the manuscript.

Over the seven seasons we had considerable help from many students, mainly from eastern Europe, who are too numerous to mention; their help was invaluable and their sense of humour and fun contributed greatly to the success of the project.

R.K. Falkner 


\section{ABBREVIATIONS}

Ancient Bulgaria Ancient Bulgaria: Papers presented to the International

Symposium on the Ancient History and Archaeology of Bulgaria, ed. A.G.

Poulter, University of Nottingham, 1983, vols 1-2

Dacia Dacia, Revue d'Archéologie et d'Histoire ancienne, Bucharest NP

Drag. Dragendorff, 1895

IAI Izvestiya na Arheologicheskiya Institut, Sofia

Iatrus I Iatrus-Krivina: Spätantike Befestigung und Frühmittelalterliche Siedlung

an der unteren Donau, vol. 1: Ergebnisse der Ausgrabungen 1966-1973, V.

Dimova et al., Berlin, 1979

Iatrus II Iatrus-Krivina: Spätantike Befestigung und Frühmittelalterliche Siedlung an der unteren Donau, vol. 2: Ergebnisse der Ausgrabungen 1966-1973, B.

Böttger et al., Berlin, 1979

Iatrus III Iatrus-Krivina: Spätantike Befestigung und Frühmittelalterliche Siedlung an der unteren Donau, vol. 3: Die Mittelalterlichen Siedlungen, ed. M. Wendel et al., Berlin, 1986

Iatrus IV Iatrus-Krivina: Spätantike Befestigung und Frühmittelalterliche Siedlung an der unteren Donau, vol. 4: Ergebnisse der Ausgrabungen 1975-1981, ed. K. Wachtel et al., Berlin, 1991

IDR Inscriptiile Daciei Romane, Inscriptitle Antice din Dacia și Scythia Minor, ed.

D. M. Pippidi and I.I. Russu, Bucharest

IGBulg. Inscriptiones Graecae in Bulgaria Repertae, vols 1-4, ed. G. Mihailov, Sofia, 1956-71

ILBR Inscriptiones Latinae in Bulgaria repertae, ed. B. Gerov, Sofia, 1989

ILS Inscriptiones latinae selectae, ed. H. Dessau, vols 1-5, Berlin, 1892-1914

O\&P Oswald and Pryce, 1920

P\&W Peacock and Williams, 1986

RCRFA Rei Cretariae Romanae Fautorum Acta

Tsarevgrad-TurnovI Tsarevgrad-Turnov: Dvoretsut na Bulgarskite Tsare prez vtorata Bulgarska Durzhava, vol. 1: Istoriya na Prooouchvaniyata, Arhitektoura, Nadpisi, Moneti, koultourni Plastove predi Izgrazhdaneto na Dvoretsa, ed. Kr.

Miyatev et al., Sofia, 1973 
Tsarevgrad-Turnov II Tsarevgrad-Turnov. Dvoretsut na Bulgarskite Tsare prez vtorata Bulgarska Durzhava, vol. 2: Keramika, bitovi Predmeti i Vuoruzhenie, Nakiti i Tukani, ed. Kr. Miyatev et al., Sofia, 1974

Tsarevgrad-Turnov III Tsarevgrad-Turnov: Patriarsheskiyat Kompleks na Tsarevets prez XII-XIV Vek, vol. 3, N. Angelov, Sofia, 1980

Tsarevgrad-Turnov IV Tsarevgrad-Turnov: Srednovekivni nadpisi, monogrami, boukvi i znatsi ot Turnovskata 'Velika Lavra', vol. 4, A. Popov, Sofia, 1984

Tsarevgrad-Turnov V Tsarevgrad-Turnov. Arheologicheski razkopki i proouchvaniya na krepostnite steni na hulma Tsaravets 1966-1979 g., vol. 5, V. Vulov, Sofia, 1992 



\title{
SECTION ONE
}

\section{The excavations and the social and economic context}

\author{
A.G. Poulter
}





\section{The aims of the programme and the excavations}

There exist very few ancient cities in the Roman Empire, especially in the European provinces, as well preserved as Nicopolis ad Istrum (fig. 1.1). Still more remarkable was the potential of the site for exploring the character of a city in Late Antiquity. Three hundred and fifty years after its foundation, Nicopolis was destroyed and abandoned about the middle of the fifth century and the early Byzantine city was constructed on a new site, immediately to the south (fig. 1.2). The city of the late fifth and sixth centuries must have been replanned, free from the constraints imposed by the original urban structure, and could be expected to conform, in its buildings and layout, to the requirements considered appropriate to a city of the early Byzantine period. The situation at Nicopolis was therefore quite unlike that which exists on the majority of ancient sites which survived into the sixth century where, even when unaffected by medieval and modern development, they comprise a palimpsest of structures, dating to different periods. Consequently, it is difficult to extract useful information about the overall development and character of these sites in any particular phase of their history.

The primary aim of the research programme was to discover whether the early Byzantine city followed the traditional form established for Roman urban planning, exemplified in the layout of Roman and late Roman Nicopolis, or whether there were significant differences which reflected changes in social organization, population and perhaps function. In order to be successful, such a programme required not only a reliably dated sequence of occupation, but also the application of the full range of modern scientific techniques, particularly a full environmental programme and the analysis of pottery and other finds which could place the city within its economic and palaeoenvironmental context. This basic requirement also presented a challenge since only a handful of sites has been systematically examined on the lower Danube with these objectives in mind.' From the outset, it was resolved that the construction of a site-based chronological sequence was essential. Only when all sources of dating from the site had been used to date the glass, pottery and other finds was the evidence compared with the results from those few sites in the region which had provided similar quantities of data. The final publication was to provide a firm basis for dating occupation at Nicopolis and other sites in the region, 


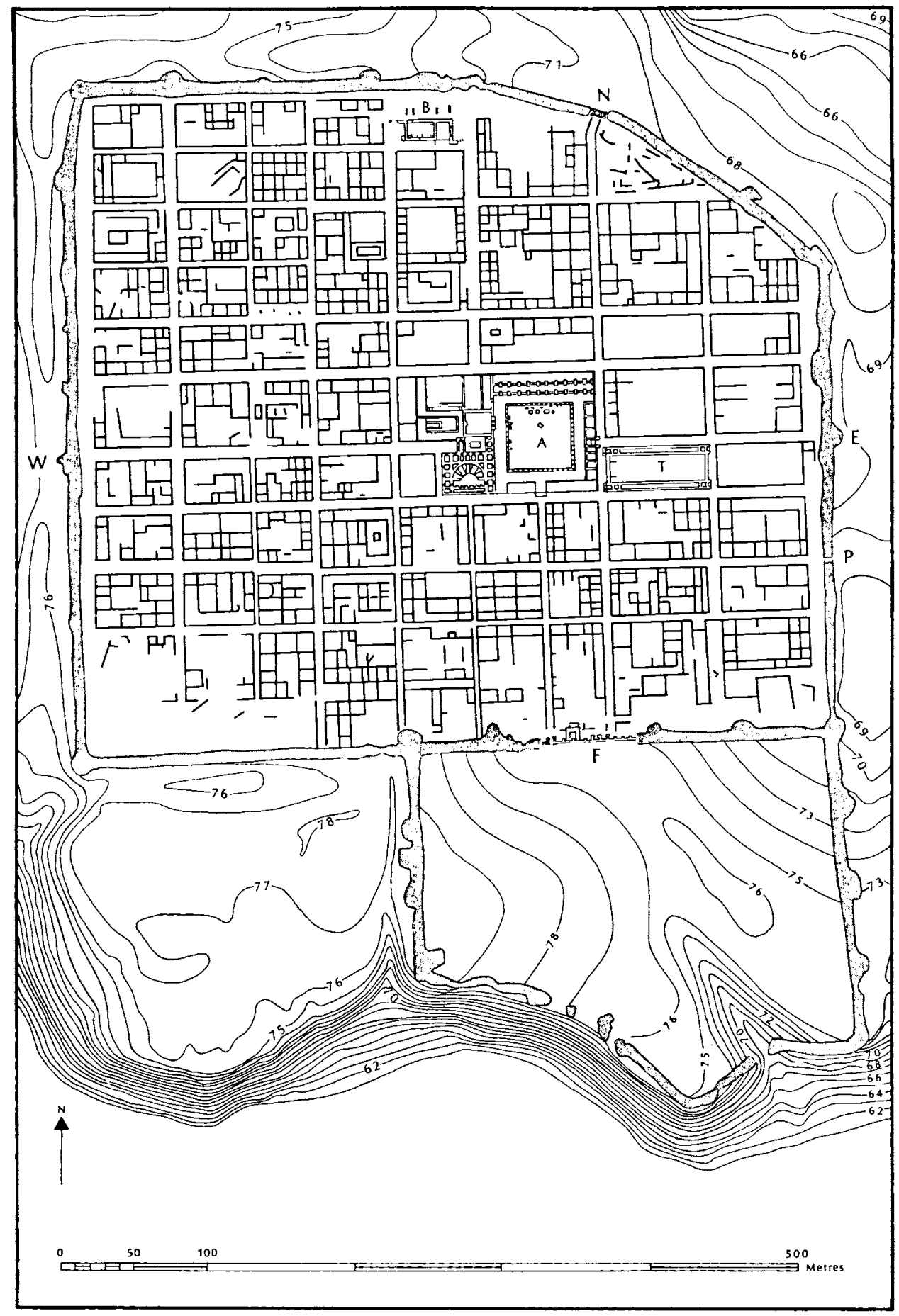

1.1 Plan of the Roman city 


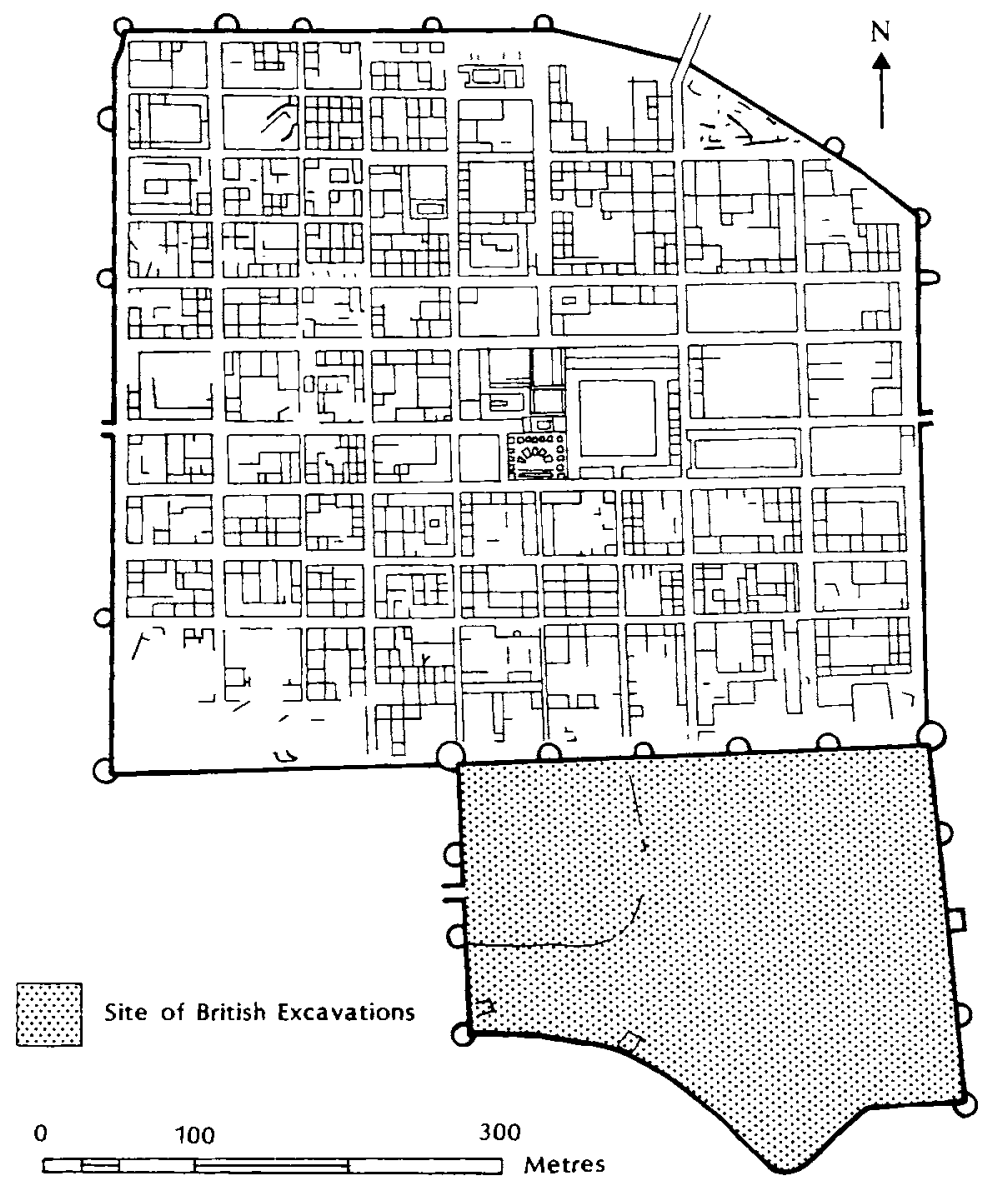

\subsection{Location plan of the Roman and early Byzantine sites}

as well as a type site sequence for the Balkans, relevant to wider studies on trade and economic development in the Roman and early Byzantine empires. Moreover, although excavations were confined to the early Byzantine city, substantial discoveries of Roman, late Roman, medieval and post-medieval date were made and this allowed the ceramic and finds programmes to be extended to include the history of the site from the early second century $\mathrm{AD}$ down to and including the post-medieval period.

Undertaking a pioneering archaeological study abroad inevitably imposes restrictions upon the extent to which all aspects of research can be carried out, partly because of the usual constraints of time and finance applicable to any excavation, but also because of the local conditions prevailing in the region of study. In particular, without comparable publications of pottery and glass from other ancient cities (especially from reliably dated contexts), the opportunities for drawing general conclusions about the region remain limited. It is not yet possible to determine, even 
in general terms, whether the fate of Nicopolis and the changes identified between the Roman and early Byzantine periods were typical or exceptional for urban centres on the lower Danube. This inevitably limits the scope for assessing fundamental issues such as regional trade. Where possible, tentative conclusions will be made but, for the most part, such secondary research, important as it is, will have to await the publication of other well-dated corpora. Also, the breadth of the programme was limited by the need to complete the primary objectives. In the case of the pottery and the glass, the principal need was to produce a clearly dated sequence, of fundamental importance in its own right and to serve as a basis for future studies. The finds and their database could be used for further work, for example, on typology and the intra-site distribution of different vessels but to have included this within the research design would have substantially delayed publication and was judged impractical.

The excavations provided a remarkable amount of information about the ancient city of Nicopolis, results which, it will be argued, require a reappraisal of our understanding of urbanism and particularly the changes which occurred in Late Antiquity. ${ }^{2}$ However, as with all excavations, the conclusions remain dependent upon the interpretation of what is inevitably a slender body of evidence derived from the excavation of only a fraction of the site and may well be modified or revised in the light of future excavations. Nevertheless, the finds constitute a unique body of material. Given that circumstances in eastern Europe are now very different from those which existed when the programme commenced in 1985 , it is likely that the results of the specialist programmes, including the pottery and glass reports, will remain of primary importance both for regional and empire-wide studies, until well into the twenty-first century. ${ }^{3}$

\title{
Dating the site and its finds
}

Within this report, the period descriptions refer to specific phases in the history of the site:

\author{
Roman c. 110-c. 296 \\ Late Roman c. 296-c. 450 \\ Early Byzantine c. 450-c. 600 \\ Slav c. 800-c. 1000 \\ Post-medieval c. 1750-c. 1850
}

Because there existed no firm chronology for pottery on the lower Danube, it was determined, as noted above, to create a site-based chronology. The director was responsible for establishing the sequence of occupation for each excavation area and for producing the matrices. Once the relative sequence was established, absolute 
dates for periods of occupation were determined using coins and datable smallfinds, supplemented, especially for the Roman period, by deductions based on external criteria, which could be used, with reasonable probability, to date changes in the development of the city (e.g. the foundation of the city, the paving of the roads, the construction of the defences). When the evidence for well dated imported pottery was compared with the chronology for the site, it was evident that the dating was essentially correct. ${ }^{4}$ Also, the finds and presumptions about the development of the site used to date the pottery from one area proved not at variance with the results from other areas where the pottery was used to date periods of occupation. Even so, the dangers apparent in using such an approach are self-evident. In the description of the excavations, it is explicitly stated where the pottery was dated by the sequence and where the sequence of occupation was dated by the pottery.

Within this site chronology, it was also possible to distinguish sub-phases, characterized by well-stratified assemblages which were used to refine the chronology still further. This was particularly successful for the second to mid third century. ${ }^{5} \mathrm{~A}$ somewhat wider date range was only possible for the period c. 300 to 450 , largely because of the lack of imported wares and the problems inherent in using coin loss to provide a chronological framework. ${ }^{6}$ The end of the Roman city, its destruction and abandonment, can be dated to $c .450$. For the early Byzantine period, two phases of occupation were identified in three areas. Although it is likely that the two phases in these areas were contemporaneous, there were too few closely dated finds to determine when the first phase ended and the second began. Therefore, in terms of dating the pottery, it was necessary to maintain the outer limits of occupation and assign all the pottery to the one general period, i.e. c. 450 to 600 . There was no way of dating the limited evidence for Slav occupation, other than by reference to other sites in the region. The coins and finds from the post-medieval settlement all belonged to the period $c .1750-1850$ and the pottery was accordingly assigned to this general period.

\section{The site archive and specialist analysis archives}

Three copies of all site drawings and records were prepared. One is stored in the Veliko Turnovo Museum, the second in the Institute of Archaeology, Sofia and a third in the Department of Archaeology, the University of Nottingham. A full computer archive of site data (context and small-find records) and copies of all specialist databases are held in the University of Nottingham. The full glass report, with the records of all finds arranged by area and the pottery data, currently in Lotus 123, form part of the archive. Requests for copies (on disk or as hard copy) should be addressed to the Museum Director, Department of Archaeology, University of Nottingham, Nottingham NG7 2RD. 


\section{The two 'cities' of Nicopolis}

Nicopolis ad Istrum (Stari Nikiup) is in north, central Bulgaria, on the northern bank of the river Rositsa, a left bank tributary of the Yantra (ancient Iatrus) which flows north to join the Danube, as the crow flies, a distance of $30 \mathrm{~km}$ from the ancient city (fig. 1.3). The site lies $3.5 \mathrm{~km}$ south of the modern village of Nikiup and $20 \mathrm{~km}$ north of Veliko Turnovo, the nearest modern town. The identification of the ancient ruins with the city of Nicopolis was made by Felix Kanitz in 1871. Excavation, notably in and around the agora, was carried out sporadically from 1899, and during the early years of this century by G. Seure and T.V. Dobrouski. The first fully documented excavation was carried out by Professor T. Ivanov in 1945 on the site of the Roman baths. From 1966, a regular programme of excavations was conducted under the supervision of Professor T. Ivanov and continued, from 1985, under the direction of Professor L. Slokoska with colleagues from the Institute of Archaeology, Sofia and the Veliko Turnovo Historical Museum. The agora and its public buildings were uncovered. The north and east gates were excavated. The paved roads surrounding the agora and an impressively preserved section of the cardo, which runs from the north gate to the centre of the city, were cleared. A large building, probably the thermoperipatos, mentioned in a building inscription of $184 / 5$, was excavated opposite the south-eastern corner of the agora and a palaestra, probably attached to the south side of the public baths, was examined. Since 1985, work has continued in the agora, exploring its drainage system and a late Roman house in the northwestern quarter of the city. Most impressive have been the excavations conducted by Professor Slokoska who has uncovered the Roman defences, including a Roman internal rectangular tower and a section of curtain-wall, reused in the construction of the early Byzantine circuit.

Only one structure is preserved almost to its original height, the castellum aquae, outside the Roman city's defences and immediately north of the west gate. Elsewhere, although large portions of architectural blocks and the paved roads survive largely intact, both the fortifications and internal buildings were extensively robbed, probably as late as the nineteenth century, since visible robber-trenches still provide a remarkably detailed and consistent outline of the city and its ancient buildings (plate $\mathrm{V}$ ). This was used by the author to produce a plan, based upon vertical aerial photographs of the site taken by the German Luftwaffe during the last war and supplemented by oblique aerial photographs taken from a radio-controlled kite during the British excavations (fig. 1.1). What is also clear from the plan, and on the ground, is that there existed a rectangular annexe of 5.74ha, attached to the southern side of the Roman city's defences and with its own fortifications, defined by the deep robber-trenches which followed the line of its own irregular circuit (plate V). No excavation had taken place within this enclosure and it had been assumed that this 


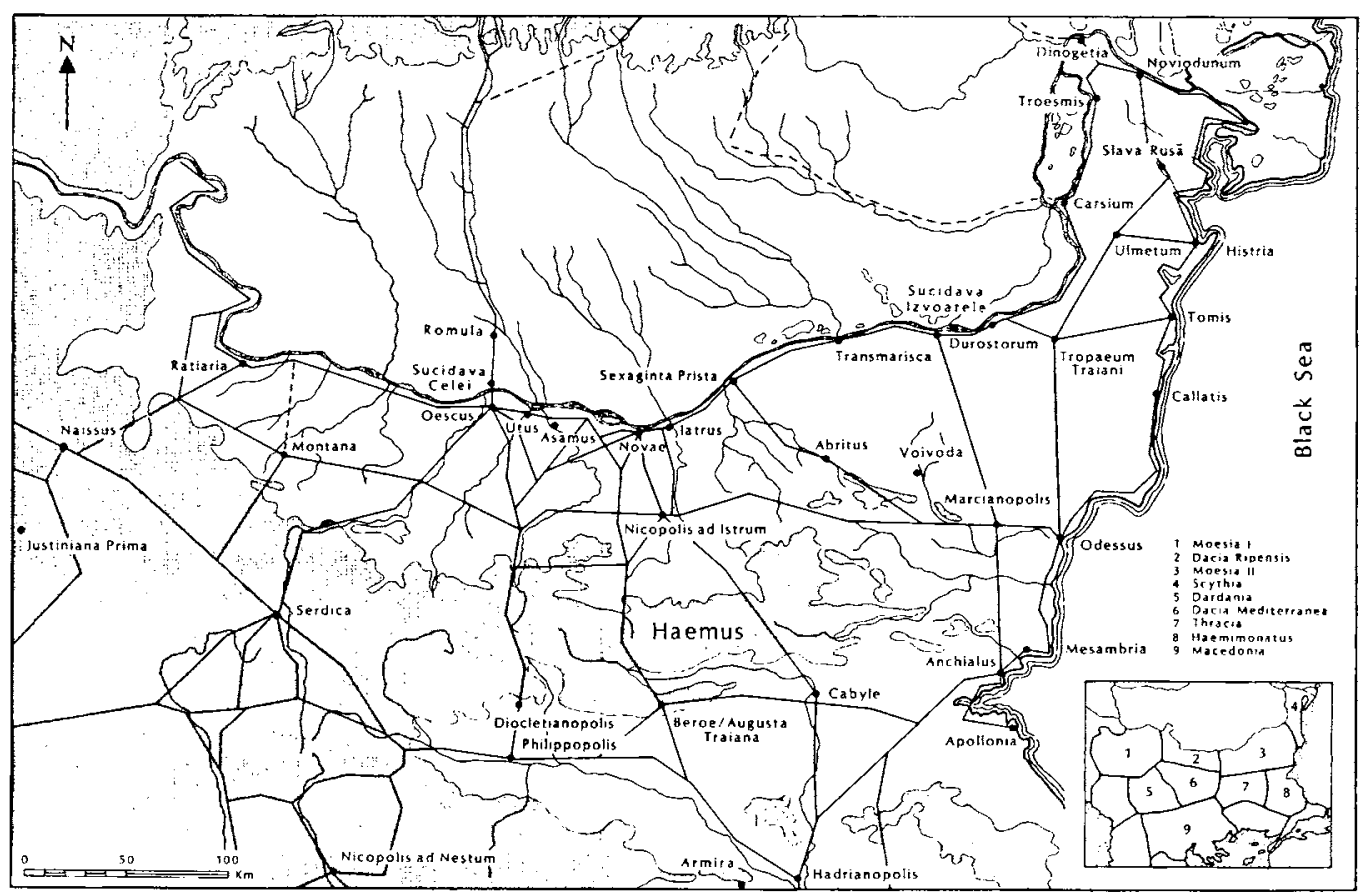

1.3 Map of the lower Danube in the late Roman period

'castellum' was a military annexe, attached to the city in the late Roman period. True, two sections of wall, built of mortared stone and brick courses on the line of the southern defences, suggested a late Roman or early Byzantine date, but, along the northern curtain, which reused the eastern portion of the Roman southern wall, towers appeared to project north into the Roman city. It therefore seemed more likely that this castellum replaced the Roman defences. In which case, the Roman city would seem to have been abandoned in favour of the greater security afforded by the new fortifications, apparent particularly where the southern wall ran along the crest of the precipitous cliff above the flood plain of the Rositsa. Since, unlike the Roman city, there was no sign that robbing had been extensively carried out within this second enclosure, and since it seemed reasonable to suggest that this was the site of Nicopolis during its final period of occupation, it was anticipated that geophysical survey, combined with excavation, would provide a unique opportunity for exploring the physical character of a late antique city. Fortunately, these deductions proved substantially correct. While Bulgarian colleagues continued their excavations within the Roman defences, the castellum was allocated to the British team (fig. 1.4). As the British excavations proved, the Roman city survived down to the middle of the fifth century when it was destroyed by fire, probably when it was sacked by the Huns. Thereafter, the site was left derelict, apart from a final phase of 


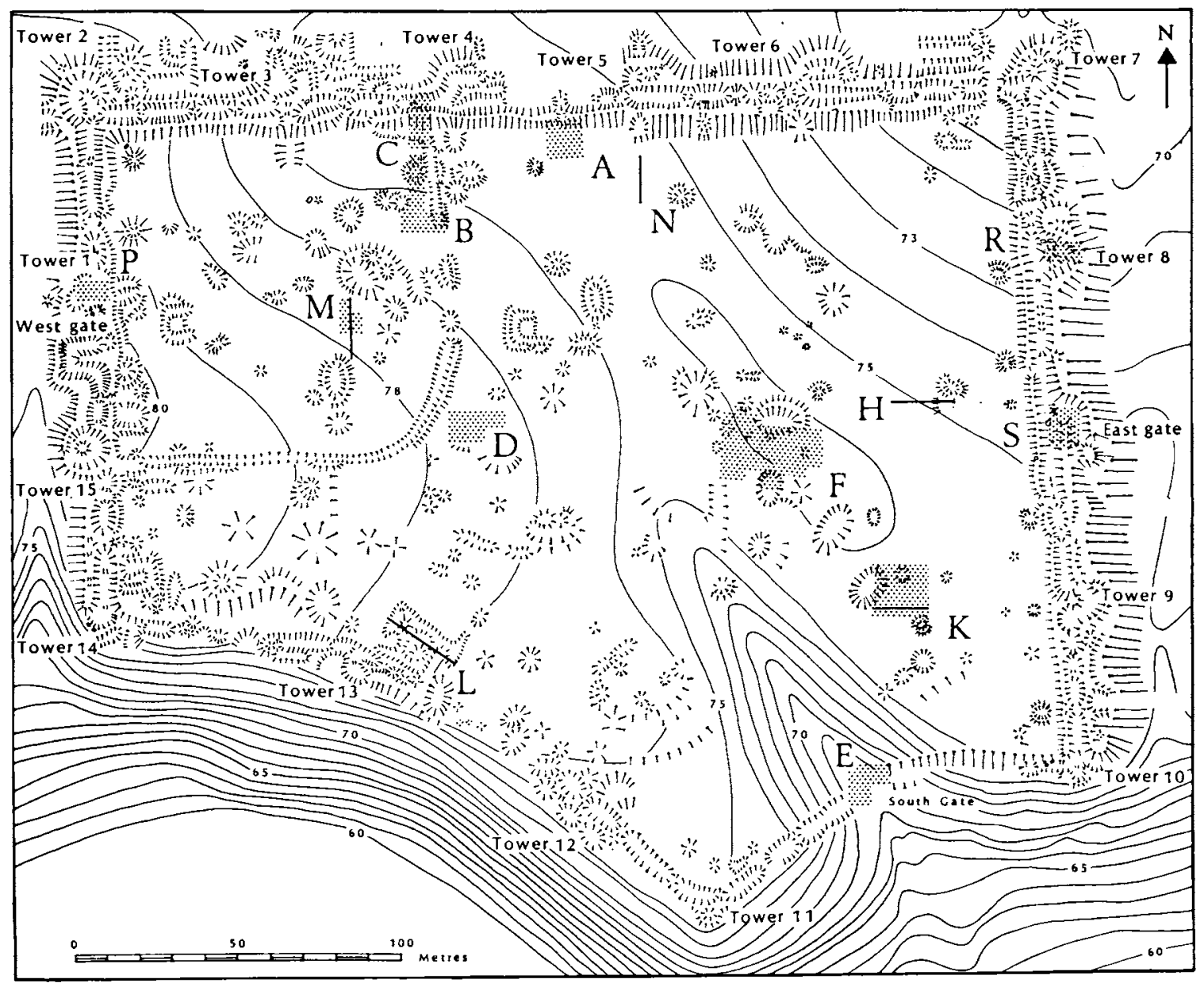

1.4 Site plan

sporadic occupation in the early Byzantine period. The late Roman defences must have been dismantled, apart from the section of curtain-wall reused in the early Byzantine walls. The new fortification was built probably c. 453, certainly before AD 500 . Despite the fact that stone and mortared structures had been extensively robbed, the geophysical survey proved remarkably successful in identifying buildings within the new fortification and excavation proved that robbing, largely confined to walls and foundations, had not disturbed, for the most part, the internal occupation surfaces. This early Byzantine fortification was finally abandoned late in the sixth or early in the seventh century. However, excavation also identified some sporadic Slav occupation during the ninth/tenth century and a reoccupation of the site during the eighteenth to early nineteenth centuries, before it was again abandoned and its inhabitants moved to the modern village of Nikiup.? 


\section{The British programme}

The British excavations commenced in 1985 and included seven seasons of excavation, survey and on-site post-excavation studies until 1991. A final short inspection of the site concluded the programme in 1992. During the first two seasons, the site was planned and a resistivity survey was carried out within the fortifications. In 1987 resistivity was used to locate the course of defensive ditches along the western and eastern walls and to explore the south-eastern corner of the Roman city where robber-trenches indicated the presence of large houses, occupying single insulae. In 1988, a magnetic survey, carried out within the early Byzantine defences, replicated the results of the resistivity programme and, in particular, confirmed that the northern and western quarters of the interior contained remarkably few structures. ${ }^{8}$

In all, fourteen separate areas were investigated (fig. 1.4). Excavation policy was partly determined by the results of the geophysical survey, partly by the existence of visible remains and partly because certain locations, notably the towers, though their walls had been clearly robbed, could be expected still to have in situ occupation deposits. Trial excavations within tower 1 (area P) confirmed that the floor of the tower was preserved. Excavations were continued here and on the site of a pentagonal tower (area $\mathrm{R}$ ) on the eastern curtain, to the south of which a rectangular gate (area $S$ ) was also excavated. Area A was located to explore the presumed site of the Roman south gate. Instead, scant traces of early Byzantine buildings were found above the backfilled Roman and late Roman defensive ditches which themselves cut through a second century Roman house. Excavation to the west (area C), where large limestone blocks appeared to be in situ, found the well-preserved remains of a Roman gate, blocked when the early Byzantine defences were constructed, and an adjacent building dating to the same period. Where a short section of masonry, part of the early Byzantine curtain-wall, had clearly survived (area E), excavations uncovered the remains of a second early Byzantine gate. Area B was located to intersect both a ditched enclosure in the north-western corner of the site (which proved to be of post-medieval date) and a significant north/south high resistance anomaly which turned out to be a paved Roman road. One conspicuous high resistance feature proved, as expected, to be the floor of an early Byzantine basilica (area F, the Large Basilica), built over a deep deposit containing late Roman occupation levels. A second, less regular anomaly proved to represent the partially eroded floor of another church (area K, the Small Basilica), underneath which there was a late Roman building as well as dump deposits, belonging both to the Roman and late Roman periods. A rectangular high resistance anomaly in the centre of the site comprised a pair of open-ended buildings, dating to the early Byzantine period which were probably workshops (area D). Underneath this building was a large, late Roman structure and, below it, a succession of occupation deposits, the lowest of which 
belonged to the very earliest years after the foundation of the Roman city. Clearly visible in the resistivity survey was a line of parallel foundations, comprising at least three long buildings, extending across the centre of the site. This range was examined in area $M$ where the excavation also investigated the apparently open area to the south and was intended to intersect the presumed line of a road running from the west to east gates. ${ }^{9}$ Here, the surprising discovery was made that the early Byzantine foundations had sliced through the well-preserved remains of an early third-century house, still standing in places $c .1 .45 \mathrm{~m}$ high, its walls decorated with frescoes. It contained a destruction deposit of burnt timber roof beams and substantial quantities of painted plaster and stucco mouldings. In 1987, trial cuttings were also made at three other locations, determined by the results of the geophysical survey. Area $\mathrm{H}$, like area $\mathrm{M}$, examined the range of west/east buildings. Area $\mathrm{N}$ proved that there existed one large early Byzantine structure with mortared foundations, east of area A. Its southern extension confirmed that the apparently open area (where no resistivity nor magnetometer anomalies were identified) was indeed devoid of buildings in the early Byzantine period. Area L discovered a large early Byzantine building with central and flanking rooms which was also one of the few buildings where the walls could also be traced on the ground as partly silted robber-trenches (fig. 1.4). Given the need to complete excavations in the areas already opened up and, in particular, the need to conserve and fully document the frescoes from the Roman house discovered in area $M$, these trial excavations were documented but not extended. ${ }^{10}$

As noted in the introduction, one of the surprises of the excavation was the discovery that beneath the early Byzantine occupation level there existed significant remains of Roman and late Roman occupation. Where possible, time and resources permitting, earlier deposits were investigated down to natural. In every case, the primary occupation could be dated no earlier than the foundation of the Roman city in the early second century. However, there remains a strong possibility, given the naturally defensive topography of the site and its strategic location, that there was also a first-century auxiliary fort in the vicinity (possibly under the Roman city itself) and pre-Roman occupation somewhere on the plateau is equally likely.

Inevitably, the quantity of material excavated for a given period in the history of the site varied from area to area. Comparatively little is known about the earliest period of occupation during the first half of the second century AD. Finds of the late second and the third century were more in evidence and the extramural occupation, dating to the fourth to mid fifth century, produced the largest quantity of finds and the best stratified deposits. Although the extent of building across the site is best known for the early Byzantine period, given that this period of occupation across the site was generally close to the modern ground level and had suffered erosion since the abandonment of the site, occupation deposits were not extensive. Slav occupation was evidenced by residual pottery but only in area $\mathrm{F}$ was a building 
(grubenhaus) identified and fully excavated. In most areas, within the defences, excavation encountered buildings, mainly grubenhäuser, belonging to a postmedieval settlement.

\section{NOTES}

1. See below, for a discussion of other major excavations in the region, pp. 30-2.

2. See below, p. 24 .

3. Another volume of finds is currently being prepared for publication. It will include the following specialist reports: metal objects, the architectural finds, intaglios, worked bone and glass beads, flints, analysis of the plaster and mortar, slag, human bones, domestic animal bones, bird, small mammal and fish bones, molluscs and seeds.

4. See below, p. 61 .

5. See below, pp. 59-60.

6. On coin loss and coin circulation, see K. Butcher in Poulter 1995, 305-9.

7. The name of the site, Stari Nikiup (Old Nikiup), indicates not only a connection, still retained in the local tradition, that the modern village represents a re-foundation of the eighteenthcentury settlement, but, uniquely in northern Bulgaria, it also suggests that the ancient name continued in use, presumably since antiquity. See below, pp. 25-7.

8. See P. Strange in Poulter 1995, 259-67.

9. The west gate was not excavated. However, robber-trenches suggested the presence, midway along the western curtain-wall, of a rectangular, projecting gate, flanked by towers, probably the main entrance into the early Byzantine enclosure. Moreover, the resistivity survey identified a causeway, where the western defensive ditch was interrupted, and which led directly to the entrance.

10. Note that areas $\mathrm{M}$ and $\mathrm{K}$ were also initially examined by trial cuttings but were extended and fully excavated during subsequent seasons. 


\section{The results of the excavations and the history of the site}

\section{The Roman city}

Trajan's 'city of victory' (Oulpia Nikopolis pros Istron) was founded in commemoration of the conquest of Dacia, probably $c$. AD 110. It was established on the Greek model. ${ }^{1}$ Both members of the city élite and artisans originated in the Greek east and, in particular, came from the two cities of Nicaea and Nicomedia. It is therefore not surprising that the planning of the agora complex and its architectural embellishment are closely paralleled in the cities of western Asia Minor. By 136, when statues were erected in the agora and dedicated to the emperor Hadrian, the main public buildings had been constructed and building was completed with the addition of a propyleion, facing towards the main west gate, and finished during the reign of Antoninus Pius (fig. 1.1). Work may have commenced on the laying of the paved streets, built from monolithic limestone slabs already under Hadrian but, assuming that priority was given to the construction of the public buildings, it is likely that the extension of the street-grid, including the roads within the area of the British excavations, was not carried out until the middle of the second century. ${ }^{2}$ On the plateau, three cardines were identified. One passed south through area A. A second crossed areas $C$ and $B$ and the edge of a third, the southern continuation of the cardo maximus which skirts the western side of the agora complex, was found, fronted on its western side by an in situ column-base, perhaps belonging to a colonnaded facade for a public building (P). It is doubtful that the street-grid extended as far as the bluff, overlooking the Rositsa, but it certainly continued at least $50 \mathrm{~m}$ south of the later defences. One town house, built with carefully mortared limestone foundations but with a mudbrick superstructure, was excavated (A) and an early hypocaust heated room probably belonged to another Antonine private residence (M). Side drains and the discovery of a piped water supply leading south-east (C) suggest that more houses existed. However, no continuous line of buildings flanked the roads $(B, C)$. It seems rather that development was piecemeal and unplanned, leaving much of the periphery of the city for agricultural purposes or the dumping of domestic, industrial and building waste (D) (fig. 2.1). 
The house in area $\mathrm{A}$ was destroyed by fire. Its remains were immediately buried in the upcast from a defensive ditch, then levelled to create a berm during the construction of the city's defences. The fortifications are identical in construction technique and plan to those erected in the late second century elsewhere in Thrace after the invasion of the Costobocci in 170. A date $c .175$ for their completion would seem probable. ${ }^{3}$ In which case the destruction of the house may be connected with this incursion which certainly caused widespread destruction to cities in the eastern Balkans. Perhaps the city was sacked. A substantial section of the curtain-wall and an internal tower have been excavated by our Bulgarian colleagues. The British excavations uncovered the impressive remains of the city's south gate, constructed from massive limestone blocks, joined by clamps, still standing $1.50 \mathrm{~m}$ high, with settings for an exterior double-winged door and, curiously, with a portcullis at the northern and interior entrance to the gate-chamber $(C)$. The curtain-wall had regularly spaced internal projections upon which mortared brick arcades supported the wall-walk. The defences included the reuse of road slabs, no doubt taken from the roads on the plateau which were outside the defences $(A, P)$. The only road within the British sector which certainly survived in use and retained its paving was the cardo which continued south through the excavated gate $(B, C)$.

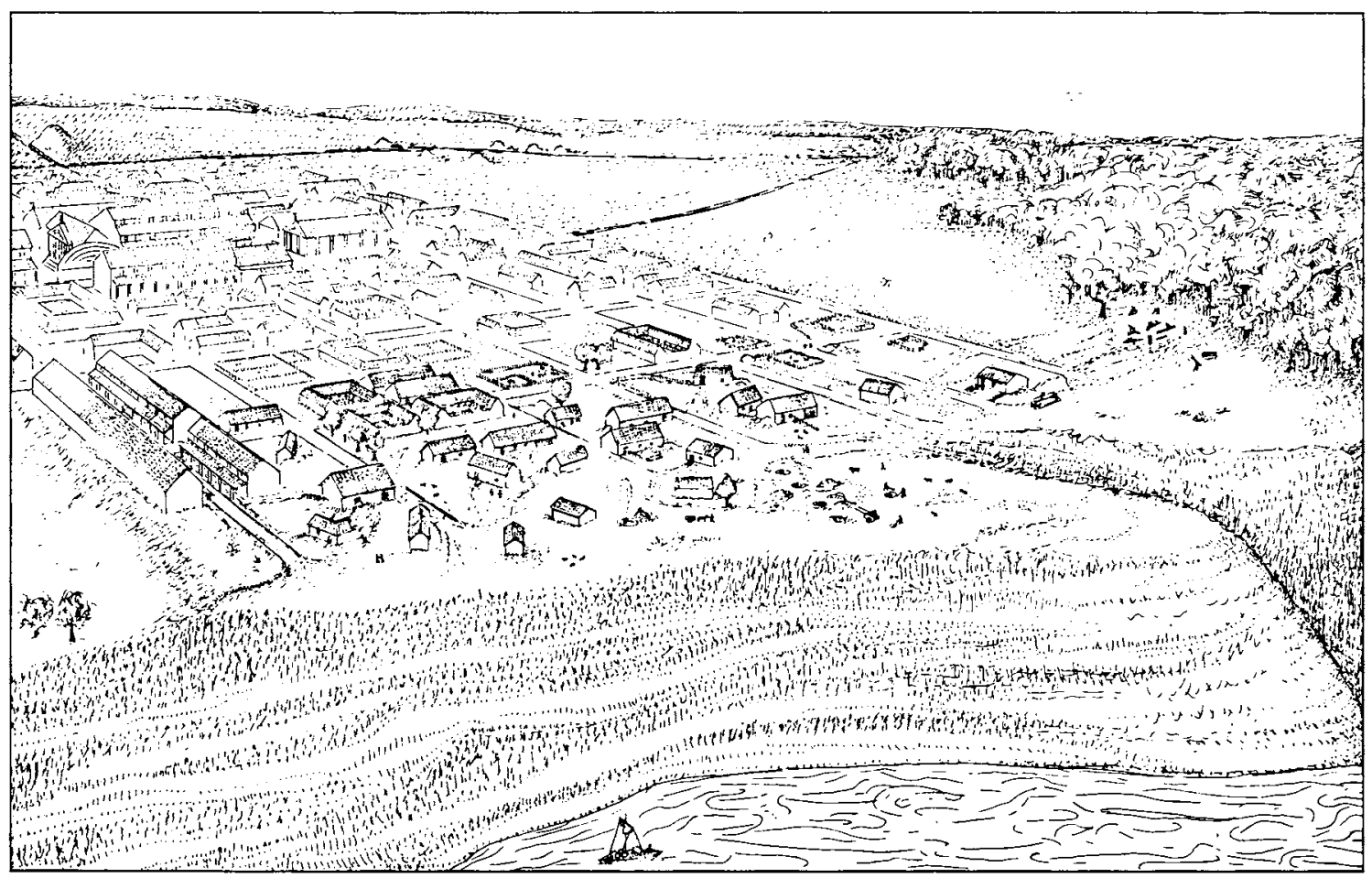

2.1 Reconstruction drawing of the site, c. 150 


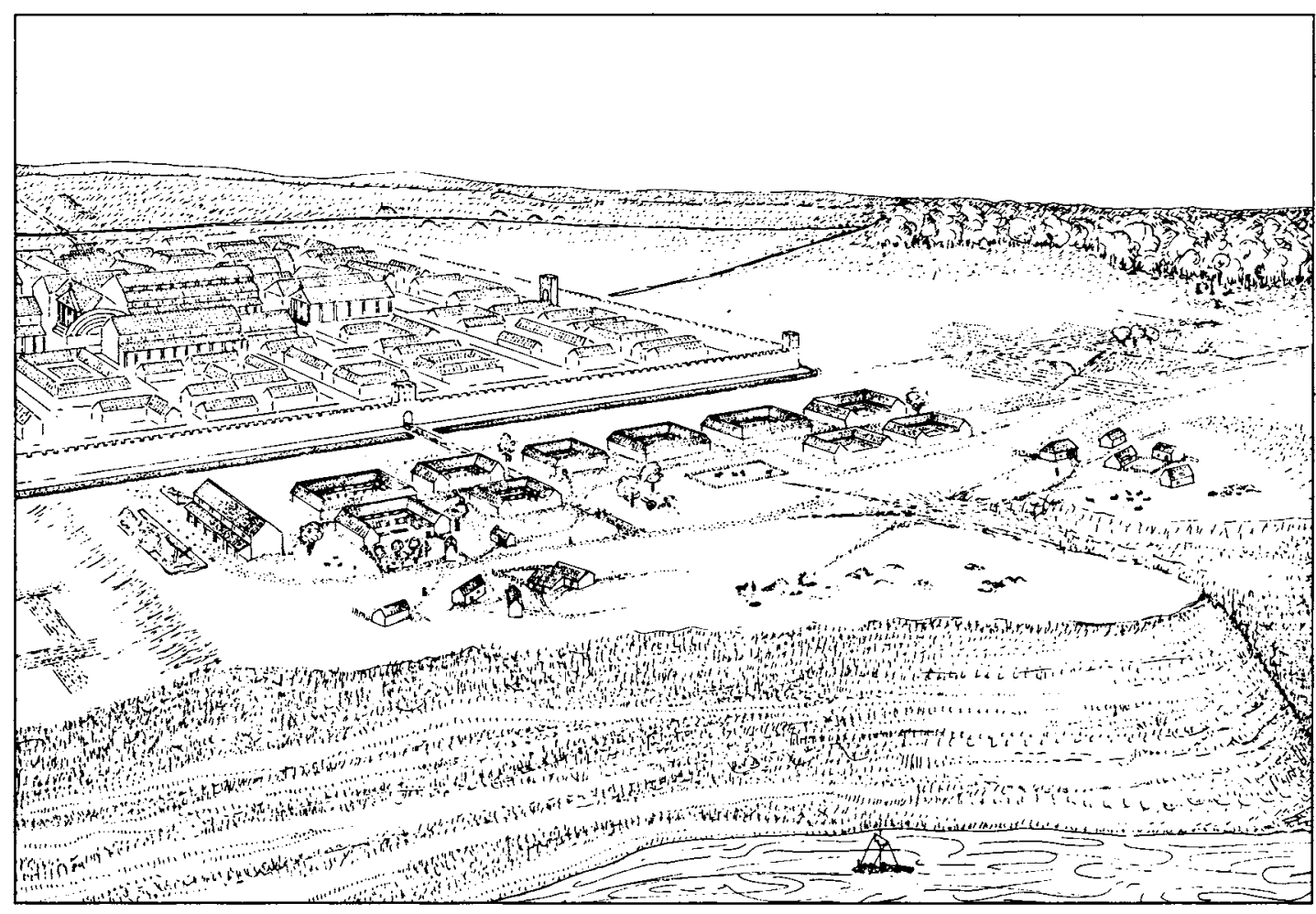

2.2 Reconstruction drawing of the site, $c .200$

Whatever the immediate effects of the barbarian invasion of 170 , the city would seem to have rapidly recovered and the Severan period would seem to mark its greatest period of prosperity. The city mint produced a greater variety of issues than ever before. Inscriptions attest renewed construction, including the dedication of the thermoperipatos, probably the heated building, constructed immediately east of the agora. More inscriptions attest the erection of statues at this time than at any other period. ${ }^{4}$ On the plateau, now an extramural area, a villa suburbana was constructed with mortared stone walls, completed in mudbrick, but with remarkably fine decoration, including frescoes depicting architectural scenes and stucco cornice mouldings with bucrania and garlands $(\mathrm{M}) .{ }^{5}$ Two sides of one house were excavated, fronting on to an internal peristyle with stone columns supported on bases and a flagged central courtyard. It is most improbable that this was the only extramural house: both to the west and east of this area, the ground slopes sharply upwards to the south, suggesting that other buildings existed across the site and were subsequently demolished (fig. 2.2). Towards the edge of the plateau there was agricultural activity and rubbish continued to be dumped (D, P). The excavated house was built no later than the early third century which proves that, less than a generation after the invasion of the Costobocci and the consequent rush to build defences, there was no longer any perceived threat to the city, and this encouraged 
wealthy individuals to live beyond the protection of the walls. It may also be that the population of the city was increasing and that there was insufficient room within the fortified area to accommodate newcomers. Even so, for a distance of $c .50 \mathrm{~m}$ south of the southern curtain, no renewed building appears to have taken place $(A, B, C)$, probably because it was prohibited, leaving a free fire zone close to the defences.

Towards the middle of the third century, the extramural house was stripped of its paved floors and furnishings and was used for agricultural purposes, a sign perhaps of increasing insecurity (M). Decius fought an indecisive battle near Nicopolis against Cniva and the Goths who invaded the province in 250 . The city was besieged by the Goths in 270 . The excavated house was burnt to the ground, its tile roof collapsed and the site was then systematically levelled (M). The defensive ditch was extended across the causeway in front of the south gate which, since it could then have served no useful function, was probably blocked (C). A building burnt down immediately west of the cardo maximus and the debris was never cleared away (P). Whether or not the Goths were responsible for the destruction of the buildings is impossible to determine. It is equally possible that the citizens themselves cleared the extramural area to deny the enemy cover in the event of an attack. It would seem that the plateau, outside the defences, was abandoned; the area was used for dumping rubbish but not apparently for occupation ( $M, D, P, F)$. It was probably then that the side slabs were removed, perhaps for repairing the defences, from the road leading south from the gate $(B, C)$. Two massive ditches, one west/east, cutting across the paved road (C), the other oriented north/south and identified towards the edge of the plateau (D) are large enough to have served a defensive function, but are too far from the city to be connected with its defences; possibly they formed part of one or more defensive enclosures, erected for a temporary garrison during this period.

\section{The late Roman city}

Sparse though the information still is, we know rather more about Nicopolis in the fourth century and its involvement in the historical events of the time. Constantius II allowed Ulfila and his Gothic followers to cross the Danube in $347 / 8$ and settle in the foothills of the Haemus, south of the city. In 378, shortly before the Battle of Adrianople, there was a Gothic garrison stationed close to Nicopolis. Under Theodosius II, the inhabitants of the city would seem to have taken up arms against local Gothic foederati, to the consternation of the emperor.

The robbing, carried out in the post-medieval period, provides a remarkably detailed impression of the urban plan which must belong to the late Roman period (plate V, fig.1.1). ${ }^{6}$ Remarkable is the significant proportion of the intramural area reserved for large town houses, taking up one or two insulae, especially on the 


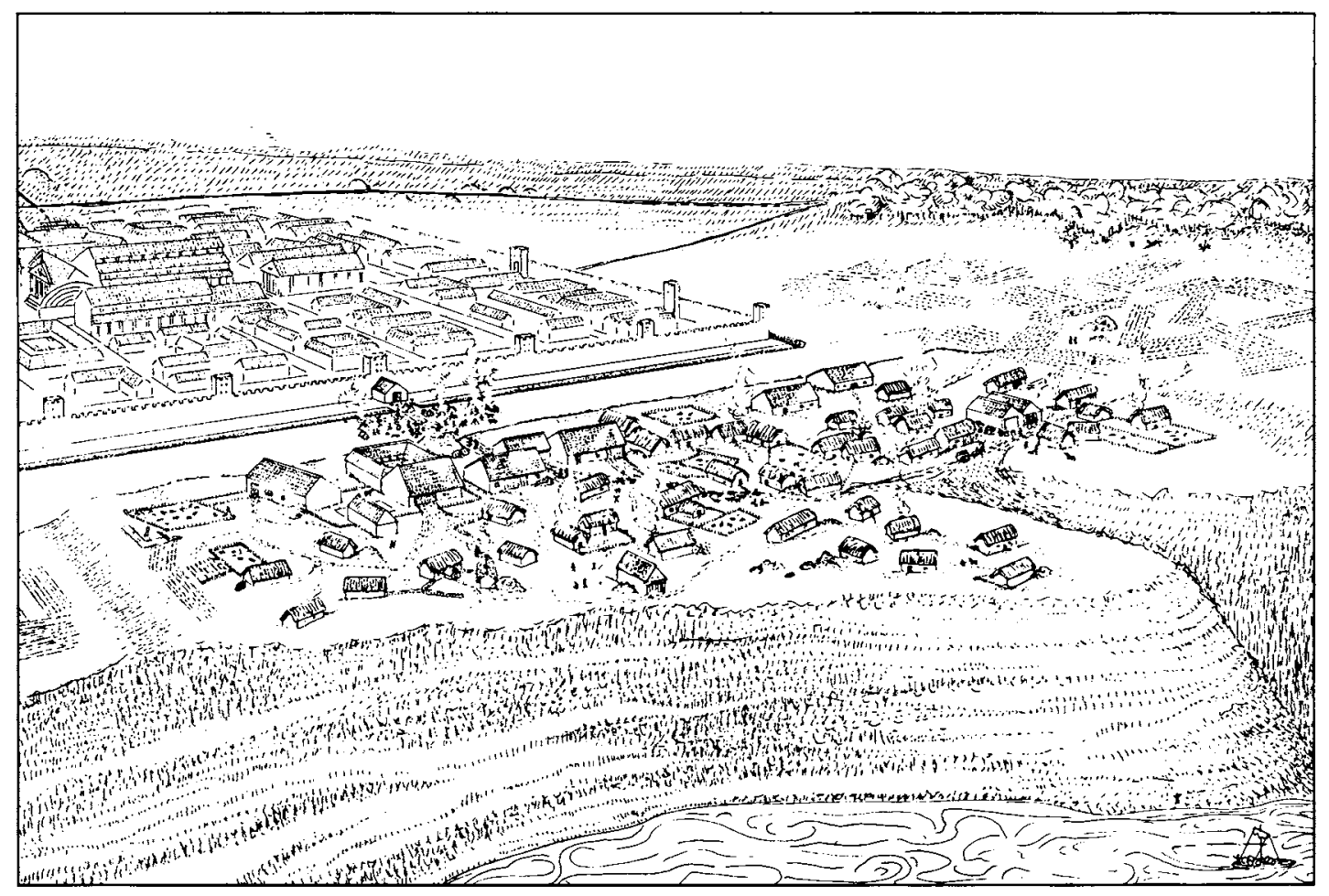

2.3 Reconstruction drawing of the site, c. 350

periphery of the city. There would seem little sign of more modest housing and, given that much of the centre is taken up by public building, it seems that the residential population was probably small, including some thirty families who apparently possessed sufficient funds and authority to build large private dwellings. Also noteworthy is the similarity in plan between the houses and villas in the countryside and the fact that several had out-buildings or store-rooms which, in a rural context, would no doubt be interpreted as serving an agricultural function.? Perhaps these town houses were occupied by wealthy landowners who, possibly in addition to owning estates in the hinterland, may have farmed the land in the immediate environs of the city. No late Roman public building inscriptions, except for one perhaps set up by the provincial governor, have been found. The only other inscription, though from a large, probably brick-built tomb, records the death of a father and daughter, no doubt members of a wealthy family but with a crudely scratched text which suggests that the relatives were unable to call upon the services of a skilled mason, as was clearly the case in the second and first half of the third century. ${ }^{8}$ Nor, interestingly, is there any sign of a church, although Nicopolis may well have had a bishop by $342 / 3$ and certainly had one by 458 . Unlike other cities on the lower Danube, especially those which were provincial capitals, there is little evidence to show a revival in the city's fortunes after the repair of the frontier under 
Diocletian. ${ }^{9}$ In particular, there is no reason to suppose that the fortifications were substantially improved.

The excavations on the plateau demonstrated a remarkable change in the character of the extramural settlement (fig. 2.3). Probably early in the fourth century, the ditch in front of the gate was backfilled and the causeway restored. The gate itself was again in use, this time supplemented by a new outer room which most probably acted as a guard-chamber where vehicles and pedestrians could be checked before entering the city: it was clearly not intended to serve a defensive function - its walls were probably of mudbrick on mortared stone foundations and outer doors were probably hung from a simple wooden frame $(\mathrm{C})$. To the south, the roadway was repaired, not with limestone blocks but with cobbles laid down around the surviving central slabs which covered the road drain $(B, C)$. The cobbled area extended appreciably east of the road, suggesting that the new surface was not simply used to repair the road but covered a larger area, immediately south of the gate. The substantial number of coins of fourth to early fifth century date found on this surface may have been lost because the area was used as an extramural market. Nor was this the only activity in the area. Finds of animal bones suggest that cattle were slaughtered nearby. Glass-working, bone-working and metal-working were also carried out here in the fourth to early fifth centuries. Despite the signs of intense activity in this area, there were no buildings, probably, as before, because they were prohibited within bow-shot of the defences.

Further south, however, there were buildings alongside a cobbled roadway (F). Another, probably agricultural building, was in use on the south-east side of the plateau $(\mathrm{K})$. In some areas, dumping continued $(\mathrm{M})$ whereas parts of the site may well have been under cultivation, notably where the southern extension of the cardo maximus was no longer in use and soil accumulated or was deposited over its surface (P). However, there were also quite large buildings, including one with a workshop cum agricultural store behind what was probably residential accommodation (D). The impression is of a large settlement, partly industrial, partly agricultural. What is particularly striking is that all buildings, including the large complex (D), were not built with mortared walls but from limestone blocks, carefully arranged herringbone fashion, bonded with soil and completed in mudbrick. It would seem that the density of settlement outside the city may have been greater than within the walled area and that those living outside were of lower status and less wealthy than the families occupying well built stone houses within the defences. Possibly, the desire for building relatively large town houses by those who had the money and authority to do so, forced the humbler inhabitants to live outside the fortifications. Just possibly, the extramural settlement represented the arrival of newcomers, perhaps from the countryside. The appearance of 'foederati ware' during the second half of the fourth century could just be because this settlement included Goths, perhaps some of those who came to settle in the city's territory with Ulfila. ${ }^{10}$ 
It is likely that this settlement was partially, if not totally, abandoned late in the fourth century. The large house in the centre of the plateau (D) was destroyed by fire, its tiled roof collapsed and the site was not subsequently reoccupied: although the area continued in use as a rubbish dump well into the fifth century. It is tempting to associate the probable reduction in the size of the extramural settlement with the rebellion of the Goths and the chaos in Thrace which followed the defeat and death of the emperor Valens in the Battle of Adrianople in 378.

\section{The fifth century and the end of the late Roman city}

All that is known about Nicopolis for certain is that it had a bishop in 458 . However, during the 440s, the Hunnic invasions caused widespread devastation south of the Danube and cities in both southern Illyricum and Thrace were sacked. It is reasonable to presume that such military success by the Huns caused widespread panic in the region, especially in such weakly defended cities as Nicopolis. Less than a generation before, the Goths, though successful on the battlefield, had proved singularly incapable of taking urban defences by storm. It is likely that the sudden appearance of this new threat explains the defensive precautions taken at Nicopolis during the first half of the fifth century. The outer gate-house was demolished, probably because it provided no additional security to the defences and, more particularly, there was now a need to gain direct access to the berm which received a cobbled surface $(\mathrm{C})$. A new large ditch was cut, further out from the curtain-wall, widening the berm, along the edge of which, above the inner lip of the ditch, a mudbrick outwork (proteichisma) was constructed (A). No doubt partly to give cover to defenders, it would also have helped to protect the city walls from siege-engines used by Attila's forces.

Whether the extramural settlement continued in occupation remains uncertain. The eastern side of the plateau may have been already abandoned and used as a cemetery (S). As noted, the large house in the centre of the site (D) may well have been destroyed before 400 . However, on the eastern side of the site, a cobbled roadway appears to have still been in use during the first half of the fifth century $(\mathrm{F})$. What is certain is that, at a date later than 430 , the proteichisma was destroyed by fire and its remains toppled into the ditch (A). Within the city, the late Roman buildings, close to the defences and in the centre of the agora complex, were covered by a deep destruction layer of mudbrick and building debris. Subsequently, no attempt was made to restore the defences. Silt accumulated in the ditch (A) and across the floor of the gate and roadway (C). Similarly, perhaps at this time, buildings in the extramural settlement were destroyed and their mudbrick superstructure left to dissolve (F). It seems most improbable that this was the result of an accidental fire. Failure to repair or rebuild implies that the city was no longer regarded as defensible. 
Given that the Huns swept past Nicopolis in 447 to sack the strongly defended city of Marcianopolis to the east, it seems most likely that they were also responsible for the destruction of Nicopolis (fig. 1.3). Not that the site was totally abandoned. A fire-place in the gate-chamber suggests that it may have been used for temporary occupation. How long this period of general dereliction lasted is difficult to ascertain. Time enough elapsed for vegetation to take hold on the sides of the defensive ditch (A) and the roadway, previously flanked by buildings, was covered by a deep layer of dissolved mudbrick (F). The silt deposits could have accumulated over a period of several months or years. However, since the pottery found in the next period resembles that in use in the late Roman city, it is difficult to believe that the period of abandonment lasted for more than a decade. ${ }^{11}$

\section{The early Byzantine city}

On historical grounds there is reason to believe that the site, abandoned to the Huns according to the terms of the treaty concluded between Theodosius II and Attila in 448 , may already have been reoccupied soon after the Huns departed for the West in 451 , perhaps as early as $c .453 .{ }^{12}$ However, the reconstruction of Nicopolis involved no mere reoccupation of an existing site but a radical change in its physical character and the building of a new defensive enclosure, reusing only the eastern portion of the late Roman southern curtain-wall as the northern perimeter of the new circuit (figs $1.2,1.4$ ).

The fortifications enclosed a rectangular area of $5.74 \mathrm{ha}$, in size little more than one quarter of the area defended by the walls of the late Roman city. The decision to construct new defences, rather than reoccupy part of the old city, was probably because of the better defensive location of the new site, perched above the steep bluff overlooking the river to the south, where its curtain-wall followed a sinuous course above the precipitous drop. Robber-trenches define the location of towers and the course of the perimeter wall. The foundations were massively constructed, c. $2.60 \mathrm{~m}$ wide, faced with small limestone blocks, reinforced with reused limestone slabs taken from the Roman city. The core was of roughly hewn limestone blocks and white mortar. The superstructure was built with regular brick bonding courses, each 5 bricks thick and both on the inner and outer faces were rendered and probably painted in imitation of regularly coursed masonry $(E, P, R)$. On the nor th side, where the late Roman wall was included in the new defences, the narrow late Roman curtain was widened. At the same time, the partly silted ditch belonging to the late Roman defences was backfilled with stone and debris from the Roman city - because it was now within the new enclosure $(\mathrm{A}, \mathrm{C})$. In all there were 15 towers, regularly spaced at intervals of $c .55 \mathrm{~m}$, except for the south-western curtain where towers were up to $80 \mathrm{~m}$ apart, no doubt because the steep slope rendered the defences less vulnerable. 
Excavation of towers 1 and 4 proved that they were rectangular and probably all those along the northern and western curtains were of similar size and shape. Less certainty attaches to the southern wall where the robber spoil had been tipped down the slope and the form of the towers is less easy to discern. Probably, they were also rectangular and perhaps, given the impregnable position, less imposing than those elsewhere along the curtain-wall. However, on the east side, two large towers appeared to have a triangular shape (fig. 1.4). Excavation proved that one was of exceptional strength (R). It was prow-shaped (with a triangular end) and projected $11.20 \mathrm{~m}$ beyond the curtain. It was also remarkable, unlike the excavated square towers, in having a ground floor paved with tiles and glass finds suggested that it had glazed windows. ${ }^{13}$ The southern tower, on the same curtain (tower 9), given that robbing suggested a similar plan, was probably also prow-shaped and of similar dimensions. Three gates can be recognized. The western and probably main gate, flanked by tower $1(\mathrm{P})$ and tower 15 , was not excavated, but the causeway leading out across the defensive ditch was identified in the resistivity survey and confirms the presence of an entrance. The east gate proved to be a rectangular chamber, flanked by guard chambers $(S)$. The south gate was remarkably well preserved (E). It also formed a rectangular chamber but straddled the curtain-wall, its foundations built from large reused limestone blocks and with a central drain leading south towards the river. As far as is known, there was no north gate. The Roman gate was blocked when the early Byzantine defences were constructed (C). Apart from the western external ditch, another ditch was identified beyond the eastern curtain. None would be needed for the southern curtain but it is surprising that survey and excavation have not located any defensive ditch immediately north of the site. ${ }^{14}$

Within the defences, excavation was determined by the results of the geophysical survey which proved notably successful in locating buildings. ${ }^{15}$ No doubt one of the most prominent features of the site was the main basilica, occupying a dominant position on high ground towards the centre of the enclosure (F). No similar anomaly suggested the presence of another large church and it is reasonable to suppose that this was the episcopal basilica. In its form, with polygonal apse, flanked by side chambers, screens running between its northern and southern colonnades, its central $a m b o$ and chancel screen, probably with an atrium to the west, it conforms to a plan typical of fifth to sixth century churches in northern Thrace. ${ }^{16}$ Even so, its standard of construction was modest. Reused material formed rough column bases and it was floored not with mosaics but with bricks, though arranged in geometric patterns. Its internal fixtures, including the screens, seating along the nave and the ambo were not of stone but made of wood. A second, smaller church was excavated in the southeastern corner of the site $(\mathrm{K})$. With a single central chamber, it, too, had a timber $a m b o$ and a plain brick floor. A dominant feature in the geophysical survey was created by two parallel foundations, $c .6 \mathrm{~m}$ apart, extending across the site from the west to the east gates. These proved to represent a range of buildings, probably 
divided into three blocks, each as much as $80 \mathrm{~m}$ in length. The foundations, $1.20 \mathrm{~m}$ wide and $3.50 \mathrm{~m}$ deep, were built of limestone blocks and bonded, not with mortar, but with earth $(\mathrm{M})$. The superstructure was completed in mudbrick $(\mathrm{H})$. Clearly, the foundations were designed to support a heavy superstructure, probably twostoried in height. What purpose these buildings served is less easy to determine; where fully examined, the floor surface failed to survive (M). Store buildings, perhaps doubling as barracks for a garrison, would seem the most likely explanation. An open-ended building, probably workshops, was discovered towards the centre of the site (D). It was roughly constructed from limestone blocks, bonded with soil, and, remarkably, would seem to have stood in isolation, despite its central location. Along the northern curtain-wall, one rectangular building of similar construction was built up against the blocked Roman gate and extended east as far as tower 4 (C). It was divided into two, with an internal partition and a central, communicating doorway, with amphorae set into the earth floor, close to the inner side of the fortification wall which also served as the north wall of the building. Its location and proximity to the tower would be appropriate to a barrack. Since robbing material from the destruction of the defences in the post-medieval period prevented geophysical survey along the curtain, it is possible that other similar buildings existed along the perimeter. However, it is certain that such buildings did not comprise a continuous line along the defences: none were found in excavations to the east, although at least one roughly constructed building can be dated to this period, but was set back $c .10 \mathrm{~m}$ from the defensive wall and continuing east of the area (A). Here, no other buildings were found, only a simple oven, perhaps used for the preparation of food. Not that all buildings which were not churches were so crudely built. A massive building with three ranges of rooms existed close to the southern defences $(\mathrm{L})$ and another in the northern part of the enclosure $(\mathrm{N})$. One especially prominent high resistance anomaly, which was not excavated, perhaps a building with associated walled enclosure, orientated north-west by south-east, existed on the western side of the valley leading down to the south gate (plate VI). The south-west quarter of the site appears to have been occupied by buildings although the resistivity survey failed to detect a clear outline of any particular structure. External surfaces and roads were generally notable by their absence. The paved Roman road which continued in use during the late Roman period was covered by silt and abandoned by this time. Excavation south of the demolished Roman house failed to locate any sign of the road which presumably ran from the west to the east gates $(\mathrm{M})$. Only a lightly cobbled surface was identified within the east gate but nowhere else (S).

At three locations evidence for two periods of occupation were found. Most clearly, at the east gate, the first period ended in destruction by fire and was followed by the blocking of the entrance, converting the structure into a tower (S). At the south gate, there was also destruction, followed by rebuilding which involved blocking the drain which passed beneath the gate chamber - perhaps a defensive 
precaution, preventing an enemy from gaining access to the interior through this impressively large, subterranean passage (E). Similarly, a destruction deposit was identified in tower 1 . Subsequently a new floor was laid and this was made from the burnt remains of mudbrick buildings. When precisely this destruction took place it is impossible to determine, though it clearly preceded the final phase of early Byzantine occupation. If all three destructions are connected, the city may have been damaged during an attack, perhaps even sacked - although it is impossible to be certain if the buildings in the interior were affected since very few had occupation surfaces preserved in situ.

The overall impression is of buildings scattered across the enclosure and a remarkably low density of occupation (plate VI). Especially on the northern and western sides, there was no sign that there were any structures at all, an impression confirmed by magnetometer survey which, since the final period of occupation ended in destruction by fire, would surely have discovered the evidence for mudbrick buildings, even if they had no stone foundations and so have escaped detection by resistivity. There is no evidence to suggest that the fortification contained a substantial population. True, the pentagonal tower, with its paved floor and window glass, may have served as accommodation, perhaps for a military detachment. Other towers could have performed the same function and, as noted above, there may have been other buildings, like the one discovered on the northern curtain $(\mathrm{C})$, along the defences where spoil from robbing would have masked any evidence for buildings in the resistivity survey. But what is certainly lacking is any sign of a civilian population, although one certainly existed in this period, living in the ruins of the late Roman city to the north, but not, it would seem, within the new defences. Moreover, there was no sign of buildings appropriate to civilian government. What seems to emerge is that Nicopolis in the early Byzantine period served as a centre of ecclesiastical administration and probably as a military base, functions appropriate to its use as a centre of imperial government but very different from the Roman city it replaced. So, despite the fact that Nicopolis is still described in this period as a polis, there is precious little sign that it could still have performed the civilian functions traditionally ascribed to a city. ${ }^{17}$

If the early Byzantine 'city' was constructed as early as c. 453 , it nevertheless seems to have been in use for less than 150 years. The latest coin is an issue of Tiberius II (578/582) and, if the site did survive as late as 598 (the last time it is mentioned and in connection with the campaigns of Comentiolus), it was no doubt abandoned later in the same century or early in the seventh when Byzantine hegemony on the lower Danube was finally lost to the Slavs and Bulgars. Occupation ended in destruction. There was fire in the east gate-tower (S) and another marked the end of occupation at the south gate (E). The workshops (D), the large buildings in the northern and southern parts of the site $(\mathrm{N}, \mathrm{L})$ all burnt down and so, too, did the central range of buildings $(\mathrm{H})$. However, it is at least possible that the destruction 
was carried out as part of a systematic evacuation and not during an enemy attack. It seems that roof tiles and internal metal fixtures, possibly also the timber ambones, were removed before the churches were set alight $(\mathrm{F}, \mathrm{K})$. In the case of tower 1, there was no sign that destruction ended in fire (P). Instead, roof tiles were roughly stacked on the ground floor and then abandoned; perhaps an abortive attempt to strip the tiles from the roof or to dismantle the roof timbers. If such building materials were taken away, it suggests that they were for reuse and probably at no great distance from the site. The possibility therefore remains that evacuation of the fortifications did not mean that all the inhabitants left the district. Even so it is difficult to believe, given the character of early Byzantine Nicopolis, that there could have survived any organization or population which continued to regard themselves as an urban community. Indeed, there is precious little reason to suppose that the city, in its classical sense, survived the invasion of the Huns and the reorganization of the site with the reimposition of Byzantine authority during the second half of the fifth century.

\section{The early medieval period (seventh to tenth centuries)}

From the early seventh century, Byzantine coin circulation ends and sites of this period have proved remarkably difficult to find. One reason is undoubtedly the arrival of Slavs and Bulgars who, it seems, produced no pottery until late in the eighth century. ${ }^{18}$ Consequently, it would be rash to assume that the site of Nicopolis must have been totally abandoned. However, in none of the areas of excavation was there any sequence of occupation continuing later than the final destruction. Here, at least, it does seem that the fortifications were abandoned and remained unused for two and perhaps three centuries. The first evidence for reoccupation can be dated no earlier than the late ninth and may well be tenth century. Slav pottery was found in residual contexts on the eastern part of the site $(K, S)$ but, immediately north of the Large Basilica, still standing as a ruin, a single grubenhaus of characteristic Slav type was excavated. It had been used as a grain store; complete pots full of millet were found in situ on its earthen floor. ${ }^{19}$

\section{The late medieval period}

From the late twelfth to late fourteenth century, Veliko Turnovo, $15 \mathrm{~km}$ away to the south, was the capital of the Second Bulgarian Kingdom and the residence of its kings. The early Byzantine fortifications at Nicopolis, though no doubt ruinous, were probably still standing at this time and, from the plateau, there is a clear view to the south, to the defile, cut by the river Yantra, which leads to the almost 
impregnable royal citadel of Tsaravets. Reuse of the ancient site at this time would seem logical since it controlled the route from the Danube to the medieval fortress. Yet, apparently, this was not so. At sites occupied in this period, Sgrafitto ware is found in abundance but only a few possible fragments were recovered during excavations at Nicopolis. Again, it would seem that the site was abandoned after the destruction of the small early medieval settlement.

In 1469 , the remains of the saint, Ivan Rilski, were transferred from Veliko Turnovo to Rila monastery in south-west Bulgaria. The description of this journey, written only a decade after the event, describes the circuitous route taken by the cortège and an overnight stop in 'The city of Nicopolis' which, from the geographical context of the passage, clearly must refer to the ancient site. It appears that Nicopolis was used as the palace of a local Bulgarian ruler and that there was a sizeable local community living close by. It is tempting to suggest that the palace was located within the ruins of the early Byzantine enclosure and that the magnate's palace (with a church attached) reused the defences and perhaps some of the still standing internal buildings. Despite this, no traces of occupation of this period have been found. However, the site was already known as 'Stari (old) Nikiup' when the ancient city was first identified by Ferdinand Kanitz in the late nineteenth century. This suggests that the ancient name was remembered, presumably by a community living in or close to the site, throughout the centuries which separated the end of the city in the late sixth century and the post-medieval settlement.

\section{The post-medieval period}

There is reason to believe that the local tradition about the site is broadly correct: namely that Stari Nikiup was a post-medieval settlement, perhaps first occupied in the seventeenth century. However, the main centre of settlement would seem to have been to the west, on the north bank of the Rositsa and outside the ancient site. Within the early Byzantine fortifications, still standing as late as the eighteenth century, houses, mostly grubenhäuser, of somewhat more sophisticated construction than those of the Slav period, were found. The density of settlement evidenced in the excavations, and the appearance of sunken features across the site, probably representing other grubenhäuser, would seem to have been low, probably because the area was only occupied late in the history of the village, possibly no earlier than the middle of the eighteenth century. Since no archaeological study of post-medieval pottery has been carried out before in the region, the assemblages published in this report can only be dated by association with coins and metal-work, all of which belong to the late eighteenth century. ${ }^{20}$ Occupation ended in destruction by fire at the end of the eighteenth or during the early years of the nineteenth century. The discovery of cannon-balls and primitive grenades in the burnt buildings together 
with implements and complete pots, suggests that there had been a hasty evacuation, precipitated by an attack on the settlement. The period was notable for unrest, civil war and repeated Russian invasions of what was then a Turkish province. Whatever the actual reason for the apparently violent end to Stari Nikiup, local tradition maintains that the inhabitants fled to the forest and founded the modern village about this time.

It was probably only during the eighteenth century that the buildings and fortifications were dismantled and the stone taken away for reuse. After the destruction of the village, robbing continued sporadically within the early Byzantine fortifications and systematically within the Roman city.

\section{NOTES}

1 Detail and references for the following summary are in Poulter 1995, chapters 1 and 2. Where discussion refers to a particular excavation area, this is indicated by the area code in round brackets.

2 This is one of the premisses upon which the chronology of the pottery was established, assigning deposits sealed by the paving slabs in area $B$ to the first half of the second century.

3 During the 170s, urban defences, probably under imperial directive, were provided for cities in both Thrace and Moesia Inferior. That this was the occasion when Nicopolis received its fortifications would seem assured; Poulter 1995, 12. This provided another case where evidence could be used to date the archaeological sequence and with it the pottery.

4 For the epigraphic evidence for civic building and the dedication of statue-bases see Poulter 1992a, 70-5 and fig. 47.

5 See T.F.C. Blagg in Poulter 1995, 243-57.

6 The reason being that the Roman city, as described below, was destroyed and abandoned c. 450 .

7 The geophysical survey of the south-eastern quarter suggested that these long, undivided rooms possessed simple earth floors, unlike the floors of rooms in the main part of the house; P. Strange in Poulter 1995, 266-7.

8 See J. Reynolds in Poulter 1995, no.1, 315-16.

9 Poulter 1992b, 114-23.

10 See below, pp. 111-12.

11 See below, p. 114.

12 The argument is at least promising; Poulter 1995, 35-7.

13 See below, pp. 309-10.

14 P. Strange in Poulter 1995, 265-7.

15 Since the early Byzantine level was immediately below topsoil, most of the high resistance anomalies proved to date to this period, with the notable exception of the Roman paved road $(\mathrm{C}, \mathrm{B})$.

16 Poulter 1994, 253-60.

17 See also the economic changes in the character of the settlement, below pp. 47-8.

18 R. Rashev, Ancient Bulgaria vol. 2, 255-69.

19 See below, p. 91.

20 See below, p. 112. 


\section{The economic and social implications of the pottery and glass}

\section{Introduction}

It is reasonable to expect that the pottery and glass finds from Nicopolis can help to reconstruct some aspects of the economic and social character of the Roman to early Byzantine city. The evidence is, for the region, unusual, both because it was recovered from well-stratified and dated contexts and because the quantities of material are singularly impressive (100,000 ceramic sherds and 7,361 glass finds). Summary discussion in the two reports draws upon the most significant implications of particular finds and developments in the character of the assemblages. Here, the intention is to explore the social and economic implications of these two studies and to compare them with other sources of information from the site and the region.

The publication of substantial quantities of glass and pottery does not in itself provide a secure basis capable of supporting models of economic or social development. However, the quantification of finds from excavations offers the opportunity to determine changes in the nature of assemblages from particular sites and to make comparisons with other excavations both in the region and in other parts of the Roman empire. ${ }^{1}$ Even so, the change to a quantitative approach is still in its infancy. Where the quantity and quality of evidence available has dramatically increased over recent years, the provisional conclusions drawn still rest, perilously, on a few well-documented sites. ${ }^{2}$ In the case of pottery, there remain problems in deciding which methods provide the most reliable results and the quantification of glass is particularly difficult. ${ }^{3}$ It remains essential that the information is presented in a form which allows the reader to judge the validity of the conclusions reached. Since the chronology of a site like Nicopolis may be refined by future excavation, the evidence also must be contained in a flexible format which can be modified in the light of further discoveries. ${ }^{4}$

There are, however, constraints which need to be considered in the interpretation of quantified assemblages. The quantification relates to the excavated 'sample' and this may not be typical for the site as a whole. Multi-period sites involve particular 
difficulties since here the crucial question is whether the material collected for each period can be legitimately compared with any other. It is likely that different activities occurred in different areas and at different times and that certain deposits may be dominated by particular kinds of material which provide an imbalance in the overall representation of finds where the excavated sample is insufficient to compensate for local variability. In the case of Nicopolis during the early Byzantine period the site comprised a defended enclosure of 5.74ha and the total area of excavations (c. 2,174 square metres) represents only c. 3.79 per cent of the interior. In the late Roman period the site lay outside the defences. To obtain a full record of rubbish deposits dating to this period, and assuming that all dumps were no more than $c .200 \mathrm{~m}$ from the fortifications, this would involve excavating an area of no less than c. 400,000 square metres. Consequently the sample actually examined represents only 0.5 per cent of this total and was restricted only to the land south of the city. The volume of material dating to any particular period varies considerably. Deposits of the second century, which are comparatively under-represented, all came from the southern periphery of the city and at the limits of occupation, whereas the largest body of material, dating to the fourth century, came from an extramural settlement. During the early Byzantine period, partly due to erosion, partly due to the character of the buildings excavated (churches, towers, store buildings), the volume of evidence for domestic occupation and rubbish deposits was demonstrably less than for earlier periods. This can be partly, but not fully explained by the fact that the site was then within the new defences and dumping of waste would no doubt have largely taken place beyond its walls and beyond the limits of excavation. Whether the sample is less than 1 per cent or as much as 4 per cent, it is clear that there are dangers in assuming that the quantification of the finds will provide a valid picture for Nicopolis in any particular period. The quantification of evidence is only applicable to those areas which have been investigated and the evidence from other parts of the site may be very different. It is important to remember that the focus of study is restricted to the areas which were excavated. This is not necessarily a disadvantage but can have useful implications, as when, in social and economic status, the occupants of the extramural settlement prove to have been very different from those living within the fortifications in the late Roman period. ${ }^{5}$

The nature of the pottery and glass also presents its own particular problems and advantages. They generally represent the largest bodies of material available for 'bulk' analysis but they are not necessarily the best indicators of economic activity. Perishable items which do not survive in the archaeological record, or finds which for other reasons are poorly represented, could have been more informative. ${ }^{6}$ There are differences in the survival and character of the two classes of find which means that it is not possible to compare directly the two kinds of evidence. The origin of pottery can often be identified which allows comparisons to be made between local production and imported wares, providing important clues to production, regional 
and long distance trade. However, the imported pottery may have arrived incidentally along with more valuable commodities which leave no archaeological evidence. ${ }^{7}$ These traces can be useful in suggesting which other parts of the empire were in economic contact with the site but what the real basis for that trade was remains uncertain. Nor need the appearance of imports simply reflect economic ties political, social and military factors may have been decisive. ${ }^{8}$ Although it is relatively easy to determine when a particular pottery type was introduced, since residuality is a distorting factor common to all urban sites, it has proved less easy to decide whether later examples of the same product were still in use or were present simply as residual material..$^{9}$

The typology of glass includes numerous forms, common to all periods and to all parts of the empire, with an apparent bias towards the West, simply because more reliably dated comparanda are available there than elsewhere. ${ }^{10}$ This is particularly noticeable when it is clear that the primary influences on the ceramic assemblages were from the East and imports from the eastern Mediterranean remained important throughout the Roman and early Byzantine periods. ${ }^{11}$ It would be curious indeed if this eastern bias was not equally true of glass imports. Rarely can particular glass forms be regarded as regional and there is little prospect in the immediate future that scientific analysis will help in determining, even in general terms, where particular types were made. ${ }^{12}$ No satisfactory methods of quantifying glass assemblages have yet been devized. Perforce, comparisons can be made with other well-attested types but this provides no basis, as yet, for the fuller analysis of supply and the elucidation of those factors which determined regional or intra-site distribution. Dating types, especially the more luxurious items, must be cautiously argued since they may have been in use over a considerable period of time. ${ }^{13}$ The clearly high level of residuality, evidenced at Nicopolis, is no less a problem for glass than it is for pottery. ${ }^{14}$

In order to assess the importance of the glass and pottery, they need to be related to other kinds of evidence from the site. The results of the excavations and the environmental evidence can be usefully compared with these two studies. ${ }^{15}$ Where different kinds of evidence suggest similar conclusions, it is the more likely that general deductions can be made. These comparisons will constitute the principal objective in the following discussion.

\section{Comparison with other sites on the lower Danube}

It is also desirable to place the glass and pottery in its regional context. The excavation and publication of other dated and quantified site assemblages should provide a basis for important studies, using the glass and pottery from Nicopolis. Unfortunately, the groundwork for this second approach is not available for the 
lower Danube. There are a few notable exceptions. The long-term Bulgarian/Polish excavations at Novae (Svishtov) have produced a regular flow of reports on finds, including glass and pottery. Established as a legionary fortress in the middle of the first century $\mathrm{AD}$, the site doubled in size in the late third/early fourth centuries, continued in use as the base of a late Roman legion and would also seem to have been a major military and ecclesiastical centre in the early Byzantine period. ${ }^{16} \mathrm{~A}$ road links Nicopolis with Novae, $50 \mathrm{~km}$ distant to the north (fig. 3.1). Iatrus (Krivina), also on the right bank of the Danube, $45 \mathrm{~km}$ as the crow flies from Nicopolis, is of singular importance, thanks to the series of monographs, published by the Bulgarian/German team. ${ }^{17}$ Since the fort commands the mouth of the Yantra and, consequently, the central part of the city's territory, it is useful to compare finds and to seek possible connections between the development of the city and the Danube frontier. However, as yet, this applies only to the late Roman and early Byzantine periods since the fort excavated was built in the Tetrarchic period and, if an earlier fort existed, as seems likely, then it was not on the site of its successor. Nevertheless, the sequence of occupation provides, for the lower Danube, a uniquely dated and complex history which, as will be noted, offers precious information about the social and economic character of its garrison. Two hill top sites, Golemanovo Kale and Sardovsko Kale, both occupied in the sixth century, provide information relevant to this period. ${ }^{18}$ Although Stobi is far to the west in the Macedonian Republic, its pottery has been published and quantified in such a form as to provide a source for useful comparison..$^{19}$ Tsaravets, an immensely strong, naturally fortified hill, perched high above the river Yantra, $15 \mathrm{~km}$ south of Nicopolis, has also been published. ${ }^{20}$ Its primary significance, as the capital of the Second Bulgarian Kingdom (twelfthfourteenth centuries) is relevant to the fate of Nicopolis in the medieval period but, still more importantly, it was also a strongly defended fortification in the sixth century of notable importance, given its well-constructed buildings. Other sites for which there are published ceramic and glass sequences are remarkably few. Of singular interest is the publication of the villa of Armira, close to the Turkish border, in southern Bulgaria. ${ }^{21}$ Although Nicopolis was in the same province of Thrace until the Severan period - geographically, Nicopolis is separated from the southern half of the province by the Haemus (Stara Planina) which, though passable, still acted as a barrier to communication. Close links with southern Thrace are unlikely, certainly by overland route, but comparison with the ceramic assemblages from Armira is of interest in demonstrating general developments common to the eastern Balkans. However, southern Thrace was economically very different from cities of the north Danubian Plain. ${ }^{22}$ Excavation elsewhere, though occasionally extensive, has not been matched by the publication of full reports. Where sites do provide sufficient grounds for comparison, these are mentioned in the following discussion but, with a few exceptions, comparanda are based upon individual finds and data has not been presented in quantifiable form. Even so, where appropriate, comment 
and comparison will be made when the finds from other sites in the region offer at least markers for future study and some tentative conclusions.

\section{The purpose and character of the reports on the glass and pottery}

It proved necessary to decide upon priorities in the study of the glass and pottery, given the need to examine substantial quantities of material and the limited time available for analysis on site. Supplementary considerations, notably the inevitable restrictions on the quantity of evidence which could be presented in book form, dictated the way the glass and pottery could be published. Without any reliable chronology for occupation at Nicopolis and without a reliable sequence of dated finds from other sites, it is inevitable that the primary aim for both classes of material was to provide an illustrated and dated catalogue of types. ${ }^{23}$

The primary aim for the pottery was to establish which were the principal types in use in each period. Intrusive examples can be weeded out, with reasonable probability, where the small quantities of later pottery in early deposits are most likely to result from contamination. Even so this is not always so easy to establish. However, the catalogue (chapter 9 ) and appendices 2 and 3 provide the reader with all appearances of a particular type and ware in each period and this can be compared with the proposed date range of particular vessels. Other studies which could have been conducted, such as the analysis of the distribution of pottery types within the site, could still be carried out but were not undertaken in time to be included in this publication.

In the case of the glass, the primary objective was to provide a full catalogue of forms from dated contexts which would prove useful, like the pottery, for the dating of similar material in the region and for comparison with assemblages from other parts of the empire. ${ }^{24}$ Space and time precluded a full discussion of all parallels for particular glass vessels. Comment was restricted to individual finds of particular interest and groups of vessels with reference to the best published evidence for the dating of comparanda. The glass was first analysed and described as discrete assemblages from each part of the site. However, since it was found that such an approach produced no obviously significant results, the finds in the published catalogue were grouped by type and date with summary accounts provided for each area.

In the case of both the pottery and the glass, full archives of the data are retained at Nottingham University and these may be consulted by anyone interested in the evidence not included in this volume. 


\section{The city, its territory, its human and natural resources}

The Trajanic conquest of Dacia precipitated a major relocation of military forces on the lower Danube. Whereas from the Flavian period there had been a substantial military garrison along the right bank of the river, after 106, upstream from Novae, the Danube was no longer a frontier. Auxiliary forces were withdrawn and the legionary base at Oescus became a colonia. However, the military presence in the region remained impressive. Apart from Novae, still a legionary base, auxiliary forces garrisoned the right bank as far as the Danube mouth with other legions stationed at Durostorum and Troesmis (fig. 1.3). Moreover, with the Hadrianic withdrawal from Walachia, a new frontier, that of Lower Dacia, was created east of the Olt, extending from the Danube north to the foothills of the Carpathians. After the abandonment of Dacia about the middle of the third century, the Danube again became an imperial frontier and remained so down to the collapse of early Byzantine control in the early years of the seventh century. Such a substantial garrison must have created a demand for imported goods as well as for agricultural and building

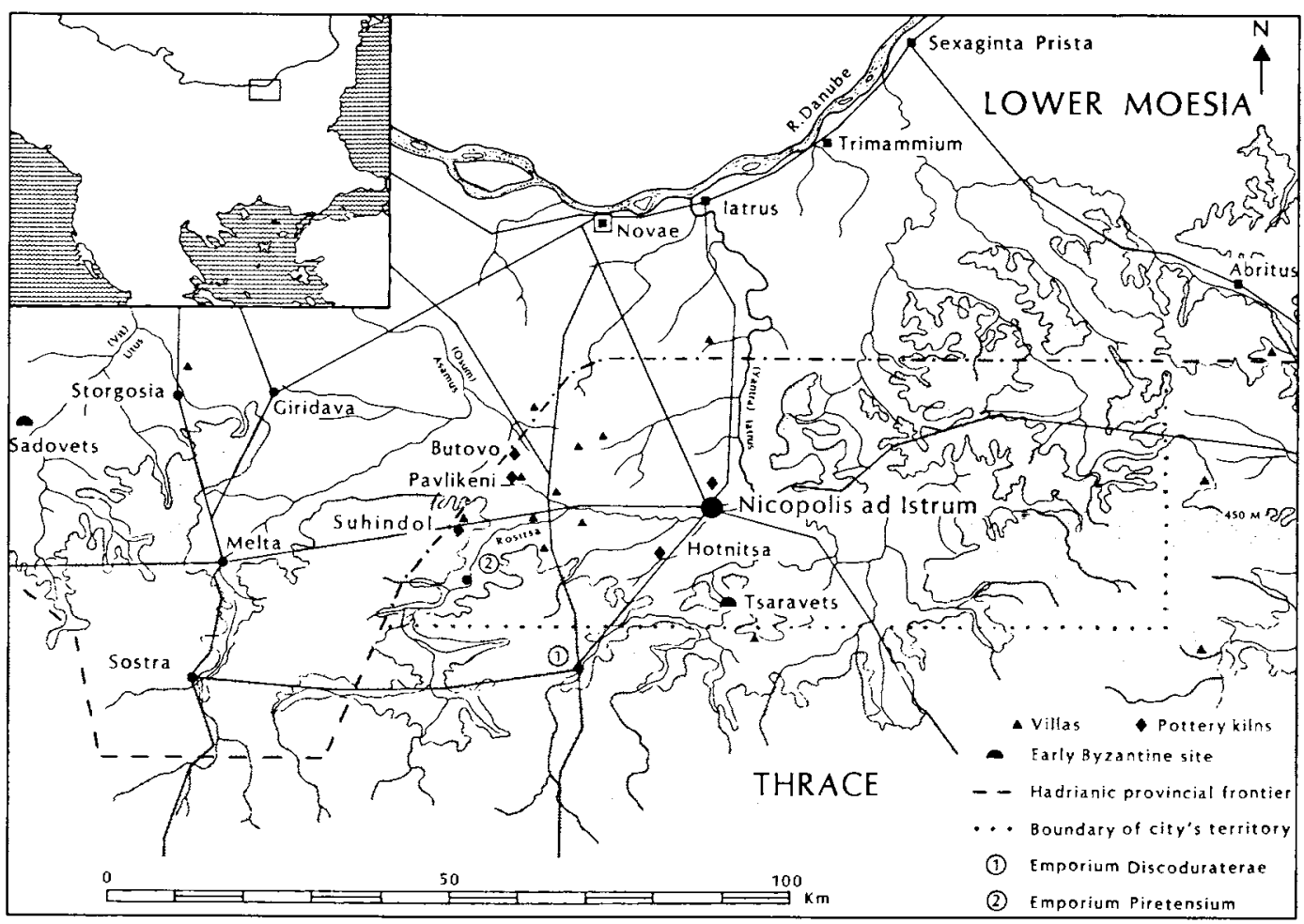

3.1 The city and its territory 
materials which could be obtained locally. It would seem reasonable to presume that the need for military supply would have affected, not just the immediate hinterland, but the cities of northern Thrace, especially Nicopolis and its twin foundation (Marcianopolis) both close to the garrisons strung out along the right bank of the Danube (fig. 1.3).

The extent of the city's territory can be determined with remarkable precision. To the north and west, its boundary must have been coterminous with the provincial frontier between Thrace and Lower Moesia, defined by boundary stones erected in $\mathrm{AD} 136$, and which here turned north then east following a course which was between 25 and $35 \mathrm{~km}$ distant from the city (fig. 3.1). ${ }^{25}$ To the south-west, the emporium of Discoduraterae remained under the control of the city of Augusta Traiana (Stara Zagora), also in Thrace, but on the southern slopes of the Haemus (Stara Planina). Consequently, the southern limit of Nicopolis' territory was also probably about $25 \mathrm{~km}$ from the city at least until the Severan period when the provincial boundary was moved south, assigning Nicopolis to the extended province of Lower Moesia. Only to the east is the extent of its territory uncertain. Assuming that the land between the two Trajanic foundations (Nicopolis and Marcianopolis) was equally apportioned, this would leave Nicopolis with a territorium which encompassed $c$. 4,000 square kilometres. The administration of such a large territory was at least partly carried out using market centres (emporia) which were officially controlled by the city. ${ }^{26}$ In the case of emporium Piretensium, there was a local administrator responsible for ensuring the correct use of weights and measures of grain and wine which were presumably produced locally (IGBulg. II 695) ${ }^{27}$ Since this emporium was on the upper reaches of the Rositsa, close to the south-western corner of the city's territory, produce bought in the market could then be shipped downstream to the city (fig. 3.1). However, another of the measures recorded in the inscription was for olive oil which must have been brought in from abroad. Consequently, the emporium was also a market for imported goods and not just for commodities available in the region.

There is a marked difference in the quality of the lands west and east of the Yantra. To the north and west, the city controlled fertile chernozem soils, well irrigated by the Rositsa and the minor tributaries of the rivers Yantra and Osum. Enjoying a moderate continental climate, this is one of the most fertile agricultural regions on the lower Danube and must have been the most densely settled and most prosperous part of its territory, as is suggested by the large number of inscriptions erected by villages and villa owners. ${ }^{28}$ Pottery centres which have been examined include Butovo, Hotnitsa and Pavlikeni and excavations have provided information on the character of local wares. ${ }^{29}$ Of these, the best investigated is Pavlikeni where a modest courtyard villa contained workshops, probably workers' accommodation and the owner's residence. Excavations have provided a valuable insight into the production process with the excavation of kilns and the discovery of finds which 
include moulds used to produce vessels, lamps and horses on wheels, presumably children's toys. ${ }^{30}$

The upland to the east of the Yantra was less well-endowed with fertile land and, more importantly, lacked surface drainage, factors which combined to reduce the value of this eastern part of the territory. This is reflected in the scarcity of settlements and the fact that few inscriptions have been found.

Other factors must have affected the local economy. The cold winters meant that olive cultivation could not have been carried out - olive-oil must have been brought in from abroad. Apart from agriculture, the city possessed few natural resources. Metal, in the form of ingots, had to be imported..$^{31}$ At Hotnitsa, south of the city, good quality limestone was mined for civic buildings and paving stones for the city and may well have been exported, especially north of the Danube where good quality stone was unavailable. ${ }^{32}$ Roman houses were regularly built of mortared stone with mudbrick superstructures. This may have been necessary because there were inadequate supplies of local timber, perhaps because deforestation had occurred even before the foundation of the Roman city.

Nicopolis commanded a central position within the North Danubian Plain. It lay astride the west/east route which started at Odessos (Varna) on the Black Sea coast, c. $250 \mathrm{~km}$ to the east and which reached Nicopolis via Marcianopolis then continued west towards Melta, Montana and forked south to reach Naissus in Moesia Superior (fig. 1.3). A major highway also connected the legionary fortress of Novae on the Danube and Nicopolis and then continued south-east to cross the Haemus, reaching Cabyle and central, eastern Thrace. Other roads ran south, crossing the Haemus to Augusta Traiana and north, along the left bank of the Yantra to meet the military road running along the right bank of the Danube, close to the fort of Iatrus. Still more important economically, were the city's river communications. Shallow draft boats could travel upstream as far at least as emporium Piretensium and probably up the Yantra to emporium Discoduraterae. From Nicopolis, river craft no doubt regularly sailed down-stream to the Yantra and on to the Danube where transshipment of goods into larger vessels would have allowed the export of materials up-stream or, still more likely, down-stream as far as the Black Sea and north, up the left bank tributaries, notably the Olt, and into Dacia Inferior. The same routes must equally have served for the import of goods, especially coming down the Danube from Pannonia and the north, or west up the Danube from the Black Sea. This was also the easiest route by which imports could be brought from the Aegean and further afield.

Little is known of the region in the late Iron Age and, so far, there is no evidence that the site was occupied before the foundation of the Roman city, despite its naturally attractive location on high ground overlooking the Rositsa. As far as can be estimated from the sparse archaeological and literary evidence, the region in the first century AD was populated by Geto-Thracian tribes which would seem not to 
have evolved into political entities of any size or importance. However, soon after the foundation of the city, new immigrants, mainly veterans of eastern origin, occupied villa estates in the fertile portion of the city's territory, as well as civilians, artisans and prominent citizens, who came from the East. A difference in language between the city and its hinterland is evidenced by the distribution of inscriptions. Founded as a city on the Greek model, Greek was the principal language of administration and was used for all civic and private monuments erected in Nicopolis, except for a few of the gravestones from its cemetery. However, the majority of inscriptions from the countryside are Latin, reflecting the dominance of veteran settlers amongst the literate, landed élite.

\section{The Roman city c. 117-250}

There is no evidence from any of the excavation areas that the site was occupied before the foundation of the city. ${ }^{33}$ Consequently, there is no reason to suspect that the earliest excavated deposits, belonging to the early years of the second century, are contaminated by residual material. ${ }^{34}$

During the first period of occupation from $c .110$ down to $c .130$, as one would expect, local Thracian pottery continued in use, including hand-made vessels in a distinctive ware (ware 25). The early Roman coarse ware (wares 30/31), both handmade and wheel-turned, derive from local Thracian types. This is hardly surprising: Thracian pottery was produced at the kiln sites of Pavlikeni and Butovo in the preRoman period and native producers no doubt quickly took advantage of the opportunities presented by the new urban market. ${ }^{35}$ However, there is a change, evidenced as early as c.130 when a new grey ware (ware 1) replaced Thracian products. This new pottery, though it includes a few early transitional forms, introduced new ranges of vessels of characteristically Roman type. The use of a new ware suggests that the earlier production centres, if they were still operating, no longer supplied the Roman city. Wherever the kilns supplying wares 30/31 were and they appear to have been local - the new grey ware was produced at the Roman kiln sites of Pavlikeni, Butovo and Hotnitsa and probably at other so far unidentified centres. Although Thracian pottery and improved products in ware 30/31 did reach Nicopolis during the very earliest years after the foundation of the city, they were rapidly replaced by vessels produced at these new centres in ware 1 which had little or nothing to do with native traditions of manufacture. Still more striking is the immediate appearance, before $c .130$, of locally produced high quality red-slipped fine ware (ware 8), with rouletted and appliqué decoration, including bowls, craters and fine cups (plates I, II). These vessels were found in assemblages which contained the early coarse ware (ware 25) and the better quality Roman coarse ware (wares $30 / 31$ ). Such a rapid start to local production of such high quality pottery is 
surprising. It proves that the new kilns were in operation only a few years after the city was founded and that the new suppliers were capable of employing sophisticated techniques of manufacture, unparalleled in the native, pre-Roman wares. There is also reason to suspect that the fine table ware was also mass-produced on a large scale from the start since, throughout the second century at Nicopolis, red-slipped wares predominate over ordinary coarse wares. ${ }^{36}$

The inspiration for the new pottery lies not with the West, still less with local Thracian vessels, but with the high quality slipped wares, of eastern origin. ${ }^{37}$ Fortunately, the inscriptions erected in the city during the second century provide a probable explanation. Not only eminent members of the boule, but also artisans (housebuilders and stonemasons) came from Asia Minor and, in particular, from the two cities of Nicaea and Nicomedia. ${ }^{38}$ The architecture of the agora, completed under Antoninus Pius, is clearly inspired by urban planning and embellishments of detail found in the Greek East. ${ }^{39}$ Immigrants of eastern origin must have formed an important element in the population of the city during the Antonine period. Moreover, since their influence on pottery production can be seen before $c .130$, craftsmen from the East were no doubt settled at Nicopolis and in its territory when the city was first established. A funerary inscription from Butovo commemorates a certain Agathodoros from Nicaea, possibly the owner of the pottery centre (ILBR 428). It is remarkable how few native Getic or Thracian names appear in the inscriptions of the city and those set up by villa owners in its territory. ${ }^{40}$ It follows that Nicopolis was in no sense a city created for the benefit of the indigenous population but that its foundation involved the settlement of new immigrants, notably from western Asia Minor. That a Trajanic city in this region should contain so many foreign citizens may not have been unusual in the region. ${ }^{4 !}$

Although less clearly datable than the pottery, a typical Roman agricultural economy was well established by the middle of the second century. Bread wheat and millet was brought in. Sheep and pigs as well as domestic fowl may have been kept on the site or close by. Beef was consumed and may have been brought in from further afield. No doubt, all basic agricultural products were supplied from the city's own fertile territory. Since inscriptions prove that villa estates were quickly established during the early second century, it is possible that agricultural production, like the pottery industries, was developed by the new landowning class of immigrants and did not represent an expansion of native Thracian farming to meet the demands of the urban market. Not all of the city's needs could have been met locally. The glass, including high quality cut-glass vessels of first century date, were imported. Oil must have been shipped in, coming up the Danube from the Black Sea. This probably explains the appearance of African amphorae (ware 38). Initially, clay lamps were also imported, perhaps incidentally as part of cargoes which contained more important commodities, but they were replaced by local products during the late Antonine period. ${ }^{42}$ 
It is striking just how little Gaulish terra sigillata reached the city during the Antonine period. This is quite unlike the situation in the provinces of Lower Dacia and Moesia Inferior where Central Gaulish ware appears to have been imported in bulk to supply both the military and newly established civilian markets ${ }^{43}$ If there had been the demand, Nicopolis could have imported Gaulish terra sigillata up the Yantra as easily as the pottery was supplied up the river Olt to Romula. No doubt, it was the high quality and the reduced cost of local fine wares which explains the lack of interest in Gaulish imports. Slightly more common are sherds of East Gaulish terra sigillata, dating to the late second and early third century. However, the quantities are so small that there would again seem to have been very little demand at Nicopolis at a time when this type of pottery was shipped down the Danube in quantity to supply military and urban sites on the right bank and in Dacia Inferior. ${ }^{44}$ In the Severan period, mortaria were imported. Since the stamps on those examples found at Nicopolis can be paralleled, not only on the lower Danube, but also in transcarpathian Dacia, it seems most likely that they were shipped downstream from a production centre in Moesia Superior or Pannonia. ${ }^{45}$

Most of the coinage in circulation was produced in the city's own mint during the Antonine and Severan periods. A few coins came from the neighbouring city of Marcianopolis and sporadically from other cities in the eastern Balkans, notably Anchialus on the coast, but not in sufficient numbers as to suggest that Nicopolis maintained any important commercial relations either with the Black Sea coast or with southern Thrace. Notable, too, is the total absence of imperial aes coinage although this circulated freely in the forts and cities on the Danube bank. ${ }^{46}$ Essentially, Nicopolis would seem to have been remarkably self-sufficient and apparently did not rely to any extent upon imports of manufactured goods, a picture reflected, for example, in the consumption of fish which was mostly of local origin, only supplemented by small quantities of catfish from the Danube and oysters, no doubt carried in barrels up the Danube from the Black Sea.

The fact that Nicopolis was able to supply most of its needs from its own territory does not mean that the city was economically isolated. Nicopolis was ideally placed to export agricultural supplies and manufactured products to the urban and military markets along the Danube and its tributaries, north into Dacia (fig. 1.3). Good quality limestone from south of the Danube was exported across the river and up the river Olt where there was no suitable local source of stone for inscriptions and monumental architecture; whether, as seems possible, the Roman quarries at Hotnitsa, were involved in this trade remains to be established. ${ }^{47}$ The fine wares from Pavlikeni would seem to have reached Novae in significant quantities. ${ }^{48}$ Nor was export limited to the Danube. Romula was also importing pottery from Nicopolis' kilns and the fine wares were shipped down the Danube to sites in the Dobrogea but not as far as the Black Sea coast. ${ }^{49}$ In particular, it would seem that Butovo was supplying fine ware not only to Novae and Oescus but also to Sucidava, on the left 
bank of the river, as well as to Romula. ${ }^{50}$ Since this kiln site commenced producing fine wares only during the latter second century and its period of maximum output belongs to the first half of the third, it is likely that economic links between the city on the one hand and the Danube bank and Dacia on the other were especially important during the Severan period.

There are several factors which may help to explain changes in the economic character of the city during the late second century. It was under Septimius Severus that the provincial boundary shifted south with the result that Nicopolis was taken out of the province of Thrace and assigned to Lower Moesia. Thereafter, Nicopolis was included within the tax district of the Publicum Portorii Illyrici et Ripae Thraciae. Before the boundary moved south, taxation would have been imposed on goods transported north from the city's territory and across the provincial frontier. After the change the duty would no longer have been exacted and this may have stimulated trade..$^{51}$ Other administrative reforms may have promoted closer links between Nicopolis and the Danube frontier. A primary concern during the first century must have been the supply of the military garrisons along the Danube bank. The reorganization of tribal groups under military control and the settlement of transdanubian civilians in Moesia was probably intended to increase production, and to ensure that regular military supplies could be obtained in the region. ${ }^{52} \mathrm{By}$ the middle of that century, local production was apparently sufficient to meet military needs since the governor, Plautius Silvanus, was able to send a surplus of grain to Rome, perhaps because the garrison of the province was reduced temporarily with the dispatch of $\mathrm{V}$ Macedonica to the East (ex ea provincia magno tritici modo annonam Populi Romani adlevavit ILS 986). Along the Danube, there was a reorganization of legionary extramural settlements during the reign of Hadrian. Not only canabae but also auxiliary extramural settlements (vici) would seem to have obtained territorial jurisdiction which, given that the settlements were on military land, presumably corresponded to territoria assigned to the garrisons. The reason for this arrangement may well be that extramural settlements were granted, not only limited rights of self-government, but privileges which included usufruct of land under military control. In return, they were probably liable to taxation in kind or in coin which could be used directly to supply or purchase supplies for the army. ${ }^{53}$ However, by the late second century this system had been abandoned. Extramural settlements declined in importance and were replaced by new urban centres, which must have acquired their own territoria, carved out of military lands. Deprived of their hinterlands, or at least significant portions of their territories, a new method of supply must have been found to meet the needs of the frontier garrisons. That the cities closest to the frontier were obliged or encouraged to contribute would seem a practical alternative arrangement. Transporting supplies from the immediate hinterland of the frontier would surely have been preferred to the cost and difficulty of importing bulk supplies from further afield. It is possible 
that some materials were levied in kind which might explain why more goods, including pottery, arrived in the forts on the Danube. Alternatively, if goods were purchased by the imperial government, this would have provided a welcome additional source of income and stimulated an increase in local production. Certainly, the citizens of Nicopolis would seem to have been able to pay other imperial impositions, including the ostensibly free donation of funds for the support of Severus' eastern wars, a gift duly acknowledged by the emperor (IGBulg. II 659). Whatever the new burdens placed upon the city or the advantages obtained by changes in military supply and the removal of a tax on exports, there is good evidence that Nicopolis enjoyed its greatest prosperity at this time, erecting new buildings, expanding beyond its fortifications with the construction of new town houses and producing coin in greater quantity than ever before..$^{54}$ Imports continue to remain few although, notably, fine quality wheel-cut glassware was still reaching the city during this period.

Changes are less easy to detect in the third century. However, there was a decline in the relative quantity of fine ware in use at Nicopolis. Although it has been suggested that the major pottery centres continued to function as late as the early fourth century, this is most improbable. ${ }^{55}$ The coin series from the kiln sites of Pavlikeni town and Pavlikeni villa both terminate with issues of Gordian III. ${ }^{56}$ Given the absence of late Roman coins from these sites, it seems most improbable that either of them continued to operate in the fourth century and, like the majority of the medium-sized Roman villas, they were probably abandoned about the middle of the third century. ${ }^{57}$ The rapid decline in the city's fortunes is suggested by the abandonment of the extramural area, new measures taken to improve the defences, and the decline, then disappearance, of public inscriptions - at a time when the collapse of the Danubian frontier and the repeated Gothic invasions must have disrupted agricultural production, quite apart from the periodic danger that the city might be captured; a threat which came perilously close to happening on at least two occasions. ${ }^{58}$

\section{The late Roman period c. $250-450$}

The proportion of fine to coarse wares continues to decline, especially during the late fourth and first half of the fifth century even though, as before, fine ware continues to be more common than coarse ware (fig. 8.1). However, although new types are introduced, there is no obvious break in production; many of the old forms and the same fabrics were used as in the Severan period. ${ }^{59}$ This is surprising given that, as noted above, the major pottery centres in the city's territory did not survive the third century. Perhaps, with the abandonment of many villas, new kilns were established at other sites which continued to be used but which have not yet been 
discovered. ${ }^{60}$ Another possibility is that workshops, which existed immediately north of the city, date to this period and that production continued here, closer to the protection of the city's defences.$^{61}$ Although still rare, imported fine wares did reach the city, notably African Red Slip and Late Roman C ware (Phocaean Red Slip ware from western Asia Minor).$^{62}$ Amphorae imports, coming from the Aegean and North Africa, are apparently more common than before and this may well explain the small quantities of fine ware, arriving along with shipments of more valuable commodities (fig. 8.2) ${ }^{63}$ The evidence, such as it is, suggests that the city's trading links lay with the Mediterranean, imports being shipped along the west coast of the Black Sea and then up the Danube. Conspicuous is the absence, apart perhaps from a single sherd, of Pannonian lead-glazed ware although this pottery reached the inland city of Stobi in the fourth century. ${ }^{64}$

There would seem still have been little demand for bulk imports, because the city was still being supplied with locally produced agricultural goods from its own lands, including bread wheat, barley and rye, pulses, and grapes. Chickens, pigs and sheep/goats were kept in the city or close by. Beef would seem less significant although cattle were brought to the city 'on the hoof' for slaughter. As with the continuity in pottery production between the Roman and late Roman periods, the lack of any change in the nature of agricultural supply is surprising given the apparent disappearance of many villa estates. Agricultural production would seem to have continued on much the same scale as before. Perhaps, the exploitation of the city's territories was now centred on a few larger estates, as the distribution and size of late Roman villas in the region suggest..$^{65}$ The local production of ceramic lamps, which had replaced imports in the second century, appears not to have continued in the late Roman period. One might conclude that demand had decreased because the citizens could no longer afford to import olive oil. In fact, it seems more likely that there was a change in the type of vessels used: there is an increase in the number of glass lamps during the fourth century and they continue to represent a significant proportion of the glass assemblage in the early Byzantine period. Other glass vessels used in this period include elaborate glass bowls, coloured beakers and high stemmed goblets which are of such quality that they are unlikely to have been made locally and must have been imported ${ }^{66}$ Where the glass came from is uncertain but, given the eastern origin of ceramic imports, it is most probable that luxury glass also came from the Mediterranean. Not that local glass production was necessarily unimportant. Even though the valuable items, which required the expertise of the glass cutter, are unlikely to have been made in the region, the manufacture of glass objects from recycled cullet certainly took place on the site, and probably during the late Roman period. ${ }^{67}$

Given that the quantity of coins of fourth century date constitutes a reasonably large sample, it is possible to draw some tentative conclusions about the volume of coinage in circulation and supply and to compare the evidence with other sites on 
the lower Danube. After the closure of the local mint under Gallienus, coin loss at Nicopolis declines sharply and remained low under the Tetrarchy. However, 'annual' loss of billon and bronze increases dramatically in the period between 317 and $388 .{ }^{68}$ This trend was in no way exceptional for the region since a similar cycle of minimal loss followed by a marked increase is true for the fortress of Sucidava beyond the Danube and at Iatrus. ${ }^{69}$ Although the number of finds suggests a major increase in the volume of base coinage arriving on the lower Danube during the middle to late fourth century, this need not reflect a corresponding increase in economic activity at Nicopolis nor is it necessarily true that the coins were all lost soon after they were minted. The majority of the finds came from the cobbled road-surfaces in areas $B$ and $\mathrm{C}$ which were still in use well into the fifth century - by which time there had been a significant reduction in the quantity of new coin being imported. It is quite possible that, when the supply of new coin declined, the older issues continued to circulate perhaps as late as the middle of the fifth century and were lost then and no earlier. Nor is there any unanimity of opinion as to the factors which determined the volume of base coinage released into circulation. ${ }^{70}$ However, although the mints of Siscia and Thessalonica supplied a substantial portion of coins found at Nicopolis until the later fourth century, the Propontis mints of Nicomedia, Cyzicus, Heraclea and Constantinople are also major sources of supply, and become dominant by the end of the century. ${ }^{71}$ At latrus, the bias in favour of the Propontis mints is still more marked..$^{72}$ In this respect, Iatrus and Nicopolis were typical of many sites on the lower Danube in having a high percentage of coin issued from the Propontis mints, even when they were located in the Diocese of Dacia which might be expected to rely upon the supply of coin from Siscia and Sirmium. ${ }^{73}$ The bias in favour of the Propontis mints in finds from the lower Danube as a whole would seem best explained by a significant level of trade between the lower Danube and the Mediterranean. ${ }^{74}$ Given the evidence for imported goods from the Mediterranean at Nicopolis in the fourth century, it would be tempting to conclude that the bias in the nature of supply also reflected the importance of the city's long distance trade. However, the city was always within the diocese of Thrace, which belonged to the Eastern Empire, and it is only reasonable to expect that the Propontis mints should be a primary source of coin. Moreover, although the importance of eastern mints amongst the coins circulating in the region is clear and may well point to commercial links with the East, this does not prove that the city itself was to any significant extent involved in that trade; its own coinage may simply reflect the circulation of coin locally available in this period.

It is worth considering the extent of trading links between the region and the Mediterranean. Again, the coinage is relevant. Quite unlike other sections of the Danube frontier, unusually large numbers of silver coin have been found beyond the river and across the Danube plain, south of the Carpathians, notably at Sucidava on the left bank, and it is reasonable to accept the suggestion that the appearance of 
so much silver is because it was used in trade across the frontier. ${ }^{75}$ Sucidava, as an important bridge-head settlement, must have been a major transit point for goods going north beyond the empire. Soldiers themselves seem to have been active in profiting from transdanubian trade (Themistius Or.X 136b, Amm. Marcell. XX.11,8; XXI.9,11). In 369 trade with the Goths was limited to two crossing points on the Danube (Themistius Or. X. 135c). One of these may have been Izvoarele (Sucidava?) in the Dobrogea where a remarkably large number of late Roman lead sealings ( $c$. 140) have been found, amongst which stamps of Smyrna and Ephesos denote imports from Asia Minor (fig. 1.3).$^{76}$ Probably Sucidava was a river port where goods were unloaded, if not for sale there, then for transferring to shallower draft vessels and transportation north up the Danube's left bank tributaries. Here, in Walachia, Roman metal-work, glass, amphorae and pottery constitute a high proportion of the assemblages on sites attributed to the so-called Sintana-de-Mureş/Cherniakov Culture. ${ }^{77}$ Quite what was exchanged for these goods and the silver coin remains uncertain; raw materials, agricultural goods and slaves were probably attractive commodities. Such perishable items leave no trace in the archaeological record and whether the inhabitants of Nicopolis continued their trading links with the region remains, at present, impossible to determine. ${ }^{78}$

Despite the regional importance of trade in the fourth century, it is difficult to see any sign that Nicopolis had recovered any of its former prosperity. The total quantity of imported fine wares was negligible and the evidence for the importation of amphorae hardly significant. The impression is that the city not only enjoyed few commercial contacts outside the region, despite the evident vitality of trade on the lower Danube, but that Nicopolis was no longer able to invest in public building projects or even erect imposing private monuments as had certainly been the case before the Gothic invasions of the third century. ${ }^{79}$ Significant probably is the fact that the fortifications were not rebuilt on an impressive scale, as happened elsewhere on the Danube, but maintained their earlier form. One explanation for the apparent decline may be the radical change in the character of the site in the late Roman period. The Roman extramural houses of the Severan period had been abandoned, their inhabitants perhaps retreating to the protection of the city walls where large stone built houses occupied single and even double insulae, suggesting that there were some thirty rich families living within the city (fig. 1.1) ${ }^{80}$ However, the plateau to the south of the city was intensively used for industrial production, agricultural buildings and houses. Indeed, there would seem to have been more activity than ever before, although the inhabitants occupied modest structures with mudbrick walls, resting on stone and earth foundations (fig. 2.3). The area was apparently densely settled by people of clearly inferior economic status to those living within the city. It could be that the extramural community comprised native settlers who moved from the countryside to the comparative safety of the settlement outside the city's walls. Certainly, the metalwork found in the extramural settlement is typical 
for sites of the period and none, in decoration or form, appears to be foreign. But there is a change in the pottery from the middle of the century when a new wheelthrown fabric (ware 14), often with burnished zig-zag decoration appears. Because local forms were also produced in this fabric, it seems that the potters were familiar with Roman manufacture but other types are new and have no parallel in earlier Roman vessels but are similar in form and decoration to the pottery associated with the Sîntana-de-Mureş/Cherniakov Culture which appears north of the Danube as early as the late third century and is dominant throughout the late Roman period and it is believed to have been produced by the Goths. ${ }^{81}$ It is inherently improbable that this coarse ware would have been imported and the fabric, though unparalleled in earlier wares, would seem to have been local. It may be that this pottery at Nicopolis was introduced by new settlers from beyond the frontier. The lack of any non-Roman metal-work and the continued use of Roman pottery would not be surprising even if the new arrivals were Goths since, as noted above, they were already importing such manufactured goods while still living beyond the Danube. ${ }^{82}$ That Goths should be living outside the city during the second half of the fourth century would not be surprising. It is known that the Goths of Ulfila were settled in the territory of Nicopolis in the middle of the fourth century..$^{83}$ If Goths did make up a significant proportion of those living outside the walls, it may explain certain unusual features of the settlement, notably the extramural market and precautions taken to control the entrance into the city through its south gate. ${ }^{84}$ What does seem certain, however, is that there existed a distinction in economic status between the intramural population of wealthy families and a large but demonstrably poorer population living in the extramural area.

For the first time, useful comparisons are possible with the military sites along the Danube. Ware 1 vessels appear at Novae and Iatrus. ${ }^{85}$ However, although similar types appear on the frontier to those used at Nicopolis, it remains most likely that forts were served by separate production centres, not those supplying the city. ${ }^{86} \mathrm{In}$ the case of latrus, it is the dominant position of imported wares which remained constant at c. 40 per cent of the assemblage from the fourth and through into the sixth century. ${ }^{87}$ Of these imports, amphorae represented no less than 30 per cent of the total during this period. ${ }^{88}$ Late Roman $\mathrm{C}$ ware was also arriving at Iatrus before the middle of the fourth century. ${ }^{89}$ Although comparable information is not available from other sites, the situation at Iatrus is very different from that at Nicopolis. Amphorae and fine wares are well attested here and at other sites along the Danubian frontier as well as on the Black Sea coast. ${ }^{90}$ Indeed, Late Roman $\mathrm{C}$ ware reached the Black Sea coast in large quantities during the late Roman period.$^{91}$ Clearly, imports were arriving by sea and then going up the Danube to supply military garrisons but were not getting to Nicopolis in any quantity. However, this need not necessarily imply that Nicopolis was in terminal decline. The lack of amphorae imports may again, as suggested for the second century, simply reflect the continued exploitation 
of its agricultural hinterland and the limited demand for the importation of most basic commodities. However, the inhabitants of the extramural area were probably not sufficiently wealthy to purchase imports which may still have been reaching the families living within the city.

From the middle of the fourth down to the middle of the fifth century, there appears little sign of any significant economic change, despite the turbulent history of the period, following the Gothic revolt and the consequences of the defeat of Valens at Adrianople. The same range of agricultural goods, no doubt still locally produced, was reaching the city. Local fine wares were still in use although they continue to decline in proportion to coarse ware, still dominated by the traditional ware 1 types alongside vessels in ware 14. Nevertheless, imports of amphorae decline slightly (fig. 8.2). Also, coin circulation, with a second if less pronounced peak during the first quarter of the fifth century, declines dramatically and matches the pattern established at both Iatrus on the Danube and Sucidava on the left bank of the river. ${ }^{92}$ There would seem to have been a partial if not total abandonment of the extramural area in the late fourth century and measures were taken to improve the security of the city during the second quarter of the fifth century. ${ }^{93}$ However, it is difficult to prove that there was any equally dramatic decline in the city's economy. Indeed, at the time of the destruction of the city in $c .450$, perhaps by the Huns, the environmental evidence suggests that agricultural production had continued at much the same level as before; a similar range of crops was reaching the city. Moreover, it is from these destruction deposits that some of the most impressive luxury glass came, including fragments of two diatreta, wheel-cut vessels, dishes, lamps, trays and high quality goblets as well as figure engraved glassware. These finds are unlikely to be residual; the probability is that the majority of vessels were actually in use during the first half of the fifth century. It is therefore of interest to note that some of the high quality glassware, such as the diatreta, which must have been prized possessions, could well have been a century old at the time of deposition. Still more striking is the appearance of a late first/second century wheelcut beaker and another of the late second to third century which came from the same destruction deposit and which may have also still been in use, despite their age at deposition: a timely reminder that luxury objects such as these could have been extant years after their manufacture and not necessarily residual when found in late contexts. ${ }^{94}$ Certainly, the high quality of the glass suggests that imports of quality were still reaching the city. It seems probable that these objects were not owned by the poor inhabitants living in the extramural settlement. More likely is it that they belonged to the wealthier inhabitants at Nicopolis who lived within its walls. Where the glass was coming from remains impossible to determine. ${ }^{95}$ However, given the origin of imported pottery in Asia Minor and North Africa, it is reasonable to suppose that glass also came from the same regions. Even diatreta, though probably manufactured in the Rhineland, may well have come from the 
East, no doubt from a major city where there was the demand for the specialized skills needed for their manufacture.

While Nicopolis seems to have had some wealthy inhabitants at the time of its destruction $c .450$, the excavations at latrus suggest that there was a radical change in the character of the fort during this period which may well have had important consequences for the economy of the city and its surrounding area. During the second period of occupation, dating to the second half of the fourth century, the regular arrangement of barracks would seem to have given way to a more haphazard plan, possibly denoting a reduction in military strength and possibly the replacement of a regular garrison with federate troops. ${ }^{96}$ There was also a marked decline in good quality local coarse ware and increased use of local pottery, perhaps made in the immediate vicinity of the fort. ${ }^{97}$ Still more remarkable is the excavation of a substantial workshop, dating to the first half of the fifth century, which contained at least twelve millstones, each set upon a mudbrick foundation. This implies that Iatrus was then a major centre for the processing and perhaps storage of grain. ${ }^{98}$ Comparable evidence is found in the fourth century quadriburgium in Moesia I where the river Porechka joins the Danube. The fortlet was built beside granaries which were too large to have supplied just this small garrison. ${ }^{99}$ Both sites were situated at the mouths of rivers, convenient for the transportation of agricultural produce from the interior and down to the Danube. In the case of Iatrus, it is probable that its role included the processing of grain brought down the river Yantra and consequently from the territory of Nicopolis. Since the size of the operation would seem unjustified for the reduced garrison of the fort, it may well be Iatrus acted, like the quadriburgium on the Porechka, as a collection point for grain and other agricultural products, which were then supplied by ship to other garrisons along the Danubian limes. As noted above, there was a marked decline in coin loss at Nicopolis from the second decade of the fifth century. ${ }^{100}$ The virtual disappearance of coinage during the reign of Theodosius II is true of Iatrus and other sites in the region. ${ }^{101}$ Not that this necessarily means that some coinage was not still being used at least down to the invasion of the Huns and the destruction of the late Roman city. ${ }^{102}$ Rather it suggests that regular payments to the military on the frontier had been reduced and perhaps by the 430 s suspended. ${ }^{103}$ If true, then it is hardly likely that military supplies were bought on the open market. More probably, agricultural produce and other materials which could be obtained locally were exacted as taxation in kind and transported directly to Iatrus for processing and redistribution.

Whatever the consequences for the rural population and possibly the residual population living outside the city in the years leading up to 450 , clearly an élite minority of the urban population, living within the protection of its fortifications, was still wealthy in this period. 


\section{The early Byzantine period}

The late Roman city was destroyed about the middle of the fifth century and left derelict until the early Byzantine fortifications were erected, possibly as early as the 450s. ${ }^{104}$ Even so, some sporadic occupation continued in the intervening period and the site may never have been completely abandoned. The pottery from the early Byzantine occupation shows no break in the continuity of either wares or types found in the latest period of occupation belonging to the late Roman city. This suggests that no long interval separated the destruction of the city from the construction of the new defences. Ware 1, the local grey ware, continues as before and the micaceous grey ware (ware 14 ) is now regularly burnished. ${ }^{105}$ The proportion of fine ware to coarse ware declines further, thus continuing the trend established in the fourth/fifth century. There is, however, a marked increase in imported amphorae (fig. 8.2) from a wide variety of sources, notably from Africa and the Aegean but also including Gaza amphorae (fig. 8.3). ${ }^{106}$ Some fine ware imports appear, though they are still not common. They include African Red Slip and Late Roman C wares and, interestingly, small quantities of Cypriot Red Slip ware, perhaps imported with other goods from western Asia Minor and the southern Aegean. Quantities are still small but the rise in imported amphorae may be connected with what seems a dramatic change in agricultural production. There was a sharp decline of winter sown grain and it was replaced by a 'market garden' economy with a predominance of spring sown crops and the consumption of a wide variety of pulses and legumes. Tentative though the evidence is, it suggests that the local economy was no longer based upon large-scale grain production as it had been during the Roman and late Roman periods. This could have been due to the fact that the frequency of barbarian inroads had made the sowing and harvesting of crops increasingly difficult. The effects of climatic change also may have been significant although, as yet, it is impossible to prove whether there was a deterioration in the climate which affected this region. ${ }^{107}$ However, the new agricultural basis of the economy may have been brought about by imperial policy. The union into a single administrative unit of the provinces of Moesia II (in which Nicopolis was situated) and Scythia together with Caria, the Cyclades and Cyprus would seem a curious arrangement, but for the fact that we are told that its purpose was to ensure that the forces on the Danube received their annona. For whatever reason, there were evidently problems in supplying the army from local resources. That Moesia II and Cyprus were now joined in the new administrative unit of the Quaestura Exercitus may well explain the appearance of Cypriot pottery at Nicopolis where it could have arrived together with grain and other basic commodities for the army. Certainly, the physical character of Nicopolis at this time suggests that it served as a major military base (plate VI). ${ }^{108}$ Moreover, the rise in the quantity of amphorae and the fine ware 
imports at Nicopolis links the site now more closely with the fort at Iatrus than ever before. ${ }^{109}$ It is remarkable that very few coins of this period were found at Nicopolis. ${ }^{110}$ Similarly, at Iatrus there were few finds of sixth century date, all folles. ${ }^{111}$ However, the same would not seem to have been true of hill top fortifications in the region. At Golemanovo Kale and Sardovsko Kale, isolated finds and hoards suggest a remarkable quantity of coins in circulation. ${ }^{112}$ Given that only five sixth-century issues were found at Nicopolis, it seems doubtful whether coin was used as a medium of exchange. The low rate of coin loss at latrus and Nicopolis could be explained if the military were not regularly in receipt of coin as pay but relied upon the official supply of food and materials from the state.

Glass was still much in evidence in this period. Glass lamps were used for lighting the basilicas but were also found on other sites which suggests that they were not just reserved for ecclesiastical use. High quality drinking vessels continued to be imported. ${ }^{113}$ However, the bulk of the glass would seem to have served utilitarian purposes and the high quality decorative vessels, found in earlier assemblages, are largely absent in this period.

That there was a shift away from local exploitation of the surrounding territory to dependence upon imports may not be because of local difficulties of supply but could be connected with the new role of the early Byzantine 'city'. Its administrative, ecclesiastical and probably military role is clear enough in the results of the excavations. ${ }^{114}$ There is little sign of civilians living within the defences. What appears to follow is that the 'city' functioned as an imperial establishment and this may explain why, instead of as formerly depending on its economic hinterland, it was now maintained and supplied directly by the imperial government.

\section{Conclusion}

This survey underlines the difficulties involved in any attempt to place Nicopolis in its economic context. Despite this, a general picture emerges, if indistinct in detail. The Roman city rapidly, almost spontaneously, acquired a full Roman economy and a remarkable degree of wealth which markedly increased in the Severan period. Of course this does not mean that the wealth was evenly distributed. No doubt it was always concentrated in the hands of a minority but a minority which could afford to be generous in funding civic building projects. Quite remarkable is the selfsufficiency of the city, the extent to which Nicopolis could rely on its own resources and, at least until the late second century, remained unaffected by the proximity of the military markets on the Danube. A period of decline from the middle third century is probable. This was followed by the emergence of a 'double city', composed of a nucleus of a small number of wealthy families living within the walls surrounded by a substantial extramural community of poorer inhabitants, perhaps Goths. The 
agricultural economy seems largely unaffected until well into the fifth century. The early Byzantine city which succeeded late Roman Nicopolis in the late fifth and sixth centuries signals a clear break in economic terms. Nicopolis now seems to have been no longer closely linked with the economy of its territory but had become reliant to a much greater degree than ever before on supplies from abroad. In fact the city was maintained by the imperial government whose interests it served as a military and ecclesiastical stronghold.

\section{NOTES}

1 Quantification in ceramic studies is as important as the publication of dated sequences. Although this has now been canvassed for more than two decades, it is a procedure which has not been universally applied; cf. Hayes 1980 , xiii.

2 cf. Fulford, 1991, 35-47.

3 See below, pp. 58-9 and p. 300.

4 See above, p. 32.

5 See above, pp. 43-4.

6 For example, coin loss. Although silver and gold must have represented a significant proportion of coins in circulation, only one silver coin was found - partly because of the obvious fact that greater care would have been taken to ensure that valuable coins were not lost - although this may not be a totally satisfactory explanation; K. Butcher in Poulter 1995, 305-9.

7 For example, at Stobi, Eastern Sigillata A from Syria/Palestine was imported in the late Hellenistic period, probably not a significant import itself but arriving along with other goods from that region for which there is no direct archaeological evidence; Anderson-Stojanović $1992,185$.

8 The importance of Italian imports at Stobi during the late Hellenistic and early Roman period may reflect, not economic considerations, but rather the military importance of the site and the number of Roman settlers living there; Anderson-Stojanović 1992, 185-8. For a possible military explanation for the eastern origin of imports at Nicopolis in the early Byzantine period, see above, pp. 47-8.

9 See below, p. 94 .

10 See below, p. 356.

11 See below, pp. 110-11.

12 The chemical fingerprinting of Roman, late Roman and early Byzantine glass to identify production sites is bedevilled by the problem of recycling. Pers. comm. Dr J. Henderson, Dept. of Archaeology, University of Nottingham.

13 See diatreta, below p. 365.

14 See below, p. 304.

15 The reports on the other finds and the environmental evidence have been submitted and will be included in a volume on the Nicopolis finds that is currently in preparation. Summaries of results have been published; Poulter 1995, passim.

16 cf. Press and Sarnowski 1990, 225-43.

17 Iatrus I-IV.

18 Uenze 1992.

19 Anderson-Stojanović 1992.

20 Tsarevgrad-Turnov I-V.

21 Kabakchieva 1986; Mladenova 1991. 
22 See, for the pottery, Soultov 1983, 126. Also, socially, southern Thrace and the Danube Plain were very different, both in terms of native population and immigration in the Roman period, see above, pp. 35-6.

23 See p. 57 and p. 299.

24 It is relevant here to point out that one of the most important sites in the Near East which does offer the potential for dating glass finds is Jerash, where Mr Falkner has provided the first study of the ceramic sequence which will establish the local chronology; cf. Falkner 1986, 247-51.

25 Poulter 1995, 11.

26 Note, Discoduraterae belonged to Augusta Traiana until the reign of Aurelian, but thereafter was assigned to Nicopolis. However, emporium Piretensium was apparently always within Nicopolis' territory.

27 Wine is produced in the region today and grape seeds from Nicopolis prove local cultivation of vines during the late Roman and early Byzantine period. No doubt, vineyards were established when the city was first founded.

28 Poulter 1992a, 77-83.

29 See below, pp. 108-9.

30 cf. Soultov (1985).

31 See the volume on other finds from Nicopolis (forthcoming) for metal production and importation of raw materials.

32 See above, p. 38.

33 See above, p. 12.

34 For the difficulties of coping with residuality, see below, p. 94 . Since this would not seem to be a problem in this period, the finds of pottery and glass provide an unusually secure group of assemblages for this primary phase of occupation.

35 Soultov 1983, 119; idem 1985, 22, 26.

36 The dominance of the new fine wares over coarse wares presumably denotes the ready availability of the former and at a cost which allowed it to compete effectively with the ordinary cooking vessels. This could only have happened if the production of fine ware was able to match demand. It is difficult to believe that coarse wares could have been in short supply, particularly as Thracian products were clearly used during the earliest years. At Stobi, for example, as is more usual, coarse wares always predominate over local fine wares (AndersonStojanović 1992, fig. 5.11,191). Although the quantity of pottery recovered from these early deposits is less than for later periods, the same dominance of fine ware over coarse ware continues into the late Roman period.

37 See below, p. 74 and pp. 110-11.

38 Poulter 1992a 76-7; idem 1995, 11.

39 Poulter (1995), 11.

40 Poulter 1992a, 76-81.

41 In the case of the cities in Dacia, including Sarmizegethusa, native Dacian names are notable by their absence. Nor later do there seem to have been many citizens of local origin. Here, too, the names are mostly eastern. There is therefore reason to believe that the Dacian cities were also largely populated by immigrants and that native Dacians appear not to have taken an active role in civic administration.

42 See the next volume on finds from Nicopolis (forthcoming).

43 For the forts along the Danube to the north of Nicopolis, evidence for terra sigillata appears slight, probably because even at sites which have been subject to extensive excavation, rarely have levels dating to the first and second centuries been extensively examined. Even so, recent excavations at Oescus have identified both the importation of Italian terra sigillata and, for the second half of the first century, South Gaulish products (Kabakchieva 1994, 148-70). Central 
Gaulish terra sigillata appears in quantity both in forts, in the city of Romula and on rural sites north of the Danube during the second century; Tudor 1968, 79-83.

44 For Novae, see Dimitrova-Milcheva 1984, 114; Popilian and Ciucă 1988, 61-78; Muşeţeanu and Elefterescu 1990, 235-44.

45 Reynolds in Poulter (1995), 318-21.

46 On the circulation of coins at Nicopolis see K. Butcher in Poulter 1995, 309-11.

47 For the export of limestone from Bulgaria to the valley of the Olt cf. Tudor 1968, 78.

48 Dimitrova-Milcheva 1984, 114.

49 Popilian 1976, 52, 148, 225.

50 Kabakchieva 1990.

51 Certainly the tax district included Moesia Inferior but not Thrace, and stationes existed on the river bank; De Laet 1949, 200-9. However, there would seem to have been other stationes in the interior and perhaps one at Nicopolis itself (ILBR 361), although it is reasonable to suppose that the tax exacted at crossroads or river crossings within the tax district was less than the probable 2 per cent imposed on exit from and entry into the tax district; ibid. 228-9, 242-5.

52 Poulter $1990,143-52$.

53 Poulter, 1987, 393-5.

54 There is a marked increase in coin loss in the period 193-222; K. Butcher in Poulter 1995, 308 and fig. 110 . The actual quantity of finds is insufficient on its own to prove that more coins were being minted at this time. However, the dramatic rise in the number of reverse issues produced under Septimius Severus and Caracalla does indicate that the actual amount of coin being produced was conspicuously more than at any other period in the history of the Nicopolis mint; Pick 1898, 332, 355-431.

55 See below, pp. 108-9.

56 Soultov 1962; idem. 1977, 19-20.

57 On the abandonment of villas cf. Poulter 1983, 92-4.

58 Of course, the decline in inscriptions is true of the empire as a whole. However, on the Black Sea coast, private dedications were still not uncommon in the fourth century and continued to be put up as late as the sixth century AD; Poulter 1992b.

59 See below, pp. 101-4 and 113-14.

60 Although apparently fewer in number, those villas which were used in the fourth century on the lower Danube are conspicuously larger, probably because they controlled extensive estates. Clearly, there may well have been some such large establishments within the city's territory which have so far escaped detection.

61 See below, p. 110.

62 See below, p. 105.

63 A similar explanation may account for the presence of African and Phocaean Red Slip wares at Stobi; Anderson-Stojanović 1992, 193 and fig. 5.13, 192.

64 Anderson-Stojanović 1992, 192.

65 Poulter 1983, 90.

66 See below, pp. 334-9 and pp. 371-3.

67 See below, pp. 376-8.

68 K. Butcher in Poulter 1995, 308-9.

69 For Sucidava see Duncan 1983, table 1 and p. 167. For Iatrus see Schönert-Geiss 1979, 167-9.

70 It has been argued that fluctuations in the quantity of coin in circulation reflect regional and chronological variations in economic activity (Fulford 1978,67-114). In the author's view, at least for the lower Danube, there appears to be a correlation between military activity and the volume of coin arriving in the region which suggests that state expenditure on the army was the principal determining factor. Even so, it remains uncertain whether the base coinage itself was paid to the soldiers or whether it was supplied to money changers who exchanged it for 
precious metal which had been given to troops as pay and which was then returned to the state by taxation; see Duncan 1993, 4-10. Either way, if military expenditure dictated the volume of coinage arriving on the lower Danube then even if all pay (which was not supplied in kind) was in precious metal, this expenditure would still be reflected in the quantities of base coinage brought in to recover the gold and silver.

71 K. Butcher in Poulter 1995, 310-13.

72 Schönert-Geiss 1979, 169-70.

73 Although Sucidava (Celei) is within the Dacian diocese and, being on the Danube, could easily have been supplied from the Pannonian mints, 55.6 per cent of its coins came from the Propontis and only 16.4 per cent from Siscia and Sirmium (Duncan 1993, 10-11, 117-18).

74 Duncan 1993,117-18. This is not to say that the actual quantities of coin in circulation were not the result of imperial expenditure on the army, simply that large quantities of coin were exchanged for issues from the eastern mints.

75 Duncan 1983, 170-3; idem 1993, 110-14.

76 cf. V. Culică, 1975, 215-62; M Still 1995, 63-4. Other sites which have been extensively investigated (Oescus, Novae and Durostorum) have produced only a few lead sealings whereas at Izvoarele no regular excavations have ever taken place. Consequently, the extraordinary number of surface finds from this site is remarkable.

77 B. Mitrea and C. Preda 1964, 211-37. The cemetery at Smîrdanu-Gălăţuiu is typical in that 25 per cent of the pottery represented imported Roman vessels; M. Comşa, 1965, 283-93.

78 It would help if more detailed analysis and publication of the Roman pottery from Muntenia and Walachia could determine whether some of the Roman imports included wares manufactured at or close to Nicopolis. As yet, however, no such studies, which should include fabric analysis, have been carried out.

79 Only one public inscription can be ascribed to the fourth century, in marked contrast to the cities on the Black Sea coast where public and private inscriptions continue into the late Roman period. More significantly, the only fourth-century private inscription, though probably from an impressive burial, is crudely cut and suggests that even for comparatively wealthy families, the services of skilled stone cutters were no longer available; J. Reynolds in Poulter 1995, no.1, p. 315-16.

80 See above, pp. 17-18.

81 See below, pp. 73-4.

82 See above, pp. $42-3$.

83 See above, p. 17.

84 See above, p. 19.

85 See below, pp. 66-73.

86 It is suggested that, during the first half of the fourth century, the kilns in Nicopolis' territory were supplying Iatrus; Böttger 1982,84. However, as noted above, the excavated kiln sites in the city's territory would seem not to have continued in use beyond the third century. See above, p. 40. Moreover, similar types to ware 1 appear at Armira in southern Thrace and therefore represent a common repertoire of forms used at opposite ends of the Thracian diocese.

87 Böttger 1982, diag. 16, p. 81 and 84 .

88 Böttger 1982, tab. 4 and diag. 2, p. 75 and p. 85.

89 Böttger 1982, 59-62, diag. 12, p. 79.

90 Böttger 1982, 90-4.

91 Böttger 1982, 62 (Histria and Tomis). African Red Slip ware and Late Roman C ware are far from rare in the Black Sea coastal cities and along the Danube but infrequently penetrated inland; Minchev 1983, 194-201.

92 K. Butcher in Poulter 1995, 308-9; Schönert-Geiss 1979, 168-9; Duncan 1983.

93 See above, p. 20. 
94 See below, glass catalogue, nos 115 and 124 . Note also the appearance of first-century glass amongst the primary deposits dating to the first half of the second century AD where they could not have been residual.

95 See above, p. 30.

96 Iatrus-Krivina IV, 15-16, 17-18.

97 Böttger 1982, 84.

98 Iatrus-Krivina $I V, 111-16$.

99 Petrović 1977, 259-75.

100 K. Butcher in Poulter 1995, 308-9 and fig. 110.

101 Schönert-Geiss 1979, 169; Duncan 1993, 116-17.

102 See above, pp. 19-20.

103 This follows if it is accepted that the primary factor dictating the quantity of base coinage in circulation was the level of state expenditure on the army, see above note 70 .

104 See above, p. 21.

105 See below, p. 105.

106 See below, p. 115.

107 It has been suggested that a drier climate was one reason why Stobi was abandoned in the late sixth century; Wiseman 1984, 309-13.

108 See above, p. 24.

109 At latrus, the importance of imported amphorae remains significant although there is a drop in the quantities of imported fine wares; Böttger 1982, 80-7.

110 K. Butcher in Poulter 1995, 309.

111 Schönert-Geiss 1979, 206-7. Sieving was carried out at Nicopolis and every attempt was made to retrieve even the smallest coins. It remains less certain whether the apparent dominance of large denomination bronze coins elsewhere indicates that small change was in short supply throughout the region.

112 Despite the modest size of these settlements, hoards of gold and bronze as well as isolated finds of sixth century date indicate that they were both receiving substantial quantities of coin. At Golemanovo Kale, 111 folles and half folles were individual finds. Three hoards contained folles and half folles, totalling 246 coins, and three hoards together amounted to 150 gold coins (solidi and tremisses); J. Werner in S. Uenze 1992, 413-14. The first season of fieldwork in 1996 on the settlement of Dichin, c. $10 \mathrm{~km}$ west of Nicopolis and directed by the author, involved limited excavation of one sector which produced 6 folles of sixth-century date, one more than was found during the entire fieldwork programme at Nicopolis.

113 See below, pp. 337-9.

114 See above, p. 24. 



\title{
SECTION TWO
}

\section{The pottery}

\author{
R.K. Falkner
}





\section{The ceramic analysis: methodology}

\section{Introduction}

One of the primary objectives of the British Archaeological Expedition to Bulgaria was to produce a secure pottery chronology for the site from its first occupation down to and including the post-medieval period. The use of pottery purely as an 'index fossil' has been generally decried recently and for good reason. Work has concentrated on the technology of production, ${ }^{1}$ scientific analysis of fabrics, ${ }^{2}$ and pottery as an anthropological tool. ${ }^{3}$ This emphasis on what may be termed 'level 2' ceramic studies is obviously desirable and possible where the pottery is well known, and well dated, as it is (relatively) in western Europe and the United States. However, in regions where the pottery chronology is not so well established, the secure dating of the ceramic assemblages must remain the primary objective. The aim of this survey is to publish the material collected during the British excavations, to date that material, and to include sufficient primary data to substantiate the conclusions drawn from the analysis of the assemblages.

Soultov (1985) has undertaken a considerable amount of work on the basic technology of local pottery production so there is no need to reproduce his conclusions here. For those wishing to conduct other 'level 2' studies, the relevant information is in the computerized archive available in the Department of Archaeology at the University of Nottingham. The pottery itself is stored in the Veliko Turnovo museum.

Local pottery centres have been excavated (Soultov 1985) and general works on early Roman ${ }^{4}$ and later Roman ${ }^{5}$ pottery have been published. Some excavation reports include comprehensive studies of ceramic finds. ${ }^{6}$ However the chronology remains by no means definitive. It was therefore decided that, in the first stages of producing a controlled chronology, only on-site evidence would be used; and evidence from other sites would only be compared with the Nicopolis material after a good relatively dated sequence had been established and only after all on-site 
evidence had been taken into account. ${ }^{7}$ It was hoped that this would avoid compounding any chronological errors that may have been made in earlier studies.

\section{Collection, recording and the archive}

All pottery from all contexts was collected, bagged and sent for washing. After cleaning, the pottery from each context was sorted by ware, ${ }^{8}$ counted and weighed. ${ }^{9}$ This information was entered on a Pottery Context Record Sheet. Diagnostic ${ }^{10}$ sherds were subject to further study and a type series was created. In this report a type is, in theory, a vessel of one particular form and ware; in fact, it is usually a rim fragment of one particular shape and ware - even minor variations in rim form were given different type series numbers. Traditional methods of type classification were used to determine what was and what was not a new type: a measurement-based classification system ${ }^{11}$ was not employed, the subjective view of the sorter was the deciding factor. ${ }^{12}$

Each type was recorded on a Pottery Type Series Catalogue Card which contained the following information fields: 1 type series number, 2 date (of type) 3 provenance (of the actual example in the type series), 4 diameter (of actual example in the type series), 5 drawing number, 6 spare field, 7 ware number, 8 fabric colour, 9 surface colour, 10 decoration, 11 method of manufacture, 12 presence or absence of ribbing, 13 description (sketch), 14 other occurrences (where provenance and diameter of other examples could be entered, along with details of any minor variations from the type series piece), 15 comparanda.

The Pottery Context Record Sheet, in addition to being used to record the different wares, was used to enter the different types (by count). The following information could also be entered: presence or absence of slip, glaze, ribbing, decoration and part of vessel. In 1985 and 1986 the percentages of rim for each type were recorded, but this was discontinued in subsequent years. This was partly due to practical problems involved in processing large quantities of material and partly because it was felt that, as the aim was primarily to date the pottery, a relatively simple recording system would suffice. Quantification of pottery is a vexed subject (see Rice 1987, 288-93, Orton 1980 and 1982). A revealing example of data producing misleading conclusions is demonstrated by the following. When studying the Nicopolis material it became evident that jugs/flagons apparently were very rare compared to other forms. This may have been because jugs were little used, or they were usually made of metal. However, it is equally possible that they are not rare at all, and only appear so because their rim sizes, being much smaller than those of other vessels, break into fewer parts, and are consequently under-represented in data relying simply on sherd counts. 
After recording on site, all sherds recovered for each context were counted and divided by ware, and a full count made of all diagnostics by type. Back in Nottingham this information was entered on computer using Lotus 123 software.

The archive comprises three parts:

1. The pottery. All handles, bases, rims and decorated sherds, together with a sample of body sherds from every context, are stored in the Veliko Turnovo Historical Museum.

2. The original data comprises the Pottery Context Record Sheets, the Type Series Cards, a book of ware descriptions, the drawings of the different types, photographs and general notes. This is stored in the Department of Archaeology, Nottingham University.

3. The computerized data in the form of data matrices on Lotus 123 includes files of all types recorded by context, all wares recorded by context, all amalgamated types ${ }^{13}$ recorded by context, all amalgamated types recorded by dated phase and all wares recorded by dated phase. This is stored in the Department of Archaeology, Nottingham University.

\section{Dating}

From the matrices, strings of contexts were drawn up by the director of the excavation, producing a relatively dated sequence; the lower down the string, the earlier the deposit, and the earlier the contents of that deposit. ${ }^{14}$ The next step was to tie in various points in the string with dates that could be inferred from other evidence. ${ }^{15}$ Obviously, some of these dates are relatively secure (the foundation date for the Roman city for example), others less so (cf. the primary fill of the ditch 294 in area B).${ }^{16}$ However, as certain deposits could be assigned to the same date range for different reasons in different areas, it was hoped that anomalous dates would be recognized by observing discrepancies between assemblages that should have been of similar composition if the deposits from which they came were in fact contemporary. ${ }^{17}$

The main chronological divisions used for dating the pottery are listed below. The reasons for the dating of the contexts and phases can be found in the relevant sections of the excavation report. ${ }^{18}$ Given that exact dates are generally impossible to assign with absolute certainty, the chronology of the pottery has been divided into general periods. For example, although the Roman city was founded between $A D 106$ and 117, it is assumed here that the earliest pottery dates no earlier than $A D$ $100 . .^{19}$ 
- $100-150$. Postdating the foundation of the Roman city but predating the laying of the paved roads, contexts in areas $\mathrm{A}$ and $\mathrm{B}$.

- 150-175. Postdating the construction of the paved roads but predating the erection of the Roman defences, contexts in area A.

- 175-250. Contexts relating to the robbing of the paved road in area $B$.

- 250-350. The contents of ditch 294 in area B.

- 350-450. Contexts that were later than the middle of the fourth century (on small-find and coin evidence), but predate the foundation of the early Byzantine city in areas $\mathrm{P}$ and $\mathrm{E}$, and contexts that are later than the middle of the fourth century (on similar grounds) but which predate the foundation of the Large Basilica, ascribed to the early Byzantine period, in area F.

- 400-450. Contexts that are fifth century (on coin evidence) but predate the foundation of the early Byzantine city in area $E$.

- 450. Contexts contemporary with the destruction of the late Roman city and the construction of the early Byzantine city in areas $\mathrm{P}$ and $\mathrm{E}$.

- 450-600. Deposits that postdate the construction of the early Byzantine city in areas $\mathrm{P}$ and $\mathrm{E}$.

Some other deposits on the site were assigned to these divisions, where suitable dating evidence was found - usually coins and well-dated small finds. In some cases, the periods could be subdivided and an approximate chronology could be inferred for phases of occupation. However, even when subdivisions of major periods could be observed in the archaeological record, it was not always possible to use this information to help date the pottery. ${ }^{20}$ Nevertheless, this procedure did allow the date ranges for some of the broader periods to be narrowed and the following phases were used to assign more precise dates to the pottery:

- 100-130. Where ware 1 was absent in the earliest levels, dated 100-150. In both areas A and B the earliest deposits (especially contexts 265, 2259, 2260 and 2277) contained none of this local grey ware. Instead, the coarse ware was the orange-brown ware 30/31, which was the common coarse ware used before the introduction of the grey ware. Since ware $30 / 31$ would seem to have been in use for only a short period, it is assumed that it was no longer in use after 130. Certainly, the grey ware replaced the orange-brown at some time before 150 .

- 130-150. Levels dated to 100-150 but which contain ware 1 .

- 250-275. The primary fills of the ditch 294 in area B. ${ }^{21}$ 
In some cases, divisions were even broader than our original phasing: a string of contexts in area $\mathrm{K}$ could be dated no more precisely than to the period 250-450. Generally the broader date ranges were of limited use, although they are all included in appendices 2 and 3.

It should be noted that, if future evidence changed the chronological sequence here adopted for the site, these periods and phases could be compressed or extended. However, though the absolute date may be modified by future research, relative dates will remain the same.

Having dated as many deposits as possible, the data was amalgamated to produce a table (appendix 1) that showed which types occurred in each period. The earliest occurrence of each type was noted, and that type dated to that period so that the appearance of those types in demonstrably later contexts could be regarded as residual. It must be noted that this method does not produce a definitive date range for the use of a type, but gives a date for the introduction of that type. It is inevitably a matter of subjective judgment as to when a particular type was no longer in use but was still found in later deposits because it was residual. If a type was represented by 10 examples in deposits dated to $100-150$, and 1 in a context dated to 450 , it was assumed that the latter example was residual. If the figures were reversed, giving 10 from the context dated to 450 and 1 from the earlier, it has usually been assumed that the isolated example was intrusive. ${ }^{22}$ When the evidence was less clear cut, other evidence (style, fabric etc.) was taken into account. ${ }^{23}$

Using this procedure many types could be tentatively dated, and that information was used to provide a preliminary date for otherwise undated contexts which had suitably large diagnostic assemblages. Then, using these preliminary dates, and any other available dating evidence, a final date was arrived at for all contexts, and any still undated types were assigned the date of the context in which they first occurred.

Having dated our material from on-site evidence, we were in a position to compare our results with those from other sites. The catalogue and discussion takes into consideration all the available evidence from Nicopolis and other published sites and suggests a date for each type or group of related types.

\section{NOTES}

1 See the work of Franken, H., van As, A. and Jacob, L. (inter alii), reported in the Newsletters of the Department of Pottery Technology University of Leiden.

2 See Rice 1987, chapter 13 for a resumé of the subject.

3 e.g. Hodder 1979 and Spriggs and Miller 1979.

4 Kabakchieva 1983.

5 Kuzmanov 1985.

6 Of particular relevance are those from Novae, Iatrus and Tsaravets because of their proximity to Nicopolis, see above, pp. 30-1. 
7 During the course of the excavations, Slav and post-medieval occupation was identified; as the pottery was generally very different from that of the Roman and early Byzantine occupation it was treated in a different way (see below, pp. 91-2).

8 Here the term ware refers to the appearance of the sherd and the components of the body as visible at 10x magnification; sherds that appeared similar and had the same inclusions were judged to be of the same ware.

9 A few very small sherds were not counted.

10 Diagnostic sherds are here taken to be: rims, handles, bases, decorated sherds and other sherds with distinctive characteristics.

11 See Orton, Tyers and Vince 1993, 152-65 for discussion on classification systems of pottery forms.

12 There are of course many different ways of ar riving at a type, often on more scientific grounds than used here; usually the delimiting factors are governed by the object of the study and the character of the assemblage. For different parameters see Rice 1987, 274-88. Also van As 1987, 29-38.

13 When two or more types were deemed to be so similar that they were amalgamated to form one single type.

14 For the matrices, see above, p. 6.

15 See above, pp. 6-7.

16 This ditch was filled with successive tips of waste during the second half of the third century. In all probability it was cut c. 250, see Poulter 1995, 73.

17 Though, of course, it is true that differences in date are not the only factor which can explain differences in the composition of assemblages.

18 See also above, p. 7.

19 The most likely date for the foundation of the city is c. 110, Poulter 1995, 10. Since no evidence was found for settlement on the site before the foundation of the city, a terminus post quem of $A D 100$ has been assumed for the earliest Roman pottery, see Poulter 1995, 22.

20 In areas $E, P, R$ and $S$, there were two phases that dated to after the construction of the early Byzantine fortifications; Poulter 1995, 43. However, there was little associated pottery, and it was not possible to distinguish any difference in the assemblages. Moreover, there was no way of proving when the second phase of occupation commenced. Accordingly, all the pottery contemporary with the early Byzantine occupation was dated 450-600.

21 On the dating of this ditch, see above, footnote 16.

22 The ground at Nicopolis has suffered fairly extensively from the burrowing of sousliks, which has resulted in some downward movement of artefacts.

23 See below for further discussion of the problem of residuality, pp. 94-6. 


\section{Wares and their associated types}

\section{Introduction}

This and the following Chapters (6-9) include descriptions of the wares and types (Chapter 5), discussions of typical assemblages by period (Chapter 6) and of local pottery production (Chapter 7), with conclusions and the implications of the pottery evidence in Chapter 8. Chapter 9 includes the catalogue and the figures. Appendix 1 lists all the wares. Appendix 2 is a table of the relative frequency of the types recovered from dated contexts and appendix 3 is a table of the relative frequency of the wares by dated phase. The layout is designed to facilitate the use of the report as a reference work in such a way that those seeking parallels for a type will be able to look through the figures, find a similar piece, check with the figure description to see if the ware is correct, refer to a summary of the dating evidence from the site, and then consult the text to find the date assigned to that particular piece. (To this end the figures group similar types in a way designed for easy reference, but do not necessarily imply a similar date: e.g. all carinated bowls will be found together irrespective of date.) Those seeking to date an assemblage can go straight to the section on typical assemblages (Chapter 6), to see which assemblage includes the closest parallels. Should further information be required, consult appendix 2 which includes all examples recovered from dated contexts. Of 100,000 sherds found in dated and uncontaminated levels, ${ }^{1} 11,789$ were diagnostics which have been assigned to 1,201 types, each of which is illustrated in the figures.

\section{Notes on terminology}

In the text, all semi-bold numbers refer to the Nicopolis catalogue. All pieces are wheel-made unless stated otherwise. It must be remembered that the dates given are the highest and lowest dates possible for a particular context: thus 150-250 does not mean necessarily that the context dates to $150-250$, but that it dates to any time within that period, e.g. it could date to $160-165$, or equally to 249 . In this part of the 
Table 5.1 Composition of dated assemblages by ware as a percentage of total sherds in that date range for common wares (to the nearest $0.5 \%$ ). Also showing (shading), the date ranges of the wares

\begin{tabular}{|c|c|c|c|c|c|c|c|c|c|}
\hline Date range & $100-130$ & $130-150$ & $150-250$ & $250-350$ & $350-450$ & $450-600$ & 600 & Slav & $P M$ \\
\hline $\begin{array}{l}\text { Ware no. } \\
1 \\
4 \\
8 \\
9 \\
10 \\
11 \\
14 \\
19 \\
23 \\
24 \\
25 \\
30 \\
31 \\
37 \\
38 \\
43 \\
55 \\
70 \\
78 \\
94 \\
96 \\
124 \\
164 \\
\text { Other }\end{array}$ & $\begin{array}{l}4.5 \\
16 \\
55\end{array}$ & $\begin{array}{c}22.5 \\
7 \\
65.5\end{array}$ & $\begin{array}{r}30.5 \\
2.5 \\
61\end{array}$ & $\begin{array}{c}30 \\
8.5 \\
55\end{array}$ & $\begin{array}{rr}39 & \\
2 & \\
51 & \\
& \\
& \\
1.5 & \\
& \\
& \\
& \\
& \end{array}$ & 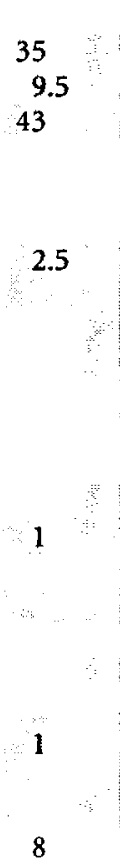 & & $\begin{array}{c}18.5 \\
2.5 \\
17\end{array}$ & $\begin{array}{l}26.5 \\
11 \\
42 \\
1 \\
2.5 \\
1 \\
3\end{array}$ \\
\hline
\end{tabular}

report, dating is discussed only when the evidence merits further comment; for types that are rare and not here commented upon in detail, the reader is referred to the figure descriptions where the context date of the piece is given. Only the more common wares are described here. Apart from wares that occur only once, which are described in the figure descriptions, a full list of wares is given in appendix 1. Bases are not included in appendix 2. Types that only occur once do not appear in appendix 2. Total number of examples refers to examples from dated contexts, not necessarily all examples identified. (Contaminated contexts have been omitted from appendix 2.) Appendix 3 does not include types which, after analysis, were amalgamated with listed types. For post-medieval and Slav pottery, context dates are not given because the contexts were themselves usually dated by the pottery. No attempt has been made to reconstruct unknown parts of vessels in the drawings, except where the drawing would be misleading without it, e.g. type 476. A type is a vessel of one particular shape and ware. A form is a group of types that share certain characteristics: e.g. types $683-709$ are one form of crater. 


\section{The Roman and early Byzantine periods}

\section{Coarse wares}

WARE 25 (FIG. 9.1)

The ware is hand-made, red to black (usually red to brown with a large black core). The surface can be buff, red, brown or grey, or a combination of one or more of these. The ware is generally poorly fired and has a very crumbly fracture. Inclusions are black and red grits, a little organic material and some mica. Usual thickness is from $1.0-1.2 \mathrm{~cm}$. Probably local. Total sherds recorded: 183 .

1-10 represent types in ware 25 , a continuation of the local Thracian tradition. Soultov $(1985,88)$ suggested that the hand-made versions are Thracian, and that the wheel-turned varieties are slightly later, ${ }^{2}$ not coming into production until the early second century. 1 and 3 have clear parallels with Soultov 1985, table XLV, 4 and 5; and the decoration on Soultov's table XLV, 1 is the same as our 8 . The evidence at Nicopolis for dating these vessels was scanty as few examples were found: less than 0.2 per cent of sherds were in ware 25 . They do, however, occur in our earliest levels, and continue to be represented down to the final phase of occupation within the early Byzantine city. Whether this is simply because these vessels are residual in the later contexts, or a small local hand-made tradition survived alongside the large local production centres, it is impossible to say. It is, however, worth noting that half of the examples came from one area (area $\mathrm{E}$ ).

WARE 30/31 (FIGS 9.1, 9.2)

The ware is either hand-made (31) or wheel-turned (30). The fabric is orange to brown with an orange surface and a moderate to crumbly fracture. Inclusions are many limestone fragments and much grit, most of which is light coloured and angular, with some pieces as large as $0.4 \mathrm{~cm}$ across. There is usually a little organic material. Average thickness is from $0.5-0.8 \mathrm{~cm}$. Almost certainly local. Total sherds recorded: 600 .

11-18 show types that are derived from the earlier 'Thracian' types, but in a finer ware. The similarities between the flaring walls of 11 and 12 , and those shown in 1 , are evident.

\section{WARE 30/31 AND l (FIGS 9.1, 9.2)}

19-26 occurred in both wares 30 or 31 and ware 1 (see below), which suggests that these types were manufactured during the transition period from the earlier fabrics. The early date for wares $30 / 31$ is clearly evidenced at Nicopolis with over 93 per cent of the 600 examples found coming from contexts dated to 100-150 (table 5.1 and appendix 3). Of the types from this group that also occur in ware 1 (given the suffix 
' $a$ ' in the catalogue) the vast majority come from contexts dated to $130-250$, thus demonstrating a continuing tradition.

WARE 1 (FIGS 9.3-9.14).

This is the common local grey ware that was prevalent throughout the Roman and Byzantine periods at the site but appears to only come into production after $c .130$ (table 5.1). ${ }^{3}$ The ware is wheel-turned; the fabric is black to grey, and occasionally brown, with a black, grey or, rarely, brown surface. The fracture is moderate to crumbly. Inclusions are white grits and quartz, usually in large quantities, and some mica. Usual thickness is between $0.4-0.8 \mathrm{~cm}$. Production centres have been found at Pavlikeni, Hotnitsa, and Butovo (Soultov 1985) and it is quite likely that other centres exist. Total sherds recorded: 32,046.

27-44 show cooking vessels with thickened sloping ledge rims with internal lips. Though a few examples occur in contexts dating to between 150 and 250, most occur later and it seems that they were common from the early third century, with use continuing at least to the end of the fourth century, and possibly well beyond. An example from Iatrus (Böttger 1982, Kessel Typ II, 98) is dated to Period A (first half of the fourth century) and an example from Armira (Kabakchieva 1986, tab. 42, 479) must date to sometime between the second and late fourth centuries.

45-54 show similar cooking vessels with ledge rims, also in ware 1 , but this time lacking the internal lip. The evidence here points towards an earlier date, with both types 49 and 50 being well established by 150 . Exact parallels are rare, but one from Iatrus (Böttger 1982, Topf Typ III, 94) is dated to the first half of the fourth century. Several occur at Armira (Kabakchieva 1986, tab. 42, 480-3). I would suggest a date of $c .140-250$.

55-58 and 64-68 show other cooking pots, related to the previous two groups, but with more upright rims; the necks have been turned out, rather than flattened into ledges, and the internal angle at the neck is less severe, being more of a curve than a definite angle. They are not common, and apart from five examples of type 67 that come from contexts dated to 130-150, they seem to date to the third and fourth centuries. 485 from Armira (Kabakchieva 1986) is a similar type, but there are no parallels at Iatrus, which may indicate that the type has gone out of use by the first half of the fourth century. At Novae a similar type is dated to the second/third centuries (Dyczek 1991, tab. III, 10).

59-62 show types with flared, slightly thickened rims. They seem to start in the period 130-150. A similar type at Novae is undated (Dyczek 1991, tab. II. 3). There are similarities with 74-81 below, and a date range of $c .130-250$ seems likely.

63 is a type with a plain thickened rim from a context dated to $130-150$. It was the only example, and has no published parallels. 
70-72 show examples of out-turned rims with inner ledges. Though a few examples occur in early contexts, they only appear in any numbers in contexts dated to after 350 . There are no exact comparanda.

74-81 are examples of vessels with out-turned rims. There are similarities in general shape with 16 and 19, where the small collar on 80 is also paralleled. This suggests that these may be some of the earliest ware 1 vessels, and the find spots of the types would support this: they appear in the period 130-150, are common up to 250 , after which only a few examples are noted which are probably residual. These types, though fairly common at Nicopolis, have no published parallels from either Novae or Iatrus; similar types, one in a brown fabric, are published from Hotnitsa (Soultov 1976, 105 and 106) dated to the second/third centuries.

82-90 show jars with out-turned, thickened rims. (73 being of the same type but exceptionally large). None occurs before 150, and though there are several examples from contexts dated to 150-250, they do not become common until after 250 , and occur in some numbers up to 600 (though they are almost certainly residual by this time). These belong to Soultov's types 1 and 3 which he dates to 'the first decades of the second century up to the middle of the fourth century' $(1985,85)$. He lists several comparanda, largely of unpublished material.

91-109 show jars with different types of thickened rims, all of which have internal ledges of varying size, from the very pronounced (106) to the very faint (102). They have similar date ranges, (with the exception of 109, see below). Though examples do occur in earlier contexts, notably 12 examples of 99 in a context dated to 175-250, a date of $c .250$, perhaps 240 , is postulated as the start of the type; as with the previous group they appear in some numbers up to 600 , but their floruit seems to be $250-450$. At least some of these examples have been included by Soultov in his types 1-3 (see above). Other parallels are common. In particular 107 can be compared with an example from Novae (Dyzcek 1987, tab. X: 2) which is undated, and 98 can be compared with another Novae type (Dyczek 1991, tab. III: 12) which is dated to the third century. The group as a whole is comparable with several pieces from Armira (Kabakchieva 1986, tab. 42: 487-9). The lack of published examples from Novae may indicate that the group had gone out of use by the fourth century, though it must be borne in mind that Soultov $(1985,85)$ says that unpublished pieces exist.

109, though seeming to fit with this group stylistically, does not fit chronologically; of 22 examples found, 11 are from contexts that date to between 100 and 150 . It may be from a different group, which is not otherwise attested in the Nicopolis assemblage.

110-125 show distinctive jars with everted bevelled rims, often with ribbing on the exterior of the neck. The necks themselves are more pronounced than on the types discussed above (which often have no true neck). The everted rim is usually slightly curved, with a corresponding concavity on the interior. Several have notches on the top of the rim. Though a few examples occur in early contexts, the over- 
whelming majority (with the exception of 115 , see below) come from contexts dated to $c$. 450-600, with a few from contexts dated immediately prior to 450 . None is published from Hotnitsa, Pavlikeni or Butovo. One similar to 114 is published from Novae (Dyczek 1991, tab. III: 8) though it is undated. Several similar types come from Iatrus (Böttger 1982, taf. 48: 595-7) where they are grouped as 'Töpfe typ VII' from Period $D$. Though there seems to be some argument over the dating of Period $D$ at Iatrus ${ }^{4}$, a date from the latter half of the fifth century to the end of the sixth or early seventh encompasses all possibilities. A similar example to 119 occurs in a sixth century deposit at Saraçhane (Hayes 1992, deposit 27,6). All of which fit well with our evidence. A date of $c .440-600$ for this group is likely, though the later material may be residual.

115 is a common type with 118 occurrences at Nicopolis. Stylistically it seems to fit with this group, yet it first appears in numbers in pre-150 contexts, and is relatively common thereafter. The only small difference is a slightly more rounded rim than the others in the group, and it does not resemble any of the early jar types; however it is found so frequently in second and third century deposits that they are unlikely to be all intrusive.

126-130 show jars with rounded thickened rims with a groove on top. There are isolated early examples, but, excluding those from post-medieval contexts, most come from contexts dated to 450 , with two coming from contexts dated 400-450, and three from contexts dated 450-600. The closest parallels are again from Iatrus (Böttger 1982, taf 47:211, 213 and 215) where they are termed 'Töpfe typ VI' of Period $\mathrm{B}$, which corresponds to the last third of the fourth century, and the first quarter of the fifth. Our dating suggests a somewhat later range: c. 425-500. 130 also occurs in ware 14 (see below) which reinforces the late date for this group.

131-134 have certain similarities with the previous group, but the rim is flatter, and the groove has become much wider so now we really have a ledge rim with rounded profile and concave top. From our evidence the type appears at some time after 350 and is common by 450 . There are parallels at Iatrus with Töpfe Typ VII of Period C, dated to the fifth century (Böttger 1982, taf. 48: 592) and a piece of similar form in a red-brown ware is illustrated from a deposit dating to the second quarter of the fifth century at Saraçhane (Hayes 1992, deposit 13,3). This fits well with our evidence, and adds weight to Böttger's conclusions on the development of the type, evolving from vessels similar to 110-125 during the fifth and sixth centuries.

135-140 depict jars with rims that are triangular in section, usually with internal lips. Only four examples are from pre- 450 contexts, and most actually come from contexts dated to 450 . There are no exact parallels, though there are similarities with a vessel from Iatrus (Böttger 1982, taf 46: 4) dated to Period B (c. 360-425). Our evidence suggests a later date: $c .425-500$, and there are similarities with early sixth century types at Saraçhane (Hayes 1992, deposit 14, 29-32). 
141-147 show jars with triangular or truncated-triangular rims, usually with flat tops and without internal lips. With the exception of three examples of 141 from a context dated to $175-250$, most of the examples come from contexts dated to between 350 and 450 , with a concentration in those dated to 400-450. Comparanda are again to be found at latrus (Böttger 1982, taf 46: 472 and 483; and taf 47:494-6) where they are split into 2 types: Töpfe types II and V, both of which are dated to Period C (fifth century); and at Saraçhane, though in a different ware (Hayes 1992, deposit 11,14$)$, where they are dated to the second quarter of the fifth century. Again these agree with our dating.

148-157 are illustrations of jars with straight, usually flaring, necks and plain flat rims. Three examples occur in a context dated to $175-250$, and three in contexts dated to 250-350, but most appear in contexts dated to 350-450. There are certain similarities with the bevelled rim group above (110-125) that was dated to c. $440-600$, and these may be the precursors of that group, dating to $350-450$. There appear to be no published parallels.

158 shows a jar with squared ledge rim and internal lip. It first appears in a context dated to $250-350$, but does not seem common until the period 400-450. It seems to have no published parallels, though the shape of the rim is similar to the following group. A date of $340-450$ is postulated here.

159-164 are a category of carinated open forms with ledge rims of varying types, though 164 has a plain squared rim. With the exception of a single example of type 162 from a context dated to $130-175$, which can safely be regarded as intrusive, the earliest examples are from contexts dated to $350-450$, with the overwhelming majority coming from contexts dated to between 400 and 450 , and a few from contexts dated 450-600. Comparanda at Novae are common, Böttger's Schüsseln Typ IV being the equivalent. He divides the group into those from Period A and those from Period C, the earlier ones having less pronounced carination. ${ }^{5}$ His largest group are those dated to Period $\mathrm{C}$ : the fifth century. An example is also published from Novae (Dyczek 1991, tab. V: 6) though it is undated. At Nicopolis there is no real evidence of a fourth century group, and I propose a date for the group as a whole of c. 400-470. However an example from Armira (Kabakchieva 1986, tab. 41:471), presumably dates to the period of the villa, which was apparently destroyed in 376-378 (Mladenova 1991, 158).

164 is slightly different from the rest of the group with its squared rim. Only one example was found, and that was from a post-medieval context. Parallels at Iatrus (Böttger 1982, taf 41:450-452) with Schüsseln Typ III exist and have been dated to the fifth century.

165 is an open bowl with an in-turned rounded rim and a flat base. This came from a context dated to $350-450$ and was the only example found. Evidence for the production of this type was found at Hotnitsa, and as the production of grey wares at Hotnitsa has been dated from the early second century to the middle of the third 
century (Soultov 1985, 21), our example may be residual. An undated example is published from Novae (Dyczek 1991, tab. V: 5).

166-179 show ledge rim bowls of various types, all of which have flat bases. This group was common, and appears in contexts as early as $130-150$, and in roughly equal numbers in most phases thereafter. 166 , which has a flatter rim than the other types, seems to have come into use somewhat later: probably around the middle of the third century. The group, especially the types with flatter ledges, belong to Soultov's 'grey ware dish type 3' (Soultov 1985, tab. XLII: 4) which was produced in some numbers at Hotnitsa and Butovo, giving an outside range of early second to last half of the fourth centuries (Soultov 1985, 21 and 29). ${ }^{6}$ Other published examples include one from Novae (Dyczek 1991, tab. V: 2) dated to the first and second centuries, and three from Armira (Kabakchieva 1986, tab. 40: 459, and tab. 41: 460 and 464). Given the spread of these vessels and their relatively simple utilitarian form, a date from the second to fourth centuries is quite likely.

180-182 and 188-191 represent types that are a cross between bowls and jars: they have out-turned rims and flat bases, and several have a band of decorative ribbing on the body. They first appear in contexts dated to between 130 and 150 , and seem to reach a peak at some time between 250 and 350, though they do occur after this. Soultov $(1985,84-5)$ says that they are one of the 'most widespread vessels produced at Hotnitsa and Pavlikeni' and deduces a date of late first to mid third century for their use in northern Bulgaria. An example from Armira is published (Kabakchieva 1986, tab.43:506). Given that this group is similar to that represented by types $45-54$ above, a similar date is likely: $140-300$.

184 is a small bowl with thick walls and a flat rim with a groove on top. This was the only example found, and though from a post-medieval context, the ware suggests a Roman/Byzantine date. There are no published parallels.

185-187 show bowls with large ledge rims with multiple concentric grooving on top. These were the only three found, and though the dating is certainly not conclusive, a second or third century date is indicated. An undated example from Novae may be of the same type (Dymaczewska and Kotecki 1981, tab. XVI: 4).

192-199 and 205-207 are open forms that fall into no easily defined category. They do not seem to have any published parallels. Little can be said as regards dating, as none is common, However, the shape of $194 \mathrm{can}$ be found in the fine red ware carinated bowl group 476-516 below, and 196, with its vertical wall and out-turned rim, is the same shape as 612 below. 198, with thickened in-turned rim, which first appears in a context dated to 130-175, may be a variant of 165 above, dated to the second to mid third centuries. (It may also be part of a very large lid, or related to certain ware 24 types, see below.) 199 and 205 have thickened folded rims and may be related; they first appear in a context dated to 175-250, but are more common between 250 and 350 . Their shape, especially of 199 , is common in fine red wares of an earlier date (see below 428 and similar types). The shape of 197 , with its carination 
and in-turned pointed rim, can be compared to a piece from Novae dated to the second and third centuries (Dymaczewska and Kotecki 1981, tab. XI: 1), though the ware is very different.

208 is a sieve/colander with an out-turned rim. It was the only coarse ware variety found, and has no exact parallels. 200-204 are miscellaneous types of closed forms. There is no definite dating evidence for any of them, though the similarity between 203 and fine red-slipped wares 878 and 879 which date to the second and third centuries may be noted.

209-210 are collared jars with tall necks and flattened rims; they are very similar to the jars in ware 14 discussed below (306-315) dated to the fifth century. 211-217 show more miscellaneous types which seem not to be present on other sites.

218-221 show examples of jars with flaring necks with internal ledges; they are very thin for ware 1 vessels. The evidence from Nicopolis points very strongly to a date between 450 and 600 .

222-225 show some of the types of base that go with the vessels in ware 1. For the most part they do not seem to be helpful for dating purposes.

226-239 show small bowls. The similarity between the rim forms of these, and the following group of lids, means that some may have been placed in the wrong group. The main reason for dividing the groups was the bases: it seems likely that most have wider flat bases, as opposed to string cut knobs. It must be borne in mind that they may also have been used as lids. Though there are a few examples in contexts dated to $150-250$, they are most common in contexts dated to $250-350 .^{7}$ They (rather surprisingly as we found 262 examples) do not seem to have any published parallels. A date of $c .240-350$ seems likely though some may go later, especially the concave rim type 234 which can be compared with the concave rim lids below.

240-260 represent lids that can be loosely divided into plain, hooked, rolled and concave; there are inevitably a few that fall between these categories. $240-243$ and 250-251 show the plain types; they first occur in numbers in contexts dated to $130-150$, and are common in contexts dated to $175-250$, after which they become rare. Two similar pieces are illustrated by Soultov (1985, tab. XLIV: 2 and 3 ) and he implies $(1985,86)$ that they were made at all three manufacturing sites - Hotnitsa, Pavlikeni and Butovo. One is published from Iatrus (Böttger 1982, taf 49:513), dated to Period C (fifth century); and there is an example from Armira (Kabakchieva 1986, tab. 43: 500).

244-246 and 254-256 are hooked rim types. This was the most common form, with 1,568 examples. They occur in very small numbers in early contexts, becoming more popular in contexts dated 175-250, and have their floruit between 250 and 450 , though they may well continue later. Soultov publishes one with the plain lids mentioned above. There are no published examples in the assemblage from Novae, which is surprising given the numbers found at Nicopolis. ${ }^{8}$ 
Rolled rim lids can be seen in 257 and 258: we found 391 examples. None is published from other sites. Again, though some examples occur before 250 , the type is not common until the period $250-350$, and seems to be at a peak at some time between 350 and 450 .

Concave rim types are shown in $247-249$, and 260 ; they were not as common as the others. There are isolated earlier examples, however they mainly appear in contexts dated later than 350 . Other examples include 253, which is a variant of the hook rimmed type; 259 , a variant of the rolled rim type where the rim has not been fully turned over, and 252 which is unique, and is probably a copy of a type of fine red ware lid (see below 865 ).

The large numbers of lids found at Nicopolis, and the fact that the different types seem to have differing chronological ranges, makes them useful finds for dating. The plain rims are certainly the earliest, dating to $c$. 130-250; the hooked rims seem to date to $c .200-450$, the rolled to $250-450$, and the concave to $c$. 350-500. (An example of a concave rim from a deposit dating to the second quarter of the fifth century is published from Saraçhane - Hayes 1992, deposit 11, 17.)

\section{WARE 24 (FIG. 9.15)}

This fabric is buff, with a buff to yellow surface which has a sandy feel, and a moderate to crumbly fracture. The fabric has many voids. Inclusions are brown, white and translucent grits, and a few gold and silver (mica?) flecks. Usual thickness c. $0.6 \mathrm{~cm}$. Origin unknown, but possibly local. Total sherds recorded: 158 .

This ware was rare, comprising just over 0.1 per cent of the total corpus. With the exception of four sherds, the ware was not found in any early contexts but first appears in those dated to 175-250. The appearance of this ware in later contexts suggests that it was probably introduced at the very end of this period, perhaps $c$. 240 . However, given that there are only isolated early examples, the similarity of its repertoire to ware 1 types and its rarity may point to it being a 'hybrid' version of ware 1 brought about either by a chemical reaction during firing, or experimentation by local potters using different clays.

261 and 263-264 are reminiscent of type 165 above, being bowls with in-turned rims and flat bases. The earliest occurrence for any of these types is in a context dated to $250-275$, and several examples occur in contexts dated to $350-450$. The only other published example is one from Novae (Dyczek 1991, tab. XII: 6), dated to the fourth century. 262 is a large vessel with no parallels that was found in a post-medieval context. 265-270 and 272 show bowls with ledge rims. Again there seem to be no parallels published from other sites. 267-269 form a distinctive group with concentric grooves on the top of the rim. 267 and 268 both occur in contexts dated to $100-130$, and their similarity with the $185-187$ group above may support an early date, though this is not matched by the date assigned to the fabric. 266 was the only 
one of its type found, in a context dated $450-600$. The similar overall shape to the 159-164 group, together with the concave top to the rim, may support this late date. 270 was from a context dated to $175-250$. It is very similar to 181 above. 271 represents the only example of its type; it was unstratified. 273-279 show closed forms in the same fabric. The similarities between 275 and 171 , and 277 and 70 are obvious. Examples are few, and no conclusions about date can be made.

\section{WARE 14 (FIGS 9.16-9.17)}

The ware is wheel-thrown; the fabric is grey with a grey to black surface (very occasionally brown) which is sometimes burnished. Moderate fracture. Inclusions are few, apart from mica, though small amounts of quartz are sometimes present. Usual thickness $c .0 .6 \mathrm{~cm}$. Origin unknown, but probably local. Total sherds recorded: 2,130 .

The ware represents about 2 per cent of the total corpus, first appearing in quantity in contexts dated to 350-450, and continuing in contexts dated 450-600 (table 5.1). ${ }^{9}$ Forms were varied, with closed forms being the most common. Published parallels at sites in the area are rare but I have seen the same ware from the late Roman sites of Abritus (Razgrad), Novae (Svishtov) and Tsaravets (Veliko Turnovo). ${ }^{10}$

280 shows a bowl with in-turned wall, and incised bands on the top of the exterior. 281 represents a ledge rim bowl, and 282 a bowl with thickened rim. 283 , of which three examples were found in contexts dated to 450 , is a bowl with off-set rim, which has parallels to the north of the Danube (Heather and Matthews 1991, fig. 3). 284 is a flat bottomed bowl. 285 and 286 are related to the 159-164 group above. 287 is a cup, and 288 a carinated bowl. 289 is another cup with a decorative handle, and 290 shows the base of a bowl with a burnished zig-zag pattern on the interior of the base. 291 and 292 are colander/sieves. None of the above types occurs in contexts that can date to pre-300, and there is a concentration (though not large) of types in contexts dated to 450 .

293-302 show jugs, several of which have burnished patterns on the neck, usually of vertical lines. 293 has certain similarities with an example from north of the Danube (Heather and Matthews 1991, fig. 5, 9). Base 303 shows that the burnished decoration also occurred on the body of such vessels. 304 shows another type of base. 305-317 show the necks of large water jars/amphorae, and 318 shows a body sherd from one, with distinctive pattern burnishing. The shape of 316 is very similar to that of amphora type 1057, and sherds of this fabric have been found with the deep combing that occurs on that type of amphora.

The ledge rim types, 305-310 and 312-315, do have parallels at Iatrus (Böttger 1982, taf 28: 24 and 174). These belong to Böttger's Amphora type IV.1 which first appear in Period A (300-360) and seem to continue into Period C (fifth century), 
though not into Period D (late fifth and sixth). As at Nicopolis, some of the material at latrus is burnished (Böttger 1982, 123-124).

Similar types of vessel are published from Novae (Majewski 1981, Ryc. 55: 1-3) and they also have burnishing on the neck. They are dated to the fourth and fifth centuries. The evidence from Nicopolis for these vessels would support a fifth century date, possibly the very end of the fourth, for their introduction. They may have continued into the sixth century, certainly the pattern-burnished tradition continues (Angelov 1973, 342).

319-321 are types of ledge rim jars that can all be compared with certain types from the principia at Novae (Majewski 1981, Ryc 56, 1-8) and 319 and 320 fit into Böttger's Töpfe type V, Period C at Iatrus (1982, taf 47: 494-499). Again these are dated to the fifth century. 323 and 324 are jars with burnished lines, and 325 is a jug with a burnished lattice decoration on the neck and a vertical burnished pattern on the body. Three examples of this type were found (one in a post-medieval context, the others in contexts dated 450-600) and the one illustrated was found on the final floor surface of the tower in area $\mathrm{P}$, (context 5038). 326 and 327 are jugs of similar type. 328 is very similar to 124 above (dated to $440-600$ ).

329 and 330 show lids that are the same types as the ware 1 concave rim types 247-249 above that were dated to 350-500. Excluding an example from a postmedieval context, ten examples were found, nine of which came from contexts that dated to between 400 and 450.331 is a base in the same fabric.

\section{Fine wares}

WARE 8 (FIGS 9.18-9.45)

This is the common red-slipped ware ${ }^{11}$ at Nicopolis. The ware is light brown to buff usually with a red slip, though it is sometimes very dark brown, and can be most shades between these colours. The fracture is sharp, sometimes splintered or hackley. The fabric is well levigated, containing a few small black and/or white grits, and often some mica. Often no inclusions are visible with the naked eye. Usual thickness is $0.4-0.8 \mathrm{~cm}$. Production centres have been found at Hotnitsa, Pavlikeni and Butovo. Others almost certainly existed. ${ }^{12}$ Total recorded sherds: 53,079.

On the bowls the lower part of the exterior is often left without slip and there are usually no signs of brush marks. On the craters the lower parts of both the inside and outside are unslipped; in nearly all cases the slip extends further down the vessel on the outside, indicating that the vessel was held by the base and dipped into the slip - the air inside the vessel preventing the slip from reaching the bottom of the pot. Closed vessels are usually slipped on the upper half of the outside and the top part of the neck on the inside, again indicating dipping. 
332-342 represent ledge rim bowls with distinctively up-turned outer edges, often with decoration on the top of the rims. With the exception of 335, which first occurs in a context dated to 100-130, and 337 which first occurs in a context dated 175-250, they do not seem to appear much before the mid-fourth century. However they come under Soultov's (1985) dish types 5 and 6 which he attributes to the late second and early third centuries. 335 is from Soultov's cup type 5 for which he gives a second century date $(1985,69)$. Examples from other sites seem rare.

343-344 show bowls with plain ledge rims, again with decoration on the top of the ledge. Both examples come from contexts dated to 450 . There are similarities with two examples from Iatrus (Böttger 1982, taf 40: 441-442), dated to Period C (fifth century), which would support this date.

345-397 and 401-410 show bowls of various sizes, all with differing types of ledge rim. With a few exceptions they do not appear until 175-250, and do not seem common until after 250. At Novae several examples are published (Dyczek 1991, tab. VI: 5 and Dyczek 1987, tab. XV: 2), both dated to the third century. Some types from Armira have features in common (Kabakchieva 1986 tab. 8-11), though none is exactly the same. 398 and 399 are larger, heavier types of ledge rim bowls. I propose a date of $c$. 230-400, or later, for this large class of vessel.

400, 411-414 and 419-426 show bowls with curved, down-turned rims, often with either rouletted or applique decoration on and over the rim, and more rarely on the inside of the base. These occur in our earlier levels in some numbers, and must have been amongst the first types produced at the local pottery centres. An example from Novae (Dyczek 1987, tab. XIII: 3 ) is comparable with 413 but is undated. These shallower types belong to Soultov's (1985,63-4) dish type 4 , which he equates with Samian types (Dragendorff 36), dating the start of production 'towards the middle of the second century'. They appear at Nicopolis earlier than this, and their paucity in the third century suggests a period of use at the site from the early to late second century.

415-418 and 427 show shallower vessels with out-turned rims. Whether or not this is a true 'group' is open to question: 415 and 416 may belong to the previous group, with 417 belonging to $505-510$ below, and 418 and 427 belonging with $587-589$. With the exception of 417 , they would seem to date to the second century.

$428-475$ is a class of carinated bowl with either rounded or angular rim forms. Decoration can be varied: rouletted, incised, applique or barbotine. Most, however, are undecorated. This group of vessels is common from the early second century and throughout the Roman and early Byzantine periods. However there is a distinct decline in numbers after contexts dated to $250-350$. There is also good evidence to suggest that the rounded-rim types first appear earlier than the angular types.

This group as a whole belongs to Soultov's bowl type 1 which he says is common throughout Bulgaria and along the Danube from the second half of the second until the beginning of the fourth century $(1985,66)$. The angular types appear at Novae 
(Dymaczewska and Kotecki 1981, tab. 10:1 and 3) one of which is dated to the second/third centuries, and one to the third/fourth centuries. Another from Novae (Dyczek 1987, tab. VIII: 3), is undated. They also occur at Armira (Kabakchieva 1986, tab. 2: 28 and 34). The group is very common, with over 680 examples of the rounded type, and over 460 of the angular type. Here, the dating proposed is $100-200$ for the rounded, and 150-300 for the angular. It is very likely that when more quantified published material becomes available it will be possible to split the angular rim types into different groups that may well belong to different periods.

476-516 show other types of carinated bowl. 476-478 are types with vertical rims and heavy flanges on the carination. The group was not common, but first appears in the second quarter of the second century. The form occurs at Armira (Kabakchieva 1986, 12), where it corresponds to bowl (panitsa), type III variant $3 a$.

479-481, 486-487 and 489 are types with thickened rims and heavy flanges. Ten examples of 480 appear in our earliest phase, though none of the others occurs before 130 at the earliest, and there seems to be a definite fall-off in numbers after 250 at the latest. Suggested dates $c .125-225$, perhaps going on slightly longer. 483-485 are types with a flattened rim and no heavy flange. They are not common, and are probably contemporary with the previous group. 490-492 are small types with plain rims and pronounced carinations. Again they are not common, but would seem to date to the second half of the second century. These groups fit into Kabakchieva's bowl type III variants 3b-g at Armira $(1986,12)$ and Soultov's dish type $1(1985,62)$ which he suggests came into production in the second half of the second century.

495 and 498-503 represent types with plain rounded vertical rims. This group first appears in contexts dated to 175-250 and, though it is hard to sort out residual examples in later contexts, they probably date to the third and early fourth centuries. These correspond to Soultov's dish type 8 , for which he suggests a start of production in the second half of the second century $(1985,65)$.

505-510 show carinated bowls with flaring walls and plain rims. The earliest examples are from contexts dated to 150-175, but they occur more often in contexts dated to 175-250. These are Soultov's dish type 7, which were produced from the second half of the second century at Butovo $(1985,65)$. Suggested dates are: $c$. 170-300. 511 with its out-turned rim can be compared with an example from Armira (Kabakchieva 1986, tab. 9, 151).

517-528 show small bowls/cups with thin walls, plain rims and flat bases, some of which have a groove cut at the outside of the base to give the impression of a shallow ring base (this can be seen on 528). They occur in limited numbers in contexts dated to 130-150, and become more popular afterwards, especially in contexts dated to 175-250, though they may continue into the fourth century. Soultov $(1985,68)$, calls the group 'cup type 1' and says that they were produced at Hotnitsa, Pavlikeni and Butovo, and have been found with coins of Hadrian and 
Antoninus Pius. An example from Novae seems to be of the same type (Dyczek 1987, tab. 5: 2), though it is undated.

Suggested dates for the group as a whole are c. 135-300. The slightly thicker versions with a slight carination $-\mathbf{5 2 2}$ and 525 may start later, towards the end of the second century.

529-545 are various bowls, all with rounded rims, some with an internal offset where the base meets the wall (534); some have 'false' ring bases (542) and some applied ring bases (529). They seem to be common from the Roman to early Byzantine periods. They correspond to bowl types 4 and 5 in Soultov's type series $(1985,67)$, the former were produced in the second half of the second century at Pavlikeni. At Iatrus they correspond with Böttger's (1982) Teller type 2, which he ascribes to Periods A-C (fourth and fifth centuries) and at Armira they correspond to Kabakchieva's bowl (panitsa) type 1, that occurs, with variations, throughout the villa's period of occupation (1986,9-11). This is a long lived type: at Nicopolis it comes in during the early second century and continues into the fifth.

546-549 are hemispherical bowls with pointed rims, usually with a single incised line below the rim on the exterior, or interior, or both. This group of vessels first occurs in contexts dated to 100-130, is more common in contexts dated to 130-150, flourishes in contexts dated to 175-250, and then declines rapidly. They are possibly related to Soultov's (1985) cup type 4 though they are not identical. There are no published comparanda in the region, which is surprising, as we have over 150 examples. The sharp decline in numbers in contexts dated to after 250 suggest that the group had probably gone out of production before then. Suggested dates: c. $110-220$.

550-555 represent a group of bowls with notched rims. 552 has thumb impressions, and 555 has incised vertical lines on the walls. One example came from a context dated to 130-150, and 6 from contexts dated to 175-250, however they are more common after this. There are no published parallels from nearby sites. Suggested dates: c. 230-350, and possibly later.

556-572 are bowls with angular rims often with an incised line immediately below the rim on the inside. The only complete example has a ring base, and it is likely that this was the norm. Over 70 examples were found, only a few of which were from deposits that could be dated earlier than 250-350; there was a marked decline in numbers in post-450 contexts. Considering the numbers it is surprising that none is published from Hotnitsa, Pavlikeni or Butovo. An example is published from Novae (Dyczek 1987, tab. XV: $3^{13}$ ), that is undated. Suggested dates: 250-400.

573-576 and 602 are bowls with flaring walls and rounded rims. It is possible that these are a sub-group of the 505-510 group above, but they are thicker and not so well executed. They are not common, but none occurs in contexts that can be dated to pre-350. There are no exact parallels, but Böttger's Teller type III (1982, taf 
40: 436-437) has certain similarities. They are dated to the fifth century, a date with which the limited evidence at Nicopolis would agree.

577-586 are bowls with thickened generally angular rims; the only near complete example has a flat base with 'false foot', with very rough rouletting on the interior. They are not very common, and have the same chronological spread as the previous group. No published comparanda exist from the region. Suggested date: fifth century.

587-591 and 593-596 are bowls with out-turned rims with grooves on the inside. They first occur in quantity in contexts dated to 130-150. There are similarities with Soultov's dish type 2. (Also see several similar types in fig. 9.23 above.) Parallels occur at Armira (Kabakchieva 1987, tab. 8: 122 and 124) where they come under type 4 variant $1(1987,12)$. None are published from Iatrus or Novae. ${ }^{14}$ Suggested dates are: $140-250$.

592 and 598 have up-turned rims and internal grooves. There are similarities with the previous group. On the other hand, they may belong with the 332-342 group above. They were rare, and can only be dated on very limited evidence: they probably date to the first half of the second century. (This would preclude their belonging with 332-342.)

600-601 are bowls with flaring walls with several incised lines on the interior. They have no published parallels and would appear to date to the first half of the second century.

603-624 are small bowls with flattened out-turned rims. The only near complete vessels have ring or 'false' ring bases. However 614 and 615 may have pedestal bases. (These two may actually be lids.) These were common at Nicopolis - over 200 examples were found - but they are rare elsewhere, though there is a published example from Iatrus (Böttger 1982, taf 41:70) as Schüsseln Typ II from Period A (first half of the fourth century) and a similar type is illustrated from Novae (Dymaczewska and Koticki 1981, tab. XII 4). At Nicopolis they sometimes occur in contexts that predate 250 , but not in any numbers, and all these examples may be intrusive. Suggested dates are: c. 300-400.

626-629 are similar types to the above group, but with one or two incised lines immediately below the rim on the inside. The earliest occurrence for these is in a context dated to $175-250$, though they are more common in later contexts. Probable date (on limited evidence): 240-350. 630-631 are again similar, but have more rounded rim profiles. Their date is uncertain.

633-639 show bowls/basins with ridged rims, few examples were found, but they seem to date from the early second to mid third century, though 635 may well be later. 640 and 641 are bowls with vertical walls and folded rims. Again they are quite rare, but a date range of $c .140-250$ is suggested here.

642-644 are deep bowls with incised horizontal bands on the exterior; the evidence is too scanty to suggest a date. 645-649 are a group of bowls with off-set rims of various degrees of severity. One similar to 647 is illustrated from Armira 
(Kabakchieva 1986, tab. 10:157). Though there is little evidence, it is possible that the thicker two with more severe off-sets, 645 and 646, date to the second and early third centuries, and that the other three date to the fourth and fifth centuries.

650-653 are types with thickened rims and in-turned walls, 651 has small knob handles that are more decorative than functional. They were not common, but of the nine examples found, five were from contexts dated to 100-130. A similar type from Pavlikeni is illustrated by Soultov, where it is referred to as a variant of his bowl type $4 .(1985,67)$ for which he gives a second century date. Two types similar to 650 are reported from Armira (Kabakchieva 1986, tab. 17:236-7). An early to mid second century date seems likely.

654-658 are types of colander/sieve. They all have one or more bands of holes in the body or base cut before firing. 657 has a large nipple in the centre of the base, the top of which is worn - a juice maker of some description? Few examples were found, and they came from contexts dated to between 100-130 and 450-600: the type cannot be dated from our evidence, though it is quite possible that they were used throughout the Roman, late Roman and early Byzantine periods. Pierced vessels were found at Armira dated to the second to fourth centuries (Kabakchieva 1986, 15). A similar class of vessel was found at Butovo, Pavlikeni and Hotnitsa, dated by Soultov to the second century to mid third century $(1985,80)$. He calls some sifters, and others, including the type with central nipple, censers. (657 showed no signs of burning.)

659-661 are small saucers of which one has a decorative handle. Only four examples were found. Apart from a similarity with an example from Armira (Kabakchieva 1986, tab. 3: 46), there are no published parallels.

662-664 are bowls with tapering semi-ledge rims which have no published parallels from nearby sites. The rarity of these vessels makes definitive dating hard, but they may date to the third and fourth centuries. 665 and 666 show vessels with flaring walls. Again there are no published parallels, and they are rare: existing evidence points to a late second or early third century date for the introduction of this type.

667-682 are miscellaneous bowls that do not fit into any particular group. 667 is a small bowl with thickened ledge rim. 668 a hemispherical bowl with a small ledge rim is probably a cross between the group comprising 603-624 and the angular rim class in the group comprising $428-475.669$ is a bowl with a heavy internal lip which may be related to an Eastern Sigillata prototype (see Crowfoot 1957,335 , form $18^{15}$ ). 670 is a small ribbed cup and 671 a small ledge rim bowl. 672 is a bowl with slightly off-set rim, which probably dates to the fifth or sixth centuries. 673 is a bowl with a vertical rounded rim and bulging body; it has decoration similar to that on 651 , and is similar in date: early to mid second century. 674 is probably of similar date (two examples were found, both in contexts dated to $100-130$ ) and its similarity with Dragendorf form 27 would support this. 676 
probably belongs with Soultov's bowl type 4 variant a $(1985,67) .677$ and 678 are bowls/cups with incised decoration; the decoration is not uncommon, though the shapes are rare: they probably date to the second century. 679 is a fine ware copy of one of the coarse ware cooking pot group 159-164. 680 is a bowl with folded rounded rim. 681 shows a bowl with rough rouletting on the interior, and 682 is a small thick-walled bowl with inturned rim.

683-707 are craters with flattened rims, vertical necks and slightly bulging bodies and ring bases. They usually had two handles, though some may have had three or four. Decoration on the body (688 and 697) was rare, that on the top of the rim slightly more common (689-691). They were very common, with over 850 examples found, occurring in most of the Roman and early Byzantine phases of the site. There seem to be two sub-classes: those with collars (698-702 and 705-707) and those without. Production certainly started sometime between 100 and 130, but for how long it lasted is uncertain as there is no way of telling if later examples are residual or not. Though the evidence is somewhat inconclusive I would suggest a date of $c$. $125-250$ for the collared group and c. 130-450 for the plain group, with an increase of production after c. 250 to compensate for the loss of the collared types.

Given the large number found at Nicopolis it is strange that for several types, there are no exact published comparanda at either Butovo, Hotnitsa or Pavlikeni; those published by Soultov (1985, tab. XXXV: 3 and 4, and XXXVI: 4 ) have sharply carinated bodies, and not an outward bulge: this points to other production sites, with Nicopolis itself being a prime candidate. They also seem rare at other sites, though Soultov $(1985,76)$ mentions some unpublished examples from elsewhere that he had seen. ${ }^{16}$

708 and 709 are variants of the collared types, and appear to be of similar date, though they were not common.

710-724 show another group of craters with upright rounded rims, usually with ribbed necks, and occasionally with applique decoration on the upper part of the bodies (plate II). This is Soultov's 'two handled earthenware' type $2(1985,76)$, of which he says they 'are very rarely to be discovered in the centres near Hotnitsa and Pavlikeni ${ }^{17}$... No additional plastic decoration had been applied on this type'. Again, as with the group above, this hints at alternative production centres. Soultov suggests a second and third century date. At Nicopolis it is possible that they continued in use into the fifth century.

Again comparanda are rare, but Tassen Typ I at Iatrus (Böttger 1982) has certain similarities - it is dated to the fifth century (Period C).

725-731 are small craters with tall necks, often with applique decoration on the neck, and sometimes on the body. 727 shows a typical base. They were made in large numbers at Butovo (Soultov 1985, 79: type 11) and many unpublished pieces have been found in the area (ibid.). The group came into use sometime before 150, and continued to be used into the third and possibly the fourth centuries. 
732-736 are small jars with the same overall shape as the preceding small craters, but with off-set rims. Soultov includes them in his type $11(1985,79)$, as a sub type (variant $11 \mathrm{~b}$ ) and suggests that they were produced at Pavlikeni. They were not very common at Nicopolis so the evidence is slim, but, though examples do appear in the second and third century, they are more common in fourth and fifth century contexts. There is a possible parallel at Novae (Dyczek 1987, tab. I: 2) and one from Iatrus (Böttger 1982, taf. 32: 402) which is dated to the fifth century (Period C).

737 and 738 are variants, with flattened vertical rims: both came from postmedieval contexts.

739-755 are small jars that can be divided into several groups. 739-743 have vertical or slightly flaring necks with in-turned rims making a slight concavity on the interior. 739 can be compared with an illustrated piece from Armira (Kabakchieva 1986, tab. 18,249) and the group as a whole roughly corresponds to Kabakchieva's cup (chasha) type $3(1986,18)$. It seems probable that they were produced at Pavlikeni from the middle of the second century (Soultov 1985, 71); they are uncommon at Nicopolis and mainly occur in fourth/fifth century contexts.

744-748 are small jars with out-turned necks and plain rims, they correspond to Soultov's jug type 1 , for which he cites several comparanda and dates to the second to early third centuries $(1985,70)$. They occur at Armira, where they are included in Kabackchieva's cup (chasha) type 3, along with the types mentioned above, and an example very similar to 748 is illustrated from Iatrus (Böttger 1982, taf. 32: 45), where it is dated to the first half of the fourth century (Period A). The dating evidence at Nicopolis is inconclusive, but, together with the published examples mentioned above, tentatively they can be ascribed to the early second to mid third century in the case of the finer types (745-747) and mid third to late fourth for the thicker types (744 and 748 ).

749-752 are small jars with off-set ribbed necks, sometimes with scale decoration (752).$^{18}$ They correspond to Soultov's 'two handled earthenware' type $9(1985,78)$ which he dates from the mid second century, with the decorated type being later: '[it] is most often to be found ... together with coins of the first half of the third century'. Published comparanda are rare, though Soultov $(1985,78)$ mentions unpublished material from both Nicopolis and Novae with the scale decoration. ${ }^{19}$ Though the group is not common at Nicopolis (19 examples were found), none was found in contexts that could be dated earlier than the mid fourth century; a date of 350-450 and possibly later, is suggested. 753-755 are miscellaneous small jars. 753 may be a variant of Soultov's 'two handled earthenware' type 3 , dated to the last half of the second century $(1985,76)$.

756-759 are cups with off-set rims with internal ledges. They often have one or two incised lines on the exterior of the rim. The types, particularly 756 with 139 examples, were common. Suggested date range: c. 130-230. Similar, though more 
rounded, vessels are' published from Armira (Kabakchieva 1986, tab. 17: 238-239) and Soultov's 'two handled earthenware' type $7(1985,77)$, is very similar.

$760-763$ are of the same form but with much plainer rims, though still slightly off-set. Though rare they can be dated with some certainty to the second century.

764-770 are cups with a more rounded profile than the previous two groups, usually with a plain rim, often with an incised line immediately below the rim on the exterior. Applique decoration is common (plate I). The evidence from Nicopolis strongly suggests a date range of $c .110-180$. The group corresponds to both Soultov's cup type 4, and 'two handled earthenware' type 6 (1985, 68 and 77), both of which he dates to the mid second century. An almost identical type to 766 is published from Novae (Dyczek 1987, tab. I, 1) and a similar one to 768 is published from Armira (Kabakchieva 1986, tab. 16: 22), dated to the second and third centuries $(1986,17)$.

771-786 are hemispherical bowls with plain out-turned rims. Decoration is common and consists of appliqué, incising, rouletting or scale decoration. Over a hundred examples were found, mostly dating from $250-450$, though production may have started slightly earlier. The group corresponds to Soultov's bowl type 6 which he says came into production at Butovo 'by the beginning of the third century' (1985, 67). An example from Novae (Dyczek 1991, tab. XIV, 2) is dated to 'II/III century (?)'.

787-792 show different bases that go with various ware 8 bowls and cups. 790 is decorated with a combed cross inside a combed circle.

793-801 show large bowls (they are really a large version of the group 771-786), over thirty were recorded and they seem to have a similar date range: $c$. 250-450. They do not appear to have any published comparanda.

802-808 are straight necked jugs with plain rims - probably biansulate, though some may have had a single handle. ${ }^{20}$ They were not very common, but probably date to the third and fourth centuries. They correspond to Soultov's 'amphorae-like earthenware' type 4 , for which he suggests a start of production at the end of the second century $(1985,75)$.

809 is a small trefoil jug and 810 is a jug with thickened rim. 811 and 812 are one-handled jugs with narrow necks and rims of triangular cross-section: they correspond to Soultov's pitcher type 7 which were common in burials in the region which date to the second and third centuries, and have been found at several sites elsewhere in Bulgaria $(1985,73)$. Examples are published from Armira and dated to the second or third century (Kabakchieva 1986, tab. 20,275-278, and p. 20). It would seem therefore that they are surprisingly rare at Nicopolis: only seven examples were found.

813 and 814 are jugs with off-set vertical rims, both from contexts dating to after the end of the third century. 815 is a jug with a rounded thickened rim; it is possibly the same as Soultov's pitcher type $2^{21}$ for which he gives an extensive list of comparative material, and dates to the last half of the second and beginning of the third century. Our evidence is slim, but suggests a date certainly within the range of 130-250. 
816 and 817 are jugs with collared necks: their shape suggests a fifth century date (see above 293 and 295), but there is little on-site evidence to support this. 818-825 show jugs with narrow necks and flaring plain rims. They were not common but seem to date from the middle of the second century. A similar example from Novae, dated to the fourth century, may be of the same type (Dyczek 1991, tab. X, 2). 826-832 show jugs with flaring necks and vertical rims. They are possibly related to Soultov's amphora types 2 and $3(1985,74)$, dated to the second and third centuries. A similar piece from Armira (Kabakchieva 1986, tab. 19, 260) falls into Kabakchieva's jug (kana) type I, for which she cites Ivanov (Ivanov et al. 1969, 176, fig. 58) who provides a third to fourth century date, though she suggests that some types are earlier. At Nicopolis they first appear in the middle of the second century.

833 represents a cross between this group and the previous one, and 834 is an exceptionally wide-mouthed jug which probably belongs to the fifth century.

835-852 are large jars with differing types of thickened rim. None are common and they do not seem to have been produced at Hotnitsa, Pavlikeni or Butovo, though the fabric indicates local production. With the exception of 835 and 852 , which may well be second century, they all come from contexts dated to the fourth century or later.

853-863 and 868-872 are miscellaneous jars. Again none is common and dating for the most part is uncertain, with the exception of 859 and 861 which are probably second century $\mathbf{8 5 9}$ has parallels at Armira, belonging with Kabakchieva's amphora type II $(1986,20)$, which is dated to the second and third centuries. 853 can be compared with a slightly larger example from Armira (Kabakchieva 1986, tab. 34, 393) and 857 may be related to Kabakchieva's jar (gurne), type IV $(1986,24) .872$ also appears at Armira, where it corresponds to jug (kana) type B (Kabakchieva 1986, 19).

864-866 and 873 show the lids which go with the closed forms. They were rare and these were the only four examples found. Similar types came from Pavlikeni and Butovo (Soultov 1986, 79). 867 and 874 show two different bases of the smaller jars.

875-882 show hole-mouth jars, some quite large (note the scale on $\mathbf{8 7 5}$ and 876 ), several of which are decorated: 876 has a large three-piece strap handle with a flat top with impressed decoration, 875,880 and 884 have incised decoration, and $\mathbf{8 8 1}$ has both incised and applied decoration on the rim. With the exception of 878 they are rare. 878 occurs in most phases of occupation but is more common in the second and third centuries, and may well be residual in post third century contexts; it, together with 877 and $\mathbf{8 7 9}$, correspond to jar (gurne) type A I at Armira (Kabakchieva 1986, 23).

885-918 show amphorae ${ }^{22}$ types. The general shape was always similar to $\mathbf{8 8 5}$, but a wide variety of rim shapes were employed. Most vessels had internal ledges, presumably to support a lid (see $\mathbf{9 7 5 - 9 7 9}$ below). Handles were usually flattish as on 896 and 903, occasionally fatter and ribbed, as on 906, and sometimes twisted, 
as on 918. They were common, with over 700 examples found. Soultov states that they were found throughout Bulgaria from the first century, and were made at Hotnitsa, Pavlikeni and Butovo from the second half of the second century (1985, 74). At Nicopolis they are present in the earliest deposits, with a marked increase in occurrences in late second and third century contexts and apparently continued until the end of the early Byzantine occupation, though how many of the pieces in later contexts are residual it is impossible to say.

It is likely that future study of this group will enable chronological divisions to be made on the different rim or handle, and possibly base, types. The only real difference that can be detected at Nicopolis is that the twisted handles are rare before the fourth century.

919-935 show the rims of large trays ${ }^{23}$ that were probably made at Butovo (Soultov 1985, 93). These may have been copies of terra sigillata types (Drag. 39) though Soultov thinks that they are more likely to have been copies of metal trays. Designs were varied, and are described in the figure descriptions. (Photographs of several of the different motifs used can be seen in Soultov 1976, 64-9.) Soultov dates the start of manufacture to the beginning of the third century. At Nicopolis they do not seem to appear until the second half of the third century.

\section{WARE 4 (FIGS 9.46-9.47)}

This is the same fabric as ware 8 , but without slip. Many vessels in ware 8 , particularly the craters and amphorae, were only slipped on the top part, so the body sherd count may be misleading. However, with the exception of some jugs, no ware 8 rim types occurred in ware 4 . Total sherds recorded: 8,950 .

936-957 are examples of a distinctive class of vessel with a thick white slip that is almost certainly lime based..$^{24}$ Some examples are undecorated, but most have either rough rouletting or finger-impressed decoration on the rim and/or the flange or carination. In some cases the rim and flange are pinched together at intervals. Two types of base exist: string cut, as on 953 , or pedestal as in 950 .

Soultov refers to these vessels as censers. However, $c .100$ examples were found but none of them showed signs of burning. They first occur in the second century and thereafter in most phases down to 600 , though the later ones may well be residual. The only tentative division that can be put forward on our evidence is that of pinched and unpinched rims; the pinched rim types seem to first occur towards the end of the first half of the second century, whereas the plain rim variety are not introduced until the second half of the century. Soultov goes into some detail in describing these vessels $(1985,81)^{25}$ where he divides them by their different bases. He dates the group as a whole to the second and third centuries. Three examples from Novae are also dated to the second to third centuries - though this is probably through reference to Soultov (Dymaczewska and Kotecki 1981, tab. XIII, 1, 2 and 4). 
958,965 and 966 show tall-necked jugs with their bases 961,967 and 968 . These first appear towards the end of the second century. They have similarities with certain red-slipped types from Hotnitsa, Pavlikeni and Butovo (Soultov 1985, tab.: XXXIII) but their closest parallels are to be found at Armira where several unslipped pitchers (stomni) and their bases are illustrated (Kabakchieva 1986, tab. 35-38 and p. 25); they are dated to the second to fourth centuries.

959 shows a jar which is probably an unslipped version of 808 , though it is larger, and 960 is an unslipped version of 868.969 can be compared to the red-slipped jug 811 above. $970-973$ are jugs that probably date to the second and third centuries, and 974 is a small cup that may be related to a piece from Novae (termed a lamp), (Dyczek 1991, tab. XIII, 3). 962-964 and 982 are miscellaneous bowls.

975-979 are amphorae stoppers - they may belong with the amphora group 885-918 above. They were not very common at Nicopolis, but appear from the second century onwards. They have a wide distribution - several are illustrated from fifth and sixth century contexts at Iatrus (Böttger 1982, taf. 25) and a fourth century one is published from Novae (Dyczek 1991, tab. XIII, 1). 980 and 981 are also traditionally called amphorae stoppers, one of which is published by Soultov (1985, tab. XLI, 5) and others have been found near Veliko Turnovo (pers. comm. P. Vladkova). It is possible that some of them were used as amphora stoppers but, of the ones found at Nicopolis, the majority are too small: none of the 23 examples was large enough to belong to any of the 700 local amphorae found at Nicopolis.

\section{WARE 78 (FIG. 9.48)}

Black slip ware. The ware is wheel-turned; the fabric is grey with a black to grey slip that occasionally appears mottled. The fracture is clean with a tendency to splinter. The fabric contains a small amount of mica but is generally free from inclusions. Total sherds recorded: 244 .

This may have been a local variant of the red-slipped wares as many of the shapes are similar although the quality is of a consistently higher standard, and the pieces have a different 'feel'. Some pieces certainly reflect the shapes that occur in Macedonian t.s. grise and the ware description given by Hayes $(1972,405)$, sounds the same ${ }^{26}$ However, at Nicopolis the ware first appears in the second century, which would seem to rule this out. Even so, it is notable that ware 78 occurs in the second and third centuries, and then hardly at all until 450-600 (see appendix 3); possibly we have two similar wares, used at different periods, and not one ware in use throughout the Roman to early Byzantine periods. If this is the case, then the first may be a local ware and the second an imported fine ware, dating only to the fifth and sixth centuries AD.

983-986 show open bowls. Evidence is limited, but they probably belong to the fourth and fifth centuries. 987-990 and 995 are reminiscent of the 556-572 group above, and a similar date would also fit: 250-400.991-993 can also be compared to 
previous red-slipped types: they closely resemble Macedonian t.s. grise pieces published in Hayes (1972, fig. 91), but our types first occur in the second century. 994 is a bowl with multiple bands of rouletting on the interior. 996-998 are miscellaneous bowls which occurred only once, and 999 may be the rim of a jar.

\section{WARE 44 AND MORTARIA (FIG. 9.49)}

The ware is reddish-brown with a brown surface and a crumbly fracture. The fabric is very grainy with many large $(1 \mathrm{~mm})$, angular white, grey, black and translucent grits and grog (c. 20 per cent of the body is composed of inclusions). Usual thickness: $1.0 \mathrm{~cm}$. Total sherds recorded: 47 .

$1000-1005$ are jars and basins, some very large, that come from contexts dating to the second and early third centuries - it is interesting that they are nearly all from area $\mathrm{D}$. These were the only types in ware 44 .

1006 is a stamped mortarium. Other mortaria fragments were found, but were too small to be drawn. For a discussion on the stamps, see J. Reynolds. ${ }^{27}$

\section{WARE 39 (FIG. 9.50)}

The ware is red, with a red interior surface, and a black slip on the exterior, sometimes a black salt glaze, though this may be due to over-firing rather than intentional glazing. The fracture is clean. The fabric contains a few black and white grits, and some silvery particles. Usual thickness $3 \mathrm{~mm}$. Total sherds recorded: 13 .

1007-1010 show jar rims and a base in this very distinctive thin fabric. 1009 is painted in white (one body sherd of this ware had a very faint painted spiral pattern on it). Few examples were found, so no date can be inferred, however similar vessels from the Athenian agora date to the third and fourth centuries (Robinson 1959, pl. $37, \mathrm{~K} 61$ and others).

\section{MisCeLLANEOUS WARES (Fig. 9.50)}

1015 and 1016 are two small crucibles and 1017-1020, and 1022-1025 show miscellaneous jars and jugs. 1011-1014 and the exceptionally thin-walled 1021 are miscellaneous bowls. 1026 is a base.

Some wares were not represented by diagnostic sherds. There were very few of such finds. They are, however, listed in appendix 1, and occurrences are entered in appendix 3.

\section{Imported Fine Wares}

SAMIAN (WARE 171) (FIG. 9.51)

Forty sherds of Samian ware were found during the excavations. Two were possibly Central Gaulish, one from Lezoux, and the rest East Gaulish. All were residual. 
Identifiable forms were Drag. 31, 32, 33, 37 and 45, and Ludowici form Tb. (1027-1040). Finds included several pieces with moulded decoration (1035-1039) all of which are probably from Drag. form 37.

One stamped example (1037) has been discussed in detail. ${ }^{28}$ In addition a small fragment of a mortarium came from area $\mathrm{K}$ (4516), a context dated 250-450.

AFriCAN RED SLIP WARE (WARE 149 AND 150) (Fig. 9.51)

Two fabrics were identified, one (150) slightly coarser than the other. Only eight sherds were found. Identifiable forms were Hayes forms 50 (1044) 59 and 104, which were too small for meaningful illustration. An example of form 59 came from context 655 , dated 350-450, and another of form 104 from context 125, dated 450-600. Both of which fit well with Hayes' dating.

\section{LATE ROMAN C WARE (WARE 174) (FIG. 9.51)}

Nine sherds were found, at least five of which came from Hayes form 4 bowls (1042), which is surprising since this is a rare form. The five examples came from contexts that dated to the fifth and sixth centuries, the earliest from a context dated 400-450. 1043 is a hybrid example, sharing similarities with Hayes forms 3 and 4. In addition two fragments of bases were found, one with stamped palmettes (1041), which may be from the same vessel as 1042, and one from the surface (not illustrated), which could have been from a Hayes form 2, 3 or 4 .

Cypriot Red SLIP WARE (WARE 175) (Fig. 9.51)

Only two examples of this ware were found, both were Hayes form 9 (1045), both from post-medieval contexts.

\section{GREEN-GLAZED WARE}

A single fragment of a grey fine ware with green glaze and 'spiky' decoration was found in an undated context (plate 4). It looks very similar to certain fourth century green-glazed vessels, one of which, from the Römisch-Germanisches Museum in Cologne, is published in Schutz 1985 (plate 5b).

\section{Amphorae ${ }^{29}$}

\section{Eastern Mediterranean amphorae (Figs 9.52 and 9.53)}

\section{WARE 76}

Gaza amphora. The fabric is brown to yellow-brown with a slightly darker surface and a moderate fracture. Many white and translucent grits are visible in the break. Usual thickness $1.0 \mathrm{~cm}$. Total sherds recorded: $11 .^{30}$ 
1046-1049 are types in this ware (corresponding to P\&W classes 48 and 49 ). Nine examples were found, five dating to the fifth and sixth centuries, and the others to the post-medieval period. Traditionally, this type of amphora is dated from the fourth to the sixth century.

\section{WARE 96}

The ware is brick red, often with a grey core (particularly evident in the handles), with a brick red surface and with a moderately crumbly fracture. The fabric contains some quartz and angular black grits, a few voids and some mica. Usual thickness $0.8 \mathrm{~cm}$. Total sherds recorded: 622 .

1050-1053 represent a distinctive type of collared amphorae, the only type found in this ware (corresponding to P\&W class 47). This was one of the most common amphora types at Nicopolis: 36 rim fragments and nearly 600 body sherds were found. A few examples came from early contexts, but the type did not appear in any quantity in contexts dated to before 250-350. Probably, this type was in use c. 260-500, although it is possible that the large numbers found in contexts later than 450 are actually residual. This type of amphora is usually considered to belong to the third and fourth century (Peacock and Williams 1986, 194).

1054 and 1055 show a cylindrical amphora and a flat base in a grey sandy fabric. These were the only two pieces found in this fabric; both are probably late fifth or sixth century (pers. comm. D. Stanchev).

\section{WARE 94}

The ware is brown with a red core with a light brown surface with a medium sharp fracture, often with deep sharp combed ribs on the exterior. The fabric contains large lime grits, the occasional translucent grit and silvery particles and a few voids. Usual thickness $0.8 \mathrm{~cm}$. Total sherds recorded: 775 .

1056-1062 are different rim forms of this distinctively combed globular amphora (corresponding to P\&W class 43). Again a well-attested form at Nicopolis, with 54 rim fragments and over 700 body sherds recorded. It first occurs in contexts dated to 175-250, though does not seem common until the late fourth century, and seems to have still been common in the sixth. The conventional dates for this type are from the fourth to the sixth centuries (Peacock and Williams 1986, 183). Hayes $(1962,66)$ however, points out that at Saraçhane it is not common until the sixth century.

1063 shows the neck of an amphora in a Nile Valley fabric. It was the only example found and may belong to P\&W class 53 , which is regarded as a fourth to sixth century type. 


\section{WARE 164}

The fabric is light brown with an orange to very light brown surface with a moderate to clean fracture, often with angular ribbing on the exterior - which appears very gritty. The fabric contains many red, black, and brown rounded and angular grits, a few white grits and the occasional void and silvery particle. Usual thickness: $0.8 \mathrm{~cm}$. Total sherds recorded: 315 .

1064-1068 are types in this distinctive gritty fabric (corresponding to P\&W class 44). It first occurs in numbers in a context dated to c. 300-450, and is also relatively common in contexts dating to 450 , and those dating to $450-600$, so a date of the fifth and sixth centuries seems likely, which is consistent with the generally accepted dates of early fifth to mid seventh century.

\section{WARE 167}

The ware is brown with a brown surface with wide shallow ribbing and a crumbly fracture. The fabric contains a large amount of mica. Stress lines are clearly visible as if the vessel was trying to 'unwind' itself. Usual thickness: $c .0 .4-0.5 \mathrm{~cm} .61$ sherds were found with a heavy concentration in contexts dated to 130-150. This corresponds to $\mathrm{P} \& \mathrm{~W}$ class 45 . No diagnostics were found.

\section{African amphorae (Fig. 9.53)}

\section{WARES 37 AND 38}

Ware 37. The fabric is brick red with a dull orange surface on the interior and a white slip on the exterior, moderate fracture and often shallow ribbing on the outside. The fabric contains some limestone, a few rounded grey grits and voids, some quartz and a little mica. Usual thickness $0.9 \mathrm{~cm}$. Total sherds recorded: 179 .

Ware 38 . The fabric is red with a light red to buff surface and a clean fracture. The fabric contains white and the odd grey or translucent grit, and the occasional shiny particle. Usual thickness $0.8 \mathrm{~cm}$. Total sherds recorded: 996 .

1069-1073 are types of amphorae with distinctive rims with internal ledges that occur in both wares 37 and 38 , corresponding to P\&W class 33 , which usually have a thin cream slip; some examples show the vertical brush strokes mentioned by Peacock and Williams $(1986,154)$. The ware occurs in all periods from 130 onwards but is much more common in the fifth and possibly sixth centuries than at any other time. Conventional dating for this type is from the second to fourth centuries (Peacock and Williams 1986, 154), so it is possible that many of our examples are residual.

1074 is an example of a Keay (1984) type VI, usually dated to the third to fifth centuries; and $\mathbf{1 0 7 5}$ is a Keay type IX, which is usually dated to the first to third centuries, somewhat earlier than our dating. 


\section{WARE 19}

The fabric is pinkish with a buff surface (probably a self-slip) and a clean fracture. The fabric is grainy with many small white grits and the occasional black, grey or red grit. Many mica flecks are visible on the surface and in the horizontal section, though none is visible in vertical fractures. Usual thickness $0.9 \mathrm{~cm}$. Total sherds recorded: 108 .

1076-1078 are amphorae with distinctive folded rims (corresponding to Keay 1984 type VIIIb). 108 body sherds were found: they were not common until at least the late third century and were most common in contexts dated 450-600, which fits well with the accepted date range for this type.

1079 has a very distinctive rim. It corresponds to Keay (1984) type LXI (sixth century) and was the only example found. 1080 in a brick red thick fabric may be the same as Keay's type XXXVI. However, if this is so, the sherd must be intrusive as the accepted date (fifth to sixth centuries) is much later than the context for this example (150-250). 1081 and 1082 correspond to Keay's type XXV, which is usually dated to the fourth and fifth centuries.

\section{Miscellaneous amphorae (Figs 9.53 and 9.54)}

1083-1085 are miscellaneous amphorae feet. 1086-1088 are a group that correspond to Keay's type XIII: the only two dated examples were from contexts dated to $175-250$, which is earlier than the usually accepted date of late third to the fifth century. 1089, from a fifth century context, corresponds to Keay's type XIX (third to mid fifth century). 1090 may be the same as Keay's type LXII (fifth and sixth centuries) and 1091 and 1092, which probably date to the fifth century, are similar to Keay's type XLVII. 1093-1096 show various amphorae forms in a gritty fabric (ware 23). 1097 is a small glazed amphora in ware 32, of which 18 body sherds were found. Similar vessels have been found in the German excavations at latrus (Böttger 1982, taf. 30, 384-5, and taf. 31, 386-8), where they are termed Kannen Typ II.2 and dated to the fifth century. A similar vessel was found by the Bulgarian team at Iatrus containing an early fifth century coin hoard. ${ }^{31}$

1098 and 1099 are two types with distinctive rims that have also been found at Iatrus (Böttger 1982, taf. 21: 14 and 15) where they are called type I.6 belonging to Period A (first half of the fourth century). Six examples were found at Nicopolis, all from fifth century contexts. The ware is very similar to ware 164 which suggests a relationship with $\mathrm{P} \& \mathrm{~W}$ class 44 . 1100-1104 show miscellaneous rims and bases, all in highly micaceous fabrics, although they are not in the same ware. 1106-1115 are types that only occurred once.

In addition to the illustrated types, some body sherds were found in other wares that probably came from unidentified amphorae. The quantities were small, but 
they are listed in appendix 3 , and a description of these wares can be found in appendix 1 . Some sherds were painted with tituli picti. ${ }^{32}$

\section{THE SLAV PERIOD}

\section{WARE 43 (Figs 9.55 AND 9.56, PLATES VII, VIII)}

The fabric is grey to brown with a grey to brown surface that is usually combed with a moderate to crumbly fracture. The fabric contains much quartz and some black and a few white grits and a little mica. Usual thickness: $0.6 \mathrm{~cm}$. Total sherds recorded: 170 .

1116-1131 show jars in this ware. They are combed over most of their bodies, and many have additional decoration. Marks on the bottom of the base are common. This type of vessel is common in Bulgaria (and elsewhere), from the period of the First Bulgarian Kingdom until well into the medieval period. There is a large published corpus from Iatrus that has been studied in some detail by Wendel (1986) who traces its development from the late seventh century onwards. ${ }^{33}$

Most of this pottery (and all the complete examples) came from a grubenhaus in area $\mathrm{F}$, which, on the evidence from the site, can only be dated later than the destruction of the Large Basilica, towards the end of the sixth century. ${ }^{34}$ The vessels found at Nicopolis probably date to the tenth century (pers. comm. Z. Genova, the Veliko Turnovo Historical Museum).

\section{THE POST-MEDIEVAL PERIOD}

(FIGS 9.57-9.61)

Various vessels were found associated with the remains of post-medieval grubenhäuser and in topsoil. Here they are treated as a single group although it is possible that the date range for these types extends over two hundred years or more. ${ }^{35}$

Not all the post-medieval sherds were recorded; the 'total sherds recorded' are therefore minimum numbers.

Ware 10. The ware is reddish-brown, often with a grey core, and a reddish-brown surface. with a moderate fracture. The fabric contains a few black grits and much mica: generally clean apart from the mica. Usual thickness: $0.6 \mathrm{~cm}$. Total sherds recorded: 226.

Ware 9. As ware 10 above, but with white-painted decoration. Total sherds recorded: 546.

Ware 11. As ware 10 above but with glaze. Total sherds recorded: 265 .

1132-1195 show the different types of vessel that were found in these wares. There was no way of dating this material with any precision. On the basis of small- 
finds, coins and historical sources, it seems likely that the post-medieval occupation dates from $c .1750$ to the late eighteenth or early nineteenth centuries and was then followed by sporadic use of the site and robbing throughout the remainder of the nineteenth and during the first half of the twentieth century. ${ }^{36}$ Consequently, some of the latest pottery could be as late as the 1940s. Some of the older people in the modern village of Nikiup remember itinerant pottery salesmen selling the same sort of wares locally during the 1930s. I saw similar pieces sold as souvenirs in Troyan in 1988 and the vendor stated that they were copies of types made during the Turkish period. I was told by the guide at the Turkish Bey's house at Ledenik, near Veliko Turnovo, that similar pottery to that found at Nicopolis could be dated to the late nineteenth and early twentieth centuries.

There are few published parallels, but there are certain stylistic comparisons with some nineteenth and twentieth century material illustrated by Bakurdjiev (1955).

1196 and 1197 show two pieces of sgraffito ware in a different fabric; it is possible that these pieces date to the period of the Second Bulgarian Kingdom. ${ }^{37} 1198-1201$ are pieces in a hard frit: they may be a degenerate form of Kütahaya ware.

\section{NOTES}

1 Note that pottery from contaminated levels is not included in the tables.

2 Though none of our material in this ware was wheel-turned.

3 True, sherds of ware 1 were found in deposits dated 100-130 but in conspicuously lesser quantity than in the subsequent periods (table 5.1). These finds are here judged intrusive or denoting the introduction of this new ware at the very end of this first period of occupation.

4 See both Wachtel and Herrman in Iatrus $1 \mathrm{ch} .1$, and Ivanov in ch. 16 of the same volume.

5 My distinction, not Böttger's.

6 However, since it seems likely that the kiln sites in Nicopolis' territory did not survive into the late Roman period, production may have ceased by 300 or was transferred to the kiln site immediately outside the ancient city. See above, p. 40 .

7 They are actually most common in post-medieval contexts, but clearly do not belong to that period.

8 None was found at Iatrus either but, since the site was first occupied at the very end of the third century, this is hardly surprising. See above, p. 31.

9 Again, there are examples from Roman contexts but the concentration in the late Roman and early Byzantine period suggests that the apparently earlier examples are probably intrusive (table 5.1).

10 For a discussion of this ware and its possible significance, see below, pp. 111-12.

11 Some authors refer to the surface of the local pottery as having a red glaze. This is not so. It has a red slip.

12 See Falkner and Strange n.d. for evidence for kilns immediately north of the ancient city.

13 The piece actually has no number, but this is presumably a misprint.

14 Soultov, however, believed that examples have been found at Novae $(1985,63)$.

15 The corpus of Eastern Sigillata from Samaria in this volume illustrates well the origins of some of the types produced by local potters. For more on the origins of the local fine ware see below, pp. 108-11. 
16 Soultov says that the vessels were used for religious purposes, with the larger ones being used as urns $(1985,75)$. Given their numbers at Nicopolis, it is likely that they had a wide variety of uses.

17 This is a somewhat ambiguous statement: it may be supposed to imply that they were common at Butovo. The original manuscript in Bulgarian may be more informative.

18 See Soultov 1976, 44 for a good photograph of this type.

19 It must be remembered, however, that the bowl types 771-786, which are much more common at Nicopolis, have the same type of decoration.

20 See Soultov 1976, 33.

21 It is occasionally hard to be exact when comparing pieces to those published by Soultov because he does not include a scale in his drawings. However, it should be noted that the work was published posthumously so this may well not be his fault.

22 These vessels are here termed amphorae because of their shape: it does not imply that they were trade containers - though they may have been.

23 In appendix 2 all recorded tray fragments are entered under 919.

24 It reacts violently with $\mathrm{HCl}$.

25 Also see Soultov 1976, 101-4 for photographs of some reconstructed vessels. He also $(1985,82)$ mentions that the same type of vessel occurs in red-slipped ware: it is possible that some of the carinated red-slipped bowls referred to above belong to this group.

26 I have not (knowingly) handled Macedonian t.s. grise, and saying that two wares are congruent from written descriptions is risky.

27 In Poulter 1995, no. 7, 319-20. See also no. 6, 318-19 and no. 8, 320.

28 J. Reynolds in Poulter 1995, no. 14, 322.

29 References given for amphora comparanda are not comprehensive. They are simply provided so that the reader can be sure which type of amphora is being discussed. Peacock and Williams' Amphorae and the Roman Economy (1986) is cited in this section when discussing the general groups. However, in the catalogue, other works, such as Keay's Late Roman Amphorae (1984), are referred to whenever more detailed information is available.

30 It is likely that other sherds of this type were not identified as such and were recorded as 'miscellaneous'.

31 Pers. comm. D. Stanchev. The hoard had not been examined in detail and the dating remains provisional.

32 See J. Reynolds in Poulter 1995, nos. 12i-v, 321-2.

33 However, against such an early date for this pottery, see above p. 25.

34 Poulter 1995, 48-51 and see above, p. 25.

35 The settlement may already have existed by the sixteenth century although, from finds and coin evidence, the post-medieval occupation can be ascribed to the eighteenth to early nineteenth century. Thereafter, some pottery may well belong to the robbing of the site, carried out during the eighteenth to early nineteenth century. See Poulter 1995, 48-51. See above, pp. 26-7.

36 See note 35 above.

37 A coin of Ivan Alexander (1355-1371) was found in a residual context but there was no other archaeological evidence for permanent occupation in this period. See Poulter 1995, 47-8. 


\section{The problem of residuality and typical assemblages by period}

In trying to date the pottery from the excavations at Nicopolis the main problem, as on many urban sites, is residuality, that is the appearance of types in contexts which date to a period when those types were no longer in production or use. On most excavated sites that produce over 100,000 sherds there are usually levels that produce pure deposits, that is deposits that contain no residual material; often rubbish pits, or in situ destruction deposits. At Nicopolis, although several such deposits were excavated, the majority belong to the second century, the very period when residuality is demonstrably not a problem since it would seem that the site was first occupied after the foundation of the Roman city c. $110 .{ }^{1}$ All contexts that produced large assemblages, dating later than $c .250$, contained large quantities of residual material. Intrusive material (material that occurs in contexts that date earlier than its manufacture, probably because of rodent burrowing) was considerably less of a problem than residual material. Consequently, it is easier to determine the date for the introduction of a type than it is to assess how long the type was being produced and used. Filtering out residual material in later contexts poses problems. This is well illustrated in the post-medieval period where there are only three post-medieval wares found in any quantity (wares 9,10 and 11), yet they account for only 4.5 per cent of all sherds found in post-medieval contexts - in other words 95.5 per cent of all sherds in post-medieval contexts are residual. Thus, the dates for the introduction of wares shown in table 5.1 are likely to be much more accurate than the terminal dates. Until further sites are excavated, with sealed deposits belonging to different periods, it will not be possible to decide confidently how long particular types remained in use. Those who wish to judge for themselves the evidence for the occurrence of types and wares in different periods should consult appendices 2 and 3.

Because of the difficulties outlined above, the following assemblages are hypothetical groups and not assemblages in the sense that all the sherds come from a single context. They merely show which forms are commonly found in each of the dated periods of occupation.

The dates of the periods are also unusual in that they do not follow the normal practice of dating by century. This is because the principal phases of occupation do not fall into convenient century blocks - and there is of course no reason why they 


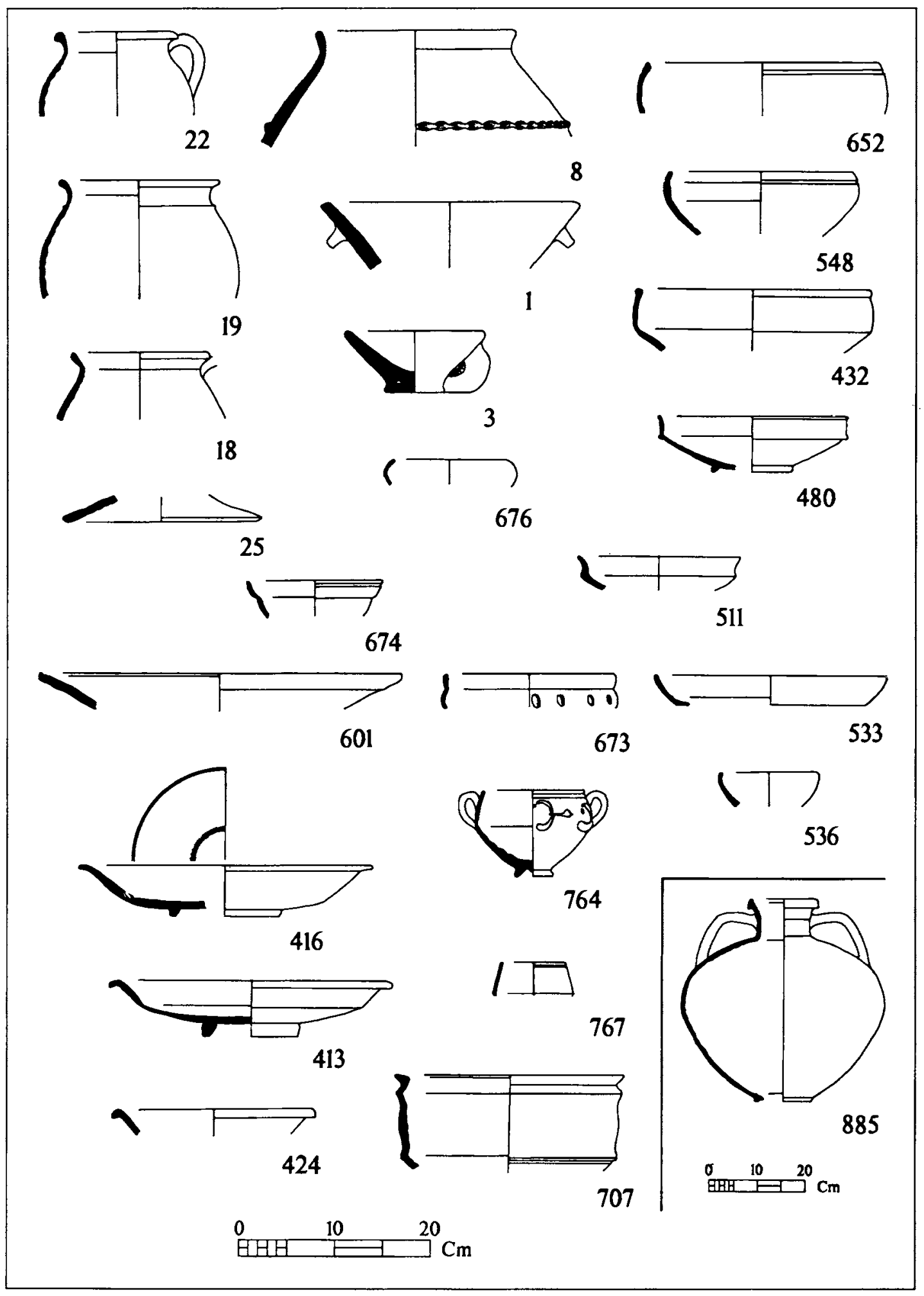

6.1 Pottery in use c. 100-130 
should! The periods used are those described in the section on methodology at the start of this report and largely rely upon datable finds and other criteria. ${ }^{2}$ Once the on-site chronology was established, evidence from other sites in the region, notably Iatrus (Krivina) and Novae (Svishtov), was compared with the site sequence. ${ }^{3}$

In order to facilitate cross referencing with the main body of the report, the same type numbers are used here as in the full catalogue (in Chapter 9).

\section{Pottery from the first years of the Roman city c. 100-130 (Fig. 6.1)}

Assemblages comprise red-brown coarse ware (ware 30/31). The occurrence of a thick rough hand-made ware denotes a continuation of the Thracian tradition (ware 25 ), although this is not common. There were also red-slipped fine wares (ware 8). Notable by its absence is the local grey ware which, during this first period after the foundation of the city, was not yet in production.

Cooking vessels in ware $30 / 31$ are closed forms with simple out-turned rims $(18,19$ and 22), sometimes with a collar as on 19. Lids are simple with plain rims (25). The coarse ware forms (ware 25) are also simple cup/bowls ( 1 and 3 ) or closed cooking vessels $(8)$.

Typical forms in the local red-slipped ware are bowls with flaring walls (601), often with out-turned rims $(413,424$ and 416$)$; hemispherical bowls (548 and 652), often with an incised line immediately below the rim; carinated bowls, either with flange ( 480 and 511) or thickened rolled rim (432); plain bowls with flat bases (533) or smaller bowls (536), again with plain rim. Cups either have off-set rims (673 and 674 ) or in-sloping walls (764 and 767). The only crater used is the wedge-rimmed collared type (707) and the only large jar is the amphora/water jar (885).

Imports are few, but two Central Gaulish Samian ware sherds may be from this period, and the lamp type with the light fabric and extended nozzle certainly dates to this period. ${ }^{4}$ Some sherds of Tunisian amphorae (ware 38 ) came from early contexts.

Decoration occurs on the ware 25 vessels in the form of thumb-impressed bands on the body. Occasionally the red-slipped wares have rouletted or appliqué decoration.

\section{Pottery in use from $c .130-250$ (Figs 6.2, 6.3)}

Assemblages consist almost entirely of local grey ware (ware 1) and local red-slipped ware (ware 8). The red-brown local ware (ware 30/31) is no longer produced.

Grey ware cooking pots consist of types with out-turned, thickened rims, sometimes with a collar (21a, 80 and 77 ), a direct development from the earlier ware 


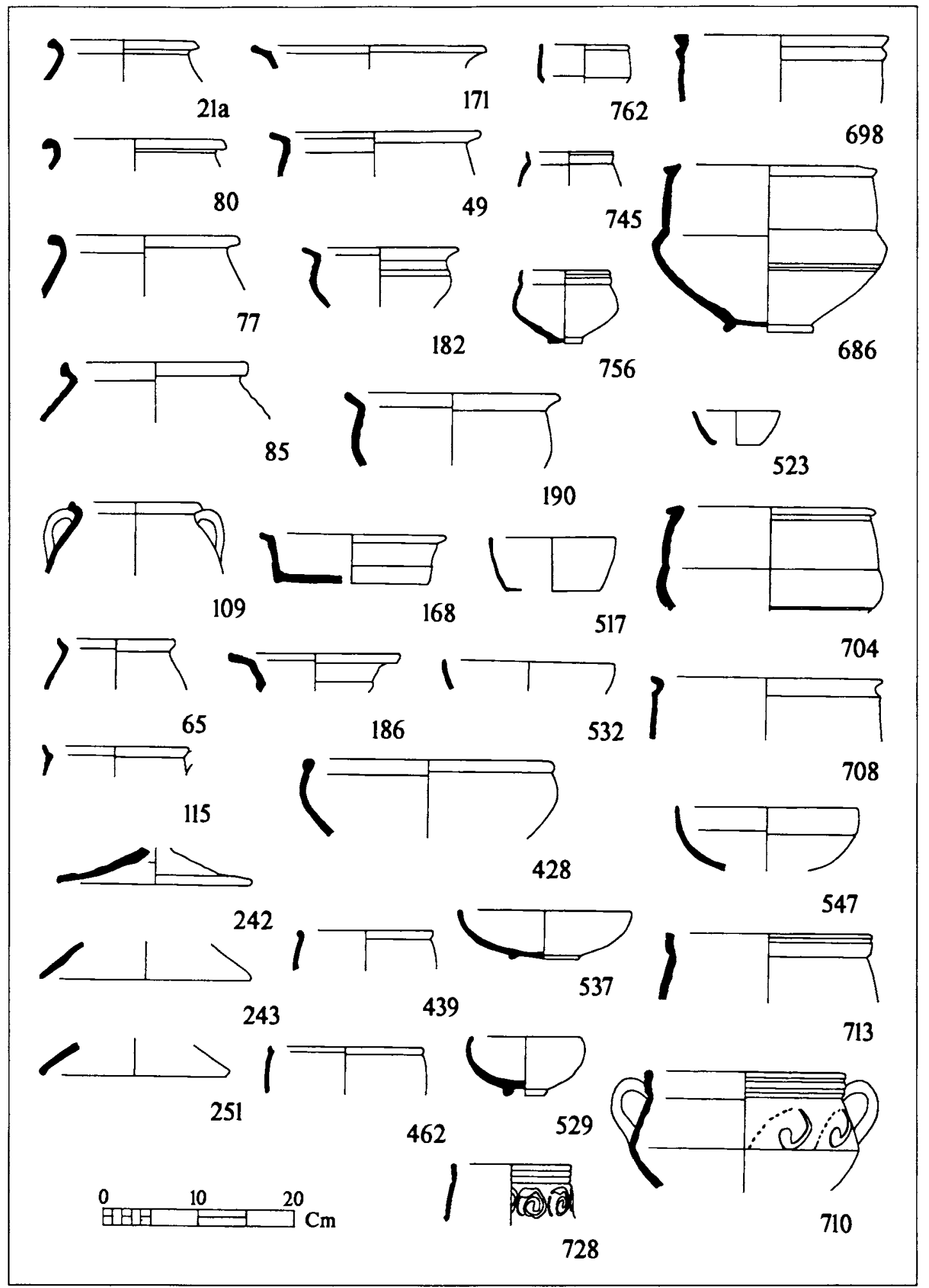

6.2 Pottery in use c. $130-250$ 


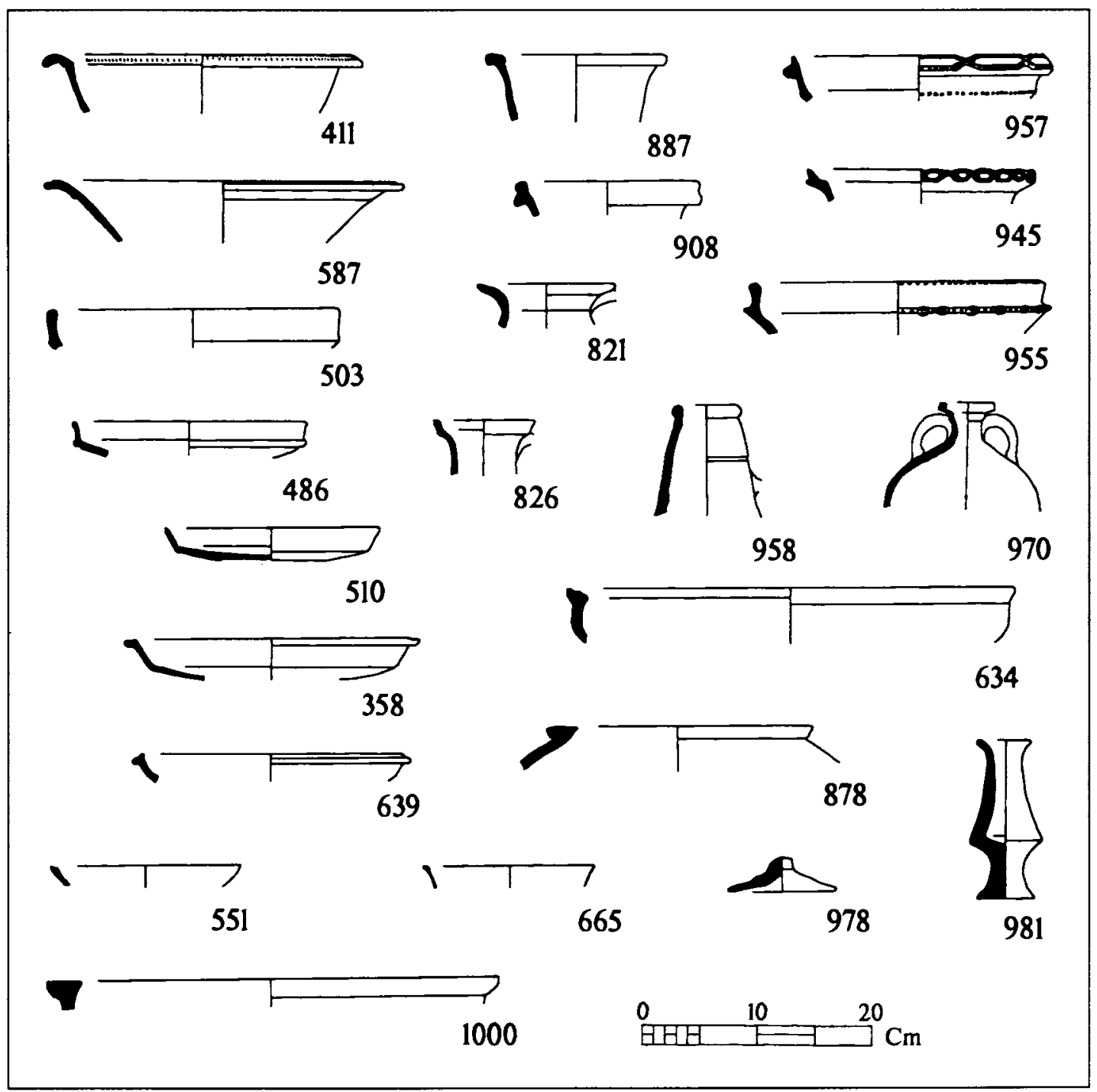

6.3 Pottery in use c. 130-250

$30 / 31$ types. A new feature that appears in this period is the internal ledge (as on 85 and 109); and a new cooking pot form with out-turned, but not thickened, rim (65 and 115). Lids for these forms are still plain, as in the preceding period ( 242 and 243 ), although the hooked rim types which become popular in the following period ( 245 and 244, fig. 6.4) are in evidence by 250.

In addition to the conventional closed forms, open cooking-pots or casseroles appear, usually in curvilinear forms $(171,49,182$ and 190), though flat bottomed, 
straight sided types do occur (168 and 186); these vessels usually have concave ledge rims, presumably to seat a lid.

Fine wares are represented by carinated bowls with thickened rims ( 428 and 439), a direct continuation of an earlier form (432). However, at some time during this period the rim becomes grooved (as on 462). Small cups with in-turned walls continue into this period (762) and are joined by hemispherical types with short necks (745 and 756) and small cups/bowls with flat bases (523 and 517).

The bowl form with the incised line below the rim continues (532 and 547), but is eventually replaced by a form with a more rounded rim that lacks the incised line (537 and 529). The everted rim bowls continue though the walls are slightly less flared (411 and 587) and the carinated bowls also continue in the same form as before (486) though here again the rims tend to become more rounded over time ( 503 and 510). Towards the end of the period the carinated bowl with ledge rim ( 358 and 369), a form that is very popular in the following period, makes its first appearance, and a small bowl with a notched rim (551) appears for the first time.

The form of the craters shows direct continuation from the first period (698 and 708), though the prominent collar is not always present (704 and 686). A new form also makes its appearance with a plain rim and straight, ribbed neck (710, plate II, 713 and 728). Amphora/water jars are common ( 887 and 908 ), with necks of the same form as type 885 in the previous period. In addition, smaller jugs appear (821 and 826) and two new vessels, a large bowl (634) and a hole-mouth jar (878) are introduced.

Some vessels, notably the 'censers', which first appear in this period, are in a limewashed version of the local fine ware (ware 4). The pinched rim types (945 and 957) seem to be earlier than the plain rim types (955). An unslipped version is also present in jugs (958 and 970) and amphora stoppers (978 and 981). A large bowl with folded ledge rim (1000) in a reddish-brown coarse ware (ware 44) probably for industrial use, also first appears in this period.

Although only one of forty Samian sherds found came from a deposit dated to before 250, it is likely that most of the Samian should belong to this period, with Drag. 37 being the most common form.

From the early years of this period, there are several sherds from P\&W class 45 amphorae (ware 167), though no rim or base sherds of this very distinctive ware were found. Other amphorae that occur are P\&W class 33/34 (ware 37/38) and P\&W class 47 (ware 96), though neither are common. However, towards the end of the period, a brown amphora fabric was common (ware 124), although its origin has not been identified.

Decoration on the red-slipped ware occurs fairly frequently, with appliqué being the most popular. 


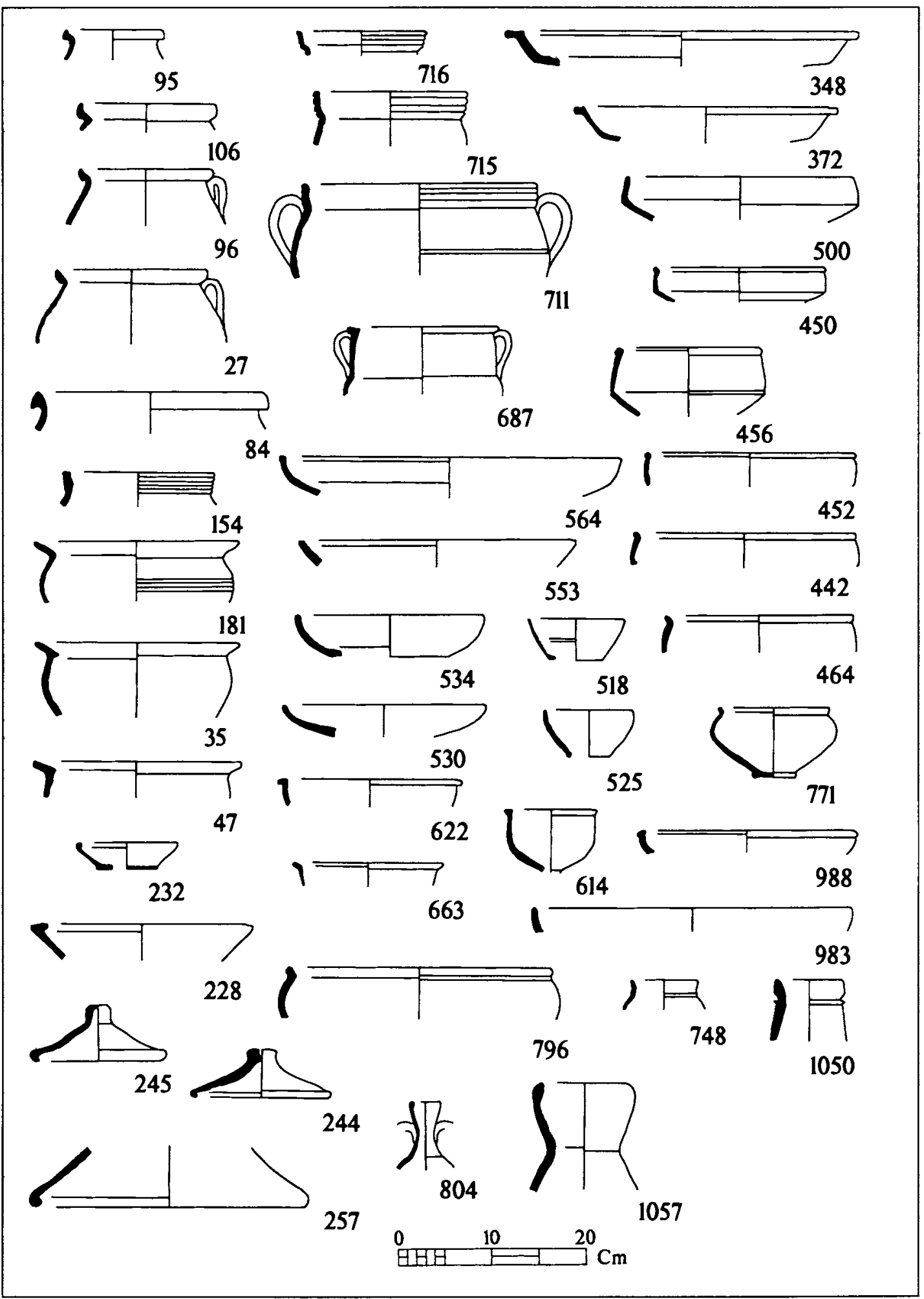

6.4 Pottery in use c. 250-350 


\section{Pottery in use c. 250-350 (Fig. 6.4)}

The assemblage is again dominated by the local grey ware and the local red-slipped ware, though some coarse yellow-buff ware (ware 24$)^{5}$ and a grey-slipped fine ware (ware 78$)^{6}$ are also present.

The common cooking pots in this period are the types with out-turned, thickened rims with internal groove that first appeared in the previous period (95, 106 and 96), though the plain thickened rim types ( 27 and 84 ) still occur. A new type of closed pot (154) with vertical plain rim, makes its first appearance during this period - probably towards the end of it. Open forms are again similar to earlier types $(47,181$ and 35$)$ though a new flat bottomed form with either a hooked (228) or rolled rim (232) is introduced. Lids follow the same pattern with hooked rims (244 and 245) and rolled rims (257), the hooked type appearing slightly earlier.

Among the fine red-slipped wares, the craters continue in the same forms as before $(716,715,711$ and 687$)$. Bowls with plain rims continue (534 and 530), often with an incised line below the rim on the inside (564), a trait which is also seen on notch rim bowls (553). The small drinking cups/bowls (518) continue, though the walls become thicker (525) and slightly curved (614). The necked cups (748) also continue; however the carinated cups with in-sloping walls (as 762) have disappeared by this period, as have the larger bowls with everted rims (as 411 ).

The carinated bowls with thickened rims continue, though the rims have become more angular $(456,450,455$ and 442$)$. Related to this form is a hemispherical bowl with up-turned rim (771), which first makes an appearance at the beginning of this period, as does the large bowl form 796 .

The most common red-slipped vessel of the period is the ledge rim bowl (372 and 348), which first appeared at the very end of the preceding period, and now dominates the assemblage in various types (see figs 9.18-9.22) until well into the following period. Another ledge rim vessel, a rectangular or oval tray, with stamped, moulded, or applied decoration (and sometimes all three) appears for the first time at the beginning of this period (see fig. 9.45).

Jugs are represented by taller, straighter necked types (804) and the large water jar/amphora seems to continue in an essentially unchanged form.

Imports are few: an example of an African Red Slip ware bowl (Hayes form 50), from a post-medieval context presumably dates to this period. The grey-slipped bowls ( 988 and 983 ) may also be imports. Amphorae types that occur are P\&W class 43 (ware 94, 1057) P\&W class 47 (ware 96, 1050) and P\&W class 33/34 (ware 37/38).

As in the preceding period, the most common form of decoration is appliqué on the red-slipped wares. 


\section{Pottery in use from c. 350-450 (Figs 6.5, 6.6)}

The assemblage is still dominated by the grey coarse wares and the local red-slipped wares, and again there is a small amount of yellow-buff ware (ware 24) and greyslipped ware (ware 78). However, more importantly, a new ware appears, probably in the middle of this period: a highly micaceous grey ware (ware 14). ${ }^{7}$

Thickened rim cooking pots continue ( 82 and 83 ) again often with the internal ledge (70, 71 and 103). The straight necked types (148 and 153), which appeared towards the end of the last period, become more common and two new forms are introduced: one with a flat ledge and internal lip (158-160) and one with an angular

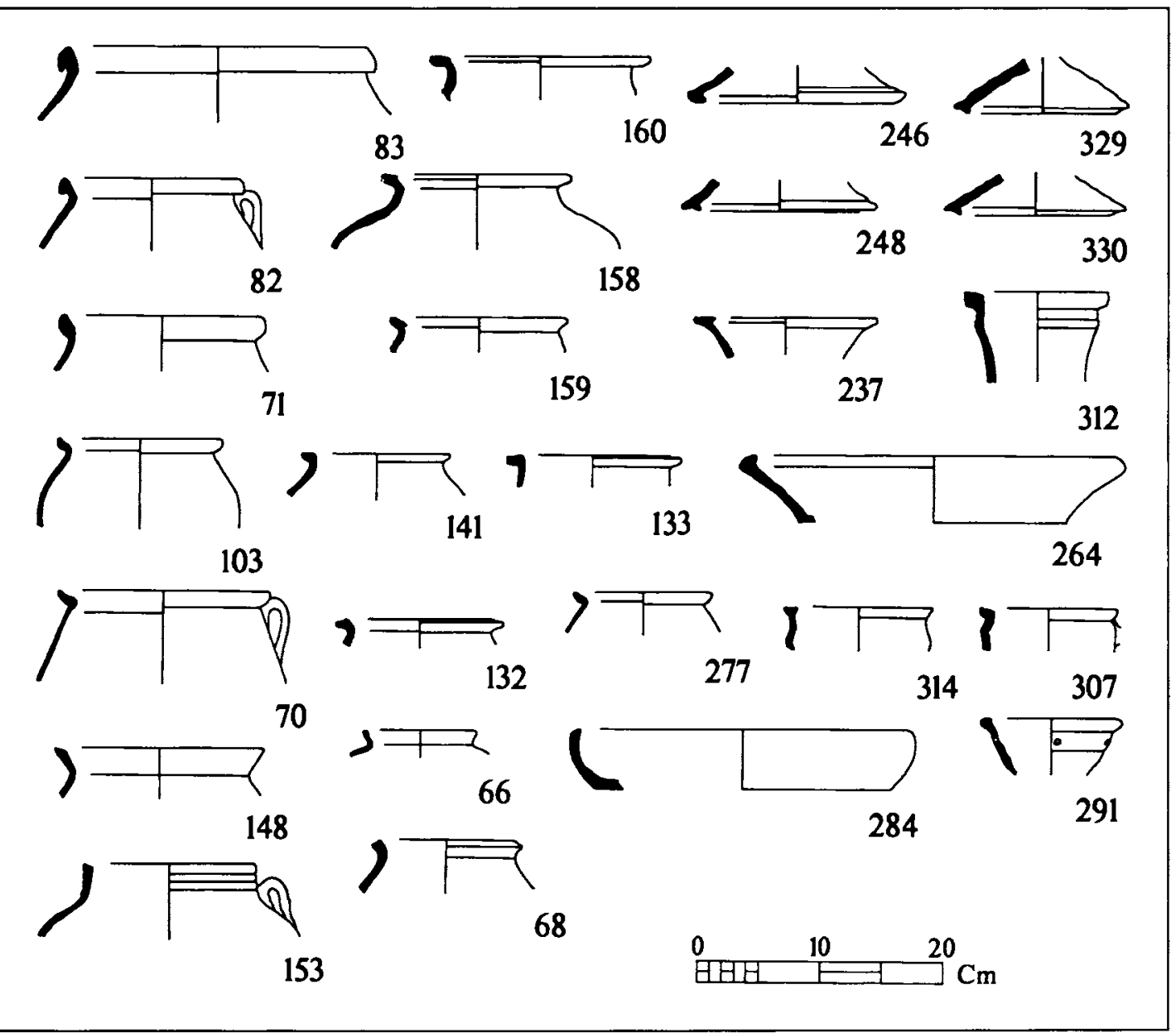

6.5 Pottery in use c. $350-450$ 


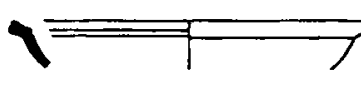

334

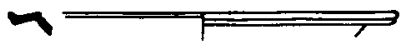

339
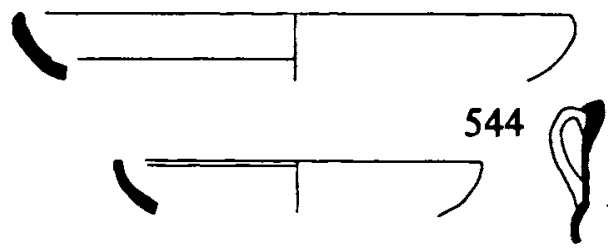

566

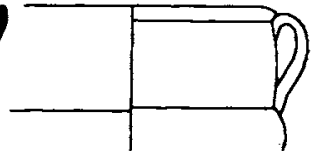

697
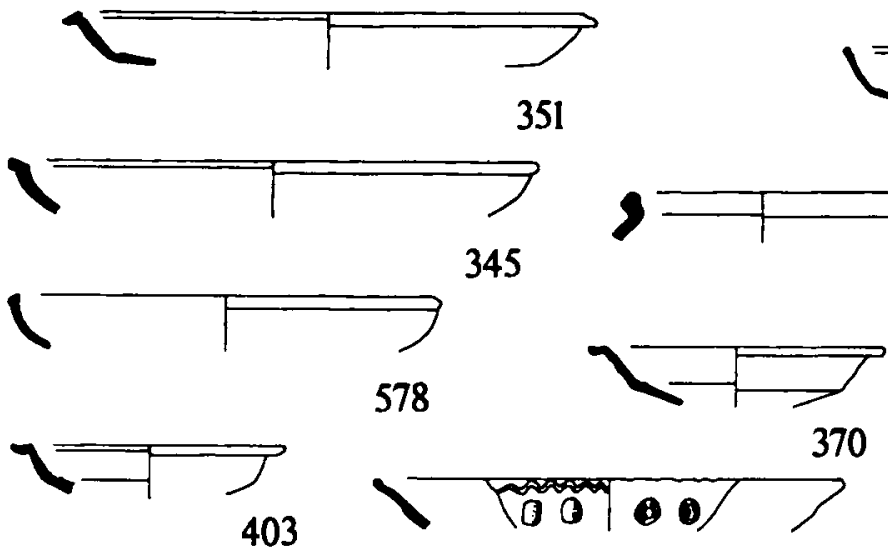

370

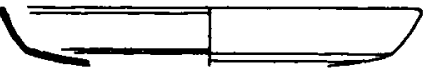

\section{5}
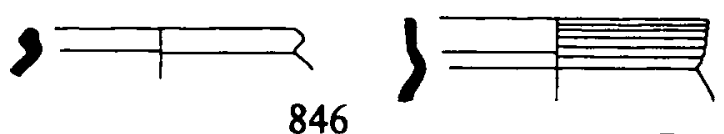

714
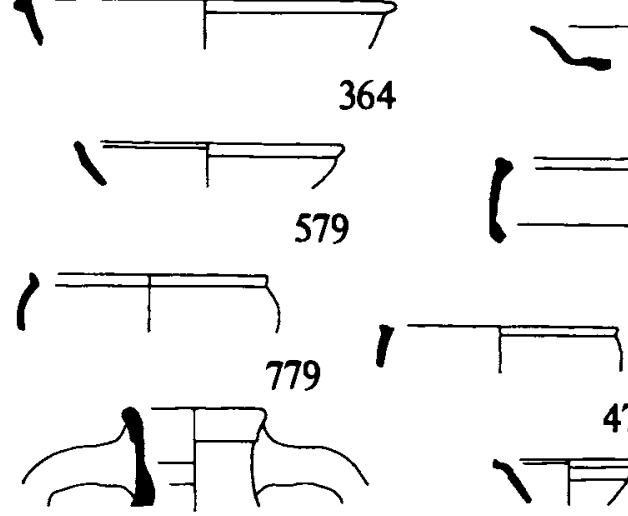

472

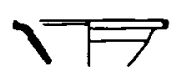

1064
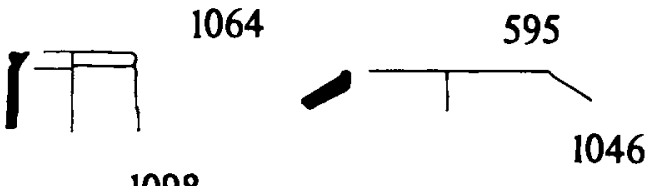

576

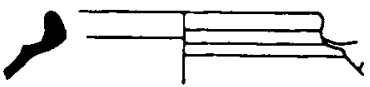

844
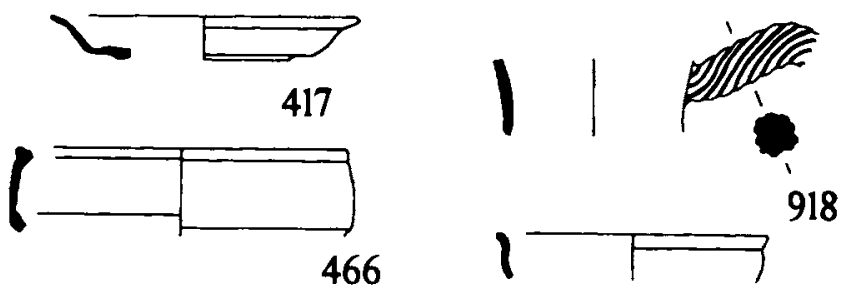

918

1098
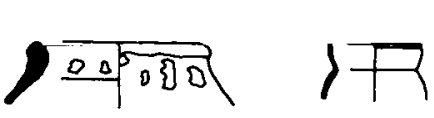

$\frac{647}{741}$

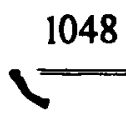

740

987

1046

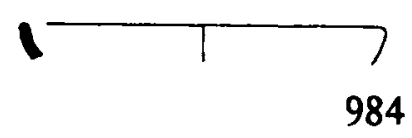

$\stackrel{0}{\mathrm{BHH}} \stackrel{10}{\stackrel{2}{\mathrm{G}}} \stackrel{20}{\mathrm{Cm}}$


$\operatorname{rim}(141)$, often with a groove on top of the $\operatorname{rim}(132$ and 133$) ; 68$ is probably a variant of this type.

Hooked rim, flat bottomed types (237) continue. The hooked rim lids (246) evolve during this period with the rim becoming grooved, or concave (248).

264 and 277 are two forms in the yellow-buff coarse ware (ware 24) which reproduce two of the grey coarse ware forms. They are not common.

The micaceous grey ware (ware 14), which first appears in the middle of this period, signals the introduction of some new forms: notably a collared water jar (307, 312 and 314). It is also used for existing local forms: 284 is a flat bottomed bowl reminiscent of the red-slipped bowl 578; 329 and 330 are hooked rim lids with concave ledges, and 291 is a sieve/colander.

Amongst the red-slipped fine wares, the ledge rim bowls $(345,351,334,370$, 364 and 403 ) are still very much in evidence, and a type with a wider ledge and upturned edge appears (339). The decorated trays (fig. 9.45) may well continue into this period too.

The hemispherical bowl form with the up-turned rim also continues (779) as does the plain rounded rim bowl with a flat base (544), often with an incised band on the inside immediately below the rim ( 566 and 565 ). There is a tendency for later types of this form to have more pointed rims of 'triangular' section (578).

Bowls with flaring walls seem to make a comeback (417 and 576) and the carinated bowls with thickened rims are still common (466 and 472), though they usually now have notched rims. The craters seem little changed $(697,714$ and 751$)$, though it is possible that they are by now residual, as may also be the case with smallnecked cups (740 and 741).

The amphorae/water jars (as 885) are still common though an innovation in the form - with the introduction of a twisted handle (918) - occurs during this period. A new type of hole-mouth jar also appears (846 and 844).

Imports are still rare, though some late Roman fine wares are in evidence: a sherd of African Red Slip ware (Hayes form 59) and three sherds of Late Roman C, including a Hayes form 4 bowl, were found. The grey-slipped ware (ware 78), which may be imported, is represented by bowl types 987 and 984 .

The most common amphorae present are P\&W class 43 (ware 94); others include P\&W class 47 (ware 96), P\&W class 44 (ware 164, 1064), P\&W class 33/34 (ware 37/38), P\&W class 48 (ware 76, 1046), P\&W class 49 (also ware 76, 1048), a type with a distinctive pointed rim (1098), and a small green-glazed amphora (ware 32).

Decoration on the red-slipped ware consists largely of scale type decoration (as on 786), though appliqué still occurs. On the micaceous grey ware (ware 14), patternburnishing starts to appear. 


\section{Pottery from the period of the early Byzantine city c. 450-600} (Fig. 6.7)

The dominant ware in this period is the local grey ware. The red-slipped ware is much less common than before, but the grey micaceous ware (ware 14), is strongly represented.

The thickened rim cooking pots have finally died out but the angular rim type, which first appeared in the previous period, continues (137, 146, 147 and 142) and a new form, with rounded and grooved rim, is introduced (136, 130, 135 and 127). The straight necked form has evolved, with the top part of an elongated neck becoming everted and slightly concave $(40,119,54$ and 105), often with an internal lip (100, 114, 122, 120 and 110). Casseroles are still used: 163, 234 and 226.

A new jar form appears which is much thinner walled than previous ware 1 forms ( 220 and 218 ). It may be an attempt to produce a finer version of ware 1 to compensate for the lack of fine wares caused by the decline of the red-slipped tradition.

The micaceous grey ware (ware 14), that appeared in the previous period continues. 319 is a cooking pot with angular rim that can be compared with examples in ware 1. A new form of lipped jug appears (325) and bowl forms 285, 282 and 283 are also new. Amongst the jars, the collared water jar (305) is still common, and two new jug forms appear (295 and 296), both with pattern-burnished necks. Sieve/ colanders continue to be represented (292), though they are never common. Patternburnishing on the micaceous grey ware is now common.

The red-slipped wares are definitely on the decline. Open forms are the ledge rim bowl with up-turned edge (332), which first appeared in the previous period, and the flat bottomed bowls, that now all have the pointed triangular section rim (580), again a type which appeared in the previous period. The form with flaring wall and plain rim is still present (574), as is the hemispherical form with up-turned rim (777 and 647). The small jars, with off-set rims ( 733 and 736 ), probably belong to this period, though they might be residual.

Imports are represented by African Red Slip ware (Hayes form 104) and several fragments of Late Roman $\mathrm{C}$ ware, including Hayes form 4 . The two examples of Cypriot Red Slip ware, which came from post-medieval contexts, should date towards the end of this period. The grey-slipped ware (ware 78) is also present.

Amphorae imports are well represented; $P \& W$ class 49 (ware 76, 1047), Keay type VIIIb (ware 19, 1076), P\&W class 43 (ware 94, 1056), P\&W class 33/34 (ware $37 / 38$ ), $P \& W$ class 47 (ware 96), $P \& W$ class 44 (ware 164) and a variant of $P \& W$ class 44 in ware $164(1065)$. 


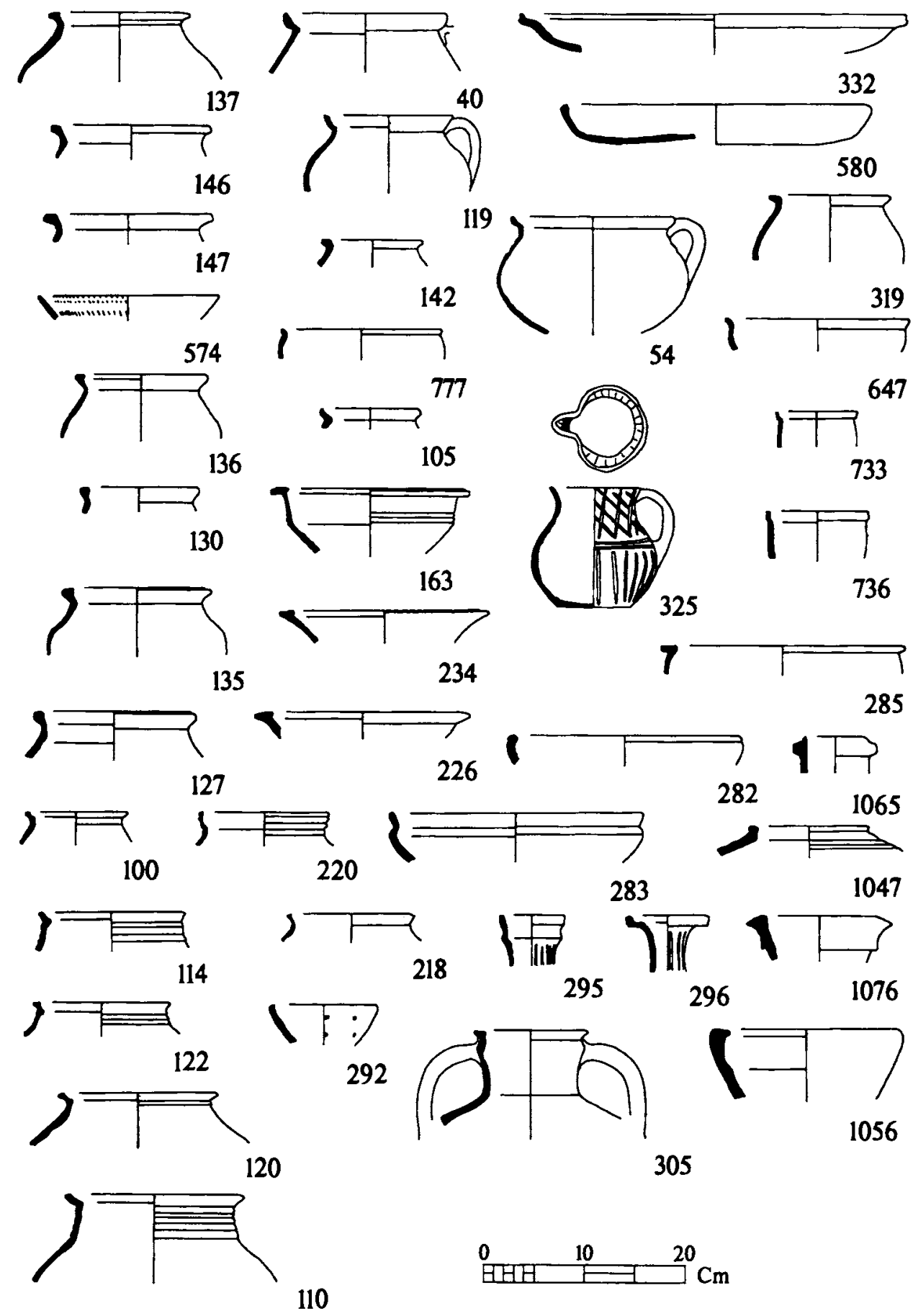

6.7 Pottery from the period of the early Byzantine city (c. 450-600) 


\section{The Slav period}

The evidence at Nicopolis for this period is limited: the only ware is a coarse grey ware (ware 43) that is sandier than the Roman/early Byzantine coarse grey ware. The only form is a jar with heavy ribbing on the exterior (see plate VII, figs 9.55 , 9.56).

\section{The post-medieval period}

There are three related wares in use in this period: a brown micaceous ware, either plain (ware 10), with white-painted designs (ware 9), or with glaze (ware 11). These appear in a variety of forms illustrated in figures 9.57-9.61.

\section{NOTES}

1 Poulter 1995, 10-11, 22.

2 See above, pp. 59-61.

3 On these sites, see above, pp. 30-1.

4 See volume on Nicopolis, the ceramic and metal finds (forthcoming).

5 For a discussion of the date of ware 24, see above, pp. 72-3.

6 For a discussion of ware 78, see above, pp. 85-6.

7 For a discussion on this ware, see below, pp. 111-12. 


\section{$7 \quad$ Pottery production and influences}

\section{Supply of pottery to the city from local kilns}

Three centres for the production of pottery within the territory of Nicopolis ad Istrum have been partly excavated.' Three others were identified, but not yet excavated. The three sites which have been examined are those at Butovo, Hotnitsa and a villa near Pavlikeni. The unexcavated centres are a site near Suhindol, another in the northern suburbs of Pavlikeni and one immediately to the north of the Roman city of Nicopolis (see fig. 3.1). ${ }^{2}$

Before his premature death, Bogdan Soultov studied the local production centres, conducting excavations at the kiln sites at Pavlikeni, Butovo and Hotnitsa. Although full publication was not completed, several articles were published, the most complete being Soultov 1985 (which has a comprehensive bibliography). The following discussion incorporates some of his results.

The centres at Pavlikeni and Hotnitsa began production in the early part of the second century - though at Hotnitsa there is evidence for the earlier production of Thracian pottery. The produce of the Pavlikeni kilns was at first confined to redslipped wares; only later did grey coarse wares join the repertoire. However, at Hotnitsa the grey wares were produced first, and red-slipped wares appeared somewhat later. At Nicopolis, we have clear evidence that the red-slipped wares were in common use before the introduction of grey wares, so we must conclude that either Hotnitsa was not supplying the site (an unlikely conclusion given that Hotnitsa is less than $7 \mathrm{~km}$ away), or that production at Hotnitsa started some years later than that at Pavlikeni, and that Pavlikeni was the only supplier during the very early years of the city's existence. This raises the problem as to where the red-brown coarse ware (that preceded the grey ware) was produced: no doubt the kiln site awaits discovery.

The centre at Butovo commenced production in the second half of the second century, and, by the early third, had eclipsed Pavlikeni as the main production centre for red-slipped wares. By the middle of the third century both Pavlikeni and Hotnitsa had ceased production, although it has been claimed that Butovo survived as the 


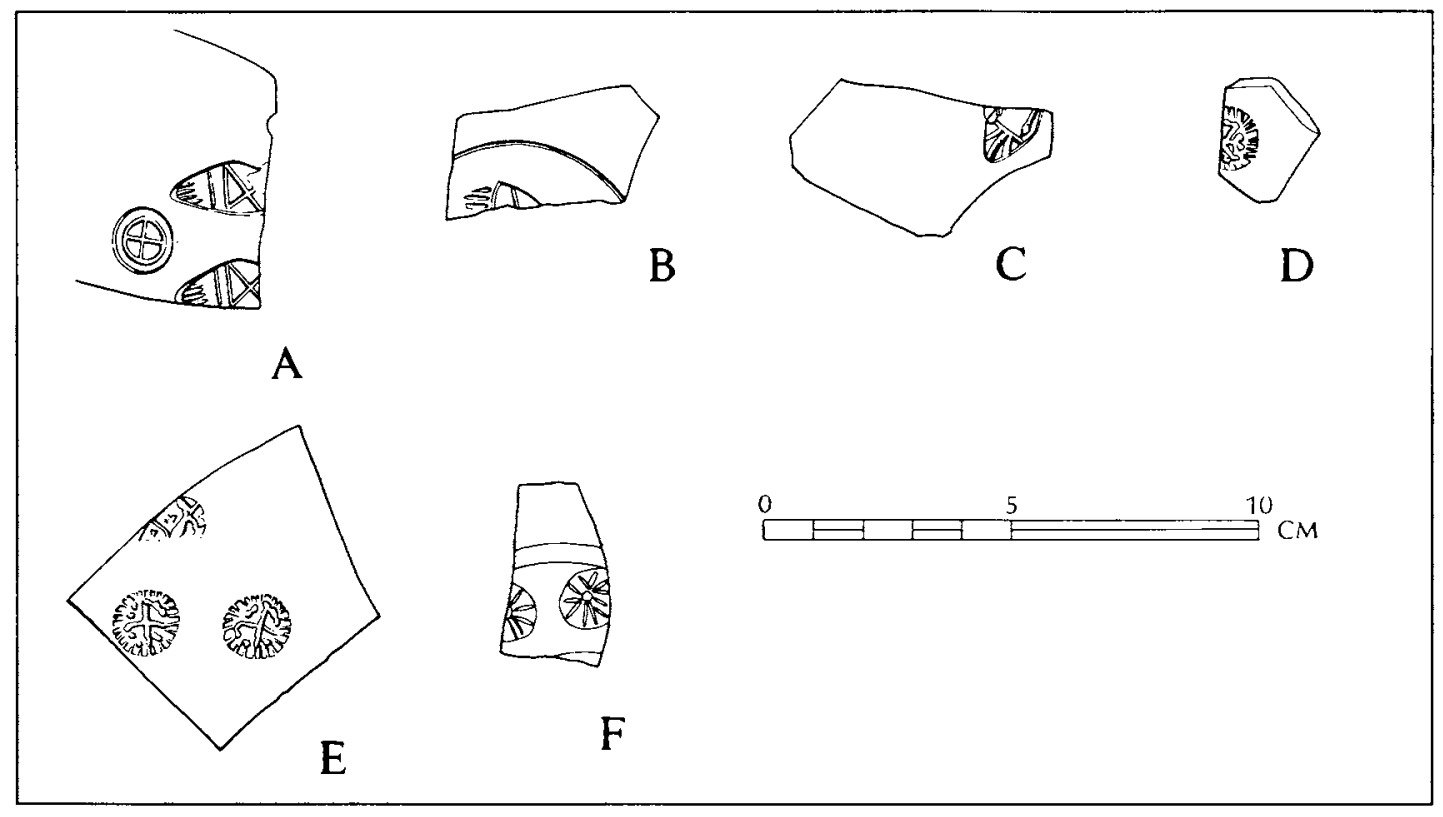

7.1 Stamped local red-slipped ware sherds

one remaining centre until the middle of the fourth century, when it too ceased production (Soultov 1985, 29). ${ }^{3}$

It is obviously desirable to identify which of these centres was supplying Nicopolis with which products and in which periods. Unfortunately, the fabric and slip of the three centres are usually indistinguishable with the naked eye. Nacheva (1984), has studied the chemical composition of the slips produced at the three local centres, and has demonstrated that there are differences. A chemical or petrographic analysis of the fabrics may also find differences. However, to test only the red-slipped wares (over 50,000 sherds), would be costly both in financial terms, and in time. (Though if differences could be ascertained by radiography the costs could be notably reduced.)

It is possible that, if a large corpus of pottery stamps is built up, it will be of help in distinguishing different workshops. However stamps were not common at Nicopolis, and we found only six stamped sherds (fig. 7.1) with either rosettes or feet, all of which were on the inside of flat or ring bases.

At present we can only make broad generalisations by comparing our repertoire with those from the three published centres. The problems here are that Soultov did not always give the provenance of the forms, and the published statements are occasionally ambiguous. ${ }^{4}$ It is also highly likely that more kilns existed than have been found, and these may have been producing different forms. However, if we do make comparisons, we find that fifteen of Soultov's common forms are absent at Nicopolis, eleven of which were only made at Pavlikeni, one was only made at 
Hotnitsa, and one, only at Butovo. (The others were made at more than one centre.) Of thirty-one common forms that do occur at Nicopolis, the majority are made at all three centres. Of five forms which were made exclusively at Pavlikeni, we have only thirty-seven examples. Though this evidence is limited, it would seem that most of the pottery in use at Nicopolis came from Butovo and Hotnitsa and that Pavlikeni was not a major supplier to Nicopolis after the first few decades of the second century. It is of course possible that the forms which occur at Nicopolis, but which were produced at all three sites, all came from Pavlikeni: however this seems unlikely.

There are also a number of forms which occur at Nicopolis which do not seem to have been produced at any of the three sites. Most of these are forms that occur after 350 (for instance the angular rim cooking pots: types 141-147), when production had already ceased at the kiln sites, so their absence can be explained on chronological grounds. However, some earlier types (of the ledge rim crater for instance), have no exact parallels at Hotnitsa, Pavlikeni or Butovo, so were probably made elsewhere, quite possibly at Nicopolis itself. ${ }^{5}$

The pottery in use at Nicopolis after $c .350$ was either produced elsewhere ${ }^{6}$, or conceivably production at Hotnitsa, Pavlikeni and Butovo continued into the fifth and sixth centuries, though this appears most unlikely. ${ }^{7}$ We do know that Hotnitsa was a pottery centre in both the period of the First and Second Bulgarian Kingdoms (Soultov 1985: 20), so cessation of production in the Roman period could not have been due to exhaustion of resources. It is tempting to suggest that, with the uncertainties and destruction caused in the region by the barbarian invasions of the mid to late third century - which included the destruction of the villa at Pavlikeni (Soultov 1985,24 ) - pottery production became concentrated close to the city where the potters could seek refuge in times of crisis. The kilns recently discovered at Nicopolis, immediately to the north of the Roman city (Falkner and Strange forthcoming), may date to this period.

\section{The origins of the local red-slipped ware}

Eastern influences in the pottery tradition are clearly apparent. Soultov, recognising that this was so, makes much of comparisons with Çandarli ware (1985: 61 et seq.) but also introduces certain comparisons with Gaulish wares. This gives an impression of an industry influenced from its outset by both East and West. However, if we look closely at the forms and their dates it becomes obvious that the Gaulish wares had only a very minor influence on the early local pottery. Looking at the forms that occur in the first years of the Roman city (c. 100-130, fig. 6.1) the cups 674, 764 (plate I) and 767, all have comparanda in the East. 674, though it has similarities with Gaulish terra sigillata (Drag. 27), can be compared with Eastern Sigillata A types from Antioch (Waagé 1948, form 450, f, k, and p) which come under Hayes form 
44 (Hayes 1985). 764 and 767 have definite parallels with Eastern Sigillata A form 61 (Hayes 1985) dated to the early second century.

The bowls that occur in this period can also be paralleled by eastern prototypes: 548 is comparable to Eastern Sigillata A (Hayes 1985: form 65) and has been found at Antioch (Waagé 1948, type 670), where it is dated to the second and third centuries, though an earlier start for production is implied (Waagé 1948, p. 40). 652 is certainly related to Eastern Sigillata A type ' $F$ tarda b' (Hayes 1985) from Antioch, though the dating at Antioch is again later.

Carinated forms (cf. 480) are compared by Soultov $(1985,62)$ to Çandarli ware prototypes, especially Loeschke (1912) form 1; however both Eastern Sigillata A forms 33-37 and Cypriot Sigillata form P9 (Hayes 1985) are probably better parallels. The bowls with thickened rolled rim that are so common at Nicopolis (cf. 432) have many eastern parallels that are recorded by Soultov $(1985,66)$. The rounded-rim bowl forms (533 and 536) are common in most areas and periods so little can be made of particular comparanda, but Eastern Sigillata A form 65, 'tarda f and tarda g', Eastern Sigillata B form 18 and Çandarli forms L6 and H4 (Hayes 1985) are all obvious parallels.

The shallow dishes with down-turned rims $(416,413$, and 424) are compared by Soultov to Gaulish type Drag. $36(1985,64)$, though the similarity between Drag. 36 and African Red Slip ware form 3 (Hayes 1972) should be noted. The deeper bowls (419-426) can also be compared to both Gaulish (Drag. 35) and African Red Slip ware forms (Hayes 1985, form 2). Though neither of these can be termed eastern types, ${ }^{8}$ they are certainly a continuation of hellenistic 'fish-plates' and they do occur in the East - cf. an example of African Red Slip ware at Antioch (Waagé 1948, type 847).

Forms that occur at the beginning of our second pottery period (130-250) also follow the same pattern. Cups (756-759) can be compared with Cypriot Sigillata form P33/P34 (Hayes 1985), though they are dated somewhat earlier. Small bowls/cups (517-528) can be compared to Eastern Sigillata B form 37 (Hayes 1985).

It is not until well into the second pottery period that new forms appear, unrelated to eastern prototypes: the flat rimmed craters (683-707) and their rounded-rim counterparts (710-724) and the ledge rim bowls (343-389), whose origins may well be North African (compare Hayes 1972, forms 28 and 29). By the end of this period the local potters seem to be influenced by a wider range of products, however the initial influence was almost entirely eastern.

\section{A note on ware 14 - 'Foederati ware'}

This distinctive grey micaceous ware is the so-called 'foederati ware' which has been associated with the Goths (Majewski 1981) and the Sîntana-de-Mureş/Cerniachov 
culture. $^{9}$ There are definite similarities with certain forms which have been found north of the Danube in Romania and in the region between the Dneister and the Don; however whether these wares are strictly the same is uncertain. The forms that are similar have been noted. ${ }^{10}$

The fact that several local forms occur in this ware suggests that it was produced locally. It is also interesting to note that the fabric is similar to that of the later postmedieval ware (ware 10), both being rich in mica, which may indicate a common clay source, as mica inclusions in pottery are more likely to be a result of using micaceous clay than mica temper (Shepard 1976, 162 and Rice 1987, 410)

\section{The Slav and post-medieval periods}

Little can be said of production in the Slav and post-medieval periods. Although Hotnitsa was producing pottery in the periods of both the First and Second Bulgarian Kingdoms (Soultov 1985, 20) there were, presumably, other production centres in the Tsaravets region when it was the capital. Even so, it is not possible to say whether the Slav pottery found at Nicopolis came from these centres or elsewhere. However, it is worth noting that the stamp on 1122 is paralleled at Iatrus (Wendel 1986 taf. 21: 14 and taf. 43a).

Little post-medieval pottery has been published and it is not certain where it was produced, though Troyan was known as a production centre in the early twentieth century (pers. comm. by the inhabitants of modern Nikiup) and Veliko Turnovo itself is still a centre for craft pottery today. ${ }^{11}$

\section{NOTES}

1 Soultov 1985.

2 Twenty-one potential kilns were located outside the north wall of the early Roman city by a magnetometer survey in 1991 (Falkner and Strange n.d.). Also, several wasters were found during the excavations, notably of the large group of rounded-rim carinated bowls (types 428-75).

3 Contra, see above, p. 40.

4 See above, Chapter 5 footnote 2.

5 See above, Chapter 5 footnote 12.

6 A late fourth century kiln is known-from Novae (Soultov 1985, 14).

7 See above, p. 40.

8 Soultov recognises this $(1985,64)$.

9 See above, p. 44.

10 See above, pp. 73-4.

11 See above, pp. 91-2 (wares). 


\section{Conclusions and future research on ceramics}

The pottery excavated at Nicopolis (excluding the Slav and later material) well illustrates the natural evolution of pottery production. The local Thracian pottery tradition was not totally ignored by the inhabitants of the Roman city; in the very early years native coarse ware forms were maintained though they were very soon all produced on the wheel. The new red-slipped wares were introduced to satisfy the aesthetic tastes of the new settlers, many of whom were of eastern origin. ${ }^{1}$ These local red-slipped wares were of a high standard, which partly explains the paucity of imported fine wares in the second and third centuries from the flourishing centres in Eastern Gaul and Asia Minor.

It should be noted that Thracian hand-made wares are rare: even in the earliest years they account for less than 0.25 per cent of the pottery assemblage (by sherd count). This suggests that new pottery workshops, producing wheel-thrown pottery, were set up and supplying the city from its foundation. On present evidence, it also seems probable that there was no occupation, either Thracian or Roman, on the site before the foundation of the Roman city. ${ }^{2}$

The red-slipped wares were always more common than the coarse wares, except possibly in the period $450-600,{ }^{3}$ though they gradually became scarcer over time: it is interesting to compare the difference in the percentages of local coarse ware to local red-slipped ware (fig. 8.1, using total numbers of body sherds). Though residuality has not been taken into account, the proportions of residual coarse ware and residual red-slipped ware should be roughly equal in the same periods, and we are only looking at a trend, not an absolute. ${ }^{4}$ In the first period we can see that redslipped ware, as a percentage of local production, was very high and on the increase. This implies that Roman influence made an immediate impact. In the second period the percentage difference was even greater (at 48 per cent). We then see a fall off from 150-350, with a more noticeable decline of 16 per cent after 350 and another decline of 10 per cent after 450 , which is probably connected with the invasions in the mid fifth century and the changed character of the city in the early Byzantine period..$^{5}$

Although these figures are split into convenient date ranges, which may exaggerate differences, it is worth noting that, though the red-slipped wares do 
decline, there is no break in the evolution of the pottery tradition. The excavations showed that there was a period of abandonment between the destruction of the late Roman city and the construction of the early Byzantine defences. However, assemblages dated to the latter years of the Roman city (400-450), are no different from those used after the construction of the early Byzantine fortifications. Among several common forms that occur in both assemblages are the angular rim cooking pots (types 141-147), the grey ware water jars (types 305-315) and the flat bottomed bowls with pointed rims (type 580); an abandonment of the site for more than a few years would be apparent in the pottery record, especially in the character of the local wares, and no such break in continuity can be discerned.

Table 8.1 Table showing both the more common amphorae, and the rarer types where their origin was identified

\begin{tabular}{|c|c|c|c|c|c|}
\hline Types & Ware & Comparanda & Total sherds & Origin & Content \\
\hline $1046-1049$ & 76 & P\&W 48, 49 & 11 & Gaza & $\begin{array}{l}\text { Wine/Olive } \\
\text { oil/Sesame oil }\end{array}$ \\
\hline $1050-1053$ & 96 & P\&W 47 & 622 & Aegean? & Unknown \\
\hline $1054-1055$ & - & - & 2 & Unknown & Unknown \\
\hline $1056-1062$ & 94 & P\&W 43 & 775 & Aegean? & Unknown \\
\hline 1063 & - & P\&W 53 & 1 & Nile valley & Wine? \\
\hline $1064-1068$ & 164 & P\&W 44 & 315 & Cyprus/North Syria? & Unknown \\
\hline $1069-1073$ & 37 & P\&W 33 & 179 & Tunisia & $\begin{array}{l}\text { Fish products/ } \\
\text { Olive oil }\end{array}$ \\
\hline $1069-1073$ & 38 & P\&W 33 & 996 & Tunisia & $\begin{array}{l}\text { Fish products/ } \\
\text { Olive oil }\end{array}$ \\
\hline 1074 & - & Keay VI & 3 & Tunisia & $\begin{array}{l}\text { Fish products/ } \\
\text { Olive oil }\end{array}$ \\
\hline 1075 & - & Keay IX & 2 & Tripolitania & Olive oil? \\
\hline $1076-1078$ & 19 & Keay VIIIb & 108 & Tunisia & Olive oil? \\
\hline 1079 & - & Keay LXI & 1 & Tunisia & Olive oil? \\
\hline 1080 & - & Keay XXXVI? & 1 & Tunisia? & Olive oil? \\
\hline $1081-1082$ & - & Keay XXV & 2 & Tunisia & $\begin{array}{l}\text { Fish products/ } \\
\text { Olive oil }\end{array}$ \\
\hline $1086-1088$ & - & Keay XIII & 3 & Spain & Olive oil \\
\hline 1089 & - & Keay XIX & 1 & Spain & $\begin{array}{l}\text { Fish products/ } \\
\text { Olive oil }\end{array}$ \\
\hline 1090 & - & Keay LXII & 3 & Tunisia & Olive oil? \\
\hline $1091-1092$ & - & Keay XLVII? & 7 & Unknown & Unknown \\
\hline $1093-1096$ & 23 & - & 212 & Unknown & Unknown \\
\hline 1097 & 32 & - & 18 & Pannonia? & Unknown \\
\hline $1098-1099$ & - & Böttger I.6 & 6 & Unknown & Unknown \\
\hline - & 27 & - & 38 & Unknown & Unknown \\
\hline - & 69 & - & 45 & Unknown & Unknown \\
\hline - & 105 & - & 13 & Unknown & Unknown \\
\hline - & 106 & - & 49 & Unknown & Unknown \\
\hline - & 124 & - & 336 & Unknown & Unknown \\
\hline - & 166 & - & 78 & Unknown & Unknown \\
\hline- & 167 & P\&W 45 & 61 & Asia Minor? & Unknown \\
\hline
\end{tabular}




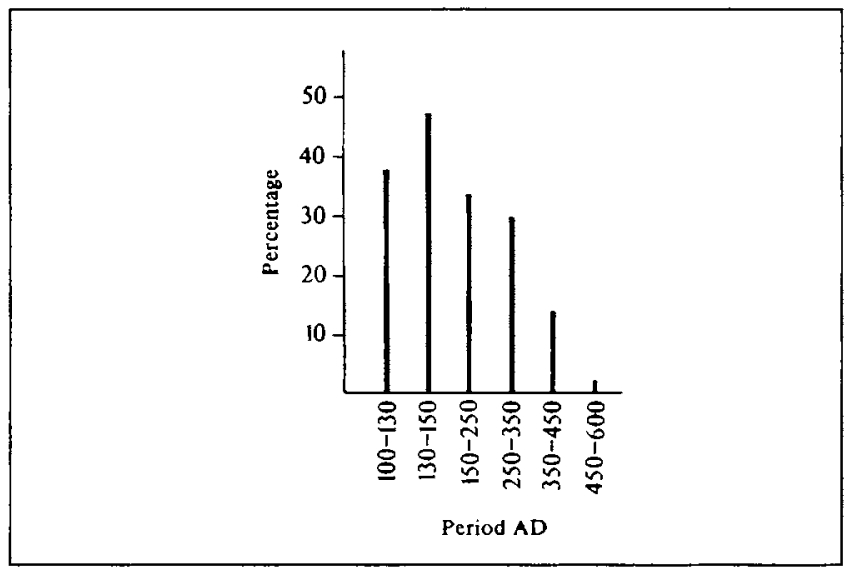

8.1 Graph showing the percentage by which ware 8 exceeds ware 1 in given periods (by sherd count)

The best pottery products for use as indicators of long-distance trade are amphorae and imported fine wares. We found few of the latter, but nearly 4,000 sherds were identified as belonging to amphorae. Some of these were from types which could not be paralleled but the majority belong to well-attested vessels. Table 8.1 shows all the common forms that occur, together with the rarer forms that could be identified: it can be seen that Nicopolis was receiving goods from throughout the Empire, especially from North Africa and the Aegean region. (This assumes that the amphorae were imported with their original contents.) Looking at Figure 8.2 we can see that bulk imports gradually increased over time, reaching a peak in the period $250-350$ before suffering a decline in the period 350-450, followed by a marked increase in the period 450-600. However, if we compare this picture with the types of amphorae being imported, we see that, although we have a steadily increasing overall diversity of types in the late Roman and early Byzantine periods (fig. 8.3), we have a remarkably consistent ratio of North African (wares 37 and 38) to Aegean (wares 94 and 96) imports (fig. 8.4). Of the imported fine wares that were found, we can say little as the number of examples was too few. However, we have demonstrated that Samian wares attested on the lower Danube (DimitrovaMilcheva 1984 and Böttger 1982) and Late Roman Fine wares on the Black Sea coast (Minchev 1983) found their way to Nicopolis, though apparently in much smaller quantities.

This large corpus of pottery from the excavations well illustrates the many different types of pottery that were used from the early second until the late sixth or early seventh century, as well as including some Slav and post-medieval material. Dates have been proposed for many of these types that sometimes support, and sometimes are at odds with, those previously published. Further excavation and research will clarify the situation: there is still considerable scope for narrowing these date ranges. Our knowledge of imported wares on the lower Danube has been considerably increased: previously unrecorded fine wares have been identified - 

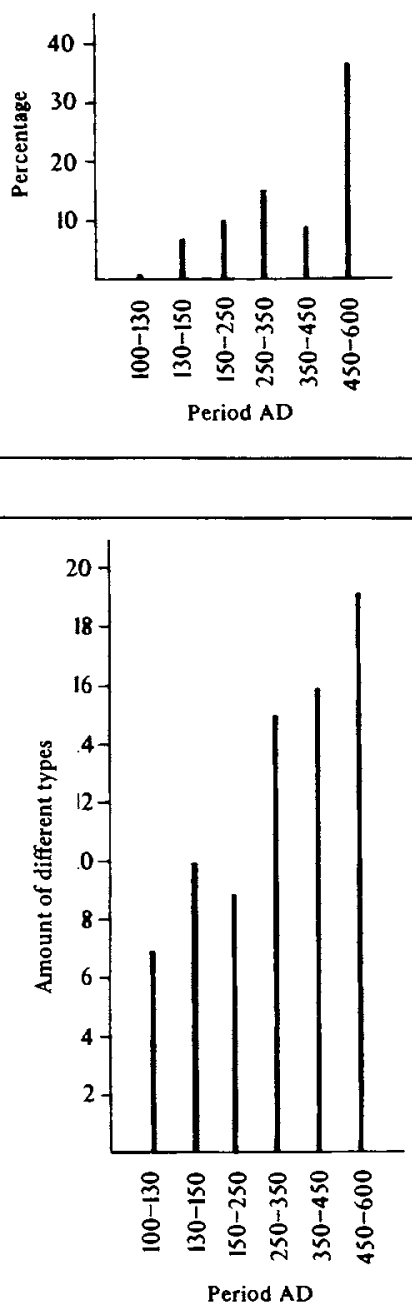

8.2 Graph showing amphorae as a percentage of total amphorae in given periods (by sherd count)
8.3 Graph showing numbers of different amphorae types present in any given period (by sherd count)

African Red Slip ware, Late Roman C ware and Cypriot Red Slip ware. More dots have been added to amphorae distribution maps which provide evidence for both local and empire-wide trade.

However, the real contribution of the study is that it presents data from a stratigraphically excavated site in such a format that it can be used in future research. There are already general studies of pottery from the region, ${ }^{6}$ but until a sufficient number of published corpora exists, presenting meaningful, quantitative data, ${ }^{7}$ any attempts at synthesis rest upon an inadequate statistical base. ${ }^{8}$

The local Roman pottery industry is well worth studying in its own right: more work is needed to publish the material from Hotnitsa, Pavlikeni and Butovo. Soultov 

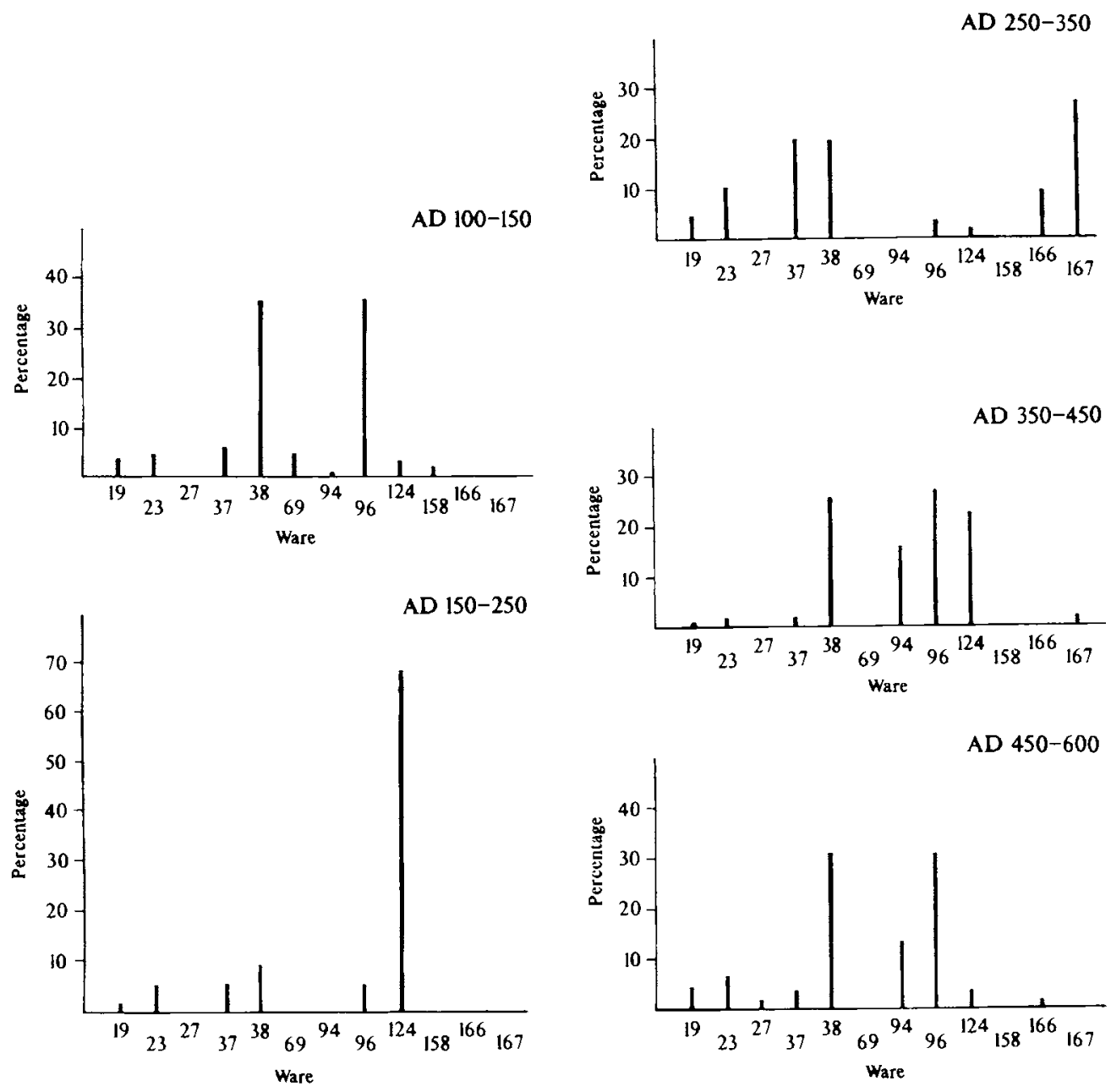

8.4 Graph showing the relative frequency of certain amphorae wares as a percentage of all amphorae in that period (by sherd count)

$(1985,3)$ states that 200,000 vessels and fragments were excavated: they must be analysed and published. Some scientific dating would be of use, e.g. thermoluminescence. A thorough survey of the region would help to find more production sites - which must exist (Soultov 1985, 75). The relationship between the military sites on the Danube and the inland cities and their territories is an obvious field for further study: Nicopolis would have been in an ideal position to supply the frontier with both manufactured goods and provisions. It is known that both Iatrus and Novae were supplied with pottery produced in the territory of 
Nicopolis (Soultov 1985, 13); and this trade stretched across the Danube into Dacia Inferior, but until quantitative data from more sites becomes available a study of regional pottery distribution is not really feasible. ${ }^{9}$

The chronology after the fourth century needs refining - a problem, of course, for many regions and not just this one. A study of the grey micaceous patternburnished ware (ware 14) will be important here: it seems to be a foreign influence and signals the end of classical pottery styles. ${ }^{10}$ Burnishing becomes more popular as time goes on: Angelov (1973, Obr. 80) illustrates pattern-burnished sherds dated to the ninth and tenth centuries, and Soultov mentions that a kiln at Hotnitsa, dating to the period of the First Bulgarian Kingdom, was producing both pattern-burnished wares and heavily combed Slav pottery $(1985,20)$.

When the pottery from the excavations at Tsaravets, the capital of the Second Bulgarian Kingdom and an important early Byzantine site, is fully published (especially that from the excavations on the site of the Bulgarian palace), many questions concerning the pottery of the fifth and sixth centuries may be resolved.

\section{NOTES}

1 For further detail on the economic implications, see above, p. 37.

2 However, see above, p. 12.

3 There seem to be many more coarse ware than red-slipped ware forms in this period, though there are more red-slipped wares by total sherd count.

4 It is also assumed that the deposits for each period are 'average' deposits and include no obvious bias in their functional composition.

5 For further discussion, see above, p. 47.

6 e.g. Kabakchieva 1983 and Kuzmanov 1985.

7 Böttger's work on the latrus pottery is the only example.

8 See above, pp. 28-9.

9 See above, p. 38.

10 See above, p. 19 and pp. 111-12. 


\section{The pottery catalogue}

The catalogue is arranged by ware and period. Beneath headings giving the description of a group and its figure references, the type series number (e.g. C604, for reference to the archive), is followed by the context number (e.g. 1031), smallfind number if assigned (e.g. SF. 1006, for reference to the small-find archive catalogue) and the size or range of the rim in centimetres where known (e.g. dia. $14 \mathrm{~cm}$ ). Other comments and dating follow. (Some examples have DG numbers instead of a type series number; this refers to the original drawing number and is also included for reference to the archive.) With a few exceptions the following drawings are reproduced at a scale of 1:4. (In all cases, scales are present.) In the catalogue, the suffix 'a' after a number is used to designate a vessel which also occurs in a different ware. For example, 19 is found in ware $30 / 31$ but also occurs in ware 1 and it is called 19a. Because the forms are the same, none of the ' $a$ ' types is illustrated. Unless otherwise stated, only the one example was found.

\section{ROMAN AND EARLY BYZANTINE POTTERY}

\section{Coarse wares}

Coarse wares: wares 25 (1-10) and 30/31 (11-14) (Fig. 9.1)

1. C604 (1031). Rim of a bowl with ledge handles, dia. $26 \mathrm{~cm}$. Hand made. The context is dated 450-600. 4 examples were found, all from contexts that dated to after 450 .

2. C452 (699). Rim of a cup, dia. $8 \mathrm{~cm}$. Hand made. The context is dated 130-150. Only 2 examples were found, both in contexts dated to pre-175.

3. C362 (2281), SF. 5304 . Rim of a cup, dia. $14 \mathrm{~cm}$. Hand made. The context is dated 100-130.

4. G165 (1036). Rim of a bowl with incised decoration on the exterior, dia. $26 \mathrm{~cm}$. Hand made. The context is dated $450-600$. 


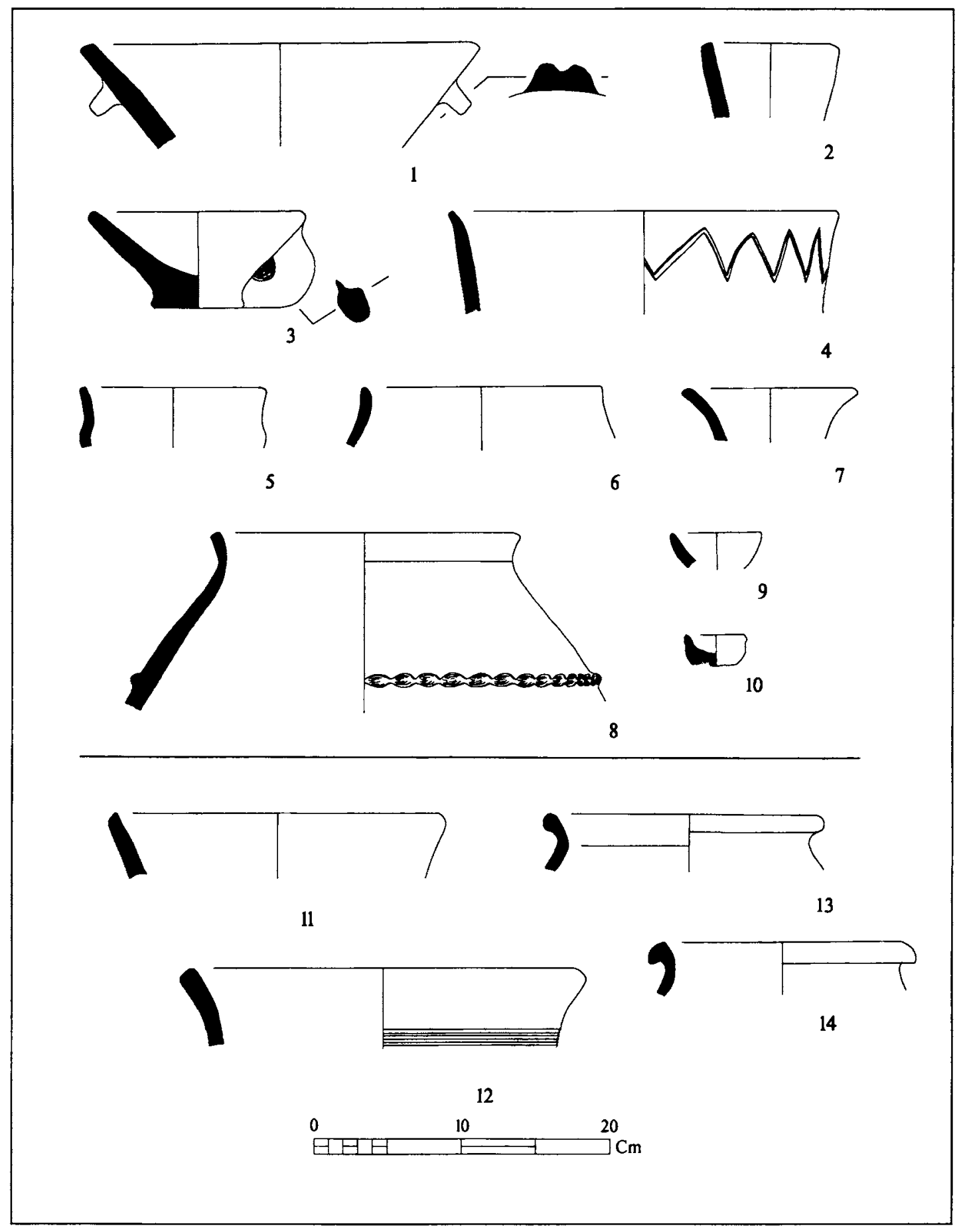

9.1 Coarse wares: ware $25(1-10)$ and 30/31 (11-14) 
5. F632 (1036). Rim of a jar, dia. $12 \mathrm{~cm}$. Hand made. The context is dated 450-600.

6. G164 (1024). Rim of a jar, burnished on the interior, dia. $16 \mathrm{~cm}$. Hand made. The context is dated 450-600.

7. C841 (3215). Rim of a jar, dia. $11 \mathrm{~cm}$. Hand made. The context is dated $450-600$.

8. F419 (265). Top part of a jar with thumb-impressed decoration on the shoulder, dia. $20 \mathrm{~cm}$. Hand made. The context is dated 100-130. Two examples were found, the earliest of which was in a context dated to $100-130$.

9. C220 (318). Small bowl, dia. $6 \mathrm{~cm}$. Hand made, The context is dated $100-130$.

10. C729 (1031). Small cup, dia. $4 \mathrm{~cm}$. Hand made. The context is dated $450-600$.

11. C333 (2277). Rim of a bowl, dia. 16-22cm. Hand made. The context is dated 100-130. 6 examples were found, all from contexts dating to 100-130.

12. F81. Unstratified. Rim of a bowl with fine combing on the exterior of the body, dia. $26 \mathrm{~cm} .2$ examples were found, the earliest of which came from a context dated to $100-130$.

13. F422 (265). Rim of a jar, dia. $19 \mathrm{~cm}$. The context is dated 100-130. 3 examples were found, all of which came from contexts dated to 100-130.

14. F688 (2207). Rim of a jar, dia. $16 \mathrm{~cm}$. The context is dated $450-600$.

Coarse wares: ware 30/31 (Fig. 9.2)

15. F192. Unstratified. Rim of a jar, dia. $20 \mathrm{~cm}$.

16. F315 (2277). Rim of a jar, dia. $24 \mathrm{~cm}$. The context is dated $100-130$.

17. F173 (2154). Rim of a jar, dia. $25-33 \mathrm{~cm}$. The context is undated. One other example was found from a context dated 100-130.

18. F316 (265). Rim of a jar, dia. $14 \mathrm{~cm}$. The context is dated $100-130.3$ examples were found, all of which came from contexts dated to 100-130.

19. F170 (2277). Rim of a jar, dia. 15-17cm. The context is dated 100-130. 18 examples were found all of which came from contexts dated to 100-130.

19a. B19. Dia. $14 \mathrm{~cm} .1$ example was found from a context dated 175-250. 

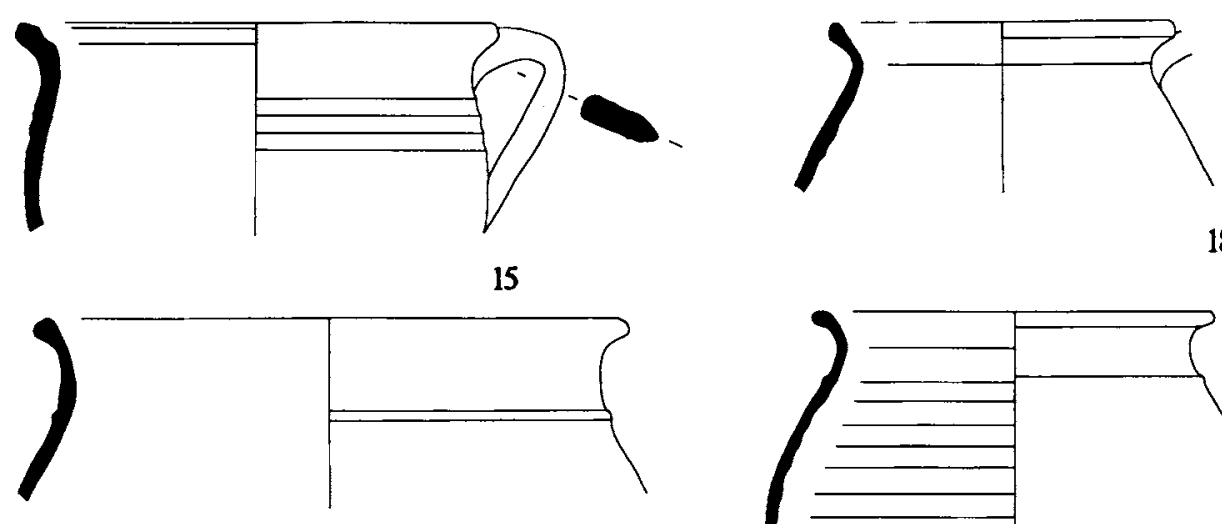

I

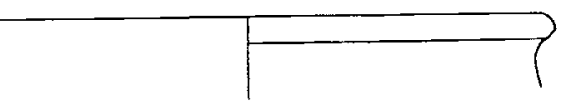

16
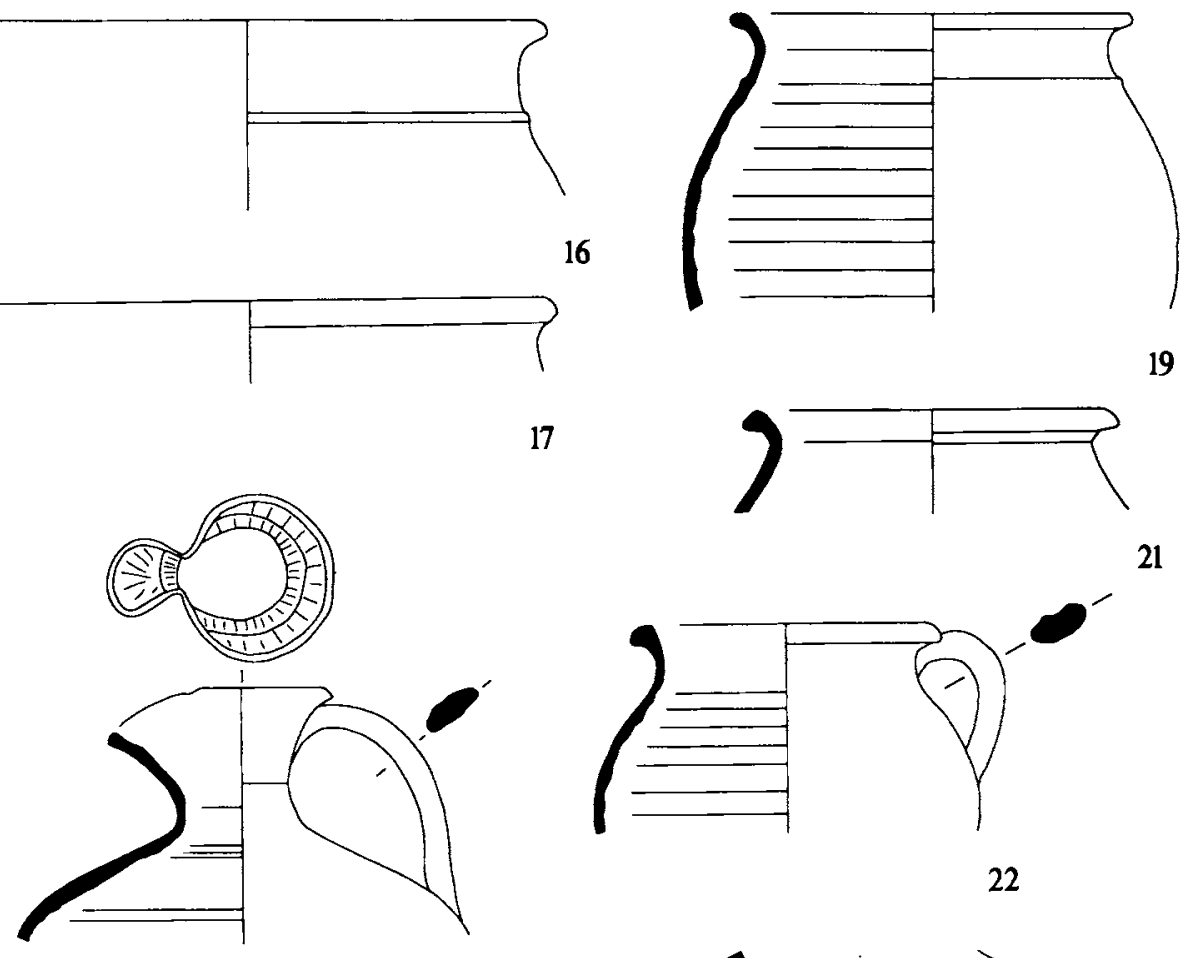

17
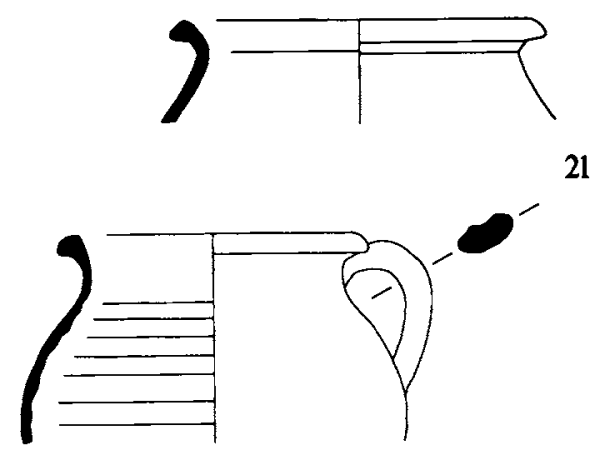

22

20
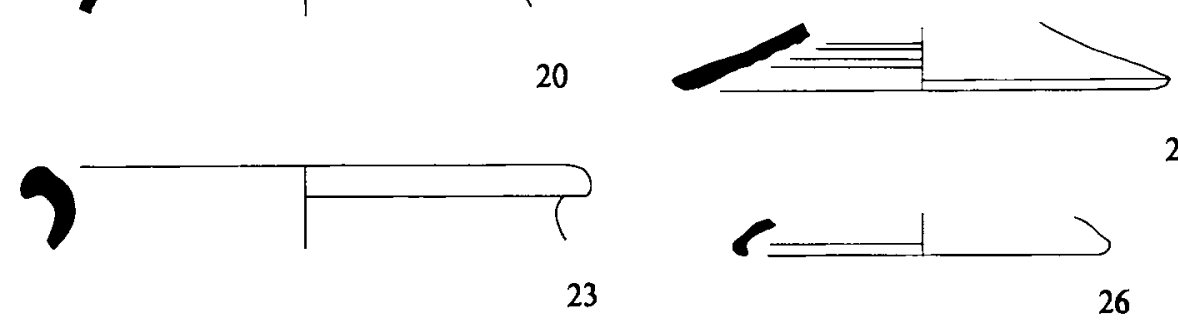

23
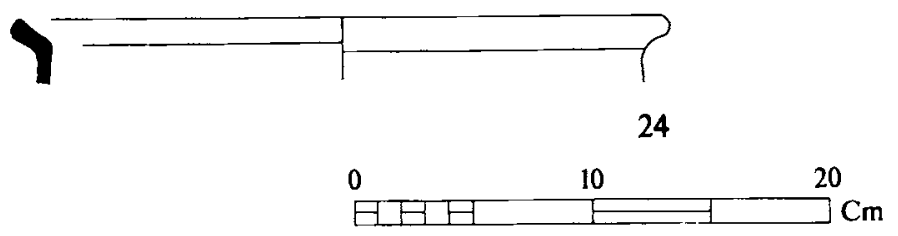

9.2 Coarse wares: ware 30/31 
20. C680 (698). Trefoil jug. The context is dated 130-150.

20a. F218.21 examples were found, most of which came from contexts dating to post-450. However the earliest came from a context dated to $130-150$ and 3 pieces from a context dated $175-250$.

21. B15 (2259). Rim of a jar, dia. 9-16cm. The context is dated 100-130.3 examples were found, all of which came from contexts dating to 100-130.

21a. B5. Dia. $9-20 \mathrm{~cm}$ (though one example is $26 \mathrm{~cm}$ ). 100 examples were found, 29 of them in contexts dating to $130-150$, and another 29 in contexts dating to $150-250$.

22. B21 (203). Rim of a jar, dia. $11-24 \mathrm{~cm}$. The context is post-medieval. 4 examples were found, of which 3 came from contexts dating to 100-130.

22a. F80. Dia. 10-20cm. 41 examples were found, 4 of which were from a context dated 130-150, but 32 came from contexts dated to $175-250$.

23. B20. (2260). Rim of a jar, dia. $22 \mathrm{~cm}$. The context is dated 100-130.

23a. F175. Dia. 16-32cm. 39 examples were found of which 9 came from contexts dated to 130-150, and 23 from contexts dated to 175-150.

24. B17 (2259). Rim of a jar, dia. $27 \mathrm{~cm}$. The context is dated $100-130$.

24a. D3. Dia. $12-30 \mathrm{~cm}$., though usually $20-30 \mathrm{~cm}$. 36 examples were found, most of them in post -450 contexts. However 1 came from a context dated $130-150$, and 6 from contexts dated to $175-250$.

25. C352 (2259). Rim of a lid, dia. $20 \mathrm{~cm}$. The context is dated $100-130.2$ examples were found, the other one coming from a context dating to $175-250$.

25a. C709. Dia. 13-20cm. 2 examples were found, only one of which was dated (to 130-175).

26. B16 (2277). Rim of a lid, dia. $15 \mathrm{~cm}$. The context is dated $100-130$.

26a. C29. Dia. $10-24 \mathrm{~cm} .20$ examples were found, most of which were from post -450 contexts. However 2 came from contexts dated to $130-175$, and 11 from contexts dating to $250-450$.

Grey coarse wares: ware 1 (Fig. 9.3)

27. F428 (5311). Rim of a jar, dia. $16-26 \mathrm{~cm}$ (though one example is $12 \mathrm{~cm}$ ). The context is dated 250-350.34 examples were found, and though most came 


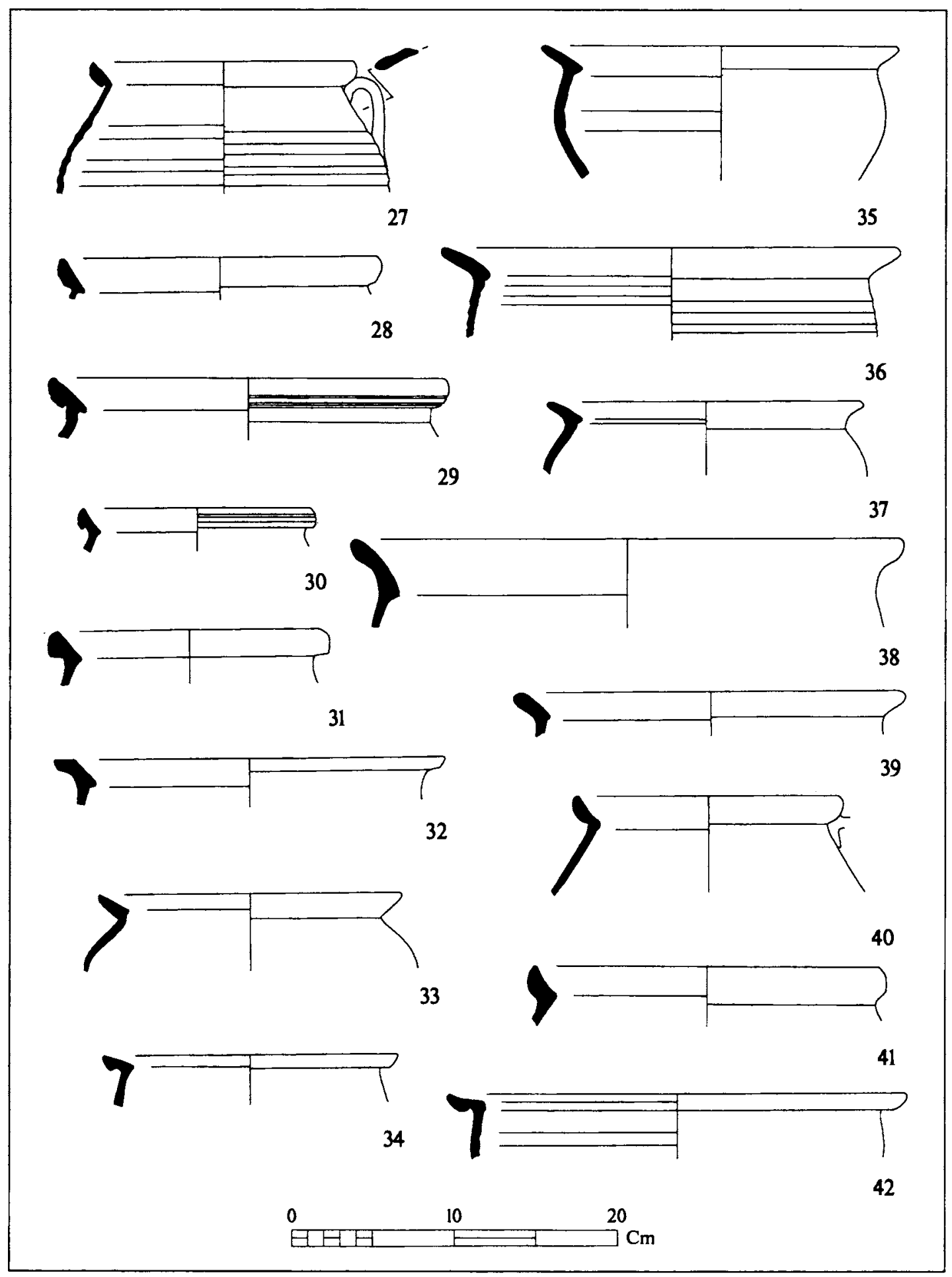

9.3 Grey coarse wares: ware 1 
from post- 450 contexts, 4 came from contexts dated to $250-350$ and 7 from contexts dated 350-450.

28. B7 (202). Rim of a jar, dia. $12-19 \mathrm{~cm}$ (though one example is $20 \mathrm{~cm}$ ). The context is post-medieval. 11 examples were found, the earliest of which (2 pieces), came from contexts dated 175-250. 4 others came from contexts dated 275-450.

29. G139 (628). Rim of a jar, dia. $24 \mathrm{~cm}$. The context is undated.

30. F125 (473). Rim of a jar, dia. $13-20 \mathrm{~cm}$. The context is dated $450-600$. Of 7 examples found, 5 were from contexts dating to $450-600$ and 2 from contexts dated to $400-450$.

31. F363 (5014). Rim of a jar, dia. 16-24cm. The context is dated to 450 . Only 2 examples were found, the other comes from a context dated to 250-350.

32. A2 (1). Rim of a jar, dia. $14-24 \mathrm{~cm}$. The context is post-medieval. 7 examples were found, the earliest occurrence being in a context dated to 150-175.

33. C725 (4838). Rim of a jar, dia. $18-22 \mathrm{~cm}$. The context is undated. 3 examples were found, the earliest two of which came from contexts dated 350-450.

34. C319 (599). Rim of a jar, dia. $16-30 \mathrm{~cm}$. The context is undated. 3 examples were found, the earliest 2 being from contexts dated to $250-350$.

35. F588 (4499). Rim of a jar, dia. $22-33 \mathrm{~cm}$ (though one example is $18 \mathrm{~cm}$ ). The context is dated 250-450. 129 examples were found ( 40 of which were from post-medieval contexts), and though 1 was from a context dated to $150-250$ and 5 from contexts dated $250-350,41$ were from contexts dated to $350-450$.

36. F588 (689). Rim of a jar, dia. $22-33 \mathrm{~cm}$. The context is dated $350-450$. The dating is as for 35 .

37. F324 (1129). Rim of a jar, dia. $18-20 \mathrm{~cm}$. The context is dated to 450.6 examples were found: 2 from contexts dated to $350-450$ and 4 from contexts dated to $450-600$.

38. A4. (4959). Rim of a jar, dia. $20-34 \mathrm{~cm}$. The context is dated 250-350. 10 examples were found, the earliest one of which came from a context dated to $150-175,2$ came from contexts dated $250-350$, and 3 from contexts dated $350-450$.

39. F610 (635). Rim of a jar, dia. $23 \mathrm{~cm}$. The context is dated $350-450$. 
40. C738 (4506). Rim of a jar, dia. $12-18 \mathrm{~cm}$. The context is dated $250-450.33$ examples were found and though the earliest piece came from a context dated 150-250, there were 6 examples from contexts dated to 350-450, and 13 from contexts dated to $450-600$.

41. D2 (1). Rim of a jar, dia. $20-39 \mathrm{~cm}$ (usually $20-30 \mathrm{~cm}$ ). The context is postmedieval. 23 examples were found, 6 of which come from contexts dated earlier than 250 , and 7 of which came from contexts dated to 350-450.

42. G92 (4495). Rim of a jar, dia. $26-29 \mathrm{~cm}$. The context is post-medieval.

\section{Grey coarse wares: ware 1 (Fig. 9.4)}

43. F280 (4928). Rim of a jar, dia. c. $50 \mathrm{~cm}$. The context is post-medieval. 14 examples were found of which 2 came from contexts dated to pre-250, 2 from contexts dated $250-350$, and 6 from contexts dated $350-450$.

44. F524 (4824). Rim of a jar, dia. $30 \mathrm{~cm}$. The context is post-medieval. 5 examples were found, the earliest of which came from a context dated $250-350$, and 3 of which came from contexts dated to 350-450.

45. C421 (677). Rim of a jar with a slightly irregular rim, dia. c. $19 \mathrm{~cm}$. The context is dated 175-250. 3 examples were found all of which came from contexts dated to $175-250$.

46. A7 (231). Rim of a jar, dia. $12-22 \mathrm{~cm}$ (usually $16-22 \mathrm{~cm}$ ). The context is dated 175-350, though it contains some later material. 18 examples were found, 3 of which were from contexts dated 250-350, and 6 from contexts dated 350-450.

47. C162 (686). Rim of a jar, dia. $18-32 \mathrm{~cm}$ (usually $20-26 \mathrm{~cm}$ ). The context is dated 175-250 though it contains some later material. 62 examples were found, 5 of which came from contexts dated 130-175, and 30 from contexts dated to $175-250$.

48. A9 (325). Rim of a jar, dia. $20-28 \mathrm{~cm}$. The context is post-medieval. 69 examples were found of which 11 came from contexts dated to 250-350, and 25 from contexts dated to $350-450$.

49. C490 (2175). Rim of a jar, dia. 18-24cm. The context is dated 130-175. 23 examples were found of which 17 came from contexts dated to 130-150.

50. F387 (5018). Rim of a jar, dia. 14-20cm. The context is dated to 450.9 examples were found of which 6 came from contexts dated to $130-150$.

51. G55 (4499). Rim of a jar, dia. $18 \mathrm{~cm}$. The context is dated $250-450$. 


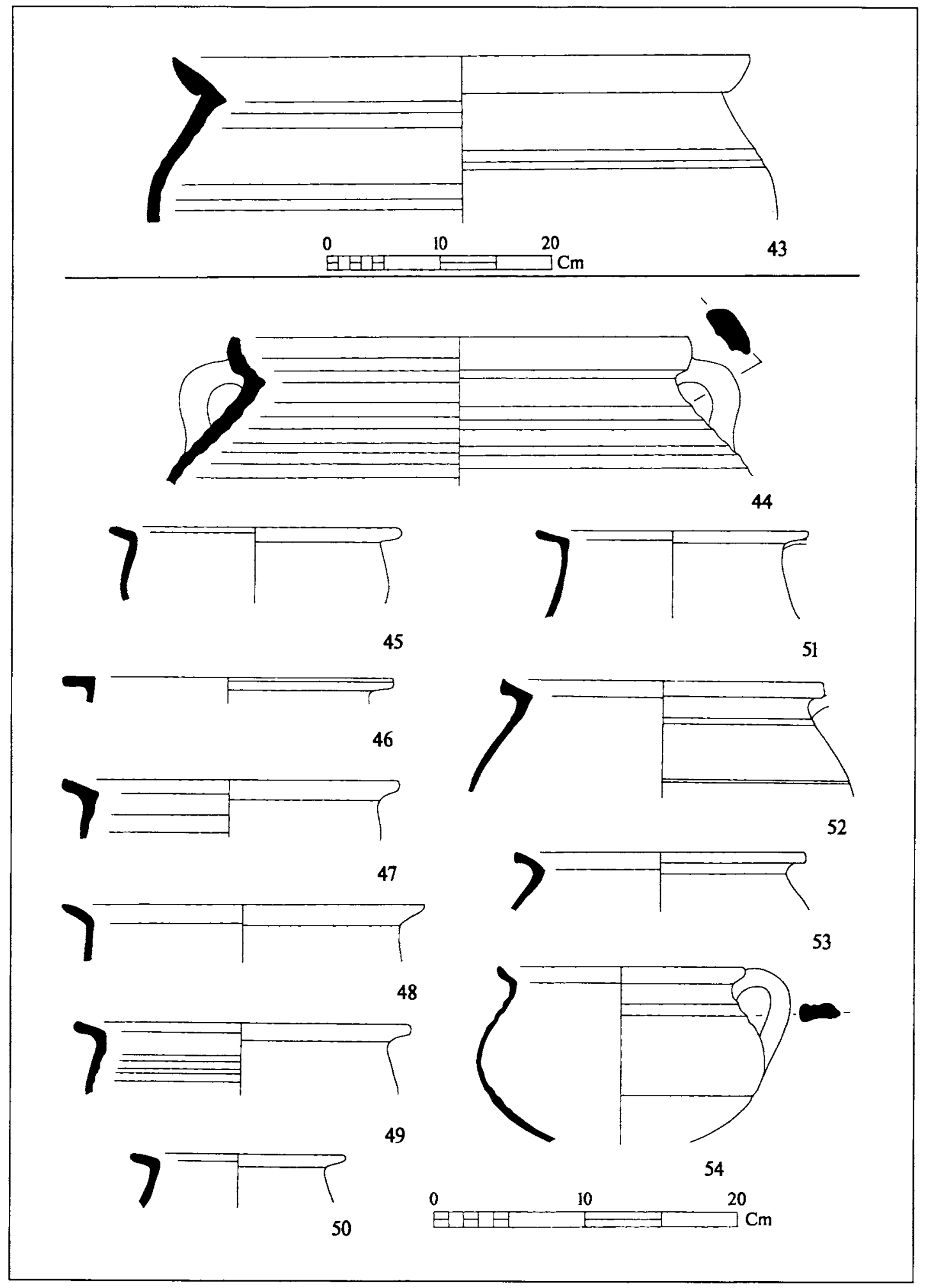

9.4 Grey coarse wares: ware 1 
52. F646 (691). Rim of a jar, dia. $21 \mathrm{~cm}$. The context is dated 150-175.7 examples were found, of which 2 were from contexts dated 150-175, and 2 from contexts dated to $250-350$.

53. F505 (2211). Rim of a jar, dia. $12-20 \mathrm{~cm}$. The context is dated to 450.3 examples were found, the earliest of which came from a context dated to $350-450$.

54. G65 (1078). Rim of a jar, dia. $12-16 \mathrm{~cm}$. The context is dated $450-600.4$ examples were found of which the earliest 3 came from contexts dated to 450-600.

Grey coarse wares: ware 1 (Fig. 9.5)

55. F467. Unstratified. Rim of a jar, dia. $30 \mathrm{~cm}$. The only example from a dated context is dated to $150-250$.

56. F487 (692). Rim of a jar, dia. $17 \mathrm{~cm}$. The context is dated $350-450$.

57. G4 (4113). Rim of a jar, dia. $14 \mathrm{~cm}$. The context is dated $250-350$.

58. F278 (4479). Rim of a jar, dia. $10 \mathrm{~cm}$. The context is post-medieval. 9 examples were found, the earliest of which came from a context dated to 250-350. 3 came from contexts dated to 350-450.

59. F608 (635). Rim of a jar, dia. $13 \mathrm{~cm}$. The context is dated $350-450.8$ examples were found, of which the earliest two came from contexts dated to 150-175; however 4 came from contexts dated to 350-450.

60. B6 (221). Rim of a jar, dia. 13-16cm. The context is dated 130-150.3 examples were found of which the earliest came from a context dated 130-150, and the other 2 from contexts dated 400-500.

61. F240 (699). Rim of a jar, dia. $15-18 \mathrm{~cm}$. The context is dated $130-150.5$ examples were found, of which 4 came from contexts dated to 130-150.

62. F399 (5018). Rim of a jar, dia. $12 \mathrm{~cm}$. The context is dated to 450 .

63. F246 (699). Rim of a jar, dia. $16 \mathrm{~cm}$. The context is dated 130-150.

64. F557 (558). Rim of a jar, dia. 10-12cm. The context is dated $350-450$. Of 3 examples found this was the only one that came from a well dated context.

65. F78 (4906). Rim of a jar, dia. $12 \mathrm{~cm}$. The context is dated $450-600.11$ examples were found of which the earliest 6 came from contexts dated to $175-250$. 


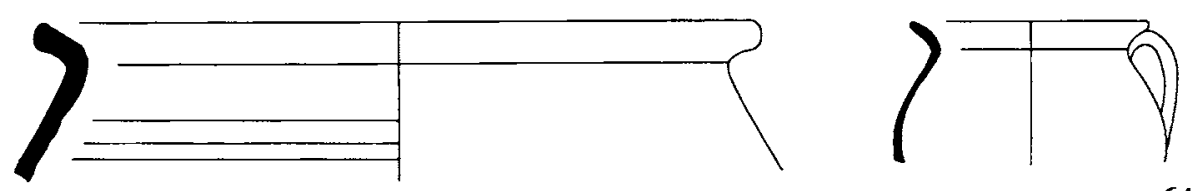

55
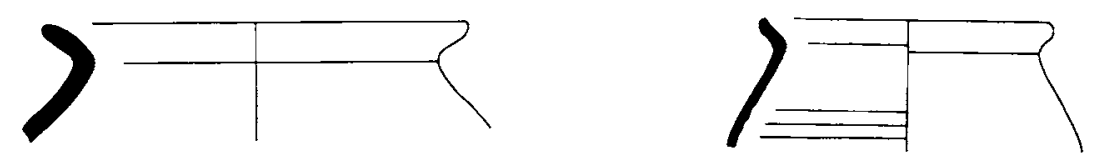

56

65
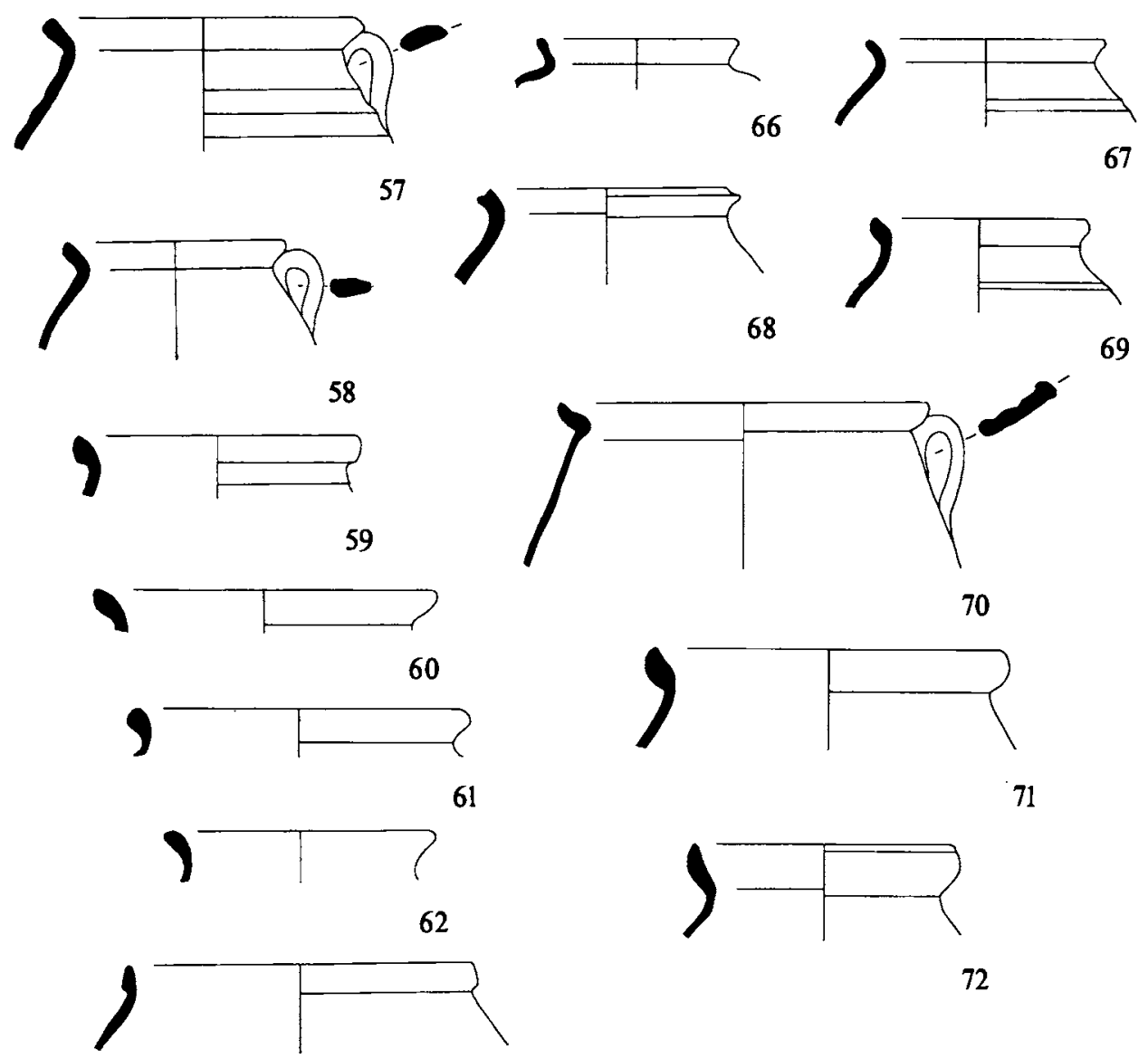

72

63

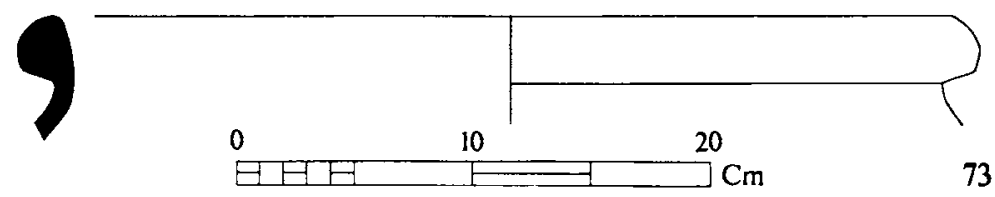

9.5 Grey coarse wares: ware 1 
66. F299. Unstratified. Rim of a jar, dia. $9 \mathrm{~cm}$. Of 3 dated examples the earliest two came from contexts dated to $350-450$.

67. F147 (4439). Rim of a jar, dia. $8-13 \mathrm{~cm}$ (though one example is $18 \mathrm{~cm}$ ). The context is post-medieval. 18 examples were found of which the earliest 3 came from contexts dated to $130-150$ and a further 3 from contexts dated to $175-250$.

68. F339 (1192). Rim of a jar, dia. $11 \mathrm{~cm}$. The context is dated $400-450.2$ examples were found, both from contexts dated to $400-450$.

69. C809 (3001). Rim of a jar, dia. $10 \mathrm{~cm}$. The context is post-medieval.

70. F45 (4507). Rim of a jar, dia. $14-18 \mathrm{~cm}$. The context is dated $250-450.8$ examples were found, 3 of which came from contexts dated to $350-450$.

71. F36 (4507). Rim of a jar, dia. $10-28 \mathrm{~cm}$ (usually $18-24 \mathrm{~cm}$ ). The context is dated 250-450. 19 examples were found, the earliest two from contexts dated to $175-250$, however 10 examples came from contexts dated to $350-450$.

72. F146 (604). Rim of a jar, dia. 12-22cm. The context is dated $350-450.7$ examples were found of which the earliest one came from a context dated $150-250$.

73. C412 (661). Rim of a jar, dia. $22-38 \mathrm{~cm}$. The context is dated $250-350.4$ examples were found of which this was the earliest; 2 others came from contexts dated to $350-450$.

Grey coarse wares: ware 1 (Fig. 9.6)

74. F66 (321). Rim of a jar, dia. $12-24 \mathrm{~cm}$. The context is dated 130-150. 28 examples were found, the earliest one of which came from a context dated to $130-150$ and a further 6 from contexts dated to $150-175$, and 11 from contexts dated 250-350.

75. F66 variant (2143). Rim of a jar, dia. $12-24 \mathrm{~cm}$. The context is dated $450-600$. See 74 for dating.

76. F66 variant (343). Rim of a jar, dia. $12-24 \mathrm{~cm}$. The context is dated $175-250$. See 74 for dating.

77. F189 (231). Rim of a jar, dia. 19-21 cm. The context is dated $175-350$, but contains some later material. 18 examples were found of which the earliest 7 came from contexts dated to $130-150$, and a further 7 from contexts dated 150-175. 
7

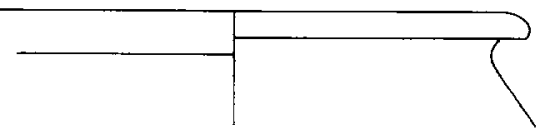

74

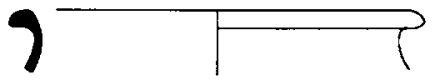

,

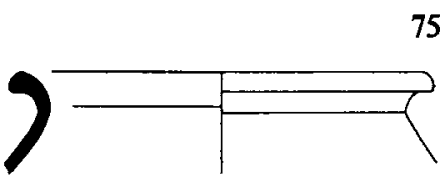

76

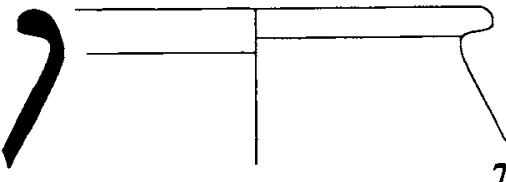

77
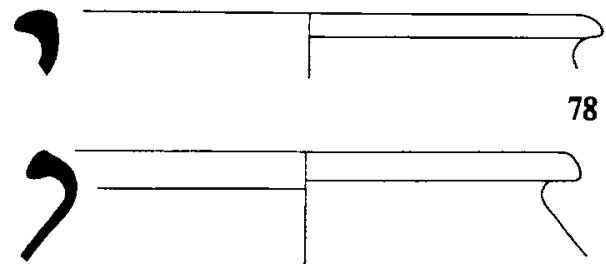

79

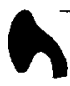

80
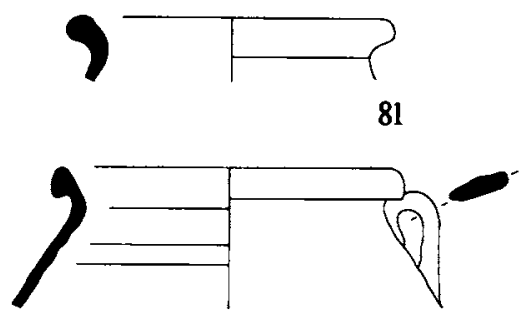

82
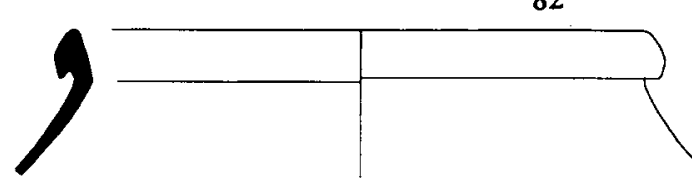

$\stackrel{0}{\mathrm{E} H \mathrm{H}} \quad 10 \quad 20 \mathrm{Cm}$
,
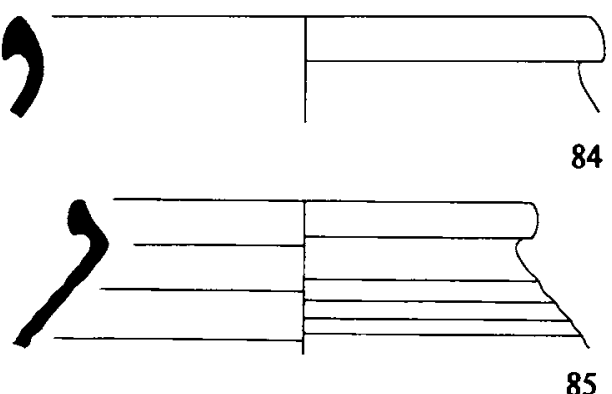

9
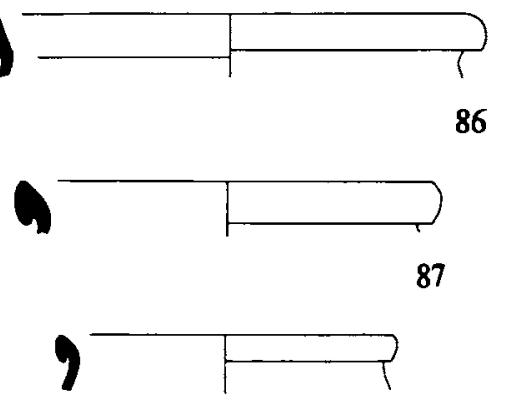

88

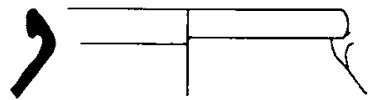

89
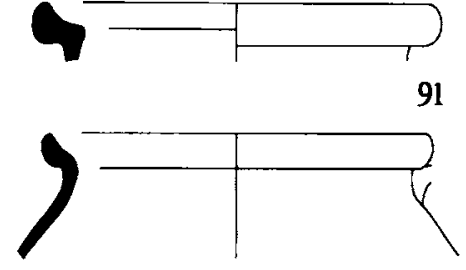

92

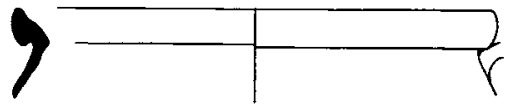

93

83

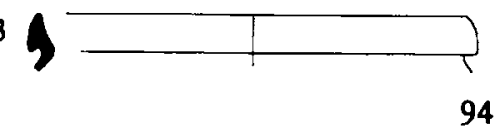

9.6 Grey coarse wares: ware 1 
78. F454 (4014). Rim of a jar, dia. $22 \mathrm{~cm}$. The context is post-medieval. The only dated example was from a context dated to $275-450$.

79. G6 (4118). Rim of a jar, dia. $23 \mathrm{~cm}$. The context is dated 175-250. All 3 examples found were from contexts dated to $175-250$.

80. C422 (677). Rim of a jar, dia. $14-18 \mathrm{~cm}$. The context is dated $175-250.21$ examples were found, the earliest two of which came from contexts dated to $130-150$, a further 10 examples came from contexts dated to $175-250$.

81. C719 (1018). Rim of a jar, dia. $13 \mathrm{~cm}$. The context is post-medieval. 14 examples were found of which 13 came from contexts dated 175-250.

82. F437 (3384). Rim of a jar, dia. $12-14 \mathrm{~cm}$. The context is post-medieval. 21 examples were found, one of which was from a pre-350 context (150-175), 7 from contexts dated to $350-450$, and another 7 from contexts dated to $450-600$.

83. F301 (573). Rim of a jar, dia. $16-24 \mathrm{~cm}$ (though one example is $13 \mathrm{~cm}$ ). The context is dated 450-600.34 examples were found, the earliest two of which came from contexts dated to $175-250$, and 2 more came from contexts dated 250-350. However 13 came from contexts dated 350-450. and a further 10 from contexts dated 450-600.

84. F160 (704). Rim of a jar, dia. $12-28 \mathrm{~cm}$ (usually $18-28 \mathrm{~cm}$ ). The context is dated 350-450. 20 examples were found of which the earliest 8 came from contexts dated to $250-350$, and a further 9 from contexts dated $350-450$.

85. F135. Unstratified. Rim of a jar, dia. $12-22 \mathrm{~cm}$ (usually $14-18 \mathrm{~cm}$ ). 60 examples were found of which the earliest 6 came from contexts dated to 150-175, with 3 more from contexts dated to $175-250$, and 6 from contexts dated 250-350.

86. F135 (4504). Rim of a jar, dia. $12-24 \mathrm{~cm}$. The context is dated $450-600$. See 85 for dating.

87. B10 (203). Rim of a jar, dia. $14-20 \mathrm{~cm}$ (though occasionally up to $24 \mathrm{~cm}$ ). The context is post-medieval. 103 examples were found, 2 of which were from contexts dated to pre-250, 18 from contexts dated to $250-350$, and 26 from contexts dated $350-450$.

88. F602 (4033). Rim of a jar, dia. $14 \mathrm{~cm}$. The context is dated to 450.3 examples were found, of which one came from a context dated to 150-175, and the other 2 from contexts dated to $350-450$. 
89. F293 (4516). Rim of a jar, dia. 10-16cm. The context is dated $250-450.35$ examples were found of which the earliest 3 came from contexts dated to 150-250, 3 more came from contexts dated to $250-350$, and 14 from contexts dated $350-450$.

90. F133 (470). Rim of a jar, dia. 17-36cm. The context is dated 450-600. 22 examples were found of which the earliest 8 were from contexts dated to 175-250, and 5 came from contexts dated to 250-350.

91. F177 (1110). Rim of a jar, dia. 16-24cm. The context dates to 450.4 examples were found, the earliest 3 of which came from contexts dated to $400-450$.

92. F333 (3182). Rim of a jar, dia. $10-16 \mathrm{~cm}$. The context is dated $800-1000.7$ examples were found of which the earliest 3 were from contexts dated 250-450.

93. Z201 (4499). Rim of a jar, dia. $20 \mathrm{~cm}$. The context is dated $250-450$.

94. F111 (1112). Rim of a jar, dia. $10-24 \mathrm{~cm}$ (usually $16-22 \mathrm{~cm}$ ). The context is dated to 450.129 examples were found, 5 of which came from contexts dated to pre-250, 17 from contexts dated 250-350, and 51 from contexts dated 350-450.

Grey coarse wares: ware 1 (Fig. 9.7)

95. F115 (583). Rim of a jar, dia. $10-22 \mathrm{~cm}$. The context is dated $350-450.24$ examples were found, of which 3 came from contexts dated to $175-250,3$ from contexts dated 250-350, and 8 from contexts dated 350-450.

96. F151 (4953). Rim of a jar, dia. $13-26 \mathrm{~cm}$. The context is dated $350-450.32$ examples were found, the earliest one of which came from a context dated to $175-250,4$ came from contexts dated to $250-350$, and a further 11 from contexts dated $350-450$.

97. B11 (4834). Rim of a jar, dia. $11-17 \mathrm{~cm}$. The context is undated. 28 examples were found, 19 of which came from post-medieval contexts. Of the rest 3 came from contexts dated to $130-250$.

98. G45 (4405). Rim of a jar, dia. $16-22 \mathrm{~cm}$. The context is post-medieval. The only example (of 4 ) not in a post-medieval context came from a context dated to $350-450$.

99. F116 (489). Rim of a jar, dia. $11-14 \mathrm{~cm}$. The context is post-medieval. 19 examples were found, of which the earliest 12 came from contexts dated to 

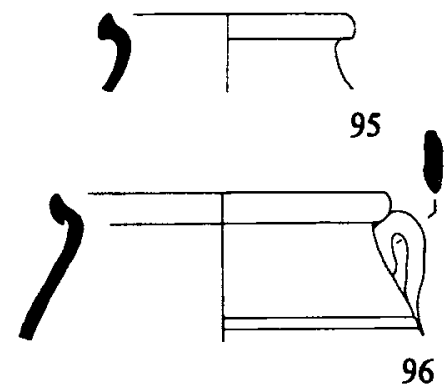
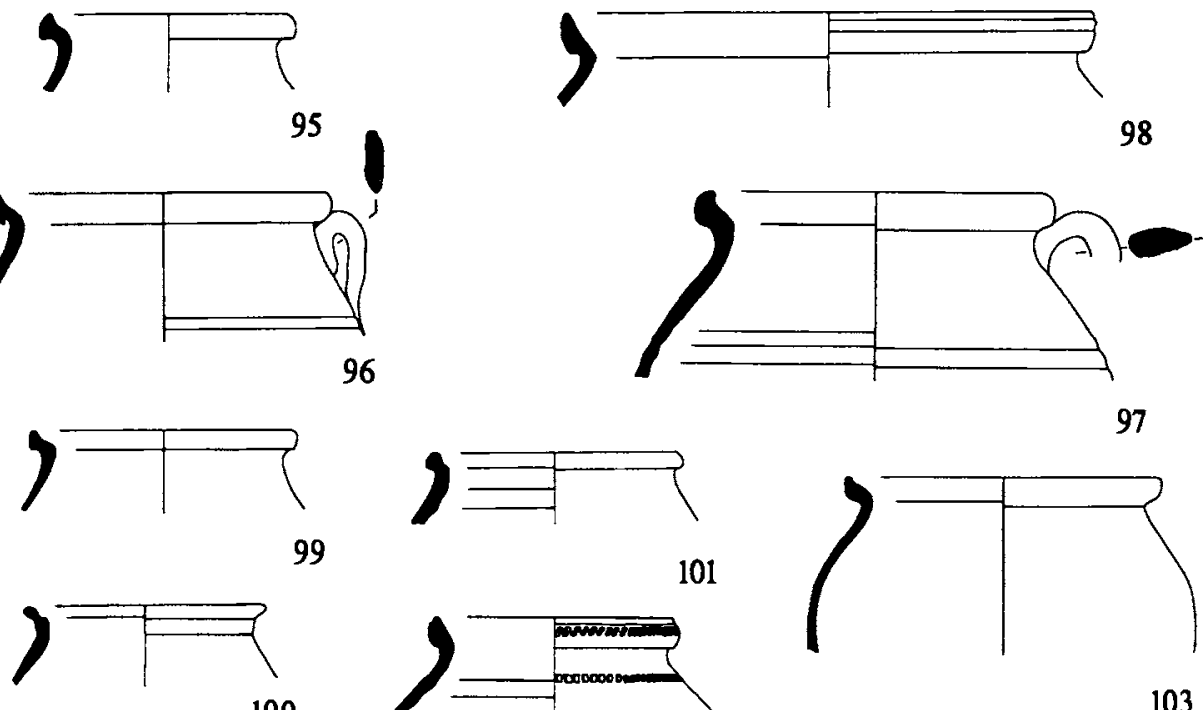

99

100

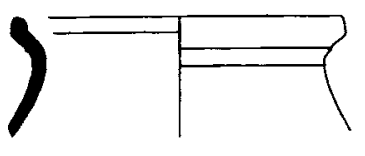

104
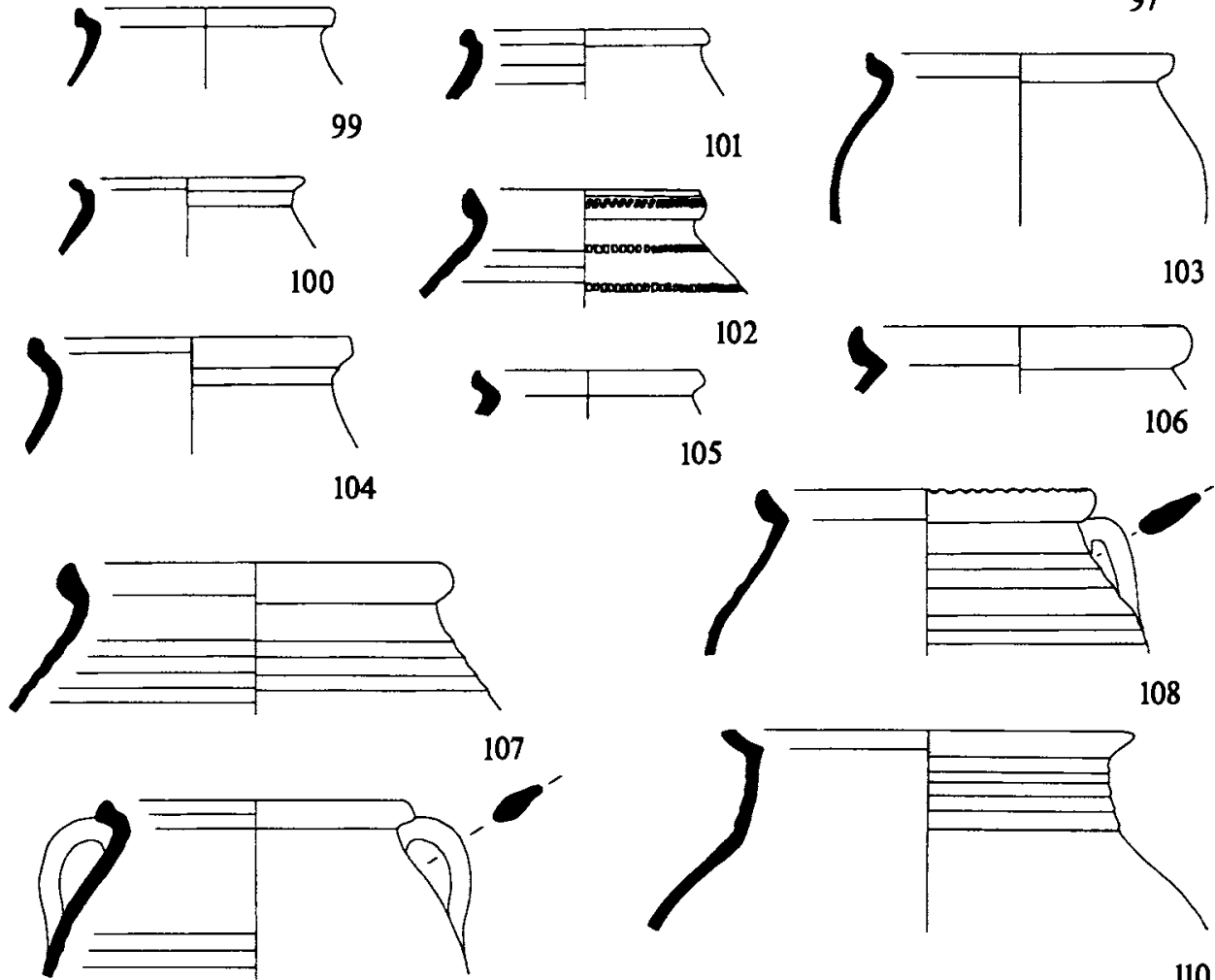

106

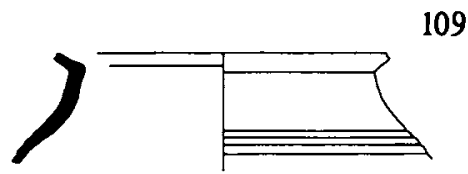

111
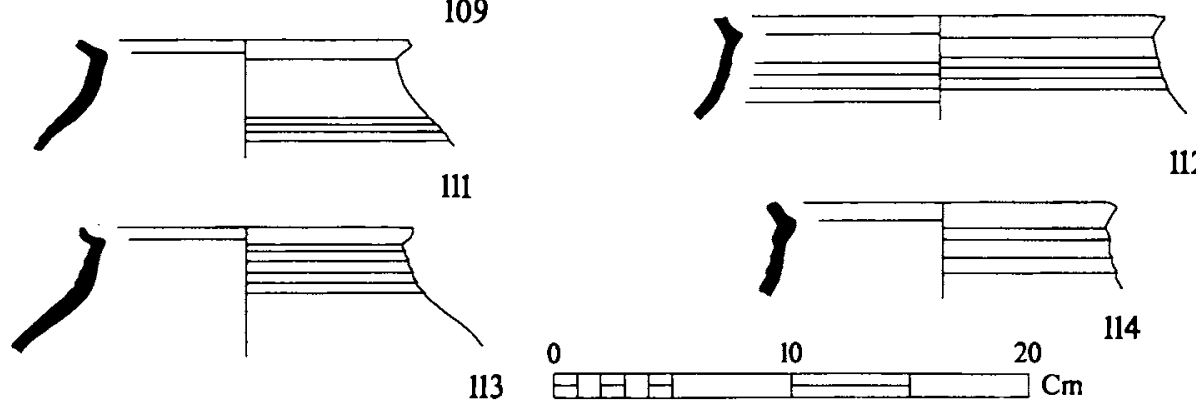

9.7 Grey coarse wares: ware 1 
99. F116 (489). Rim of a jar, dia. $11-14 \mathrm{~cm}$. The context is post-medieval. 19 examples were found, of which the earliest 12 came from contexts dated to $175-250$.

100. G105 (5203). Rim of a jar, dia. $8-10 \mathrm{~cm}$. The context is post-medieval. 3 examples were found, the other 2 being from a context dated to 450-600.

101. C758 (662). Rim of a jar, dia. $10 \mathrm{~cm}$. The context is dated $250-350.6$ examples were found from contexts dating to $250-450$.

102. F599 (4033). Rim of a jar, dia. 10-12cm. Irregular rouletted pattern on the exterior. The context is dated to 450.2 other examples were found, both from contexts dated to $250-450$.

103. F46 (489). Rim of a jar, dia. $12-26 \mathrm{~cm}$ (usually $12-16 \mathrm{~cm}$ ). The context is post-medieval. 25 examples were found the earliest one of which came from a context dated 250-275, with 11 more from contexts dating 250-450.

104. C845 (4405). Rim of a jar, dia. $13-15 \mathrm{~cm}$. The context is post-medieval.

105. F5 (203). Rim of a jar, dia. $7-12 \mathrm{~cm}$ (usually $10-12 \mathrm{~cm}$ ). The context is postmedieval. 15 examples were found: 1 from a context dated 100-130, 1 from a context dated $275-450,6$ from contexts dated $450-600$ and the rest from post-medieval deposits.

106. G89 (3132). Rim of a jar, dia. $11-30 \mathrm{~cm}$ (usually $16-22 \mathrm{~cm}$ ). The context is post-medieval. 42 examples were found, the earliest 7 of which came from contexts dated to $150-250$, and a further 5 from contexts dated to $250-350$.

107. Z202. Unstratified. Rim of a jar, dia. $16 \mathrm{~cm}$.

108. Z203 (4915). Rim of a jar with denticulated decoration on the top of the rim, dia. $14 \mathrm{~cm}$. The context is dated $350-450$.

109. F39-2250). Rim of a jar, dia. $11-13 \mathrm{~cm}$. The context is dated 130-175. 22 examples were found, of which the earliest one came from a context dated 100-130, with 10 more coming from contexts dated to 130-175.

110. G69 (2035). Rim of a jar, dia. 8-23cm. The context is dated $450-600.34$ examples were found, the earliest of which came from a context dated to 130-150, 3 came from contexts dated 250-350, and 8 from contexts dated to $350-450$.

111. G69 variant (2234). Rim of a jar, dia. $10-20 \mathrm{~cm}$. The context is dated 450-600. See 110 for dating.

112. F120 (513). Rim of a jar, dia. $18 \mathrm{~cm}$. The context is dated $450-600$. 
113. Bl (1018). Rim of a jar, dia. $12-20 \mathrm{~cm}$ (though one example is $26 \mathrm{~cm}$ ). The context is post-medieval. 11 examples were found, of which the earliest two came from contexts dated to 130-150, and a further two from contexts dated to $175-250$.

114. F33 (2011). Rim of a jar, dia. $12-14 \mathrm{~cm}$. The context is dated $450-600.18$ examples were found, the earliest 4 of which came from contexts dated to $350-450$, with 10 more coming from contexts dated $450-600$.

Grey coarse wares: ware 1 (Fig. 9.8)

115. G71 (2011). Rim of a jar, dia. $15 \mathrm{~cm}$. The context is dated $450-600.3$ examples were found, all from contexts dated to 450-600.

116. D5 (449). Rim of a jar, dia. 10-26cm (usually $14-18 \mathrm{~cm}$ ). The context is post-medieval. 17 examples were found, 7 of which were from contexts dated to $350-450,1$ from a context dated to $450-600$, and the rest from post-medieval contexts.

117. F33 (240). Rim of a jar, dia. $12 \mathrm{~cm}$. The context is post-medieval. For dating see 114 .

118. F188 (1087). Rim of a jar, dia. $10-12 \mathrm{~cm}$. The context is dated $450-600.5$ examples were found, of which the earliest one was from a context dated to 250-350, 2 more examples came from contexts dated to $350-450$, and 2 from contexts dated to 450-600.

119. F302 (4007). Rim of a jar, dia. $10-18 \mathrm{~cm}$ (usually $12-14 \mathrm{~cm}$ ). The context is post-medieval. 49 examples were found of which the earliest 5 came from contexts dated to 350-450, however 39 came from contexts dated 450-600.

120. C701 (2287). Rim of a jar, dia. 10-16cm. The context is dated to 175.18 examples were found, and apart from the illustrated piece, the earliest two were from contexts dated to 450 , with 11 more coming from contexts dated to $450-600$.

121. F684 (5218). Rim of a jar, dia. $10 \mathrm{~cm}$. The context is dated to 450.3 examples were found, all of which came from contexts dating to 450 .

122. F302 (2014). Rim of a jar, dia. $12-16 \mathrm{~cm}$. The context is dated $450-600$. For dating see 119.

123. G75 (2015). Rim of a jar, dia. 10-15cm. The context is dated 450-600. 3 examples were found, of which the earliest two came from contexts dated to $450-600$. 

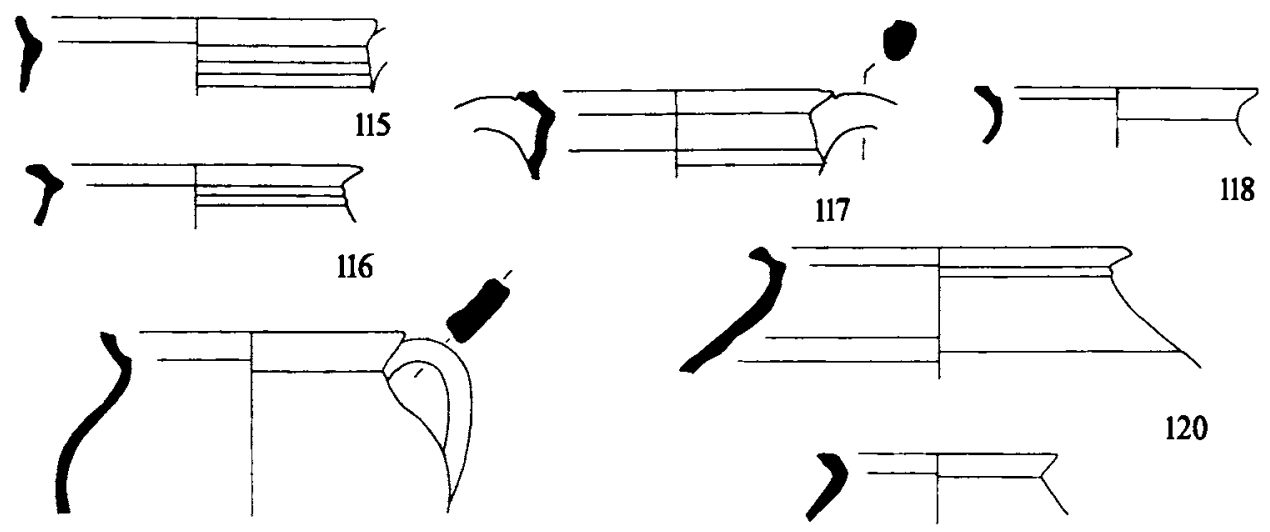

119

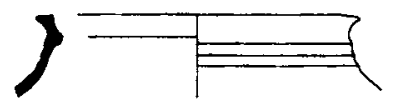

122
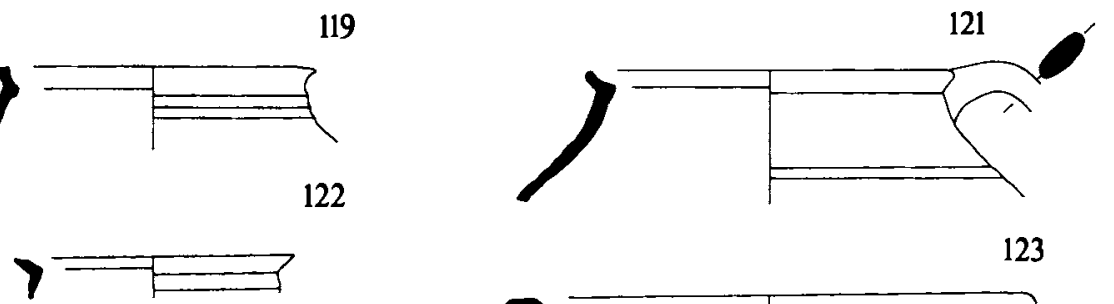

123

124
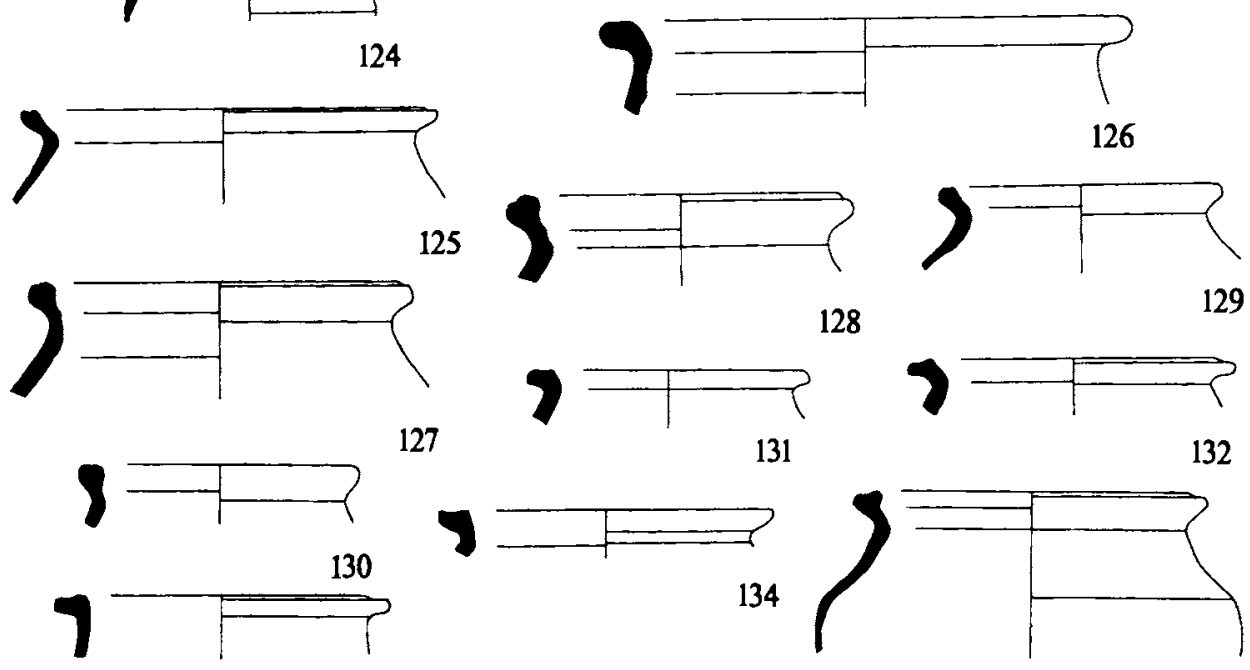

127

131

132
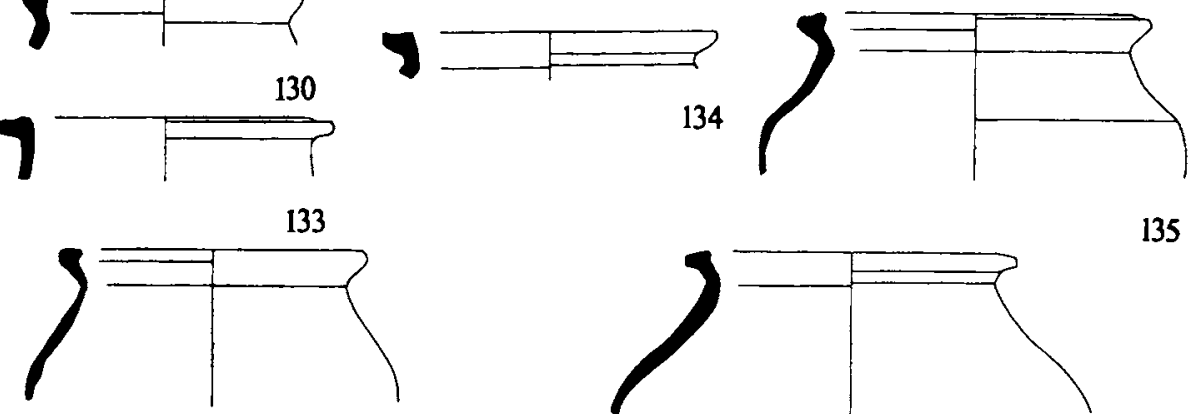

135

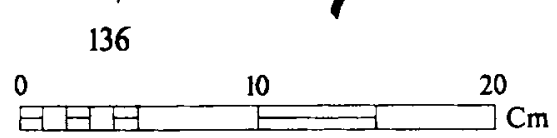

9.8 Grey coarse wares: ware 1 
124. F94 (537). Rim of a jar, dia. $12 \mathrm{~cm}$. The context is dated $350-450$.

125. F298. Unstratified. Rim of a jar, dia. $17 \mathrm{~cm}$. The only stratified example was from a context dated to $350-450$.

126. F128 (471). Rim of a jar, dia. $20 \mathrm{~cm}$. The context is post-medieval. 3 examples were found, all of which were from post-medieval deposits.

127. F383 (4031). Rim of a jar, dia. 10-16cm. Undated context. 10 examples were found, of which the earliest one came from a context dated to 130-175. However the 4 remaining dated pieces came from contexts dated to $400-450$.

128. F575 (4014). Rim of a jar, dia. $11-13 \mathrm{~cm}$. The context is post-medieval. 2 examples were found, both of which came from post-medieval deposits.

129. C854 (4405). Rim of a jar, dia. $11 \mathrm{~cm}$. The context is post-medieval.

130. C96 (3139). Rim of a jar, dia. $11-18 \mathrm{~cm}$. The context is post-medieval. 15 examples were found, the earliest one of which came from a context dated to $250-350,7$ came from contexts dated $350-450$, and 3 from contexts dated 450-600. (This type also occurs in ware 14.)

131. F355 (1189). Rim of a jar, dia. 11-14cm. The context is dated $400-450.5$ examples were found, 2 of which came from contexts dated $350-450$, and 3 from contexts dated to 450 .

132. F138 (665). Rim of a jar, dia. $12-20 \mathrm{~cm}$. The context is dated $250-350.36$ examples were found, of which 3 came from contexts dated to pre-350, but 11 came from contexts dated to $350-450$ and a further 9 from contexts dated to 450 .

133. F430 (5018). Rim of a jar, dia. $11-15 \mathrm{~cm}$. The context is dated to 450.17 examples were found, the earliest 11 of which came from contexts dated to $350-450$.

134. F138 (5018). Rim of a jar, dia. $13-16 \mathrm{~cm}$. The context is dated to 450 . See 132 for dating.

135. F453 (5019). Rim of a jar, dia. 10-16cm. The context is dated to 450.11 examples were found, the earliest 10 came from contexts dated to $400-450$.

136. F452 (5019). Rim of a jar, dia. $12-13 \mathrm{~cm}$. The context is dated to 450.3 examples were found: 2 from contexts dated to 450 , and the other from a context dated to $450-600$. 
137. G108 (5050). Rim of a jar, dia. $12-14 \mathrm{~cm}$. The context is dated to 450.3 examples were found, of which one was in a post-medieval deposit, and the other two in contexts dated to 450 .

Grey coarse wares: ware 1 (Fig. 9.9)

138. G128 (2124). Rim of a jar, dia. $9-18 \mathrm{~cm}$. The context is undated. 20 examples were found, of which the earliest were in contexts dated to 350-450, 3 were from contexts dated to 450 , and a further 9 from contexts dated to $450-600$.

139. F335 (1190). Rim of a jar, dia. $9 \mathrm{~cm}$. The context is dated $400-450$.

140. G82 (5049). Rim of a jar, dia. $12 \mathrm{~cm}$. The context is dated to 450 .

141. F162 (537). Rim of a jar, dia. 9-13cm. The context is dated 350-450. 32 examples were found, of which the earliest 3 were from a context dated to 175-250, however 12 were from contexts dated to 350-450, and a further 6 from contexts dated to $450-600$. The rest were from post-medieval deposits.

142. F371 (5018). Rim of a jar, dia. $8-17 \mathrm{~cm}$. The context is dated to 450.27 examples were found, of which the earliest 8 were from contexts dated to $350-450$, with a further 14 coming from contexts dated to 450 .

143. F359 (1189). Rim of a jar, dia. $15 \mathrm{~cm}$. The context is dated $400-450.4$ examples were found, 2 from contexts dating to $400-450$, and 2 from contexts dating to $450-600$.

144. B3 (402). Rim of a jar, dia. $10-20 \mathrm{~cm}$. The context is post-medieval. 9 examples were found, of which 8 were in post-medieval deposits, the other came from a context dated to $350-450$.

145. G119 (5218). Rim of a jar, dia. $20 \mathrm{~cm}$. The context is dated to 450 .

146. F106 (542). Rim of a jar, dia. 15-16cm. The context is dated 450-600. 2 examples were found, both of which came from contexts dated to 450-600.

147. F385 (3206). Rim of a jar, dia. $15-17 \mathrm{~cm}$. The context is post-medieval. 3 examples were found, the other 2 came from contexts dated to $400-450$.

148. F75 (4906). Rim of a jar, dia. 12-18cm. The context is dated 450-600. 39 examples were found, of which apart from 2 from contexts dated to pre350 , the earliest were 14 from contexts dated to $350-450$, with a further 11 coming from contexts dated to 450-600.

149. F75 variant (4906). Rim of a jar with thumb-impressed decoration on the exterior, dia. $18 \mathrm{~cm}$. The context is dated $450-600$. See 148 for dating. 


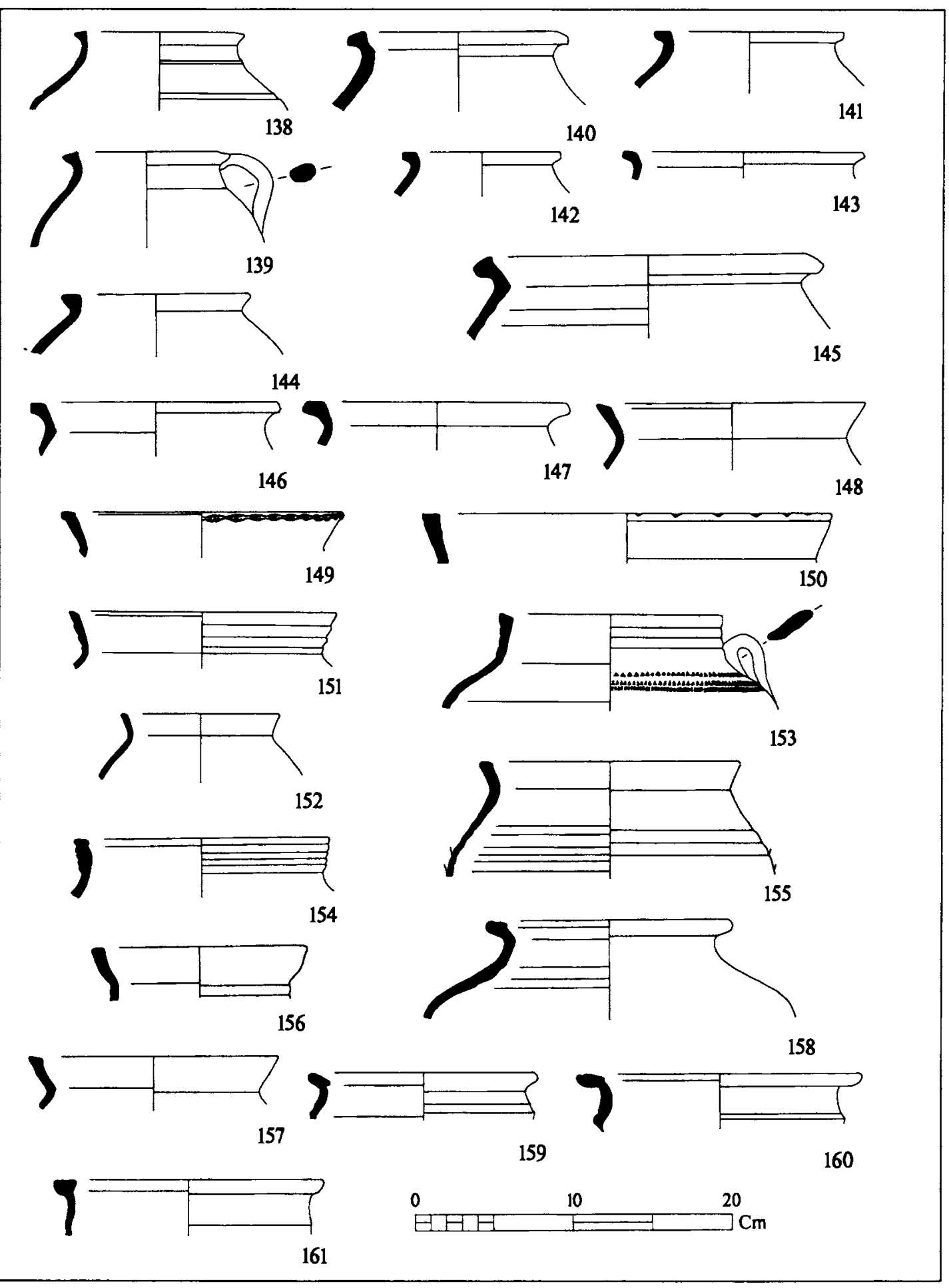

9.9 Grey coarse wares: ware 1 
150. F627 (4489). Rim of a jar with denticulated pattern on the top of the rim, dia. $26 \mathrm{~cm}$. The context is post-medieval. 3 examples were found, 2 from post-medieval contexts, and 1 from a context dated to $450-600$.

151. F75 variant (4896). Rim of a jar, dia. $17 \mathrm{~cm}$. The context is post-medieval. See 148 for dating.

152. F28 (4942). Rim of a jar, dia. $8-14 \mathrm{~cm}$. The context is dated $350-450.8$ examples were found, of which the earliest 5 came from contexts dated to $350-450$.

153. F113 (4507). Rim of a jar with rough rouletting on the exterior, dia. $13-16 \mathrm{~cm}$. The context is dated $250-450.13$ examples were found, of which the earliest 10 came from contexts dated to $350-450$.

154. C739 (4506). Rim of a jar, dia. $16 \mathrm{~cm}$. The context is dated $250-450.5$ examples were found of which the earliest two came from contexts dated to $250-350$.

155. B8 (453). Rim of a jar, dia. $10-16 \mathrm{~cm}$. The context is post-medieval. 5 examples were found, 3 from post-medieval deposits, 1 from a context dated to $175-350$, and another from a context dated to 275-450.

156. B8 variant (7). Rim of a jar, dia. $10-16 \mathrm{~cm}$. The context is post-medieval. See 155 for dating.

157. D4 (4896). Rim of a jar, dia. $16-18 \mathrm{~cm}$. The context is post-medieval. 6 examples were found: 3 from contexts dating to $175-250$ and the other 3 from post-medieval contexts.

158. F117 (540). Rim of a jar, dia. $12-17 \mathrm{~cm}$ (though one example is $24 \mathrm{~cm}$ ). The context is dated 350-450.21 examples were found, of which the earliest two came from contexts dated to $250-350$, and a further 10 were from contexts dated to $350-450$.

159. F357 (1189). Rim of a jar, dia. $14 \mathrm{~cm}$. The context is dated $400-450$.

160. F341 (1192). Rim of a jar, dia. $18 \mathrm{~cm}$. The context is dated $400-450$.

161. C128 (405). Rim of a jar, dia. $13-18 \mathrm{~cm}$. The context is post-medieval. 7 examples were found: 5 from post-medieval deposits, and 2 from contexts dated $350-450$. 
Grey coarse wares: ware 1 (Fig. 9.10)

162. F432 (5018). Rim of a jar, dia. $16-18 \mathrm{~cm}$. This type is known with roughly rouletted decoration on the top of the rim. The context is dated to 450.3 examples were found: 1 from a context dated to $130-175$, and the other 2 from a context dated to 450 .

163. F332 (1128). Rim of a jar, dia. $11-20 \mathrm{~cm}$. The context is dated to 450.38 examples were found, the earliest 5 of which came from contexts dated to $400-450$, with a further 23 coming from contexts dated to 450 .

164. Z38 (1). Rim of a jar, dia. $18 \mathrm{~cm}$. The context is post-medieval.

165. C366 (531). Rim of a bowl, dia. $34 \mathrm{~cm}$. The context is dated $350-450$.

166. A12 (1008). Rim of a bowl, dia. 23-32 cm (though one example is only $18 \mathrm{~cm}$ ). The context is post-medieval. 41 examples were found, of which the earliest two came from contexts dated to 175-250, a further 8 came from contexts dated to $250-350$, with 20 coming from contexts dated $350-450$.

167. C183 (278). Rim of a bowl, dia. $20 \mathrm{~cm}$. The context is dated $300-450.2$ examples were found, the other came from a context dated to 450 .

168. C365 (341). Rim of a bowl, dia. $20 \mathrm{~cm}$. The context is dated $175-250.2$ examples were found, the other came from a post-medieval deposit.

169. G73 (2011). Rim of a bowl, dia. $23-32 \mathrm{~cm}$. The context is dated $450-600.6$ examples were found: 4 from contexts dated to $450-600$, and 2 from postmedieval deposits.

170. C423 (677). Rim of a bowl, dia. $20-29 \mathrm{~cm}$ (though one example is $39 \mathrm{~cm}$ ). The context is dated 175-250. Of the examples not found in post-medieval contexts: 1 came from a context dated to $175-250,1$ from a deposit dated 275-450, 2 from contexts dated 350-450, and 5 from contexts dated $450-600$.

171. C324 (2037). Rim of a bowl, dia. $24-30 \mathrm{~cm}$. The context is post-medieval. 45 examples were found, of which the earliest 12 came from contexts dated to 130-175.

172. F242 (699). Rim of a bowl, dia. 18-22cm. The context is dated $130-150.4$ examples were found: 3 from contexts dated to $130-150$, and 1 from a context dated to 450 .

173. C735 (422). Rim of a bowl, dia. $29 \mathrm{~cm}$. The context is post-medieval. 


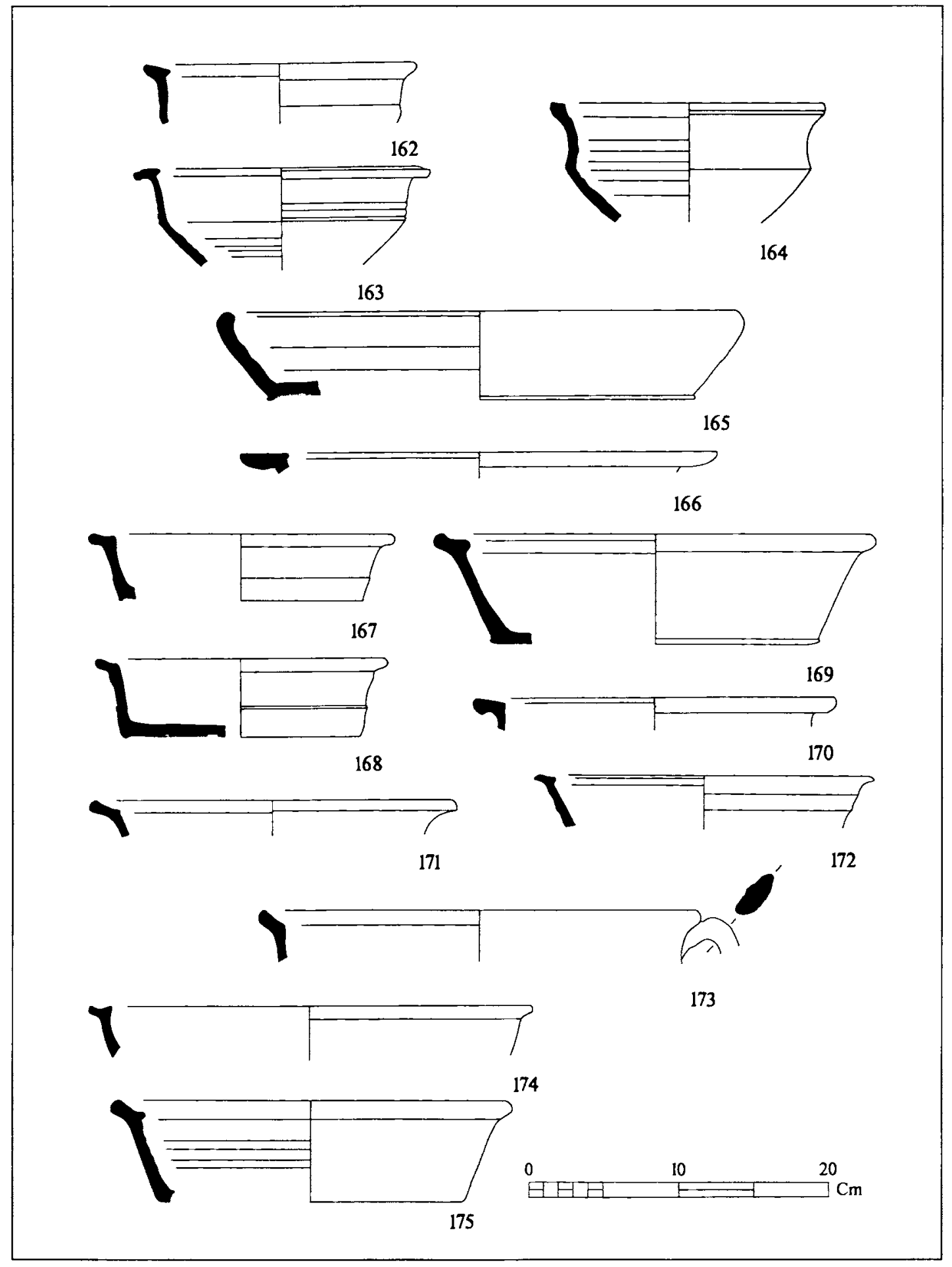

9.10 Grey coarse wares: ware 1 
174. D7 (2017). Rim of a bowl, dia. $12-30 \mathrm{~cm}$ (usually $12-16 \mathrm{~cm}$ ). The context is dated to 450. 12 examples were found: 2 from contexts dated to 175-250,2 from contexts dated to $350-450,1$ from a context dated to $450-600$, and 7 from post-medieval deposits.

175. C693 (4104). Rim of a bowl, dia. 24-36cm. The context is dated 300-450. 5 examples were found, of which the earliest two came from contexts dated to $350-450$, and a further 2 from contexts dated to $450-600$.

Grey coarse wares: ware 1 (Fig. 9.11)

176. F465 (706). Rim of a bowl, dia. $24 \mathrm{~cm}$. The context is dated $350-450.5$ examples were found, 1 was from a post-medieval context and the other 4 came from contexts dated to $250-450$.

177. C324 variant (570). Rim of a bowl, dia. $18 \mathrm{~cm}$. The context is dated $350-450$. See 171 for dating.

178. C184 (2254). Rim of a bowl, dia. $20-24 \mathrm{~cm}$. The context is dated $130-175.7$ examples were found, of which the earliest one came from a context dated to $100-130$, another came from a context dated to $130-175$, and a further 2 from a context dated 175-250.

179. C50 (402). Rim of a bowl, dia. $22 \mathrm{~cm}$. Faint impressions on top of rim. The context is post-medieval. 2 examples were found, both in post-medieval deposits.

180. C870 (4920). Rim of a bowl, dia. $28-30 \mathrm{~cm}$. The context is dated $350-450.2$ examples were found: both came from contexts dated to $350-450$.

181. C270 (4515). Rim of a bowl, dia. $15-34 \mathrm{~cm}$ (usually $20-30 \mathrm{~cm}$ ). The context is dated 250-450. 27 examples were found, of which the earliest 10 came from contexts dated 250-350, and a further 9 came from contexts dated $350-450$.

182. C373 (618). Rim of a bowl, dia. $16-18 \mathrm{~cm}$. The context is dated $350-450.9$ examples were found, of which the earliest 7 came from contexts dated to $130-150$.

183. F652 (5051). Rim of a bowl, dia. $14 \mathrm{~cm}$. The context is dated to 450 .

184. C28 (203). Rim of a bowl, dia. $16 \mathrm{~cm}$. The context is post-medieval.

185. G24 (2259). Rim of a bowl, dia. $16 \mathrm{~cm}$. The context is dated 100-130, though there is a small amount of later material. 


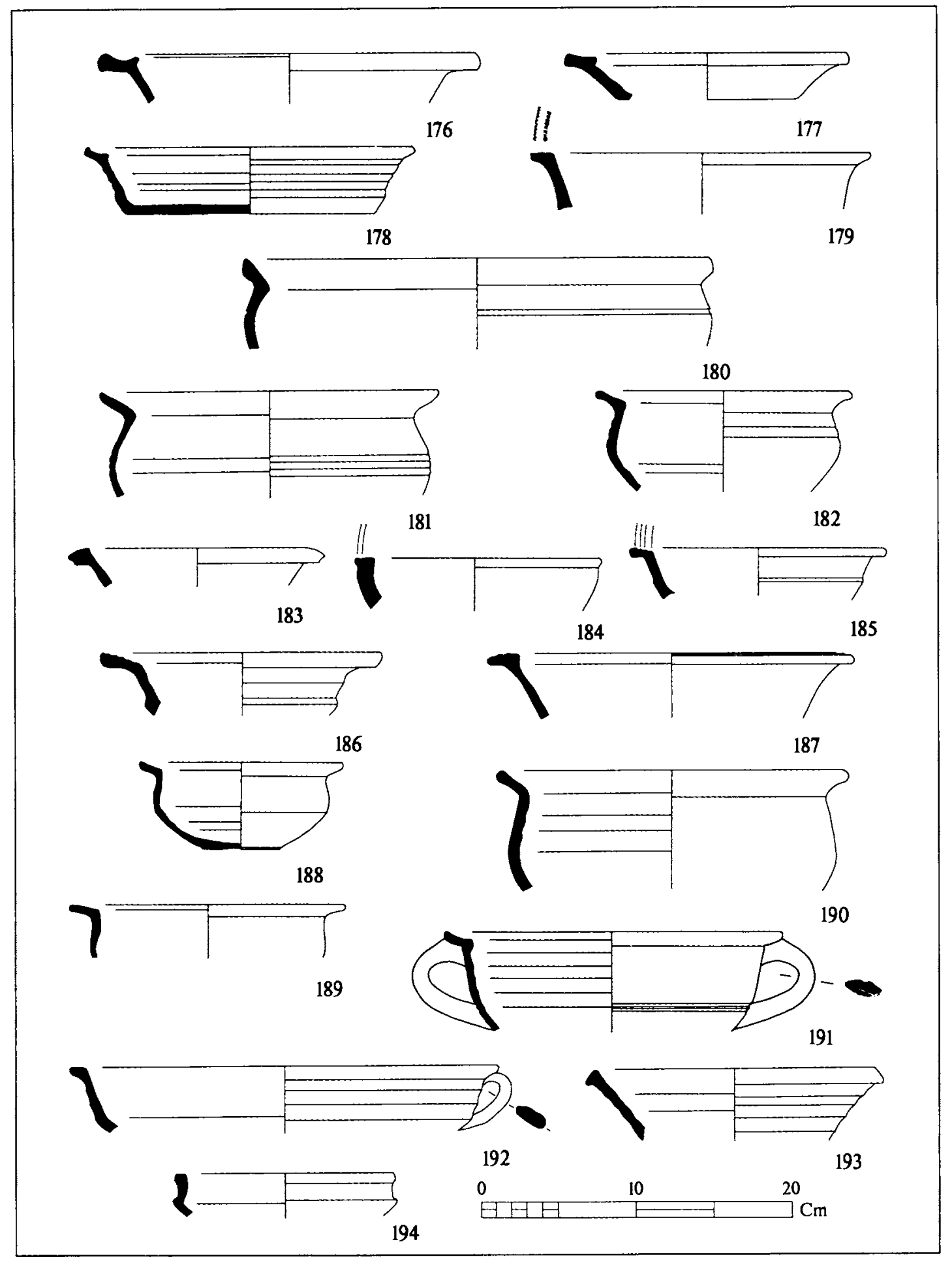

9.11 Grey coarse wares: ware 1 
186. G154 ( 4069). Rim of a bowl, dia. $18 \mathrm{~cm}$. The context is dated $175-250$.

187. G129 (2059). Rim of a bowl, dia. $21 \mathrm{~cm}$. The context is undated.

188. C549 (231). Rim of a bowl, dia. $13 \mathrm{~cm}$. The context is dated $175-350$, but contains some later material.

189. G63 (2040). Rim of a bowl, dia. $18 \mathrm{~cm}$. The context is dated to 450 .

190. C664 (699). Rim of a bowl, dia. $20-28 \mathrm{~cm}$. The context is dated $130-150.20$ examples were found, of which this was from the earliest dated context, with a further 8 coming from contexts dating to 150-175.

191. D3 variant. Rim of a bowl, dia. $18-22 \mathrm{~cm}$. The context is post-medieval. 36 examples were found, many of which were in post-medieval deposits, however the earliest occurrence was in a context dated to 130-150, with a further 6 examples coming from contexts dated to 175-250.

192. C790 (4802). Rim of a bowl, dia. $28 \mathrm{~cm}$. The context is post-medieval.

193. C638 (4115). Rim of a bowl, dia. $18 \mathrm{~cm}$. The context is dated $175-250$.

194. G59 (1078). Rim of a bowl, dia. $18-26 \mathrm{~cm}$. The context is dated $450-600.2$ examples were found, the other coming from a context dated to $250-350$.

Grey coarse wares: ware 1 (Fig. 9.12)

195. F653 (5051). Rim of a bowl, dia. $14 \mathrm{~cm}$. The context is dated to 450 .

196. G150 (114). Rim of a bowl, dia. $18 \mathrm{~cm}$. The context is undated.

197. C867. Rim of a bowl. Unstratified, dia. $27 \mathrm{~cm}$.

198. A8 (235). Rim of a large bowl, dia. $22-30 \mathrm{~cm}$ (though one example is $38 \mathrm{~cm}$ ). The context is dated 130-175. 8 examples were found, of which the earliest one came from a context dated to $130-175$, with one coming from a context dated $175-250$, and 3 from contexts dated 350-450.

199. F131 (4507). Rim of a bowl, dia. $14-24 \mathrm{~cm}$. The context is dated $250-450.14$ examples were found, of which the earliest 3 came from contexts dated 175-250, with a further 2 coming from contexts dated to $250-350$.

200. C694 (4817). Rim of a jar, dia. 14-20cm. The context is post-medieval. 6 examples were found, 5 of which were from post-medieval contexts and 1 from a context dated to $250-350$.

201. F165 (570). Rim of a jar, dia. $22 \mathrm{~cm}$. The context is dated $350-450$. 


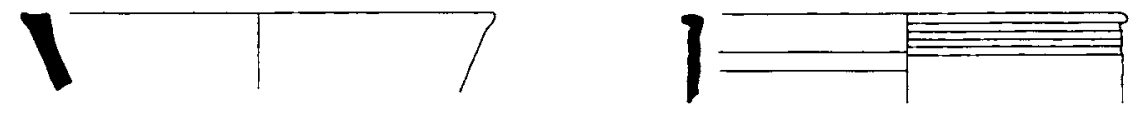

195

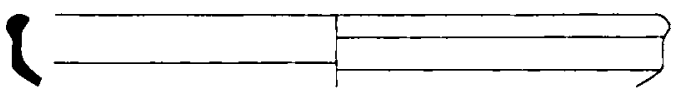

197

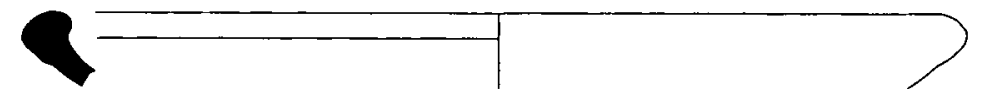

198

1

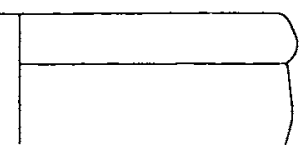

199
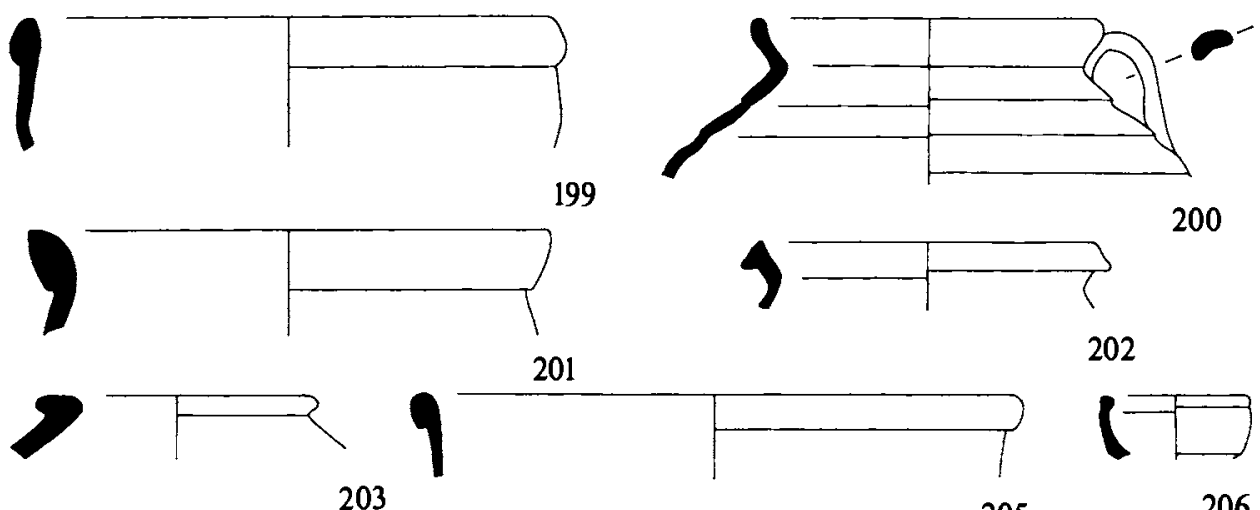

200
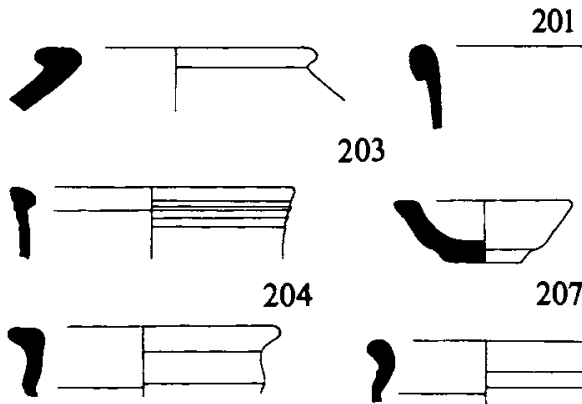

207

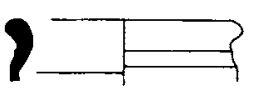

208
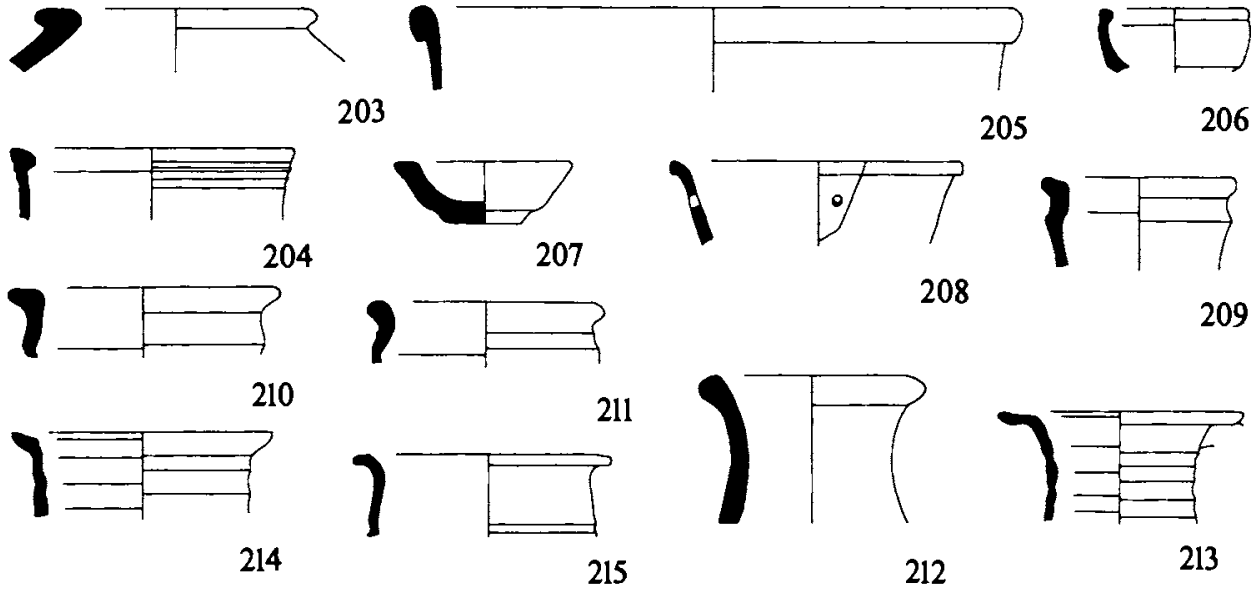

215
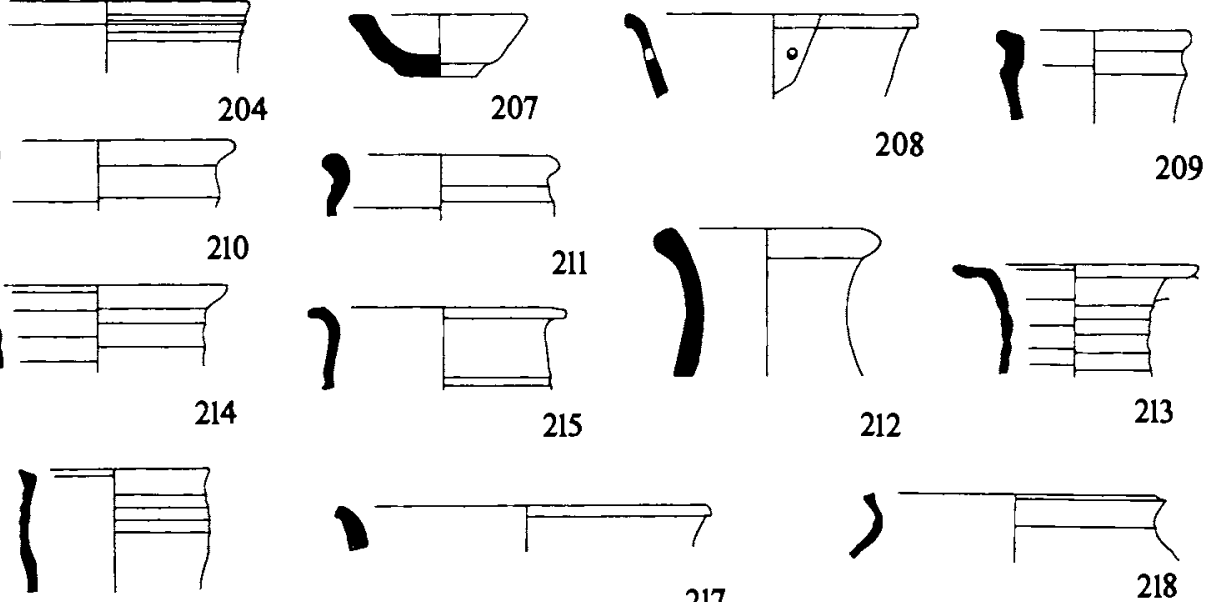

212
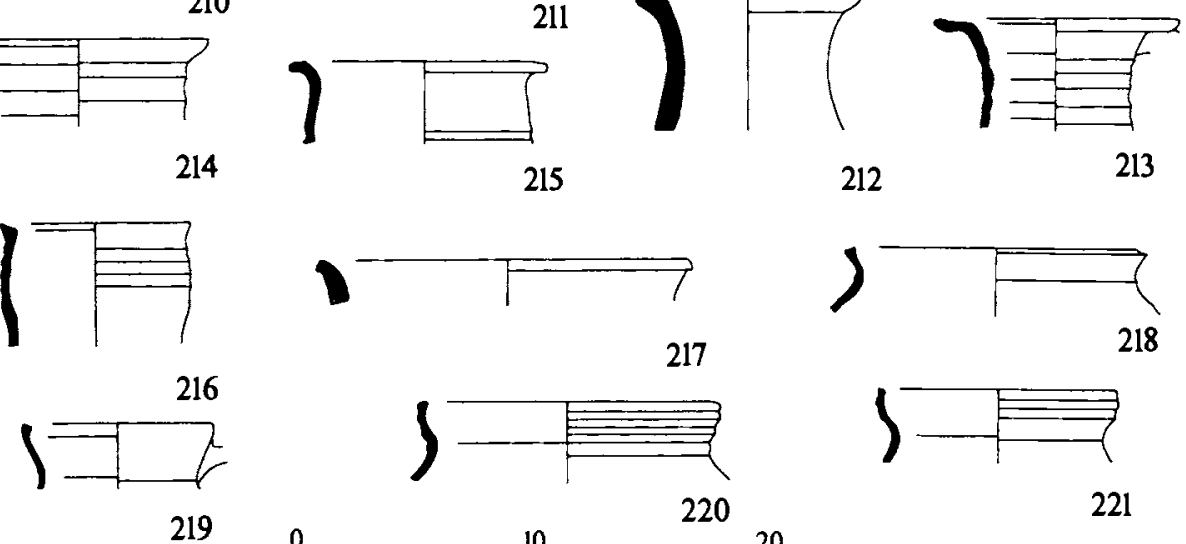
$\stackrel{20}{C} \mathrm{Cm}$

9.12 Grey coarse wares: ware 1 
202. F394 (5018). Rim of a jar, dia. 14cm. The context is dated to 450 .

203. F51 (250). Rim of a jar, dia. $11-21 \mathrm{~cm}$. The context is dated 300-450. 2 examples were found, the other coming from a context that was dated to $175-250$.

204. G70 (2018). Rim of a jar. dia. $12 \mathrm{~cm}$. The context is post-medieval.

205. F386 (4495). Rim of a bowl, dia. $35-36 \mathrm{~cm}$. The context is post-medieval. 9 examples were found, of which the earliest one came from a context dated 250-350, with a further 4 coming from contexts dated to 350-450.

206. C588 (5018). Rim of a bowl, dia. $6 \mathrm{~cm}$. The context is dated to 450 .

207. C182 (412). Rim of a moulded bowl, dia. $7 \mathrm{~cm}$. The context is dated $450-600$.

208. G170 (4856). Rim of a bowl that has been perforated before firing, dia. $12 \mathrm{~cm}$. The context is dated $350-450$.

209. F448 ( 4096 ). Rim of a jar, dia. $8-10 \mathrm{~cm}$. The context is dated $400-500$, but contains some later material. 2 examples were found, the other coming from a context dated $350-450$.

210. C298 (462). Rim of a jar, dia. $11 \mathrm{~cm}$. The context is dated $450-600$, but contains some later material.

211. F47 (449). Rim of a jar, dia. 7-9cm. The context is post-medieval. 4 examples were found, of which the earliest two came from a context dated to $175-250$, and one from a context dated to 450 .

212. G100 (4422). Rim of a jar, dia. $8 \mathrm{~cm}$. Burnished horizontally on the exterior. The context is post-medieval.

213. G144 (584). Rim of a jar, dia. $10 \mathrm{~cm}$. The context is dated $350-450$.

214. G162 (1056). Rim of a jar, dia. $10 \mathrm{~cm}$. The context is post-medieval.

215. F388 (5018). Rim of a jar, dia. 8-11 cm. The context is dated to 450.4 examples were found, of which the earliest one came from a context dated to $250-275,1$ from a context dated $275-450$, and 2 from contexts dated to 450.

216. F633 (1036). Rim of a jar, dia. 8cm. The context is dated $450-600$.

217. C51 (402). Rim of a jar, dia. $12-22 \mathrm{~cm}$. The context is post-medieval. The only other example came from a context dated to $350-450$.

218. G68 (2035). Rim of a jar, dia. $12 \mathrm{~cm}$. The context is dated $450-600$. 
219. C716 (2135). Rim of a jar, dia. $8 \mathrm{~cm}$. The context is dated $450-600$.

220. C703 (4007). Rim of a jar, dia. $12-15 \mathrm{~cm}$. The context is post-medieval. 16 examples were found, 1 from a context dated to $250-350,10$ from contexts dated $450-600$, and 5 from post-medieval deposits.

221. F167. Unstratified. Rim of a jar, dia. $10-12 \mathrm{~cm}$. The only other example was from a post-medieval context.

Grey coarse wares: ware 1 (Fig. 9.13)

222. Z165 (4973) SF. 12450 . Base of a jar, dia. $6.5 \mathrm{~cm}$. The context is dated 250-350.

223. Z32 (2250) SF. 14439. Base of a jar, dia. $9 \mathrm{~cm}$. The context is dated 130-175.

224. $Z 4$ (5288). Base of a jar with holes bored before firing, dia. $9.5 \mathrm{~cm}$. The context is dated $400-450$.

225. Z3 (4480). Base of a jar, dia. $10.5 \mathrm{~cm}$. The context is post-medieval.

226. C536 (1123). Rim of a bowl with rough rouletted decoration on the top of the rim, dia. $19 \mathrm{~cm}$. The context is dated to 450.3 examples were found, all from contexts dated to $400-450$.

227. F210 (4516). Rim of a bowl, dia. $16-26 \mathrm{~cm}$. The context is dated $250-450.7$ examples were found, of which the earliest one came from a context dated $175-250$, with a further 2 from contexts dated $250-350$.

228. F210 (659). Rim of a bowl, dia. $16-26 \mathrm{~cm}$. The context is dated $250-350$. See 227 for dating.

229. C38 (203). Rim of a bowl, dia. $18-22 \mathrm{~cm}$. The context is post-medieval. 4 other examples were found: 1 from a context dated to 130-150, and 3 from contexts dated to $175-250$.

230. C103 (446). Rim of bowl, dia. $12-26 \mathrm{~cm}$. The context is post-medieval. 7 examples were found, of which the earliest one came from a context dated $175-250$, and 2 came from a context dated 350-450. ( 3 were from postmedieval contexts.)

231. Z39 (22). Rim of a bowl, dia. $14 \mathrm{~cm}$. The context is post-medieval.

232. C6 (4515). Rim of a bowl, dia. $10-30 \mathrm{~cm}$ (usually $14-20 \mathrm{~cm}$ ). The context is dated to 250-450. 197 examples were found, of which 123 were from postmedieval deposits. The earliest one came from a context dated to 175-250, and a further 26 came from contexts dated to $250-350$. 

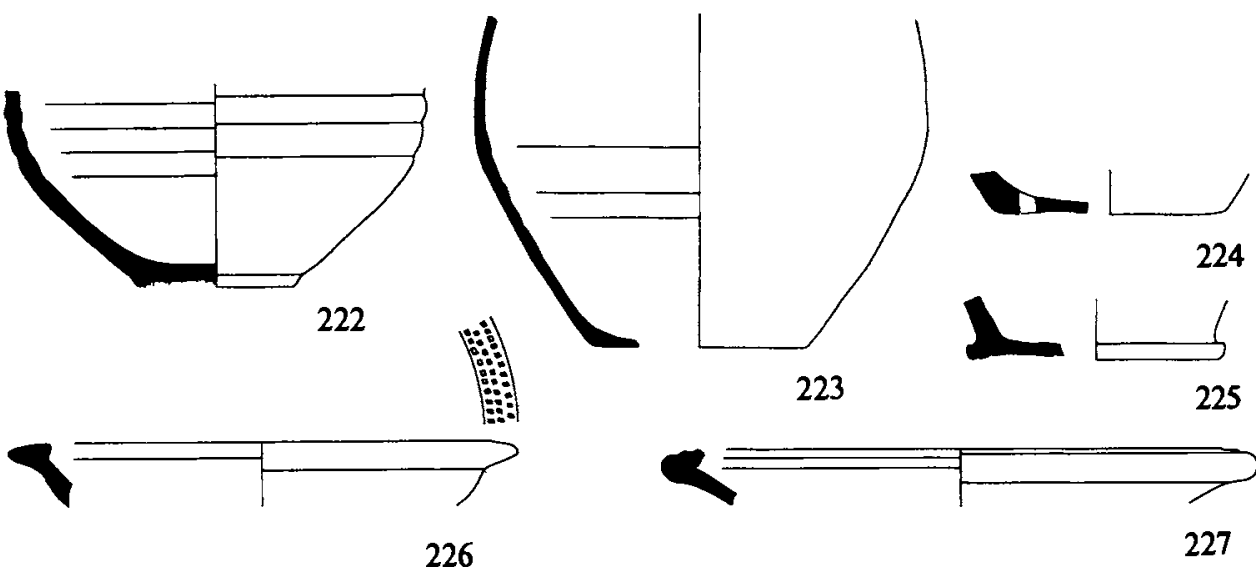

226
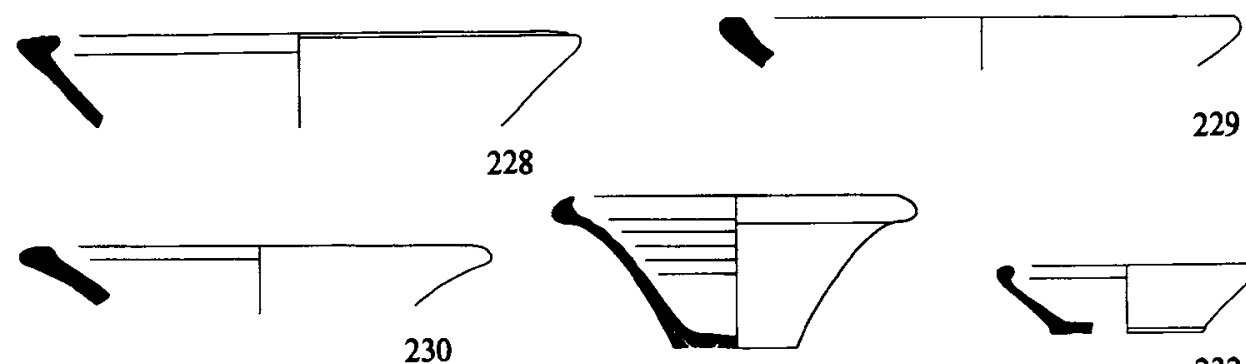

231
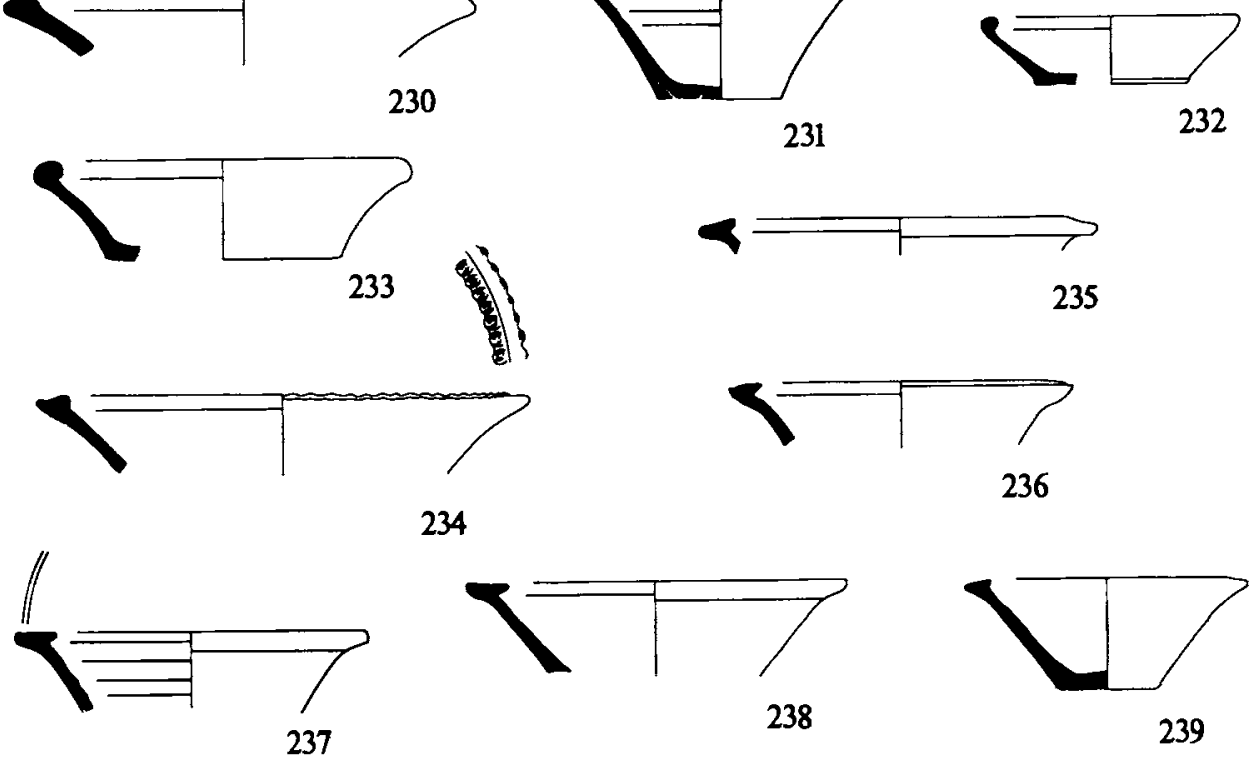

234

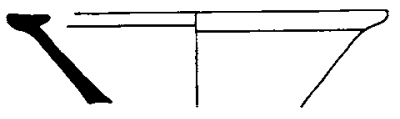

238
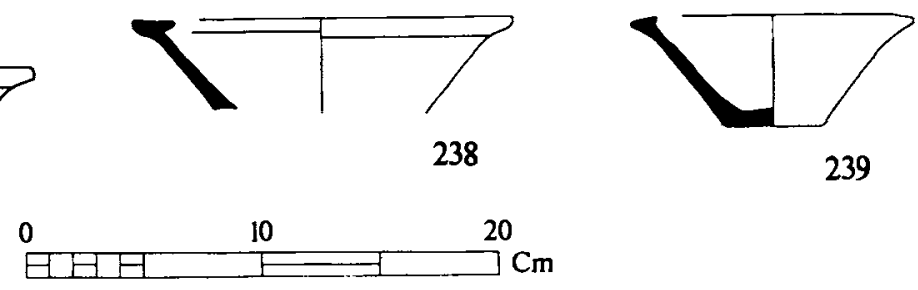

9.13 Grey coarse wares: ware 1 
233. C307 (4515). Rim of a bowl, dia. $15-32 \mathrm{~cm}$. The context is dated $250-450.8$ other examples were found, of which the earliest one came from a context dated to 175-250, 1 from a context dated to 250-350 and 2 from contexts dated to $350-450$.

234. C560 (4912). Denticulated rim of a bowl, dia. $1619 \mathrm{~cm}$. The context is dated 450-600. 14 examples were found, of which the earliest one came from a context dated to 150-175. However, 1 was from a context dated to 350-450, 5 from contexts dated to 450 , and the rest from post-medieval deposits.

235. F332 variant (1189). Rim of a bowl, dia. $14 \mathrm{~cm}$. The context is dated 400-450. See 163 for dating.

236. C302 (555). Rim of a bowl, dia. $12 \mathrm{~cm}$. The context is undated. 7 examples were found, of which the earliest 5 were from contexts dated 400-450.

237. C97 (2017). Rim of a bowl, dia. $14-24 \mathrm{~cm}$ (usually $18-24 \mathrm{~cm}$ ). The context is dated to 450.12 examples were found, of which 7 were from post-medieval deposits. Of the others the earliest 4 were from contexts dated 350-450.

238. C560 variant (96). Rim of a bowl, dia. $16 \mathrm{~cm}$. The context is undated. See 234 for dating.

239. C807 (581). Rim of a bowl, dia. $12 \mathrm{~cm}$. The context is dated $350-450$.

Grey coarse wares: ware 1 (Fig. 9.14)

240. C688 (2213). Rim of a lid, dia. $38 \mathrm{~cm}$. The context is dated $450-600$.

241. C275.(571). Rim of a lid, dia. $12-24 \mathrm{~cm}$. The context is dated $450-600.6$ examples were found, of which the earliest two came from contexts dated to 250-350, and a further 2 from contexts dated to 350-450.

242. C550 (319). Rim of a lid, dia. $20 \mathrm{~cm}$. The context is dated 130-150. 12 examples were found, of which 11 came from contexts dated to 130-150.

243. F567.(352). Rim of a lid, dia. $16-40 \mathrm{~cm}$ (usually $20-30 \mathrm{~cm}$ ). The context is dated 100-130.50 examples were found, of which the earliest came from a context dated 100-130, 6 from contexts dated 130-175, and a further 30 from contexts dated 175-250.

244. C61.(4507). Rim of a lid, dia. 11-40cm (though usually between $14-20 \mathrm{~cm}$ ). The context is dated 250-450. 1555 examples were found, of which 26 come from contexts dating to pre-175, 75 come from contexts dated to 175-250, 147 from contexts dated to 250-350, 128 from contexts dated 250-450, and a further 505 from contexts dated $350-450$. 
245. C61 (662). Rim of a lid, dia. $11-40 \mathrm{~cm}$ (though usually between $14-20 \mathrm{~cm}$ ). The context is dated $250-350$. See 244 for dating.

246. C271 (576). Rim of a lid, dia. 16-20cm. The context is dated $350-450.12$ examples were found: 3 from contexts dated to $250-450$, and 9 from contexts dated to $350-450$.

247. G110 (4906). Rim of a lid, dia. $13 \mathrm{~cm}$. The context is dated $450-600$.

248. C590 (5018). Rim of a lid, dia. $13-29 \mathrm{~cm}$. The context is dated to 450.4 examples were found, 1 from a context dated to 250-450, 1 from a context dated 275-450, and 2 from contexts dated to 450 .

249. C313 (5018). Rim of a lid, dia. $12-20 \mathrm{~cm}$. The context is dated to 450.43 examples were found, of which one came from a context dated to 250-275, 2 came from contexts dated to $250-350,10$ from contexts dated to 350-450, and 11 from contexts dated to 450 .

250. C428 (677). Rim of a lid, dia. $20-36 \mathrm{~cm}$. The context is dated $175-250.7$ examples were found, of which the earliest one came from a context dated to $100-130$, with 3 coming from contexts dated to $175-250$.

251. C76. Unstratified. Rim of a lid, dia. $12-36 \mathrm{~cm}$ (usually $16-25 \mathrm{~cm}$ ). 83 examples were found, of which the earliest 3 came from contexts dated to $100-130$, a further 26 from contexts dated to $130-175$, and 10 from contexts dated 175-250.

252. G83 (5037). Rim of a lid, dia. $6 \mathrm{~cm}$. The context is dated $450-600$.

253. C130 (445). Rim of a lid, dia. $19 \mathrm{~cm}$. The context is dated $450-600$.

254. G137 (3011). Rim of a lid, dia. $18 \mathrm{~cm}$. The context is post-medieval.

255. C61 (4506). Rim of a lid, dia. $11-40 \mathrm{~cm}$ (though usually between $14-20 \mathrm{~cm}$ ). The context is dated $250-450$. See 244 for dating.

256. C61 (3041). Rim of a lid, dia. $11-40 \mathrm{~cm}$ (though usually between $14-20 \mathrm{~cm}$ ). The context is post-medieval. See 255 for dating.

257. C511 (5306). Rim of a lid, dia. $19-33 \mathrm{~cm}$. The context is dated $250-350.351$ examples were found, of which the earliest one came from a context dated to $130-175,2$ came from contexts dated to $150-175,8$ from contexts dated $175-250,49$ from contexts dated 250-350, 38 from contexts dated to $250-450$, and 72 from contexts dated 350-450. 


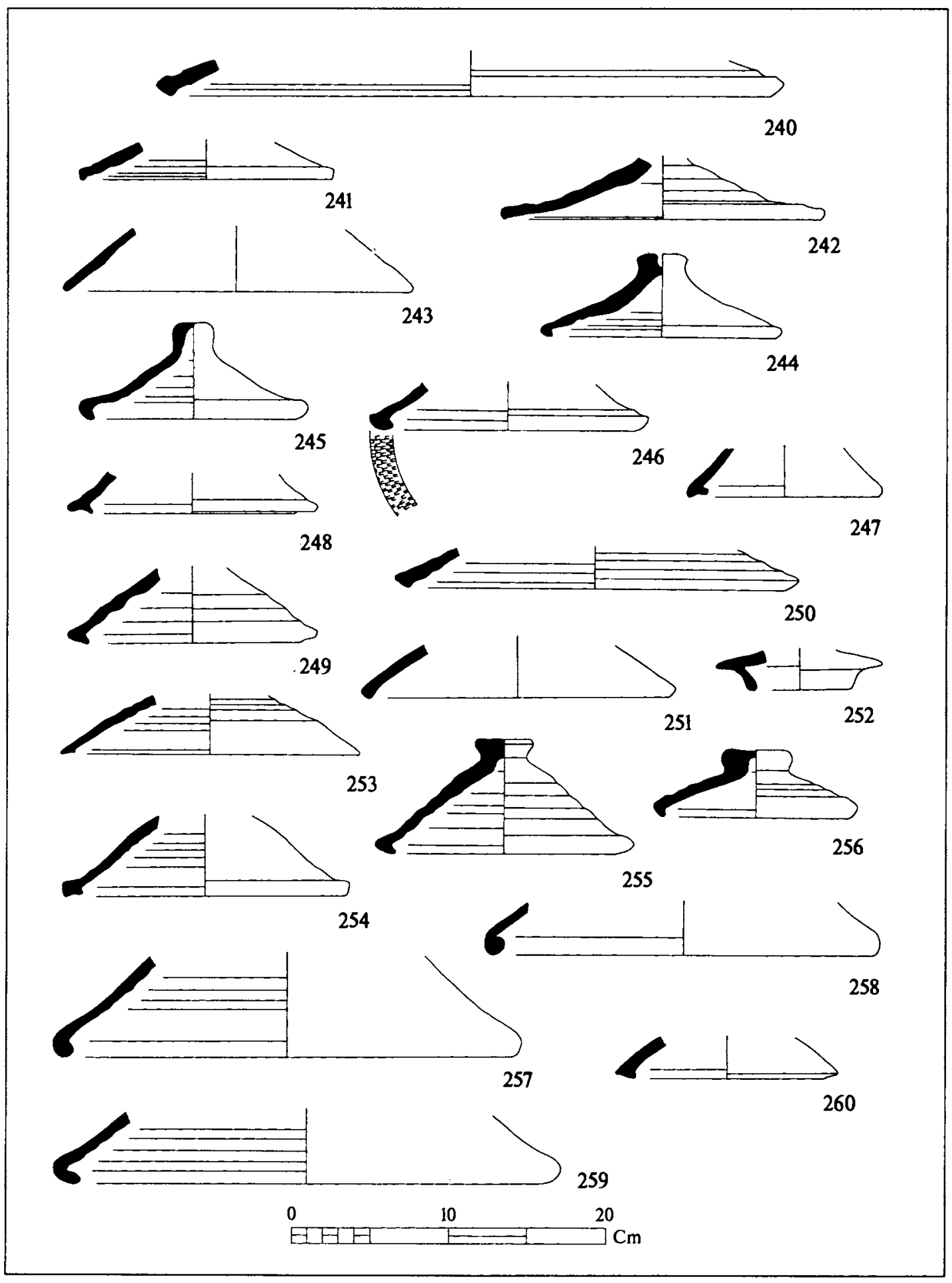

9.14 Grey coarse wares: ware 1 
258. C572 (3355). Rim of a lid, dia. 16-24cm. The context is dated $450-600.11$ examples were found: 4 from contexts dated to $350-450,2$ from contexts dated to 450 , and a further 5 from contexts dated to $450-600$.

259. C564 (682). Rim of a lid, dia. $18-30 \mathrm{~cm}$ (though one example is $36 \mathrm{~cm}$ ). The context is dated 350-450. 14 examples were found, of which the earliest one came from a context dated $250-350$,and a further 7 from contexts dated to $350-450$.

260. C591 (5018). Rim of a lid, dia. 10-16cm. The context is dated to 450.4 examples were found: 2 from contexts dated to $350-450$, and 2 from contexts dated to 450 .

\section{Buff coarse wares: ware 24 (Fig. 9.15)}

261. F578 (558). Rim of a large bowl, dia. $60 \mathrm{~cm}$. The context is dated $350-450$.

262. C691 (4817). Rim of a bowl, dia. $45 \mathrm{~cm}$. The context is post-medieval.

263. G42 (636). Rim of a bowl, dia. $18-24 \mathrm{~cm}$. The context is dated $450-600.4$ examples were found: 1 from a context dated to $250-350,1$ from a context dated to $350-450$, and 2 from contexts dated to $450-600$.

264. C768 (3139). Rim of a bowl, dia. $29 \mathrm{~cm}$. The context is post-medieval. 12 examples were found, of which the earliest one came from a context dated to $250-275,1$ came from a context dated $250-350$, and 6 from contexts dated to $350-450$.

265. G44 (636). Rim of a bowl, dia. $24 \mathrm{~cm}$. The context is dated $450-600$.

266. G43 (636). Rim of a bowl, dia. $31 \mathrm{~cm}$. The context is dated $450-600$.

267. C334 (1011). Rim of a bowl, dia. $32-37 \mathrm{~cm}$. The context is dated $450-600.6$ examples were found: 1 from a context dated to 100130,1 from a context dated 150-250, 1 from a context dated 175-250, and 3 from a context dated to $450-600$.

268. C334 variant (2260). Rim of a bowl, dia. $32 \mathrm{~cm}$.. The context is dated 100-130. See 267 for dating.

269. C692 (4817). Rim of a bowl, dia. $24 \mathrm{~cm}$. The context is post-medieval.

270. C718 (4140). Bowl, dia. $24 \mathrm{~cm}$. The context is dated 175-250.

271. G121. Unstratified. Rim of a small bowl, dia. $8 \mathrm{~cm}$. The rim is irregular (maybe waster or start of lip). String cut base. 


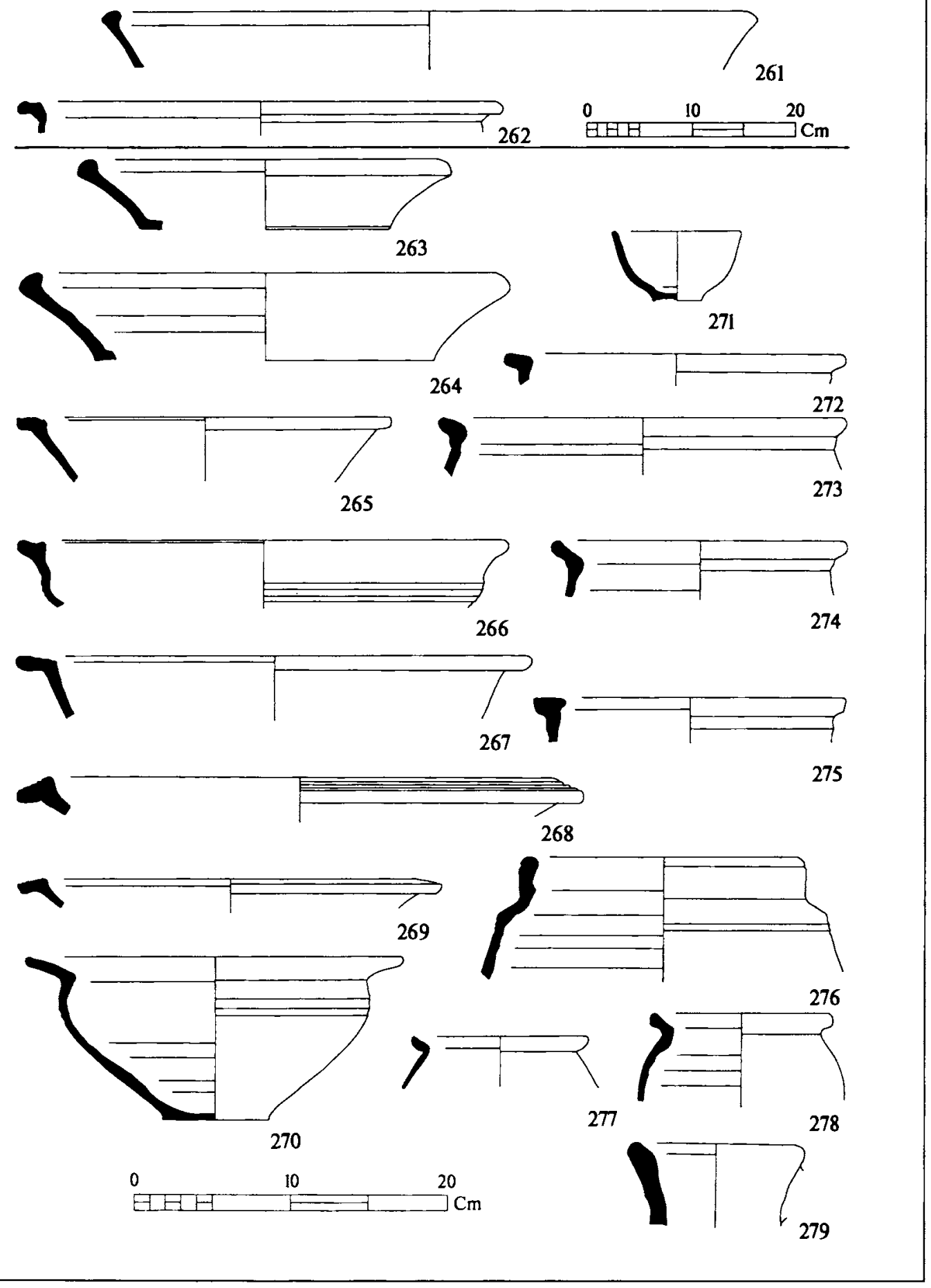

9.15 Buff coarse wares: ware 24 
272. C748 (550). Rim of a bowl, dia. $21 \mathrm{~cm}$. The context is dated $450-600$.

273. G86 (4896). Rim of a jar, dia. $25 \mathrm{~cm}$. The context is post-medieval. Apart from this example, 2 others were found, both in post-medieval deposits.

274. G118 (5218). Rim of a jar, dia. $18 \mathrm{~cm}$. The context is dated to 450 .

$275 \mathrm{C} 710$ (96). Rim of a jar, dia. $20 \mathrm{~cm}$. Undated context. One other example was found in a context dated to $450-600$.

276. F661 (4507). Rim of a jar, dia. $17 \mathrm{~cm}$. The context is dated $250-450$.

277. F611 (635). Rim of a jar, dia. $11-16 \mathrm{~cm}$. The context is dated $350-450.5$ examples were found: 3 from contexts dated to $350-450$ and 2 from contexts dated to 450 .

278. G167 (4848). Rim of a jar, dia. $11 \mathrm{~cm}$. The context is dated $350-450$.

279. H13 (451). Rim of an amphora, dia. $10 \mathrm{~cm}$. Handle stub just visible on neck. The context is post-medieval.

Grey micaceous coarse wares: ware 14 (Fig. 9.16)

280. F559 (1024). Rim of a bowl, dia. $30 \mathrm{~cm}$. The context is dated $450-600$.

281. F560 (1024). Rim of a bowl, dia. $20 \mathrm{~cm}$. The context is dated $450-600$.

282. C351 (1110). Rim of a bowl, dia. $22 \mathrm{~cm}$. Burnished. The context is dated to 450.4 examples were found, 1 from a context dated to 450,2 from contexts dated to $450-600$ and 1 from a post-medieval deposit.

283. F401 (5018). Rim of a bowl, dia. $25 \mathrm{~cm}$. The context is dated to 450.3 examples were found, all from deposits dated to 450 .

284. F691 (4896). Bowl, dia. $26-27 \mathrm{~cm}$. The context is post-medieval. 3 other examples were found from contexts dated to $350-450$.

285. G77 (2012). Rim of a bowl with incised bands on top of the rim, dia. $24 \mathrm{~cm}$. The context is dated 450-600. One other example was found from a context dated to 450 .

286. F654 (5051). Rim of a bowl with two incised bands on top of the rim, dia. $24 \mathrm{~cm}$. The context is dated to 450 . One other example was found from a context dated to $350-450$.

287. G102 (2170). Rim of a bowl, dia. $12 \mathrm{~cm}$. The context is dated to 450 .

288. F635 (1078). Rim of a bowl, dia. $22 \mathrm{~cm}$. The context is dated $450-600$. 


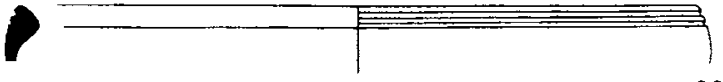

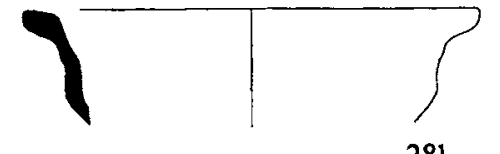

281

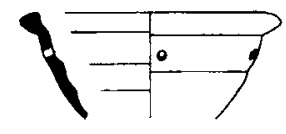

291
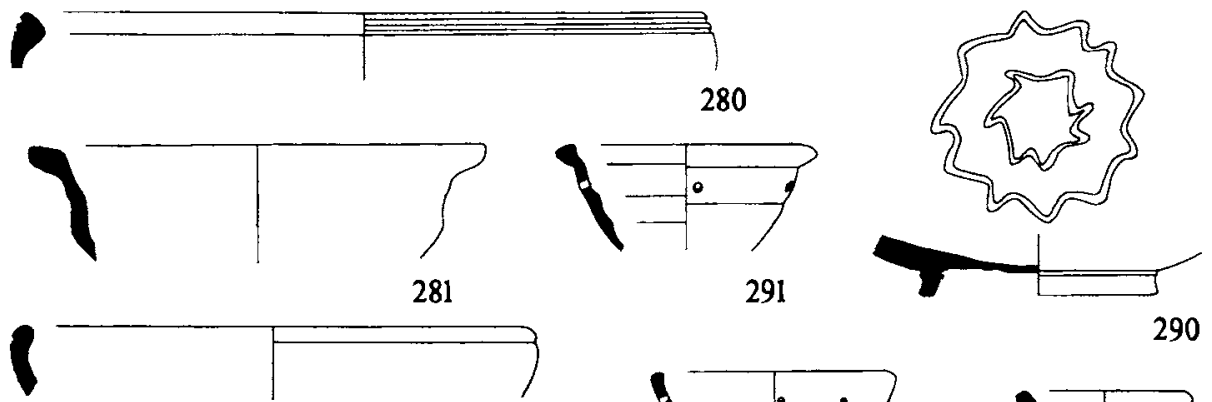

282

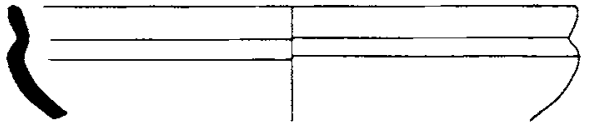

283
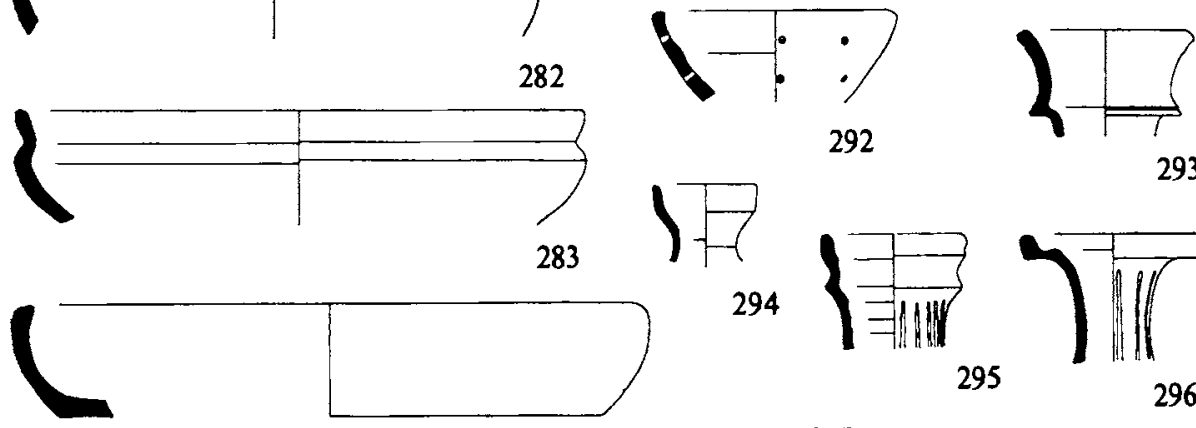

293

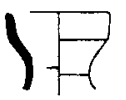

294
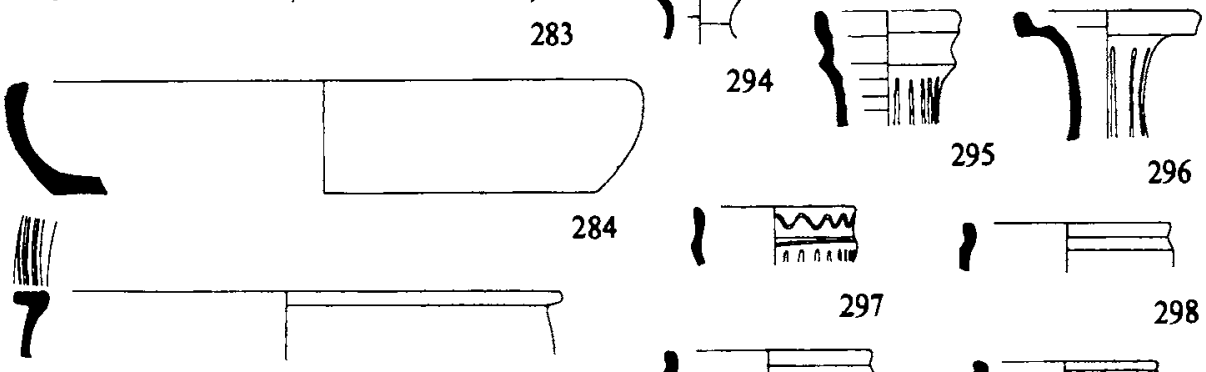

284

285

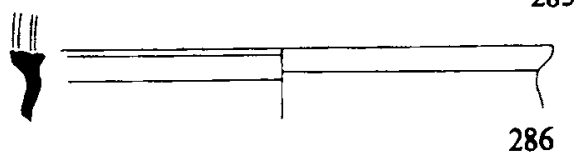

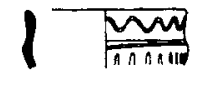

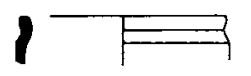

297
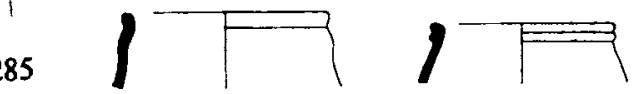

299
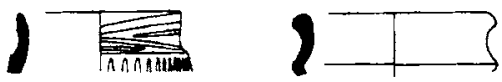

301

302
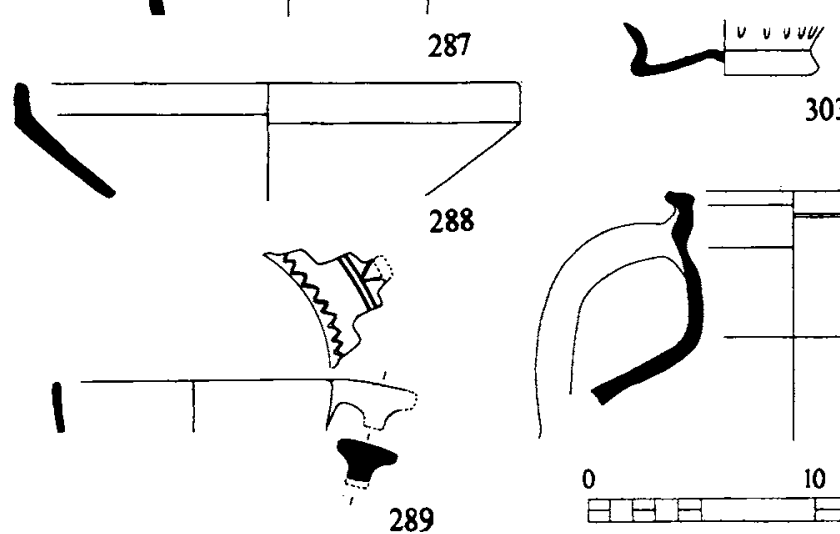

303
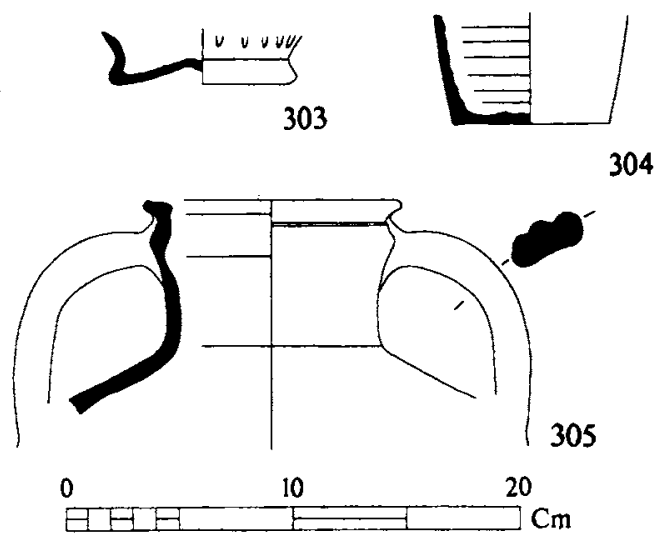

9.16 Grey micaceous coarse wares: ware 14 
289. Z21 (4804). Bowl with an ornate ledge handle with incised decoration, dia. $12 \mathrm{~cm}$. The context is post-medieval.

290. Z172 (4896). Base of a bowl with incised decoration on the inside, dia. $10 \mathrm{~cm}$. The context is post-medieval.

291. F672 (4915). Part of a perforated bowl, dia. $10 \mathrm{~cm}$. The context is dated 350-450. 3 examples were found, all from contexts dated to 350-450.

292. F374 (5018). Part of a perforated bowl, dia. $13 \mathrm{~cm}$. The context is dated to 450.3 examples were found, all from contexts dated to 450 .

293. G130 (2051). Rim of a jug, dia. $7 \mathrm{~cm}$. The context is post-medieval.

294. C792 (467). Rim of a jug, dia. $4.5 \mathrm{~cm}$. The context is dated $450-600$.

295. E9 (445). Rim of a jug with vertical burnished lines on neck, dia. $6 \mathrm{~cm}$. The context is dated $450-600$.

296. G41 (636). Rim of a jug with pattern-burnishing, dia. $7.5 \mathrm{~cm}$. The context is dated 450-600.

297. F303 (1121). Rim of a jar/jug with pattern-burnishing on neck, dia. $7 \mathrm{~cm}$. The context is dated to 450 .

298. G107 (5051). Rim of a jar/jug, dia. $9 \mathrm{~cm}$. The context is dated to 450 .

299. C802. Unstratified. Rim of a jar, dia. $9 \mathrm{~cm}$.

300. F389 (5018). Rim of a jar, dia. $8 \mathrm{~cm}$. The context is dated to 450 .

301. G157 (5024). Rim of a jar/jug with pattern-burnishing on the neck. dia. $7 \mathrm{~cm}$. The context is dated $150-250$.

302. F450 (4096). Rim of a jar/jug, dia. $8 \mathrm{~cm}$. The context is dated $400-500$, though there is later material.

303. Z15 (96). Base of a jar/jug with pattern-burnishing on exterior, dia. $7.5 \mathrm{~cm}$. Undated context.

304. Z27 (31). Base of a jar/jug which has been extensively burnt, dia. $7 \mathrm{~cm}$. The context is post-medieval.

305. F326 ( 5303 ). Rim of a jar/amphora, dia. $11 \mathrm{~cm}$. Undated context. 4 examples were found, 1 from a context dated to 450 and 2 from contexts dated to $450-600$. 
Grey micaceous coarse wares: ware 14 (Fig. 9.17)

306. G161 (133). Rim of a jar/amphora, dia. $11 \mathrm{~cm}$. The context is dated $300-450$.

307. C736 (158). Rim of a jar/amphora, dia. $11 \mathrm{~cm}$. The context is dated $300-450$. 4 examples were found: 2 from contexts dated to $300-450$, and 2 from contexts dated 400-500.

308. F592 (4033). Rim of a jar/amphora, dia. $11 \mathrm{~cm}$. The context is dated to 450 .

309. F382 (5018). Rim of a jar/amphora, dia. $10 \mathrm{~cm}$. The context is dated to 450 . One other example was found in the same context.

310. G106 (5281). Rim of a jar/amphora with traces of pattern-burnishing on exterior. dia. $12 \mathrm{~cm}$. The context is dated to 450 .

311. Z181 (4207). Rim of a large jug/amphora with knob handle, dia. $12 \mathrm{~cm}$. The context is undated.

312. C131 (452). Rim of a jar/amphora, dia. $11-16 \mathrm{~cm}$. The context is postmedieval. 6 other examples were found: 2 from a context dated to 300-450, 2 from contexts dated to $400-450,1$ from a context dated to 450 , and 1 from a context dated to $450-600$.

313. F121 (511). Rim of a jar/amphora, dia. $10 \mathrm{~cm}$. The context is dated $450-600$.

314. F340 (1192). Rim of a jar/amphora, dia. $12 \mathrm{~cm}$. The context is dated $400-450.2$ other examples were found from a context dated to $350-450$.

315. F331 (1128). Rim of a jar/amphora, dia. $9 \mathrm{~cm}$. The context is dated to 450.3 examples were found, 2 from contexts dated to 450 , and 1 from a context dated to $400-450$.

316. C848 (3064). Rim of an amphora, dia. $9 \mathrm{~cm}$. The context is post-medieval. One other example came from the same context.

317. G151 (101). Rim of a jar/amphora, dia. $11 \mathrm{~cm}$. The context is dated $450-600$.

318. Z179 (3139). Body sherd from the shoulder of a jar. Pattern-burnished decoration. The context is post-medieval.

319. F373 (5018). Rim of a jar, dia. 12-16cm. The context is dated to 450.19 examples were found of which the earliest one came from a context dated to $175-250$, and a further 1 from a context dated to 250-350. However 8 came from contexts dated to $400-450$ and 4 from contexts dated to $450-600$. (The remaining dated examples were from post-medieval contexts.) 


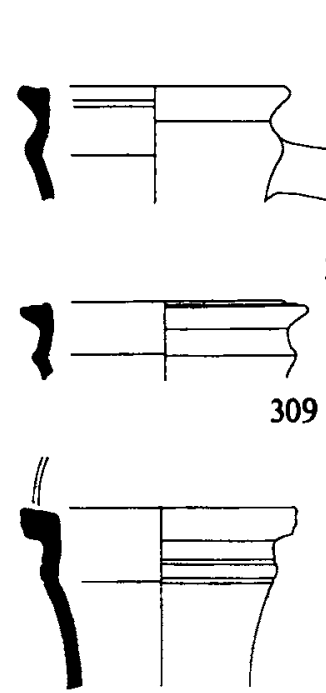

)
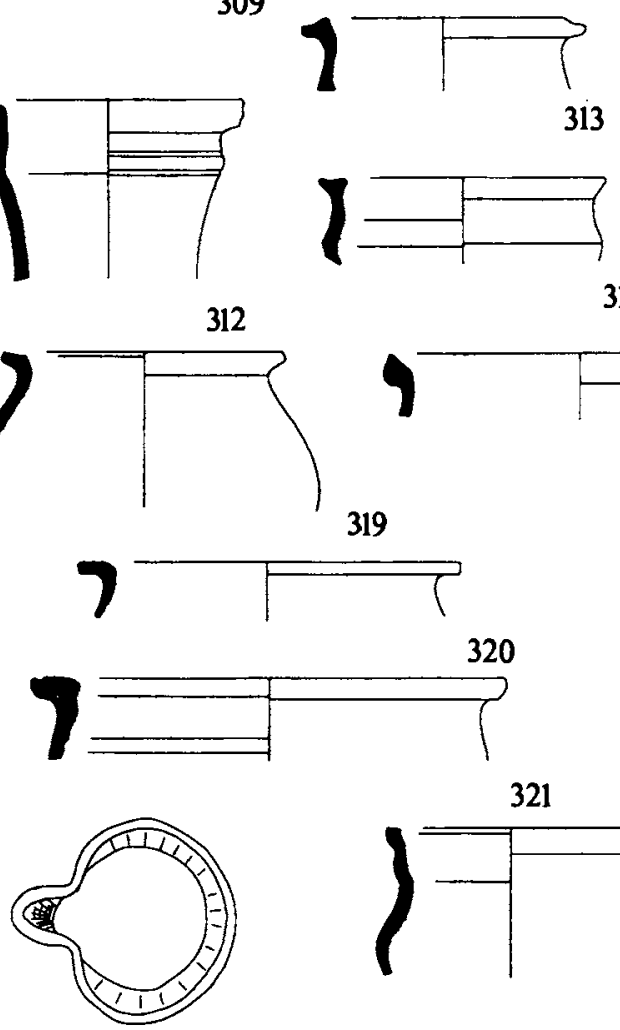

314
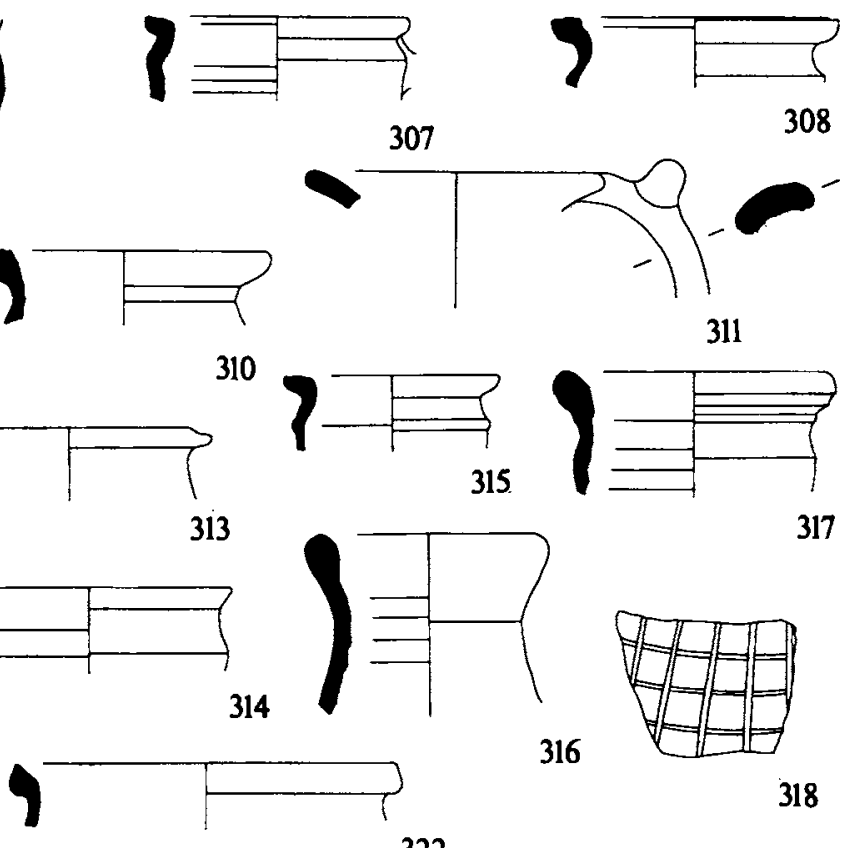

315.
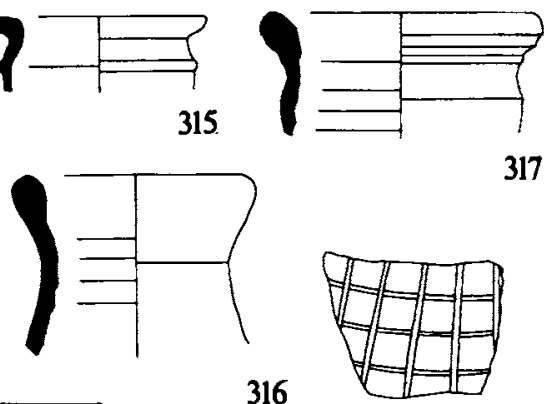

318

323

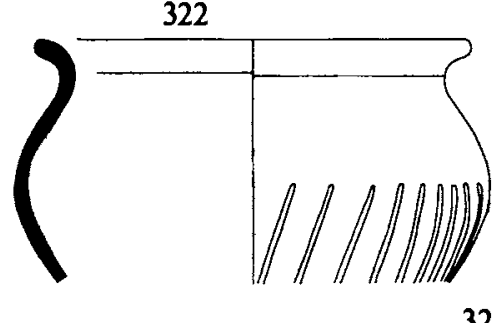

321
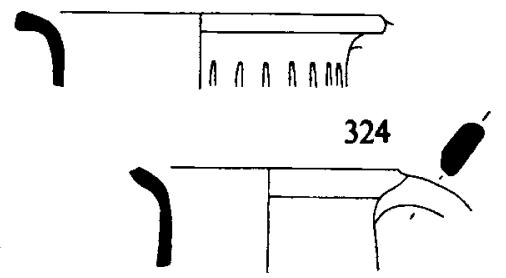

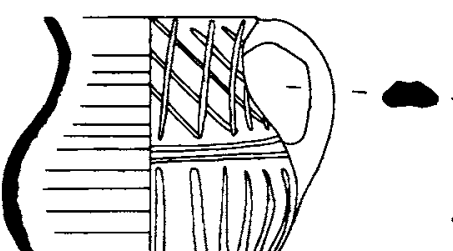

326

327

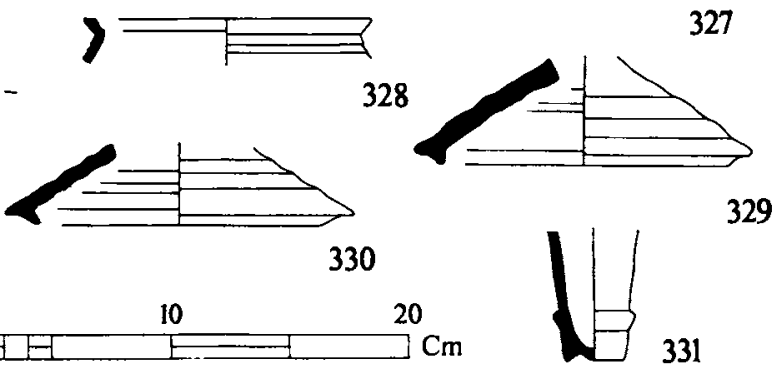

9.17 Grey micaceous coarse wares: ware 14 
320. F373 variant (96). Rim of a jar, dia. $16 \mathrm{~cm}$. Undated context. See 319 for dating.

321. G135 (3011). Rim of a jar, dia. $20 \mathrm{~cm}$. The context is post-medieval. One other example was found in a context dated to $400-500$.

322. F593 (4033). Rim of a jar, dia. $16 \mathrm{~cm}$. The context is dated to 450 .

323. Gl66 (4479). Rim of a jar with pattern-burnishing on the body, dia. $18 \mathrm{~cm}$. The context is post-medieval.

324. F322 (11 29). Rim of a jar with pattern-burnishing on the body (handle stub visible), dia. $13 \mathrm{~cm}$. The context is dated to 450 . One other example came from a context dated to $150-175$.

325. C761 (5039) SF. 14366. Brown lipped jug with pattern-burnishing on the exterior, dia. $9 \mathrm{~cm}$. The context is dated $450-600$. One other example came from a context dated to $450-600$, and one from a post-medieval deposit.

326. C860 (3274). Rim of a jar, dia. $10.5 \mathrm{~cm}$. The context is dated $450-600$.

327. F439 (4099). Rim of a jar, dia. $11 \mathrm{~cm}$. The context is dated $400-500$.

328. C776 (1087). Rim of a jar, dia. $12 \mathrm{~cm}$. The context is dated 450-600. One other example came from a post-medieval context.

329. C563 (1190). Lid, dia. $1218 \mathrm{~cm}$. The context is dated 400-450. Another example came from the same context, and one from a context dated to $450-600$.

330. C561 (1190). Lid, dia. 11-20cm. The context is dated 400-450. 8 examples were found: 3 from contexts dated to $400-450,4$ from contexts dated to 450 , and 1 from a post-medieval deposit.

331. Z178 (4502). Base of a jug/amphora, dia. $2.5 \mathrm{~cm}$. The context is dated 450-600.

\section{Fine wares}

Red-slipped fine wares: ware 8 (Fig. 9.18)

332. C567 (4912). Rim of a bowl, dia. 24-38cm. The context is dated $450-600.11$ examples were found: 1 from a context dated to $250-450,1$ from a context dated to $400-450,4$ from contexts dated to $450-600$, and 5 from postmedieval deposits. 
333. G25 (4405). Rim of a bowl with wavy incised band and denticulations on top of the rim, dia. $32 \mathrm{~cm}$. The context is post-medieval. 2 other examples were found: 1 from a context dated to $250-450$, and 1 from a context dated $350-450$.

334. F667 (701). Rim of a bowl, dia. $24 \mathrm{~cm}$. The context is dated $350-450$. One other example was found also from a context dated to $350-450$.

335. C369 (3359). Rim of a bowl, dia. 14-20cm. The context is dated $400-450.10$ examples were found, of which the earliest came from a context dated to $100-130$, with others from a context dated to $150-175$, and from a context dated to $175-250$.

336. C369 (3001). Rim of a bowl with notch decoration on the exterior of the rim, and incised decoration on the top, dia. $26 \mathrm{~cm}$. The context is postmedieval. See 335 for dating.

337. C214 (336). Rim of a bowl, dia. $26 \mathrm{~cm}$. The context is dated $175-250$. One other example was found in a post-medieval deposit.

338. Z204 (3251). Rim of a bowl with notch decoration on the exterior of the rim and faint incisions on the top, dia. $26 \mathrm{~cm}$. The context is post-medieval.

339. C142 (453). Rim of a bowl, dia. $26-34 \mathrm{~cm}$. The context is post-medieval. 2 other examples were found, both from contexts that dated to $350-450$.

340. C634 (4104). Rim of a bowl, dia. $28 \mathrm{~cm}$. The context is dated $300-450.6$ other examples were found in a context also dating to $300-450$.

341. C58 (458). Rim of a bowl with notch decoration on the exterior of the rim, dia. $18-21 \mathrm{~cm}$. The context is post-medieval. 3 examples were found, all in post-medieval deposits.

342. C567 (5005). Rim of a bowl, dia. $19 \mathrm{~cm}$. The context is post-medieval. See 332 for dating.

343. G103 (2176). Rim of a bowl, dia. $34 \mathrm{~cm}$. The context is dated to 450 . One other example was found in a post-medieval deposit.

344. G125 (5051). Rim of a bowl with notch decoration on the exterior of the rim, dia. $30 \mathrm{~cm}$. The context is dated to 450 .

345. C671 (665). Rim of a bowl, dia. $34-38 \mathrm{~cm}$ (though one example is $22 \mathrm{~cm}$ ). The context is dated 250-350. 6 examples were found, of which the earliest came from a context dated to $250-350$, with 2 more coming from a context dated to $350-450$. 

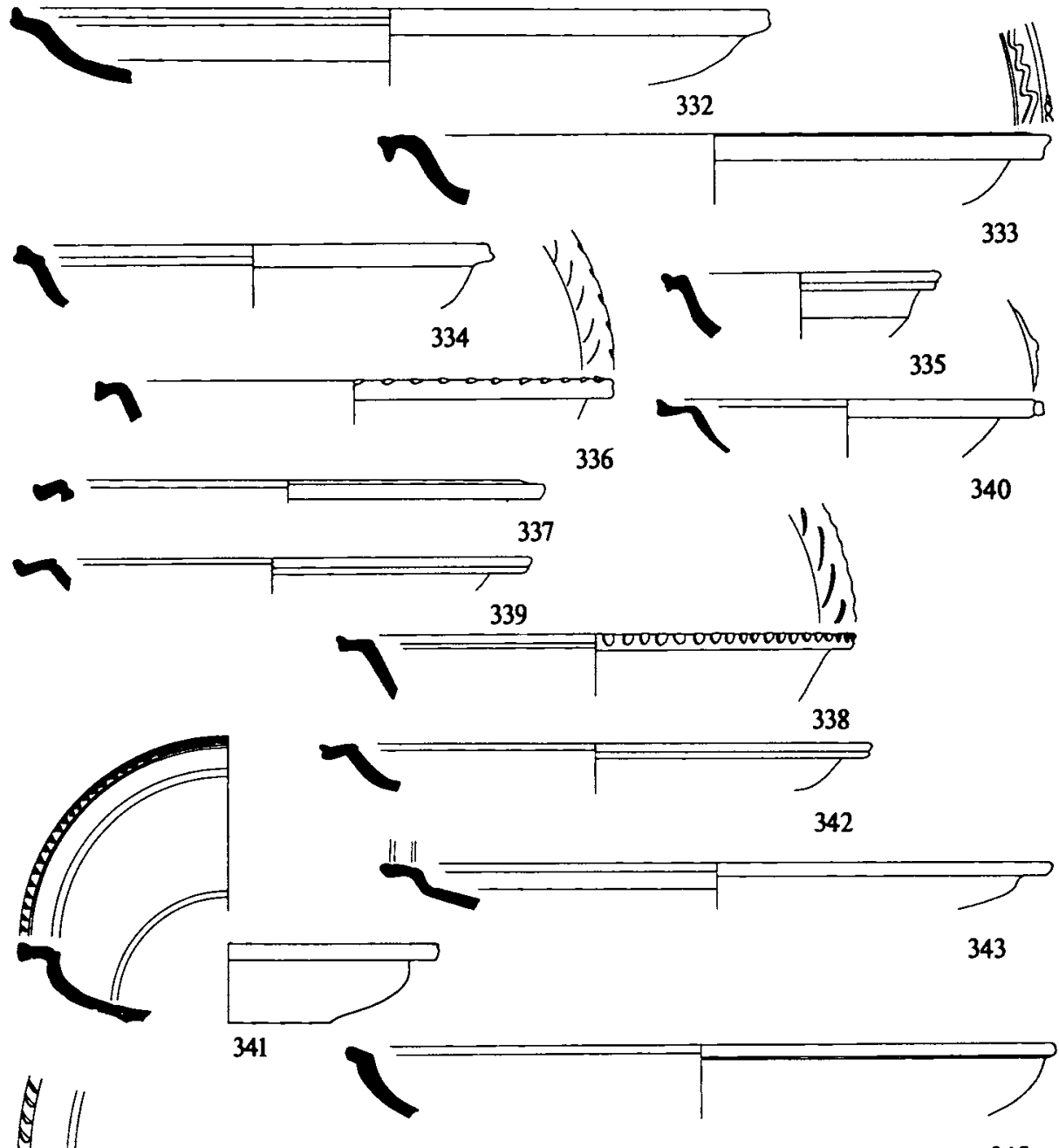

c
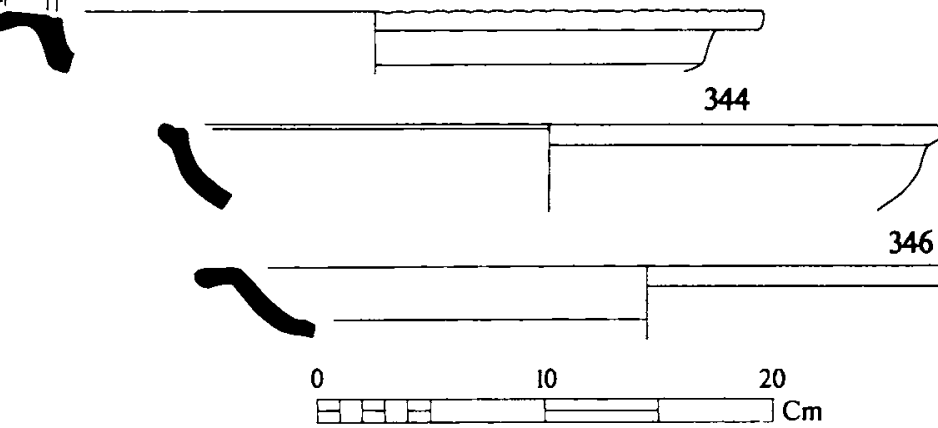

9.18 Red-slipped fine wares: ware 8 
346. C295 (3241). Rim of a bowl, dia. $28-36 \mathrm{~cm}$. The context is dated $400-450.47$ examples were found, of which the earliest one came from a context dated to $175-250$. One more came from a context dated to $250-350,6$ from contexts dated to $250-450$, and 15 from contexts dated to $350-450$.

347. F582 (689). Rim of a bowl with stamped decoration on top of rim, dia. $40 \mathrm{~cm}$. The context is dated $350-450$.

Red-slipped fine wares: ware 8 (Fig. 9.19)

348. C838 (3249). Rim of a bowl, dia. $27-38 \mathrm{~cm}$. The context is post-medieval. 33 examples were found ( 13 of them in post-medieval deposits), of which the earliest 3 came from contexts dated to 175-250, with a further 4 from contexts dated to $250-350$.

349. C290 (471). Rim of a bowl, dia. $34 \mathrm{~cm}$. The context is post-medieval.

350. C305 (4507). Rim of a bowl, dia. $27-30 \mathrm{~cm}$. The context is dated $250-450$. One other example was found in a context dated to $450-600$.

351. C819 (4033). Rim of a bowl, dia. $22-36 \mathrm{~cm}$. The context is dated to 450.40 examples were found ( 17 of them in post-medieval deposits), of which the earliest two came from contexts dated to $250-350$, with a further 14 in contexts dated to $350-450$.

352. C285 (516). Rim of a bowl, dia. $34 \mathrm{~cm}$. The context is dated $450-600.3$ examples were found, 1 from a context dated to 350-450, and 2 from contexts dated to $450-600$.

353. C562 (688). Rim of a bowl, dia. $26-30 \mathrm{~cm}$. The context is dated $350-450.10$ examples were found, of which the earliest came from a context dated to $150-175$, with another from a context dated to 250-350. However 3 came from contexts dated to $350-450$, and 2 from contexts dated to 450 .

354. C742 (4506). Rim of a bowl, dia. $30-32 \mathrm{~cm}$. The context is dated $250-450.2$ other examples were found, 1 from a context dated to $150-250$, and 1 from a context dated to $400-450$.

355. F495 (2215). Rim of a bowl, dia. $28-34 \mathrm{~cm}$. The context is dated $450-600.3$ other examples were found, 1 from a context dated to $150-250,1$ from a context dated to $175-250$, and 1 from a context dated to $400-500$.

356. F680 (4844). Rim of a bowl, dia. $32-36 \mathrm{~cm}$. The context is post-medieval. One other example was found in a context dated to $150-250$. 


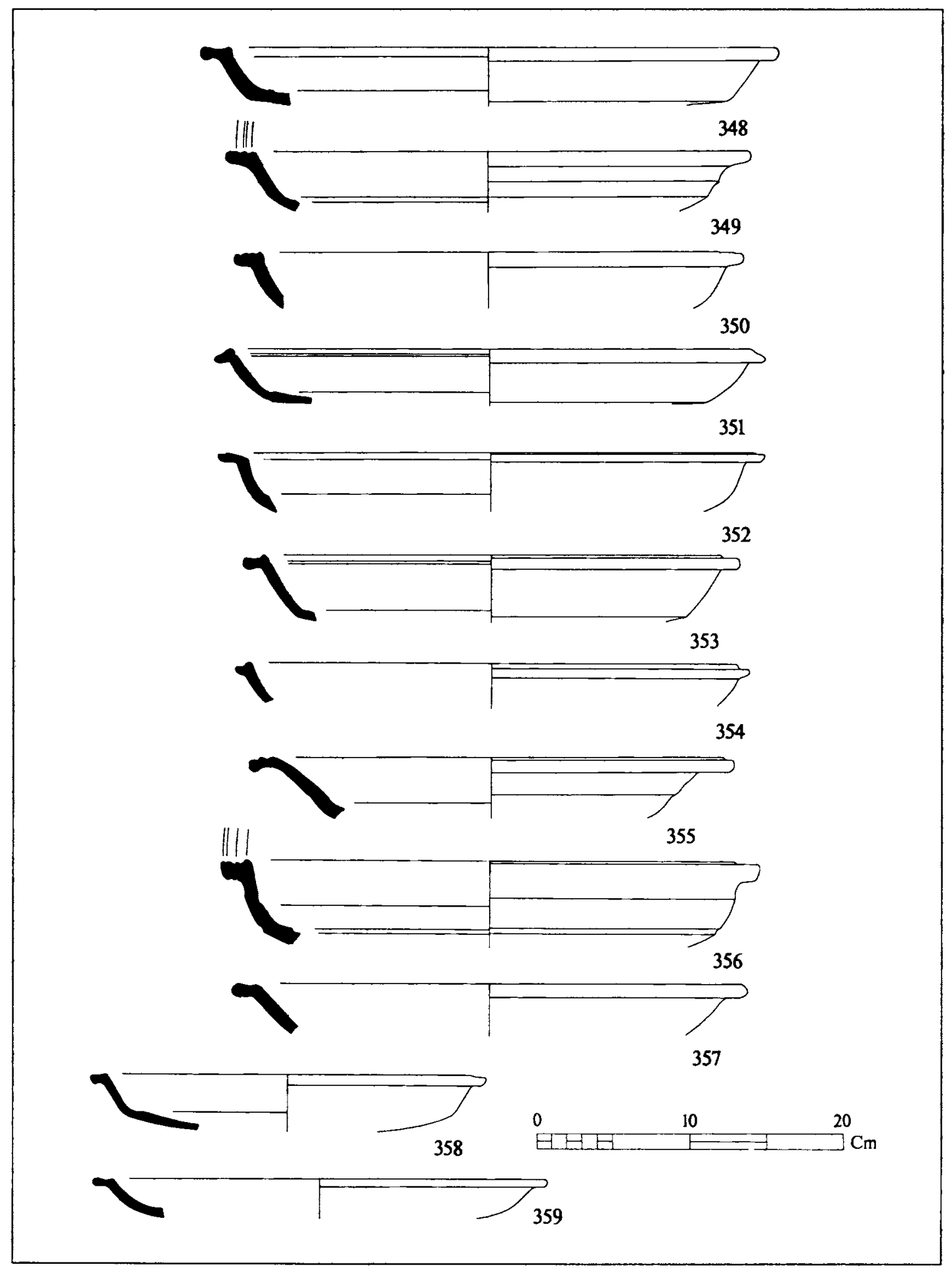

9.19 Red-slipped fine wares: ware 8 
357. F519 (4814). Rim of a bowl, dia. $27-33 \mathrm{~cm}$. The context is post-medieval. 4 other examples were found: 2 from contexts dating to $250-450,1$ from a context dated to $350-450$, and 1 from a context dated to $450-600$.

358. C322 (2208). Rim of a bowl, dia. $18-32 \mathrm{~cm}$. The context is dated $450-600$. 145 examples were found, the earliest two of which were from a context dated to 100-130, 2 more came from contexts dated to 150-175, 8 from contexts dated to $175-250$, and 24 from contexts dated $250-350$.

359. F193 (676). Rim of a bowl, dia. 20-33cm. The context is dated 175-250. 12 examples were found, of which the earliest two came from a context dated to $175-250$, with 3 coming from contexts dated to $350-450$, and 2 more from contexts dated to 450 .

Red-slipped fine wares: ware 8 (Fig. 9.20)

360. G127 (2137). Rim of a bowl, dia $24 \mathrm{~cm}$. The context is dated $450-600$.

361. C322 (662). Rim of a bowl, dia. $18-32 \mathrm{~cm}$. The context is dated $250-350$. See 358 for dating.

362. C322 (489). Rim of a bowl, dia. $18-32 \mathrm{~cm}$. The context is post-medieval. See 358 for dating.

363. C203 (339). Rim of a bowl, dia. $22-26 \mathrm{~cm}$. The context is dated $175-250.22$ examples were found, of which the earliest 3 came from contexts dated to 175-250, with 6 from contexts dated to 350-450, 3 from contexts dated to 450 , and 7 from contexts dated to $450-600$.

364. C245 (537). Rim of a bowl, dia. $24-30 \mathrm{~cm}$. The context is dated $350-450.7$ examples were found: 1 from a context dated $250-350,5$ from contexts dated $350-450$, and 1 from a post-medieval deposit.

365. Z5 (4804). Rim of a bowl, dia. $29 \mathrm{~cm}$. The context is post-medieval.

366. G46 (636). Rim of a bowl, dia. 8-16cm. The context is dated $450-600.5$ examples were found, of which the earliest one came from a context dated to $250-350$, with another from a context dated $350-450$, and one more from a context dated to 450 .

367. C499 (1018). Rim of a bowl, dia. $20-25 \mathrm{~cm}$. The context is post-medieval. 14 examples were found, of which the earliest two came from contexts dated to 250-350, 2 came from contexts dated 250-450, 2 from contexts dated to $350-450$, and a further 2 from contexts dated to $400-450$. 
368. C321 (581). Rim of a bowl, dia. 18-19cm. The context is dated $350-450.9$ examples were found, of which the earliest one came from a context dated to $150-175$, and a further 4 from contexts dated to $175-450$.

369. C753 (550). Rim of a bowl, dia. $20-26 \mathrm{~cm}$. The context is dated $450-600.6$ examples were found, 1 from a context dated to 250-350, 2 from contexts dated to $350-450,2$ from contexts dated to $400-450$, and 1 from a context dated to $450-600$.

370. C15 (4949). Rim of a bowl, dia. $28-36 \mathrm{~cm}$ (though one example is $48 \mathrm{~cm}$ ). The context is dated $250-350.68$ examples were found ( 26 from postmedieval contexts), of which the earliest one came from a context dated to $100-130,3$ came from a context dated to $175-250,5$ from contexts dated to $250-350$, and a further 9 from contexts that dated to $350-450$.

371. F615 (635). Rim of a bowl, dia. $16-25 \mathrm{~cm}$. The context is dated $350-450.8$ examples were found, of which the earliest 3 came from contexts dated to $350-450$, with 2 more coming from contexts dated to $400-450$.

372. C16 (4902). Rim of a bowl, dia. $18-30 \mathrm{~cm}$ (though occasionally larger). The context is dated 450-600. 153 examples were found ( 53 of them in postmedieval contexts), of which the earliest one came from a context dated to $130-150$, with 5 coming from a context dated to $175-250,6$ from contexts dated to $250-350,9$ from contexts dated $275-400$, and 29 from contexts dated to $350-450$.

373. F573 (4032). Rim of a bowl, dia. $28-32 \mathrm{~cm}$. The context is dated to 450.14 examples were found, of which the earliest one came from a context dated to $150-250,2$ more came from contexts dated to $250-450$, and 5 from contexts dated to 450 .

374. C754 (704). Rim of a bowl, dia. $22-26 \mathrm{~cm}$. The context is dated $350-450.3$ other examples were found, 2 came from contexts dated to $250-450$ and another from a context dated to 450-600.

375. C576 (5014). Rim of a bowl, dia. $27-32 \mathrm{~cm}$. The context is dated to 450 . There was one other example which came from a context dated to $350-450$.

376. F666 (705). Rim of a bowl, dia. $30 \mathrm{~cm}$. The context is dated $350-450$.

377. G90 (4489). Rim of a bowl, dia. $30 \mathrm{~cm}$. The context is post-medieval.

378. Z35 (4804). Rim of a bowl, dia. $26 \mathrm{~cm}$. The context is post-medieval. 

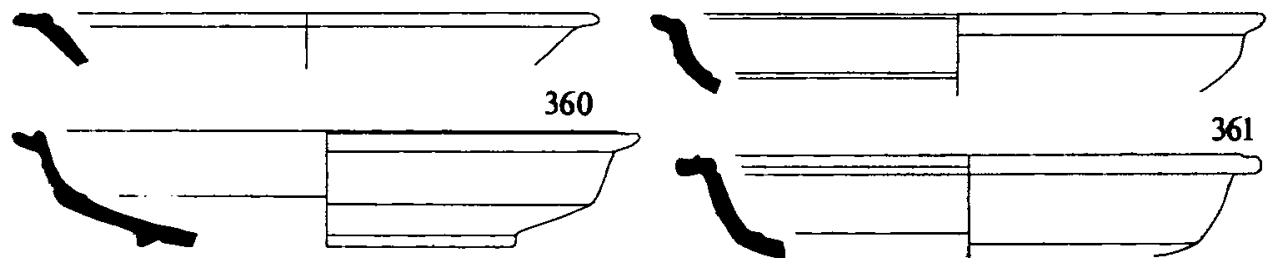

362

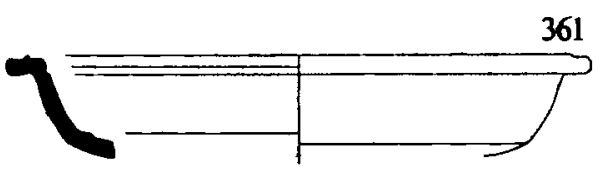

363
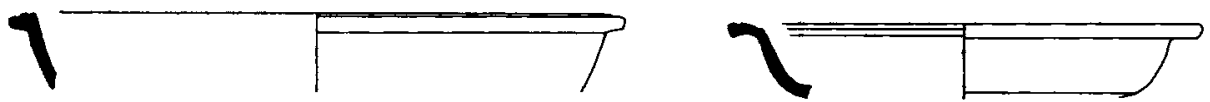

364
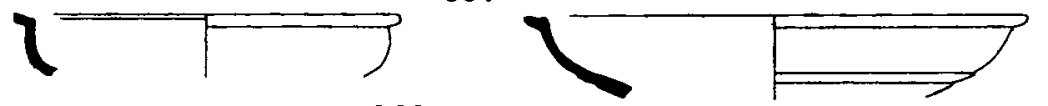

366

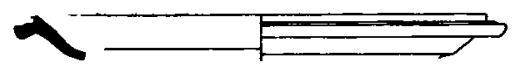

368

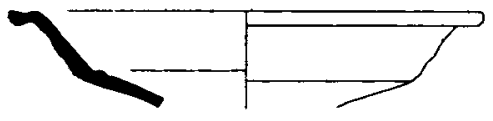

370

367
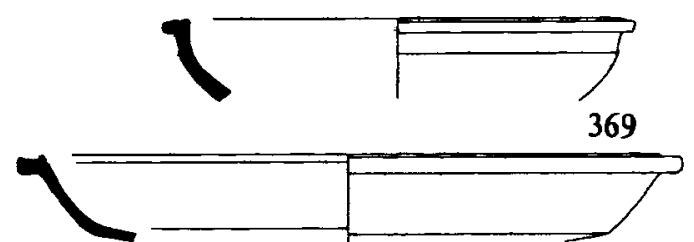

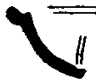

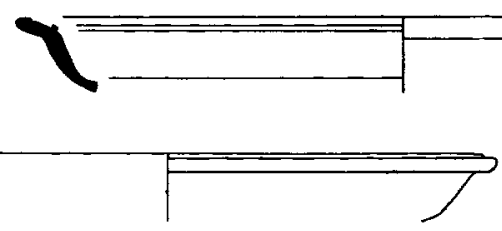

374

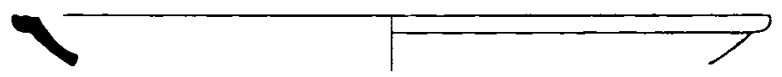

375
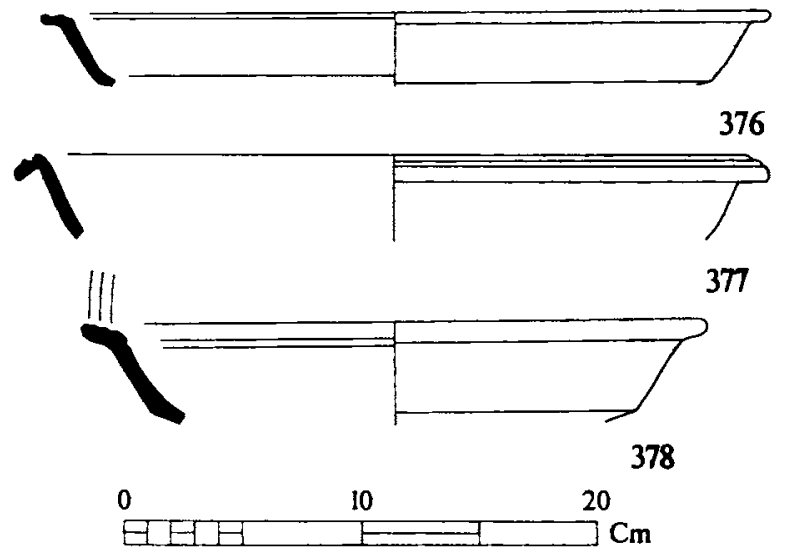

9.20 Red-slipped fine wares: ware 8 
Red-slipped fine wares: ware 8 (Fig. 9.21)

379. G38 (682). Rim of a bowl, dia. $28 \mathrm{~cm}$. The context is dated $350-450.4$ examples were found, 2 from contexts dated to $350-450,1$ from a context dated to 450 , and 1 from a context dated to $450-600$.

380. C301 (462). Rim of a bowl, dia. $26 \mathrm{~cm}$. The context is dated $450-600$, but also contains some post-medieval material. 5 examples were found: 4 from contexts dated to $450-600$, and 1 from a post-medieval context.

381. C509 (665). Rim of a bowl, dia. $24-28 \mathrm{~cm}$. The context is dated $250-350.7$ examples were found, of which the earliest 4 came from contexts dated to $175-250$, and a further example came from a context dated to $250-350$.

382. C249 (540). Rim of a bowl, dia. $22-36 \mathrm{~cm}$. The context is dated $350-450.11$ examples were found, 1 from a context dated to $250-350,6$ from contexts dated to $350-450,2$ from contexts dated to 450 , and a further 2 from postmedieval deposits.

383. C241 (342). Rim of a bowl, dia. $23 \mathrm{~cm}$. The context is dated $175-250$. One other example was found from a context dated to $450-600$.

384. C56 (402). Rim of a bowl, dia. 16-24cm. The context is post-medieval. One other example was found, which was also from a post-medieval deposit.

385. C15. Unstratified. Rim of a bowl with horizontal ledge handle, dia. $21 \mathrm{~cm}$. See 370 for dating.

386. C823 (4033). Rim of a bowl, dia. 16-20 cm. The context is dated to 450 . There were 4 other examples, 1 from a context dated to 250-450, 1 from a context dated to $350-450,1$ from a context dated to $400-450$, and 1 from a post-medieval context.

387. C20 (1). Rim of a bowl with notch decoration on exterior of the rim, dia. $16 \mathrm{~cm}$. The context is post-medieval.

388. G22 (4911). Rim of a bowl, dia. $20 \mathrm{~cm}$. The context is post-medieval. There were 2 other examples from post-medieval deposits, 1 from a context dated to $250-450,2$ from contexts dated $350-450$, and another from a context dated to 450 .

389. C322. Unstratified. Rim of a bowl, dia. $18 \mathrm{~cm}$. See 358 for dating.

390. C505 (665). Rim of a bowl, dia. $22-24 \mathrm{~cm}$. The context is dated $250-350$. One other example was found in a context dated to $450-600$. 

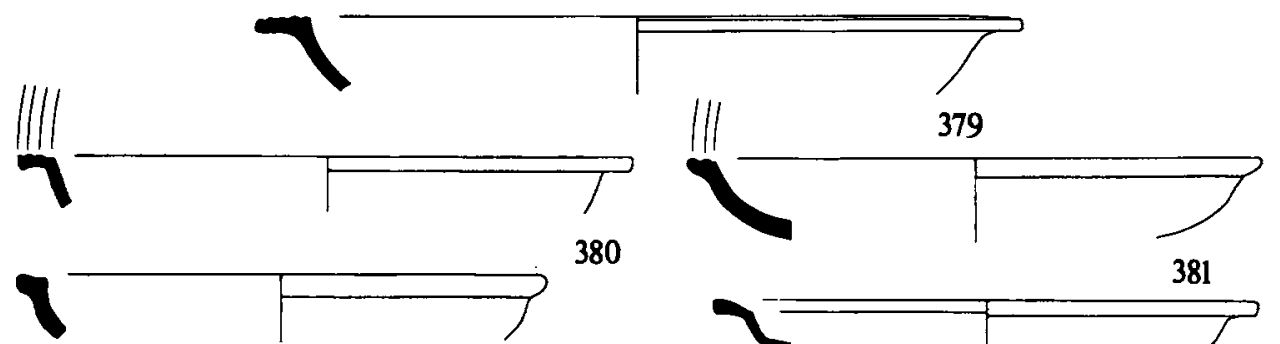

380

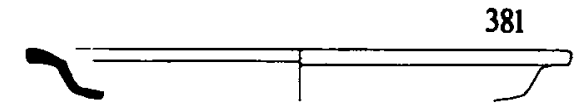

382
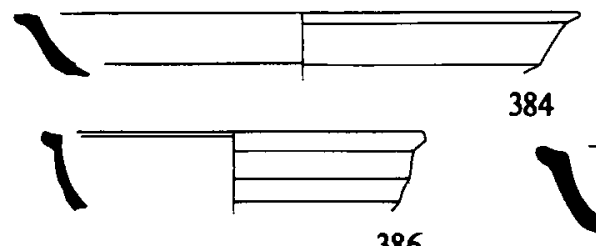

384

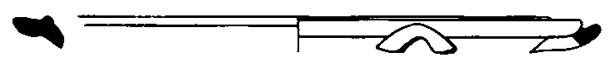

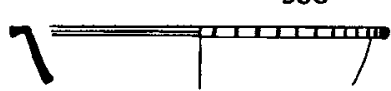

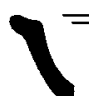

385

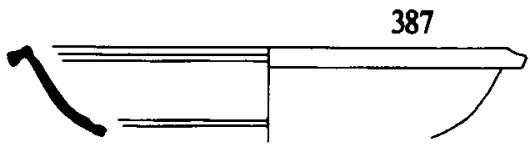

388
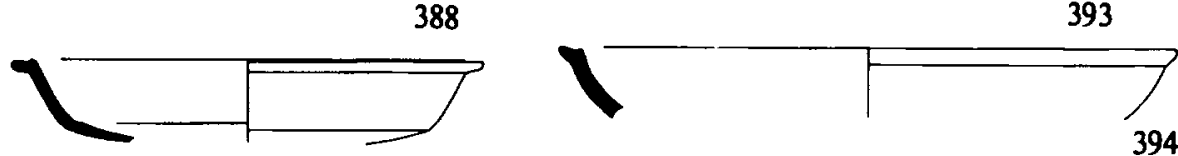

\section{2}

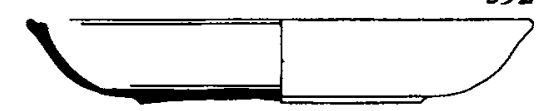

391
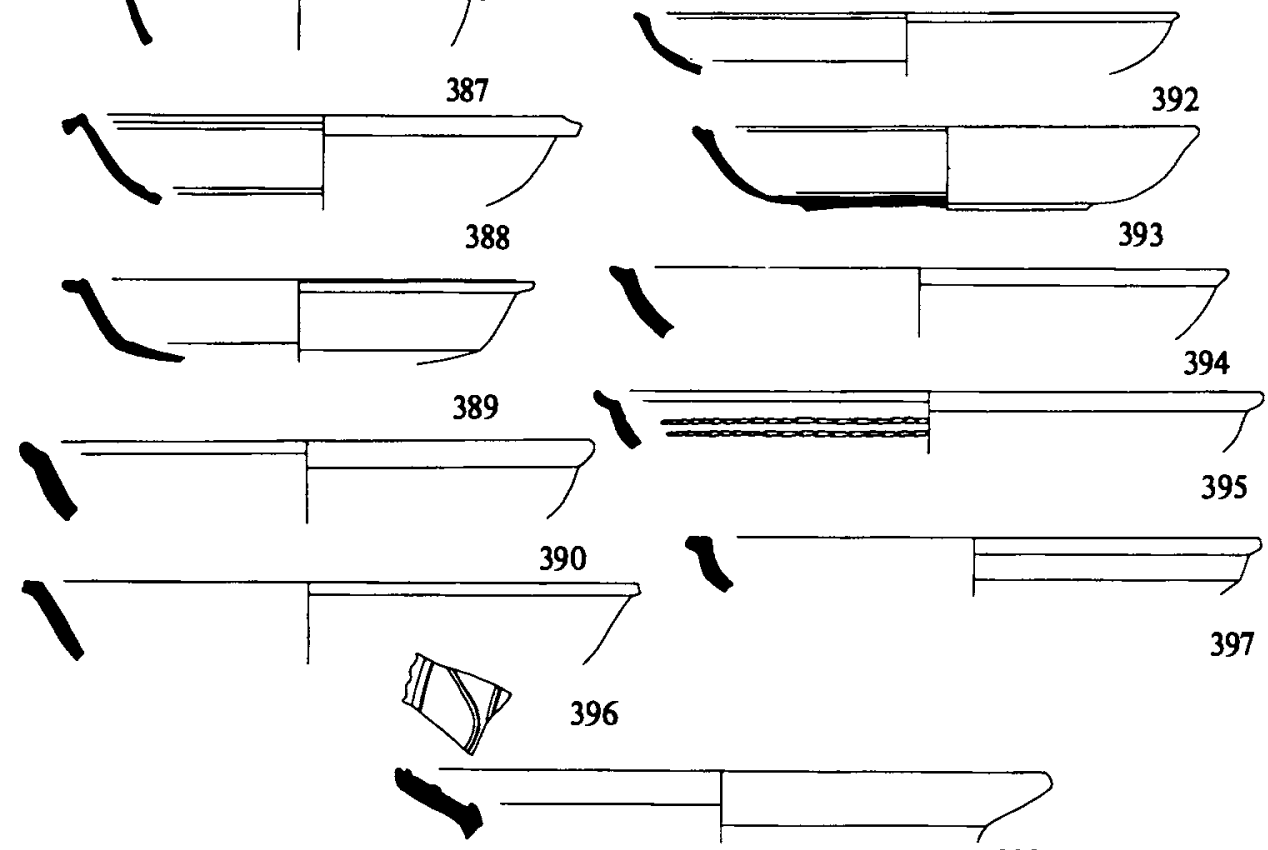

398

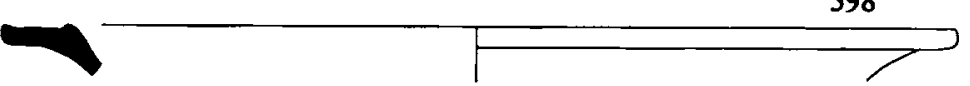

399

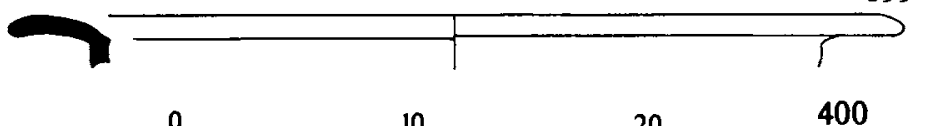

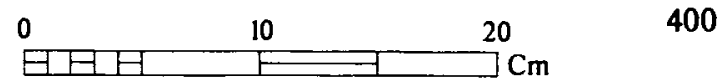

9.21 Red-slipped fine wares: ware 8 
391. C295 (3241). Rim of a bowl with rouletted decoration on the exterior, dia. $28-36 \mathrm{~cm}$. The context is dated $400-450$. For dating see 346.

392. C49 (681). Rim of a bowl, dia. $22 \mathrm{~cm}$. The context is dated 175-250. One other example was found in a post-medieval deposit.

393. C72 (221). Bowl, dia. 14-24cm. The context is dated 130-150. 17 examples were found, of which this was the earliest one, 1 came from a context dated to $175-250,1$ from a context dated $275-400,2$ from contexts dated to $350-450$, and 8 from contexts dated 450-600.

394. C144 (453). Rim of a bowl, dia. $23-26 \mathrm{~cm}$. The context is post-medieval. 2 other examples were found, both from contexts dated to $350-450$.

395. C668 (667). Rim of a bowl with heavy rouletting on the interior, dia. $28 \mathrm{~cm}$. The context is dated 175-250.

396. F273 (664). Rim of a bowl, dia. $17-26 \mathrm{~cm}$. The context is dated 250-350. One other example was found, also from a context dated to 250-350.

397. C127 (405). Rim of a bowl, dia. 16-24cm. The context is post-medieval. 6 examples were found, 1 from a context dated to 175-250, 1 from a context dated to $250-450,1$ from a context dated to $350-450,1$ from a context dated to $450-600$, and 2 from post-medieval deposits.

398. C45 (203). Rim of a bowl with applied decoration on interior of flange and piecrust decoration on the exterior of rim, dia. $28 \mathrm{~cm}$. The context is postmedieval.

399. C212 (258). Rim of a bowl, dia. $40 \mathrm{~cm}$. The context is dated 100-130. 2 other examples were found, 1 from a context dated to 250-350, and 1 from a context dated to 450 .

400. C329 (2277). Rim of a bowl, dia. $32-37 \mathrm{~cm}$. The context is dated 100-130. There was one other example found in a context dated to 175-250.

Red-slipped fine wares: ware 8 (Fig. 9.22)

401. C72 (675). Rim of a bowl, dia. $15-24 \mathrm{~cm}$. The context is dated $175-250$. See 393 for dating.

402. C513 (667). Rim of a bowl, dia. $13-24 \mathrm{~cm}$. The context is dated $175-250.4$ examples were found, of which the earliest two came from contexts dated to 175-250, 1 came from a context dated to 250-350, and the other from a context dated to 450 . 
403. F670 (4920). Rim of a bowl, dia. $18-22 \mathrm{~cm}$. The context is dated $350-450.2$ other examples came from contexts that were also dated to $350-450$.

404. C795 (4405). Rim of a bowl with bands of rouletting on the interior, dia. $18-22 \mathrm{~cm}$. The context is post-medieval. One other example was found in a context dated to 450 .

405. G2 (4034). Bowl, dia. $17 \mathrm{~cm}$. The context is dated to 450 .

406. G74 (2022). Rim of a bowl, dia. $16 \mathrm{~cm}$. The context is dated $450-600$.

407. F656 (537). Rim of a bowl with notch decoration on the top of the rim, dia. $14 \mathrm{~cm}$. The context is dated $350-450$.

408. C730 (1031). Rim of a bowl, dia. $14 \mathrm{~cm}$. The context is dated $450-600$.

409. C596 (5018). Rim of a bowl with scalloped rim, dia. $17 \mathrm{~cm}$. The context is dated to 450 .

410. C251 (542). Rim of a bowl, dia. $15 \mathrm{~cm}$. The context is dated $450-600$.

411. C461 (672). Rim of a bowl with rouletted decoration on the top of the rim, dia. $18-28 \mathrm{~cm}$. The context is dated $175-250.7$ examples were found, 1 from a context dated to 100-130, 3 from contexts dated to 130-150, 2 from contexts dated to $175-250$, and 1 from a context dated $250-350$.

412. C239 (342). Rim of a bowl, dia. $26-28 \mathrm{~cm}$. The context is dated $175-250$. One other example was found, also in a context dated to $175-250$.

413. C92 (342). Bowl, dia. $19-30 \mathrm{~cm}$ (though one example is only $15 \mathrm{~cm}$ ). The context is dated 175-250. 7 examples were found, the earliest 3 of which were from contexts dated to $100-130$, with another from a context dated to $130-175$.

414. C706 (2175). Rim of a bowl, dia. 30-34cm. The context is dated 130-175. One other example was found in the same context.

415. F689 (2207). Rim of a bowl, dia. $30 \mathrm{~cm}$. The context is dated $450-600$.

416. C195 (2260). Bowl with rouletted decoration on the inside of the base, dia. $20-31 \mathrm{~cm}$. The context is dated 100-130. 18 examples were found, of which the earliest 12 came from contexts dated to 100-130.

417. G26 (4406). Rim of a bowl, dia. $22-26 \mathrm{~cm}$. The context is post-medieval. 8 examples were found, 2 from contexts dated to $350-450,2$ from contexts dated to 450,1 from a context dated $450-600$, and 3 were from postmedieval deposits. 


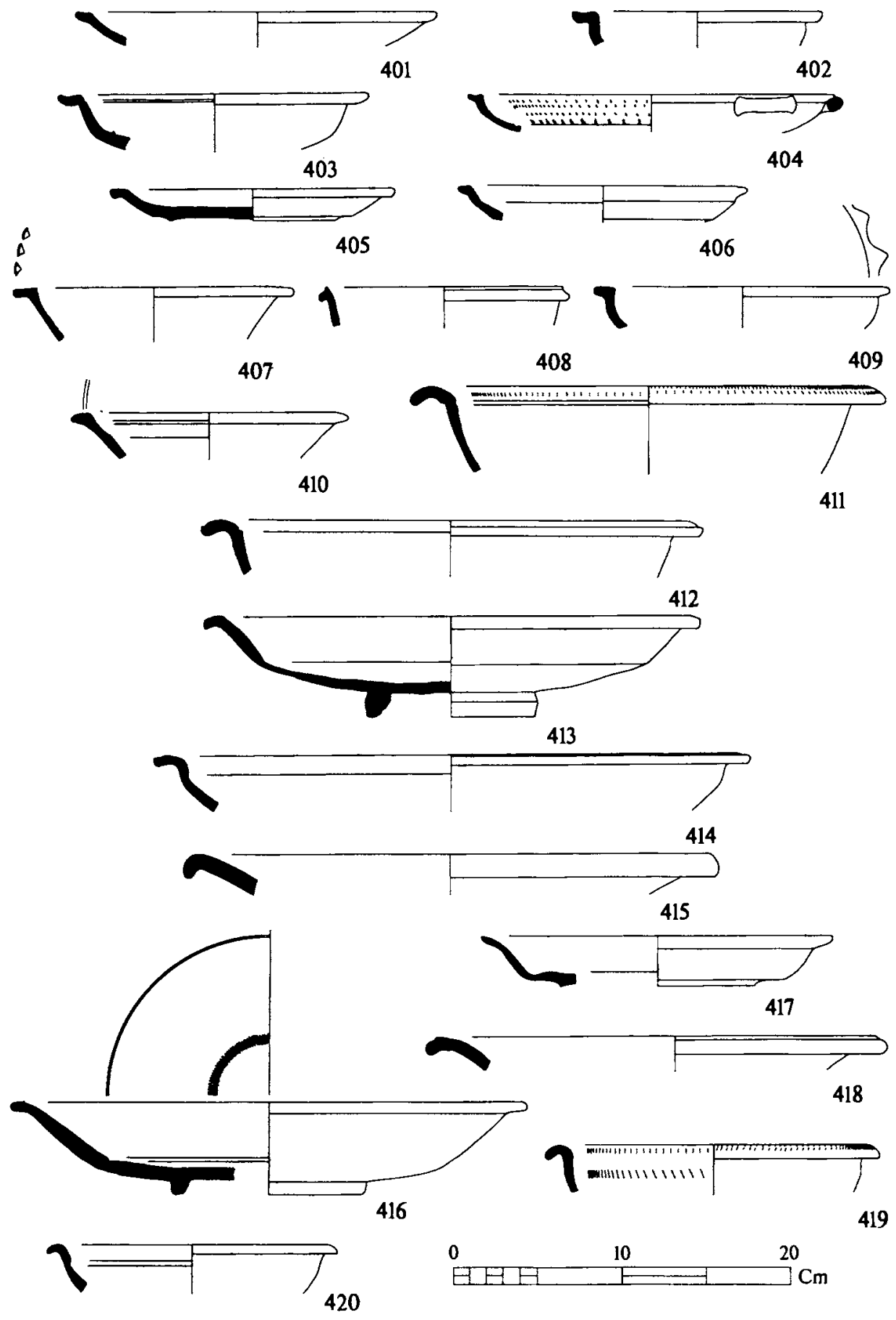

9.22 Red-slipped fine wares: ware 8 
418. C335 (2260). Rim of a bowl, dia. $26-28 \mathrm{~cm}$. The context is dated $100-130$. One other example came from a context dated to the same period.

419. C461 (699). Rim of a bowl with rouletted decoration on top of rim and on the interior, dia. $18-28 \mathrm{~cm}$. The context is dated $130-150$. See 411 for dating.

420. Z113 (618). Rim of a bowl, dia. $16 \mathrm{~cm}$. The context is dated $350-450$.

Red-slipped fine wares: ware 8 (Fig. 9.23)

421. G16 (2235). Rim of a bowl, dia. $10 \mathrm{~cm}$. The context is dated to 450 .

422. C454 (4962). Rim of a bowl with applied decoration on rim, dia. $10-12 \mathrm{~cm}$. The context is dated 250-350. One other example was found in a context dated to $130-150$.

423. C454 (699). Rim of a bowl, dia. 10-12cm. The context is dated 130-150. See 422 for dating.

424. C121 (4436). Rim of a bowl, dia. $20-30 \mathrm{~cm}$. The context is post-medieval. 7 examples were found, of which the earliest 4 were from contexts dated to $100-130$, and a further 1 from a context dated to $175-250$.

425. C584 (5018). Rim of a bowl, dia. $12 \mathrm{~cm}$. The context is dated to 450 . One other example was found in a context dated to $350-450$.

426. C529. Unstratified. Rim of a bowl, dia. $11 \mathrm{~cm}$.

427. C617 (5020). Rim of a bowl, dia. $18-27 \mathrm{~cm}$. The context is dated $250-350$.

428. C457 (699). Rim of a bowl, dia. $17-28 \mathrm{~cm}$ (usually $22-28 \mathrm{~cm}$ ). The context is dated 130-150. 44 examples were found, of which the earliest one came from a context dated to 100-130, with a further 21 examples coming from contexts dated to $130-150$.

429. C462 (699). Rim of a bowl, dia. $16-40 \mathrm{~cm}$ (usually $24-32 \mathrm{~cm}$ ). The context is dated 130-150. 111 examples were found, of which the earliest 7 came from contexts dated to 100-130, with a further 50 from contexts dated 130-150, and 25 from contexts dated 175-250.

430. C457 (2235). Rim of a bowl, dia. $22-28 \mathrm{~cm}$. The context is dated to 450 . See 428 for dating.

431. C459 (699). Rim of a bowl, dia. 25-30cm. The context is dated 130-150.6 examples were found, of which the earliest 5 came from contexts dated to $130-150$. 


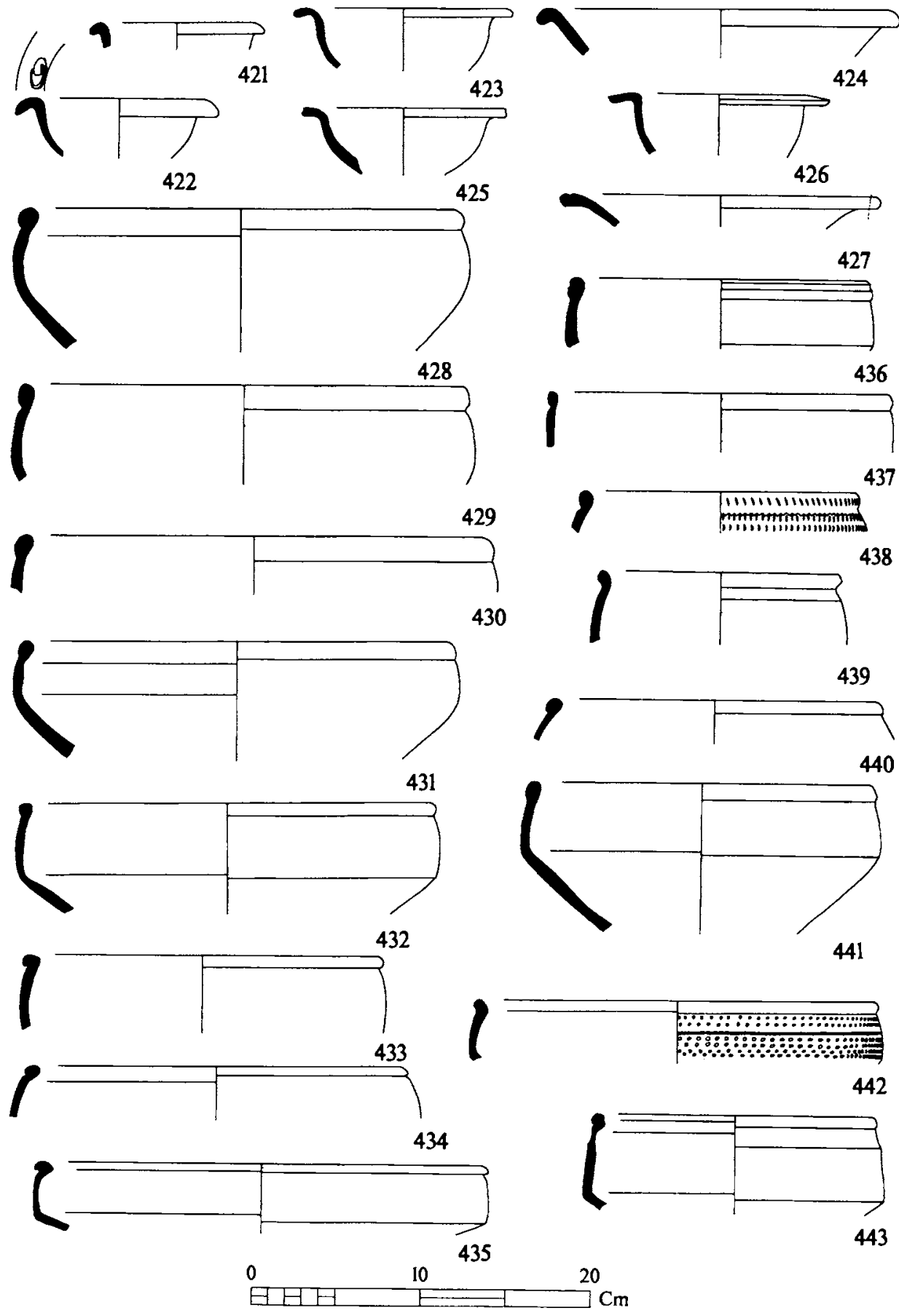

9.23 Red-slipped fine wares: ware 8 
432. C88 (5309). Rim of a bowl, dia. $14-40 \mathrm{~cm}$ (usually $20-30 \mathrm{~cm}$ ). The context is dated 250-350. 371 examples were found, of which the earliest 31 came from contexts dated to 100-130, with a further 58 coming from contexts dated to 130-150, 46 coming from contexts dated to 150-175, and 58 more from contexts dated to $175-250$.

433. C495 (672). Rim of a bowl, dia. 18-26cm. The context is dated 175-250. 23 examples were found, of which the earliest came from a context dated to 130-175, 4 more came from contexts dated to 175-250, and 2 from contexts dated to $250-350$.

434. C32 (4504). Rim of a bowl, dia. 15-22cm. The context is dated 450-600. 6 examples were found, 1 from a context dated $250-450,1$ from a context dated to $400-450,1$ from a context dated to $450-600$, and 3 from postmedieval deposits.

435. C786 (4808). Rim of a bowl, dia. $26 \mathrm{~cm}$. The context is post-medieval. 8 examples were found, 1 came from a context dated to 250-350, 3 from contexts dated 250-450, 1 from a context dated to 350-450, 1 from a context dated to 450 , and a further 2 were from post-medieval deposits.

436. C712 (96). Rim of a bowl, dia. $17 \mathrm{~cm}$. Undated context.

437. C620 (4099). Rim of a bowl, dia. $16-30 \mathrm{~cm}$. The context is dated 400-500.7 examples were found, of which the earliest came from a context dated to 175-250, however the next 4 were from contexts dated to $350-450$.

438. F290 (667). Rim of a bowl with bands of rouletting on the exterior, dia. $18-34 \mathrm{~cm}$. The context is dated $175-250.7$ examples were found, of which the earliest 5 were from contexts dated to $175-250$.

439. C310 (640). Rim of a bowl, dia. 14-26cm (usually $20-26 \mathrm{~cm}$ ). The context is dated 350-450. 22 examples were found, of which the earliest 4 were from contexts dated to $130-150,3$ more came from contexts dated to $175-250$, and 7 others from contexts dated to $250-350$.

440. F150 (604). Rim of a bowl, dia. $20-36 \mathrm{~cm}$. The context is dated 350-450. 145 examples were found, of which 114 were from context 699 in area D dated to 130-150. A further 30 examples came from contexts dated to $175-250$.

441. C88 (2259). Rim of a bowl, dia. $20-30 \mathrm{~cm}$. The context is dated $100-130$. See 432 for dating.

442. C63 (5306). Rim of a bowl with bands of rouletting on the exterior, dia. $12-24 \mathrm{~cm}$. The context is dated 250-350. 46 examples were found, of which the earliest two came from a context dated to $130-175,6$ more came from 
contexts dated to $250-350,7$ from contexts dated to $250-450$, and 11 from contexts dated 350-450.

443. C361. Unstratified. Rim of a bowl, dia. $16 \mathrm{~cm}$.

Red-slipped fine wares: ware 8 (Fig. 9.24)

444. C495 (2254). Rim of a bowl, dia. $23 \mathrm{~cm}$. The context is dated $130-175$. See 433 for dating.

445. G145 (1124). Rim of a bowl, dia. $22 \mathrm{~cm}$. The context is dated to 450 .

446. G53 (4896). Rim of a bowl with scale decoration on the exterior, dia. $20 \mathrm{~cm}$. The context is post-medieval.

447. C485 (699). Rim of a bowl, dia. 24-26cm. The context is dated 130-150. 2 examples were found, both from contexts dated to 130-150.

448. C757 (662). Rim of a bowl, dia. 10-23cm. The context is dated 250-350. 23 examples were found, of which the earliest one came from a context dated to $150-175,3$ came from contexts dated to $250-350$, and 6 from contexts dated to $350-450$.

449. C507 (584). Rim of a bowl, dia. $16-20 \mathrm{~cm}$. The context is dated $350-450.6$ examples were found, 2 from contexts dated to 250-350, 3 from contexts dated to $350-450$, and 1 from a context dated to 450 .

450. C299 (4499). Rim of a bowl, dia. $11-26 \mathrm{~cm}$ (usually $16-26 \mathrm{~cm}$ ). The context is dated 250-450. 103 examples were found, of which the earliest one came from a context dated to 130-175, one more came from a context dated to 150-175, with 6 coming from contexts dated 175-250, and 20 from contexts dated to $250-350$.

451. C284 (574). Rim of a bowl, dia. $14-19 \mathrm{~cm}$. The context is dated 450-600. 10 examples were found, of which the earliest 3 were from contexts dated to 175-250, with one coming from a context dated to 250-350, and another from a context dated to $350-450$.

452. C755 (4034). Rim of a bowl, dia. $16-26 \mathrm{~cm}$. The context is dated to 450.20 examples were found, of which the earliest 5 came from contexts dated to $250-350$, and a further 8 from contexts dated to $350-450$.

453. C63 (3011). Rim of a bowl, dia. $12-28 \mathrm{~cm}$ (usually $15-20 \mathrm{~cm}$ ). The context is post-medieval. See 442 for dating. 
l

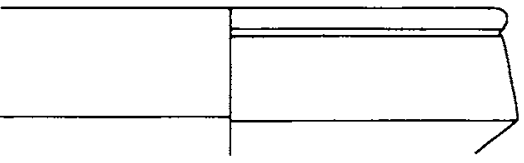

1
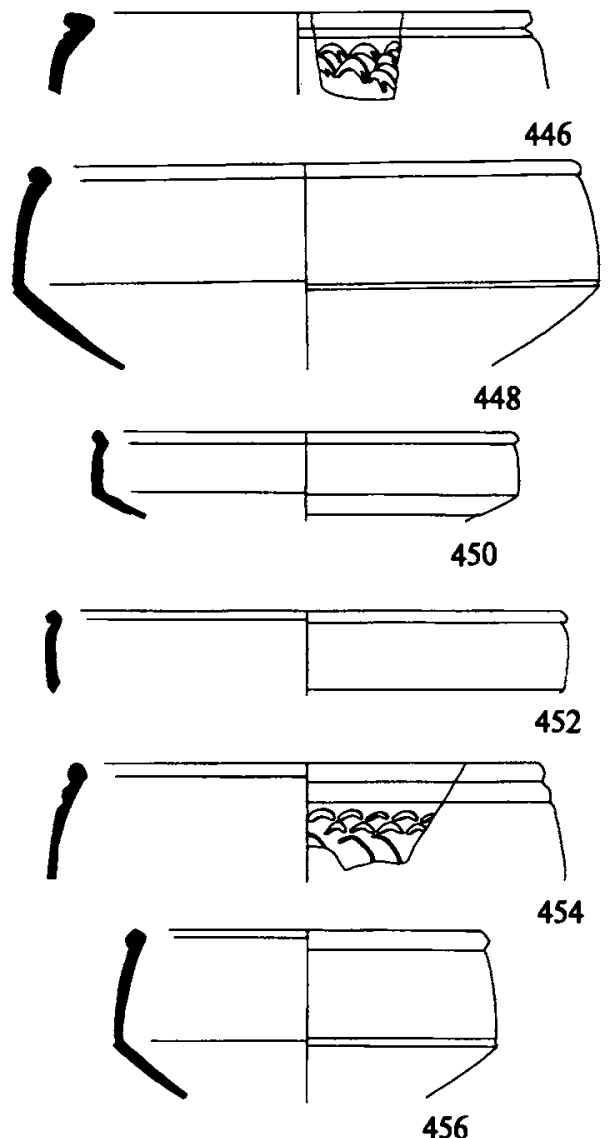

454
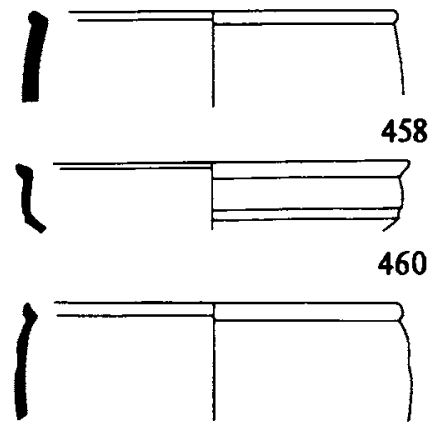

462

0
1
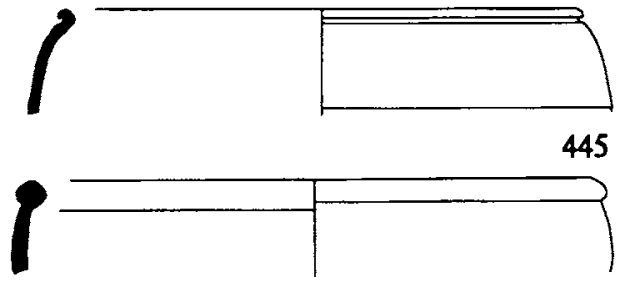

1
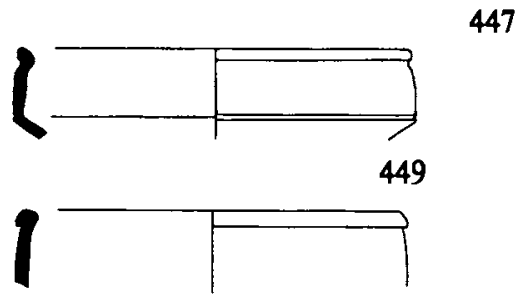

451
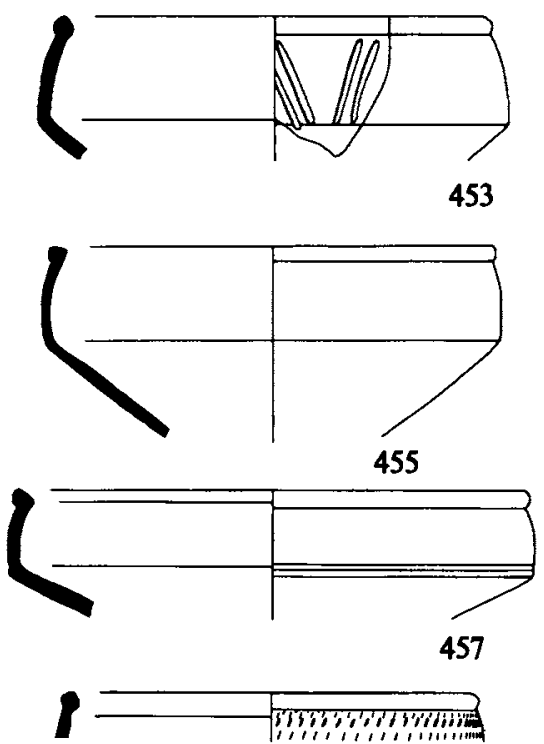

459

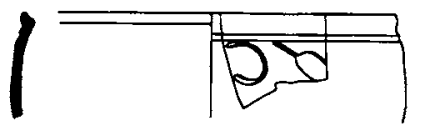

461

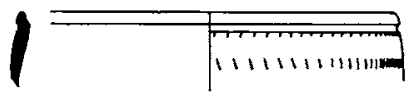

10

463

9.24 Red-slipped fine wares: ware 8 
454. F629 (4920). Rim of a bowl with scale decoration above appliqué on the exterior, dia. $20 \mathrm{~cm}$. The context is dated $350-450$. One other example was found also from a context dated to $350-450$.

455. C88 (318). Rim of a bowl, dia. $14-40 \mathrm{~cm}$ (usually $20-30 \mathrm{~cm}$ ). The context is dated 100-130. See 432 for dating.

456. F488 (4507). Rim of a bowl, dia. $15-20 \mathrm{~cm}$. The context is dated $250-450.28$ examples were found, the earliest 7 of which came from contexts dated to 250-450, with a further 7 coming from contexts dated to $350-450$.

457. C299 (5311). Rim of a bowl, dia. 16-26cm. The context is dated $250-350$. See 450 for dating.

458. C99 (2017). Rim of a bowl, dia. 15-24cm (though two larger examples were found). The context is dated to 450.25 examples were found, of which the earliest came from a context dated to 150-250, 4 examples came from contexts dated to 175-250, 4 more from contexts dated to $250-350,2$ from contexts dated to 250-450, and another 4 from contexts dated 275-450.

459. C507 (665). Rim of a bowl with rouletted decoration on the exterior, dia. $16-20 \mathrm{~cm}$. The context is dated $250-350$. See 449 for dating.

460. G18 (4118). Rim of a bowl, dia. $14-17 \mathrm{~cm}$. The context is dated $175-250.5$ examples were found, 1 from a context dated to $175-250,2$ from contexts dated to $250-350$, and 2 from contexts dated to 450 .

461. C227 (240). Rim of a bowl with applique decoration on the exterior, dia. $10-17 \mathrm{~cm}$. The context is post-medieval. 11 examples were found, of which the earliest one came from a context dated to $100-130$, with 5 more coming from contexts dated to $175-250$.

462. F284 (667). Rim of a bowl, dia. 15-16cm. The context is dated $175-250.9$ examples were found, of which the earliest two came from contexts dated to 130-150, and another 4 came from contexts dated to 150-175.

463. F284 (4430). Rim of a bowl, dia. $15-16 \mathrm{~cm}$. The context is post-medieval. See 462 for dating.

Red-slipped fine wares: ware 8 (Fig. 9.25)

464. C552 (1129). Rim of a bowl, dia. 14-21 cm. The context is dated to 450.20 examples were found, of which the earliest one came from a context dated to $150-175$, with 4 coming from contexts dated to $250-350,5$ from contexts dated to 450 , and 7 from contexts dated to $450-600$. 
465. C468 (699). Rim of a bowl with a small flat strap handle (which is more decorative than functional), dia. $28 \mathrm{~cm}$. The context is dated $130-150$. One other example was found also from a context dated to 130-150.

466. C868 (4515). Rim of a bowl, dia. 20-22cm. The context is dated 250-450. 36 examples were found, of which the earliest one came from a context dated to 175-250, with another coming from a context dated to 250-350, but 14 coming from contexts dated to $250-450$, and 7 coming from contexts dated to $350-450$.

467. C73 (221). Rim of a bowl with incised decoration on the exterior, dia. $28-34 \mathrm{~cm}$. The context is dated $130-150$. One other example was found, also from a context dated to 130-150.

468. C337 (2260). Rim of a bowl with appliqué decoration on the exterior, dia. $18 \mathrm{~cm}$. The context is dated $100-130$.

469 C521 (667). Rim of a bowl with incised decoration on the exterior, dia. $20 \mathrm{~cm}$. The context is dated 175-250. This was the only example found.

470. C109 (1). Rim of a bowl with appliqué decoration on the exterior, dia. $20-24 \mathrm{~cm}$. The context is post-medieval. 3 other examples were found: 1 from a context dated to $250-350,1$ from a context dated to $350-450$, and 1 from a context dated to $450-600$.

471. C648 (4115). Rim of a bowl, dia. 14-21cm. The context is dated 175-250. 5 examples were found, of which the earliest two were from contexts dated to $130-150$, with a further one from a context dated to $175-450$.

472. C279 (704). Rim of a bowl with incised decoration on the exterior, dia. $15-18 \mathrm{~cm}$. The context is dated $350-450.66$ examples were found, of which 2 were from pre- 250 contexts, 7 from contexts dated to $250-350,8$ from contexts dated to $250-450$, and 16 from contexts dated to $350-450$.

473. F584 (689). Rim of a bowl, dia. $20-28 \mathrm{~cm}$. The context is dated $350-450$. One other example was found in a context dated to 450 .

474. G159 (2149), SF. 5188. Rim of a bowl with applied handle and incised lattice work decoration on the exterior, dia. $20 \mathrm{~cm}$. The context is dated $450-600$.

475. F637 (691). Rim of a large bowl with incised decoration on the exterior, dia. $32 \mathrm{~cm}$. The context is dated 150-175. 2 other examples were found in the same context (which may come from the same bowl).

476. C548 (1134). Rim of a bowl, dia. $16 \mathrm{~cm}$. The context is dated to 450 . 


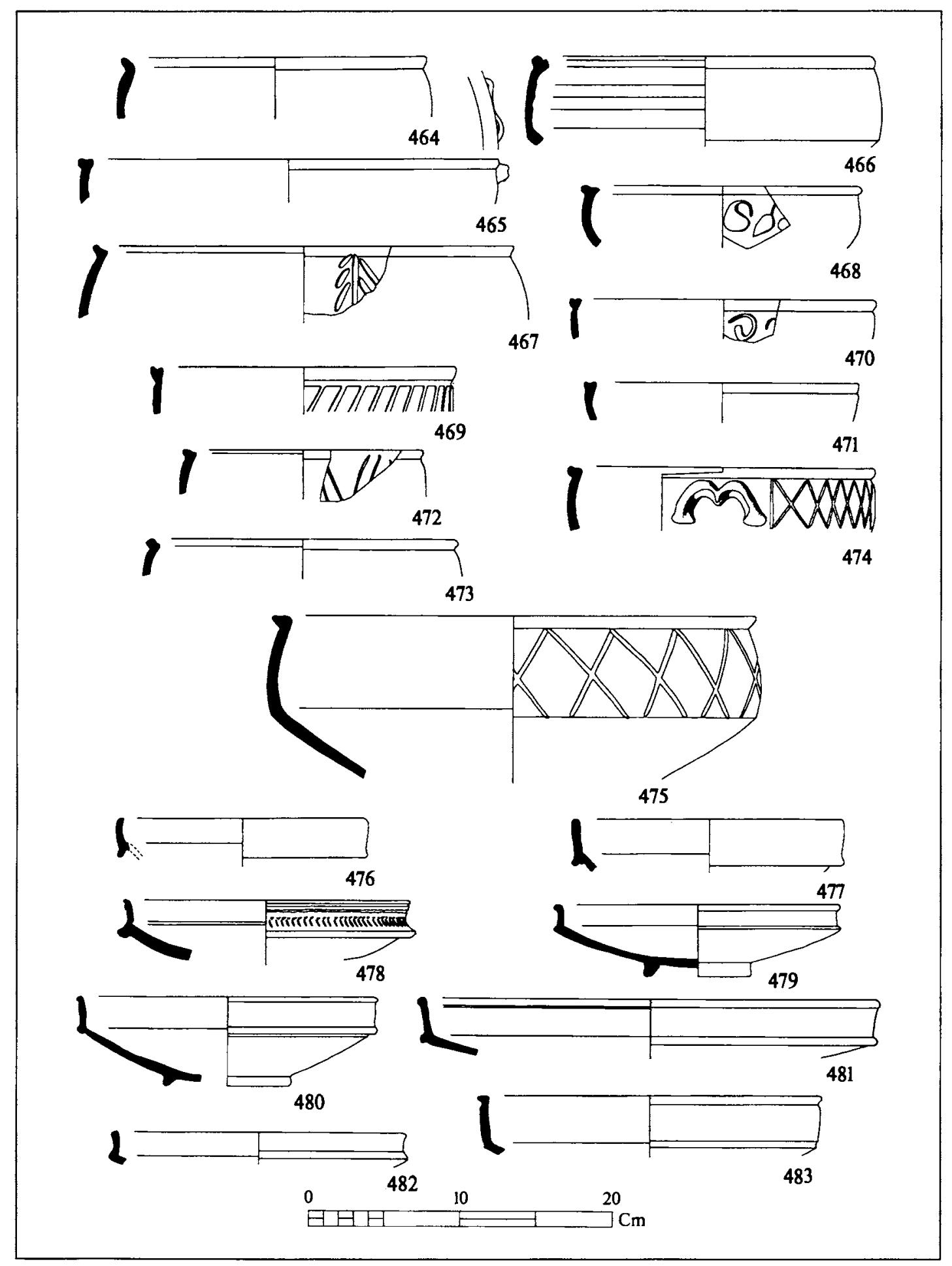

9.25 Red-slipped fine wares: ware 8 
477. C471 (699). Rim of a bowl, dia. $17-19 \mathrm{~cm}$. The context is dated $130-150$. One other example was found in a context dated to $350-450$.

478. F639 (691). Rim of a bowl with rouletted decoration on the exterior, dia. $18-30 \mathrm{~cm}$. The context is dated $150-175.5$ examples were found, 1 from a context dated to 130-175, 1 from a context dated to 150-175, 2 from contexts dated 175-250, and 1 from a context dated to $350-450$.

479. C379 (2254). Rim of a bowl, dia. $19 \mathrm{~cm}$. The context is dated 130-175.

480. F638 (691). Rim of a bowl, dia. 17-39cm. The context is dated $150-175.73$ examples were found, of which the earliest 10 came from contexts dated 100-130, with another 20 from contexts dated to 130-150.

481. F638 (248). Rim of a bowl, dia. $17-39 \mathrm{~cm}$. The context is dated $300-450$. See 480 for dating.

482. C455 (699). Rim of bowl, dia. 19-21cm. The context is dated 130-150.3 examples were found, 2 from contexts dated to $130-150$, and 1 from a context dated to $450-600$.

483. C771 (686). Rim of a bowl, dia. $20 \mathrm{~cm}$. The context is dated $175-250$, but contains some later material. 5 examples were found, 1 from a context dated to $150-175,1$ from a context dated to $175-250$, with the other 3 coming from post -400 contexts.

Red-slipped fine wares: ware 8 (Fig. 9.26)

484. C646 (4115). Rim of a bowl, dia. 19-30cm (though one example is only $11 \mathrm{~cm}$ ). The context is dated 175-250. 8 examples were found, 3 from a context dated to $175-250,1$ from a context dated to $350-450,1$ from a context dated $450-600$ and 3 from post-medieval deposits.

485. C378 (248). Rim of a bowl, dia. $22 \mathrm{~cm}$. The context is dated $300-450$.

486. F257 (691). Rim of a bowl, dia. $21 \mathrm{~cm}$. The context is dated 150-175. 10 examples were found, 1 from a context dated to $130-150$, and 9 from contexts dated to $150-175$.

487. Z205 (691). Rim of a bowl, dia. $30 \mathrm{~cm}$. The context is dated $150-175$.

488. C869 (4071). Rim of a bowl, dia. $19 \mathrm{~cm}$. The context is dated $175-250$.

489. G155 (4069). Rim of a bowl, dia. 19-25cm. The context is dated $175-250.4$ examples were found, 1 from a context dated to 130-150, 1 from a context dated $175-250$, and 2 from post-medieval contexts. 

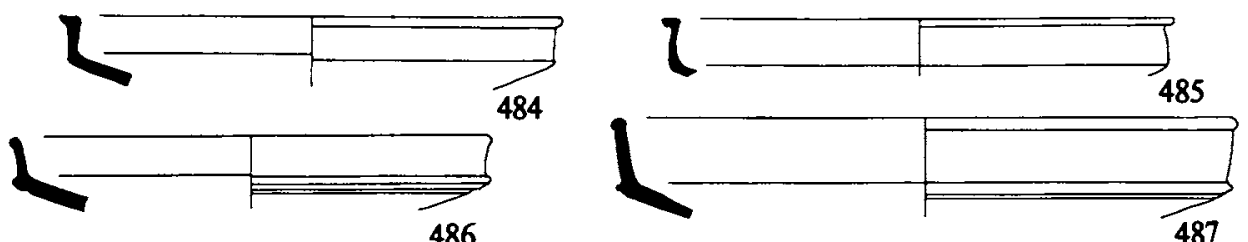

484
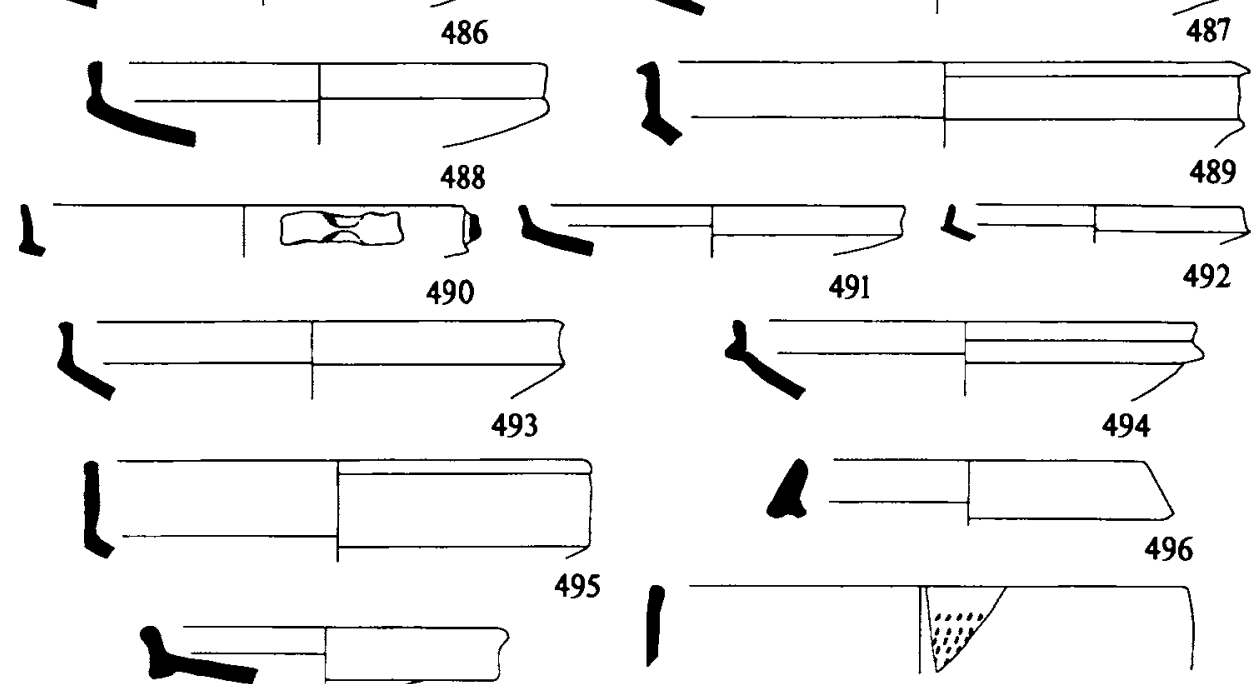

497
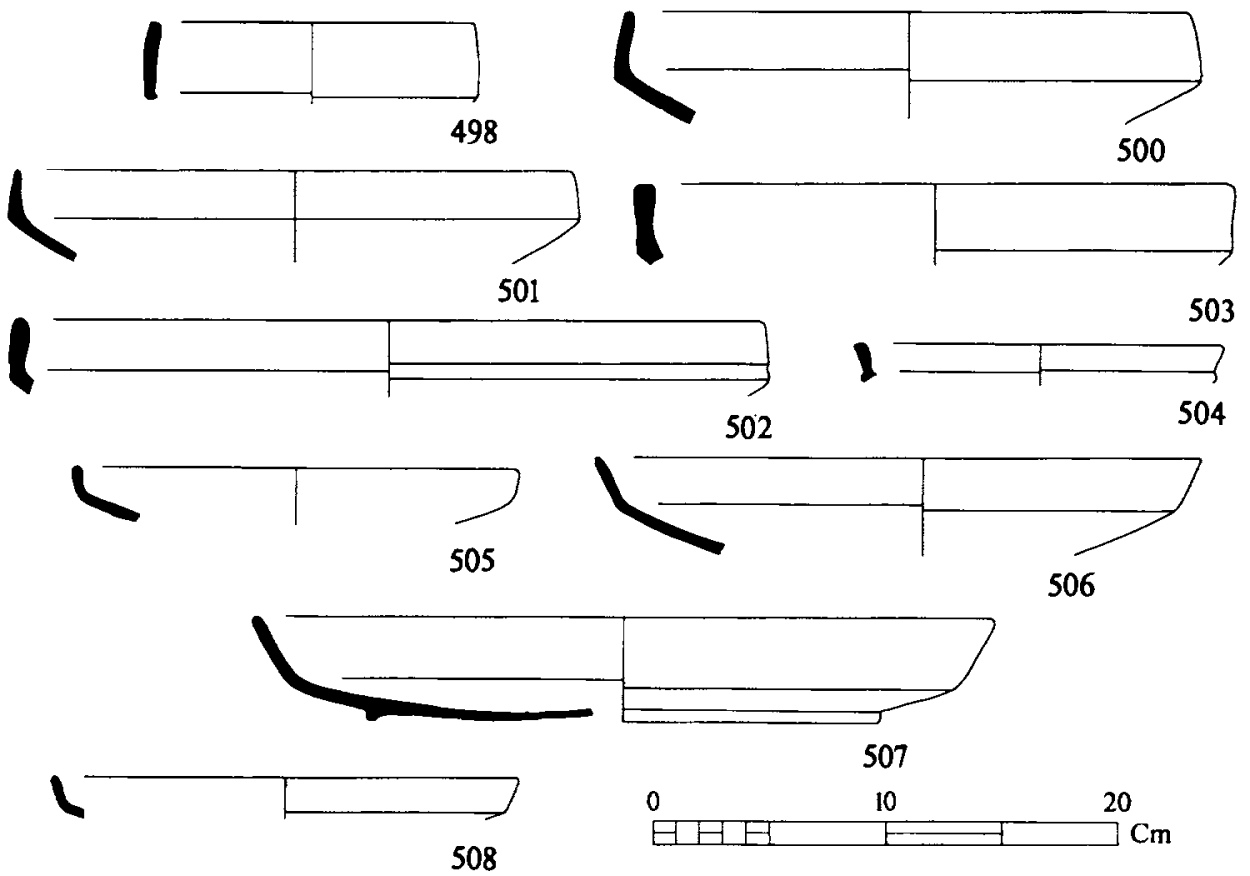

9.26 Red-slipped fine wares: ware 8 
490. C689 (2210). Rim of a bowl, dia. 18-20cm. The context is dated $450-600.6$ examples were found, 3 from contexts dated to $150-175,1$ from a context dated 175-250, and 2 from deposits dated to 450-600.

491. G27 (4401). Rim of a bowl, dia. 16-18cm. The context is post-medieval. The only other example was also from a post-medieval deposit.

492. C486 (699). Rim of a bowl, dia. $14-18 \mathrm{~cm}$. The context is dated $130-150.5$ examples were found, of which the earliest came from a context dated to $130-150$, with another coming from a context dated to $150-175$, and a further one from a context dated to 175-250.

493. C455 (550). Rim of a bowl, dia. 19-21 cm. The context is dated 450-600. See 482 for dating.

494. G8 (4118). Rim of a bowl, dia. $20 \mathrm{~cm}$. The context is dated $250-350$.

495. C523 (667). Rim of a bowl, dia. $20-24 \mathrm{~cm}$. The context is dated $175-250.3$ other examples were found, 1 from a context dated to $450-600$, and 2 from post-medieval deposits.

496. F651 (4507). Rim of a bowl, dia. $15 \mathrm{~cm}$. The context is dated $250-350$.

497. C831 (4405). Rim of a bowl, dia. $15 \mathrm{~cm}$. The context is post-medieval.

498. C498 (665). Rim of a bowl, dia. 14-23cm. The context is dated $250-350.2$ other examples were found: both from contexts dated to 250-350.

499. F194 (676). Rim of a bowl with rouletted decoration on the exterior, dia. $18-24 \mathrm{~cm}$. The context is dated $175-250.12$ examples were found, 3 from contexts dated to $175-250,1$ from a context dated to $250-350,2$ from contexts dated to $350-450,1$ from a context dated to $400-450$, and 5 from contexts dated to $450-600$.

500. C155 (667). Rim of a bowl, dia. $18-28 \mathrm{~cm}$. The context is dated $175-250.57$ examples were found ( 15 from post-medieval deposits), of which the earliest 7 came from contexts dated to 175-250, with another coming from a context dated to 250-275, and 3 from contexts dated to 250-350.

501. Z206 (243). Rim of a bowl, dia. $24 \mathrm{~cm}$. The context is dated $300-450$.

502. F616 (655). Rim of a bowl, dia. $32 \mathrm{~cm}$. The context is dated $350-450$.

503. C243 (337). Rim of a bowl, dia. $20-35 \mathrm{~cm}$. The context is dated $175-250.3$ examples were found, 2 from contexts dated to $175-250$, and 1 from a context dated to $450-600$. 
504. C83 (231). Rim of a bowl, dia. $12-18 \mathrm{~cm}$. The context is dated $175-350$, but contains some later material. One other example was found, also from a context dated to $175-350$.

505. G11 (4118). Rim of a bowl, dia. $20 \mathrm{~cm}$. The context is dated $175-250$.

506. C407 (676). Rim of a bowl, dia. 20-32cm. The context is dated 175-250. 17 examples were found, of which the earliest came from a context dated to 130-175, with another from a context dated to 150-175, and a further 8 from contexts dated to $175-250$.

507. Z24 (677). Bowl, dia. $32 \mathrm{~cm}$. The context is dated 175-250. 15 examples were found, of which the earliest two came from contexts dated to 175-250, 1 from a context dated to 250-350, 1 from a context dated to 250-450, and 6 from contexts dated to between $350-450$.

508. C647 ( 4115$)$. Rim of a bowl, dia. $20-21 \mathrm{~cm}$. The context is dated $175-250$. One other example was found in a context dated to $450-600$.

Red-slipped fine wares: ware 8 (Fig. 9.27)

509. C120 (686). Rim of a bowl, dia. $18-26 \mathrm{~cm}$. The context is dated $175-250$, but contains some later material. 16 examples were found, of which the earliest one came from a context dated to 130-150, with 7 more coming from contexts dated to $175-250$.

510. F636 (691). Bowl, dia. $19 \mathrm{~cm}$. The context is dated $150-175$.

511. C340 (2260). Rim of a bowl, dia. $17 \mathrm{~cm}$. The context is dated 100-130. 2 other examples were found, both from contexts dated to 250-350.

512. C770 (2253). Rim of a bowl, dia. 10-12cm. The context is dated 100-130. One other example was found in a context dated to 450-600.

513. C491 (699). Rim of a bowl, dia. $8-12 \mathrm{~cm}$. The context is dated 130-150. One other example was found in a context dated to 250-350.

514. C828 (4405). Rim of a bowl, dia. $18 \mathrm{~cm}$. The context is post-medieval.

515. C67 (415). Rim of a bowl, dia. $16-24 \mathrm{~cm}$. The context is post-medieval. 4 examples were found, 1 from a context dated to $275-450,1$ from a context dated to $350-450$, and 2 from post-medieval deposits.

516. C117 (451). Rim of a bowl, dia. $11-24 \mathrm{~cm}$. The context is post-medieval. 4 other examples were found, 2 from contexts dated to $275-450$, and 2 from contexts dated to $450-600$. 
517. C81 (231). Small bowl, dia. 12-14cm, w8. The context is dated 175-350, but contains some later material. 10 examples were found, of which the earliest two came from contexts dated 130-150, with another 2 from contexts dated to $175-250$, and 3 from contexts dated to $175-350$.

518. C374 (676). Small bowl, dia. 10-20cm. The context is dated 175-250. 39 examples were found, of which the earliest one came from a context dated to $130-175,15$ more came from contexts dated to $175-250$, and 8 from contexts dated to $250-350$.

519. C817 (4033). Rim of a small bowl, dia. 10-12cm. The context is dated to 450. 15 examples were found ( 5 being from post-medieval deposits), of which the earliest one came from a context dated to 150-175, another came from a context dated to 175-250, with 3 from contexts dated to 250-450.

520. C374 (618). Small bowl, dia. $7 \mathrm{~cm}$. The context is dated $350-450$. See 518 for dating.

521. C760 (4118). Small bowl, dia. $14 \mathrm{~cm}$. The context is dated $175-250$.

522. F655 (5051). Small bowl, dia. $9 \mathrm{~cm}$. The context is dated to 450 .

523. C98 (3271). Bowl, dia. 9-26cm. The context is post-medieval. 22 examples were found, of which the earliest one was in a context dated to 130-150,2 others were from a context dated to 130-175, a further 2 from contexts dated to $175-250$, and 2 from contexts dated to $250-350$.

524. F613 (635). Small bowl, dia. 10-11cm. The context is dated 350-450. 19 examples were found, of which the earliest 14 were in contexts dated to 150-175.

525. C170 (280). Small bowl, dia. 9-16cm. The context is dated 250-350. 58 examples were found, the earliest 15 of which were from contexts dated to $175-250,3$ more came from contexts dated to $250-350$, and 4 from contexts dated $250-450$.

526. C140 (1033). Small bowl, dia. 10-18cm. The context is dated $450-600.28$ examples were found, of which the earliest 4 came from contexts dated to 175-250, 1 came from a context dated 175-350, 3 more from contexts dated $250-350$, and 8 from contexts dated 350-450.

527. C371 (550). Small bowl, dia. 9cm. The context is dated 450-600.

528. G98 (4907). Small bowl, dia. 10-12cm. The context is post-medieval. One other example was found, also in a post-medieval deposit. 


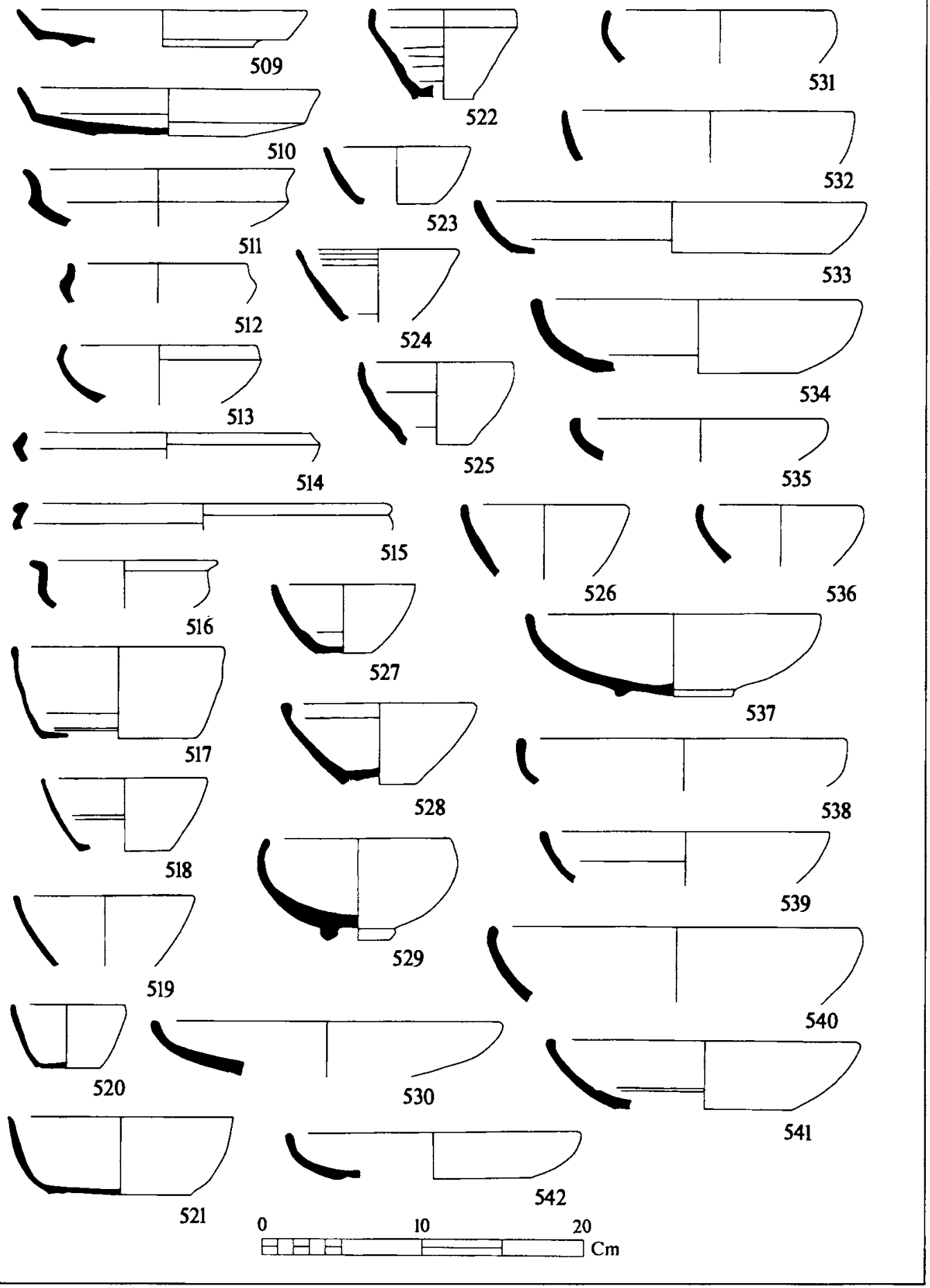

9.27 Red-slipped fine wares: ware 8 
529. Cl4 (2277). Bowl, dia. $9-22 \mathrm{~cm}$ (though usually $10-16 \mathrm{~cm}$ ). The context is dated 100-130. 115 examples were found, of which the earliest 4 came from contexts dated to 100-130, and 17 come from contexts dated to 130-150.

530. C656 (665). Rim of a bowl, dia. 20-22cm. The context is dated $250-350.7$ examples were found, of which the earliest two came from contexts dated to $250-350,1$ came from a context dated to $250-450$, and 2 came from contexts dated to $350-450$.

531. Z207 (602). Rim of a bowl, dia. $14 \mathrm{~cm}$. The context is dated $350-450$.

532. C410 (2156). Rim of a bowl, dia. $10-18 \mathrm{~cm}$. The context is dated $450-600.15$ examples were found, of which the earliest 5 came from contexts dated to 150-175, and 4 came from contexts dated 175-250.

533. C133 (1034). Bowl, dia. $11-28 \mathrm{~cm}$ (usually $14-18 \mathrm{~cm}$ ). The context is dated 450-600. 40 examples were found, of which the 7 earliest came from contexts dated to $100-130,1$ came from a context dated to $130-175$, and 5 from contexts dated to $175-250$.

534. C 367 (1112). Bowl, dia, $16-32 \mathrm{~cm}$ (usually $22-26 \mathrm{~cm}$ ). The context is dated to 450.108 examples were found, of which the earliest 5 were in contexts dated to 100-130, 1 came from a context dated 150-250, 4 from contexts dated 175-250, and 6 from contexts dated 250-350. However 43 came from contexts dated to between 350 and 450 .

535. C100 (2017). Rim of a bowl, dia. 10-22 cm. The context is dated to 450.32 examples were found, of which the earliest two came from contexts dated to 130-150, 3 more came from contexts dated 175-250, 2 from contexts dated $175-350$, and 2 from contexts dated to $250-350$.

536. C205 (1036). Rim of a bowl, dia. 10-18cm. The context is dated $450-600.65$ examples were found, of which the earliest 29 came from contexts dated to $100-130$.

537. C297 (662). Bowl, dia. 10-24cm. The context is dated 250-350. 134 examples were found, of which the earliest 59 came from contexts dated to 130-150 (57 from the same context: area D 699).

538. C367 (2174). Rim of a bowl, dia. 16-32cm (usually $22-26 \mathrm{~cm}$ ). The context is dated to 450 . See 534 for dating.

539. C133 (4516). Rim of a bowl with a ridge below the rim on the interior, dia. $11-28 \mathrm{~cm}$ (usually $14-18 \mathrm{~cm}$ ). The context is dated $250-450$. See 533 for dating. 
540. C316 (5218). Rim of a bowl, dia. 20-22cm. The context is dated to 450 . One other example was found from a context dated to $350-450$.

541. C820 (4906). Bowl, dia. 14-22cm. The context is dated 450-600. 8 examples were found, of which the earliest one came from a context dated to $130-175,2$ other examples came from contexts dated to $250-450$, and 1 from a context dated to 450 .

542. Z208 (577). Bowl, dia. $18 \mathrm{~cm}$. The context is dated $350-450$.

Red-slipped fine wares: ware 8 (Fig. 9.28)

543. C367 (635). Bowl, dia. $16-32 \mathrm{~cm}$ (usually $22-26 \mathrm{~cm}$ ). The context is dated $350-450$. See 534 for dating.

544. C312 (600). Rim of a bowl, dia. $26-39 \mathrm{~cm}$. The context is dated $250-450.18$ examples were found, of which the earliest one came from a context dated to $250-350,4$ came from contexts dated to $250-450$, and a further 7 came from contexts dated to $350-450$.

545. C46 (406). Rim of a bowl, dia. $22-32 \mathrm{~cm}$. The context is undated. 12 examples were found, of which the earliest came from a context dated to 175-250, 2 came from contexts dated 250-450, and 7 from contexts dated $350-450$.

546. C855 (4405). Rim of a bowl with an incised band on the exterior, dia. $26-28 \mathrm{~cm}$. The context is post-medieval.

547. C173 (677). Bowl with an incised band on the interior and exterior, dia. $16-19 \mathrm{~cm}$. The context is dated 175-250. 112 examples were found, of which the earliest 3 came from contexts dated to 100-130, 24 came from contexts dated to $130-150$, and 60 from contexts dated 175-250.

548. C330 (2277). Rim of a bowl with an incised band on the exterior, dia. 19-20cm. The context is dated 100-130.21 examples were found, of which the earliest 9 came from contexts dated to 100-130, with 8 more coming from contexts dated to $130-150$.

549. C161 (319). Rim of a bowl with an incised band on the interior, dia. 14-20cm. The context is dated 130-150. 22 examples were found, of which the earliest 12 were from contexts that dated to $130-150$.

550. F544 (686). Rim of a bowl, dia. $18-20 \mathrm{~cm}$. The context is dated $175-250$ but contains some later material. This was the only dated example. 


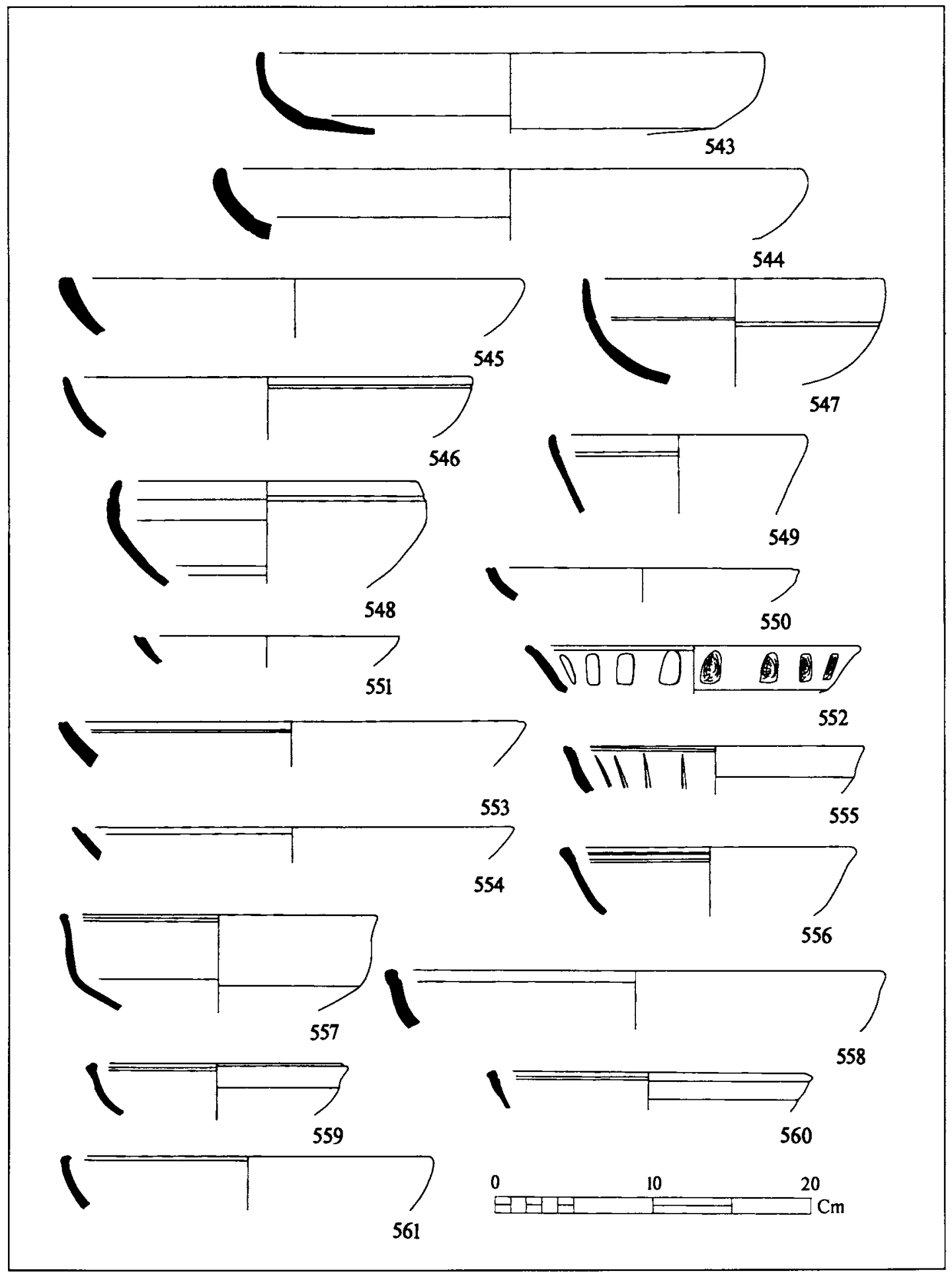

9.28 Red-slipped fine wares: ware 8 
551. C143 (677). Rim of a bowl, dia. $20-28 \mathrm{~cm}$ (though one example is $17 \mathrm{~cm}$ ). The context is dated 175-250. 32 examples were found, of which the earliest one came from a context dated to 130-150, 4 came from contexts dated to 175-250, and another 4 from contexts dated 250-350.

552. F690 (4871). Rim of a bowl with thumb impressions on the exterior, dia. $20-22 \mathrm{~cm}$. The context is dated $350-450.3$ examples were found, 2 from contexts dated to 350-450, and 1 from a post-medieval deposit.

553. G169 (4866). Rim of a bowl, dia. $15-30 \mathrm{~cm}$. The context is dated to 250.3 examples were found, 1 from a context dated to $250-275,1$ from a context dated to $350-450$, and 1 from a context dated to $450-600$.

554. C143 (453). Rim of a bowl, dia. $20-28 \mathrm{~cm}$. The context is post-medieval. For dating see 551 .

555. Cr37 (458). Rim of a bowl with impressed decoration on the interior, dia. $19-20 \mathrm{~cm}$. The context is post-medieval. 3 other examples were found, 2 from contexts dated to $175-250$, and 1 from a context dated to 450 .

556. F522 (4826). Rim of a bowl with two incised bands on the interior, dia. $18 \mathrm{~cm}$. The context is dated $350-450$. One other example was found in a post-medieval deposit.

557. G158 (4955). Bowl with an incised band on the interior, dia. $20 \mathrm{~cm}$. The context is dated 250-350.2 other examples were found, both from contexts dated to $350-450$.

558. C555 (1147). Rim of a bowl, dia. $31 \mathrm{~cm}$. The context is dated $400-450$. One other example was found in a context dated to 450 .

559. C741 (4506). Rim of a bowl, dia. $17 \mathrm{~cm}$. The context is dated $250-450$.

560. F522 (4480). Rim of a bowl, dia. $20 \mathrm{~cm}$. The context is post-medieval. For dating see 556.

561. C283 (573). Rim of a bowl, dia. $22 \mathrm{~cm}$. The context is dated $450-600$.

Red-slipped fine wares: ware 8 (Fig. 9.29)

562. C376 (542). Bowl with rouletted decoration on the interior, dia. $30 \mathrm{~cm}$. The context is dated $450-600$.

563. Gi48 (682). Rim of a bowl, dia. $18 \mathrm{~cm}$. The context is dated $350-450$.

564. F595 (4033). Rim of a bowl, dia. $20-38 \mathrm{~cm}$. The context is dated to 450.24 examples were found, of which the earliest one came from a context dated 
to $150-250,9$ came from contexts dated to $250-350$, and 6 from contexts dated to $350-450$.

565. C821 (4499). Rim of a bowl, dia. $18-34 \mathrm{~cm}$. The context is dated 250-450. 15 examples were found, of which the earliest two came from contexts dated to $250-450,3$ came from contexts dated to 350-450, 2 from contexts dated to 450 , and 4 from contexts dated to $450-600$.

566. C104 (4516). Rim of a bowl, dia $17-32 \mathrm{~cm}$ (usually $22-28 \mathrm{~cm}$ ). The context is dated 250-450. 13 other examples were found: 1 from a context dated to $175-250,5$ from contexts dated to $350-450,3$ from contexts dated to 450-600 and 4 from post-medieval deposits.

567. G149 (682). Rim of a bowl, dia. $22-24 \mathrm{~cm}$. The context is dated 350-450. One other example was found in a context dated to $250-350$.

568. C126 (4848). Rim of a bowl, dia. $24-38 \mathrm{~cm}$. The context is dated $350-450.12$ other examples were found, 3 from contexts dated to 175-250, 1 from a context dated $275-450,6$ from contexts dated to 450 , and 2 from postmedieval contexts.

569. G115 (4953). Rim of a bowl, dia. 19-26cm. The context is dated 350-450. 2 other examples were found, 1 from a context dated to 450-600, and 1 from a post-medieval deposit.

570. F286 (667). Rim of a bowl, dia. $22 \mathrm{~cm}$. The context is dated $175-250$.

571. C315 (604). Rim of a bowl, dia. $26 \mathrm{~cm}$. The context is dated $350-450$.

572. G54 (4896). Rim of a bowl, dia. $24 \mathrm{~cm}$. The context is post-medieval.

573. Z209 (4405). Rim of a bowl, dia. $28 \mathrm{~cm}$. The context is post-medieval.

574. F634 (1036). Rim of a bowl with bands of rouletting on the interior, dia. $18 \mathrm{~cm}$. The context is dated $450-600$.

575. C844 (4433). Rim of a bowl, dia. $30 \mathrm{~cm}$. The context is post-medieval.

576. C779 (4915). Bowl with notched rim, incised wavy band on exterior and thumb impressions on interior, dia. $31 \mathrm{~cm}$. The context is dated to $400-450$. 4 other examples were found, 2 from contexts dated to $350-450,1$ from a context dated to $450-600$, and 1 from a post-medieval context. 

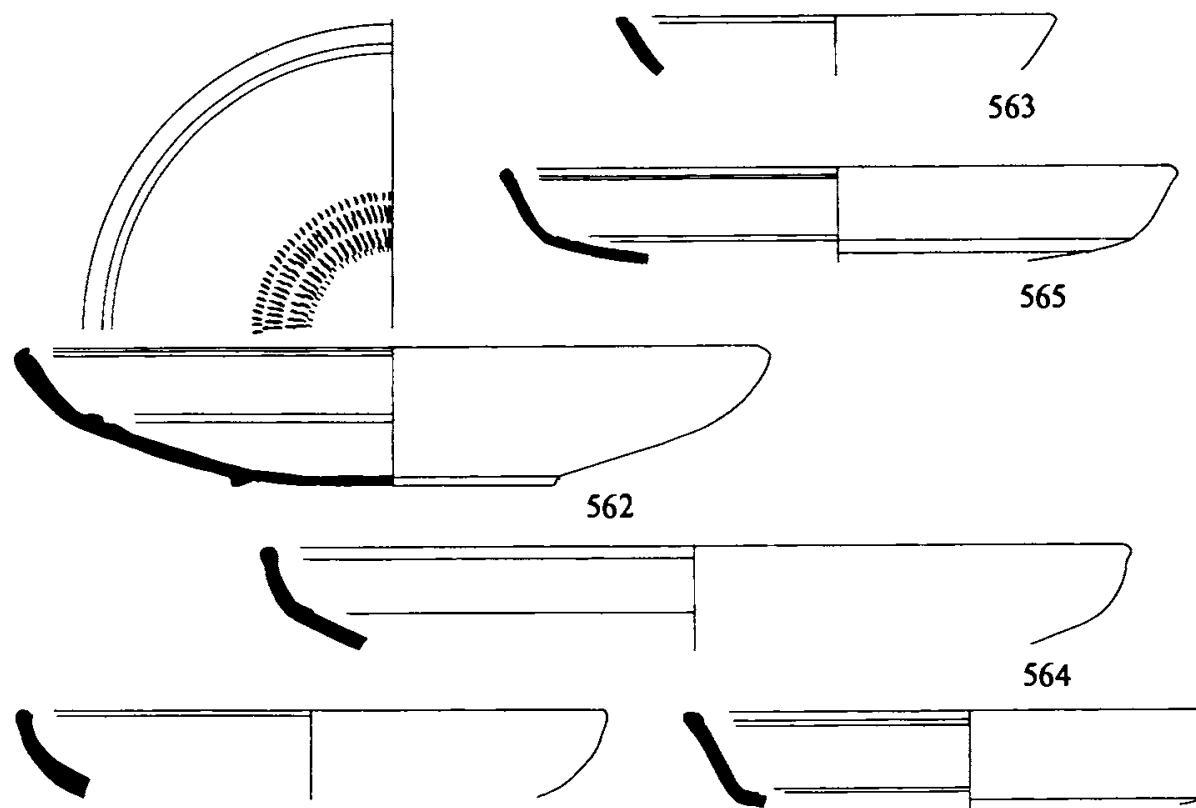

566
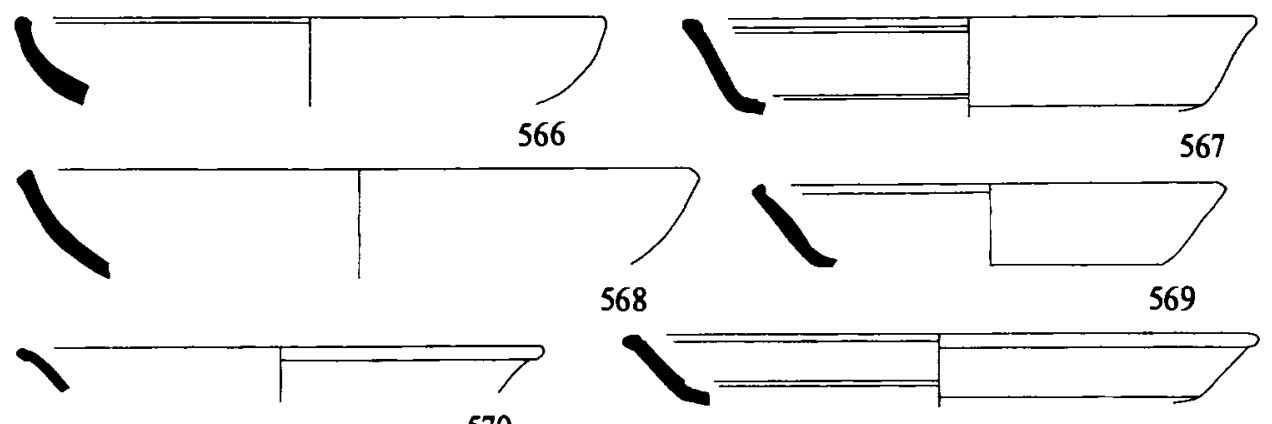

568
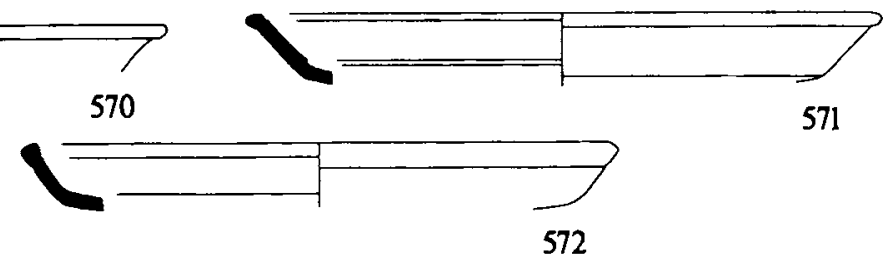

571
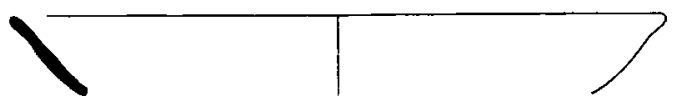

|

573

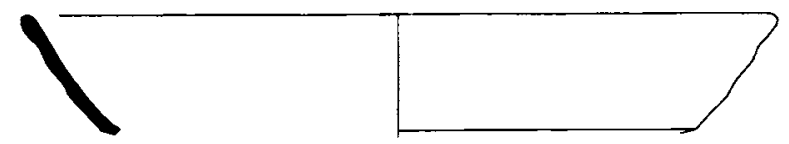

575

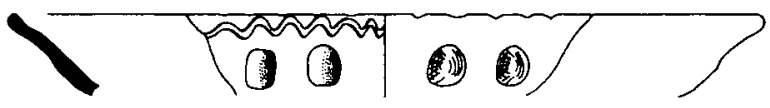

576

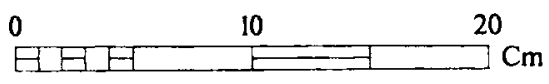

9.29 Red-slipped fine wares: ware 8 
Red-slipped fine wares: ware 8 (Fig. 9.30)

577. C136 (3288). Rim of a bowl, dia. $20-30 \mathrm{~cm}$. The context is dated to $400-450$. 2 other examples were found, 1 from a context dated to $350-450$, and 1 in a post-medieval deposit.

578. C28 (535). Rim of a bowl, dia. $24-31 \mathrm{~cm}$. The context is dated $450-600.11$ examples were found, 1 from a context dated to $250-350,1$ from a context dated $250-450,2$ from contexts dated $350-450,5$ from contexts dated to $450-600$, and 2 from post-medieval contexts.

579. C325 (570). Rim of a bowl, $18 \mathrm{~cm}$. The context is dated $350-450.2$ other examples were found, both of which were also from contexts dated to $350-450$.

580. C364 (550). Bowl with rouletted decoration on the interior, dia. $30 \mathrm{~cm}$. The context is dated $450-600$.

581. C273 (571). Rim of a bowl, dia. $37 \mathrm{~cm}$. The context is dated 450-600.One other example was found in a context dated to $400-450$.

582. C687 (2214). Rim of a bowl, dia. $25 \mathrm{~cm}$. The context is dated $450-600$.

583. C865 (4515). Rim of a bowl, dia. 24-26cm. The context is dated $250-450.4$ examples were found, 2 from contexts dated to $250-450$, and 2 from postmedieval contexts.

584. C139 (3139). Rim of a bowl, dia. $20-28 \mathrm{~cm}$ (though one example is $16 \mathrm{~cm}$ ). The context is post-medieval. 6 examples were found, 1 from a context dated to $250-350,1$ from a context dated to $350-450,2$ from contexts dated to $450-600$ and 2 from post-medieval deposits.

585. F585 (689). Rim of a bowl, dia. $18 \mathrm{~cm}$. The context is dated $350-450$.

586. C190 (341). Rim of a bowl, dia. 19-24cm. The context is dated 175-350. 2 other examples were found, 1 from a context dated to $250-450$, and 1 from a context dated $400-450$.

587. C470 (677). Rim of a bowl, dia. $20-35 \mathrm{~cm}$. The context is dated $175-250.34$ examples were found, of which the earliest 23 came from contexts dated to 130-150.

588. C470 (699). Rim of a bowl with rouletted decoration on the interior, dia. $20-35 \mathrm{~cm}$. The context is dated $130-150$. See 587 for dating.

589. F630 (3384). Rim of a bowl, dia. $24 \mathrm{~cm}$. The context is post-medieval. One other example was found in a context dated to $350-450$. 
I
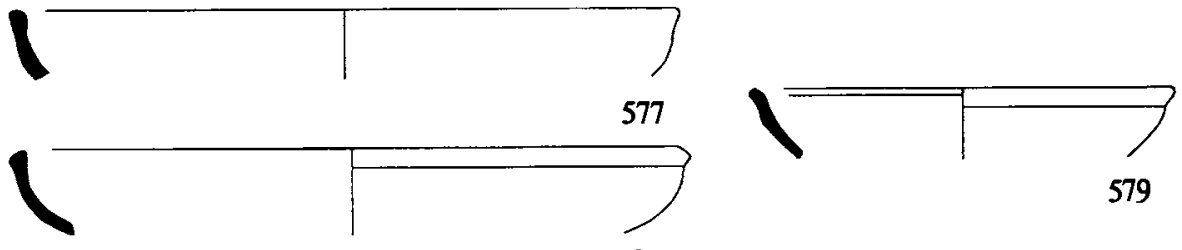

578
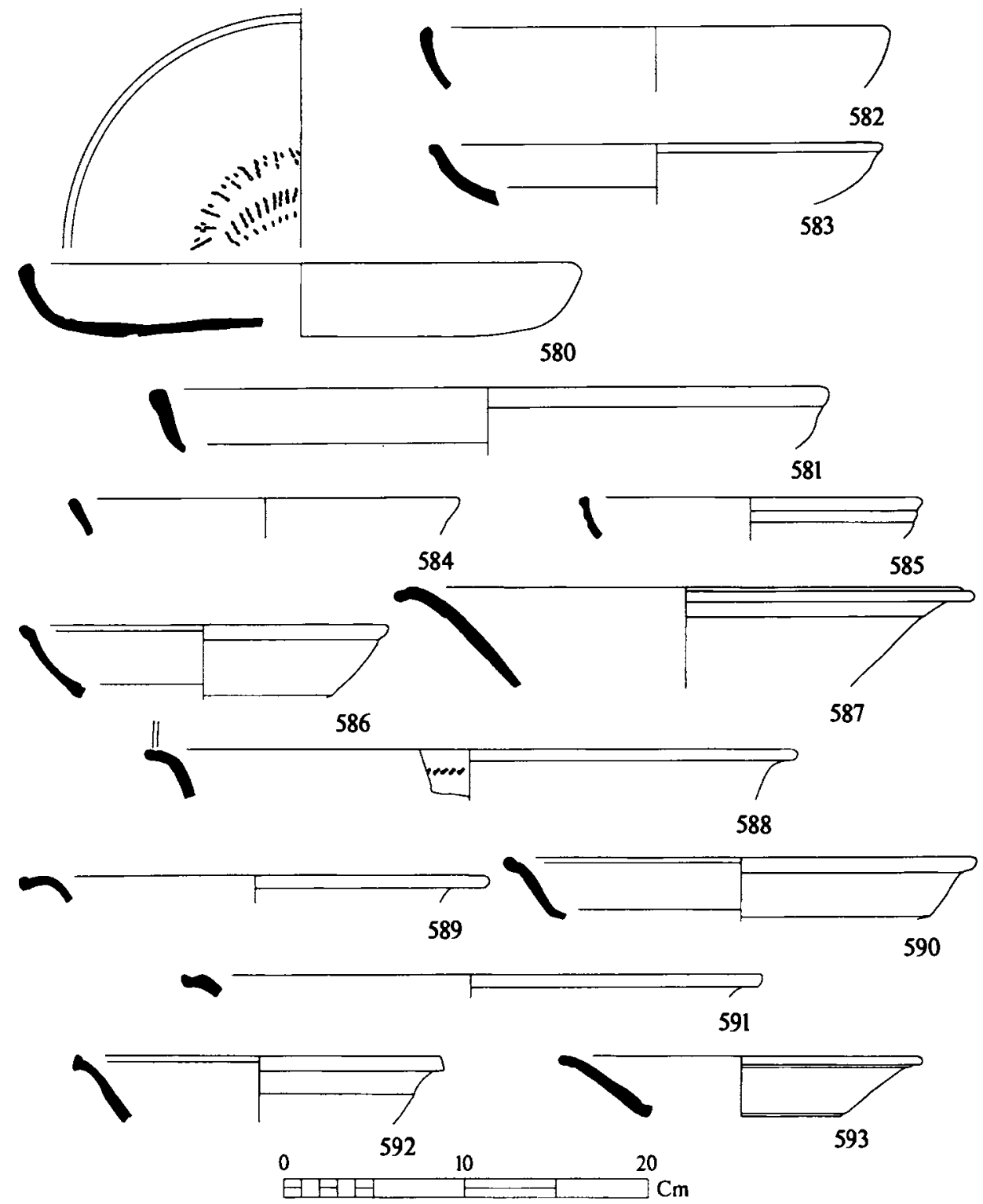

9.30 Red-slipped fine wares: ware 8 
590. G33 (2188). Rim of a bowl, dia. $24-30 \mathrm{~cm}$. The context is dated $450-600.2$ other examples were found, 1 came from a context dated to 450 , and the other was from a post-medieval context.

591. C818 (4033). Rim of a bowl, dia. $30-34 \mathrm{~cm}$. The context is dated to 450 . One other example was found from a context dated to 450-600.

592. C159 (265). Rim of a bowl, dia. $20 \mathrm{~cm}$. The context is dated 100-130. One other example was found in a context dated to $350-450$.

593. C338 (2260). Rim of a bowl, dia. 15-20cm. The context is dated 100-130. 3 other examples were found, 1 from a context dated to $250-350,1$ from a context dated to $400-450$, and 1 from a context dated to $450-600$.

Red-slipped fine wares: ware 8 (Fig. 9.31)

594. C135 (458). Rim of a bowl, dia. $10-22 \mathrm{~cm}$. The context is post-medieval. 3 other examples were found, 1 from a context dated to $175-250,1$ from a context dated to $275-450$, and 1 from a context dated to $400-450$.

595. C152 (248). Rim of a bowl with applied 'decorative' ledge handle, dia. $10 \mathrm{~cm}$. The context is dated 300-450. 2 other examples were found, 1 from a context dated to $275-450$, and 1 from a context dated to $450-600$.

596. C470 (699). Rim of a bowl, dia. $20-35 \mathrm{~cm}$. The context is dated 130-150. See 587 for dating.

597. C650 (4124). Rim of a bowl, dia. $14 \mathrm{~cm}$. The context is dated 150-350. One other example was found in a context dated to $350-450$.

598. C359 (2260). Rim of a bowl, dia. 21-31 cm. Rouletted decoration on the interior. The context is dated 100-130. One other example was found in a context dated to $250-350$.

599. C437 (677). Rim of a bowl, dia. $23 \mathrm{~cm}$. The context is dated $175-250$.

600. Z210 (4835). Rim of a bowl dia. $38 \mathrm{~cm}$. The context is dated $450-600$.

601. C158. Unstratified. Rim of a bowl, dia. $20-38 \mathrm{~cm}$. 6 other examples were found, of which the earliest 3 came from contexts dated to $100-130$, with 2 more coming from contexts dated to $175-250$.

602 C779. Unstratified. Rim of a bowl with thumb-impressions on the exterior, dia. $40 \mathrm{~cm}$. See 576 for dating.

603. Z211 (5018). Rim of a small bowl, dia. $13 \mathrm{~cm}$. The context is dated to 450 . 

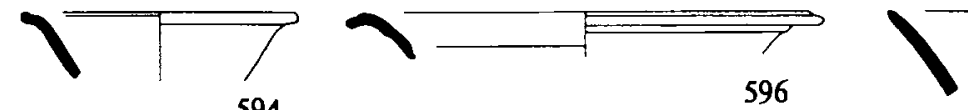

594
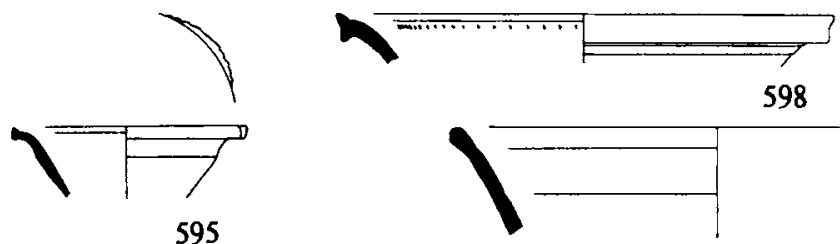

595
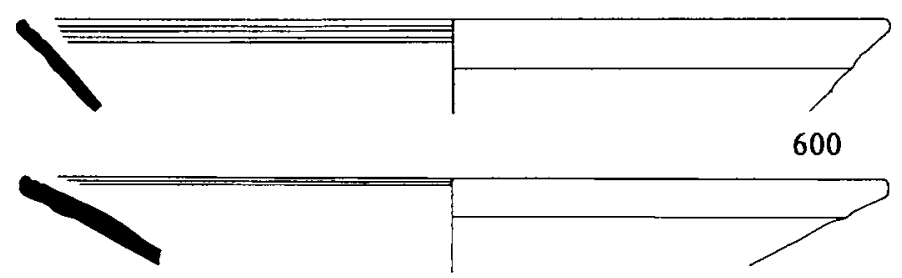

601
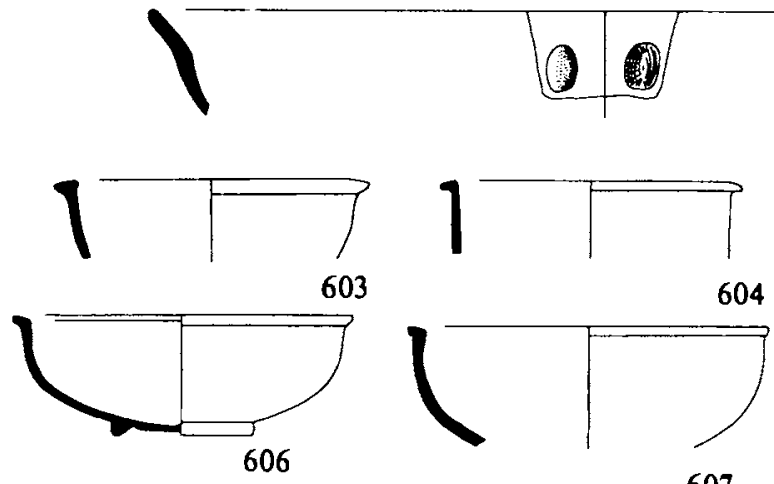

604
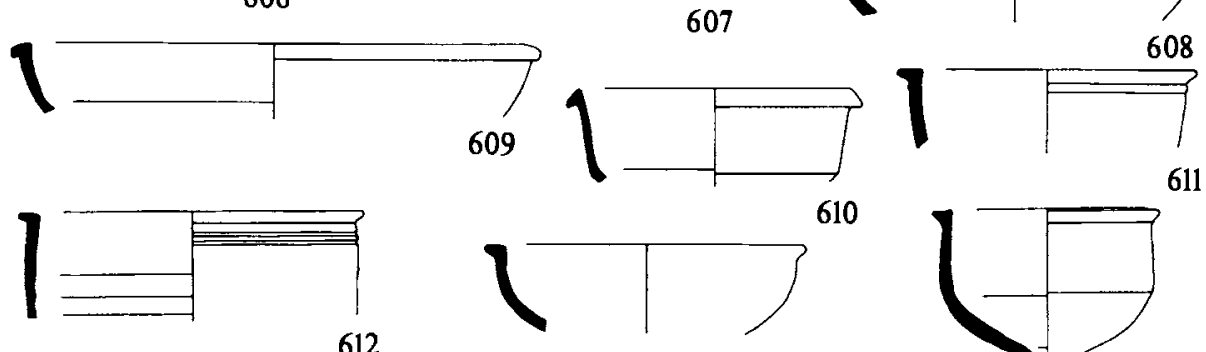

612
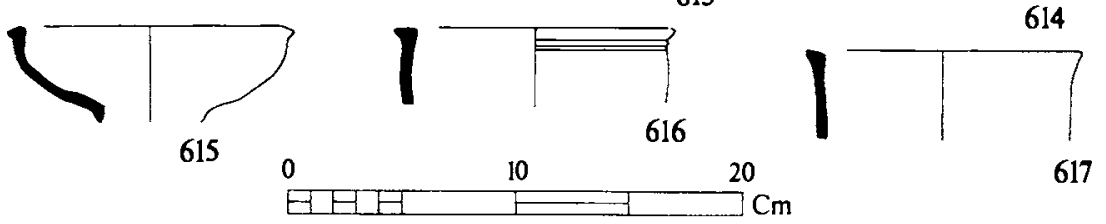

9.31 Red-slipped fine wares: ware 8 
604. C829 (4436). Rim of a small bowl, dia. $10-13 \mathrm{~cm}$. The context is postmedieval. 3 other examples were found, all in post-medieval deposits.

605. F590 (701). Small bowl, dia. 12-24cm. The context is dated $350-450.83$ examples were found ( 39 of them from post-medieval deposits), of which the earliest 3 were from a context dated to 130-150, 2 came from contexts dated to $175-250,1$ from a context dated to $175-350$, and 5 more from contexts dated to $250-350$.

606. C377 (542). Small bowl, dia. $15 \mathrm{~cm}$. The context is dated $450-600$.

607. F209 (672). Rim of a bowl, dia. 15-20cm. The context is dated 175-250. 4 other examples were found, 1 from a context dated to 130-150, 2 from contexts dated to 250-350, and 1 from a context dated to 350-450.

608. C743 (550). Rim of a bowl, dia. $16-32 \mathrm{~cm}$. The context is dated $450-600.3$ other examples were found, 1 from a context dated to 250-350, 1 from a context dated to $250-450$, and 1 from a context dated to $350-450$.

609. C566 (1192). Rim of a bowl, dia. $22-26 \mathrm{~cm}$. The context is dated $400-450.3$ other examples were found, 1 in a context dated to $450-600,1$ in a Slav deposit, and the other in a post-medieval context.

610. G132 (4915). Rim of a small bowl, dia. $12 \mathrm{~cm}$. The context is dated to 450 .

611. C186 (278). Rim of a small bowl, dia. $12 \mathrm{~cm}$. The context is dated 300-450. One other example was found in a context dated to 250-350.

612. F73 (279). Rim of a bowl with two incised bands on the exterior, dia. $15 \mathrm{~cm}$. The context is dated $300-450$.

613. F114 (4436). Rim of a bowl, dia. 10-20cm. The context is post-medieval. 31 examples were found, of which the earliest 3 came from a context dated to 150-175, with 4 others coming from a context dated to 250-350. However 18 examples came from contexts dated to 450-600.

614. C803 (4809). Rim of a small bowl, dia. $9-17 \mathrm{~cm}$. The context is postmedieval, 46 examples were found, of which the earliest 6 were from contexts dated to 250-350, with 10 coming from contexts dated 350-450, 4 from contexts dated to $400-450$, and 5 from contexts dated to 450 .

615. C474 (4479). Rim of a small bowl, dia. $12-24 \mathrm{~cm}$. The context is postmedieval. 7 other examples were found, 3 from contexts dated to 130-150, 3 from contexts dated to $350-450$, and 1 from a context dated to $450-600$.

616. F65 (249). Rim of a small bowl with two incised bands on the exterior, dia. $20-30 \mathrm{~cm}$. The context is dated $300-450.6$ examples were found, 2 from 
contexts dated to $175-250,2$ from contexts dated to $250-275$, and 2 from contexts dated to $275-450$.

617. C332 (2277). Rim of a bowl, dia. $11-23 \mathrm{~cm}$. The context is dated $100-130.6$ examples were found, 2 from contexts dated to 100-130, 1 from a context dated $250-350$, and 3 from contexts dated to 450 .

Red-slipped fine wares: ware 8 (Fig. 9.32)

618. C138 (453). Rim of a bowl, dia. $13-16 \mathrm{~cm}$. The context is post-medieval. The only example from before a post-medieval context was from one dated to $175-250$.

619. C698 (4817). Rim of a bowl, dia. $14-18 \mathrm{~cm}$. The context is post-medieval. 3 examples were found, of which the earliest one came from a context dated to $130-150$.

620. C129 (548). Rim of a bowl, dia. $12-20 \mathrm{~cm}$. The context is dated $450-600.6$ other examples were found, 1 from a context dated to 130-150, 3 from contexts dated to $250-350,1$ from a context dated $350-450$, and 1 from a context dated to 450 .

621. F481 (3089). Rim of a bowl, dia. 16-18cm. The context is dated $450-600.2$ other examples were found, both from contexts dated to $350-450$.

622. C253 (535). Rim of a bowl, dia. $17-20 \mathrm{~cm}$. The context is dated $450-600.3$ other examples were found, all in contexts dated to 250-350.

623. C535 (4848). Rim of a bowl, dia. $14-18 \mathrm{~cm}$. The context is dated $350-450$. One other example was found in a context dated to 450 .

624. C803 (4033). Rim of a bowl, dia. $9-17 \mathrm{~cm}$. The context is dated to 450 . See 614 for dating.

625. C553 (550). Rim of a bowl, dia. $13-18 \mathrm{~cm}$. The context is dated $450-600.3$ other examples were found, 1 from a context dated to 350-450, 1 from a context dated to 450 , and 1 from a context dated to $450-600$.

626. C502 (1123). Rim of a bowl with incised band on the interior, dia. $9-17 \mathrm{~cm}$. The context is dated to 450.8 examples were found, of which the earliest 3 came from contexts dated to 175-250, 1 came from a context dated to 250-350, and another from a context dated 350-450.

627. C763 (544). Rim of a bowl with incised band on the interior, dia. $26 \mathrm{~cm}$. The context is dated $350-450$. 


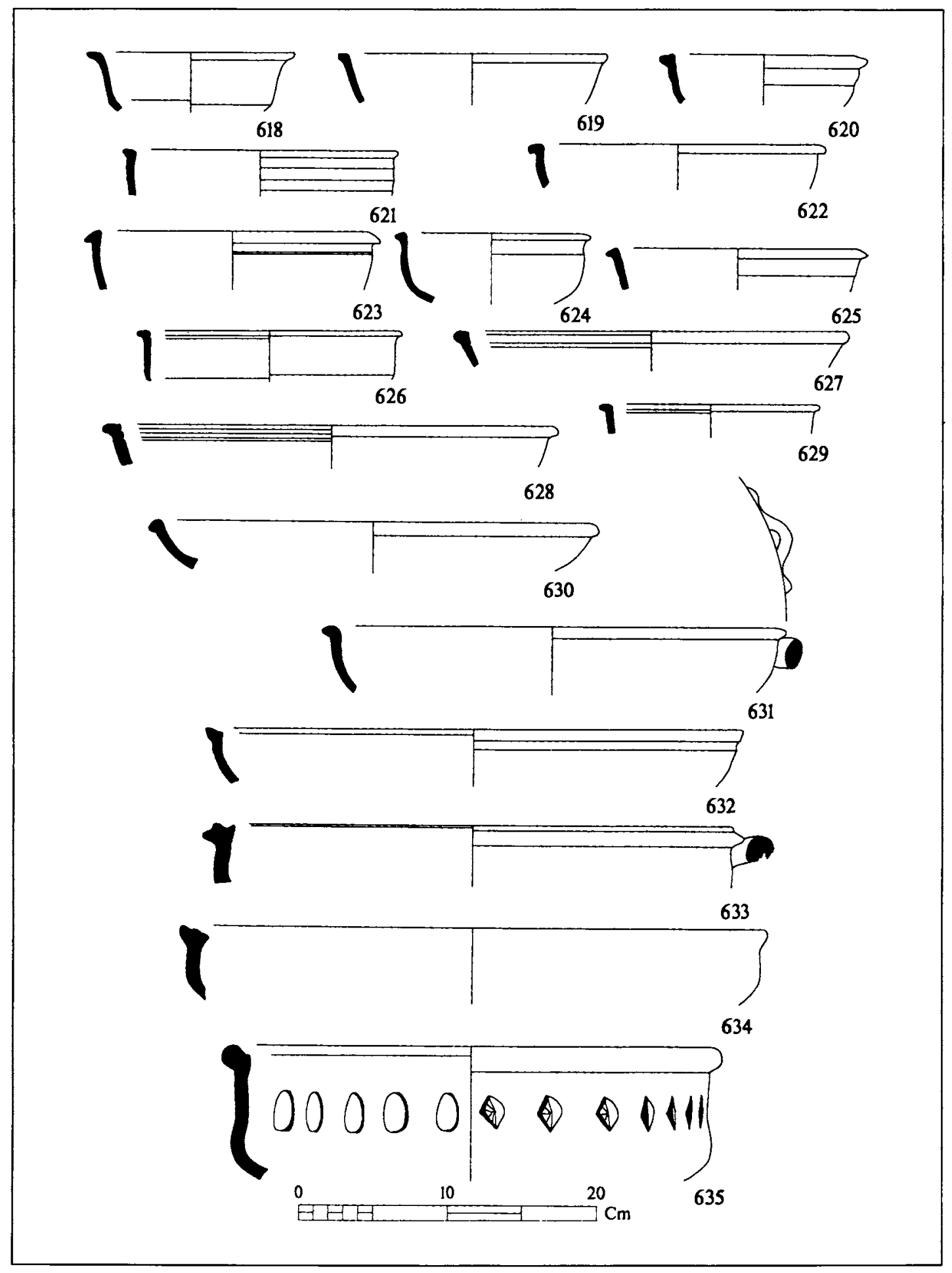

9.32 Red-slipped fine wares: ware 8 
628. C510 (665). Rim of a bowl with two incised bands on the interior, dia. $30 \mathrm{~cm}$. The context is dated $250-350$.

629. C502 (665). Rim of a bowl with an incised band on the interior, dia. $11-14 \mathrm{~cm}$. The context is dated $250-350$. See 626 for dating.

630. F597 (4033). Rim of a bowl, dia. $28-32 \mathrm{~cm}$. The context is dated to 450 . One other example was found in a context dated to $350-450$.

631. C487 (699). Rim of a bowl with horizontal strap handle, dia. $30 \mathrm{~cm}$. The context is dated $130-150$.

632. C839 (3209). Rim of a large bowl, dia. $36 \mathrm{~cm}$. The context is post-medieval. One other example was found in a context dated to 450 .

633. C466 (699). Rim of a large bowl with horizontal strap handle, dia. $35 \mathrm{~cm}$. The context is dated $130-150$.

634. C460 (699). Rim of a large bowl, dia. $34-39 \mathrm{~cm}$. The context is dated 130-150. 2 other examples came from the same context.

635. Z176 (3292). Large bowl with heavily impressed decoration on the exterior which has caused corresponding bumps on the interior, dia. $32.5 \mathrm{~cm}$. The context is dated $400-450$.

Red-slipped fine wares: ware 8 (Fig. 9.33)

636. C240 (342). Rim of a bowl, dia. $30 \mathrm{~cm}$. The context is dated $175-250$.

637. C822 (4033). Rim of a bowl, dia. $20 \mathrm{~cm}$. The context is dated to 450 .

638. C864 (5288). Rim of a bowl, dia. $18 \mathrm{~cm}$. The context is dated $400-450$.

639. C483 (699). Rim of a bowl, dia. $23 \mathrm{~cm}$. The context is dated $130-150.6$ examples were found, 4 from contexts dated to $130-150,1$ from a context dated to $400-450$, and 1 from a context dated to $400-600$.

640. F480 (1). Rim of a bowl, dia. $13-16 \mathrm{~cm}$. The context is post-medieval. 20 examples were found ( 8 from post-medieval deposits), of which the earliest 3 came from contexts dated to $130-150,1$ came from a context dated to $175-250$, and 2 more from contexts dated to $250-350$.

641. F376 (5018). Rim of a bowl, dia. $11 \mathrm{~cm}$. The context is dated to 450 .

642. C288 (511). Rim of a bowl, dia. $26 \mathrm{~cm}$. The context is dated $450-600$.

643. G156 (5025). Rim of a bowl, dia. $12-19 \mathrm{~cm}$. The context is dated $150-250$. One other example was found in a context dated to $275-450$. 
644. F30 (243). Rim of a bowl, dia. $19 \mathrm{~cm}$. The context is dated $300-450$.

645. C866 (4433). Rim of a bowl, dia. $13 \mathrm{~cm}$. The context is post-medieval.

646. C94 (235). Rim of a bowl, dia $8-15 \mathrm{~cm}$. The context is dated $130-175.4$ other examples were found, 1 from a context dated to $130-175,2$ from contexts dated to $175-250$, and 1 from a context dated to $250-275$.

647. C601 (5018). Rim of a bowl, dia. 14-18cm. The context is dated to 450.6 other examples were found: 2 from contexts dated to $350-450,2$ more from contexts dated to 450 , and 2 from contexts dated to $450-600$.

648. G87 (4516). Rim of a bowl, dia. $14 \mathrm{~cm}$. The context is dated $250-450.2$ more examples were found, 1 from another context dated to $250-450$, and 1 from a context dated to $350-450$.

649. C558 (1124). Rim of a bowl, dia. $22-30 \mathrm{~cm}$. The context is dated to 450 . One other example was found in a context dated to 400-450.

650. F98 (542). Rim of a bowl, dia. $13 \mathrm{~cm}$. The context is dated $450-600$.

651. C336 (2253). Rim of a bowl, dia. 10-20cm. The context is dated $100-130.2$ more examples came from contexts dated to 100-130.

652. C331 (2277). Rim of a bowl, dia $24-26 \mathrm{~cm}$. The context is dated $100-130$. One other example was found, also in a context that dated to 100-130.

653. C314 (604). Rim of a bowl, dia. $26-30 \mathrm{~cm}$. The context is dated $350-450$. One other example was found in a context dated to 450 .

654. C794 (2277). Rim of a perforated bowl, dia. $18 \mathrm{~cm}$. The context is dated 100-130.

655. C519 (667). Rim of a perforated bowl, dia. $10-13 \mathrm{~cm}$. The context is dated 175-250.

656. G94 (4912). Rim of a perforated bowl, dia. $10-14 \mathrm{~cm}$. The context is dated $450-600.3$ other examples were found, 1 from a context dated to 175-250, 1 from a context dated 350-450, and 1 from a post-medieval deposit.

657. Z182 (4857). Base of a perforated bowl, dia. $7.5 \mathrm{~cm}$. There are 3 holes cut in the base (before firing), and 4 or more in the body wall. The slip on top of the central nipple is worn. The context is dated $350-450$.

658. Z13. Unstratified. Base with bored holes around edge at $2 \mathrm{~cm}$ intervals, dia. $9 \mathrm{~cm}$.

659. Z212 (4479). Rim of a saucer, dia. $16 \mathrm{~cm}$. The context is post-medieval. 

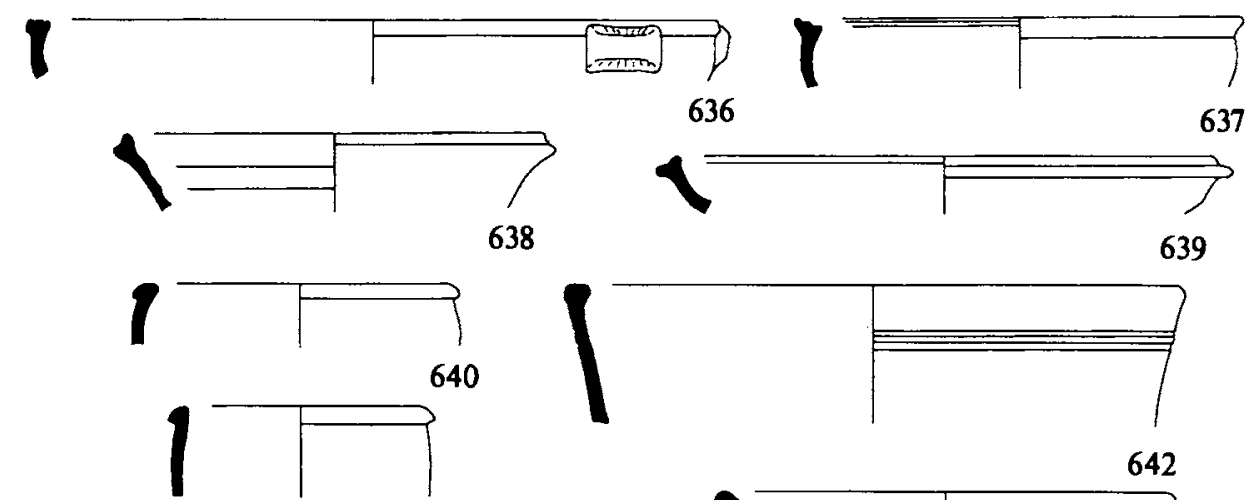

639

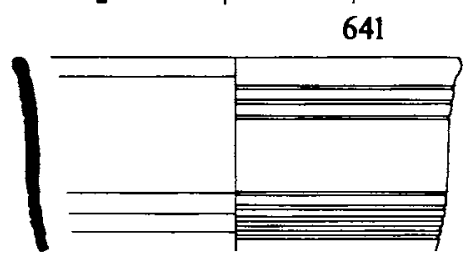

643
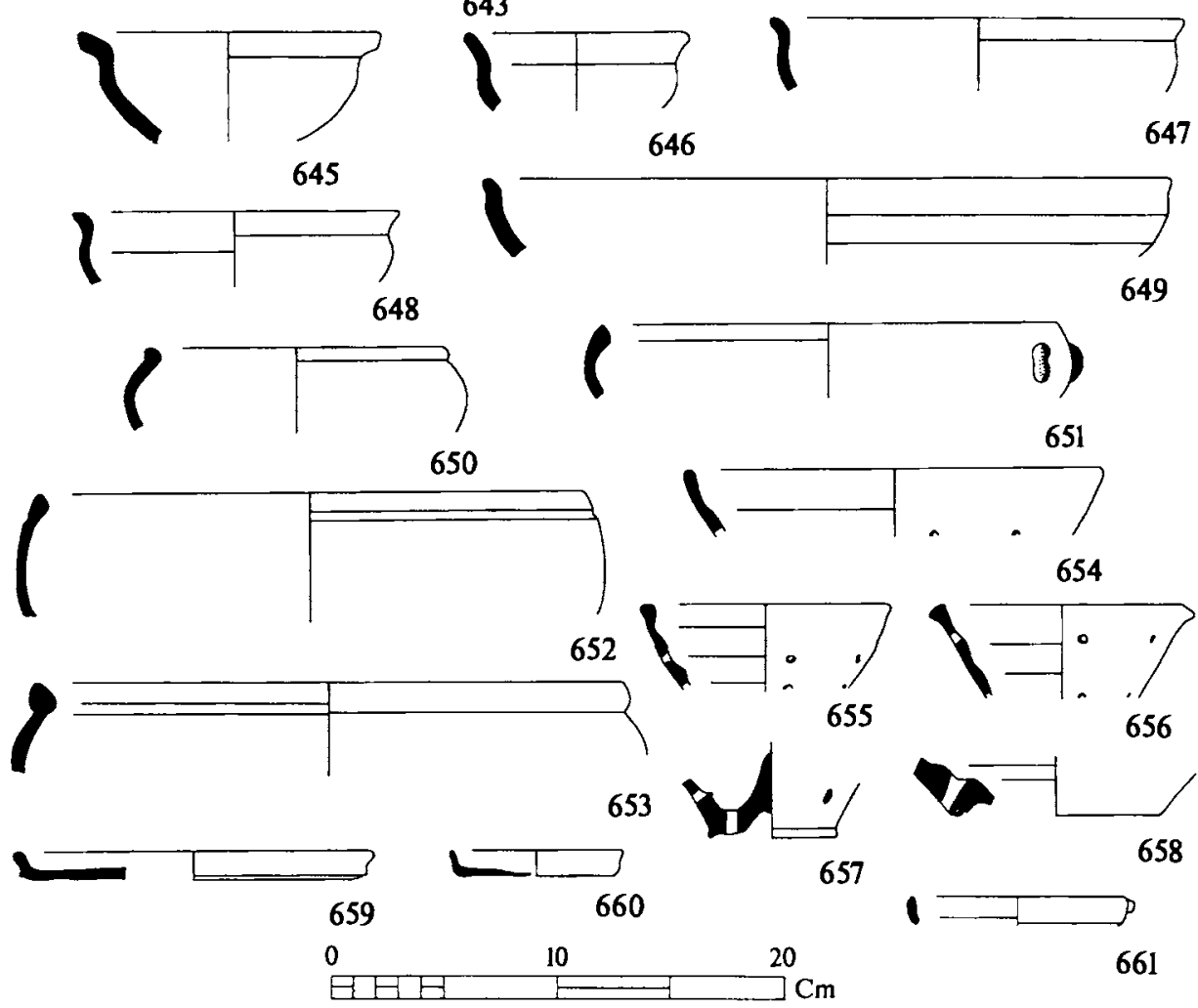

9.33 Red-slipped fine wares: ware 8 
660. C637 (4097). Rim of a small saucer, dia. $8 \mathrm{~cm}$. The context is dated $300-450$. One other example was found in a context dated to $250-450$.

661. C78 (231). Rim of a small saucer with a very small ledge handle (more decorative than functional), dia. $9 \mathrm{~cm}$. The context is dated $175-350$, but contains some later material.

Red-slipped fine wares: ware 8 (Fig. 9.34)

662. F249 (699). Rim of a bowl, dia. $22 \mathrm{~cm}$. The context is dated 130-150.

663. C723 (1018). Rim of a bowl, dia. $14-23 \mathrm{~cm}$. The context is post-medieval. 13 examples were found, of which the earliest one came from a context dated to $130-150,4$ came from contexts dated to $250-350,1$ from a context dated to $250-450$, and 2 more from contexts dated to $350-450$.

664. C339 (2260). Rim of a bowl with incised lines on the top of the rim. dia. $15-23 \mathrm{~cm}$. The context is dated 100-130. 7 other examples were found, of which 7 came from contexts dated to 250-350, and 1 from a context dated $350-450$.

665. F196 (676). Rim of a bowl, dia. 14-20cm. The context is dated 175-250. 4 other examples were found, 3 more from contexts dated to $175-250$, and 1 from a context dated to $350-450$.

666. Gl47 (682). Rim of a bowl, dia. $16 \mathrm{~cm}$. The context is dated $350-450$.

667. F197 (676). Rim of a bowl, dia. $13 \mathrm{~cm}$. The context is dated $175-250$.

668. F166. Unstratified. Rim of a bowl, dia. $12-23 \mathrm{~cm}$. 3 other examples were found, 1 from a context dated to 130-150,1 from a context dated to $275-450$, and 1 from a context dated to $350-450$.

669. C626 (4096). Rim of a bowl, dia. $16 \mathrm{~cm}$. The context is dated $400-500$, but contains later material.

670. G131 (4923). Rim of a small cup, dia. $6 \mathrm{~cm}$. The context is dated 350-450. One other example was found, also in a context dated to $350-450$.

671. C488 (677). Small bowl, dia. 7cm. The context is dated 175-250. One other example was found in a context dated to 250-350.

672. C259 (542). Rim of a bowl, dia. $10-15 \mathrm{~cm}$. The context is dated $450-600.4$ examples were found, all from contexts dated to $450-600$.

673 C469 (699). Rim of a bowl with applied knobs on the exterior, dia. $16-20 \mathrm{~cm}$. The context is dated 130-150.9 examples were found, of which 


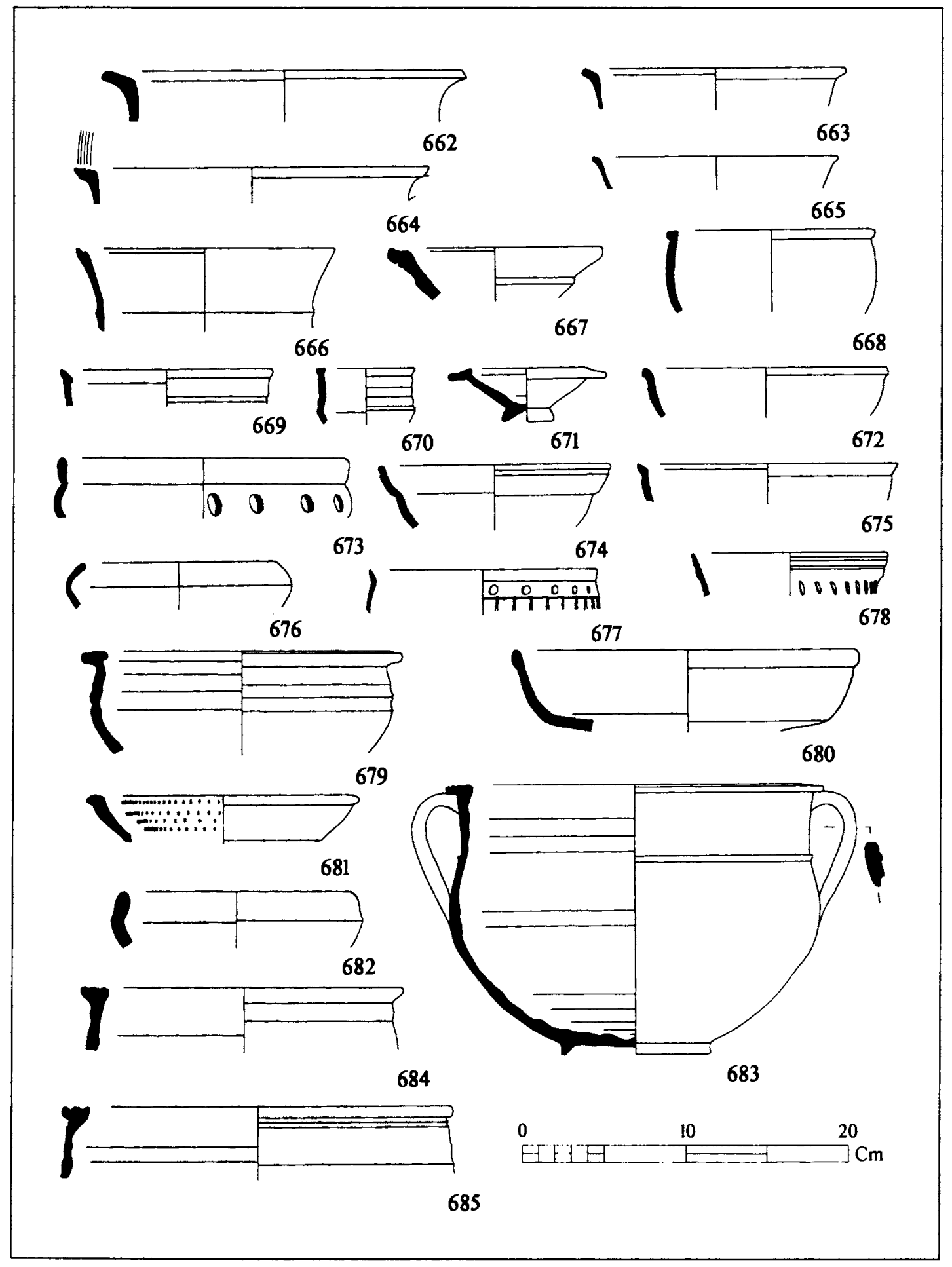

9.34 Red-slipped fine wares: ware 8 
the earliest 3 came from contexts dated to 100-130, and 3 more came from contexts dated to $130-150$.

674. C194 (267). Rim of a bowl, dia. $14 \mathrm{~cm}$. The context is dated 100-130. One other example came from the same context.

675. C494 (672). Rim of a bowl, dia. $16-23 \mathrm{~cm}$. The context is dated $175-250$. Two other examples were found, 1 from a context dated to $175-250$, and 1 from a context dated to $350-450$.

676. C119 (248). Rim of a bowl, dia. $10-14 \mathrm{~cm}$ (though one example is $18 \mathrm{~cm}$ ). The context is dated 300-450. 19 examples were found, of which the earliest 7 came from contexts dated to $100-130$, and a further 4 from contexts dated to $130-150$.

677. C863 (3360). Rim of a bowl with circular impressions and incised lines on the exterior, dia. $14 \mathrm{~cm}$. The context is dated $400-450$.

678. F264 (699). Rim of a bowl with impressed decoration on the exterior, dia. $12 \mathrm{~cm}$. The context is dated 130-150. There was one other example from the same context.

679. $\mathrm{C} 858$ (3271). Rim of a bowl, dia. $18 \mathrm{~cm}$. The context is post-medieval.

680. Z36 (1). Rim of a bowl, dia. $21 \mathrm{~cm}$. The context is post-medieval.

681. G99 (4907). Rim of a bowl with rouletted decoration on the interior, dia. $16 \mathrm{~cm}$. The context is post-medieval.

682. C125 (405). Rim of a bowl, dia. $14-28 \mathrm{~cm}$. The context is post-medieval. One other example was found in a context dated to $450-600$.

683. Z30. Unstratified. Crater, dia. $20.5 \mathrm{~cm}$.

684. A10 (1003). Rim of a crater, dia. $14-28 \mathrm{~cm}$ (usually $19-28 \mathrm{~cm}$ ). The context is post-medieval. 4 other examples were found, 2 from contexts dated to $175-250$, and 2 from contexts dated to $350-450$.

685. F96 (542). Rim of a crater, dia. 15-24cm. The context is dated 450-600. 7 examples were found, 5 from contexts dated to $350-450$, and 2 from contexts dated to $450-600$.

Red-slipped fine wares: ware 8 (Fig. 9.35)

686. C2. Unstratified. Crater, dia. 13-28cm (usually $16-22 \mathrm{~cm}$ ). 578 examples were found evenly distributed between contexts dated from 100-600. 
687. F139 (544). Rim of a crater, dia. $12-22 \mathrm{~cm}$ (usually $16-22 \mathrm{~cm}$ ). The context is dated 350-450. 45 examples were found, of which the earliest two came from contexts dated to 130-150, with 3 more coming from contexts dated to $175-250$, and 22 from contexts dated to $250-350$.

688. F282 (4906). Rim of a crater with cut pattern on exterior, dia. $14-20 \mathrm{~cm}$ (though one example is $26 \mathrm{~cm}$ ). The context is dated $450-600.55$ examples were found, of which the earliest two came from contexts dated to 150-250, and a further 9 came from contexts dated to $175-250$.

689. C467 (4516). Rim of a crater, dia. $15-20 \mathrm{~cm}$. The context is dated $250-450$. 12 examples were found, of which the earliest 6 came from contexts dated to $130-150$.

690. F199 (676). Rim of a crater with faintly stamped decoration on top of the rim, dia. 16-20 cm. The context is dated 175-250.9 examples were found, of which the earliest one came from a context dated to 150-250, 1 more from a context dated to $175-250$, and 2 from contexts dated to 250-350.

691. G117 (681). Rim of a crater with impressed decoration on top of the rim, dia. $22 \mathrm{~cm}$. The context is dated $175-250$.

692. F261 (699). Rim of a crater, dia. 9-16cm. The context is dated 130-150. 4 examples were found, 2 from contexts dated to $130-150,1$ from a context dated to 150-250, and 1 from a context dated to 250-350.

693. C732 (1031). Rim of a crater, dia. $16 \mathrm{~cm}$. The context is dated $450-600$.

694. F122 (511). Rim of a crater, dia. $15-23 \mathrm{~cm}$. The context is dated $450-600.6$ examples were found, 2 from contexts dated to 350-450, 2 from contexts dated to 450-600, and 2 from post-medieval deposits.

695. Z217 (4912). Rim of a crater, dia. $22 \mathrm{~cm}$. The context is dated $450-600$.

696. C2 (5306). Rim of a crater, dia. $16-22 \mathrm{~cm}$. The context is dated 250-350. See 686 for dating.

697. C244. (665). Rim of a crater with combed pattern on neck, dia. $12-28 \mathrm{~cm}$. The context is dated 250-350.60 examples were found, of which the earliest one came from a context dated to $150-175,1$ came from a context dated 175-250, 9 from contexts dated to 250-350, and 27 from contexts dated to $350-450$.

698. F258 (699). Rim of a crater, dia. $20-22 \mathrm{~cm}$. The context is dated 130-150. One other example was found in a context that also dated to 130-150.

699. G10 (4118). Rim of a crater, dia. $17 \mathrm{~cm}$. The context is dated $175-250$. 

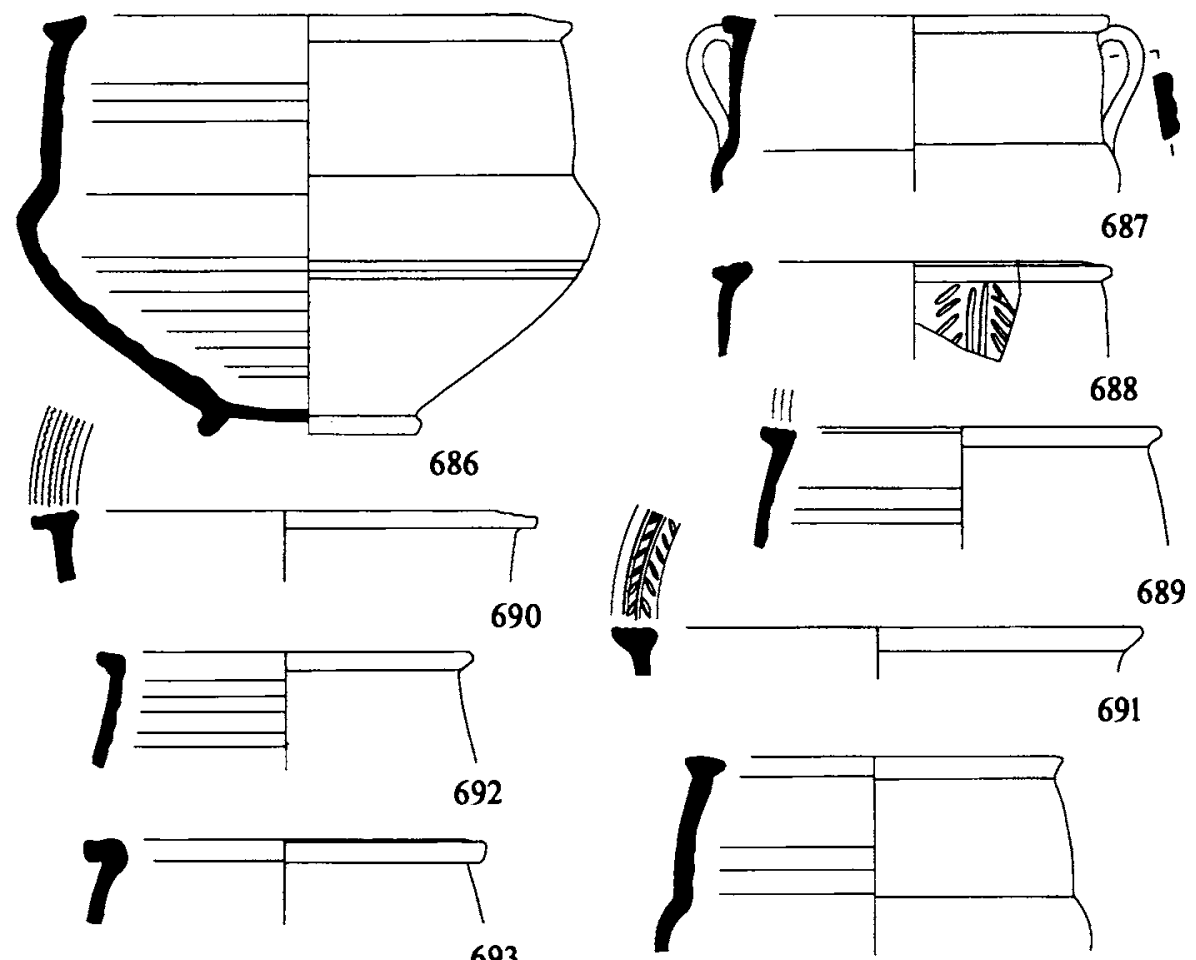

7
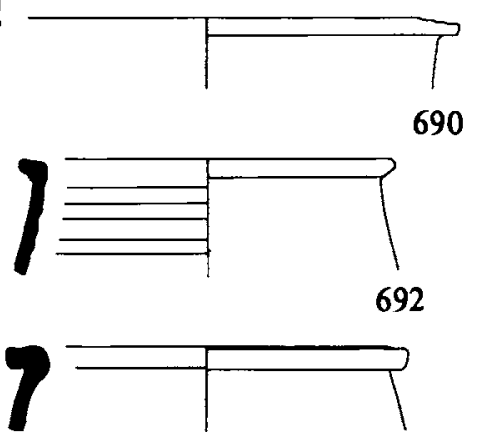

693
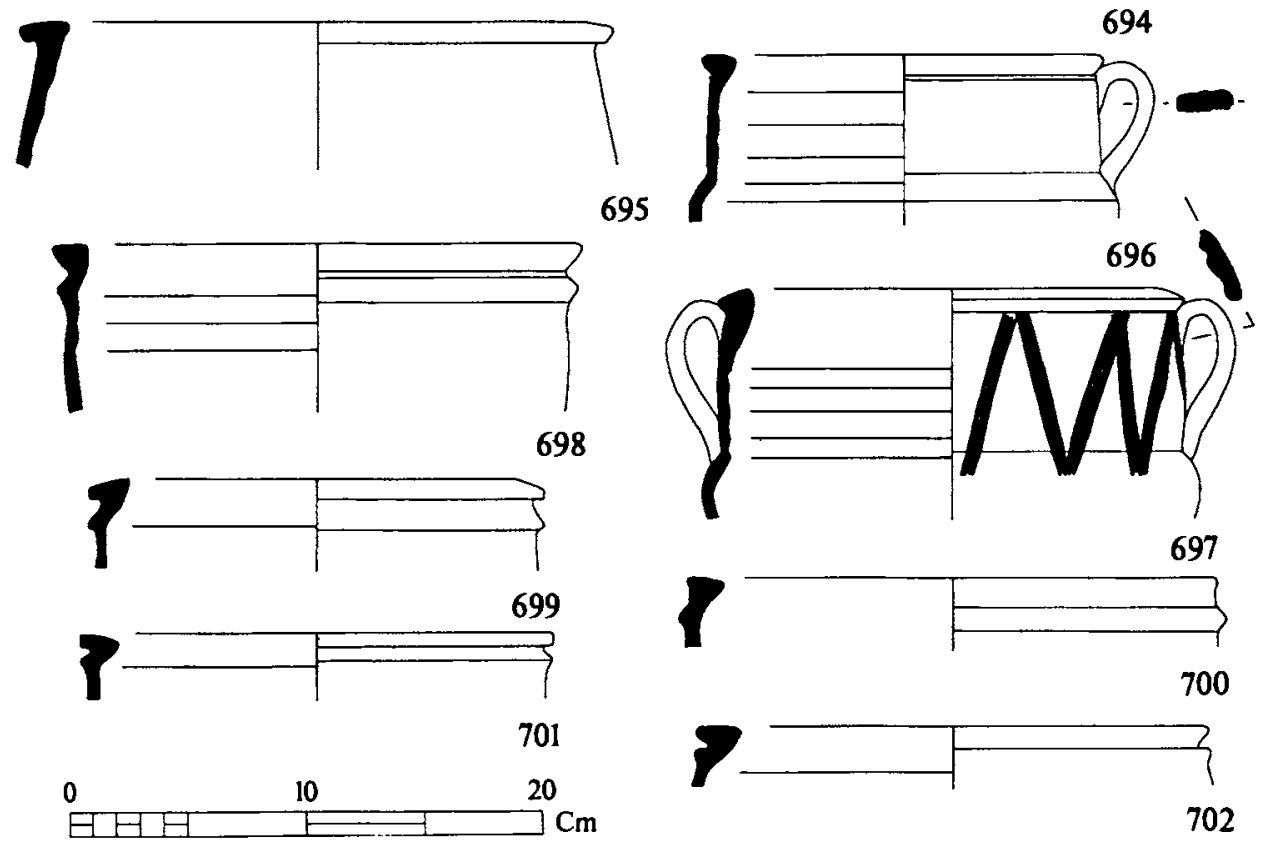

9.35 Red-slipped fine wares: ware 8 
700. F468 (4128). Rim of a crater, dia. $22 \mathrm{~cm}$. The context is dated $250-350$.

701. F509 (2211). Rim of a crater, dia. $20 \mathrm{~cm}$. The context is dated to 450.8 examples were found, 3 from contexts dated to $250-350$, and 1 each from contexts dated to $400-450,400-500,450,450-600$ and a post-medieval deposit.

702. F260 (699). Rim of a crater, dia. $18-21 \mathrm{~cm}$. The context is dated $130-150.3$ other examples were found, all from contexts dated to 450-600.

Red-slipped fine wares: ware 8 (Fig. 9.36)

703. Z213 (3011). Rim of a crater with incised lines on the top of the rim, dia. $19 \mathrm{~cm}$. The context is post-medieval.

704. F82. Unstratified. Rim of a crater, dia. 15-26cm. 21 examples were found, of which the earliest two came from contexts dated to 100-130, 1 came from a context dated to 130-150, 6 from contexts dated to 150-175, and a further 7 from contexts dated to $175-250$.

705. F248 (699). Rim of a crater, dia. $18-25 \mathrm{~cm}$. The context is dated $130-150.17$ examples were found, of which the earliest one came from a context dated to $130-150,4$ came from contexts dated to $175-250$, and 4 from contexts dated to $250-450$.

706. C2 (699). Rim of a crater, dia. 16-22cm. The context is dated 130-150. See 686 for dating.

707. F62 (2277). Rim of a crater, dia. $20-24 \mathrm{~cm}$. The context is dated $100-130.42$ examples were found, 7 from contexts dated to 100-130, 11 from contexts dated to $130-150,1$ from a context dated to $150-175$, and 21 from contexts dated to $175-250$.

708. G7 (4118). Rim of a crater, dia. $17-25 \mathrm{~cm}$. The context is dated $175-250.8$ examples were found, 2 from contexts dated to $130-150,5$ from contexts dated to 175-250, and 1 from a context dated to 250-350.

709. C744 (4117). Rim of a crater, dia. $16 \mathrm{~cm}$. The context is dated $175-250$. One other example was found in a context dated to 450-600.

710. C463 (699). Rim of a crater with appliqué decoration on the exterior, dia. $20 \mathrm{~cm}$. The context is dated 130-150. 9 examples were found, all in the same context, and it is very likely that most come from the same vessel - all had the same diameter. 


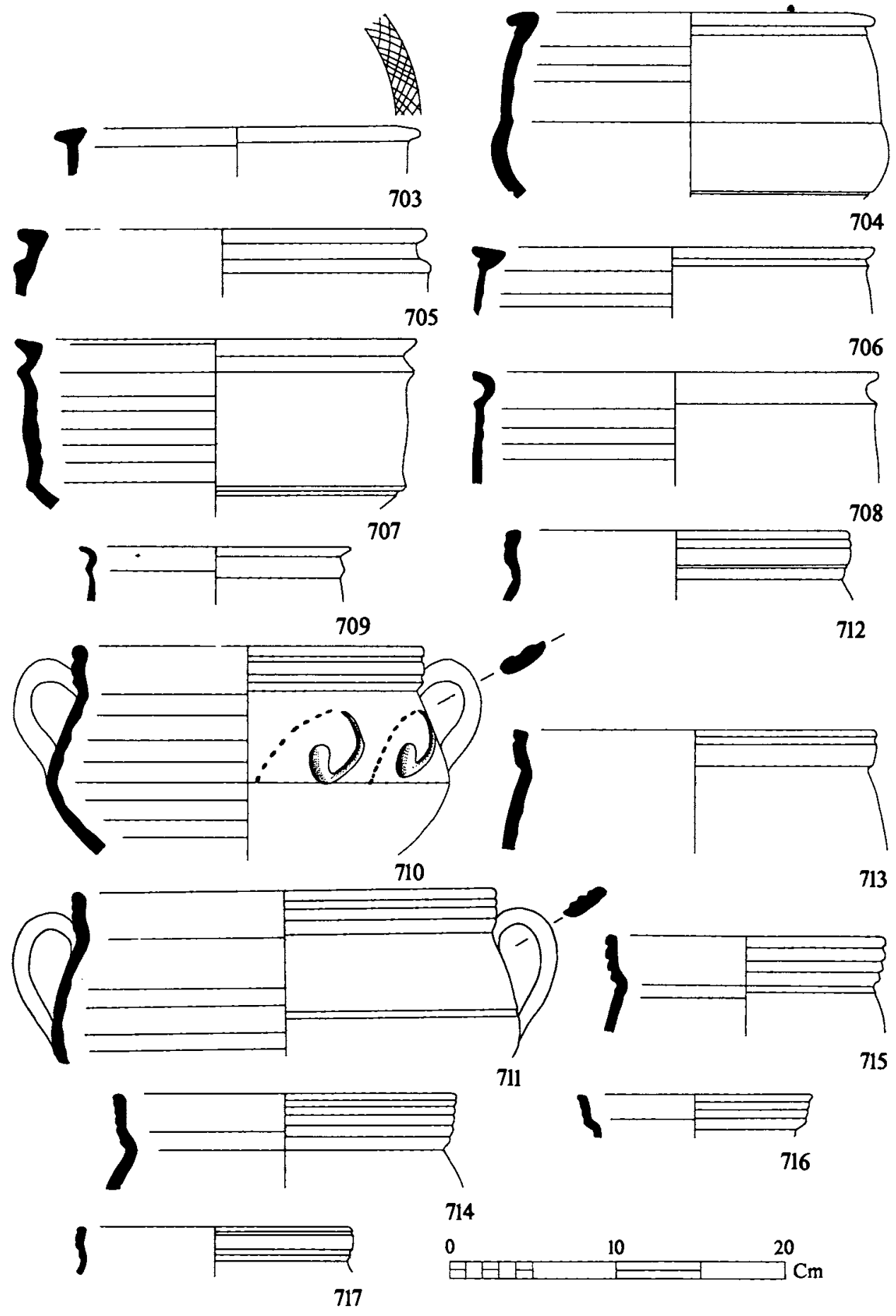

9.36 Red-slipped fine wares: ware 8 


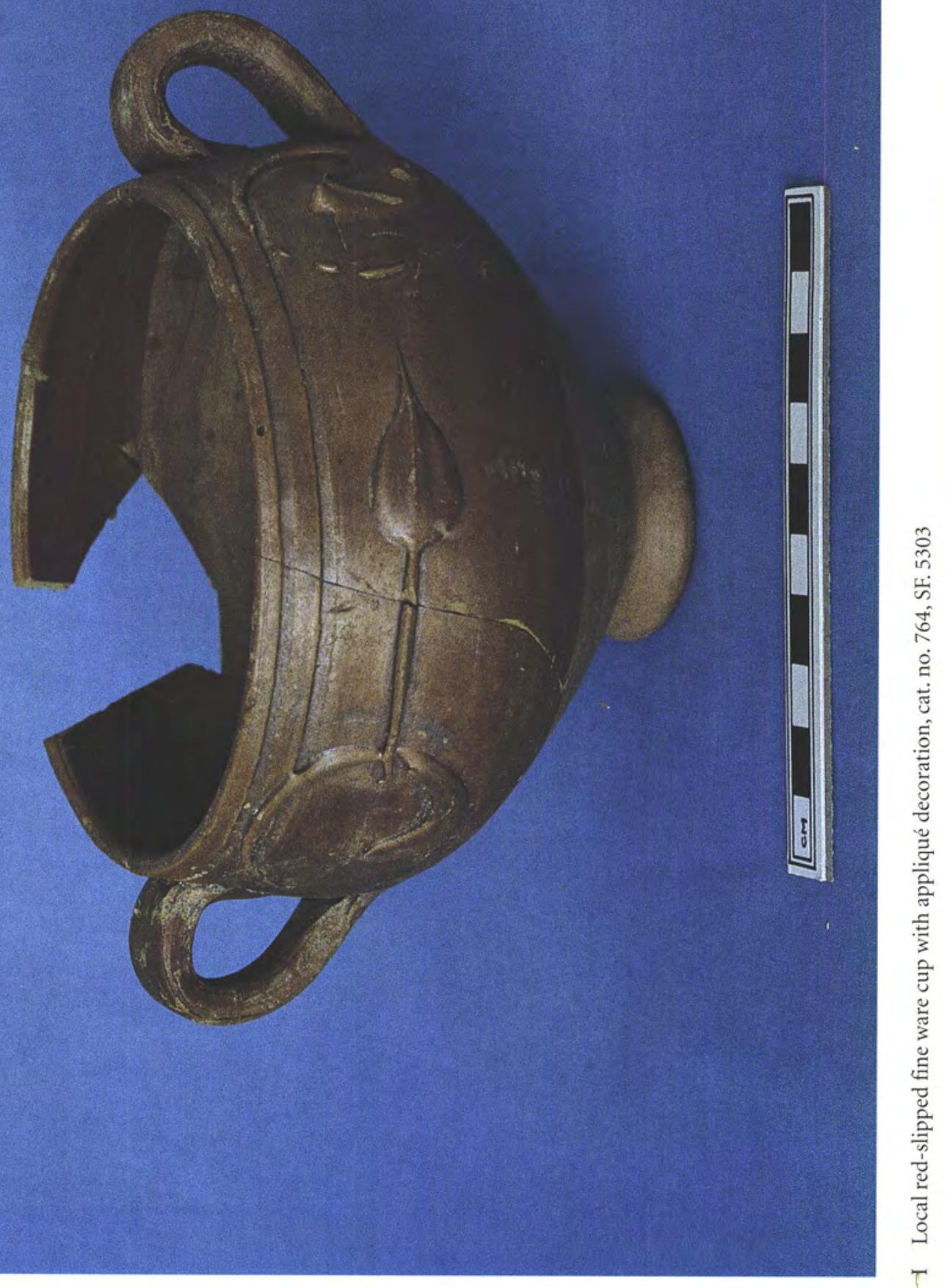




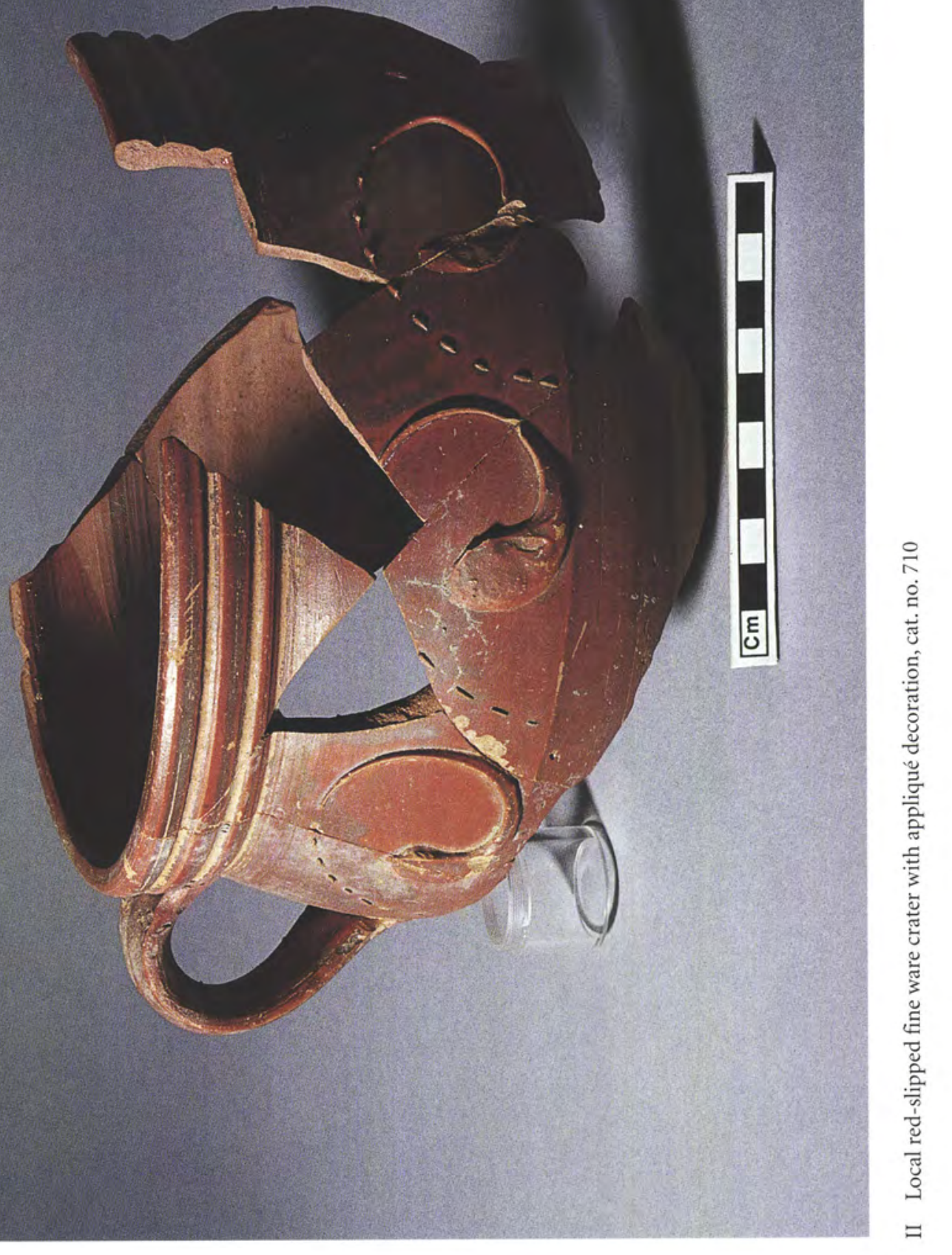



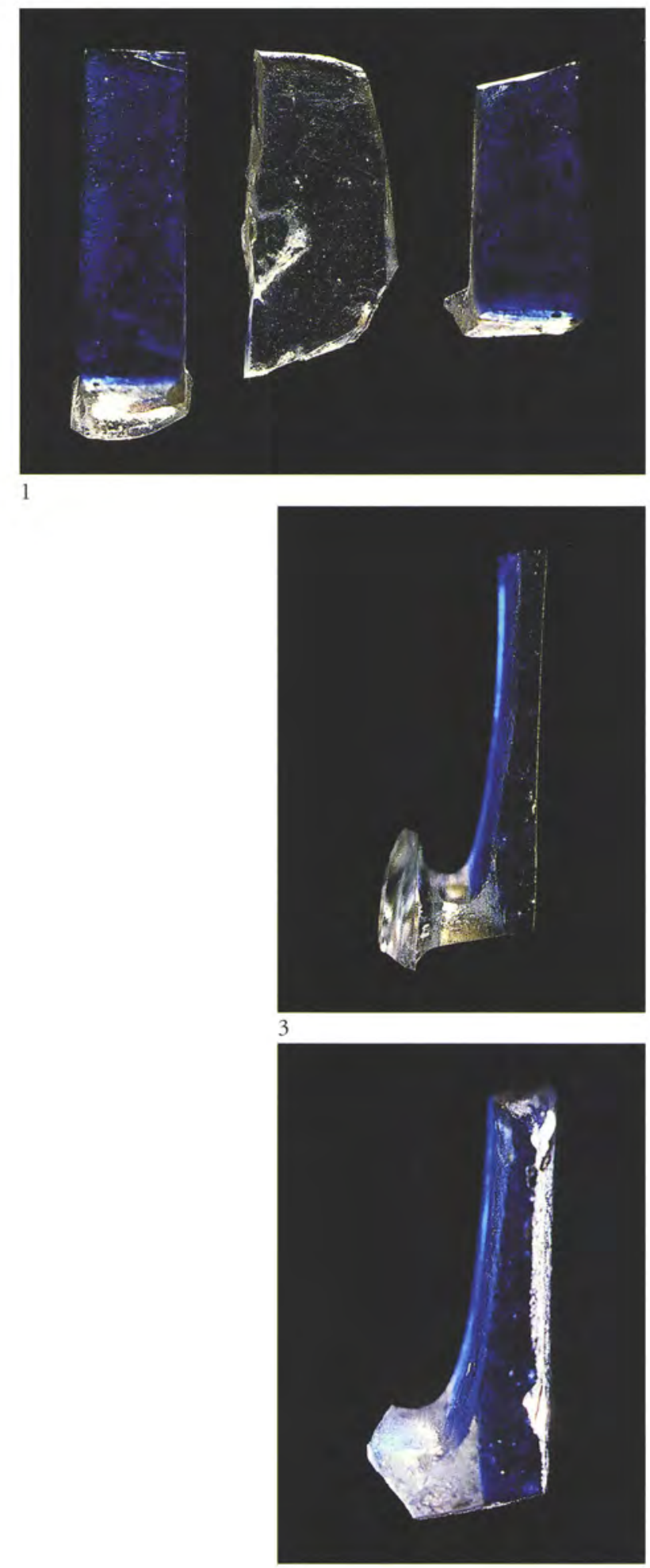

5
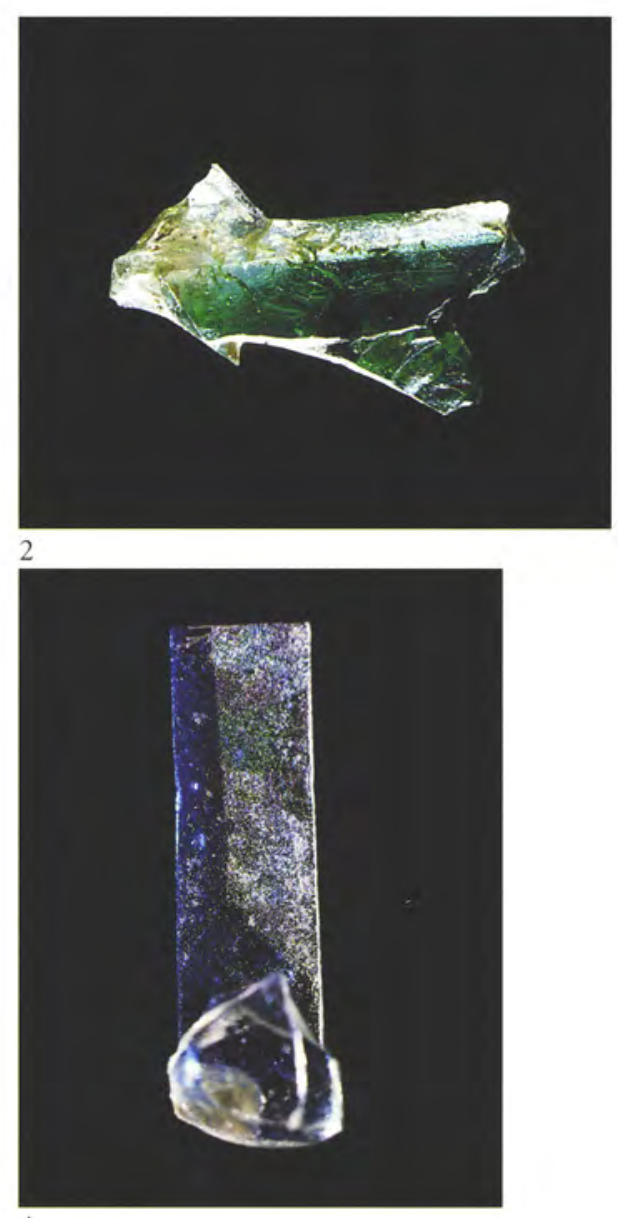

4

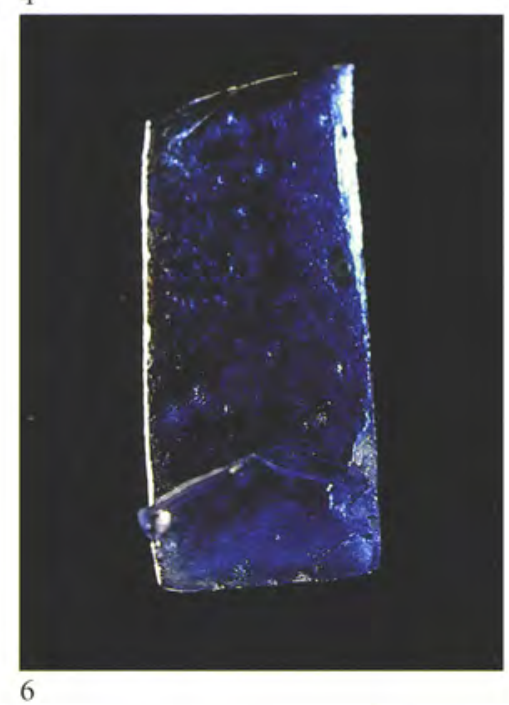

III Fragments of diatretum (cat. nos 41-63); 1, SF. 14145a, 14145b, 14167; 2, SF. 14639; 3 and 4, SF. 14145a; 5 and 6, SF. 14167. 

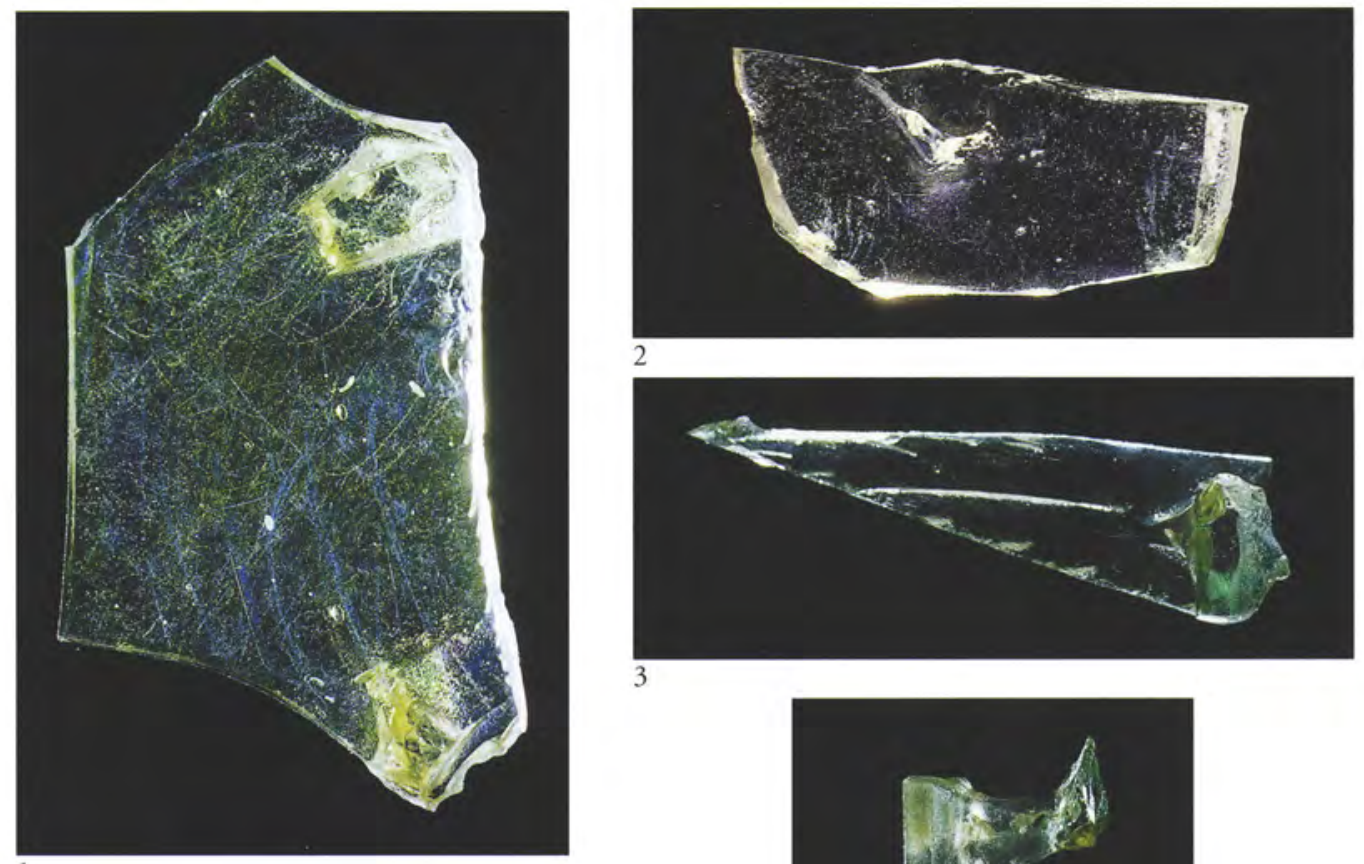

2

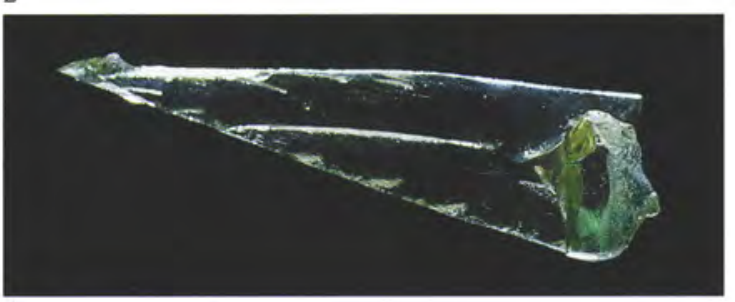

3
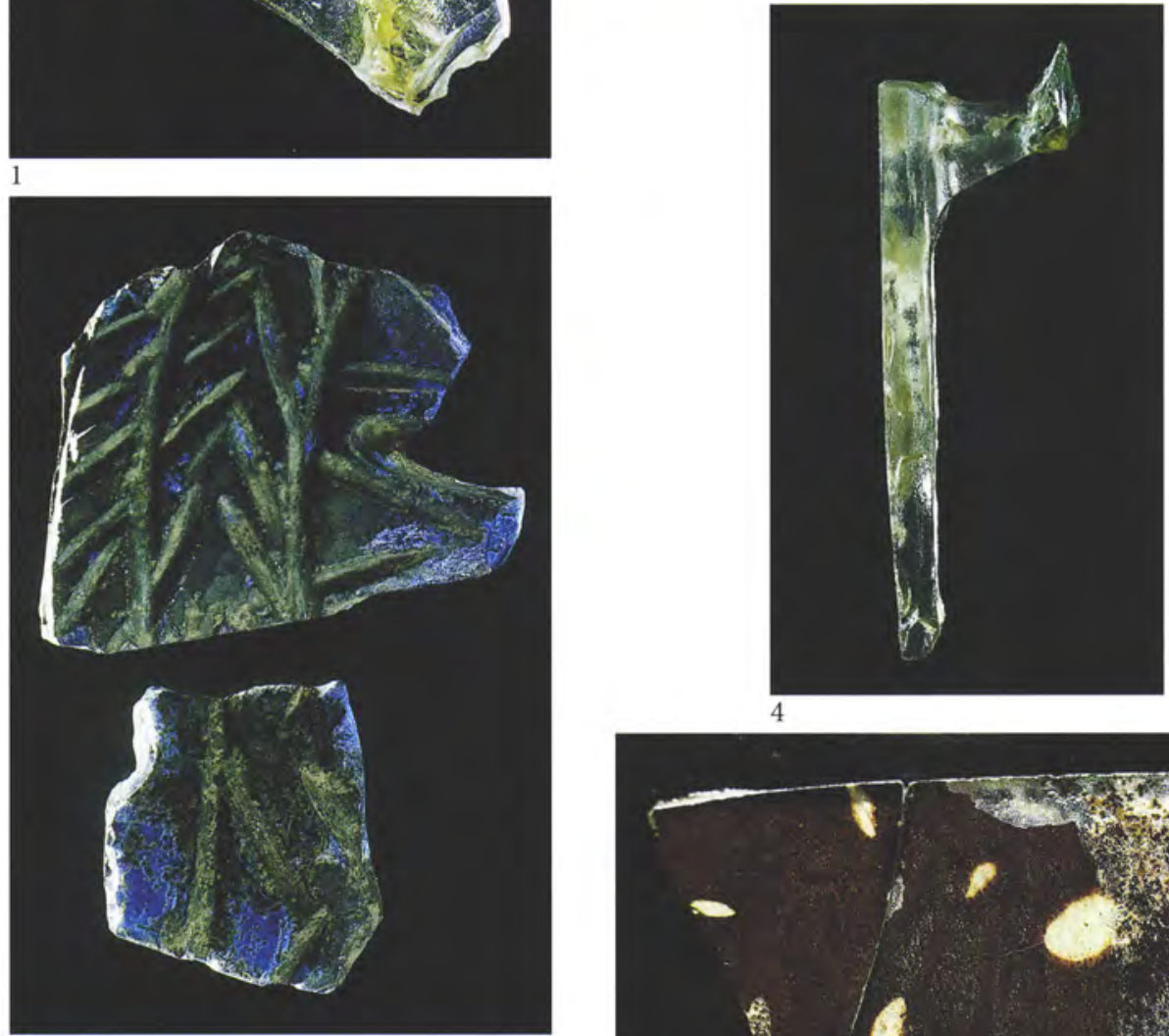

4

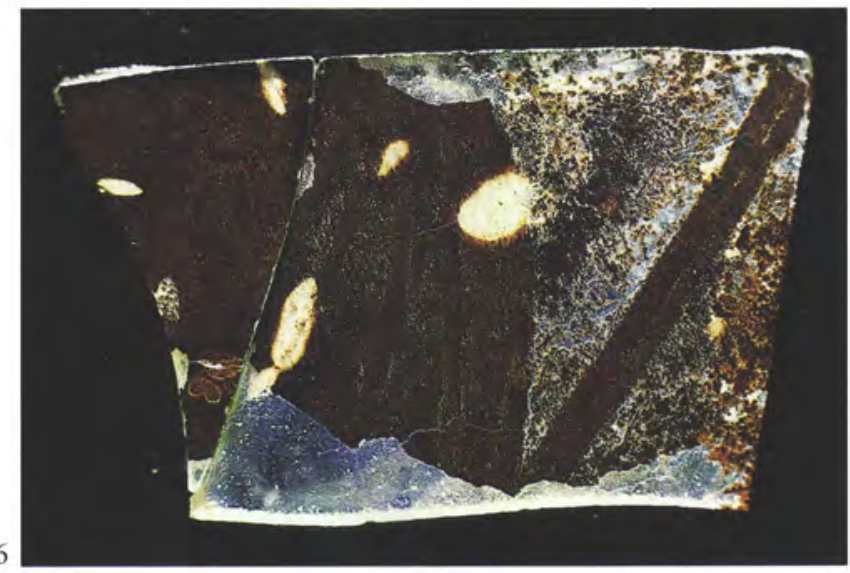

IV Fragments of diatretum (cat. nos 41-63); 1, SF. 14622; 2, SF. 14145b; 3 and 4, SF. 14630.

Fragments of diatretum (cat. no. 64); 5, SF. 13034 and 13036. Fragment from the side of a glass bowl, 6, cat. no. 310 . 


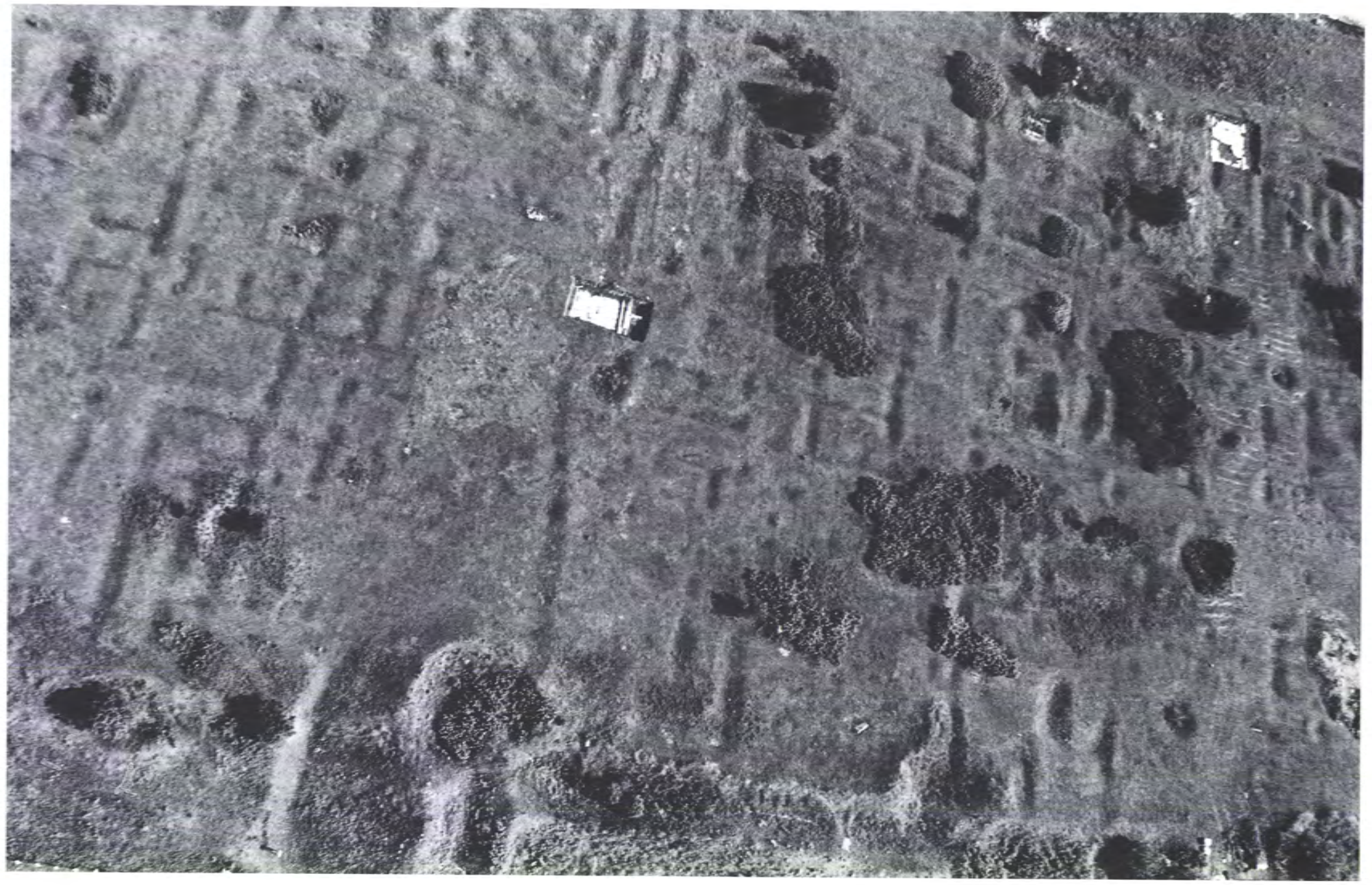

V Aerial view of the central southern part of the Roman/late Roman city and the northwestern corner of the early Byzantine defences (bottom), taken with a radio-controlled kite, 1986 


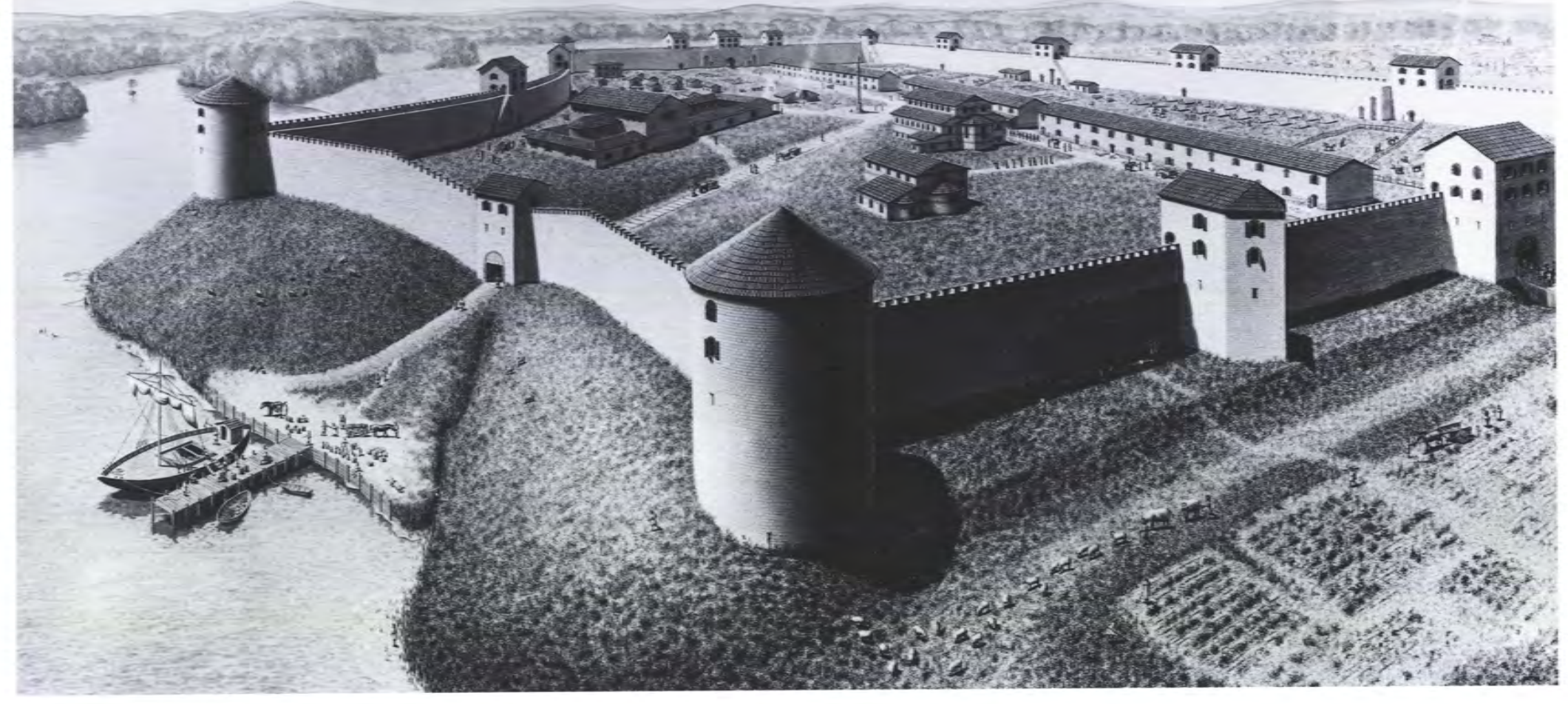

VI Reconstruction painting of the early Byzantine city, c. 500 (reproduced by permission of The Roman Society) 


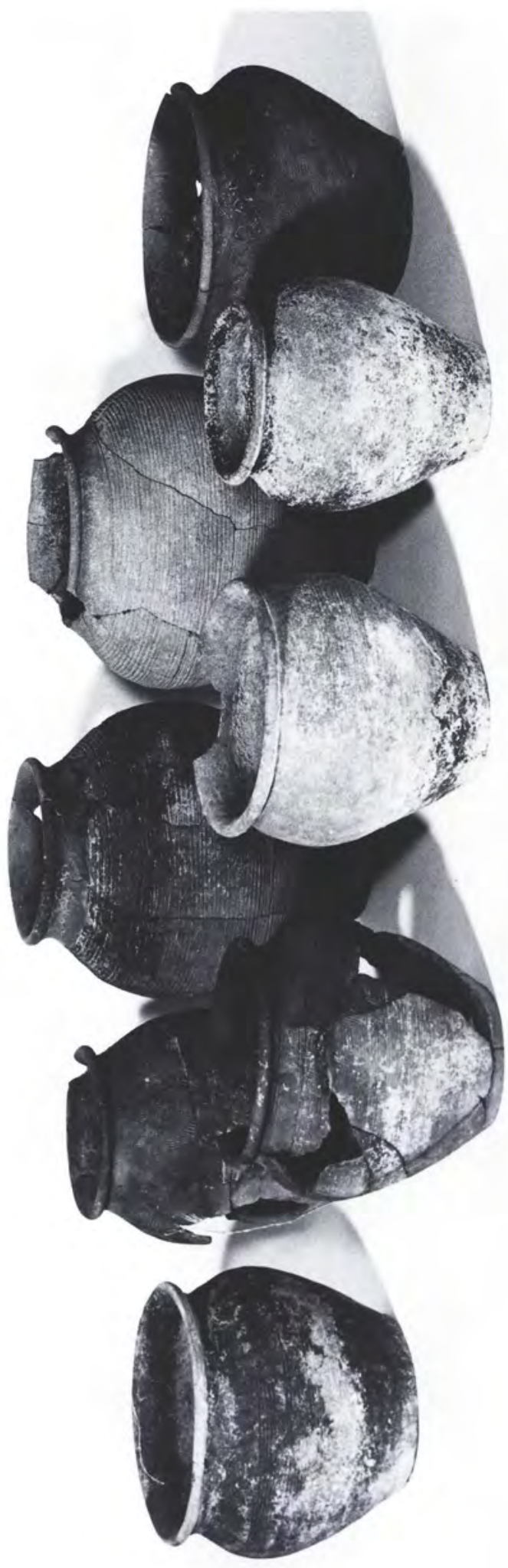

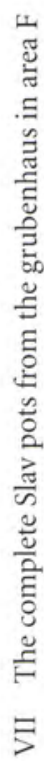




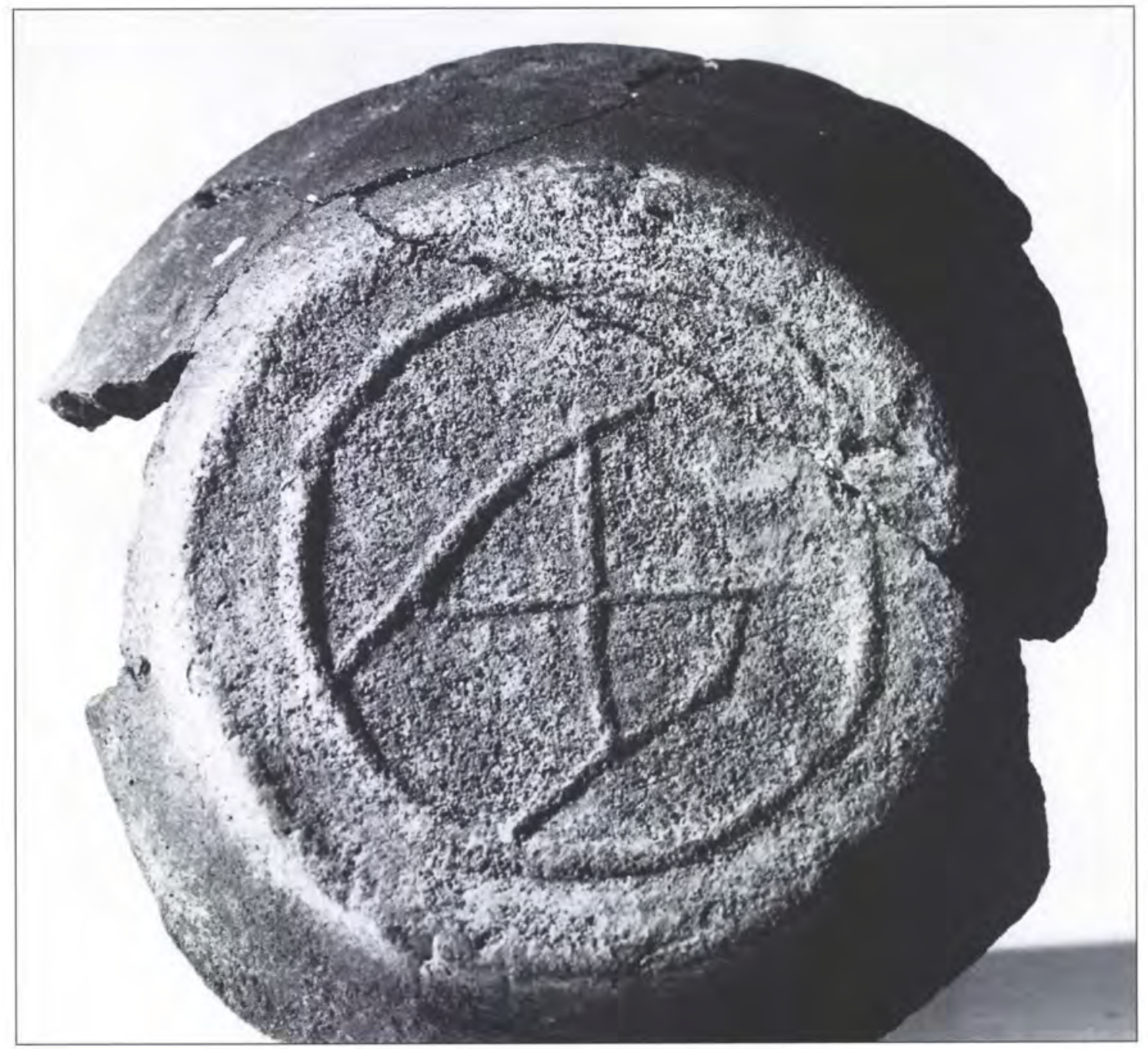

VIII Maker's mark on the base of a Slav pot, cat. no. 1123, SF. 8041 
711. F596 (4033). Rim of a crater, dia. $18-40 \mathrm{~cm}$ (usually $18-30 \mathrm{~cm}$ ). The context is dated to 450.28 examples were found, of which the earliest came from a context dated to 150-275, 5 came from contexts dated to 250-350, 2 from contexts dated to $250-450$, and 3 from contexts dated 275-450.

712. C210 (4506). Rim of a crater, dia. $18-28 \mathrm{~cm}$. The context is dated $250-450$. 41 examples were found, of which the earliest 3 came from contexts dated to $130-150,3$ came from contexts dated to $150-175$, and 9 from contexts dated to $175-250$.

713. C232 (5309). Rim of a crater, dia. $14-25 \mathrm{~cm}$. The context is dated $250-350$. 27 examples were found, of which the earliest 3 came from contexts dated to $100-130,5$ more came from contexts dated to $130-150,1$ from a context dated to $130-175,1$ from a context dated to $150-350$, and 4 from contexts dated to $175-250$.

714. F277 (657). Rim of a crater, dia. $13-26 \mathrm{~cm}$. The context is dated $250-350.18$ examples were found, 2 from contexts dated to $250-350,4$ in contexts dated to $350-450,3$ in contexts dated to 450,7 in contexts dated to $450-600$, and 3 in post-medieval deposits.

715. G36 (4431). Rim of a crater, dia. $12-22 \mathrm{~cm}$. The context is post-medieval. 13 examples were found, of which the earliest one came from a context dated to $175-250,2$ came from contexts dated to $250-350,2$ from contexts dated to $250-450$, and 2 from contexts dated to $350-450$.

716. F508 (2211). Rim of a small crater, dia. $8-18 \mathrm{~cm}$. The context is dated to 450 . 27 examples were found, of which the earliest two came from contexts dated to $250-350,5$ came from contexts dated to $250-450,3$ from contexts dated to $350-450$, and 4 from contexts dated to 450 .

717. F271 (699). Rim of a crater, dia. $16 \mathrm{~cm}$. The context is dated $130-150$.

Red-slipped fine wares: ware 8 (Fig. 9.37)

718. C464 (657). Rim of a crater, dia. $17-21 \mathrm{~cm}$. The context is dated $250-350.3$ other examples were found, 1 came from a context dated to 130-150, 1 from a context dated to $175-250$, and 1 from a context dated to $450-600$.

719. F501 (2208). Rim of a crater, dia. $15-18 \mathrm{~cm}$. The context is dated $450-600.3$ other examples were found, 1 from a context dated to $400-450,1$ from a context dated to 450 , and another from a context dated to 450-600.

720. C232 (4912). Rim of a crater, dia. $19 \mathrm{~cm}$. The context is dated $450-600$. See 713 for dating. 
721. C210 (699). Rim of a crater, dia. $18-28 \mathrm{~cm}$. The context is dated $130-150$. See 712 for dating.

722. F277 (682). Rim of a crater, dia. $21 \mathrm{~cm}$. The context is dated $350-450$. See 714 for dating.

723. F224 (677). Rim of a crater with notch decoration on the exterior of the rim, dia. $17-24 \mathrm{~cm}$. The context is dated $175-250.3$ other examples were found: 2 came from contexts dated to $250-350$, and 1 from a post-medieval context.

724. F238 (699). Rim of a crater, dia. $25 \mathrm{~cm}$. The context is dated 130-150. One other example was found in a context dated to $150-175$.

725. F631 (3045). Rim of a crater, dia. $18-22 \mathrm{~cm}$. The context is post-medieval. One other example was found in a context dated to 450 .

726. F191. Unstratified. Rim of a small crater with appliqué decoration on the exterior, dia. $14 \mathrm{~cm}$.

727. Z29 (550). Base of a small crater with brown slip on the upper part of the exterior, dia. $7 \mathrm{~cm}$. The context is dated $450-600$.

728. F44 (4919). Rim of a small crater with appliqué decoration on the exterior, dia. $8-16 \mathrm{~cm}$ (though one example is $20 \mathrm{~cm}$ ). The context is post-medieval. 51 examples were found, of which the earliest 4 came from contexts dated to $130-150,1$ came from a context dated to $150-175,1$ from a context dated to $150-250$, and 11 from contexts dated to $175-250$.

729. Z214 (4506). Rim of a small crater, dia. $12 \mathrm{~cm}$. The context is dated $250-450$.

730. F44 (4405). Rim of a small crater with appliqué decoration on the exterior, dia. $10 \mathrm{~cm}$. The context is post-medieval. See 728 for dating.

731. F662 (4507). Rim of a jar, dia. 10cm. The context is dated 250-450.

732. F664 (4507). Rim of a jar, dia. $10 \mathrm{~cm}$. The context is dated $250-450$. One other example was found in a context dated to $450-600$.

733. F41 (451). Rim of a jar, dia. $6-16 \mathrm{~cm}$ (usually $6-10 \mathrm{~cm}$ ). The context is postmedieval. 11 examples were found, 1 from a context dated to 175-250, 2 from contexts dated to $275-450,1$ from a context dated to $350-450,5$ from contexts dated to $450-600$, and 2 from post-medieval deposits.

734. C804. Unstratified. Rim of a jar, dia. $7 \mathrm{~cm}$. 5 other examples were found, 1 came from a context dated to 250-350, 2 from contexts dated to 250-450, 1 from a context dated to 450-600, and 1 from a post-medieval deposit. 
1

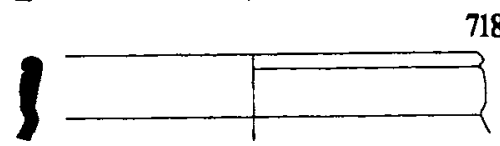

720

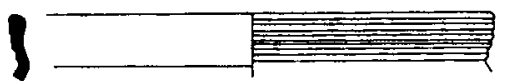

722

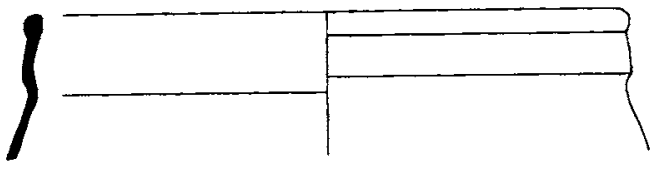

724
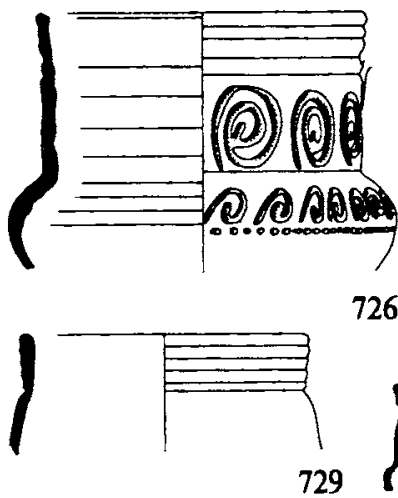

$1 \equiv \overrightarrow{\partial \pi}$

729

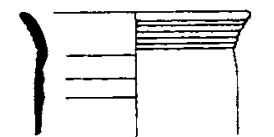

730

1

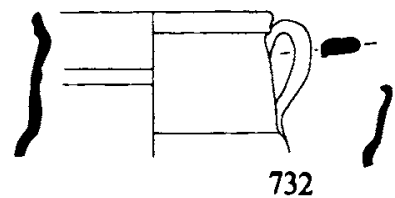

$\left.\left.\longrightarrow\right|_{733}\right)$

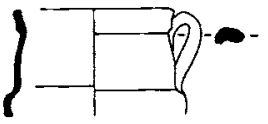

734

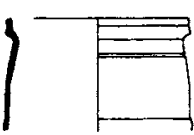

1

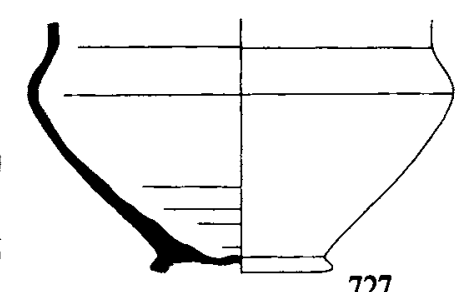

727
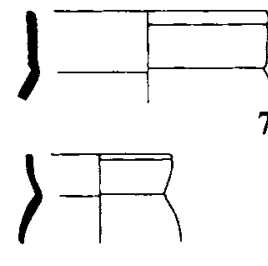

735

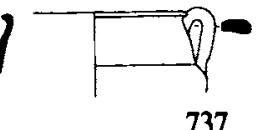

736

737
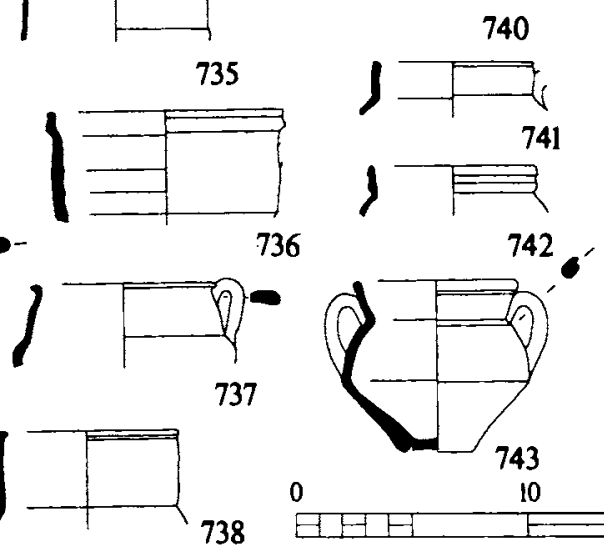

743

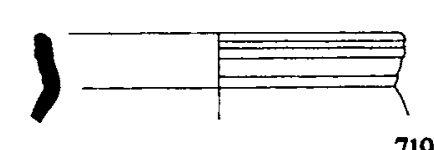

719

721

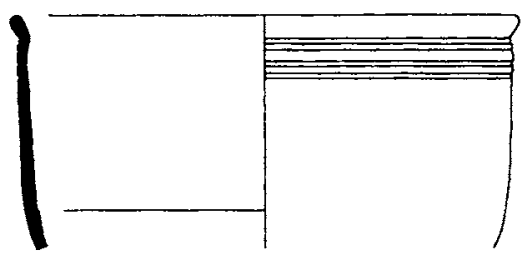

725

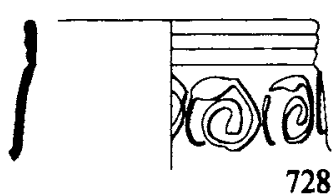

728
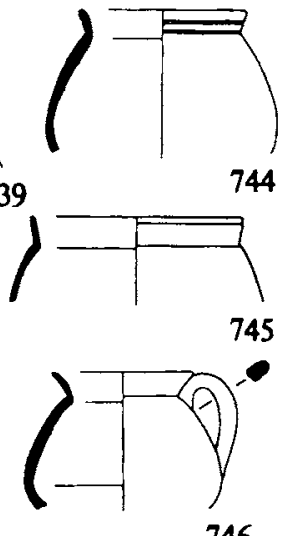

746
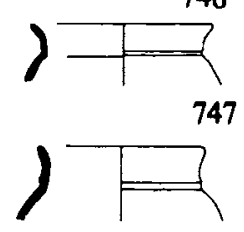

748

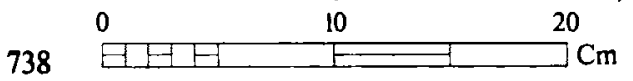

9.37 Red-slipped fine wares: ware 8 
735. F244 (699). Rim of a jar, dia. 8-12cm. The context is dated 130-150. 2 other examples were found, 1 from a context dated to $250-450$, and 1 from a context dated to $450-600$.

736. F244 (2188). Rim of a jar, dia. $8-12 \mathrm{~cm}$. The context is dated $450-600$. See 735 for dating.

737. C859 (3271). Rim of a jar, dia. $8 \mathrm{~cm}$. The context is post-medieval.

738. C816 (3011). Rim of a jar, dia. $8 \mathrm{~cm}$. The context is post-medieval. 6 other examples were found: 5 from contexts dated to $450-600$, and another from a post-medieval deposit.

739. F270 (699). Rim of a jar, dia. 10-12cm. The context is dated 130-150. One other example was found in a context dated to $450-600$.

740. F154 (704). Rim of a jar, dia. $6-9 \mathrm{~cm}$. The context is dated $350-450$. Two other examples were found, both in contexts dated to $350-450$.

741. F102 (540). Rim of a jar, dia. $6-7 \mathrm{~cm}$. The context is dated $350-450.5$ examples were found, 3 from contexts dated to $350-450,1$ from a context dated to $400-450$, and 1 from a context dated to $450-600$.

742. F441 (4096). Rim of a jar, dia. $7-10 \mathrm{~cm}$. The context is dated $400-500$, but contains some later material. 3 other examples were found, 2 in a context dated to $175-250$, and 1 in a post-medieval deposit.

743. Z33 (4976) SF. 12378. Section of jar (not very well made), dia. $7 \mathrm{~cm}$. The context is dated to 250 .

744. F15 (231). Rim of a jar, dia. 7-10cm. The context is dated $175-350$, but contains later material. One other example was found in a post-medieval context.

745. F12 (449). Rim of a jar, dia. 7-9cm. The context is post-medieval. 13 examples were found, of which the earliest one came from a context dated to $100-130$, and 5 more came from contexts dated 130-150.

746. F427 (610). Rim of a jar, dia. $6-10 \mathrm{~cm}$. The context is dated $350-450$. One other example was found in a context dated to $100-130$.

747. Z215 (221). Rim of a jar, dia. $7.5 \mathrm{~cm}$. The context is dated $130-150$.

748. C443 (635). Rim of a jar, dia. $5-12 \mathrm{~cm}$. The context is dated $350-450.14$ examples were found, the earliest 4 of which came from contexts dated to $175-250,2$ came from contexts dated to $250-350,1$ from a context dated $250-450$, and 5 from contexts dated to $350-450$. 
Red-slipped fine wares: ware 8 (Fig. 9.38)

749. F687 (4407). Rim of a jar, dia. $8-10 \mathrm{~cm}$. The context is post-medieval. One other example was found in a context dated to $250-450$.

750. C751 (550). Rim of a small jar, dia. 5-6cm. The context is dated $450-600$. One other example was found in a context dated to $350-450$.

751. F9 (402). Rim of a jar, dia. $7-10 \mathrm{~cm}$. The context is post-medieval. 14 examples were found, 5 from contexts dated to $350-450,6$ from contexts dated to $450-600$, and 3 in post-medieval deposits.

752. F657 (475). Rim of a jar with scale decoration on the exterior, dia. $7 \mathrm{~cm}$. The context is dated $450-600$.

753. F64l (691). Rim of a jar with incised decoration on the exterior, dia. $8 \mathrm{~cm}$. The context is dated 150-175.2 other examples were found, 1 in a context dated $150-175$, and 1 in a post-medieval context.

754. C862 (1036). Rim of a jar, dia. $8 \mathrm{~cm}$. Multi-rows of rouletted decoration on the exterior. The context is dated 450-600. One other example was found in a context dated to $400-450$.

755. G116 (4945). Rim of a jar, dia. $9 \mathrm{~cm}$. The context is dated $250-350$.

756. F20 (576). Cup, dia. $5-16 \mathrm{~cm}$ (usually $7-10 \mathrm{~cm}$ ). The context is dated 350-450. 139 examples were found, of which the earliest 3 came from contexts dated to $100-130,34$ from contexts dated 130-150, 4 from contexts dated to $150-175$ and 24 from contexts dated to $175-250$.

757. F20 (4118). Rim of a cup, dia. 7-10cm. The context is dated $175-150$. See 756 for dating.

758. C769 (2257). Rim of a cup, dia. 10-12cm. The context is dated 130-175. 3 other examples were found, 1 from a context dated to $250-350$, and 2 from post-medieval deposits.

759. F201 (675). Rim of a large cup, dia. $21-23 \mathrm{~cm}$. The context is dated $175-250$.

760. C670 (699). Rim of a cup, dia. $13 \mathrm{~cm}$. The context is dated $130-150$.

761. F642 (610). Rim of a cup, dia. $12-15 \mathrm{~cm}$. The context is dated $350-450$. One other example was found in a context dated to $150-175$.

762. F236 (699). Rim of a cup, dia. $7-10 \mathrm{~cm}$. The context is dated $130-150.7$ examples were found, 1 from a context dated to $100-130,5$ from contexts dated to $130-150$, and 1 from a context dated to $450-600$. 
763. G104 (1089). Rim of a cup, dia. $12 \mathrm{~cm}$. The context is dated to 450 .

764. C343 (2281) SF. 5303. Cup with applique decoration on the top part of the exterior, dia. $9-16 \mathrm{~cm}$. The context is dated 100-130. 16 examples were found, of which the earliest 4 came from contexts dated to 100-130, 5 came from contexts dated to $130-150$, and 4 from contexts dated to 175-250.

765. C733 (1031). Rim of a cup with scale decoration on the exterior, dia. $9 \mathrm{~cm}$. The context is dated $450-600$.

766. F265 (699). Rim of a cup with applique decoration on the exterior, dia. $8-10 \mathrm{~cm}$. The context is dated $130-150.2$ other examples came from the same context.

767. C147 (258). Rim of a cup, dia. $6-14 \mathrm{~cm}$. The context is dated 100-130. 25 examples were found, of which the earliest 6 came from contexts dated to $100-130$, with a further 19 from contexts dated to $130-150$.

768. C605 (265). Rim of a cup, dia. 7-8cm. The context is dated 100-130. One other example came from a context dated to $175-250$.

769. C493 (699). Rim of a cup, dia. $8-16 \mathrm{~cm}$. The context is dated $130-150.5$ examples were found, 2 from contexts dated to $130-150,2$ from contexts dated to $175-250$, and 1 from a context dated to $350-450$.

770. C192 (341). Rim of a cup, dia. $8-13 \mathrm{~cm}$. The context is dated $175-250.13$ examples were found, 1 from a context dated to $100-130,9$ from contexts dated to $130-150$, and 3 from contexts dated to $175-250$.

771. F521 (4971). Bowl, dia. 10-20cm. The context is dated to 250.12 examples were found, of which the earliest 3 came from contexts dated to 250-350, 1 came from a context dated $250-450$, and 3 more from contexts dated to $350-450$.

772. F140 (569). Rim of a bowl with applique decoration on the exterior, dia. $10-16 \mathrm{~cm}$. The context is dated $450-600.8$ examples were found, 1 from a context dated to 250-350, 3 from contexts dated to $450-600$, and 4 from post-medieval deposits.

772a. C861 (3264). As 772 but in a white ware, dia. $14 \mathrm{~cm}$. The context is postmedieval.

773. C10 (4902). Rim of a bowl with incised decoration on the exterior, dia. $14-20 \mathrm{~cm}$. The context is dated $450-600$. See 779 for dating. 


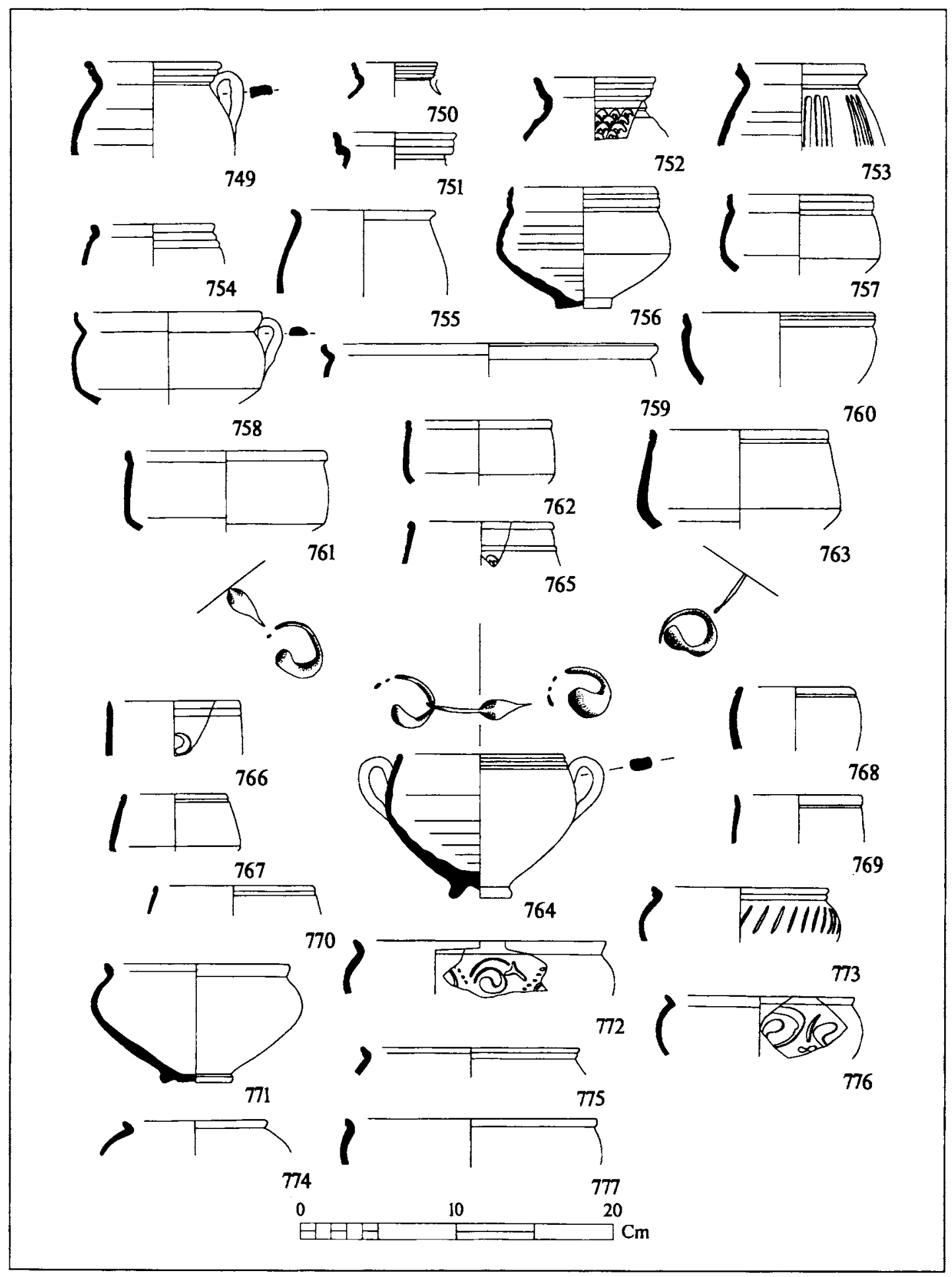

9.38 Red-slipped fine wares: ware 8 
774. C625 (3139). Rim of a bowl, dia. $9 \mathrm{~cm}$. The context is post-medieval. 4 other examples were found, 2 from contexts dated to $150-250,1$ from a context dated to $250-350$, and 1 from a context dated to $400-450$.

775. C35 (203). Rim of a bowl, dia. $10-14 \mathrm{~cm}$. The context is post-medieval. 3 other examples were found all in post-medieval contexts.

776. F550 (4495). Rim of a bowl with applique decoration on the exterior, dia. $10-16 \mathrm{~cm}$. The context is post-medieval. 3 other examples were found: 1 in a context dated to 450 , and 2 from contexts dated to $450-600$.

777. C669 (1123). Rim of a bowl, dia. $10-20 \mathrm{~cm}$ (usually $14-16 \mathrm{~cm}$ ). The context is dated to 450.11 examples were found, 1 came from a context dated to $275-450,2$ from contexts dated to 350-450, 4 from contexts dated to 450,3 from contexts dated to $450-600$, and 1 from a post-medieval deposit.

Red-slipped fine wares: ware 8 (Fig. 9.39)

778. C700 (2250). Bowl, dia. $20.5 \mathrm{~cm}$. The context is dated 130-175.

779. C10 (604). Rim of a bowl, dia $14-20 \mathrm{~cm}$. The context is dated $350-450.30$ examples were found, of which the earliest two came from contexts dated to $175-250$, One came from a context dated to $175-350,3$ from contexts dated to $250-350,2$ from contexts dated to $250-450$, and 12 from contexts dated to $350-450$.

780. C539 (4846). Rim of a bowl with faint rouletted decoration on the exterior, dia. $26 \mathrm{~cm}$. The context is dated $350-450$. One other example was found in a context dated to 450 .

781. G141 (607). Rim of a bowl, dia. $10-12 \mathrm{~cm}$. The context is dated $450-600$.

782. F614 (635). Rim of a bowl, dia. 10-14cm. The context is dated $350-450$.

783. F26 (434). Rim of a bowl, dia. $8-16 \mathrm{~cm}$. The context is post-medieval. 6 other examples were found, of which the earliest two came from contexts dated to $175-250$, and 1 from a context dated 250-350.

784. C833 (4405). Rim of a bowl, dia. $13 \mathrm{~cm}$. The context is post-medieval. 8 examples were found, 1 from a context dated to $175-250,2$ from contexts dated to $350-450,1$ from a context dated to 450,2 from contexts dated to 450-600, and 2 from post-medieval deposits.

785. G61 (4502). Rim of a bowl, dia. $12 \mathrm{~cm}$. The context is dated $450-600$. 


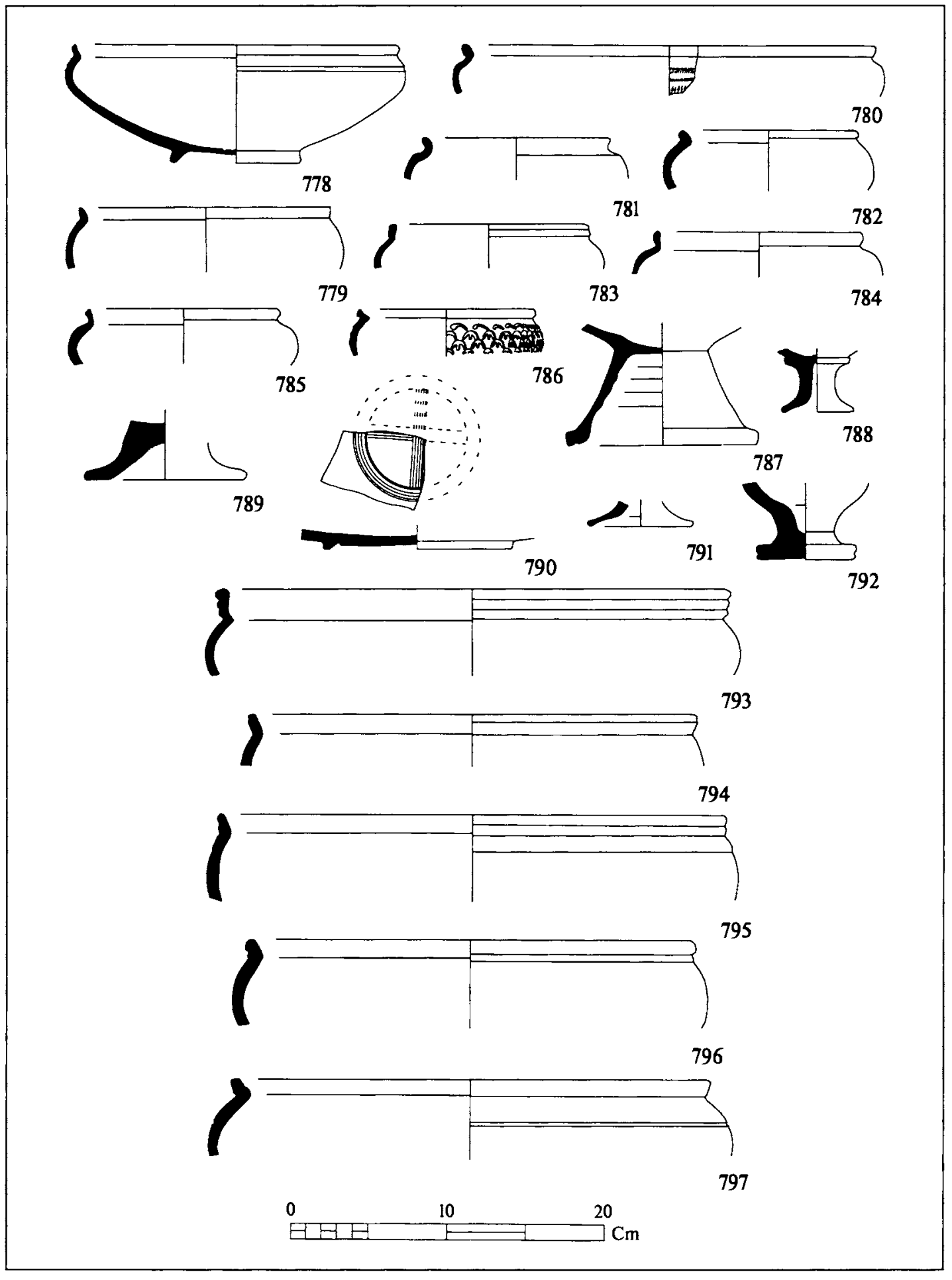

9.39 Red-slipped fine wares: ware 8 
786. C808 (662). Rim of a bowl with scale decoration on the exterior, dia. $8-12 \mathrm{~cm}$. The context is dated $250-350.5$ other examples were found, 3 from a context dated to 250-450, 1 from a context dated to 450, and 2 from post-medieval deposits.

787. Z25 (2254). Large pedestal base, dia. $12 \mathrm{~cm}$. The context is dated 130-175.

788. Z180 (434). Pedestal base of a cup, dia. $4 \mathrm{~cm}$. The context is post-medieval.

789. C269 (542). Pedestal base, dia. $10 \mathrm{~cm}$. The context is dated 450-600.

790. Z170 (516) SF. 14533. Base of a bowl with 'combed' cross inside circle, dia. $12 \mathrm{~cm}$. The context is dated $450-600$.

791. Z110 (5253). Pedestal base, dia. $6 \mathrm{~cm}$. The context is post-medieval.

792. Z41 (2200). Pedestal base, dia. $6 \mathrm{~cm}$. The context is undated.

793. Z216 (4033). Rim of a large bowl, dia. $32 \mathrm{~cm}$. The context is dated to 450 .

794. F462 (4097). Rim of a large bowl, dia. 20-30 cm. The context is dated $300-450.6$ other examples were found, 1 came from a context dated to 175-250, 1 from a context dated to 350-450, 2 from contexts dated to 450, 1 from a context dated to $450-600$, and 1 from a post-medieval context.

795. F99 (628). Rim of a large bowl, dia. $32 \mathrm{~cm}$. Undated context. One other example came from a context dated to 450-600.

796. F677 (4515). Rim of a large bowl, dia. $28 \mathrm{~cm}$. The context is dated $250-450$. 12 examples were found, of which the earliest came from a context dated to 250-275, 2 came from contexts dated 250-350, and 1 from a context dated to $250-450$. However 6 came from a context dated to $450-600$.

797. C612 (1073). Rim of a large bowl, dia. $26-35 \mathrm{~cm}$. The context is dated 450-600. 10 examples were found, 1 from a context dated to 250-350, 2 from contexts dated to $250-450,2$ from contexts dated to $350-450,1$ from a context dated to 450,2 from contexts dated to $450-600$, and 2 from postmedieval contexts.

Red-slipped fine wares: ware 8 (Fig. 9.40)

798. F677 (1004). Rim of a large bowl, dia. $28 \mathrm{~cm}$. The context is dated $450-600$. See 796 for dating.

799. C597 (5014). Rim of a large bowl, dia. $27-30 \mathrm{~cm}$. The context is dated to 450 . One other example was found in a post-medieval context. 
800. C772 (686). Rim of a large bowl, dia. $20-28 \mathrm{~cm}$. The context is dated 175-250, but contains some later material. One other example came from a context dated to $350-450$.

801. C746 (4104). Rim of a large bowl with applique decoration on the exterior, dia. $22 \mathrm{~cm}$. The context is dated $300-450$.

802. F100 (542). Rim of a jug, dia. $3-3.5 \mathrm{~cm}$. The context is dated $450-600.7$ other examples were found, 1 from a context dated to 250-350, 1 from a context dated to $250-450,2$ from contexts dated to $350-450$, and 3 from post-medieval deposits.

803. G47 (636). Rim of a jug, dia. $2 \mathrm{~cm}$. The context is dated $450-600.2$ other examples were found: 1 in a context dated to $250-450$, and 1 in a context dated 400-450.

804. E7 (4515). Rim of a jug, dia. $2.5-3 \mathrm{~cm}$. The context is dated $250-450.15$ other examples were found, of which the earliest one came from a context dated to $150-175,3$ came from contexts dated to $250-350$, and 5 from contexts dated to $350-450$.

805. C383 (681). Rim of a jug, dia. $4-10 \mathrm{~cm}$. The context is dated $175-250.7$ examples were found, 3 from contexts dated to $175-250,1$ from a context dated to $275-450,1$ from a context dated to $350-450,1$ from a context dated to 450-600, and 1 from a post-medieval deposit.

806. F445 (4096). Rim of a jug, dia. $4.5 \mathrm{~cm}$. The context is dated $400-500$, but contains post-medieval material.

807. F287 (667). Rim of a jug, dia. $4-6 \mathrm{~cm}$. The context is dated $175-250$. One other example came from a context dated to $400-450$.

808. G160 (198). Rim of a jug, dia. $7 \mathrm{~cm}$. Undated context.

809. C813 (3003). Rim of a trefoil jug. The context is post-medieval. 11 examples were found, 2 from contexts dated to $130-175,1$ from a context dated to $350-450,2$ from contexts dated to 450, 2 from contexts dated to 450-600, and 3 from post-medieval contexts.

810. C778 (4416). Rim of a jug, dia. $2.5 \mathrm{~cm}$. The context is post-medieval.

811. F245 (699). Rim of a jug, dia. $2.5 \mathrm{~cm}$. The context is dated $130-150$.

812. F470 (2188). Rim of a jug, dia. $1.5-4 \mathrm{~cm}$. The context is dated $450-600.6$ examples were found, 1 from a context dated to $175-250,2$ from contexts dated to $250-450,1$ from a context dated to $350-450$, and 2 from contexts dated to $450-600$. 
813. F76 (278). Rim of 'a jug, dia. $4-8 \mathrm{~cm}$. The context is dated $300-450$. One other example came from a context dated to 450-600.

814. G113 (4959). Rim of a jug, dia $5 \mathrm{~cm}$. The context is dated 250-350.

815. C385 (676). Rim of a jug, dia. 4-5cm. The context is dated 175-250.9 examples were found, 4 from contexts dated to 130-150, 4 from contexts dated to $175-250$, and 1 from a context dated to $250-350$.

816. C697 (4817). Rim of a jug, dia. $6 \mathrm{~cm}$. The context is post-medieval. One other example came from a context dated to $250-450$.

817. G124. Unstratified. Rim of a jug, dia. $7 \mathrm{~cm}$.

818. F119 (574). Rim of a jug with an applied knob on the top of the handle, dia. $7 \mathrm{~cm}$. The context is dated 450-600. 4 examples were found, 1 from a context dated to 450,2 from contexts dated to 450-600, and 1 from a post-medieval context.

819. F156 (604). Rim of a jug, dia. $10 \mathrm{~cm}$. The context is dated $350-450$.

820. C589 (4433). Rim of a jug, dia. $9-10 \mathrm{~cm}$. The context is post-medieval. One other example was found in a context dated to 450 .

821. C384 (676). Rim of a jug, dia. 8-12cm. The context is dated 175-250.6 examples were found: 4 from contexts dated to $130-150$, and 2 from contexts dated to $175-250$.

822. H31. Unstratified. Rim of a jug, dia. $8-9 \mathrm{~cm}$.

823. F40 (451). Rim of a jug, dia. $10 \mathrm{~cm}$. The context is post-medieval.

824. E2 (203). Rim of a jug, dia. $6 \mathrm{~cm}$. The context is post-medieval.

825. F472 (4105). Rim of a jug, dia. $8 \mathrm{~cm}$. The context is dated $300-450$. One other example was found in a context dated to 450 .

826. F79 (706). Rim of a jug, dia. 8-9cm. The context is dated $350-450.9$ examples were found, 1 from a context dated to $130-150,1$ from a context dated to $150-175,3$ from contexts dated to $175-250$, and 4 from contexts dated to $350-450$.

827. C440 (4834). Rim of a jug, dia. $6-10 \mathrm{~cm}$. Undated context. 2 other examples were found, 1 from a context dated to $175-250$, and 1 from a context dated to $450-600$.

828. F63 (453). Rim of a jug, dia. $6-7.5 \mathrm{~cm}$. The context is post-medieval. One other example also came from a post-medieval deposit. 


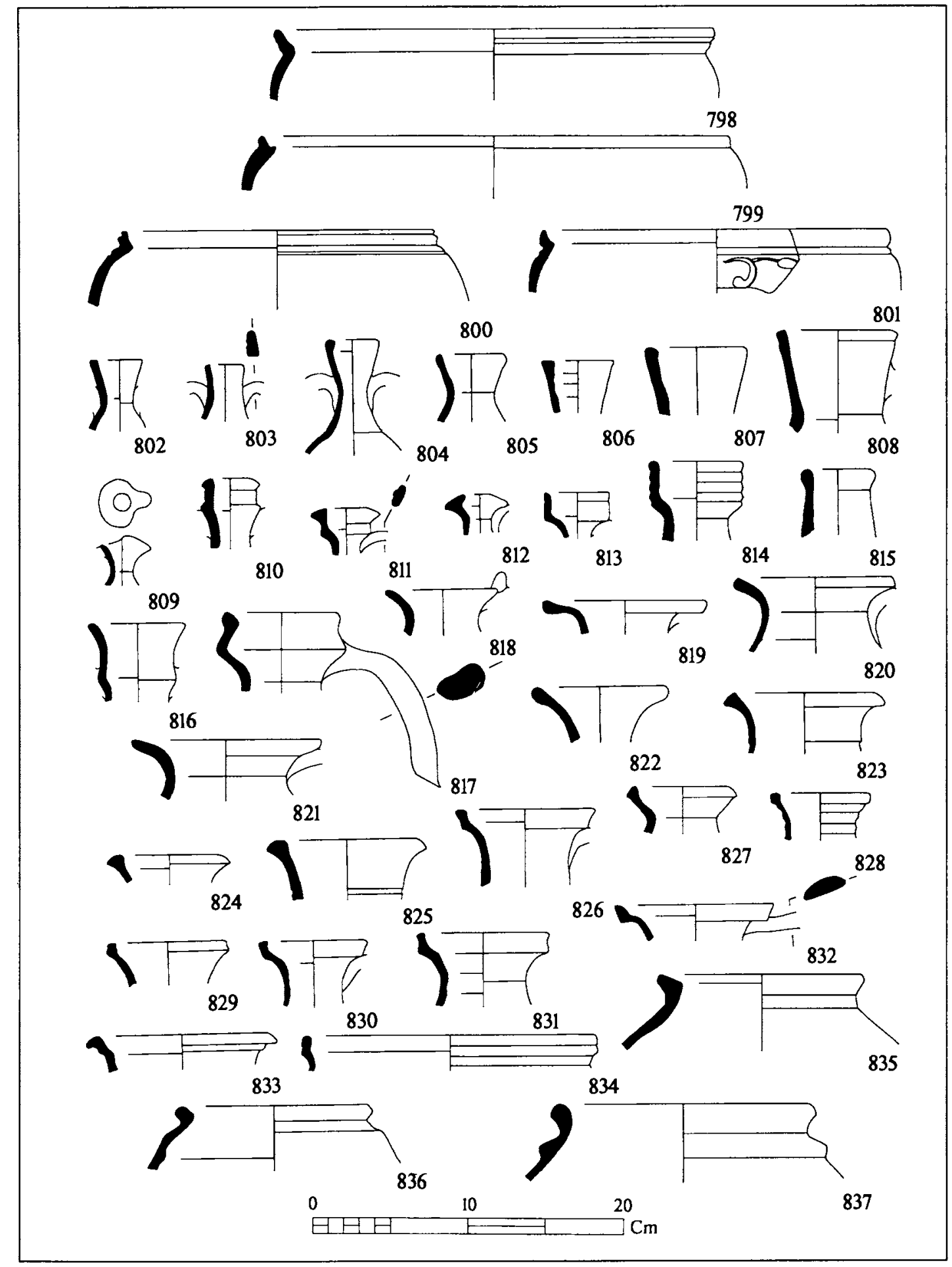

9.40 Red-slipped fine wares: ware 8 
829. F683 (4123). Rim of a jug, dia. $6-7 \mathrm{~cm}$. The context is dated $150-175$. One other example came from a context dated to $250-350$.

830. C722 (4480). Rim of a jug, dia. $6-7 \mathrm{~cm}$. The context is post-medieval. 3 other examples were found, 1 from a context dated to $250-450,1$ from a context dated to $400-450$, and 1 more from a post-medieval context.

831. F650 (4516). Rim of a jug, dia. 8-9cm. The context is dated $250-450.7$ examples were found, of which the earliest two came from a context dated to $250-450,2$ more came from contexts dated to $350-450$, and 1 from a context dated to $450-600$.

832. C850 (4405). Rim of a jug, dia. $10-12 \mathrm{~cm}$. The context is post-medieval. One other example was found in a context dated to $175-250$.

833. C114 (434). Rim of a jug, dia. $11 \mathrm{~cm}$. The context is post-medieval.

834. F384 (5018). Rim of a jar/jug, dia. $18 \mathrm{~cm}$. The context is dated to 450.4 other examples were found, all in contexts dated to 450-600.

835. F50 (258). Rim of a jar, dia. $13-16 \mathrm{~cm}$. The context is dated $100-130.4$ examples were found, 2 from contexts dated to $100-130,1$ from a context dated to $130-150$, and 1 from a post-medieval deposit.

836. F143 (640). Rim of a jar, dia. $12 \mathrm{~cm}$. The context is dated $350-450$.

837. G123 (4402). Rim of a jar, dia. $16 \mathrm{~cm}$. The context is post-medieval. One other example was found in a context that dated to $350-450$.

Red -slipped wares: ware 8 (Fig. 9.41)

838. F35 (402). Rim of a jar, dia. $16 \mathrm{~cm}$. The context is post-medieval.

839. F674 (4883). Rim of a jar, dia. $14 \mathrm{~cm}$. The context is post-medieval.

840. F56 (248). Rim of a jar, dia. $15 \mathrm{~cm}$. The context is dated $300-450$.

841. C750 (550). Rim of a jar, dia. $15 \mathrm{~cm}$. The context is dated $450-600$.

842. C292 (489). Rim of a jar, dia. $14-18 \mathrm{~cm}$. The context is post-medieval. 6 examples were found, 1 from a context dated to $400-450,3$ from contexts dated to 450 , and 2 from post-medieval deposits.

843. F377 (414). Rim of a jar, dia. $14-18 \mathrm{~cm}$. The context is post-medieval. 4 examples were found, 1 from a context dated to $275-450,1$ from a context dated to 450 , and 2 from post-medieval contexts.

844. F421 (243). Rim of a jar, dia. $18 \mathrm{~cm}$. The context is dated $300-450$. 


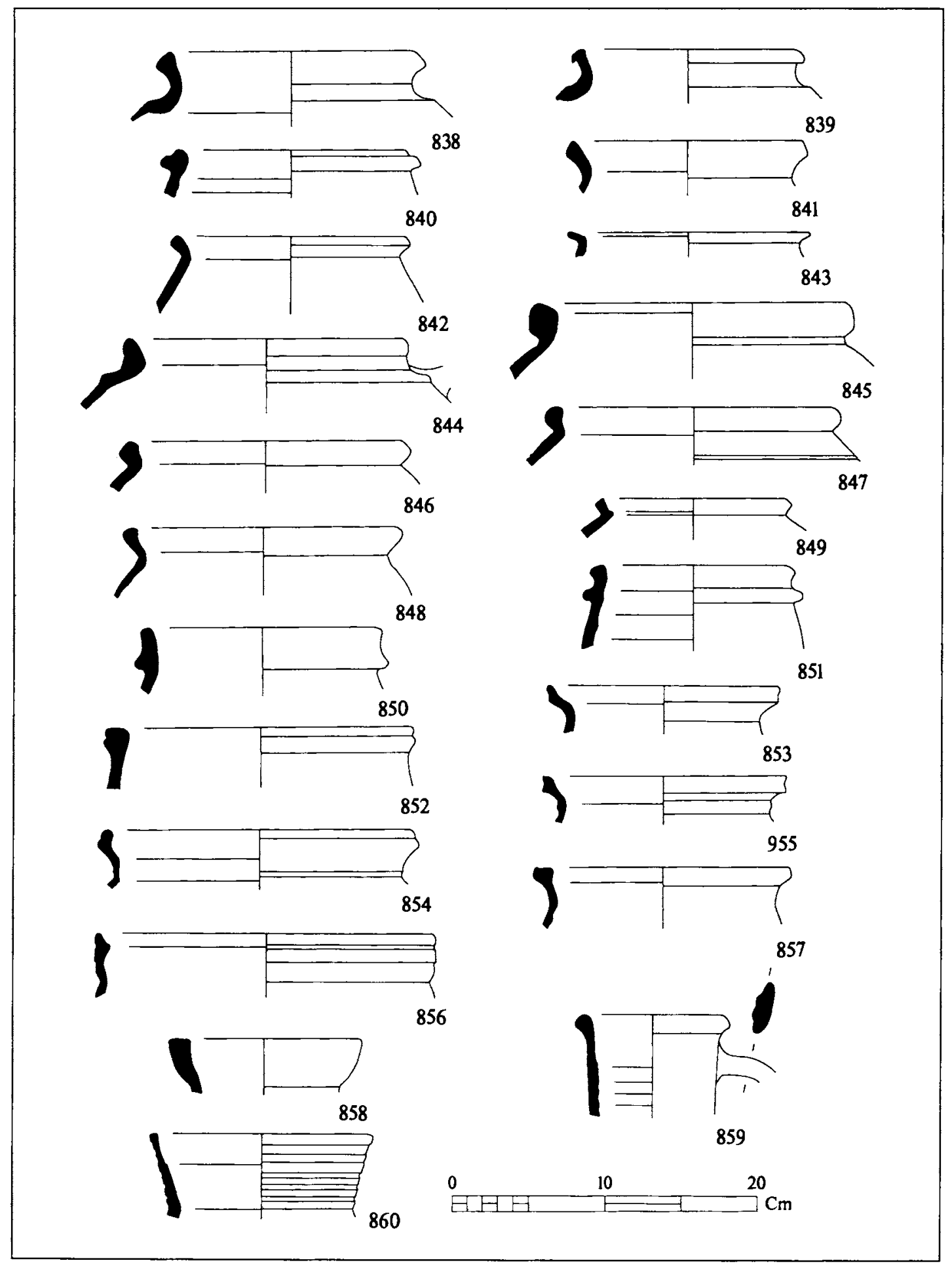

9.41 Red-slipped fine wares: ware 8 
845. F64 (343). Rim of a large jar, dia. $20-28 \mathrm{~cm}$. The context is dated $175-250$.

846. F681 (4843). Rim of a jar, dia. $16-18 \mathrm{~cm}$. The context is dated $350-450$. One other example was found in a post-medieval deposit.

847. F527 (3132). Rim of a jar, dia. $16-18 \mathrm{~cm}$. The context is post-medieval. One other example was found in a context dated to 250-350.

848. C837 (3258). Rim of a jar, dia. $15-17 \mathrm{~cm}$. The context is post-medieval. One other example was found in a context dated to $450-600$.

849. F250 (699). Rim of a jar, dia. $12 \mathrm{~cm}$. The context is dated 130-150.

850. F279 (667). Rim of a jar, dia. $15-20 \mathrm{~cm}$. The context is dated $175-250$.

851. F510 (2211). Rim of a jar, dia. $11-12 \mathrm{~cm}$. The context is dated to 450 . One other example was found in a context dated to 400-500.

852. F83 (224). Rim of a jar, dia. $20 \mathrm{~cm}$. The context is dated $130-150$.

853. F504 (2208). Rim of a jar, dia. $15 \mathrm{~cm}$. The context is dated $450-600$.

854. F381 (5018). Rim of a jar, dia. $20-22 \mathrm{~cm}$. The context is dated to 450 . One more example came from the same context.

855. Z112. Unstratified. Rim of a jar, dia. $16 \mathrm{~cm}$.

856. F239 (699). Rim of a jar, dia. $22 \mathrm{~cm}$. The context is dated 130-150.

857. F648 (4508). Rim of a jar, dia. $18 \mathrm{~cm}$. The context is dated to $250-450$.

858. F440 (126). Rim of a jar, dia. $12 \mathrm{~cm}$. The context is dated $300-450$.

859. F171 (2260). Rim of a jar, dia. 9-11 cm. The context is dated 100-130. 5 examples were found, 2 from contexts dated to $100-130,2$ from contexts dated to 130-150, and 1 from contexts dated to 250-350.

860. F669 (4920). Rim of a jar, dia. $14 \mathrm{~cm}$. The context is dated $350-450$. One other example was found in a post-medieval context.

Red-slipped fine wares: ware 8 (Fig. 9.42)

861. F184 (2260). Rim of a jar, dia. $9-11 \mathrm{~cm}$. The context is dated 100-130. One other example came from another context dated to 100-130.

862. G114 (4953). Rim of a jar, dia. $5 \mathrm{~cm}$. The context is dated $350-450$.

863. G134 (4912). Rim of a jar, dia. $6 \mathrm{~cm}$. The context is dated $450-600$.

864. C695 (4817). Rim of a lid, dia. $10 \mathrm{~cm}$. The context is post-medieval. 


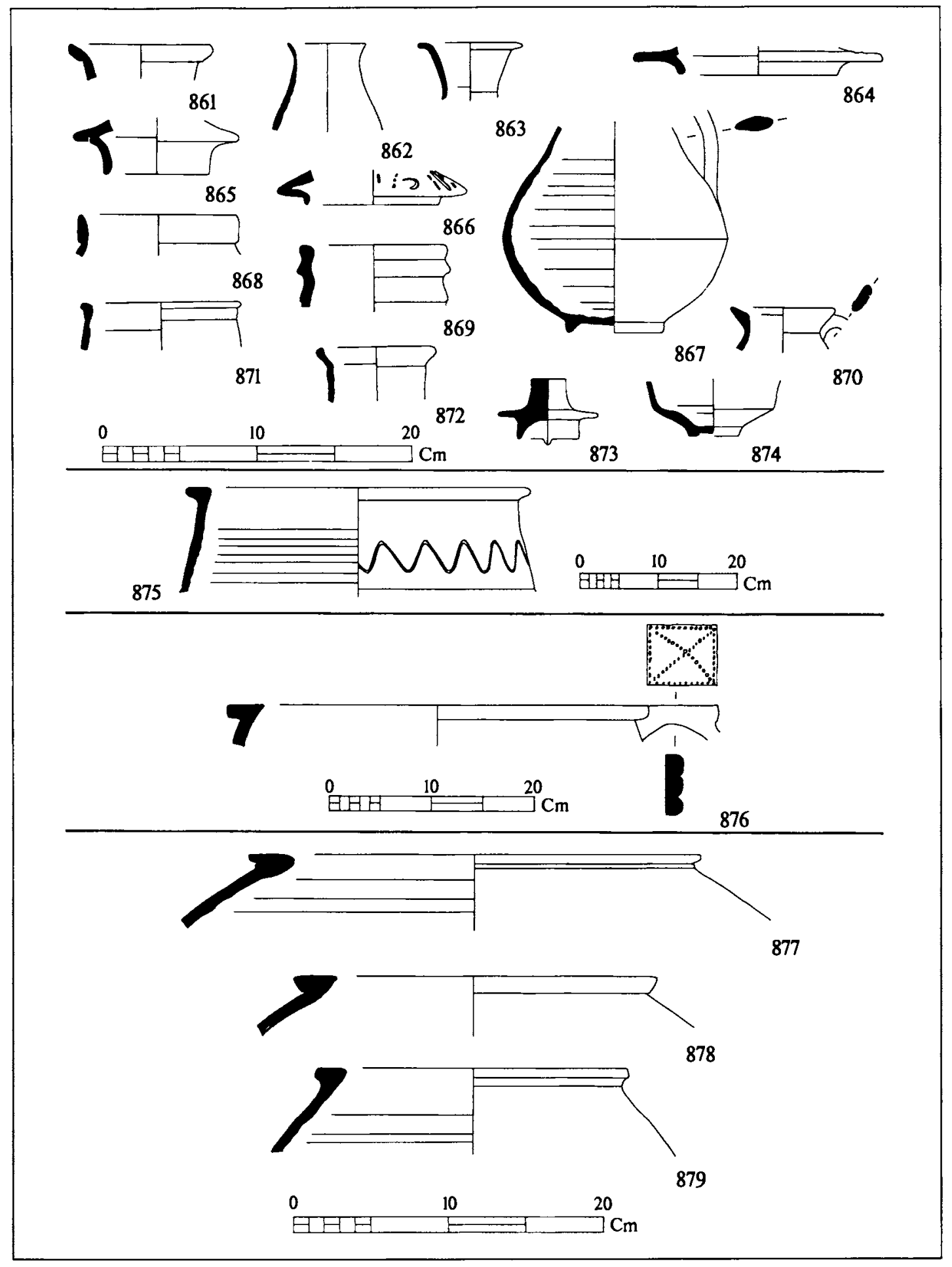

9.42 Red-slipped fine wares: ware 8 
865. F163 (537). Rim of a lid, dia. $6.5 \mathrm{~cm}$. The context is dated $350-450$.

866. F241 (699). Rim of a lid, dia. $8.5 \mathrm{~cm}$. The context is dated 130-150.

867. Z26 (4034) SF. 14483 . Base of a jug, dia. $6 \mathrm{~cm}$. The context is dated to 450 .

868. F57 (240). Rim of a jar, dia. $9-10 \mathrm{~cm}$. The context is post-medieval. One other example came from a context dated to 450 .

869. C684 (698). Rim of a jar, dia. $9 \mathrm{~cm}$. The context is dated 130-150.

870. F52 (249). Rim of a jar, dia. $6.5 \mathrm{~cm}$. The context is dated $300-450$.

871. C814 (3012). Rim of a jar, dia. $10 \mathrm{~cm}$. The context is post-medieval.

872. F22 (691). Rim of a jar, dia. $7 \mathrm{~cm}$. The context is dated $150-175$. One other example came from a post-medieval context.

873 Z177. Unstratified. Lid with two small lugs opposite each other on the rim, dia. $4 \mathrm{~cm}$.

874. Z171 (4835). String cut base, dia. $3.5 \mathrm{~cm}$. The context is dated $450-600$.

875. Z191 (2277). Rim of a jar, dia. $44 \mathrm{~cm}$. The context is dated 100-130.

876. Z103 (677). Rim of a jar with a triple-loop handle with a decorated flat top, dia. $40 \mathrm{~cm}$. The context is dated $175-250$.

877. G60 (5303). Rim of a jar, dia. $18-29 \mathrm{~cm}$. Undated context. 4 other examples were found, 1 from a context dated to $250-350,1$ from a context dated to 450 , and 2 from contexts dated to $450-600$.

878. F34 (2260). Rim of a jar, dia $14-30 \mathrm{~cm}$ (usually $18-24 \mathrm{~cm}$ ). The context is dated 100-130.71 examples were found, the earliest one came from a context dated to $100-130$, and a further 19 came from contexts dated to $130-150$.

879. F34 (699). Rim of a jar, dia. $14-30 \mathrm{~cm}$ (usually $18-24 \mathrm{~cm}$ ). The context is dated $130-150$. See 878 for dating.

Red-slipped fine wares: ware 8 (Fig. 9.43)

880. Z218 (2186). Rim of a jar with incised decoration on the exterior and notch decoration on the top of the rim, dia. $19 \mathrm{~cm}$. The context is dated to 450 .

881. Z219 (4405). Rim of a jar with incised and applied decoration on rim, dia. $22 \mathrm{~cm}$. The context is post-medieval. 
882. F254 (699). Rim of a jar, dia. 32-34cm. The context is dated 130-150. 2 other examples were found, 1 from a context dated to 400-450, and 1 from a post-medieval context.

883. C785 (4843). Rim of a jar, dia. 10-12cm. The context is dated 350-450. 6 examples were found, 1 from a context dated to $275-450,2$ from contexts dated to $350-450$, and 3 from post-medieval contexts.

884. C699 (4817). Rim of a jar with an incised wavy line on the exterior of the rim, dia. $14 \mathrm{~cm}$. The context is post-medieval.

885. H5 (2175). Nearly complete amphora, dia. $12-14 \mathrm{~cm}$. The context is dated 130-175. 352 examples were found, of which the earliest 14 came from contexts dated to 100-130, 9 came from contexts dated to 130-150, and 15 from contexts dated to 150-175. The remainder were evenly distributed amongst contexts of all periods.

886. C172 (279). Rim of an amphora, dia. $12-16 \mathrm{~cm}$. The context is dated 300-450. 19 examples were found, of which the earliest one came from a context dated to 100-130,2 came from contexts dated to 130-150, and 4 from contexts dated to $175-250$.

887. F351 (628). Rim of an amphora, dia. 9-19cm (usually $12-16 \mathrm{~cm}$ ). Undated context. 127 examples were found, of which the earliest 4 came from contexts dated to $130-150,4$ came from contexts dated to $130-175,14$ from contexts dated to $175-250$, and 7 from contexts dated to $250-275$.

888. C836 (3258). Rim of an amphora, dia. $12-16 \mathrm{~cm}$. The context is postmedieval. 74 examples were found, of which the earliest 4 were from contexts dated to $130-150,18$ came from contexts dated to 175-250, and 12 from contexts dated to $175-350$.

889. F503 (4492). Rim of an amphora, dia. $14 \mathrm{~cm}$. The context is post-medieval. 8 other examples were found, 1 from a context dated to 175-250, 1 from a context dated to $250-450,2$ from a context dated to $350-450$, and 4 from a context dated to $450-600$.

890. G84 (4834). Rim of an amphora, dia. $12 \mathrm{~cm}$. Undated context.

891. C3 (202). Rim of an amphora, dia. $12-18 \mathrm{~cm}$. The context is post-medieval. One other example came from a context dated to $275-450$.

892. C300 (462). Rim of an amphora, dia. $12 \mathrm{~cm}$. The context is dated $450-600$, but contains some later material.

893. F471 (4105). Rim of an amphora, dia. $11 \mathrm{~cm}$. The context is dated $300-450$. 


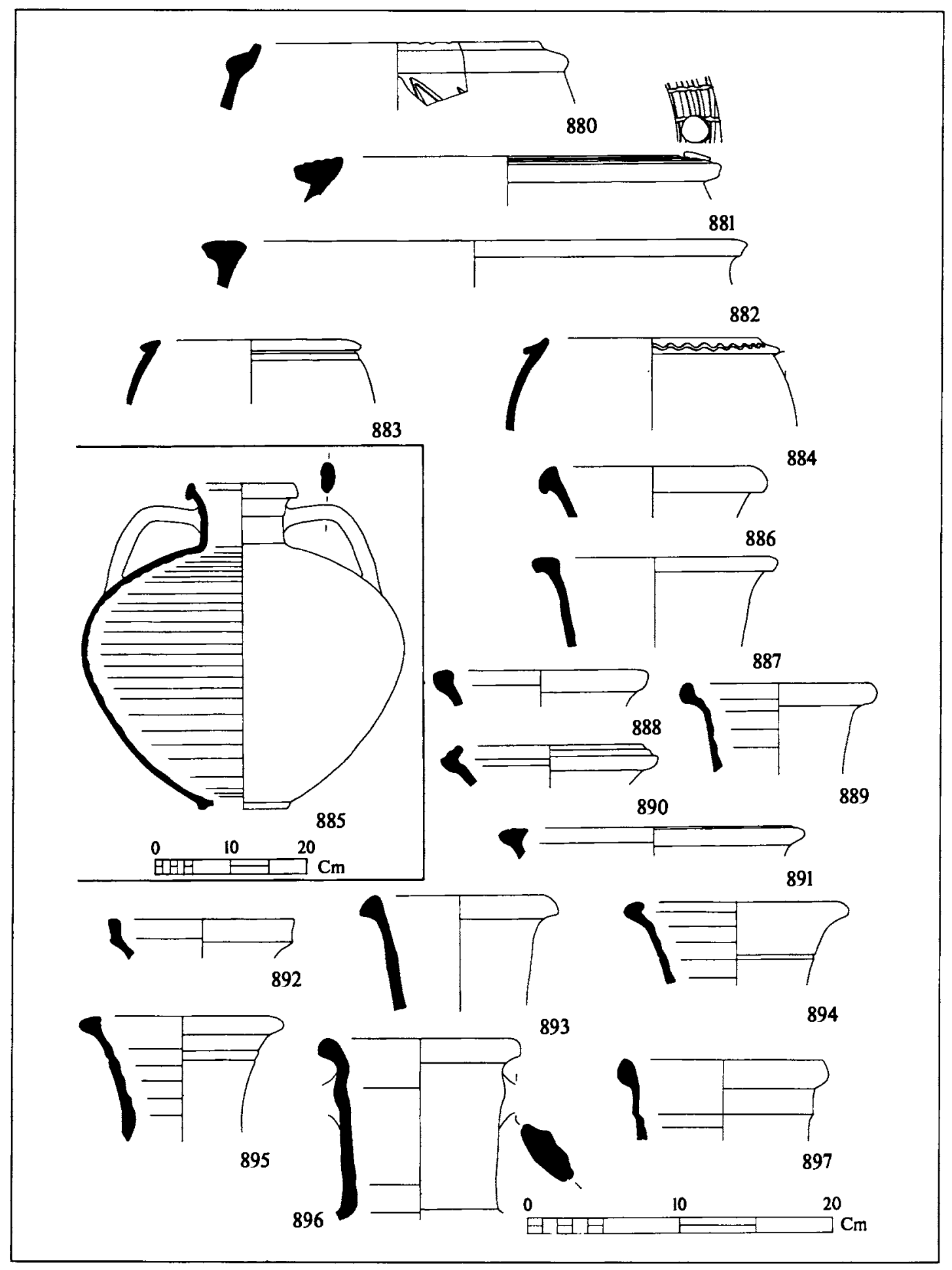

9.43 Red-slipped fine wares: ware 8 
894. G95 (4912). Rim of an amphora, dia. $13 \mathrm{~cm}$. The context is dated $450-600.9$ examples were found, 1 from a context dated to $350-450,1$ from a context dated to 450,2 from contexts dated to $450-600$, and 5 from post-medieval deposits.

895. H5 (2262). Rim of an amphora, dia. 9-18cm (usually $12-16 \mathrm{~cm}$ ). The context is dated $100-130$. See 885 for dating.

896. H5 (677). Rim of an amphora, dia. $9-18 \mathrm{~cm}$ (usually $12-16 \mathrm{~cm}$ ). The context is dated $175-250$. See 885 for dating.

897. F92 (267). Rim of an amphora. dia. $12-17 \mathrm{~cm}$. The context is dated 100-130. 8 examples were found, of which the earliest 3 came from contexts dated to 100-130, and 4 others from contexts dated to 150-175.

Red-slipped fine wares: ware 8 (Fig. 9.44)

898. H5 (699). Rim of an amphora, dia. $9-18 \mathrm{~cm}$ (usually $12-16 \mathrm{~cm}$ ). The context is dated $130-150$. See 885 for dating.

899. F675 (4480). Rim of an amphora, dia. $15 \mathrm{~cm}$. The context is post-medieval. The only example from a dated context was from one dated to 130-150.

900. C606 (5021). Rim of an amphora, dia. $14 \mathrm{~cm}$. The context is dated $250-350$.

901. F576 (4114). Rim of an amphora, dia. $13 \mathrm{~cm}$. The context is dated 250-350.

902. C622 (4096). Rim of an amphora, dia. $17-30 \mathrm{~cm}$. The context is dated $400-500$, but contains later material. 14 examples were found, of which the earliest one came from a context dated to $175-250$, and 4 came from contexts dated to $250-350$.

903. G9 (4880). Rim of an amphora, dia. $8-16 \mathrm{~cm}$. The context is dated $150-175$. 7 other examples were found, 1 from a context dated to $150-175,2$ from contexts dated to 250-350, 2 from contexts dated to 450-600, and 2 from post-medieval deposits.

904. F686 (5218). Rim of an amphora, dia. $15 \mathrm{~cm}$. The context is dated to 450 .

905. C745 (4104). Rim of an amphora, dia. $12 \mathrm{~cm}$. The context is dated $300-450$.

906. H5 (2257). Rim of an amphora, dia. 9-18cm (usually $12-16 \mathrm{~cm}$ ). The context is dated $130-175$. See 885 for dating.

907. C484 (699). Rim of an amphora, dia. $16 \mathrm{~cm}$. The context is dated 130-150. 


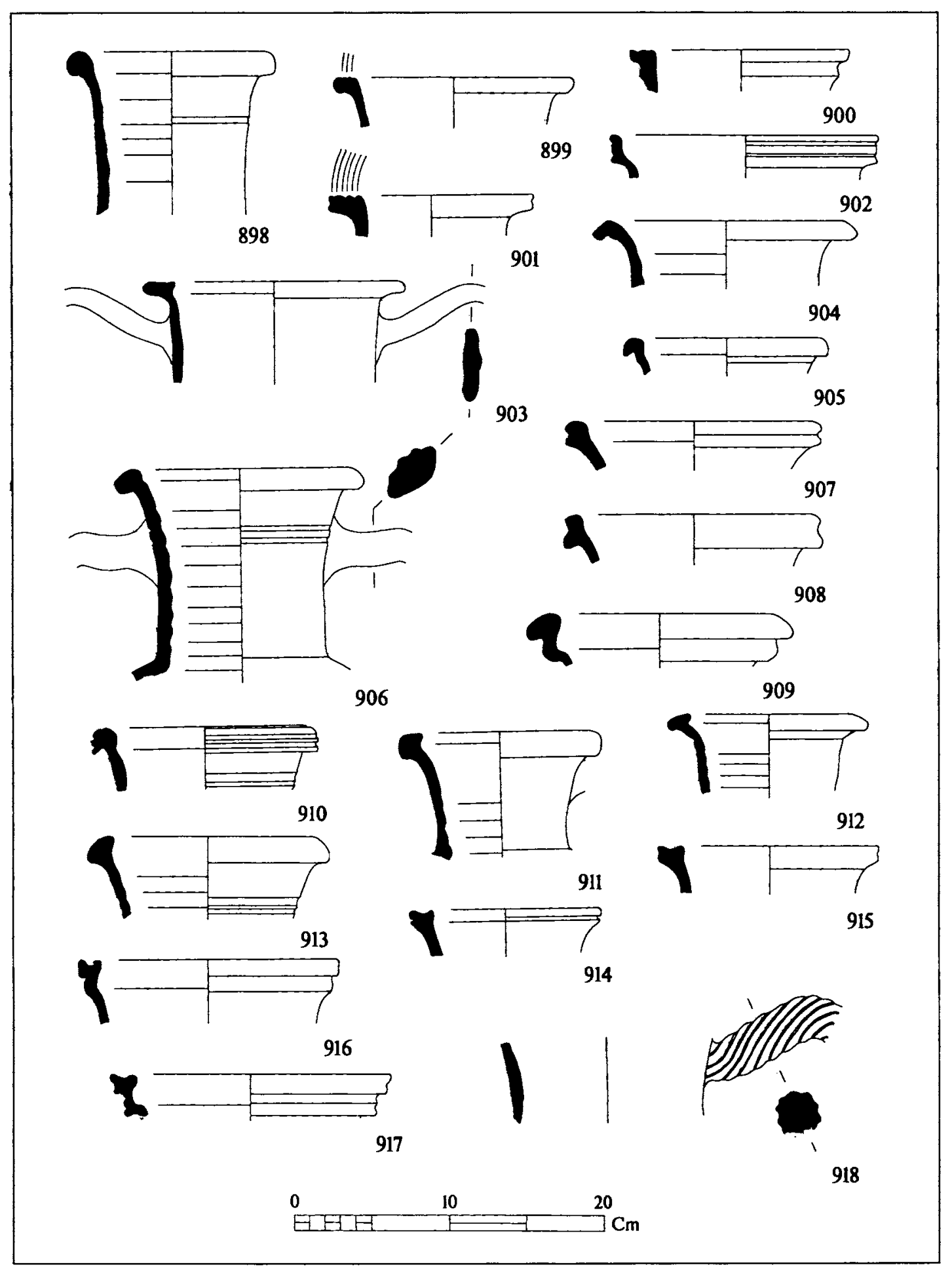

9.44 Red-slipped fine wares: ware 8 
908. C453 (699). Rim of an amphora, dia. $15 \mathrm{~cm}$. The context is dated 130-150. 4 examples were found, all in contexts dated to 130-150.

909. F325 (424). Rim of an amphora, dia. 14-15cm. The context is postmedieval. One other example came from a context dated to 450-600.

910. F345 (5005). Rim of an amphora, dia. $13 \mathrm{~cm}$. The context is post-medieval. 6 other examples were found, 1 from a context dated to 250-350, 3 from contexts dated to $250-450,1$ from a context dated to 450 , and 1 from a context dated to $450-600$.

911. C836 (676). Rim of an amphora, dia. $12-16 \mathrm{~cm}$. The context is dated 175-250. See 888 for dating.

912. Z220 (312). Rim of an amphora, dia. $10.5 \mathrm{~cm}$. The context is dated $250-275$.

913. F305 (1123). Rim of an amphora, dia. 9-16cm. The context is dated to 450 . 28 examples were found, 2 came from contexts dated to $100-130,6$ from contexts dated to $175-250,1$ from a context dated to $250-450,4$ from contexts dated to $350-450,2$ from contexts dated to $400-450,4$ from contexts dated to 450 , and 9 from contexts dated to $450-600$.

914. C436 (677). Rim of an amphora, dia. $12-16 \mathrm{~cm}$. The context is dated 175-250. One other example was found, also in a context dated to 175-250.

915. C224 (331). Rim of an amphora, dia. $12-14 \mathrm{~cm}$. The context is dated 175-250. 9 examples were found, of which the earliest one came from a context dated to 150-250, 2 more came from contexts dated to 175-250, and 1 more from a context dated 250-350.

916. C64 (432). Rim of an amphora, dia. $16 \mathrm{~cm}$. Undated context. 2 other examples were found, 1 from a context dated to 130-150, and 1 from a context dated to $175-250$.

917. C389 (676). Rim of an amphora, dia. $17 \mathrm{~cm}$. The context is dated $175-250$. One other example was found in a context dated to $400-450$.

918. Z175. Unstratified. Neck of an amphora with 'twisted' handle.

Red-slipped fine wares: ware 8 (Fig. 9.45)

919. DG782 (4515) SF. 14889. Fragment from an oval tray. Moulded circles and stars on top of the ledge rim. The context is dated 250-450.

920. DG879 (3194) SF. 14888. Fragment from an oval tray. Moulded design on top of the ledge rim. The context is post-medieval. 
921. DG761 (701) SF. 14891. Fragment from a rectangular tray. Moulded floral decoration on the top of the ledge rim. The context is dated 350-450.

922. DG764 (621) SF. 14887. Fragment from an oval tray. Moulded circle and dot pattern on top of the ledge rim. The context is dated $350-450$.

923. DG797 (4516) SF. 14880. Fragment from a rectangular tray. Moulded decoration on top of the ledge rim. The context is dated $250-450$.

924. DG763 (4507) SF. 14884. Fragment from a tray. Moulded star decoration on the top of the ledge rim. The context is dated $250-450$.

925. DG762 (1011) SF. 3131. Fragment from an oval tray. Moulded star pattern on the top of the ledge rim. The context is dated 450-600.

926. DG758 (4516) SF. 14879. Fragment from an oval tray. Moulded decoration on the top of the ledge rim. The context is dated 250-450.

927. DG757 (402) SF. 14896. Fragment of an oval tray. Moulded decoration on top of the ledge rim; motifs include a chalice, a human head wearing a laurel wreath, a tree, a horse and possibly an incense burner. The context is post-medieval.

928. DG854 (1003) SF. 3118 . Fragment of a rectangular tray. Moulded decoration on the top of the ledge rim; motifs include a hare, a dog, a human head and an unidentified animal. The context is dated postmedieval.

929. DG75 (1002) SF. 3003. Fragment of an oval tray. Moulded figure of a wild boar on the top of the ledge rim. The context is dated post-medieval.

930. DG880 (464) SF. 4290. Fragment of a tray. Moulded decoration on the top of the ledge rim; motifs include circles, stars and the hind part of an animal, perhaps a deer. The context is dated 450-600.

931. DG787 (4499) SF. 14883. Fragment of an oval tray. Moulded decoration of several indeterminate animals and a crude human figure on the top of the ledge rim. The context is dated $250-450$.

932. DG853 (1110) SF. 14878. Fragment of a rectangular tray. Moulded decoration on the top of the ledge rim; motifs include parts of two animals, possibly a leopard and a lion. The context is dated 450 .

933. DG796 (5051) SF. 14882. Fragment of a rectangular tray. Moulded decoration showing a lion on the top of the ledge rim. The context is dated 450 . 

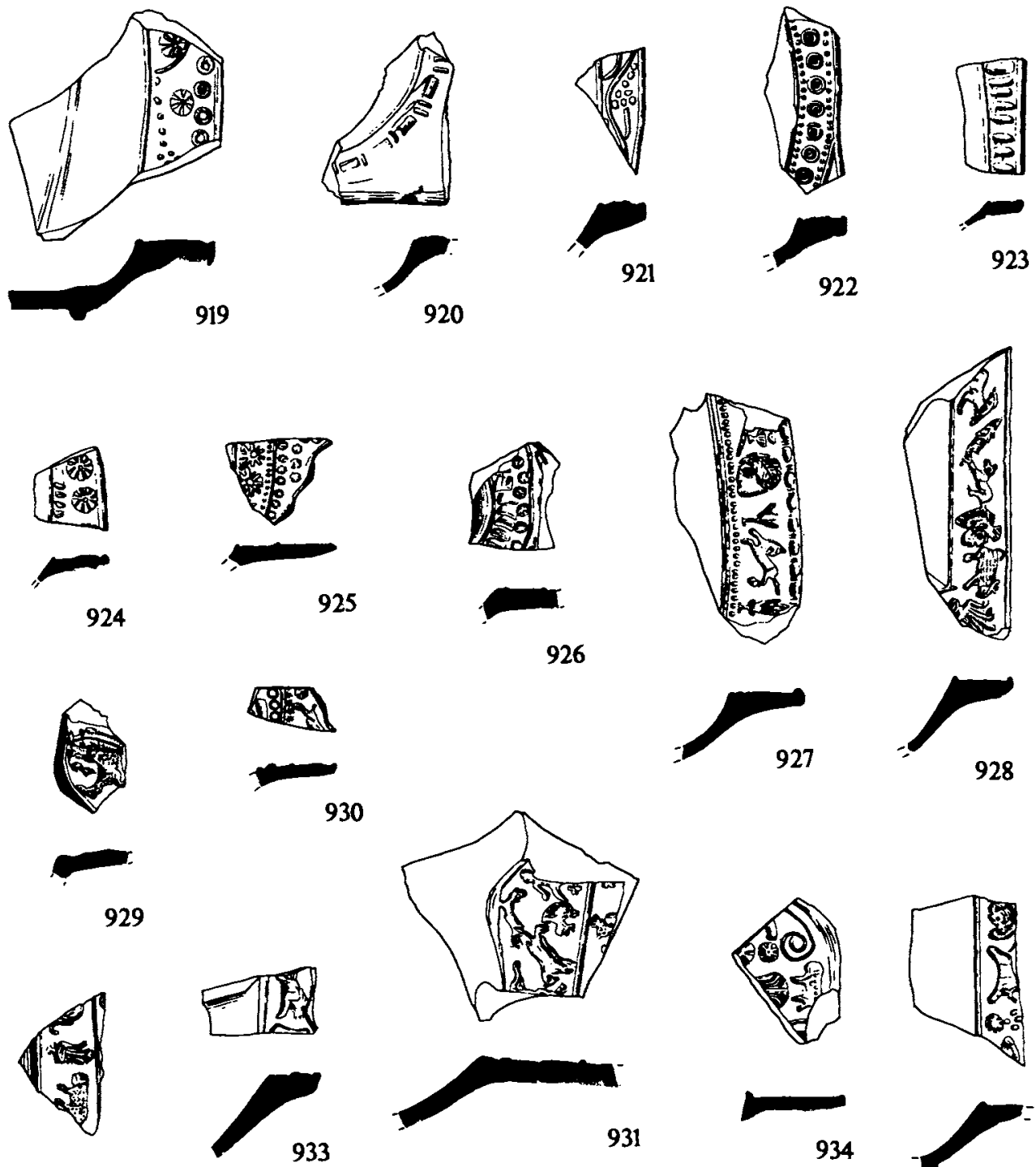

932

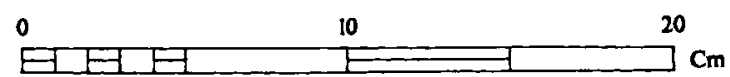

9.45 Red-slipped fine wares: ware 8 
934. DG881 (4843) SF. 14885. Fragment of an oval tray. Moulded decoration on the top of the ledge rim; motifs include a star and an unidentified crude animal. The context is dated $350-450$.

935. DG852 (601) SF. 14893. Fragment of a rectangular tray. Moulded decoration on the top of the ledge rim; motifs include the head of a soldier wearing a helmet, a star and an unidentified crude animal. The context is dated $350-450$.

Fine wares: ware 4, white-slipped censers (Fig. 9.46)

936. C642 (4128). Rim of a censer, dia. 9-11 cm. The context is dated 250-350.3 examples were found, 1 from a context dated to $150-175$, and 2 from contexts dated to $250-350$.

937. C526 (584). Rim of a censer, dia. $12-26 \mathrm{~cm}$. The context is dated $350-450.12$ examples were found, of which the earliest two were from contexts dated to 175-250, 1 came from a context dated to $250-350,1$ from a context dated to $250-450$, and 4 from contexts dated to $350-450$.

938. C111 (4512). Rim of a censer, dia. $17 \mathrm{~cm}$. The context is dated $250-450$.

939. C644 (4128). Rim of a censer, dia. $18 \mathrm{~cm}$. The context is dated $250-350.2$ other examples were found, 1 from a context dated to $150-250$, and 1 from a context dated to $400-450$.

940. C181 (255). Rim of a censer with impressed decoration on the exterior of the flange, dia. $16-22 \mathrm{~cm}$. The context is dated $300-450.5$ examples were found: 2 from contexts dated to $150-250,1$ from a context dated to $175-250,1$ from a context dated $275-450$, and 1 from a context dated to $350-450$.

941. C289 (511). Rim of a censer with rough rouletted decoration on the exterior, dia. $14-26 \mathrm{~cm}$. The context is dated $450-600.7$ examples were found, 2 in contexts dated to $175-250,1$ from a context dated to $350-450,3$ from contexts dated to $450-600$, and 1 from a post-medieval deposit.

942. C445 (677). Rim of a censer with a double band of impressed decoration on the exterior, dia. $18-33 \mathrm{~cm}$. The context is dated $175-250.3$ other examples were found, 2 from contexts dated to $130-150$, and 1 from a context dated to 450 .

943. C237 (342). Censer with bands of impressed decoration on the exterior, dia. $12-15 \mathrm{~cm}$. The context is dated $175-250.2$ other examples were found, both in contexts dated to $350-450$. 
944. G138 (4095). Rim of a censer with impressed decoration on the flange, the rim has been string-cut, suggesting that the vessel was made, or at least finished, upside down, dia. $22 \mathrm{~cm}$. The context is dated $400-500$. One other example was found in a context dated to $250-350$.

945. C197 (267). Rim of a censer with pinched decoration on the exterior, dia. $20 \mathrm{~cm}$. The context is dated $100-130$.

946. C200 (4841). Rim of a censer, dia. $22-36 \mathrm{~cm}$. The context is post-medieval. 6 examples were found, of which the earliest came from a context dated to 175-250, with 2 coming from a context dated to 450 , and 2 from contexts dated to $450-600$.

947. F679 (4843). Rim of a small censer, dia. $10 \mathrm{~cm}$. The context is dated $350-450$.

948. F612 (4507). Rim of a censer, dia. $14 \mathrm{~cm}$. The context is dated $250-450.10$ examples were found, 1 from a context dated to 150-250, 1 from a context dated to $250-450,2$ from contexts dated to $350-450,1$ from a context dated to $400-450,2$ from contexts dated to $450-600$, and 3 from post-medieval deposits.

949. C737 (4143). Rim of a censer with impressed decoration on the top of the rim and on the flange, dia. $14 \mathrm{~cm}$. The context is dated $175-250.3$ other examples were found, 1 from a context dated to 250-450, 1 from a context dated to $450-600$, and 1 from a post-medieval context.

950. C148 (250). Base of a censer, dia. $11 \mathrm{~cm}$ (no white slip). The context is dated $300-450$.

951. F579 (558). Rim of a censer, dia. $11 \mathrm{~cm}$. The context is dated $350-450$.

952. G78 (3258). Censer, dia. $11 \mathrm{~cm}$. The context is post-medieval.

953. C363 (610). Censer with impressed decoration on the top of the rim and on the flange, string-cut base, dia. $13 \mathrm{~cm}$. The context is dated $350-450$.

954. C666 (667). Rim of a censer with bands of rough rouletted decoration on the exterior, dia. $24 \mathrm{~cm}$. The context is dated $175-250.3$ other examples were found, 1 from a context dated to $250-350,1$ from a context dated to $400-450$, and 1 from a context dated to $450-600$.

955. C110. Unstratified. Rim of a censer with rough rouletted decoration on the rim and rouletted and thumb-impressed decoration on the flange, dia. $12-30 \mathrm{~cm} .16$ examples were found, of which the earliest came from a context dated to $130-150$, with 7 coming from contexts dated to $175-250$, 


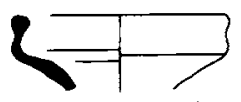

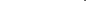

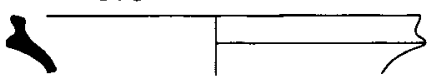

939
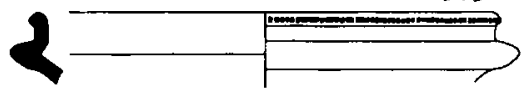

941

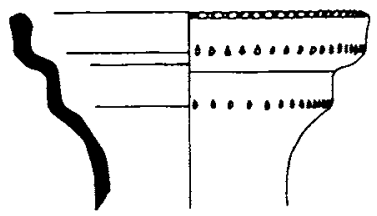

943

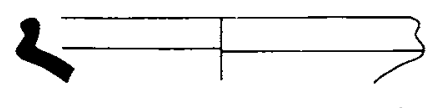

937

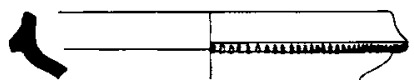

940

938
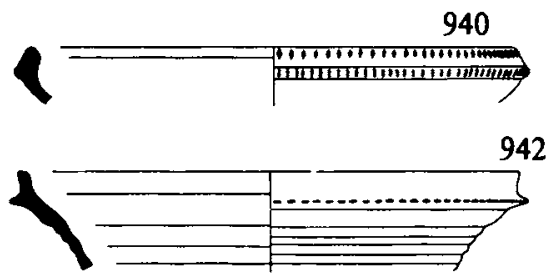

944
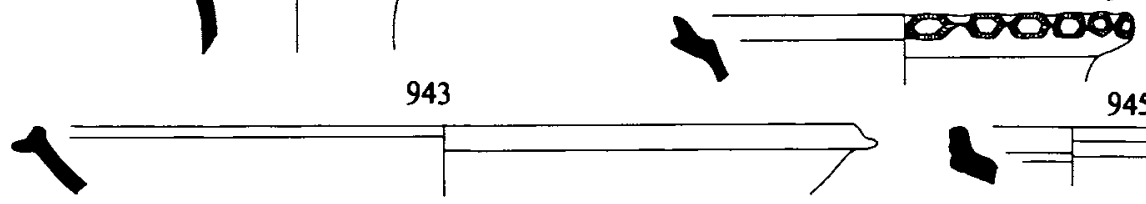

945
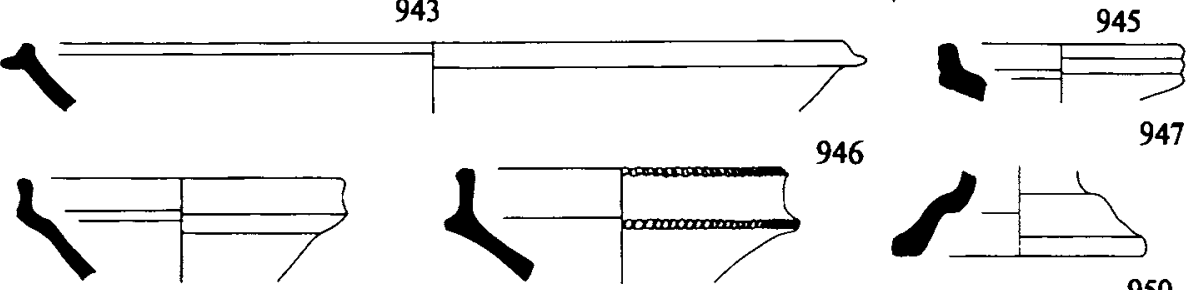

946
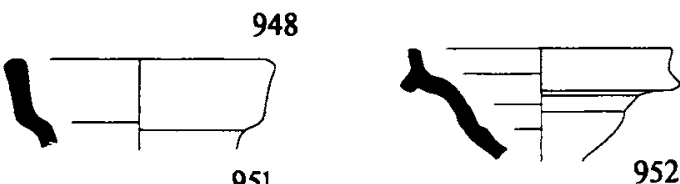

949
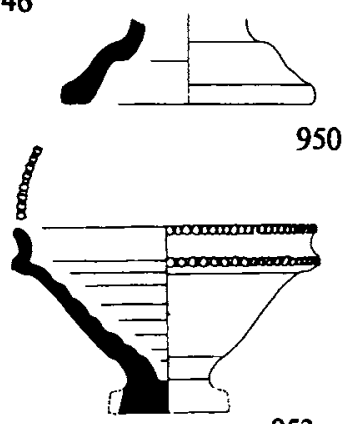

954

953

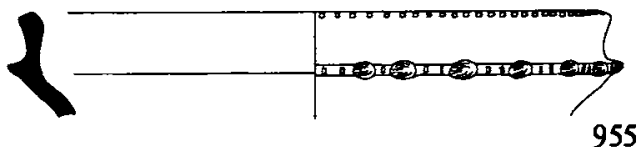

955

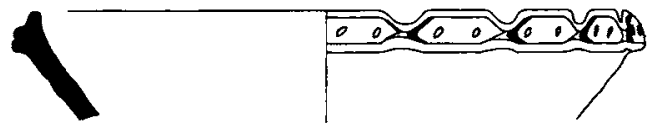

956

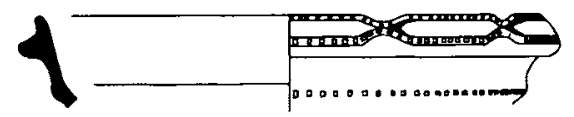

957

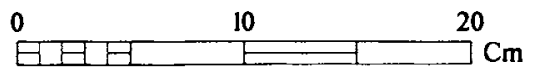

9.46 Fine wares: ware 4 , white-slipped censers 
context dated to $130-150$, with 7 coming from contexts dated to $175-250$, and 1 from a context dated to $175-350$.

956. F659 (3374). Rim of a censer with impressed and pinched rim, dia. $22-26 \mathrm{~cm}$. The context is dated 450-600. 2 other examples were found, 1 from a context dated to $150-250$, and 1 from a context dated to $275-400$.

957. C207 (224). Rim of a censer with rouletted decoration on the rim and the flange which have been pinched together, there is a further band of decoration on the exterior of the body, dia. $18-26 \mathrm{~cm}$. The context is dated 130-150. 5 examples were found, of which the earliest one came from a context dated to $130-150$, and 2 more came from contexts dated to 150-175.

Fine wares: ware 4 (Fig. 9.47)

958. C387 (4511). Rim of a jar, dia. 4-5cm. The context is dated $250-450.19$ examples were found, of which the earliest two were from contexts dated to $150-175,3$ from contexts dated to $175-250,1$ from a context dated to $250-350$, and 3 from contexts dated to $250-450$.

959. C231 (243). Rim of a jar, dia. $6-11 \mathrm{~cm}$. The context is dated $300-450.2$ other examples were found, both in contexts dated to $175-250$.

960. F235 (699). Rim of a jar, dia. $9 \mathrm{~cm}$. The context is dated $130-150$. One other example was found in the same context, which may be part of the same vessel.

961. Z2 (4942). Ring-omphalos base of a jar, dia. $8-9 \mathrm{~cm}$. The context is dated $350-450$.

962. F546 (1002). Rim of a bowl with incised straight and wavy decoration on the exterior, dia. $26 \mathrm{~cm}$. The context is post-medieval.

963. G81 (5314). Rim of a bowl, dia. $30 \mathrm{~cm}$. The context is dated $250-350$.

964. G133 (4912). Rim of a bowl, dia. $19 \mathrm{~cm}$. The context is dated $450-600$.

965. C793. Unstratified. Rim of a jar, dia. $5.5 \mathrm{~cm}$.

966. G122. Unstratified. Rim of a jar, dia. $4.5 \mathrm{~cm}$.

967. Z34 (686). Omphalos base of a jar, dia. $7 \mathrm{~cm}$. The context is dated $175-250$, but contains some later material.

968. Z16 (4480). Ring-omphalos base of a jar, dia. $6 \mathrm{~cm}$. The context is postmedieval. 
969. G112 (5306). Rim of a jug, dia. $3.5 \mathrm{~cm}$. The context is dated $250-350$.

970. C216 (34). Upper part of a jug, dia. 4.5-5cm. The context is dated 175-250. 4 examples were found, 2 from contexts dated to $175-250,1$ from a context dated to 250-350, and 1 from a post-medieval deposit.

971. F628 (4920). Rim of a jug, dia. $6 \mathrm{~cm}$. The context is dated $350-450$.

972. F314 (1096). Rim of a jug, dia. 4-5cm. The context is dated $450-600$. One other example was found in a context dated to 150-175.

973. F208 (661). Rim of a jug, dia. $7 \mathrm{~cm}$. The context is dated $250-350$. One other example came from a context dated to 450 .

974. C767 (3139). Very small cup, dia. $3-3.5 \mathrm{~cm}$. The context is post-medieval. One other example was found, also in a post-medieval context.

975. Z8 (3141). Amphora stopper, max. dia. 8cm. Undated context.

976. Z9 (3218). Amphora stopper, max. dia. $7.5 \mathrm{~cm}$. The context is dated $450-600$.

977. Z23 (3365). Amphora stopper, max. dia. $9 \mathrm{~cm}$. The context is dated $400-450$. 4 examples were found, 2 from contexts dated to $400-450$, and 2 from postmedieval contexts.

978. C635 (2175). Amphora stopper, max. dia. $9.5 \mathrm{~cm}$. The context is dated 130-175. 4 other examples were found, 2 from contexts dated to $175-250,1$ from a context dated to $250-350$, and 1 from a post-medieval context.

979. Z200. Unstratified. Amphora stopper, max. dia. $8.5 \mathrm{~cm}$.

980. F673 (4103) SF. 6640. Candlestick amphora stopper with a string-cut base, dia. $3.5-5 \mathrm{~cm}$ (max. dia. $6.5 \mathrm{~cm}$ ). The context is dated $300-450.16$ examples were found, of which the earliest two came from contexts dated to 130-150, 1 came from a context dated to $150-175,2$ from contexts dated to $175-250$, and 3 from contexts dated to $250-350$.

981. F673 SF. 4720. Unstratified. Amphora stopper with a string-cut base, dia. $3.5-5 \mathrm{~cm}$ (max. dia. $6.5 \mathrm{~cm}$ ). See 980 for dating.

982. G168 (4848). Bowl, dia. $12 \mathrm{~cm}$. The context is dated $350-450$. 

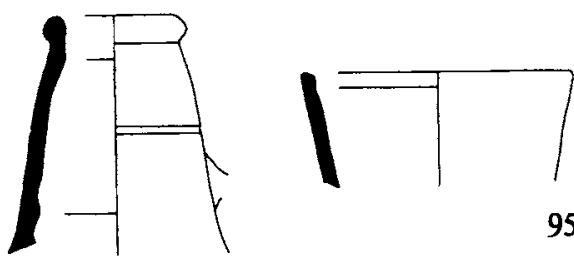

959
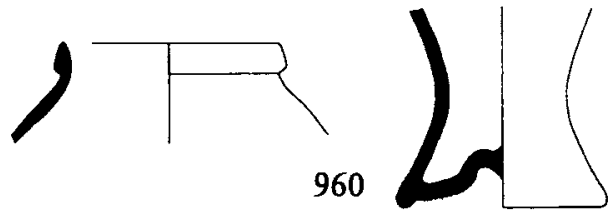

958

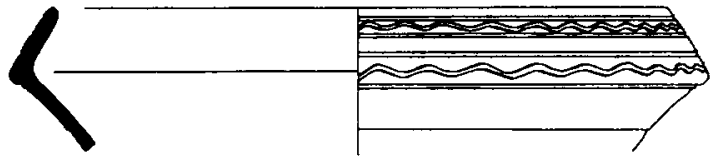

962
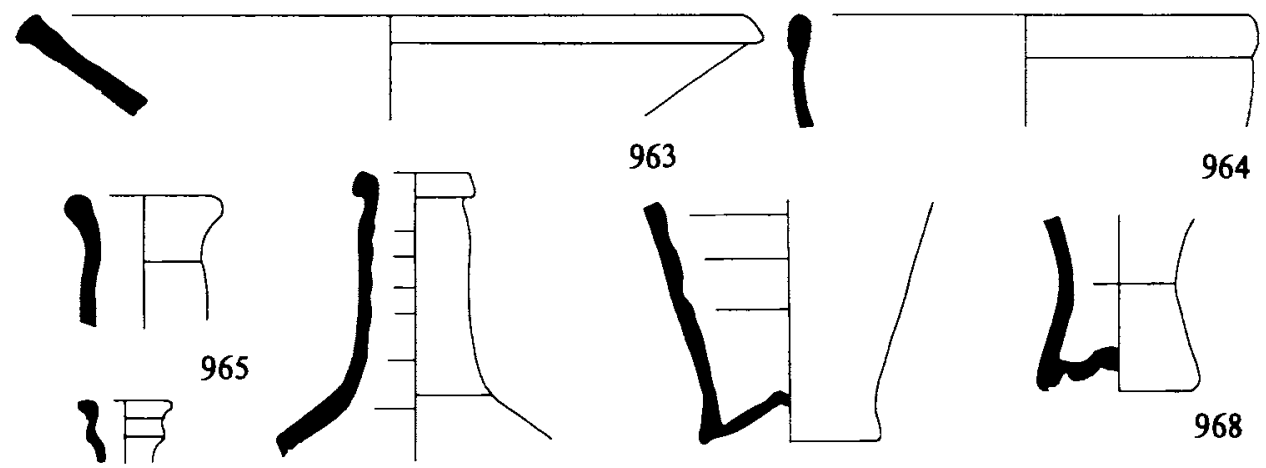

963

964

阴

969
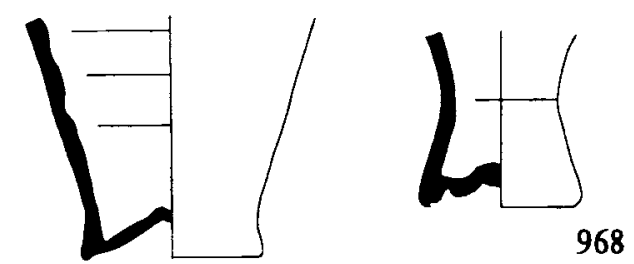

966
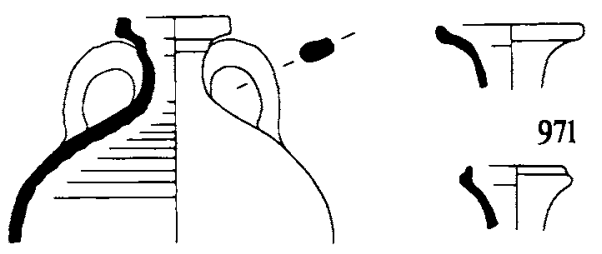

972
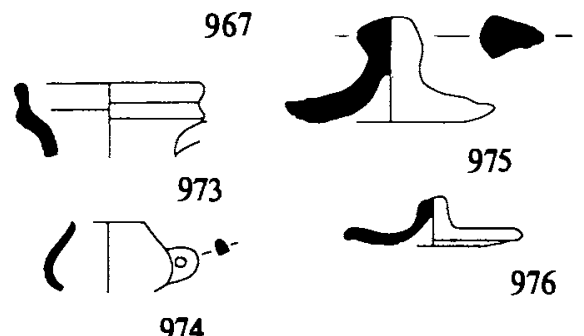

975
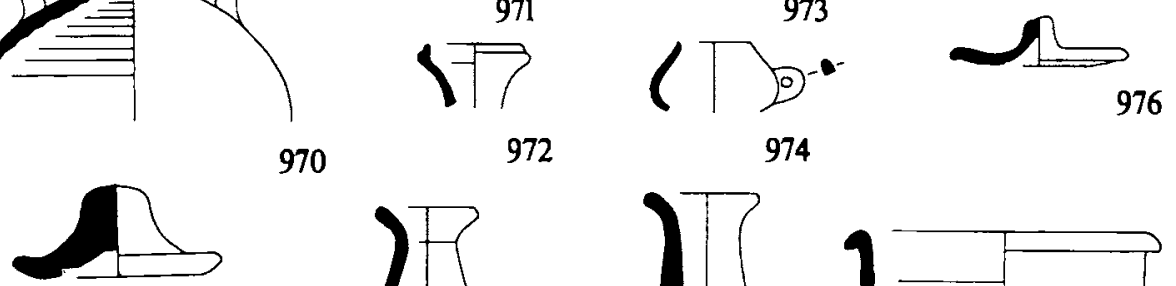

977
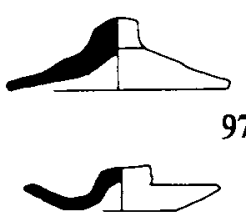

978

979
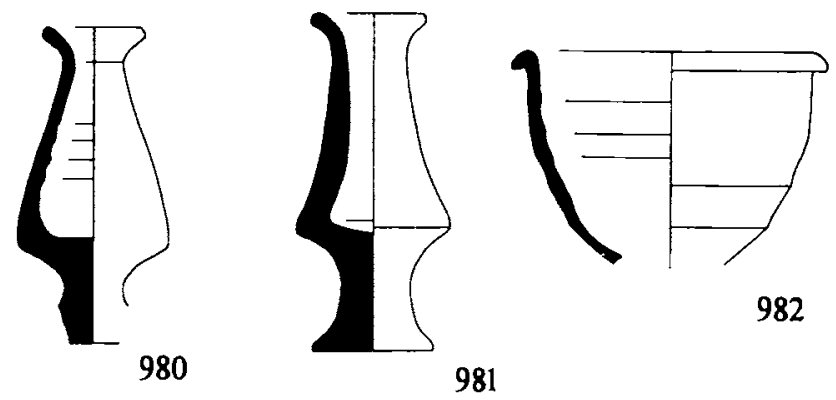

981

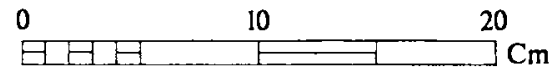

9.47 Fine wares: ware 4 
Black-slipped fine wares: ware 78 (Fig. 9.48)

983. C416 (661). Rim of a bowl, dia. $23-34 \mathrm{~cm}$. The context is dated $250-350.2$ other examples came from the same context, and 1 came from a context dated to 450 .

984. C349. Unstratified. Rim of a bowl, dia. $20-24 \mathrm{~cm} .5$ other examples were found, 2 from contexts dated to $350-450,1$ from a context dated to $450-600$, and 2 from post-medieval deposits.

985. G91 (4495). Rim of a bowl, dia. 10-12cm. The context is post-medieval.

986. G140 (607). Rim of a bowl, dia. $34 \mathrm{~cm}$. The context is dated $450-600$.

987. F492 (4515). Rim of a bowl, dia. $15-23 \mathrm{~cm}$. The context is dated $250-450.4$ other examples were found, all from contexts dated to $350-450$.

988. F216 (659). Rim of a bowl, dia. $17-22 \mathrm{~cm}$. The context is dated $250-350$. One other example was found in the same context.

989. G57 (1036). Rim of a bowl, dia. $21 \mathrm{~cm}$. The context is dated $450-600$.

990. C350 (1110). Rim of a bowl, dia. $12 \mathrm{~cm}$. The context is dated to 450 . One other example was found in a context dated to $450-600$.

991. C446 (677). Bowl with a flat ledge handle, dia. $19 \mathrm{~cm}$. The context is dated $175-250$. One other example was found in the same context - probably from the same vessel.

992. C77 (221). Rim of a bowl, dia. $21-23 \mathrm{~cm}$. The context is dated $130-150.4$ other examples were found, 1 from a context dated to $250-275$, and 3 in a context dated to $275-450$.

993. C784 (4430). Rim of a bowl, dia. $22 \mathrm{~cm}$. The context is post-medieval.

994. C501 (665). Rim of a bowl with bands of fine rouletting on the interior, dia. $20 \mathrm{~cm}$. The context is dated $250-350$. One other example was found in a post-medieval context.

995. Z221 (682). Rim of a bowl, dia. $28 \mathrm{~cm}$. The context is dated $350-450$.

996. C328 (570). Rim of a bowl, dia. $18 \mathrm{~cm}$. The context is dated $350-450$.

997. C268 (534). Rim of a bowl, dia. $16 \mathrm{~cm}$. The context is dated $450-600$.

998. C752 (550). Rim of a bowl, dia. $26 \mathrm{~cm}$. The context is dated $450-600$.

999. Z186. Unstratified. Rim of a jar, dia. $16 \mathrm{~cm}$. 


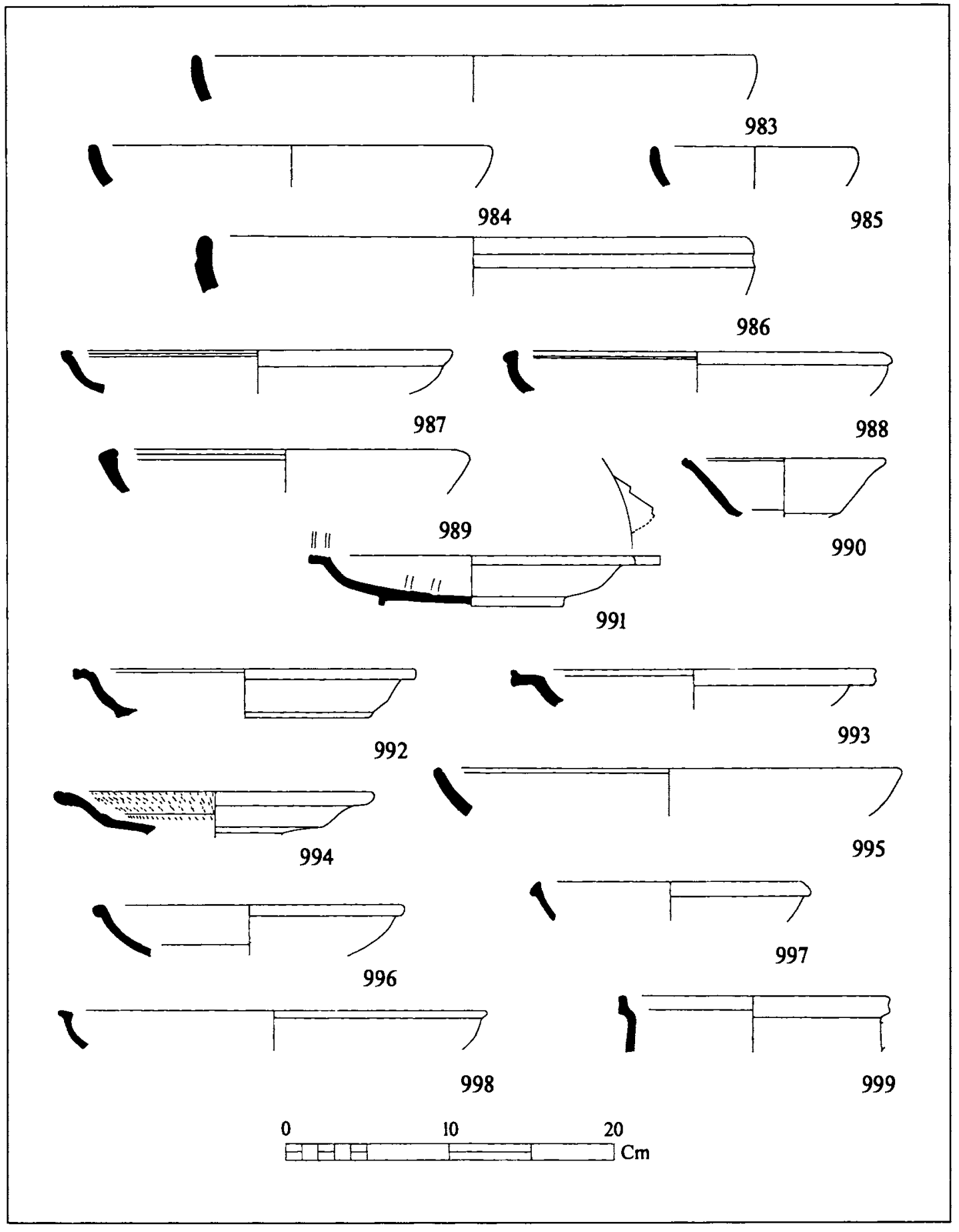

9.48 Black-slipped fine wares: ware 78 


\section{Industrial wares and mortaria}

Industrial wares: ware 44 and a mortarium (Fig. 9.49)

1000. C676 (698). Rim of a large basin, dia. c. $60 \mathrm{~cm}$. The context is dated 130-150. 5 examples were found, all from the same context.

1001. F230 (677). Rim of a large hole-mouth jar, dia. $57 \mathrm{~cm}$. The context is dated 175-250.

1002. F296 (667). Rim of a large hole-mouth jar, dia. $22-28 \mathrm{~cm}$. The context is dated 175-250. There was one other example from the same context, and 1 from a context dated to $150-175$.

1003. F296 (667). Rim of a large hole-mouth jar, dia. $22-28 \mathrm{~cm}$. The context is dated 175-250. See 1002 for dating.

1004. F297 (667). Rim of a basin, dia. $21 \mathrm{~cm}$. The context is dated $175-250$.

1005. F228 (3132). Rim of a very large basin, dia. $64-74 \mathrm{~cm}$. The context is postmedieval. 4 other examples came from a context dated to $175-250$.

1006. Z40 (665). Mortarium with stamp, dia. 39cm. The context is dated 250-350. 2 other examples, though unstamped, came from a context dated to $250-450$.

\section{Miscellaneous wares}

Miscellaneous wares (Fig. 9.50)

1007. C667 (699). Rim of a small jar, dia. $8-9 \mathrm{~cm}$. Ware 39 . The context is dated 130-150. One other example was found, in a context dated to 250-350.

1008. G85 (4492). Rim of a small jar, dia. $7 \mathrm{~cm}$. Glazed on exterior. Ware 39 . The context is post-medieval. 2 other examples were found in contexts dated to 450-600.

1009. Z188 (4431). Rim of a jar with white-painted pattern, dia. 7cm. Ware 39. The context is post-medieval.

1010. Z183 (682). Base of a small jar dia. $3 \mathrm{~cm}$. Ware 39 . Black glaze outside. The context is dated $350-450$.

1011. C856 (4405). Upper part of a bowl, dia. $18 \mathrm{~cm}$. Grey fabric. The context is post-medieval. 


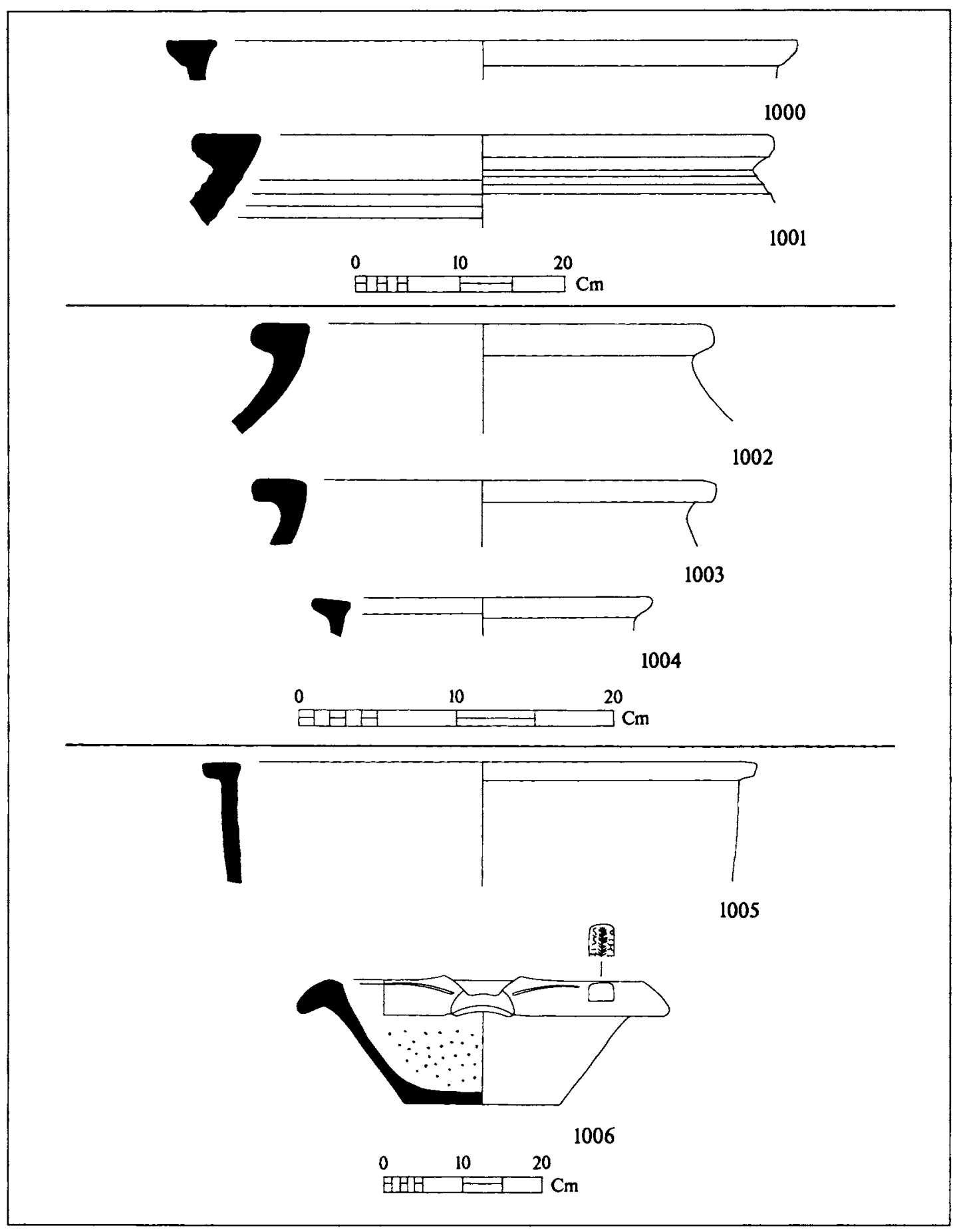

9.49 Industrial wares: ware 44 and a mortarium 
1012. Z111 (4962). Rim of a flanged bowl, dia. $16 \mathrm{~cm}$. The ware is light brown to orange with a moderate fracture. The fabric is grainy and contains a few black and translucent grits and the occasional shiny particle and small void. The surface has a horizontally brushed patchy black slip. The context is dated 250-350.

1013. G101 (4424). Rim of a bowl, dia. $24-30 \mathrm{~cm}$. Brown fabric. The context is post-medieval.

1014. C740 (4506). Ledge rim of a bowl, dia. $20 \mathrm{~cm}$. The ware is red-brown with a clean fracture, with many white grits, a few grey grits and some mica, black slip outside. The context is dated 250-450.

1015. Z152 (2249). Hand-made crucible, dia. $6 \mathrm{~cm}$. The ware is grey with a crumbly fracture. The fabric contains large grey grits (up to $2 \mathrm{~mm} \mathrm{dia.)}$, organic matter and a large amount of mica. The context is dated to 450 .

1016. Z114 (2200). Lipped crucible, dia. $3 \mathrm{~cm}$. The fabric is grey with the appearance of pumice. Undated context. 2 other examples were found in contexts dated to $450-600$.

1017. C853 (4405). Rim of a jar, dia. $9 \mathrm{~cm}$. Orange fabric. The context is postmedieval. 2 other examples were found in a context dated to $250-450$.

1018. F625 (4480). Rim of a jar, dia. $10 \mathrm{~cm}$. Orange fabric. The context is postmedieval.

1019. F23 (1). Rim of a jar, dia. $8 \mathrm{~cm}$. Ware 55 . The context is post-medieval. 3 other examples were found, 1 from a context dated to 350-450, and 2 from post-medieval deposits.

1020. C774 (1084). Rim of a bowl, dia. $15-20 \mathrm{~cm}$. Ware 55 . The context is dated 450.2 other examples came from a context dated to $450-600$.

1021. C632 (4096). Rim of a bowl, dia. 10cm. Buff fabric with a shiny brown slip. The context is dated $400-500$, but contains some later material.

1022. H14 (449). Rim of a jug, dia. $4-5 \mathrm{~cm}$. The ware is light brown with a clean fracture and rough spalling surface. The fabric contains angular grey grits, some up to $2 \mathrm{~mm}$ dia. (these may be flint), a few white and translucent grits and the occasional shiny particle. The context is post-medieval. One other example was found in a context dated to $175-250$.

1023. G152 (96). Rim of a jar, dia. $11 \mathrm{~cm}$. Grey fabric. Undated context.

1024. C810 (3001). Rim of a jar, dia. $10 \mathrm{~cm}$. Red fabric with a thin red washy slip. The context is post-medieval. 

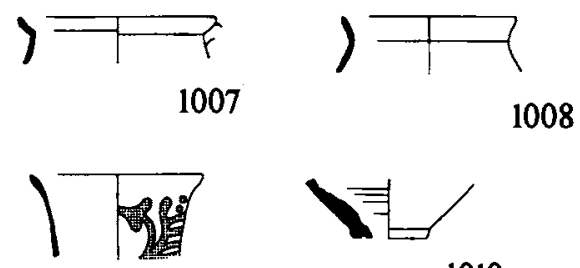

1

\section{8}
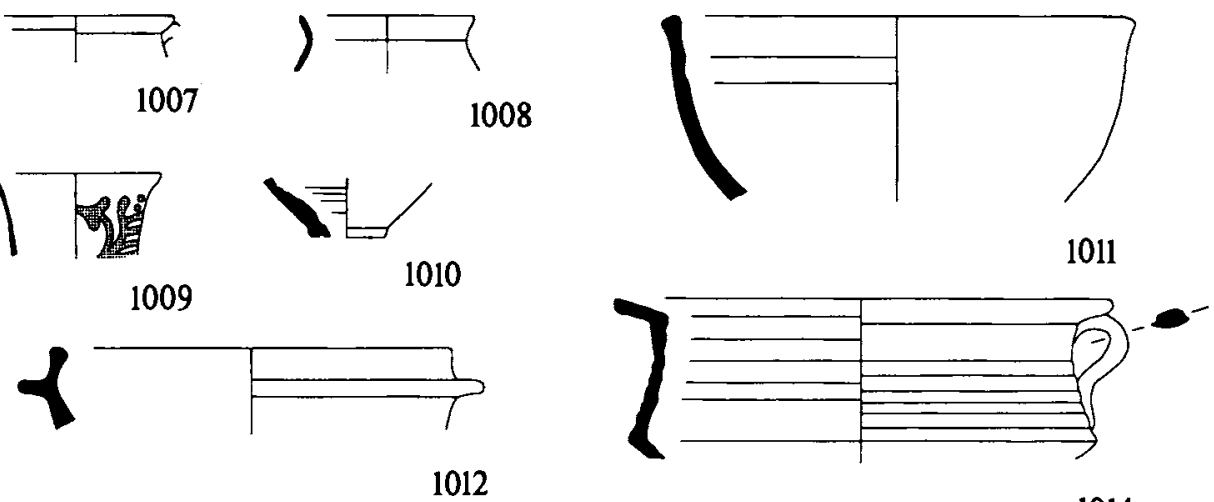

1014

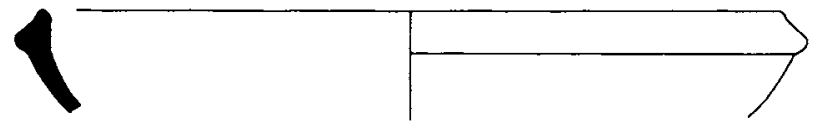

1013

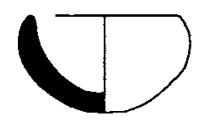

1015

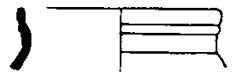

1019

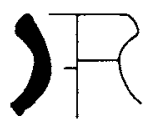

1022

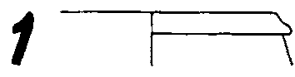

1025

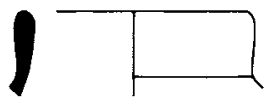

1017

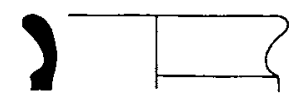

1018
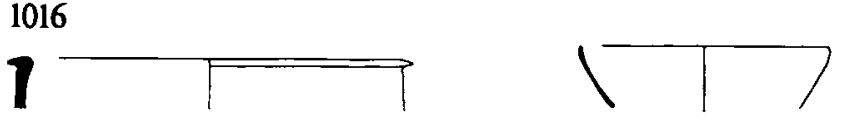

1020

1021

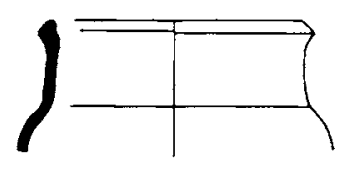

1023

1024

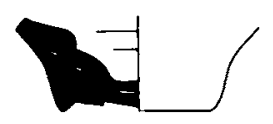

1026

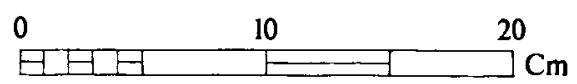

9.50 Miscellaneous wares 
1025. C417 (659). Rim of a jar, dia. $10 \mathrm{~cm}$. The ware is red with a rough surface and crumbly fracture. The fabric is grainy and contains many white and quartz grits. The context is dated $250-350$.

1026. Z19 (4809). Base of a jar/amphora, dia. $6 \mathrm{~cm}$. The ware is light brown with a few quartz grains and black grits, and many shiny particles. The bottom part of the base has been applied after the body was thrown, the join line being clearly visible. The fabric here is different: very sandy with shiny particles, much quartz and black sand. The context is post-medieval.

\section{Imported fine wares}

Imported fine wares (Fig. 9.51)

1027. Z160 (4512). Rim of a bowl, dia. $16.5 \mathrm{~cm}$. Samian (East Gaulish), Drag 37. Part of ovoli just visible. This came from a context dated 250-450.

1028. C849 (1054). Rim of a bowl, dia. 24cm. Samian (East Gaulish), Drag 37. This came from a post-medieval context. One other example was found in a context dated to $400-500$.

1029. Z158. Unstratified. Rim of a bowl, dia. $28 \mathrm{~cm}$. Samian (East Gaulish), Drag 31.2 other examples were found, 1 from a context dated to $400-450$, and 1 from a context dated to $450-600$.

1030. C805 (3064). Rim of a cup, dia. $11 \mathrm{~cm}$. Samian (East Gaulish), Drag 33. There is a single incised band on the exterior. This came from a postmedieval context. 3 other examples were found, 2 from contexts dated to $250-450$, and 1 from a post-medieval deposit.

1031. Z157 (3310). Rim of a bowl, dia. 26cm. Samian (East Gaulish), Drag 32. This came from a context dated $400-450$.

1032. Z156 (4463). Rim of a mortarium, dia. $18 \mathrm{~cm}$. Samian (East Gaulish ?), Drag 45. (O\&P pl. LXXIV 5). This came from a post-medieval context, and was the only example found. A small fragment from the body of a Samian mortarium came from 4516, a context dated $250-450$.

1033. Z154. Unstratified. Base of a bowl, dia. $9 \mathrm{~cm}$. Samian (East Gaulish).

1034. Z153 (2208). Base of a bowl, dia. 7cm. Samian (East Gaulish), probably Drag 37. This comes from a context dated 450-600.

1035. DG786 (3041) SF. 14886. Decorated body sherd. Samian (East Gaulish), probably from a Drag 37 (see O\&P pl. XXXVII: 84-85). Part of a chevron 
wreath is visible alongside what may be part of a rosette. It is from a postmedieval context.

1036. DG784 (4007) SF. 14876. Decorated body sherd. Samian (East Gaulish), probably from a Drag 37 . The sherd shows parts of two medallions with an indeterminate object (standard?) in between, in the medallion on the left a hand and leg are visible. It is from a post-medieval context.

1037. DG855 (4414) SF. 10246. Decorated body sherd. Samian (East Gaulish), probably from Drag 37 . The sherd shows an 'advertisement' stamp of FIRMU[S] below a medallion with an indeterminate figure inside. (See Oswald 1931 for other examples.) It came from a context dated 250-450.

1038. DG785 (70) SF. 14898. Decorated body sherd. Samian (East Gaulish), probably from a Drag 37 . The sherd shows an indeterminate figure inside a medallion below the usual ovoli. It came from a post-medieval context.

1039 DG783 (4513) SF. 10247. Decorated body sherd. Samian (East Gaulish), probably from a Drag 37. The sherd shows a horse in a medallion with indeterminate decoration outside the medallion. It came from a context dated $800-1000$.

1040. C368 (401). Rim of a bowl/plate, dia. $33 \mathrm{~cm}$. Samian (East Gaulish) Ludowici type $\mathrm{Tb}$ (see O\&P pl. LIX: 5 and 9). Single faintly incised line on top of rim, and three incised lines on internal carination. This example came from a post-medieval deposit. One other example was found, also in a post-medieval context

1041. DG768 (1189) SF. 14897. Decorated sherd from the base of a bowl. Late Roman C ware. Palmettes in typical palm branch style (Hayes 1972, 350). It is highly likely that this is part of the same vessel as bowl 1042 as it came from the same context. The context is dated $400-450$.

1042. C141 (1189). Rim of a bowl, dia. $34 \mathrm{~cm}$. Late Roman C ware, Hayes form 4 (dated c. 425-450). This example came from a context dated 400-450. 4 other examples were found, 1 from a context dated to $400-500,2$ from contexts dated to $450-600$, and 1 from a post-medieval context.

1043. C141 (453). Rim of a bowl, dia. $28 \mathrm{~cm}$. Late Roman C ware, Hayes form $3 / 4$ (dated to mid fifth century?). This example comes from a post-medieval context. See 1042 for dating.

1044. C60 (434). Rim of a bowl, dia. $30 \mathrm{~cm}$. African Red Slip ware, Hayes form 50 , probably A (dated c. 230-325). This example was from a post-medieval context. 


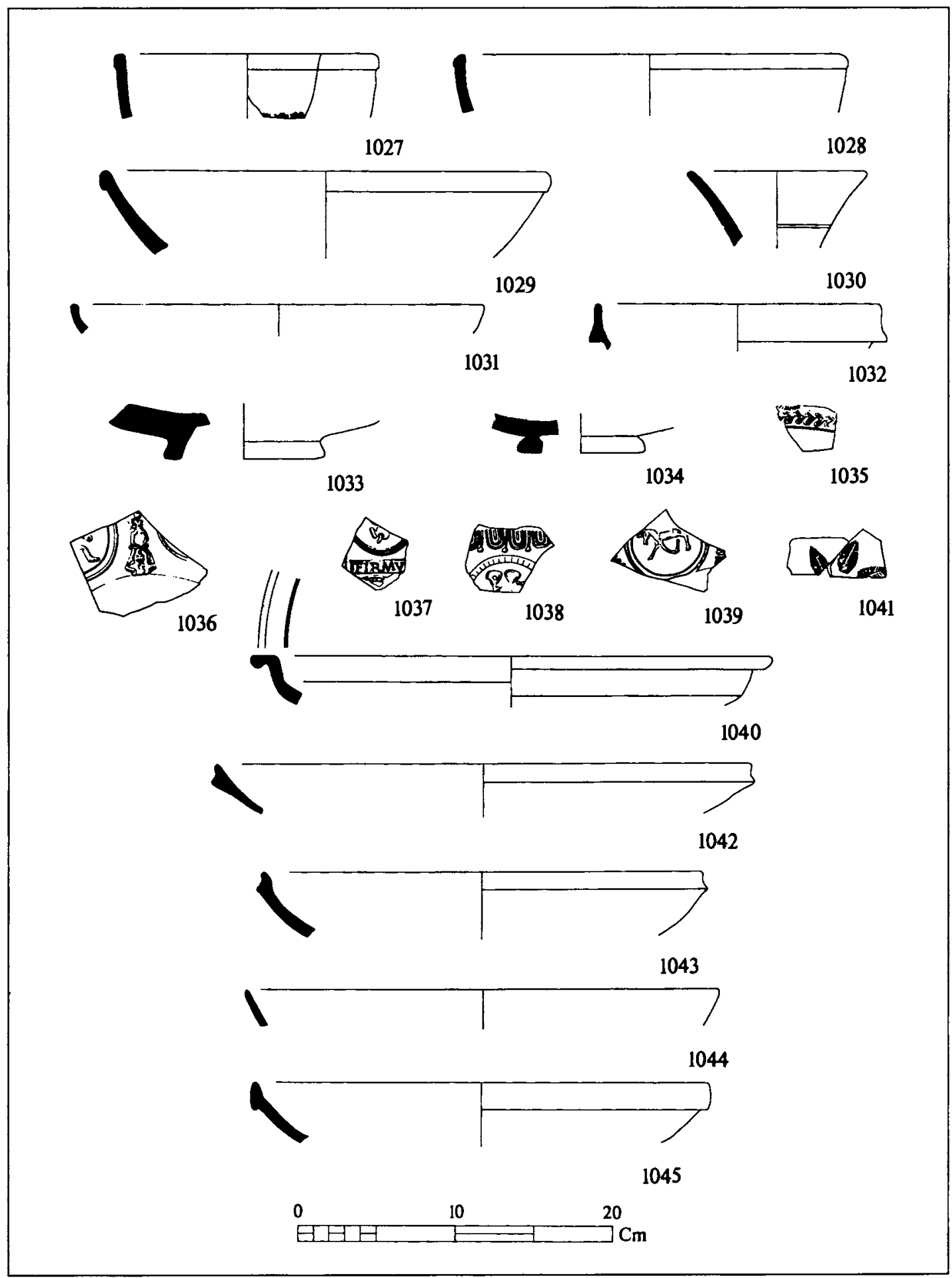

9.51 Imported fine wares 
1045. C14 (453). Rim of a bowl, dia 30-32cm. Cypriot Red Slip ware, Hayes form 9 (dated 550-700). Two examples were found, both in post-medieval contexts.

\section{Amphorae}

Eastern Mediterranean amphorae (Fig. 9.52)

1046. H52 (5051). Rim of an amphora, dia. $14 \mathrm{~cm}$. P\&W 48/49. The context is dated to 450 .

1047. H18 (451). Rim of an amphora, dia. $11 \mathrm{~cm}$. P\&W 48/49. The context is postmedieval. One other example was found in a context dated to 450-600.

1048. H46 (4430). Rim of an amphora with clay crudely smeared on the top of the exterior (prior to firing), dia. $10-11 \mathrm{~cm}$. P\&W 48/49. The context is postmedieval. 5 examples were found, 1 from a context dated to $350-450,1$ from a context dated to 450 , and 3 from post-medieval contexts.

1049. H46 (4405). Rim of an amphora with clay smeared on the top of the exterior (prior to firing), dia. $10-11 \mathrm{~cm}$. P\&W 48/49. The context is postmedieval. See 1048 for dating.

1050. H20 (449). Rim of an amphora with prominent collar, dia. $7-10 \mathrm{~cm}$. P\&W 47. The context is post-medieval. 22 examples were found, 1 from a context dated to 150-250, 2 from contexts dated to 250-350, 5 from contexts dated to $250-450,1$ from a context dated to $350-450,1$ from a context dated to 450,2 from contexts dated to $450-600$, and 10 from post-medieval contexts.

1051. H19 (3101). Rim of an amphora with prominent collar, dia. 7-10cm. P\&W 47. The context is post-medieval. 12 examples were found, 1 from a context dated to $150-175,1$ from a context dated to $250-350,1$ from a context dated to $250-450,1$ from a context dated to $350-450,1$ from a context dated to 450,1 from a context dated to $450-600$, and 6 from post-medieval contexts.

1052. H37 (5051). Rim of an amphora, dia. $8 \mathrm{~cm}$. P\&W 47. The context is dated to 450 . One other example was found in a post-medieval context.

1053. Z173 (4840). Base of an amphora, dia. $8 \mathrm{~cm}$. P\&W 47. The context is dated 350-450.

1054. Z187 (4610, area L) SF. 11004. Body of an amphora. The ware is severely burnt, but was probably originally buff, with a moderate fracture. The fabric contains many grey and translucent grits. The outside is pared vertically and 
has a sandy feel. The context is not dated, as area $L$ was a trial cutting which was not extended. However, it would almost certainly be dated to 450-600.

1055. Z1 (4835). The base of a jar/amphora with signs of heavy vertical paring on the exterior, dia. $6 \mathrm{~cm}$. Fabric as 1054 . The context is dated $450-600$.

1056. H48 (3289). Rim of an amphora, dia. $12-18 \mathrm{~cm}$. Keay LXV. The context is dated 450-600. 5 examples were found: 1 from a context dated to 450,2 from contexts dated to $450-600$, and 2 from post-medieval contexts.

1057. F53 (4952). Rim of an amphora, dia. $919 \mathrm{~cm}$. Keay LXV. The context is dated 350-450. 31 examples were found, of which the earliest 6 came from contexts dated to $175-250,3$ came from contexts dated to $250-350,5$ from contexts dated to $275-450$, and 6 from contexts dated to $350-450$.

1058. H55 (5311). Rim of an amphora, dia. $14 \mathrm{~cm}$. Keay LXV. The context is dated 250-350. One other example was found in a context dated to 275-450.

1059. H25 (665). Rim of an amphora, dia. 12-16cm. Keay LXV. The context is dated 250-350. 12 examples were found, of which the earliest one came from a context dated to $175-250,1$ came from a context dated to $250-275,1$ from a context dated to $250-350$, and 4 from contexts dated to $350-450$.

1060. F622 (635). Rim of an amphora, dia. $13 \mathrm{~cm}$. Traces of white slip on interior. Keay LXV. The context is dated 350-450. One other example was found, also in a context dated to 450 .

1061. H27 (542). Rim of an amphora with an incised wavy band on the neck, dia. $12 \mathrm{~cm}$. Keay LXV. The context is dated $450-600$.

1062. H45 (2142). Rim of an amphora, dia. 14cm. Keay LXV. The context is dated $450-600$.

1063. Z199 (4499). Neck of an amphora. The ware is earthy brown with a brown surface with a moderate fracture. The fabric contains a few white and some black and brown grits and the occasional mica particle. This may well be a Nile valley fabric and is possibly from a P\&W class 53 . The context is dated $250-450$.

1064. H29 (129). Rim of an amphora, dia. $9 \mathrm{~cm}$. Keay LIIIa. The context is dated 300-450. 2 other examples came from a context dated to 450 .

1065. Z118 (4498). Rim of an amphora, dia. $6 \mathrm{~cm}$. Keay fabric 18 . The context is dated 450-600.

1066. H2 (406). Rim of an amphora, dia. 5-8cm. Keay LIIla. Undated context. 4 other examples were found, 1 from a context dated to $130-150,1$ from a 


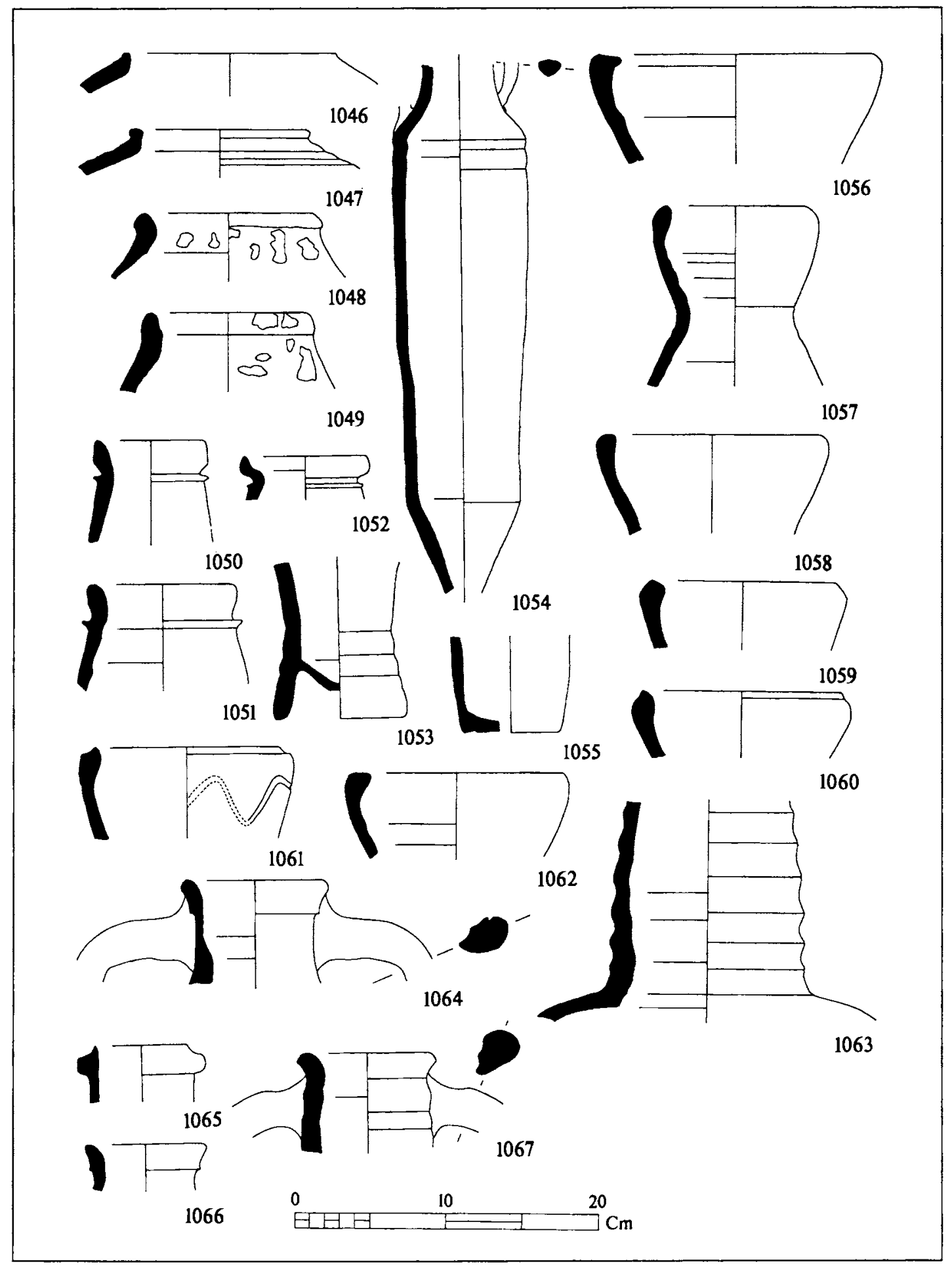

9.52 Eastern Mediterranean amphorae 
context dated to $350-450,1$ from a context dated to 450 , and 1 from a postmedieval context.

1067. H58 (4422). Rim of an amphora, dia. 8-9cm. Keay LIIIb. The context is post-medieval.

Eastern Mediterranean, African and miscellaneous amphorae (Fig. 9.53)

1068. Z185 (4053). Lower half of an amphora. Keay LIII (probably b). The context is dated $300-450$.

1069. H47 (3288). Rim of an amphora, dia. 12-14cm. Keay IIIb. The context is dated 400-450. 5 other examples were found, 1 from a context dated to $175-250,1$ from a context dated to $250-350,1$ from a context dated to $275-450$, and 2 from contexts dated to 450 .

1070. H22 (341). Rim of an amphora, dia. 10-13cm. Probably Keay IIIb. The context is dated 175-250. 4 other examples were found, 1 from a context dated to $175-250,2$ from a context dated to $350-450$, and 1 from a context dated to $450-600$.

1071. H16 (243). Rim of an amphora, dia. $14 \mathrm{~cm}$. Cream slip. Keay IIIb. The context is dated $300-450$.

1072. H50 (5051). Rim of an amphora, dia. $12 \mathrm{~cm}$. Keay IIIb. The context is dated to 450 .

1073. Z198 (5311). Base of an amphora. The ware is orange with an orange surface and a moderate fracture. The fabric contains a few white and translucent grits and the occasional black grit and shiny particle. Keay III. The context is dated 250-350.

1074. F534 (3132). Rim of an amphora, dia. $12 \mathrm{~cm}$. Keay VI. The context is postmedieval. 2 other examples were found, 1 from a context dated to 250-350, and 1 from a context dated to $250-450$.

1075. G50 (5051). Rim of an amphora, dia. $12 \mathrm{~cm}$. Keay IX. The context is dated to 450. One other example was found in a post-medieval context.

1076. G49 (5051). Rim of an amphora, dia. 11-15cm. Buff slip. Keay VIIIb. The context is dated to 450.4 examples were found, 3 others from the same context, and 1 from a post-medieval deposit.

1077. Z115 (4912). Rim of an amphora, dia. $15 \mathrm{~cm}$. The ware is light brown with a yellow-brown core and moderate fracture. The fabric contains many small 
mica plates and a medium amount of angular grey grits and the occasional void. Pinkish cream slip. Keay VIIIb. The context is dated 450-600.

1078. Z167 (5051). Rim of an amphora, dia. $11 \mathrm{~cm}$. White slip. Keay VIIIb. The context is dated to 450 .

1079. H33. Unstratified. Rim of an amphora, dia. $14 \mathrm{~cm}$. Buff slip. Keay LXI (central Tunisian fabric 3).

1080. H53 (4126). Rim of an amphora, dia. $14 \mathrm{~cm}$. The ware is brick red with a moderate fracture. The fabric is grainy and contains many white and translucent grits, the occasional darker grit and some shiny particles. Keay XXXVI(?) The context is dated 150-250.

1081. F485 (3089). Rim of an amphora, dia. $10 \mathrm{~cm}$. Keay XXVc. The context is dated 450-600.

1082. Z161 (3366). Foot of an amphora. The ware is orange with a moderate fracture. The fabric is grainy and contains many white grits and a few rounded opaque buff grits and the occasional mica particle. Keay XXV foot variant 3 (especially fig. 90: 7, 8). The context is dated 400-450.

1083. Z12. Unstratified. Base of an amphora. The fabric is grainy, brown with many shiny specks and the occasional small void. Buff slip on exterior.

1084. Z14 (4405). Foot of an amphora. Fabric as 1083. Buff slip on exterior. The context is post-medieval.

1085. Z18 (3349). Foot of an amphora. Fabric as 1083. Buff slip (Keay misc. fig. 180: 3 ). The context is dated $400-450$.

1086. H23 (335). Rim of an amphora, dia. $11 \mathrm{~cm}$. Keay XIII. The context is dated $175-250$.

1087. G153 (4069). Rim of an amphora, dia. $10 \mathrm{~cm}$. Orange fabric with a cream coloured exterior (probably not a slip), containing a few small white and black grits and much mica. The context is dated 175-250.

1088. H60 (2102). Rim of an amphora, dia. $9 \mathrm{~cm}$. Keay XIIIc. Undated context.

1089. Z166 (4099). Lower part of an amphora. The ware is orange brown-with a yellow-brown surface outside and a moderate fracture. The fabric contains a few white grits and some grog, a few voids, a moderate amount of translucent grits and many shiny particles. The outside has been 'smoothed' vertically though the surface is still rough. Keay XIX. The context is dated 400-500. 

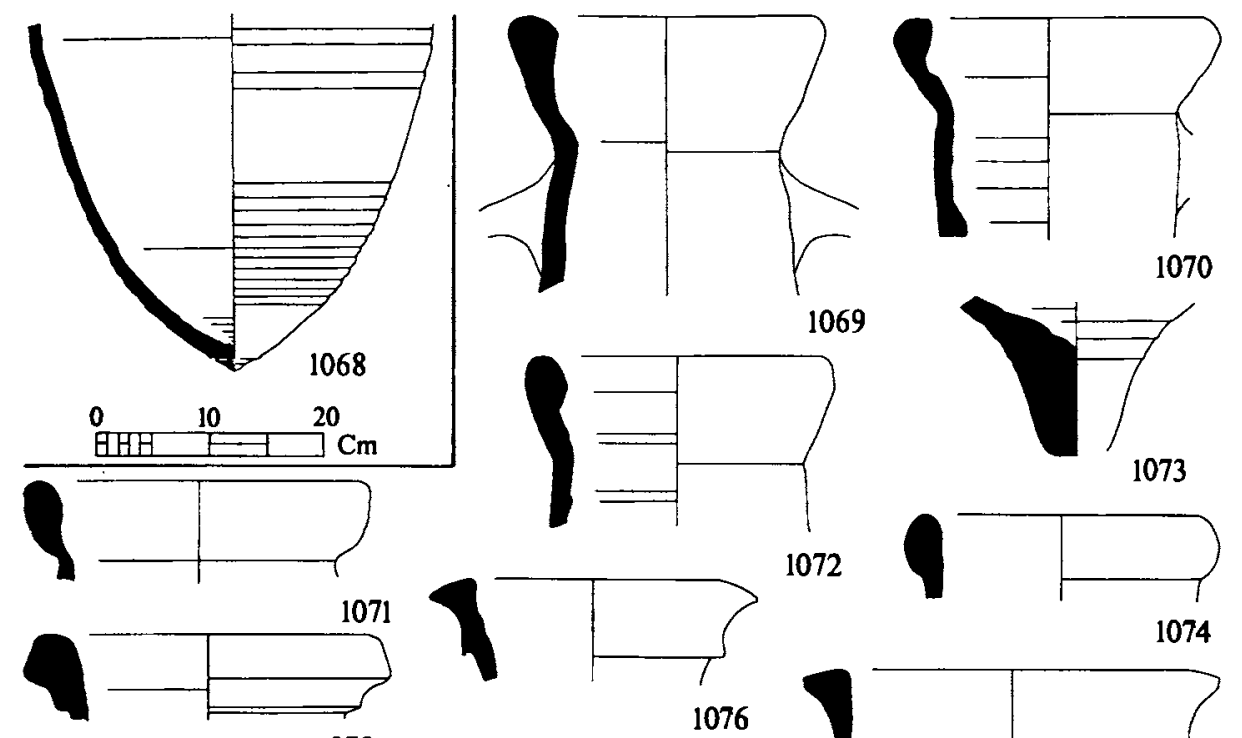

1072
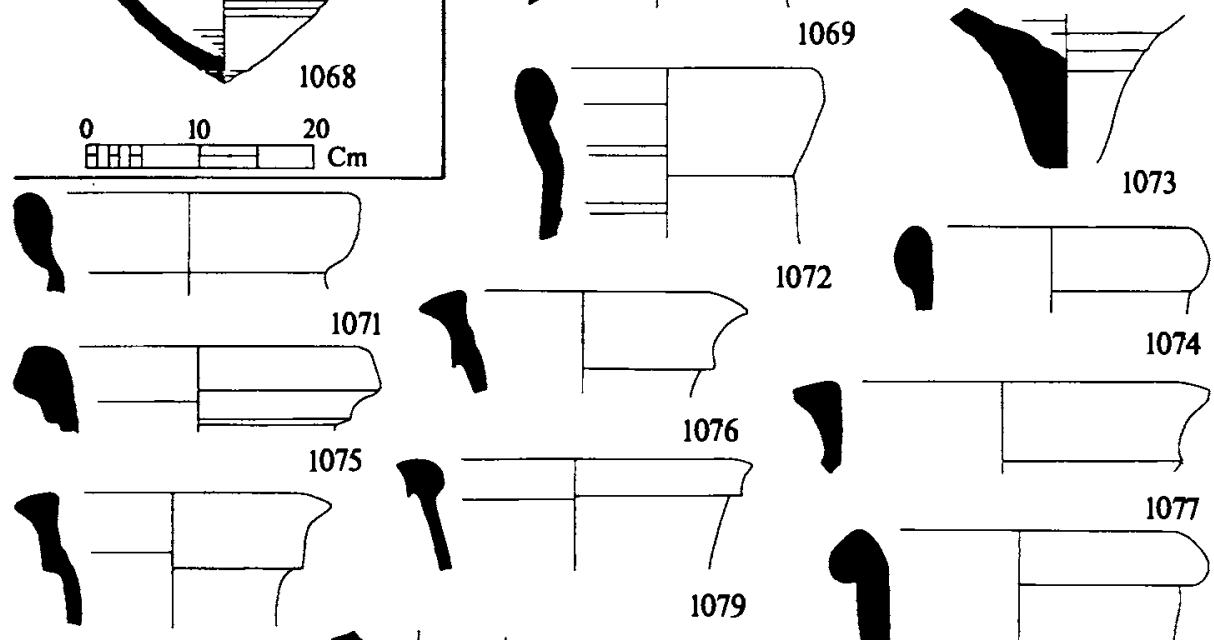

1076
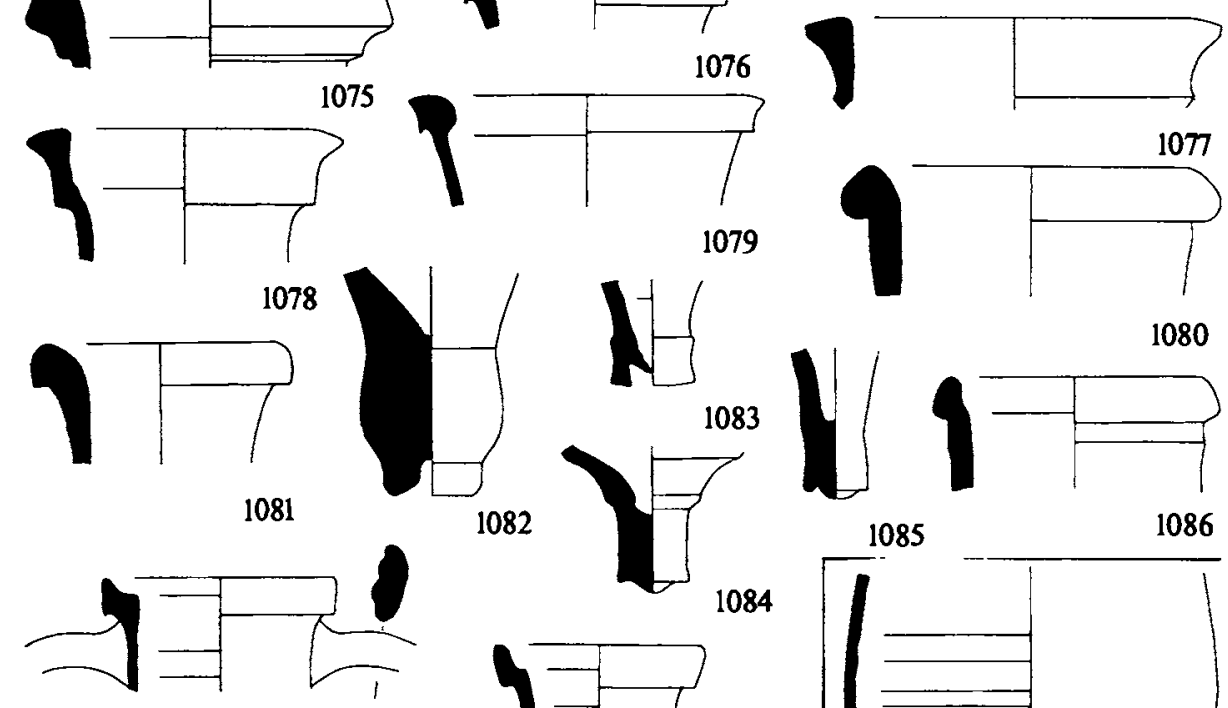

1082
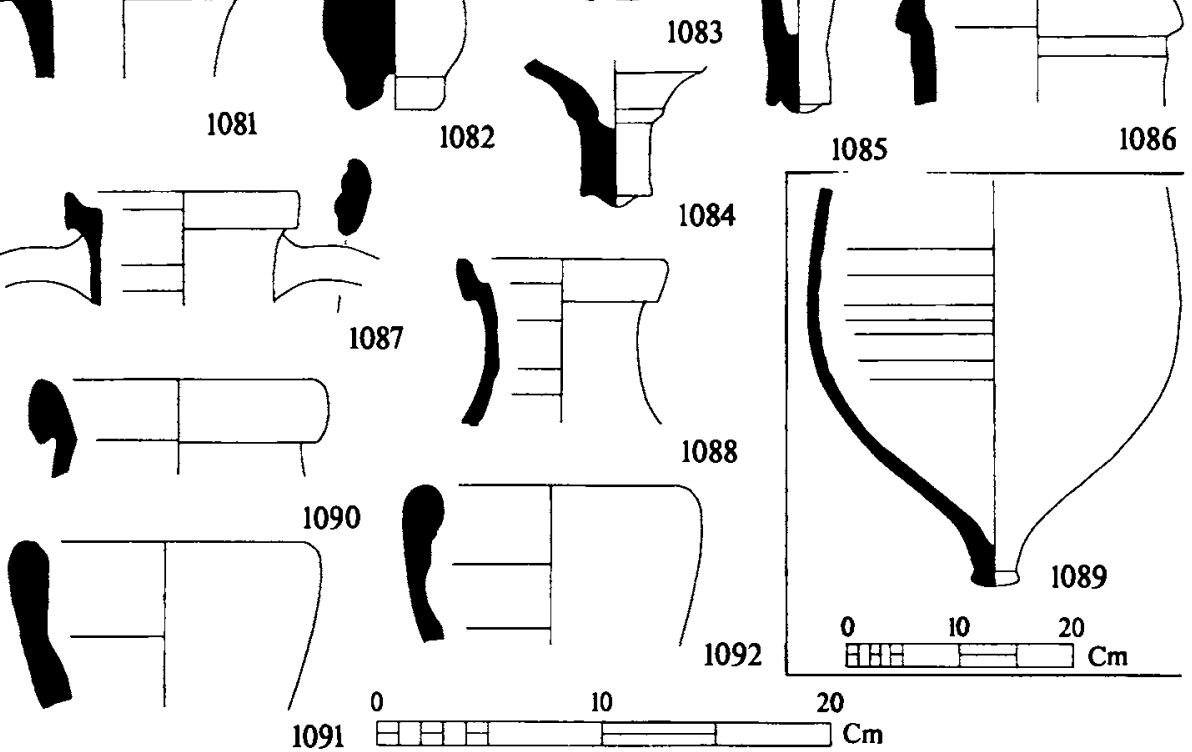

1087
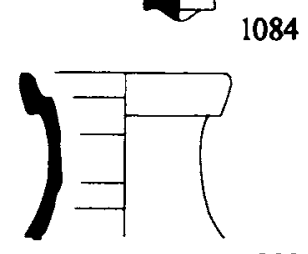

9.53 Eastern Mediterranean, African and miscellaneous amphorae 
1090. H17 (445). Rim of an amphora, dia. $12 \mathrm{~cm}$. Keay LXII(?). The context is dated 450-600. 2 other examples were found, both in post-medieval contexts.

1091. F570. Unstratified. Rim of an amphora, dia. $12 \mathrm{~cm}$. Keay XLVII(?). 6 other examples were found, 2 from contexts dated to 175-450, 1 from a context dated to $350-450$, and 3 from a context dated to 450 .

1092. H51 (5051). Rim of an amphora, dia. 11-13cm. Keay XLVII(?). The context is dated to 450 .

Miscellaneous amphorae (Fig. 9.54)

1093. C411 (5303). Rim of an amphora with a stamped handle, dia. $10-14 \mathrm{~cm}$. Undated context. 7 other examples, though unstamped, were found, 1 from a context dated to $250-350,1$ from a context dated to 275-450, 1 from a context dated to $350-450,1$ from a context dated to $400-450,1$ from a context dated to $450-600$, and 2 from post-medieval deposits.

1094. H61 (4838). Rim of an amphora, dia. $7 \mathrm{~cm}$. The ware is light brown with a moderate fracture. The fabric contains angular black (volcanic), red and brown grits, the occasional white grit and some plate mica and other tiny shiny particles. Undated context.

1095. Z117 (4906). Rim of an amphora, dia. $10 \mathrm{~cm}$. The ware is light brown to orange with a yellow-brown core and moderate fracture. The fabric is grainy and contains white, red and black grits and the occasional piece of plate mica and many voids. The context is dated $450-600$.

1096. H59 (4426). Rim of an amphora, dia. $12 \mathrm{~cm}$. The context is post-medieval.

1097. Z108 (402). Rim of an amphora, dia. $6 \mathrm{~cm}$. The ware is pinkish with a very large grey core and a moderate fracture. The fabric contains many black, grey, red and white grits and the very occasional mica fleck. Patchy green to brown glaze. The context is post-medieval.

1098. H41 (2249). Rim of an amphora, dia. $8 \mathrm{~cm}$. Note start of handle. Iatrus type I.6 (Böttger 1982). The context is dated to 450.

1099. H12 (451). Rim of an amphora, dia. 8-11 cm. latrus type I.6 (Böttger 1982). The context is post-medieval. 5 examples were found: 1 in a context dated to $400-450,1$ in a context dated to 450,1 in a context dated to $450-600$, and 2 were from post-medieval contexts. 
1100. Z102 (665). Neck of an amphora. The ware is light pinkish-brown with a clean fracture and an off-white slip on the exterior. The fabric contains a few tiny voids, many small shiny particles and a moderate amount of gold flakes. The context is dated $250-350$.

1101. H32. Unstratified. Rim of an amphora, dia. $9 \mathrm{~cm}$. The ware is light brown with a moderate fracture. The fabric contains a few white grits and many shiny mica plates that are especially visible on the surface.

1102. H39 (689). Rim of an amphora, dia. $11 \mathrm{~cm}$. The ware is light brown with a moderate fracture. The fabric contains some white, translucent and the occasional red grit and much mica. Cream slip on the exterior. The context is dated $350-450.2$ other examples were found in a context dated to $130-150$.

1103. Z116. Unstratified. Foot of an amphora. The ware is brown with a moderate fracture. The fabric is grainy with a few black grits and many shiny particles.

1104. Z7 (3003). Foot of an amphora. The fabric is light brown to orange with light grey core, many white and translucent grits, some up to $1 \mathrm{~mm}$ in diameter, occasional small black grits and voids and many tiny shiny particles. The context is post-medieval.

1105. Z20 (4433). Foot of an amphora. Fabric as 1104 . The context is postmedieval.

1106. H44 (686). Rim of an amphora, dia. $14 \mathrm{~cm}$. Orange fabric. The context is dated to $175-250$, but contains some later material.

1107. H36 (2281). Rim of an amphora, dia. $14 \mathrm{~cm}$. Red fabric with a large grey core. The context is dated to $100-130$.

1108. Z119 (4902). Rim of an amphora, dia. $22 \mathrm{~cm}$. The ware is orange with a moderate fracture. The fabric contains black (some up to $2 \mathrm{~mm}$ in diameter), and white grits, a few voids and the occasional translucent grit and very small shiny particles. The context is dated 450-600.

1109. Z106. Unstratified. Rim of an amphora, dia. $21 \mathrm{~cm}$. The ware is light brown with a crumbly fracture and light brown surface. The fabric contains a few black grits (usually small, though occasionally they are up to $3 \mathrm{~mm}$ in diameter), and some tiny silvery particles.

1110. H26 (540). Rim of an amphora, dia. $7 \mathrm{~cm}$. The ware is brick red with a moderate to crumbly fracture and a spalling surface. The fabric contains large ( $2 \mathrm{~mm}$, sometimes up to $4 \mathrm{~mm}$, in diameter), rounded and sub-angular 


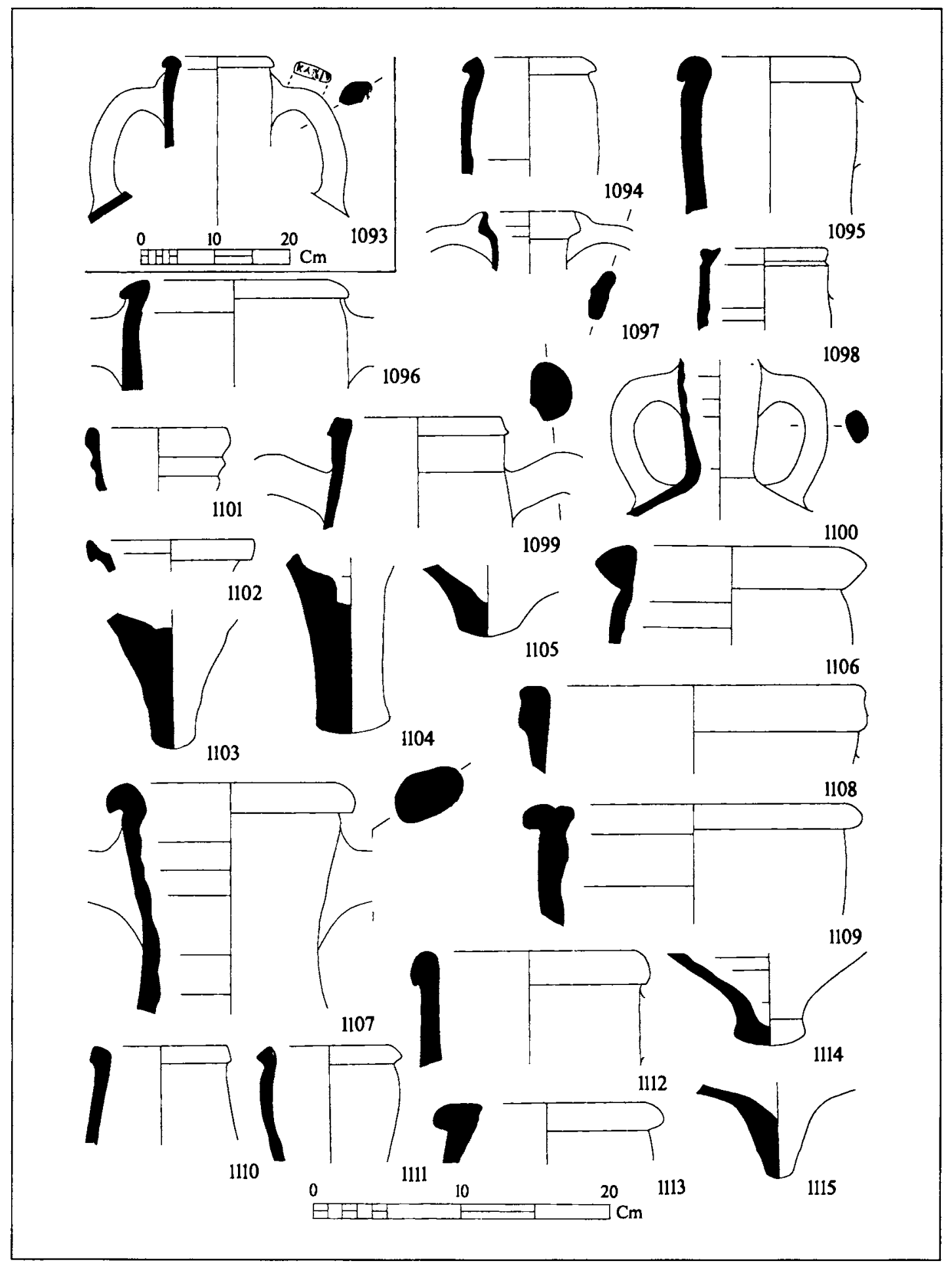

9.54 Miscellaneous amphorae 
black grits, smaller white and translucent grits. The context is dated 350-450.

1111. Z121 (4887). Rim of an amphora, dia. $8 \mathrm{~cm}$. The ware is yellow-buff with a moderate to clean fracture and an orange to pink surface. The fabric contains many dark grey, rust coloured and white grits and a few shiny black grits. Some gold plate mica is visible on the surface. The context is post-medieval.

1112. Z120 (4896). Rim of an amphora, $14 \mathrm{~cm}$. The ware is orange with a moderate fracture. The fabric is grainy and contains many black and some white grits - many angular black grits (volcanic), are visible on the surface. There are also a few shiny particles and the odd large ( $2 \mathrm{~mm}$ in diameter), rust coloured inclusion. The context is post-medieval.

1113. H56 (5311). Rim of an amphora, dia. $13 \mathrm{~cm}$. The ware is brick red with a light brown core and moderate fracture. The fabric is grainy and contains many angular translucent grits and some white grits. The context is dated 250-350.

1114. Z174 (2222). Foot of an amphora. The ware is brown towards the outside and grey on the inside with a sharp fracture. The fabric contains white grits, a few angular and rounded black grits, some voids and a little mica. The context is dated to 450 .

1115. Z6 (4809). Base of an amphora. Red brown fabric with few quartz grits and the odd shiny particle. Buff slip. The context is post-medieval.

\section{SLAV POTTERY}

Slav pottery: ware 43 (Fig. 9.55, plate VII)

1116. F456 (3151) SF. 8039. Jar/cooking pot, dia. $17 \mathrm{~cm}$. Combed body and incised wavy line on the shoulder. Maker's mark on base.

1117. Z194 (3151) SF.8033. Jar/cooking pot base, dia. $9 \mathrm{~cm}$. The body is combed and there is a maker's mark on the base. 1120 and 1127 have similar makers' marks.

1118. Z195 (3151) SF. 8096. Jar/cooking pot base, dia. $7 \mathrm{~cm}$. The body is combed and there is a maker's mark on the base.

1119. F185 (3151) SF. 8018. Jar/cooking pot, dia. 16-17cm. Straight combing on the body, wavy combing on neck. Maker's mark on base. One other example 


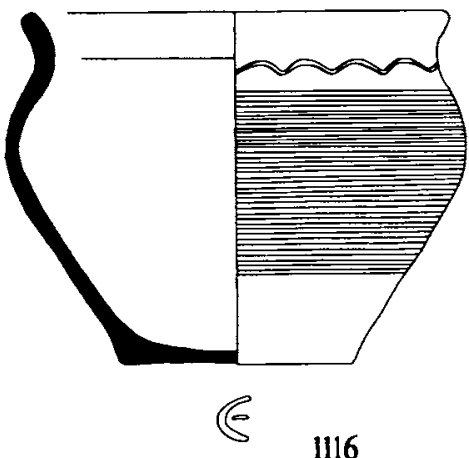

1116
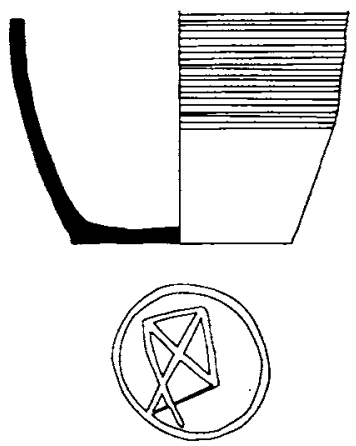

1117
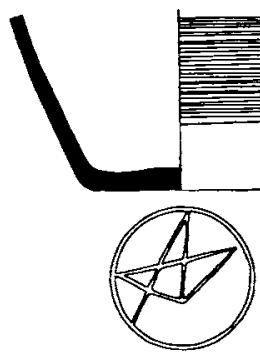

1118
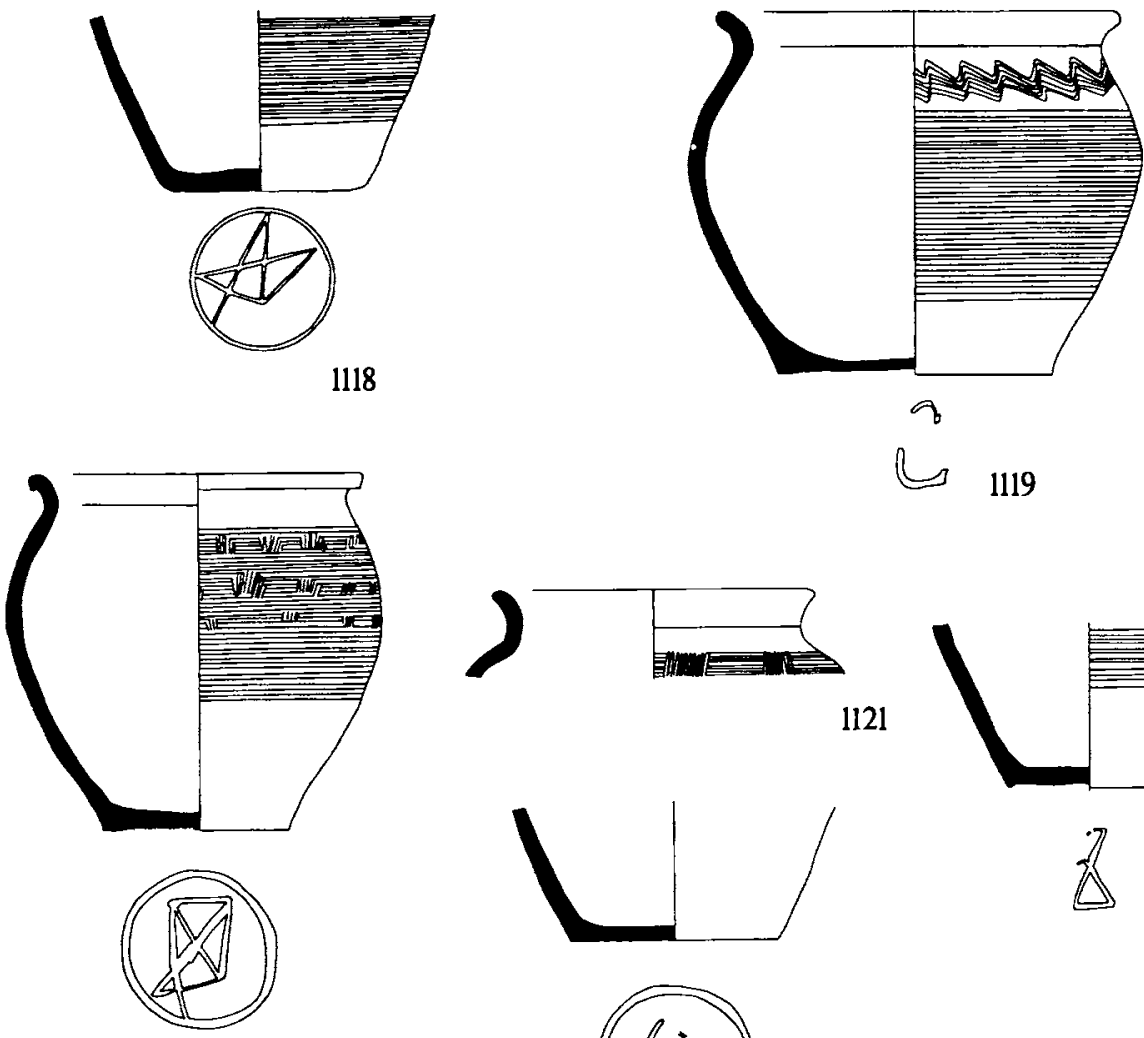

U 1119

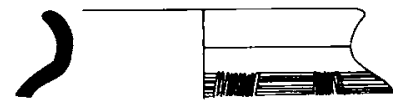

1121

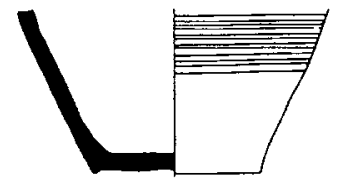

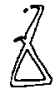

1120

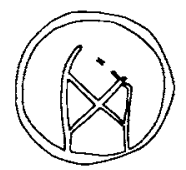

1123

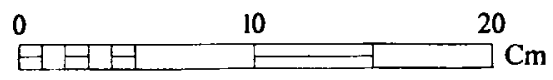

9.55 Slav pottery: ware 43 
1119. F185 (3151) SF. 8018. Jar/cooking pot, dia. 16-17cm. Straight combing on the body, wavy combing on neck. Maker's mark on base. One other example was found in a post-medieval deposit.

1120. F459 (3151) SF. 8040. Jar/cooking pot, dia. $13.5 \mathrm{~cm}$. Straight combing on the exterior with patches of vertical combing. Maker's mark on base. 1117 and 1127 have similar makers' marks.

1121. F460 (3151). Jar/cooking pot, dia. $13 \mathrm{~cm}$. Vertical and horizontal combed decoration on the body.

1122. Z196 (3151) SF. 8037. Jar/cooking pot base, dia. $7 \mathrm{~cm}$. Straight combing on the body and a maker's mark on the underside.

1123. Z197 (3151) SF. 8041. Jar/cooking pot base, dia. $8.5 \mathrm{~cm}$. Maker's mark on the underside.

Slav pottery: ware 43 Fig. 9.56)

1124. F455 (3151) SF. 8038. Jar/cooking pot, dia. $15.5 \mathrm{~cm}$. Combed body, Maker's mark on base.

1125. F186 (3151) SF. 8034. Jar/cooking pot, dia. $15 \mathrm{~cm}$. Combed decoration on exterior of body, notch decoration on the shoulder - probably done with a finger nail. 2 other examples were found, both in a post-medieval context.

1126. F185 (4480). Jar/cooking pot, dia. $18 \mathrm{~cm}$. Combed body with notch decoration on the exterior of the neck. The context is post-medieval. See 1119 for dating.

1127. F458 (3151) SF. 8032. Jar/cooking pot, dia. $11.5 \mathrm{~cm}$. Horizontal and vertical combing on the exterior. Maker's mark on the base. See 1117 and 1120 for similar makers' marks.

1128. F187 (3151) SF. 8035. Jar/cooking pot, dia. $11 \mathrm{~cm}$. Combed decoration on exterior of body, notch decoration on the shoulder - probably done with a finger nail.

1129. G88 (3151). Jar/cooking pot, dia. $11 \mathrm{~cm}$. Incised decoration on the exterior.

1130. F186 (4480). Jar/cooking pot, dia. $12 \mathrm{~cm}$. Straight and wavy combed decoration on the exterior. The context is post-medieval.

1131. F457 (3151) SF. 8019. Jar/cooking pot, dia. $12 \mathrm{~cm}$. Combed decoration on the body with patches of vertical combing. 


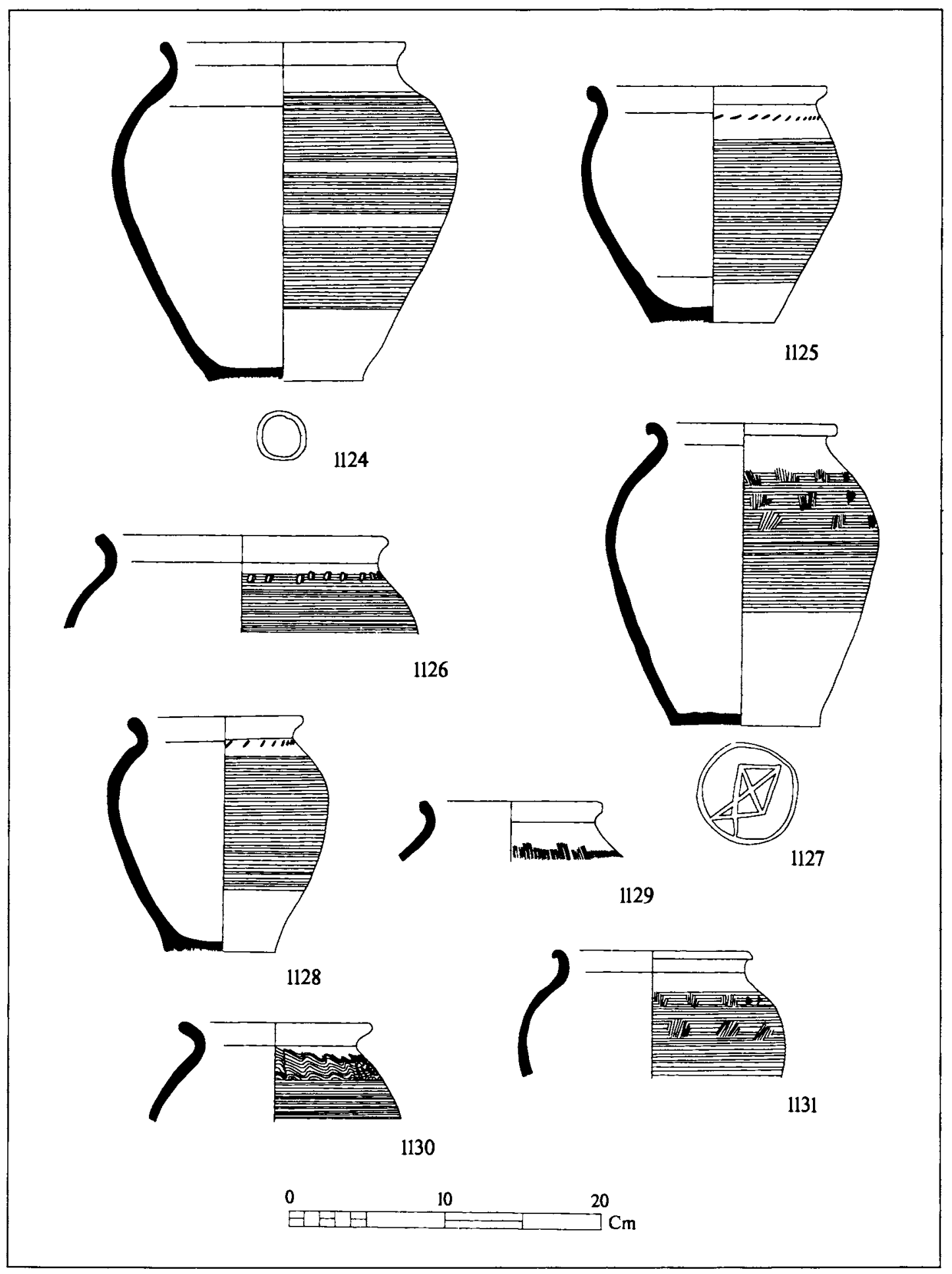

9.56 Slav pottery: ware 43 


\section{POST-MEDIEVAL POTTERY}

Post-medieval pottery (Fig. 9.57)

1132. F318 (3197) SF. 8095. Jar, dia. 8-10cm. 3 examples were found, 1 example had traces of clear glaze on the rim.

1133. F11 (414). Jar, dia. 7-11 cm. 2 examples were found.

1134. F348 (5005). Jar, dia. $10 \mathrm{~cm}$.

1135. G19 (3119). Jar, dia. $11 \mathrm{~cm}$.

1136. Z141 (90). Jar, dia. $11 \mathrm{~cm}$.

1137. F1 (202). Jar, dia. 9-12cm. 4 examples were found.

1138. C827 (4405). Jar/jug. dia. $6 \mathrm{~cm}$.

1139. Z147 (4401). Jar, dia. $13 \mathrm{~cm}$. White-painted decoration on the exterior.

1140. F7 (402). Jar, dia. 13-22cm. White paint on the exterior. 2 examples were found.

1141. C846 (4405). Jar, dia. $9.5 \mathrm{~cm}$. White-painted pattern on the exterior.

1142. Z142 (25). Jar, dia. $12 \mathrm{~cm}$. White-painted decoration on the exterior.

1143. Z192 (403). Jar, base dia. $10 \mathrm{~cm}$. The exterior is decorated with white paint showing a plant growing from a spouted single handled vessel.

1144. Z31 (3119). Jar, base dia. $10 \mathrm{~cm}$. White-painted decoration on the exterior of the neck, and blobs of green glaze both on the exterior and interior of the body.

1145. Z138 (4433). Jar, dia. $13 \mathrm{~cm}$. Thin green glaze outside and over rim.

1146. F571 (4402). Jar, dia. $12 \mathrm{~cm}$. Green glaze on rim.

Post-medieval pottery (Fig. 9.58)

1147. Z124 (4416). Jar/coking pot, dia. 14cm. Thin green glaze inside and over rim.

1148. Z136 (4801). Jar/cooking pot, dia. $16 \mathrm{~cm}$. Thin green glaze all over.

1149. Z148 (24). Jar, dia. $11 \mathrm{~cm}$. Rouletted bands on the exterior below the rim. Green glaze all over. 


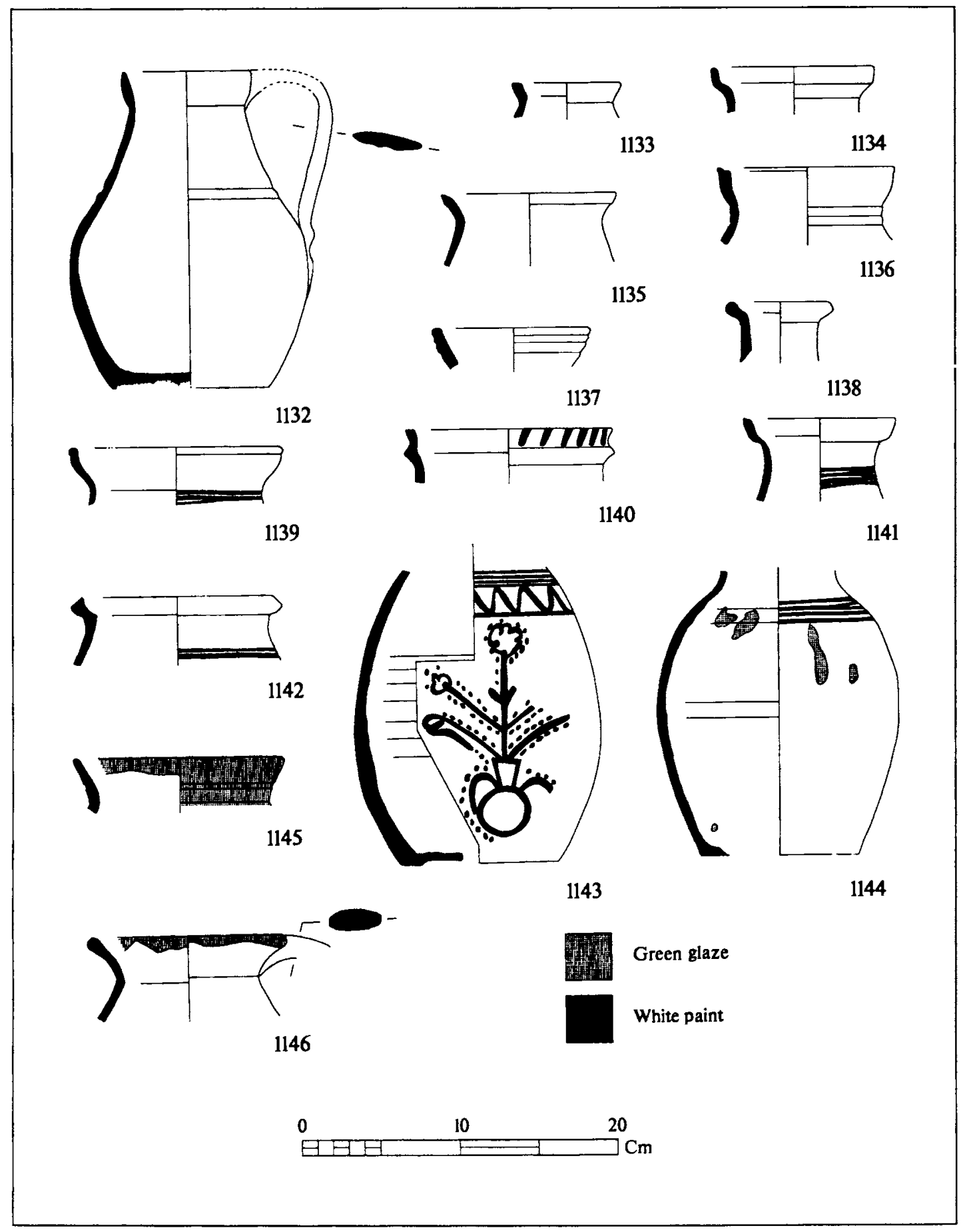

9.57 Post-medieval pottery 


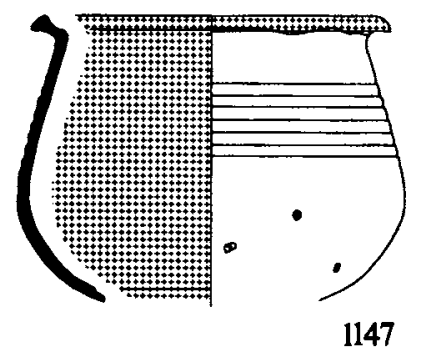

1147

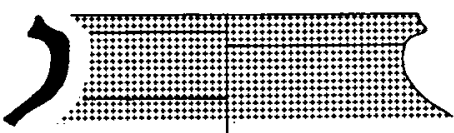

1148

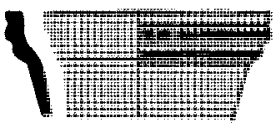

1149
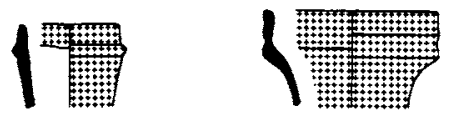

1151

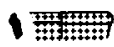

1153

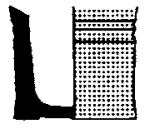

1154

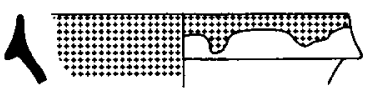

1157

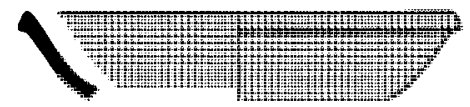

1158

(

1159

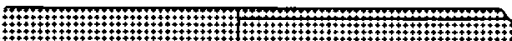

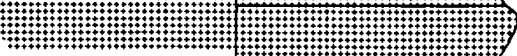

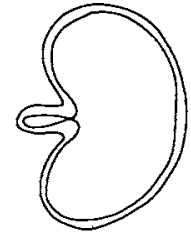

1155

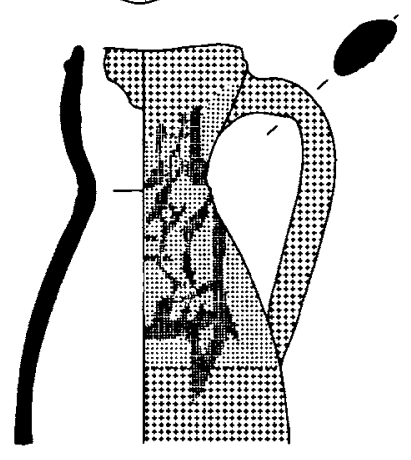

1156

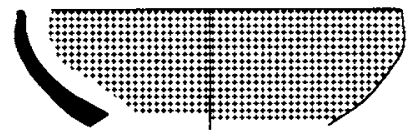

1155 \& 1153. Yellow

Others. Thin green

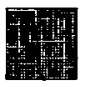

1155. Dark brown Others: Dark green
1155. Reddish brown Others. Light green

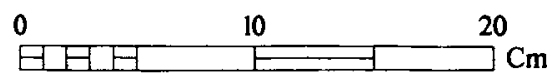


1150. C834 (4405). Jug, dia. 6cm. Green glaze over rim.

1151. C797. Unstratified. Jug, dia. 4cm. Green glaze outside and over rim.

1152. Z130 (3078). Jug, dia. $7 \mathrm{~cm}$. Thin green glaze all over.

1153. Z162 (5049). Jug, dia. $4 \mathrm{~cm}$. The ware is buff with no macroscopically visible inclusions. Yellow glaze all over. This is the only example: it came from a context dated to 450 , but would seem to be out of place in a fifth century assemblage. A medieval or post-medieval date is more likely.

1154. Z122 (4433). Base of a jar/jug, dia. $5 \mathrm{~cm}$. Thin green glaze on a white slip inside.

1155. Z128 (4433). Jar, dia. $6 \mathrm{~cm}$. Red-brown and dark brown painted pattern on a white slip covered by a thin yellow glaze which appears as a strong yellow when over the slip, but appears almost clear when not (as on the top of the outside).

1156. Z193. Unstratified. 'Rakia jug'. Irregular trefoil rim. Thin green glaze on the outside and over the rim. The exterior has underglaze painting in brown and white, making the glaze appear either light green or brown.

1157. Z137 (4888). Bowl, dia. $14 \mathrm{~cm}$. Thin green glaze inside and over rim.

1158. C105 (7). Bowl, dia. $18 \mathrm{~cm}$. Green glaze all over.

1159. C702 (4007). Bowl, dia. $20 \mathrm{~cm}$. Thin green glaze inside and over rim.

1160. C7 (202). Bowl, dia. $22 \mathrm{~cm}$. Green glaze all over.

1161. Z127 (24). Bowl, dia. $16 \mathrm{~cm}$. Thick green glaze all over.

Post-medieval pottery (Fig. 9.59)

1162. F572 (4402). Bowl, dia. 16cm. Light green glaze over white-slipped pattern.

1163. C798. Unstratified. Bowl, dia. $23 \mathrm{~cm}$. Thin green glaze on a white slip inside and over rim.

1164. Z150 (4401). Bowl, dia. 19cm. Deteriorated green glaze over white-slipped pattern inside, white slip outside. 4 examples were found.

1165. Z144 (24). Bowl, dia. $20 \mathrm{~cm}$. Green glaze - appearing light green in places when over splashes of white slip.

1166. Z135 (3197) SF. 8147. Base of a bowl, dia. $5.5 \mathrm{~cm}$. Very deteriorated green glaze on white slip on the interior. 


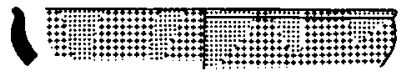

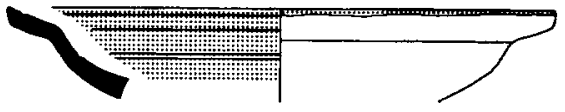

1162

1163

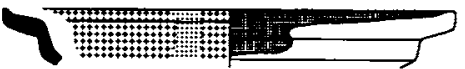

1164

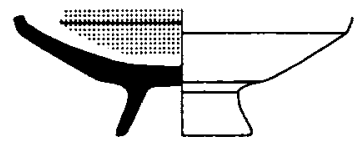

1166

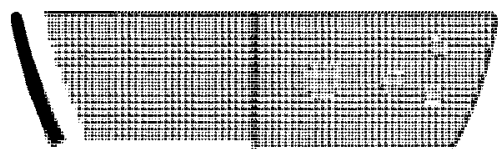

1165
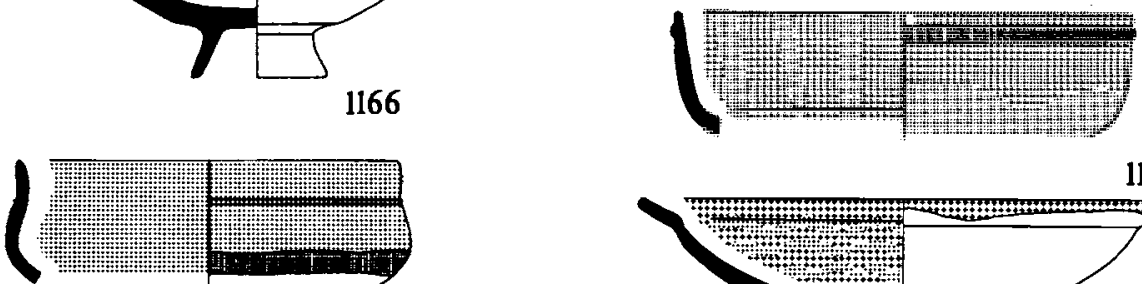

1168

1169

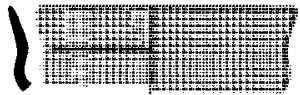

1170

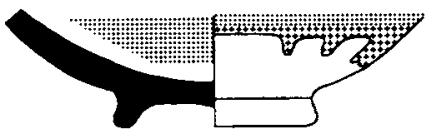

1171
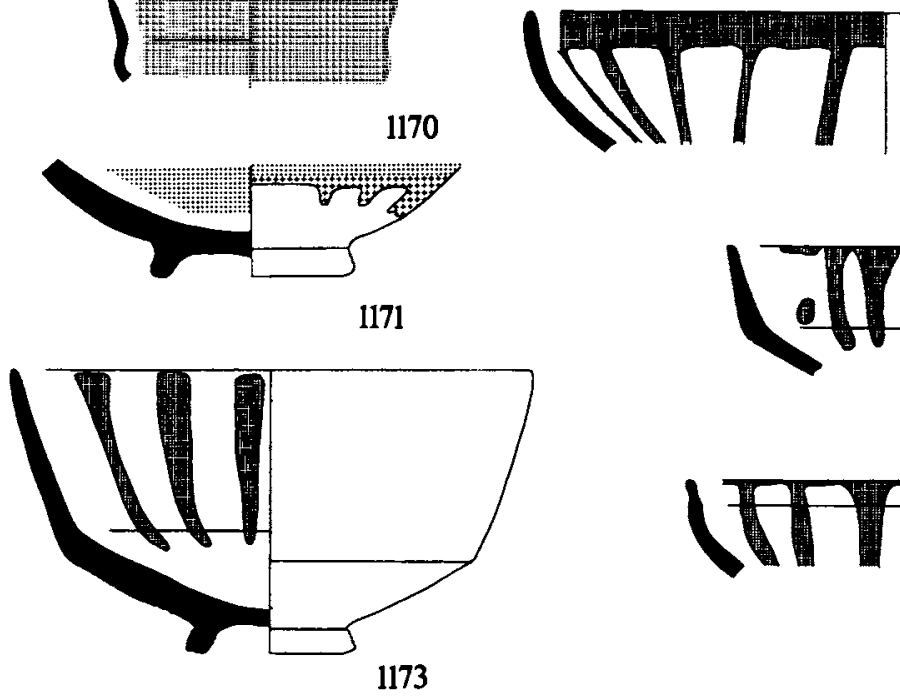

1167
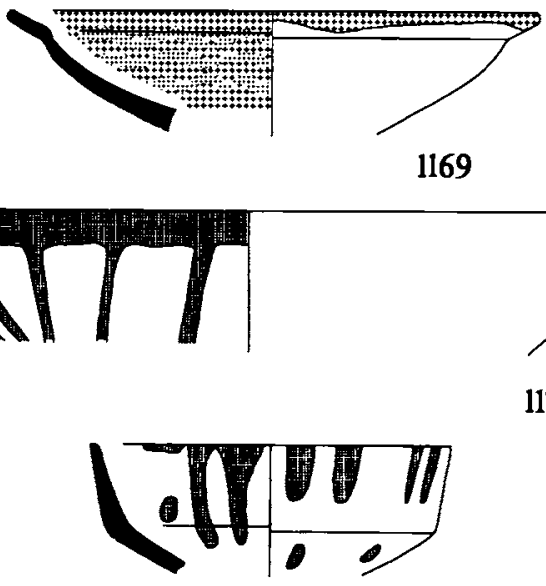

1174

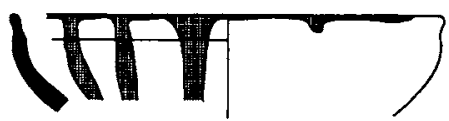

1175
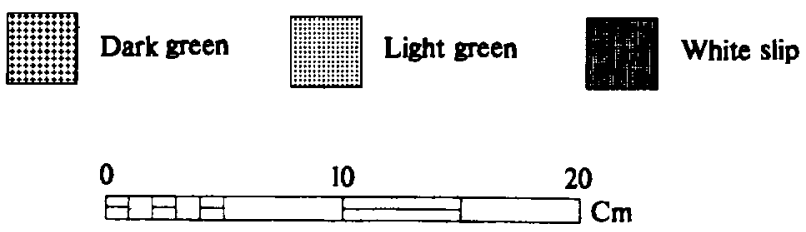

9.59 Post-medieval pottery 
1167. C799. Unstratified. Bowl, dia. $19 \mathrm{~cm}$. Green glaze over white-slipped pattern - appearing light green when over slip. Notched band below exterior of rim.

1168. Z145 (90). Bowl, dia. $16 \mathrm{~cm}$. White slip all over with thin green glaze on the inside and top part of outside.

1169. C375 (402). Bowl, dia. $22 \mathrm{~cm}$. Green glaze inside and over rim, with a whitepainted pattern under the glaze on the interior.

1170. Z149 (12). Bowl, dia. $12 \mathrm{~cm}$. Thin green glaze all over with a white-slipped pattern on the inside.

1171. Z169 (3061). Base of a bowl, dia. $8 \mathrm{~cm}$. Green glaze on a white slip - appears light green when over slip and dark green when not.

1172. Z139 (12). Bowl, dia. $30 \mathrm{~cm}$. White-painted decoration on the interior.

1173. Z100 (4897). Bowl, dia. $22 \mathrm{~cm}$. White-painted pattern on the inside.

1174. C796. Unstratified. Bowl, dia. $15 \mathrm{~cm}$. Splashed white paint inside and out.

1175. Z126 (24). Bowl, dia. $18 \mathrm{~cm}$. Splashed white paint inside and over rim.

\section{Post-medieval pottery (Fig. 9.60)}

1176. C52 (42). Bowl, dia. $17.5 \mathrm{~cm}$. Splashed white paint inside and over the rim.

1177. C8 (1). Bowl, dia. 19-21.5cm. White-painted decoration on the inside, splashed white on the outside. 2 examples were found.

1178. C830 (405). Bowl, dia. $18 \mathrm{~cm}$. White paint inside and out.

1179. Z125 (3054). Bowl, dia. $18 \mathrm{~cm}$. White-painted pattern on the interior.

1180. F346 (5005). Bowl, dia. $20 \mathrm{~cm}$. White paint on the interior and over the rim. 4 examples were found.

1181. C53 (202). Bowl, dia. 20-24cm. White-painted decoration on the interior. 4 examples were found.

1182. Z129 (3054). Bowl, dia. $23 \mathrm{~cm}$. Splashed white paint inside and out.

1183. Z11 (3001). Base of a bowl, dia. $6 \mathrm{~cm}$. Splashed white paint inside and out.

1184. C5 (202). Bowl, dia. 16-19cm. Yellow glaze on white slip with patches of brown under-glaze painting. 2 examples were found.

1185. Z131 (4433). Bowl, dia. 19cm. Thin green glaze over white slip with reddish-brown under glaze painting inside that appears olive brown and 


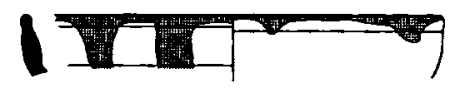

1176

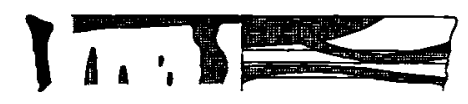

1178

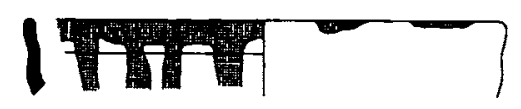

1180

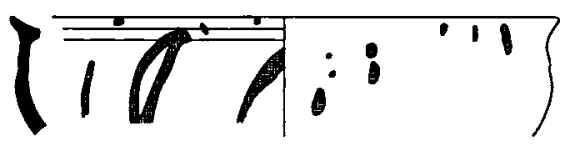

1182
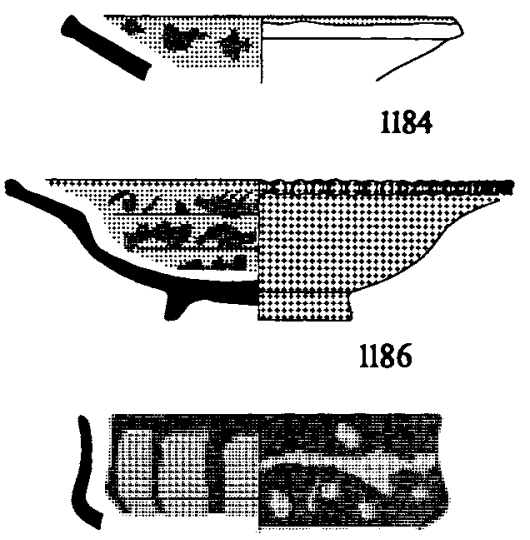

1188

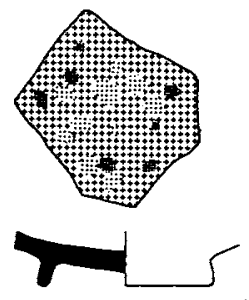

1189

\section{$|1| \cdots\rangle$}

1177

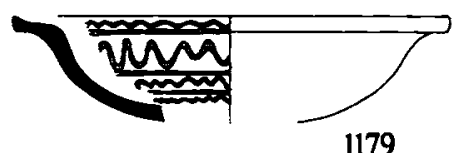

1179

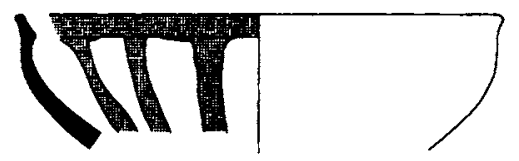

1181

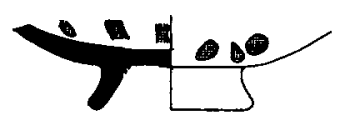

1183

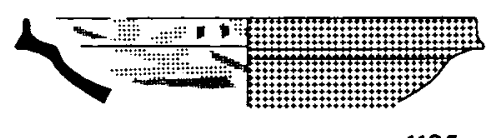

1185

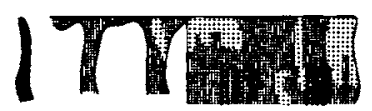

1187

1189. Yellow

Others. Thin green

1176-1183. White slip

1188. Light green

Others. Dark brown

1185. Yellowish green

Others. Unglazed

1184 \& 1186. Yellow

1187. Reddish brown

Others. Light brown

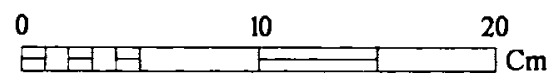

9.60 Post-medieval pottery 
1185. Z131 (4433). Bowl, dia. 19cm. Thin green glaze over white slip with reddish-brown under glaze painting inside that appears olive brown and dark brown; thin green glaze outside.

1186. C380 (4416). Bowl, dia. $21 \mathrm{~cm}$. Thin green glaze outside and over rim, yellow glaze on white slip inside, with under glaze brown painting. Fingerimpressed pattern on rim.

1187. C811 (3001). Bowl, dia. $14 \mathrm{~cm}$. White slip with reddish-brown painted 'dribble' pattern. On the exterior there are groups of three band rouletting with ridges between the bands.

1188. Z133 (4416). Bowl, dia. $15 \mathrm{~cm}$. White slip with dark brown and red-brown painted decoration under a thin green glaze which appears light green where it is over the slip and brown green where there is no slip - as on parts of the inside.

1189. Z123. Unstratified. Base of a bowl, dia. $7 \mathrm{~cm}$. Yellow glaze over white slip with light and dark brown under glaze painting on the inside.

Post-medieval pottery (Fig. 9.61)

1190. C1 (202). Bowl, dia. 24cm. Yellow glaze on a white slip.

1191. Z146 (24). Bowl, dia. $16 \mathrm{~cm}$. White-painted horizontal lines covered by thin brown glaze - which makes the lines appear yellow.

1192. Z134 (24). Base of a bowl, dia. $15 \mathrm{~cm}$. Clear and blue glaze over a white slip.

1193. C825 (3163). Bowl, dia. $20 \mathrm{~cm}$. Very deteriorated surface: originally green glaze on white slip inside and over rim with sgraffito design on the inside, however the design is indeterminate.

1194. Z140 (24). Part of the body of a bowl. Sgraffito design in white slip under green glaze on the interior.

1195. Z132 (4204). Bowl, dia. $26 \mathrm{~cm}$. Inside there is a sgraffito design under thin green glaze on thin white slip which appears mottled blue-green on the surface; patches of slip are thinner which makes the surface appear yellow. The thin green glaze goes over the rim.

1196. Z151 (3137). Bowl, dia. $30 \mathrm{~cm}$. The ware is reddish-brown with a moderate fracture. The fabric is grainy and contains tiny black and white grits, the occasional void and a medium amount of mica. Sgraffito design in cream slip under clear and green glaze. It came from a post-medieval context but may possibly be medieval. 

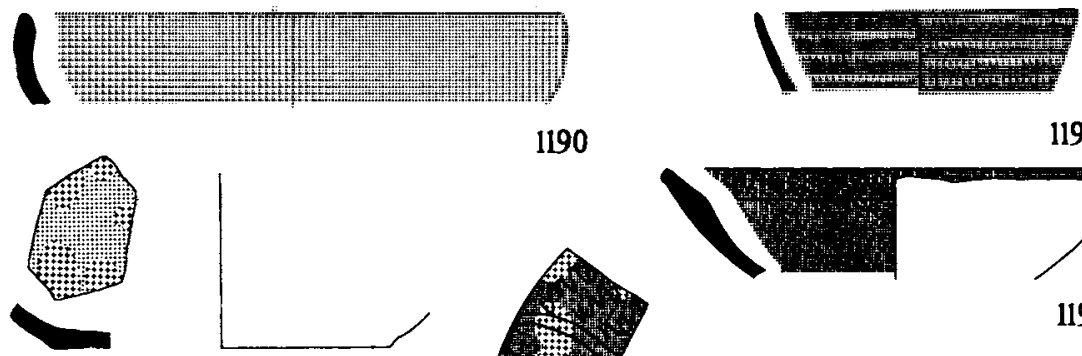

1190

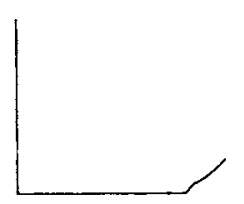

1192
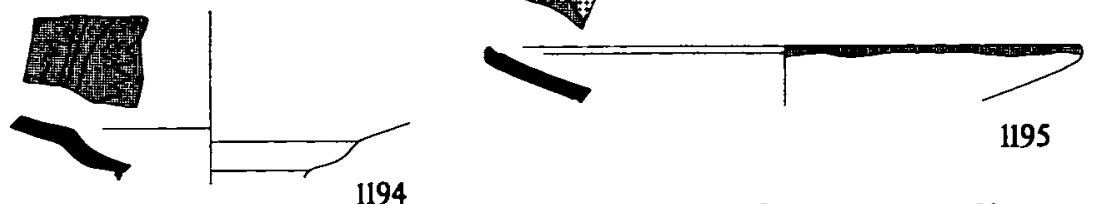

1194
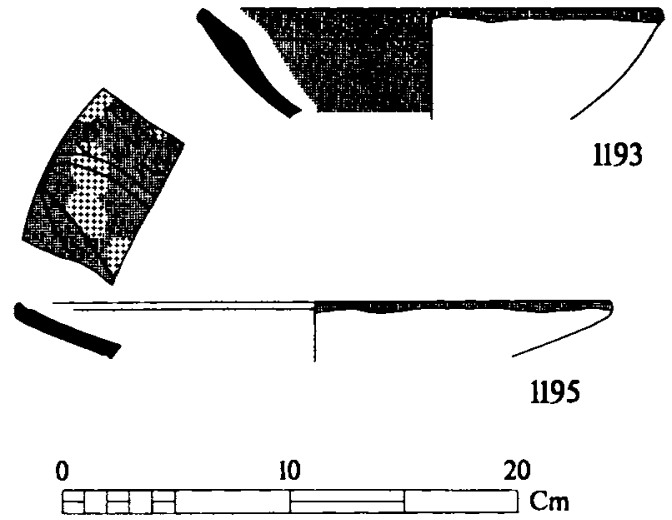

(r)
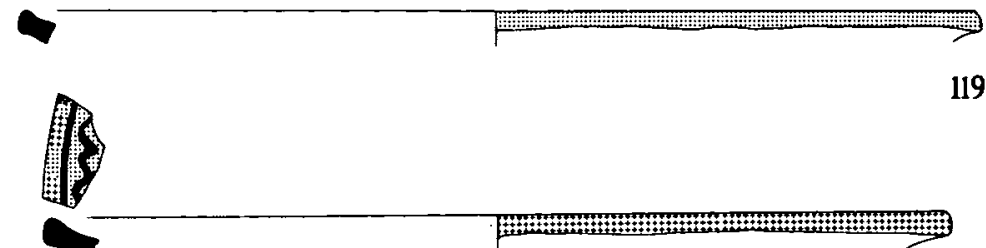

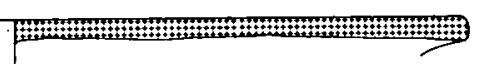

1197
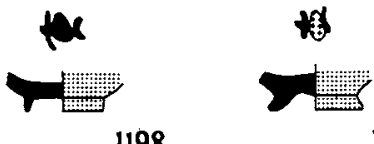

进努

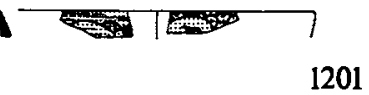

1198

1199

$$
1200
$$

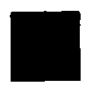

Black

Red

Others. Green

1191. Brown

0
1192. 1196 \& 1197. Cream

Others White

1190. 1191 \& 1195. Yellow

1197. Brown

Others. Blue 
1197. Z163 (4407). Bowl, dia. $28 \mathrm{~cm}$. Fabric as 1196. Sgraffito design in white slip under clear, green and brown glaze on the interior, with the brown glaze going over the rim. It came from a post-medieval context, but may possibly be medieval.

1198. Z104 (402). Base of a cup, dia. $2.4 \mathrm{~cm}$. The fabric is a hard frit. There is a design in black (probably manganese) on white glaze in the centre of the base. A similar design can be seen on 1199 .

1199. Z105. Unstratified. Base of a cup, dia. $2.8 \mathrm{~cm}$. Fabric as 1198 . There is a design in blue and black on white glaze in the centre of the base. (See also 1198.)

1200. C118 (456). Bowl or cup, dia. $10 \mathrm{~cm}$. The fabric is a hard frit. Clear, blue and green glaze over black-painted pattern, red-painted splash under glaze. This was the only example of this type of bowl/cup rim - though a body sherd from a similar vessel (if not the same vessel) was also found (see 1201).

1201. Z189. Unstratified. Body sherd from a bowl/cup. Fabric as 1200. Clear and blue glaze over black-painted decoration on the exterior, clear glaze inside. (See also 1200.) 


\section{Appendix 1: The wares}

The term ware refers to the appearance of the sherd and the components of the body visible at 10x magnification; sherds that appeared similar and had similar inclusions were said to be of the same ware.

During the excavations 174 different wares were recorded, but closer inspection reduced this number to 64 . (There is a category in the tables for miscellaneous wares (172) which includes both wares that were unidentified and very small fragments of known wares that were not sorted.) Many of these were represented by only a few examples, with over 87 per cent of all sherds being in three wares $(1,4$ and 8$)$. The list that follows describes each of the wares present. ${ }^{1}$

The relative frequency of wares by dated phase can be seen in appendix 3 and table 5.1 shows the composition of dated assemblages by ware as a percentage of total sherds in a date range (to the nearest 0.5 per cent). It also shows, by shading, the date ranges of the more common wares (those with more than 100 occurrences).

\section{The ware descriptions}

1. The ware is black to grey and sometimes brown with black, grey or brown surface, crumbly fracture. The fabric contains white grits and quartz, usually in large quantities, and some mica. Thickness: $0.4-0.8 \mathrm{~cm}$.

4. As 8 with no slip.

7. As 14 with sharp ribbing.

8. The ware is light brown to buff with a red slip on the exterior or a buff to pink surface where there is no slip, The fracture is very sharp, sometimes splintered. The fabric is well levigated and contains a few small black and/or white grits and often some mica. Often no inclusions are visible with the naked eye. Thickness: $0.4-0.8 \mathrm{~cm}$.

9. As 10 with white paint. 
10. The ware is reddish-brown often with a grey core and reddish-brown surface, moderate fracture. The fabric contains a few black grits and much mica: generally clean apart from the mica. Thickness: $0.5-0.7 \mathrm{~cm}$.

11. As 10 with glaze.

13. The ware is buff to white with a buff to white surface with wide shallow ribbing, moderate fracture. The fabric contains many shiny black (volcanic ?) and a few red and translucent grits. Thickness: $c .0 .7 \mathrm{~cm}$.

14. The ware is grey with a grey to black surface (occasionally brown with a brown surface), which is often pattern-burnished, moderate fracture. The fabric contains a small amount of quartz and some mica; generally little apart from the mica. Thickness: $c .0 .6 \mathrm{~cm}$.

19. Amphora. The ware is pinkish with a buff surface (probably a self-slip), clean fracture. The fabric is grainy with many small white grits and the occasional black grey or red grit; many mica flecks are visible on the surface and in the horizontal fracture, though none is visible in a vertical fracture. Thickness: c. $0.9 \mathrm{~cm}$.

23. Amphora. The ware is reddish-brown with a light brown core and a reddishbrown surface, moderate fracture. The fabric contains many shiny black (volcanic ?) and a few red and white grits. Thickness: $c .0 .8 \mathrm{~cm}$.

24. The ware is buff with a buff to yellow surface which has a sandy feel, moderate to crumbly fracture. The fabric has many voids, brown, white and translucent grits, and a few gold and silvery mica flecks. Thickness: $c .0 .6 \mathrm{~cm}$.

25. The ware is hand-made, red to black (usually red to brown with a large black core: poorly fired), with a buff, red, brown, or grey surface with a very crumbly fracture. The fabric contains black and red grits, a little organic material and some mica. Thickness: $c 1.2 \mathrm{~cm}$.

27. Amphora. The ware is orange-brown with an orange interior surface and a buff slip on the exterior, moderate fracture. The fabric contains many soft, large $(c .1 \mathrm{~mm}$ in diameter) white and yellow grits and the occasional red grit and some mica. Thickness: $c .0 .8 \mathrm{~cm}$.

30. Orange to brown fabric with an orange surface and moderate to crumbly fracture. The fabric contains many limestone fragments and much grit temper, with some pieces as large as $4 \mathrm{~mm}$ in diameter. Most of the grits are light coloured and angular. Also a little organic material. Thickness: $0.5-0.8 \mathrm{~cm}$.

31. As 30 , but hand-made. 
32. The ware is usually orange-brown with a grey core, but is sometimes grey or orange throughout, the interior surface is orange to grey, and the exterior surface has an orange-brown and/or green salt glaze, the fracture is moderate to crumbly. The fabric contains much quartz, the occasional white grit and some mica. Thickness: $c .0 .5 \mathrm{~cm}$.

36. The ware is red to grey with a brown surface that has a very slippery feel, moderate fracture. The fabric contains some small voids and black grits and the occasional red grit and large amounts of mica. Thickness: $c .0 .6 \mathrm{~cm}$.

37. Amphora. The ware is brick red with a dull orange surface on the interior and a white slip on the exterior with a moderate fracture, shallow ribbing on exterior. The fabric contains some limestone, a few voids and rounded grey grits and a few small quartz grits and a little mica. Thickness: $c .0 .9 \mathrm{~cm}$.

38. Amphora. The ware is red with a light red to buff surface and a clean fracture. The fabric contains white and the odd grey or translucent grit and the occasional shiny particle. Thickness: $c .0 .8 \mathrm{~cm}$.

39. The ware is red with a red interior surface and a black slip or salt glaze on the exterior. (The glaze maybe accidental.) Clean fracture. The fabric contains a few black and white grits and some silvery particles. Thickness: $c .0 .3 \mathrm{~cm}$.

41 The ware is brown with a light to dark brown surface with gold mica plates visible, moderate fracture. The fabric is grainy and contains quartz and a few black and white grits. Thickness: $c .1 .4 \mathrm{~cm}$.

42 As mortaria.

43 The ware is grey to brown with a grey to brown surface that is usually combed, moderate to crumbly fracture. The fabric contains much quartz and some black and white grits (though usually not many), and a little mica. Thickness: $c .0 .6 \mathrm{~cm}$.

44. The ware is reddish-brown with a brown surface, crumbly fracture. The fabric is very grainy with many large $(1 \mathrm{~mm})$, angular white, grey, black and translucent grits and grog (c.20 per cent of the body is made up of inclusions). Thickness: $c .1 .0 \mathrm{~cm}$.

51. The ware is brown with a very wide black core and brown surface which is as gritty as a mortarium (though it is not a mortarium), very crumbly fracture. The fabric contains many large black grits and angular quartz grits and a small amount of mica. Thickness: $c .0 .6 \mathrm{~cm}$.

55. The ware is black with a black surface with a moderate fracture. The fabric contains small amounts of quartz and mica. Thickness: $c .0 .4 \mathrm{~cm}$. 
56. The ware is reddish-brown with a light brown surface on which many white specks can be seen, crumbly fracture. The fabric contains many soft white grits and appears layered. Thickness: $c .0 .6 \mathrm{~cm}$.

69. Amphora. The ware is brown with a brown surface and moderate fracture. The fabric is grainy with a few voids, some white and rounded translucent grits and flecks of mica. Thickness: $c .0 .8 \mathrm{~cm}$.

70. The ware is orange-brown with a light brown ribbed surface and crumbly fracture. The fabric contains many white grits and a few black and red grits. Thickness: $c .0 .6 \mathrm{~cm}$.

74. The ware is buff to white with a buff to white surface and moderately crumbly fracture. The fabric has no visible inclusions except for some tiny silvery particles. Thickness: $c .0 .2 \mathrm{~cm}$.

76. Amphora. The ware is brown to yellow-brown with a slightly darker surface and a moderate fracture. Many white and translucent grits are visible in the break. Thickness: $c .1 .0 \mathrm{~cm}$.

78. The ware is grey with a grey slipped surface that occasionally appears mottled, clean fracture with a tendency to splinter. The fabric contains a small amount of mica but is generally free from inclusions. Thickness: c. $0.6 \mathrm{~cm}$.

83. Sgraffito ware.

86. The ware is red with a red surface on the interior and an orange slip on the exterior, moderate fracture. The fabric is grainy and contains the occasional white grit and some mica though generally free from inclusions. Thickness: c. $0.6 \mathrm{~cm}$.

87. Amphora. The ware is orange-brown with a reddish-buff to orange-brown surface with a medium sharp fracture, wide shallow ribbing on the exterior. The fabric is grainy with many gold and silver coloured particles visible on the surface, inclusions are much mica, a few crushed limestone and translucent grits, the occasional red grit and a little fine grog. Thickness: c. $0.7 \mathrm{~cm}$.

94. Amphora. The ware is brown with a red core with light brown surface with a medium sharp fracture, deep, sharp combed ribs on the exterior. The fabric contains large lime grits, the occasional translucent grit and silvery particle and there are a few voids. Thickness: $c .0 .8 \mathrm{~cm}$. 
96. Amphora. The ware is brick red with a brick red surface with a moderately crumbly fracture. The fabric contains some quartz and angular black grits, a few voids and some mica. Thickness: $c .0 .8 \mathrm{~cm}$.

98. Amphora. The ware is light brown with a light brown surface pock-marked on the inside, clean break. The fabric contains a few voids, some limestone and the occasional grey grit. Thickness: $c .1 .0 \mathrm{~cm}$.

103. Amphora. The ware is red-brown with a red to red-brown surface and sharp fracture. The fabric is grainy with the occasional void and a few white grits and some mica. Thickness: $c .1 .0 \mathrm{~cm}$.

104. Amphora. The ware is brick red to orange with a brick red to orange surface with a moderate fracture, often with wide shallow ribbing on the exterior. The fabric contains many limestone grits and a few angular black, grey and quartz grits, the occasional piece of grog and mica and the odd void. Thickness: $c .1 .0 \mathrm{~cm}$.

105. Amphora. The ware is buff with a buff surface and crumbly fracture, ribbed on the exterior. The fabric is grainy with voids, angular white and translucent grits, the odd red grit and small amount of mica. Thickness: $c .1 .0 \mathrm{~cm}$.

106. Amphora. The ware is light brown with a light brown surface inside and a thick off-white slip on the exterior, which is very faintly ribbed, the fracture is crumbly. The fabric contains quartz, rounded and angular grey grits, a few voids and grog. Thickness: $c .0 .8 \mathrm{~cm}$.

108. Amphora. The ware is brown with a brown surface and crumbly fracture. The fabric contains much sand, a few gold flecks and black grits, and the occasional larger (c. $1 \mathrm{~mm}$ in diameter), quartz grain. Thickness: $c .1 .2 \mathrm{~cm}$.

113. Amphora. The ware is reddish-brown with a brown interior surface and a thin cream slip on the exterior which has been applied with a brush; moderate fracture. The fabric is grainy with a few large $(c .10 \mathrm{~mm}$ in diameter) quartz grits and some large rounded and small angular black grits. Thickness: $c$. $0.8 \mathrm{~cm}$.

116. Amphora. The ware is light brown with a light brown surface, sharp fracture. The fabric contains voids, red, white, shiny black (volcanic ?) and shiny white grits. Thickness: $c .1 .0 \mathrm{~cm}$.

117. Amphora. The ware is yellow-buff with a buff surface, ribbed on the exterior, crumbly fracture. The fabric is grainy with many small and large voids, white grits and grog and a few grey and black grits. Thickness: $c .0 .9 \mathrm{~cm}$. 
123. Amphora. The ware is light brown with a redder core and a brown surface, ribbed on the interior, clean fracture. The fabric contains a few voids and white specks and a little mica. Thickness: $c .1 .6 \mathrm{~cm}$.

124. Amphora. The ware is brown with a pink core and a reddish-brown pitted surface. The fabric is grainy with a few translucent and white grits and the occasional void, generally few inclusions. Thickness: $c .1 .1 \mathrm{~cm}$.

125. Amphora. The ware is orange-brown with an orange surface and moderate fracture. The fabric contains many tiny voids, white and translucent and a few black grits and some mica. Thickness: $c .0 .5 \mathrm{~cm}$.

133. Amphora. The ware is light pinkish-brown with a light brown surface and moderate fracture. The fabric contains many black angular grits some of which are shiny (volcanic?), a few lime and red grits and the occasional mica particle. Thickness: $c .1 .0 \mathrm{~cm}$.

140. Amphora. The ware is light brown with a light brown rough surface, moderate fracture. The fabric contains some quartz, the occasional black grit and white speck and some mica. Thickness: $c .1 .0 \mathrm{~cm}$.

145. Amphora. The ware is orange-brown with an orange-brown surface on the interior and a red slip on the exterior which has wide shallow ribbing, moderate to crumbly fracture. The fabric contains some rounded red grits (occasionally large: $2 \mathrm{~mm}$ in diameter), much grog and mica and a little quartz. Thickness: $c .0 .9 \mathrm{~cm}$.

149. The ware is red with a smoothed red-slipped surface, medium clean fracture. The fabric is grainy with a little mica. Thickness: $c .0 .4 \mathrm{~cm}$.

150. The ware is red with a red slip, often with a pock-marked surface, moderate to clean fracture. The fabric is grainy with the occasional white and/or black grit and a small amount of mica. Thickness: $c .0 .6 \mathrm{~cm}$.

156. Amphora. The ware is pinkish with a yellow-brown to pinkish-brown surface and a clean fracture. The fabric contains angular black and rounded red grits, a little grog and quartz, some organic material, soft yellow grits and mica. Thickness: $c .0 .8 \mathrm{~cm}$.

158. Amphora. The ware is buff with a faintly orange core with a sharp fracture, ribbed on exterior. The fabric is grainy and contains a few small black and the occasional white and translucent grits. Thickness: $c .0 .7 \mathrm{~cm}$.

160 Amphora. The ware is red with a red surface on the interior and a thick cream slip on the exterior, irregular shallow ribbing on exterior, moderate fracture. 
The fabric contains angular and rounded white and translucent grits, some grog and a little limestone and mica. Thickness: $c .1 .0 \mathrm{~cm}$.

164. Amphora. The ware is light brown with an orange to very light brown surface with a moderate to clean fracture, with square ribbing on the exterior, which appears very gritty. The fabric contains many red, black and brown rounded and angular grits, a few white grits and voids and the occasional silvery particle. Thickness: $c .0 .8 \mathrm{~cm}$.

165. Amphora. The ware is red with a light grey core with red-brown to dark brown surface and a crumbly fracture; many silvery particles are visible on the surface that has been vertically burnished. The fabric is grainy containing a few quartz and many tiny silvery particles. Thickness: $c .0 .8 \mathrm{~cm}$.

166. Amphora. The ware is reddish-brown with a reddish-brown to buff surface with a sharp fracture. The fabric contains a few quartz and red grits. Thickness: $c .0 .8 \mathrm{~cm}$.

167. Amphora. The ware is brown with a brown surface with wide shallow ribbing, crumbly fracture. The fabric contains a large amount of mica. Stress lines are clearly visible as if the vessel is trying to 'unwind' itself. Thickness: $0.4-0.5 \mathrm{~cm}$.

171. Samian.

172. Miscellaneous.

173. Stoneware.

174. Late Roman C ware.

175. Cypriot Red Slip ware.

\section{NOTES}

1 Original ware numbers have been used to facilitate reference to the archive. This means that the numbers in the list are not consecutive. 


\section{Appendix 2: Relative frequency of types by dated phase}

\begin{tabular}{|c|c|c|c|c|c|c|c|c|c|c|c|c|c|c|c|c|c|c|c|c|c|}
\hline \multicolumn{22}{|c|}{ Dated Phases } \\
\hline$\stackrel{\widetilde{\varpi}}{\cong}$ & $\frac{m}{8}$ & $\frac{8}{\frac{n}{n}}$ & $\frac{n}{\frac{1}{n}}$ & $\frac{n}{2}$ & 点 & $\begin{array}{l}\stackrel{n}{n} \\
\frac{n}{n} \\
n\end{array}$ & 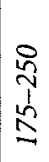 & \begin{tabular}{l}
$\stackrel{8}{n}$ \\
1 \\
\multirow{2}{2}{}
\end{tabular} & $\begin{array}{l}\stackrel{n}{\hat{N}} \\
\stackrel{d}{N} \\
\end{array}$ & $\begin{array}{l}\stackrel{8}{n} \\
\stackrel{1}{1} \\
\stackrel{n}{7}\end{array}$ & $\begin{array}{l}\frac{8}{5} \\
\frac{1}{2} \\
\stackrel{5}{2}\end{array}$ & $\frac{8}{\stackrel{7}{1}}$ & $\frac{\stackrel{8}{7}}{\stackrel{1}{2}}$ & $\begin{array}{l}\frac{8}{5} \\
\frac{1}{7} \\
\frac{5}{7}\end{array}$ & 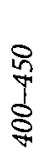 & 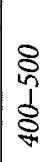 & 8 & $\begin{array}{l}8 \\
8 \\
0 \\
8 \\
7 \\
7\end{array}$ & $\frac{\vec{c}}{\omega}$ & $\begin{array}{l}0 \\
\sum_{1}^{0} \\
5 \\
0 \\
0\end{array}$ & E \\
\hline 1 & & & & & & & & & & & & & & & & & & 3 & & 1 & 4 \\
\hline 2 & & 1 & 1 & & & & & & & & & & & & & & & & & & 2 \\
\hline 8 & 1 & & & & & & & & & & & & & 1 & & & & & & & 2 \\
\hline 11 & 6 & & & & & & & & & & & & & & & & & & & & $\underline{6}$ \\
\hline$\overline{13}$ & 3 & & & & & & & & & & & & & & & & & & & & $\overline{3}$ \\
\hline 18 & 3 & & & & & & & & & & & & & & & & & 1 & & & $\overline{4}$ \\
\hline 19 & 18 & & & & & & & & & & & & & & & & & & & & 18 \\
\hline $20 a$ & & 1 & & & & & 3 & & & 1 & 3 & & & 1 & & & 1 & 8 & & 8 & 26 \\
\hline 21 & 3 & & & & & & & & & & & & & & & & & & & & 3 \\
\hline $21 \mathrm{a}$ & 1 & 31 & 1 & 10 & 4 & & 8 & 3 & & 1 & & & 17 & 4 & & 1 & 3 & 5 & 11 & & 100 \\
\hline 22 & 3 & & & & & & & & & & & & & & & & & & & 1 & 4 \\
\hline $22 \mathrm{a}$ & & 4 & & & & & 32 & & & 2 & & & & 1 & & & 1 & & & 1 & 41 \\
\hline $23 a$ & & 10 & & & & & 22 & & & 1 & & 1 & & 1 & & & 2 & 2 & & & 39 \\
\hline $24 a$ & & 1 & & & & & 6 & 1 & & 2 & & & 4 & & & & 4 & 5 & & 13 & 36 \\
\hline 25 & 1 & & & & & & 1 & & & & & & & & & & & & & & $\underline{2}$ \\
\hline $26 a$ & & 1 & 1 & & & & & & & 3 & 2 & & & 3 & & & & 6 & & 4 & 20 \\
\hline 27 & & & & & & & & & & 4 & 3 & & & 7 & & & 1 & 14 & & 6 & 35 \\
\hline 28 & & & & & & & 2 & & & & & & 2 & 2 & & & & 3 & & 2 & 11 \\
\hline 30 & & & & & & & & & & & & & & & 1 & & 1 & 5 & & & $\overline{7}$ \\
\hline 31 & & & & & & & & & & 1 & & & & & & & 1 & & & & 2 \\
\hline 32 & & & & 1 & & & 1 & & & & & & 1 & 1 & & & & 1 & & 2 & 7 \\
\hline 33 & & & & & & & & & & & & & & 1 & 1 & & & 1 & & & 3 \\
\hline 34 & & & & & & & & & & 2 & & & & & & & 1 & & & & 3 \\
\hline 35 & & & & & 1 & & & & & 5 & 16 & & & 27 & 7 & & 7 & 26 & & 40 & 129 \\
\hline 37 & & & & & & & & & & & & & & 1 & & & 1 & 4 & & & 6 \\
\hline 38 & & & & 1 & & & & & & 2 & 1 & & & 3 & & & 1 & & & 2 & 10 \\
\hline 40 & & & & & 1 & & & & & 1 & 4 & & & 1 & 5 & & & 13 & & 8 & 33 \\
\hline 41 & & 2 & & & & & 4 & & & & & & 1 & 7 & & & 2 & & & 7 & 23 \\
\hline 42 & & & & & & & & & & 1 & 2 & & & & & & & 1 & & & 4 \\
\hline 43 & & & & & 1 & & 1 & & & 2 & 1 & & & 3 & 2 & & & 3 & & 1 & 14 \\
\hline 44 & & & & & & & & & & 1 & & & & 2 & 1 & & & & & 1 & 5 \\
\hline 45 & & & & & & & 3 & & & & & & & & & & & & & & $\overline{3}$ \\
\hline 46 & & & & & & & 1 & 2 & & & & & 3 & 3 & & & 1 & 2 & & 6 & 18 \\
\hline
\end{tabular}




\section{Dated Phases}

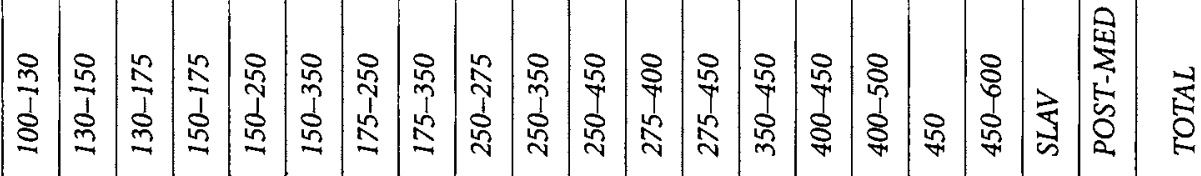

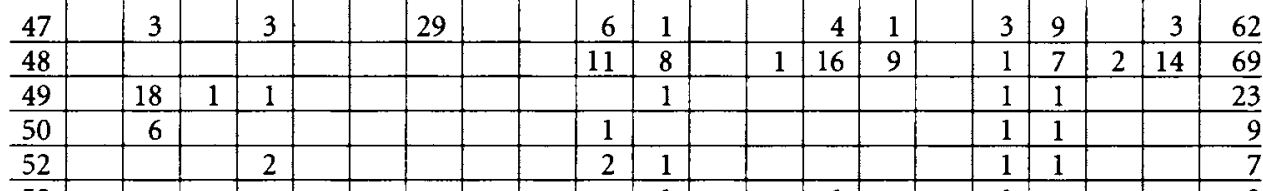
53 5 58 5 60 61 $\frac{64}{65}$ 66 67 $\frac{68}{70}$ $\frac{70}{7}$

$\frac{7}{72}$

$\frac{7}{7}$

$\frac{7}{79}$

80

8

82

8

85

87

88

$\frac{8}{90}$

91

92

95

96

96

98

99

100

101

102

\begin{tabular}{l|l|l|l|l|l|l|l|l|l|l|l|l|l|l|l|l|l|l|l|l|l}
\hline 103 & & & & & & & & & 1 & 1 & 5 & & & 5 & 1 & & & 8 & & 4 & 25 \\
\hline 105 & 1 & & & & & & & & & & & & 1 & & & & & 6 & & 7 & 15 \\
\hline
\end{tabular}

\begin{tabular}{l|l|l|l|l|l|l|l|l|l|l|l|l|l|l|l|l|l|l|l|l|l}
\hline 103 & & & & & & & & & 1 & 1 & 5 & & & 5 & 1 & & & 8 & & 4 & 25 \\
\hline 105 & 1 & & & & & & & & & & & & 1 & & & & & 6 & & 7 & 15 \\
\hline
\end{tabular}

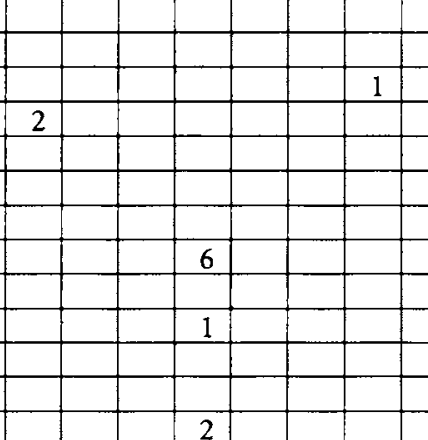

\begin{tabular}{|l|l|l|l|l|l|l|l}
\hline 1 & & & 1 & \\
\hline & & & & \\
\hline & & & 2 & \\
\hline
\end{tabular}

\begin{tabular}{|l|l|l|l|l|l|l|l}
\hline 1 & & & 1 & & & & 3 \\
\hline 2 & 1 & & 2 & 1 & & 2 & 9 \\
\hline 4 & & & & & & 1 & 8 \\
\hline & & 2 & & & & & 3 \\
\hline
\end{tabular}

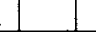

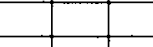

(68

(1)

5

2

3

\begin{tabular}{l|l|l|l|}
\hline 1 & & & 1 \\
\hline & & 1 & \\
\hline
\end{tabular}

1

3

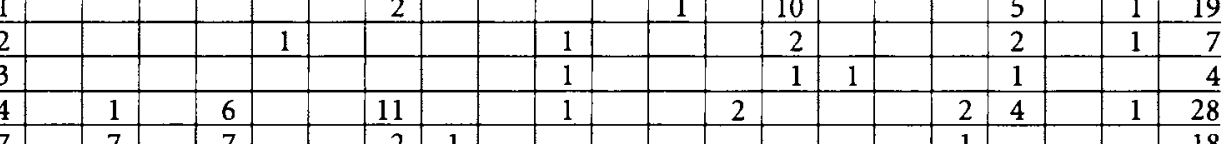

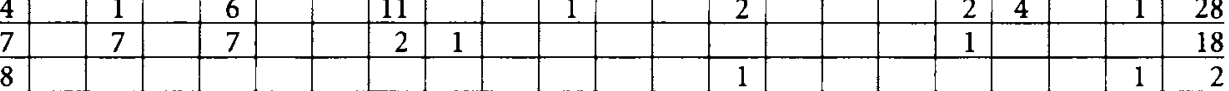

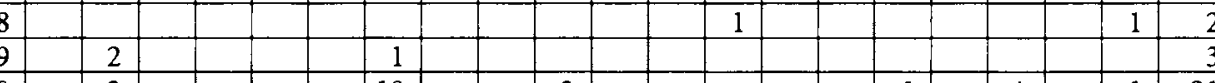

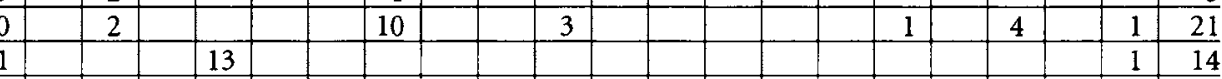

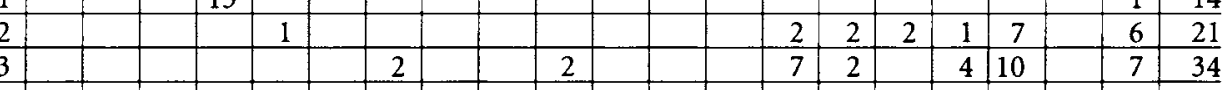

\begin{tabular}{|l|l|l|l|l|l|l|l|l|l|l|l|l|l|l|l|l|l|l}
84 & & & & & & 8 & 2 & & & 6 & 1 & & 2 & 1 & & & 20 \\
\hline & 6 & & 3 & & 6 & 7 & & 8 & 3 & 4 & 15 & & 8 & 60 \\
\hline
\end{tabular}

\begin{tabular}{r|r|l|l|l|l|l|r|r|r|r|r|r|r|r|r|r|r|}
\hline 85 & 6 & & 3 & & 6 & 7 & & & 8 & 3 & & 4 & 15 & & 8 & 60 \\
1 & & & 1 & & & 18 & & & 5 & 24 & 2 \\
\hline 8
\end{tabular}

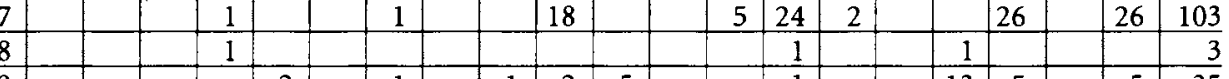

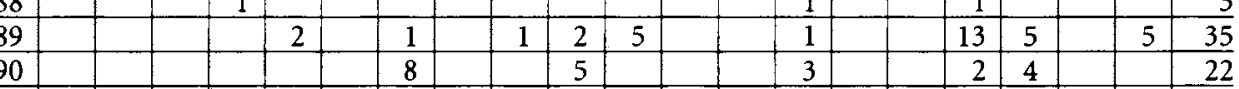

\begin{tabular}{l|l|l|l|l|l|l|l|l|l|l|l|l|l|l|l|l|l|l|r|r}
\hline 2 & & & & & & & & & & 2 & & & & & & 1 & 2 & & 2 & 7 \\
\hline
\end{tabular}

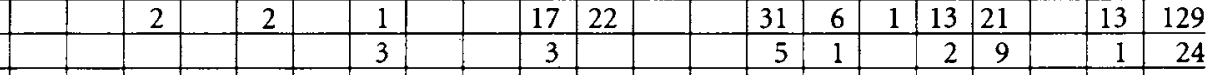

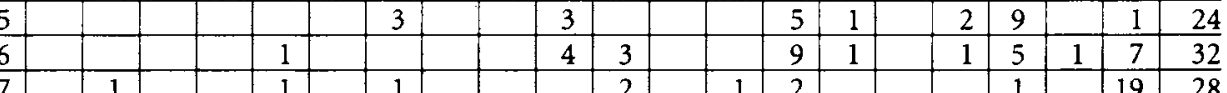

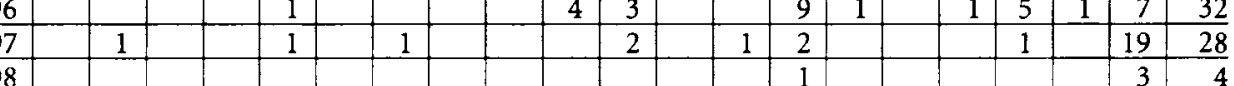

\begin{tabular}{llllllllllll|l|l|l|l|l|l|l|l|}
98 & \\
\hline 9
\end{tabular}

\begin{tabular}{llllllllllll|l|l|l|l|l|l|l|l|r|r} 
\\
\hline
\end{tabular} 
Dated Phases

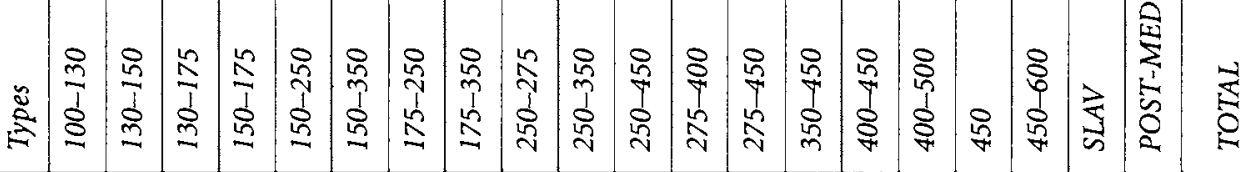

\begin{tabular}{|c|c|c|c|c|c|c|c|c|c|c|c|c|c|c|c|c|c|c|c|}
\hline 106 & & & & & 5 & 2 & & & 5 & & & 1 & 4 & 2 & 15 & 5 & & 3 & 42 \\
\hline 109 & 1 & 9 & 1 & & & 1 & & 1 & & & & & & & 4 & 2 & & 3 & 22 \\
\hline 110 & & 1 & & & & & & & 3 & & 3 & 3 & & & 2 & 11 & & 11 & 34 \\
\hline 113 & & 2 & & & & 2 & & & & 1 & 1 & 1 & & & & 1 & & 3 & 11 \\
\hline 114 & & & & & & & & & & & 1 & 2 & & & 1 & 10 & & 4 & 18 \\
\hline 115 & 4 & 18 & 1 & & & 8 & 1 & & 3 & 3 & 24 & 10 & & & & 18 & & 28 & 118 \\
\hline 116 & & & & & & & & & & & 3 & & & & 4 & 1 & & 9 & 17 \\
\hline \begin{tabular}{l|}
118 \\
\end{tabular} & & & & & & & & & 1 & & & & & & & 2 & & 2 & 5 \\
\hline 119 & & & & & & & & & & & 1 & 2 & & & 2 & 39 & & \begin{tabular}{l|}
5 \\
\end{tabular} & $\overline{49}$ \\
\hline 120 & & & & & & & & & & & & & & & 2 & 11 & & 4 & 17 \\
\hline 121 & & & & & & & & & & & & & & & 3 & & & & $\sqrt{3}$ \\
\hline 123 & & & & & & & & & & & & & & & & 2 & & 1 & 3 \\
\hline 126 & & & & & & & & & & & & & & & & & & 3 & 3 \\
\hline 127 & & & 1 & & & & & & & & & & 1 & & 3 & & & 5 & 10 \\
\hline 128 & & & & & & & & & & & & & & & & & & 2 & 2 \\
\hline 130 & & & & & & & & & 1 & & 1 & & 1 & & 5 & 3 & & 4 & 15 \\
\hline 131 & & & & & & & & & & 1 & & & 1 & & 3 & & & & 5 \\
\hline 132 & & & 1 & & & 1 & & & 1 & & 5 & 6 & & & 9 & 7 & & 6 & 36 \\
\hline 133 & & & & & & & & & & & 4 & 2 & $\mathrm{l}$ & & 4 & & & 6 & 17 \\
\hline 135 & & & & & & & & & & & & & 2 & & 8 & & 1 & & 11 \\
\hline 136 & & & & & & & & & & & & & & & 2 & 1 & & & 3 \\
\hline 137 & & & & & & & & & & & & & & & 2 & & & 1 & 3 \\
\hline 138 & & & & & & & & & & & 3 & 2 & & & 3 & 9 & & 10 & 27 \\
\hline 141 & & & & & & 3 & & & & & 2 & 4 & 2 & & 4 & 6 & & 11 & 32 \\
\hline 142 & & & & & & & & & & 1 & 2 & 2 & 3 & & 14 & 3 & & 2 & 27 \\
\hline 143 & & & & & & & & & & & & {$\left[{ }_{0}\right.$} & 2 & & & 2 & & & 4 \\
\hline 144 & & & & & & & & & & & & 1 & & & & & & 8 & 9 \\
\hline 146 & & & & & & & & & & & & & & & & 2 & & 1 & 3 \\
\hline 147 & & & & & & & & & & & & & 1 & & 1 & & & 1 & 3 \\
\hline$\underline{148}$ & & & & & & 1 & & & 1 & & 1 & 7 & 1 & & 5 & 11 & & 12 & 39 \\
\hline 150 & & & & & & & & & & & & & & & & 1 & & 2 & 3 \\
\hline 152 & & & & & & & & & & & 2 & 1 & & & 2 & 1 & & 2 & 8 \\
\hline 153 & & & & & & & & & & 1 & & 8 & & & 1 & 2 & & 1 & 13 \\
\hline 154 & & & & & & & & & 2 & 1 & & 1 & & & & & & 1 & 5 \\
\hline 155 & & & & & & & 1 & & & & 1 & & & & & & & 3 & 5 \\
\hline 157 & & & & & & 3 & & & & & & & & & & & & 3 & 6 \\
\hline 158 & & & & & & & & & 2 & 1 & 1 & 3 & 3 & & 4 & 5 & & 2 & 21 \\
\hline 161 & & & & & & & & & & & 1 & 1 & & & & & & 5 & 7 \\
\hline 162 & & & 1 & & & & & & & & & & & & 2 & & & & 3 \\
\hline 163 & & & & & & & & & & & & & 5 & & 23 & 3 & & 7 & 38 \\
\hline 166 & & & & & & 2 & & & 8 & & 1 & 16 & 2 & & 2 & 7 & & 3 & $\overline{41}$ \\
\hline 167 & & & & & & & & & & & 1 & & & & 1 & & & & $\underline{2}$ \\
\hline 168 & & & & & & & 1 & & & & & & & & & & & 1 & 2 \\
\hline$\underline{169}$ & & & & & & & & & & & & & & & & 4 & & 2 & 6 \\
\hline 170 & & & & & & 1 & & & & & 1 & 2 & & & & 5 & & 5 & 14 \\
\hline \begin{tabular}{l|l}
171 \\
\end{tabular} & & 3 & & 9 & & 4 & & & 1 & & 3 & 1 & & & 3 & 7 & & 14 & 45 \\
\hline 172 & & 3 & & & & & & & & & & & & & 1 & & & & 4 \\
\hline
\end{tabular}




\section{Dated Phases}

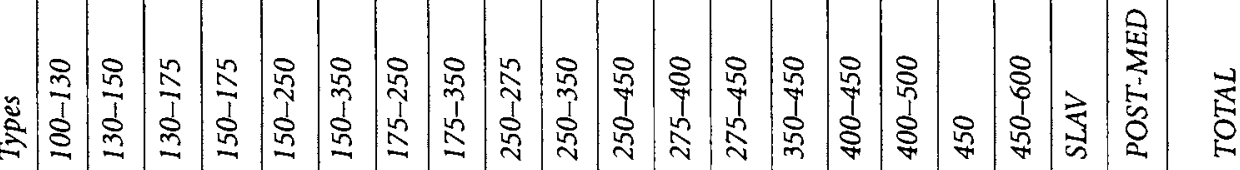

174

175

176

178

179

180

181

182

190

194

198

199

200

203

205

209

211

215

217

220

223

226

227

229

230

232

233

234

236

237

241

24

24

244

246

248

249

250

251

258

259

260

263

264

$\frac{267}{273}$

2

2

\begin{tabular}{l|l|l|l|l|}
\hline & & & \\
\hline & & & \\
\hline
\end{tabular}

8

\begin{tabular}{|r|r|r|r|r|r|r|r|r|r|r|r} 
& & & & & & & & & & 2 & 2 \\
\hline 10 & 2 & & & 9 & & & 1 & 6 & & & 28 \\
\hline
\end{tabular}

\begin{tabular}{l|r|r|r|r|r|r|r|r|r|r|r}
\hline & & & & 2 & & & & & & & 2 \\
\hline 0 & 2 & & & 9 & & & 1 & 6 & & & 28 \\
\hline
\end{tabular}

\begin{tabular}{l|l|l|l|}
1 & 1 & 7 & 12 \\
\hline
\end{tabular}

\begin{tabular}{r|r|r|r|r}
1 & 2 & & 1 & 5 \\
\hline & & & 1 & 5 \\
\hline
\end{tabular}

\begin{tabular}{l|l|l|l|l|} 
& & 1 & & \\
\hline & & 1 & 2 & \\
\hline
\end{tabular}

1

\begin{tabular}{l|l}
1 & 7 \\
\hline 2 & 2 \\
\hline
\end{tabular}

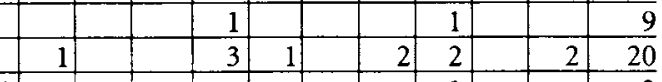

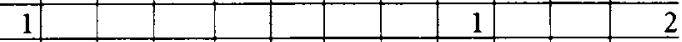

\begin{tabular}{|r|r|r|r|r|r|r|r|r|r|r|r|r|r}
\hline 1 & & & & & & 1 & 1 & & 1 & 1 & & 2 & 8 \\
\hline 3 & & 2 & 2 & & & 1 & & & 1 & 3 & & 2 & 14 \\
\hline
\end{tabular}

1

1 1 1

1

2

1

$-1$

\begin{tabular}{l|l|l|l|l|l|l|l} 
& & & & & & & 2 \\
\hline 1 & 1 & & 2 & 3 & & 1 & 9 \\
\hline & & 1 & & & & & 2
\end{tabular}

1

1

1

1

1.

10

$\begin{array}{lllll}2 & 1 & & 1\end{array}$

2

10

3

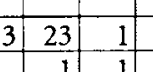

\begin{tabular}{l|l|l|} 
& 2 & \\
13 & 9 & 3 \\
\hline & 2 &
\end{tabular}

5 12

1 1.49

1

\begin{tabular}{ll|l|l|l|l|l}
\hline & & & & & \\
\hline
\end{tabular}

\begin{tabular}{l|l|l|}
\hline & \\
\hline
\end{tabular}

\begin{tabular}{l|l|}
1 & 3 \\
\hline & 3
\end{tabular}

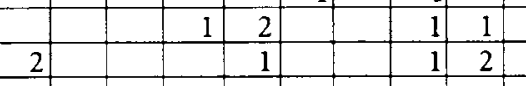

\begin{tabular}{l|l|l|}
\hline 4 & &
\end{tabular}

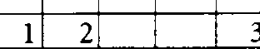

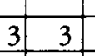

\begin{tabular}{r|r|r|r|r|r|r|}
13 & 330 & 61 & 2 & 112 & 390
\end{tabular}

3

\begin{tabular}{r|r|r|r|r|r|r|r|r}
\hline & 8 & & & 1 & & & & 12 \\
\hline 1 & & & & 2 & & & & 4 \\
\hline
\end{tabular}

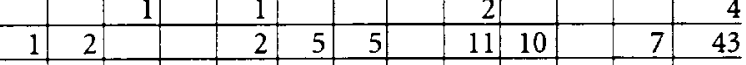

\begin{tabular}{|l|l|l|l|l|r|r|r|r|r|r|r|r|r|r|r|r|r|r}
1 & & & & & 3 & & 1 & & & & & & & 2 & & & 7 \\
\hline
\end{tabular}

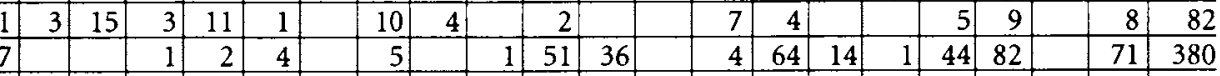

\begin{tabular}{|l|l|l|l|l|l|l|l|l|r|r|r|r|r|r|r|r|r|r|r|r|}
\hline \\
\hline
\end{tabular}

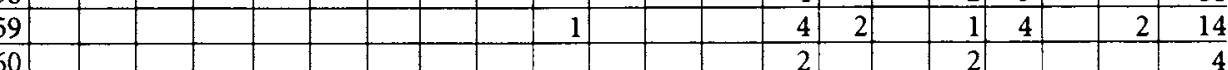

\begin{tabular}{|l|l|l|l|l|l|l|l|l|l|l|l|l|l|l|l|l|l}
4 & \\
\hline
\end{tabular}

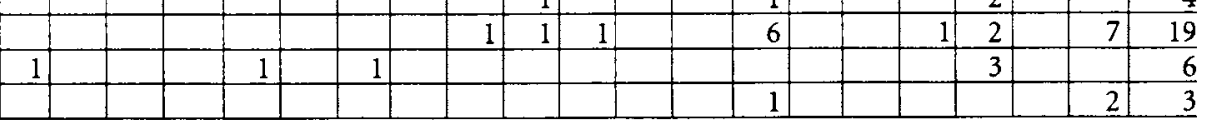




\section{Dated Phases}

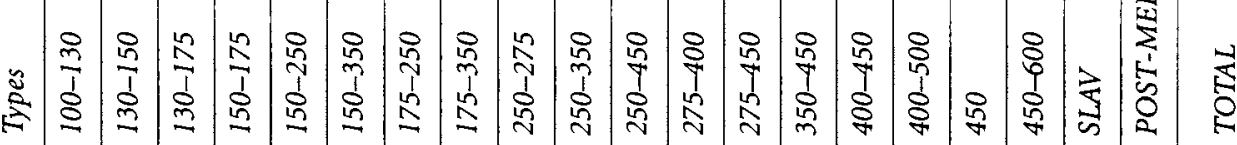

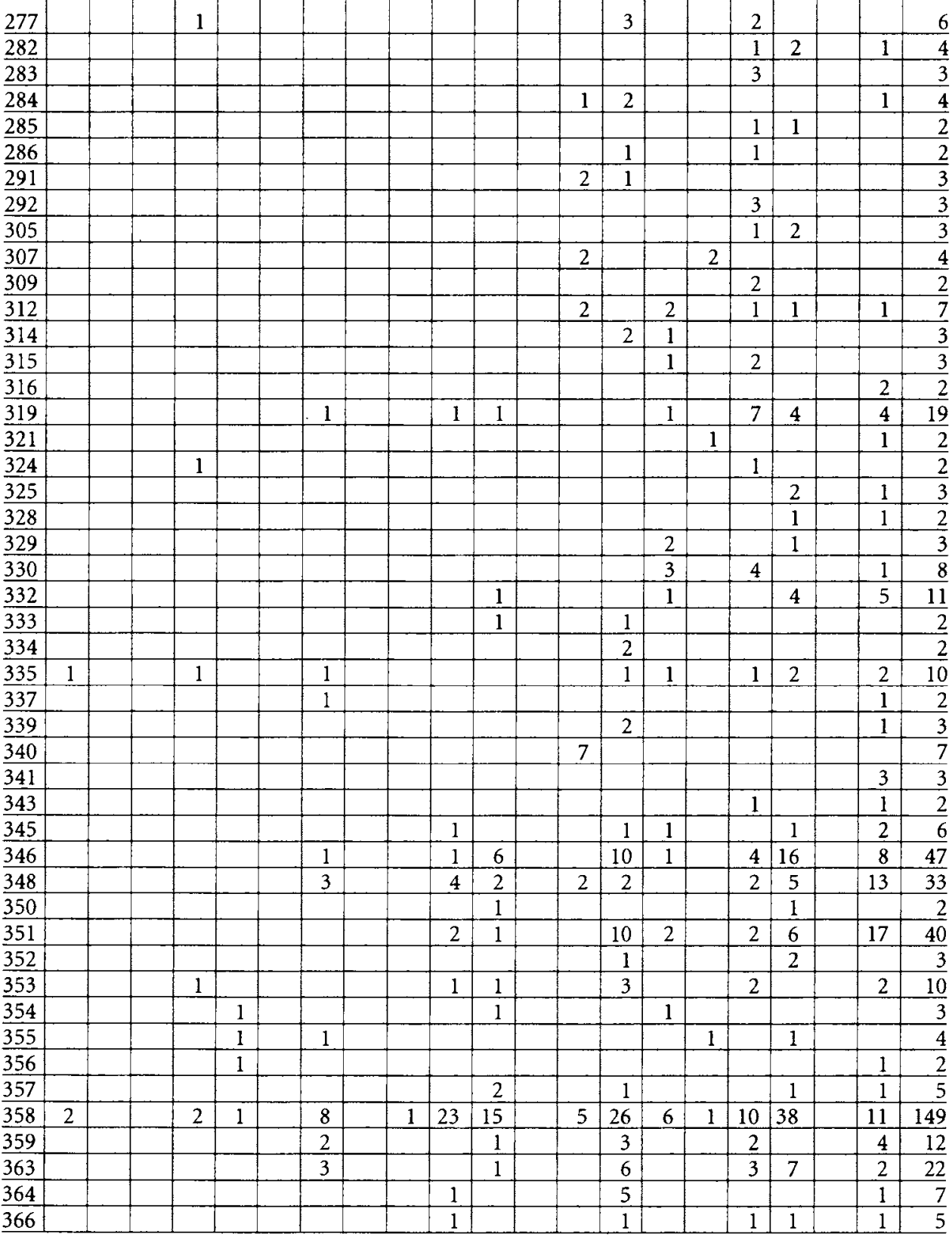


Dated Phases

\begin{tabular}{|c|c|c|c|c|c|c|c|c|c|c|c|c|c|c|c|c|c|c|c|c|c|}
\hline$\stackrel{\Xi}{\Xi}$ & $\frac{8}{7}$ & $\begin{array}{l}\frac{8}{n} \\
\frac{1}{1} \\
n \\
n\end{array}$ & $\frac{n}{1}$ & $\frac{n}{1}$ & 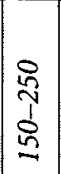 & $\begin{array}{l}0 \\
m \\
1 \\
0 \\
2\end{array}$ & 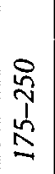 & 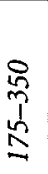 & 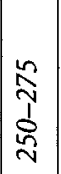 & $\left|\begin{array}{c}8 \\
2 \\
1 \\
0 \\
n \\
7\end{array}\right|$ & 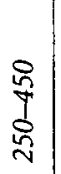 & 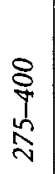 & $\begin{array}{c}\frac{8}{n} \\
\frac{n}{v} \\
\hat{v}\end{array}$ & $\begin{array}{l}8 \\
\frac{6}{4} \\
0 \\
m \\
m\end{array}$ & $\begin{array}{l}8 \\
7 \\
8 \\
8\end{array}$ & $\left|\begin{array}{l}8 \\
8 \\
1 \\
8 \\
8 \\
7\end{array}\right|$ & $\frac{8}{7}$ & $\begin{array}{l}8 \\
8 \\
1 \\
0 \\
7\end{array} \mid$ & 空 & 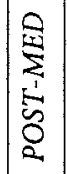 & 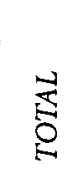 \\
\hline 367 & & & & & & & & & & 2 & 2 & & & 2 & 2 & & 1 & 2 & & 3 & 14 \\
\hline 368 & & & & 1 & & & 4 & & & & & & & 2 & & & & 1 & & 1 & 9 \\
\hline 369 & & & & & & & & & & 1 & & & & 2 & 2 & & & $\mathrm{I}$ & & & 6 \\
\hline 370 & 1 & & & & 3 & & & & & 5 & 1 & & 2 & \begin{tabular}{l|}
9 \\
\end{tabular} & \begin{tabular}{|l|}
3 \\
\end{tabular} & & 10 & 8 & & 26 & 68 \\
\hline 371 & & & & & & & & & & & & & & \begin{tabular}{|l|l|}
3 \\
\end{tabular} & 2 & & & 1 & & 2 & 8 \\
\hline 372 & & 1 & & & & & 5 & & & 6 & & 9 & 10 & 29 & 4 & 1 & 9 & 30 & & 53 & 157 \\
\hline 373 & & & & & 1 & & & & & & 2 & & & 1 & & & 5 & 3 & & 2 & 14 \\
\hline 374 & & & & & & & & & & & 2 & & & 1 & & & & 1 & & & $\overline{4}$ \\
\hline 375 & & & & & & & & & & & & & & 1 & & & 1 & & & & 2 \\
\hline 379 & & & & & & & & & & & & & & 2 & & & 1 & 1 & & & 4 \\
\hline 380 & & & & & & & & & & & & & & & & & & 4 & & 1 & 5 \\
\hline 381 & & & & & & & 4 & & & 1 & 1 & & & & & & & & & 1 & 7 \\
\hline 382 & & & & & & & & & & 1 & & & & 6 & & & 2 & & & 2 & 11 \\
\hline 383 & & & & & & & 1 & & & & & & & & & & & 1 & & & 2 \\
\hline 384 & & & & & & & & & & & & & & & & & & & & 2 & 2 \\
\hline 386 & & & & & & & & & & & 1 & & & 1 & 1 & & 1 & & & 1 & 5 \\
\hline 388 & & & & & & & & & & & 1 & & & 2 & & & 1 & & & 3 & 7 \\
\hline 390 & & & & & & & & & & 1 & & & & & & & & 1 & & & 2 \\
\hline 392 & & & & & & & 1 & & & & & & & & & & & & & 1 & 2 \\
\hline 393 & & 1 & & & & & 1 & & & & & 1 & 1 & 2 & & & 1 & 8 & & 2 & 17 \\
\hline 394 & & & & & & & & & & & & & & 2 & & & & & & 1 & $\sqrt[3]{3}$ \\
\hline 396 & & & & & & & & & & 2 & & & & & & & & & & & 2 \\
\hline 397 & & & & & & & 1 & & & & 1 & & & 1 & & & & 1 & & 2 & 6 \\
\hline 399 & 1 & & & & & & & & & 1 & & & & & & & 1 & & & & 3 \\
\hline 400 & 1 & 1 & & & & & & & & & & & & & & & & & & & 2 \\
\hline 402 & & & & & & & 2 & & & 1 & & & & & & & 1 & & & & $\overline{4}$ \\
\hline 403 & & & & & & & & & & & & & & 3 & & & & & & & 3 \\
\hline 404 & & & & & & & & & & & & & & & & & 1 & & & 1 & 2 \\
\hline 411 & 1 & 3 & & & & & 2 & & & 1 & & & & & & & & & & & 7 \\
\hline 412 & & & & & & & 2 & & & & & & & & & & & & & & 2 \\
\hline 413 & 3 & & 1 & & & & 1 & & & & & & & & & & 1 & & & 1 & 7 \\
\hline 414 & & & 2 & & & & & & & & & & & & & & & & & & 2 \\
\hline 416 & 12 & & & & & & & & & & & & & 2 & & & 1 & 1 & & 2 & 18 \\
\hline$\overline{417}$ & & & & & & & & & & & & & & 2 & & & 2 & 1 & & 3 & 8 \\
\hline 418 & 2 & & & & & & & & & & & & & & & & & & & & 2 \\
\hline$\underline{422}$ & & 1 & & & & & & & & 1 & & & & & & & & & & & 2 \\
\hline 424 & 4 & & & & & & 1 & & & & & & 1 & & & & & & & 1 & 7 \\
\hline 425 & & & & & & & & & & & & & & 1 & & & 1 & & & & 2 \\
\hline 428 & 1 & 21 & & & 1 & & 3 & & & 11 & 2 & & & & 1 & & 2 & 2 & & 1 & 45 \\
\hline 429 & 7 & 51 & 1 & & & & 24 & 3 & & & & & 8 & 6 & & & 2 & 7 & & 2 & 111 \\
\hline 431 & & 5 & & & & & & & & & & & & & & & 1 & & & & 6 \\
\hline 432 & 31 & 62 & 4 & 46 & 7 & & 56 & 3 & 1 & 10 & 11 & 1 & 34 & 27 & 5 & 2 & \begin{tabular}{|l|}
11 \\
\end{tabular} & 44 & 1 & 20 & 376 \\
\hline 433 & & & 1 & & & & 4 & & & 2 & 2 & & & \begin{tabular}{l|l}
4 \\
\end{tabular} & & & 1 & 4 & & 5 & 23 \\
\hline 434 & & & & & & & & & & & 1 & & & & 1 & & & 1 & & 3 & 6 \\
\hline 435 & & & & & & & & & & 1 & 3 & & & 1 & & & 1 & & & 2 & $\overline{8}$ \\
\hline 437 & & & & & & & 1 & & & & & & & 1 & & 1 & 2 & 1 & & 1 & 7 \\
\hline 438 & & & & & & & 5 & & & 1 & & & & & & & & & & 1 & 7 \\
\hline
\end{tabular}


Dated Phases

\begin{tabular}{|c|c|c|c|c|c|c|c|c|c|c|c|c|c|c|c|c|c|c|c|c|c|}
\hline$\stackrel{\Xi}{\Xi}$ & $\frac{8}{2}$ & $\frac{8}{\frac{8}{5}}$ & $\begin{array}{l}n \\
\frac{n}{1} \\
\frac{1}{n} \\
n\end{array}$ & $\frac{n}{1}$ & 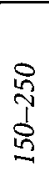 & $\begin{array}{l}8 \\
n \\
1 \\
0 \\
n \\
n\end{array}$ & $\begin{array}{c}0 \\
5 \\
1 \\
1 \\
-1 \\
-1\end{array}$ & $\begin{array}{l}\stackrel{8}{n} \\
1 \\
1 \\
N\end{array}$ & 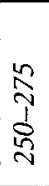 & $\mid \begin{array}{l}0 \\
m \\
1 \\
0 \\
n \\
n\end{array}$ & $\left|\begin{array}{l}8 \\
7 \\
8 \\
2 \\
2\end{array}\right|$ & $\begin{array}{l}8 \\
8 \\
2 \\
\hat{y}\end{array}$ & 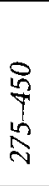 & $\begin{array}{l}0 \\
7 \\
0 \\
n \\
m\end{array}$ & $\begin{array}{l}0 \\
7 \\
8 \\
7\end{array}$ & $\mid \begin{array}{l}8 \\
0 \\
1 \\
8 \\
7\end{array}$ & $\frac{8}{7}$ & $\begin{array}{l}8 \\
8 \\
1 \\
8 \\
7\end{array}$ & 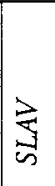 & 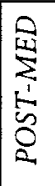 & $\underset{E}{E}$ \\
\hline 439 & & 4 & & & & & 3 & & & 7 & & & 1 & 3 & & & 2 & & & 2 & 22 \\
\hline 440 & & 114 & & & & & 30 & & & & & & & 1 & & & & & & & 145 \\
\hline 442 & & & 2 & & & & & & 1 & 5 & 7 & & & 11 & & & & 11 & & 9 & 46 \\
\hline 447 & & 2 & & & & & & & & & & & & & & & & & & & 2 \\
\hline 448 & & & & 1 & & & & & & 3 & 1 & & & 6 & 1 & & 1 & 4 & & 6 & 23 \\
\hline$\overline{449}$ & & & & & & & & & & 2 & & & & 3 & & & 1 & & & & 6 \\
\hline 450 & & & 1 & 1 & & & 6 & & & 20 & 7 & & 2 & 11 & 11 & 1 & 10 & 14 & & 20 & 104 \\
\hline 451 & & & & & & & 3 & & & 1 & & & & 1 & & & 2 & 2 & & 1 & 10 \\
\hline 452 & & & & & & & & & & 5 & & & & 8 & 1 & & 1 & 1 & & 4 & 20 \\
\hline 454 & & & & & & & & & & & & & & 2 & & & & & & & 2 \\
\hline 456 & & & & & & & & & & & 7 & & & 7 & 2 & & & 6 & & 6 & 28 \\
\hline 458 & & & & & 1 & & 4 & & & 4 & 2 & & 4 & 4 & & & 1 & 2 & & 3 & 25 \\
\hline 460 & & & & & & & & & & 2 & & & & & & & 2 & & & & 4 \\
\hline 461 & 1 & & & & & & 5 & & & & 2 & & & & & & 1 & & & 2 & 11 \\
\hline 462 & & 2 & & 4 & & & 1 & & & 1 & & & & & & & & & & 1 & 9 \\
\hline 464 & & & & 1 & & & & & & 4 & & & & & 1 & & 5 & 7 & & 2 & 20 \\
\hline 465 & & 2 & & & & & & & & & & & & & & & & & & & 2 \\
\hline 466 & & & & & & & 1 & & & 1 & 14 & & & 7 & & & 2 & 9 & & 2 & 36 \\
\hline 467 & & 2 & & & & & & & & & & & & & & & & & & & 2 \\
\hline 470 & & & & & & & & & & 1 & & & & 1 & & & & 1 & & 1 & 4 \\
\hline 471 & & 2 & & & & & 1 & & & & & & & & & & 1 & & & 1 & 5 \\
\hline 472 & & & & & & & 1 & 1 & 1 & 7 & 8 & & 2 & 16 & 3 & & 5 & 7 & & 15 & 66 \\
\hline 475 & & & & 3 & & & & & & & & & & & & & & & & & 3 \\
\hline 477 & & 1 & & & & & & & & & & & & 1 & & & & & & & $\overline{2}$ \\
\hline 478 & & & 1 & 1 & & & 2 & & & & & & 1 & & & & & & & & 5 \\
\hline 480 & 10 & 20 & & 5 & & & 22 & 1 & & 1 & & & 5 & 5 & & & & 2 & & 2 & 73 \\
\hline 482 & & 2 & & & & & & & & & & & & & & & & 1 & & & 3 \\
\hline 483 & & & & 1 & & & 1 & & & & & & & & 1 & & 1 & 1 & & & 5 \\
\hline 484 & & & & & & & 3 & & & & & & & 1 & & & & 1 & & 3 & 8 \\
\hline 486 & & 1 & & 9 & & & & & & & & & & & & & & & & & 10 \\
\hline 489 & & 1 & & & & & 1 & & & & & & & & & & & & & 2 & 4 \\
\hline 490 & & & & 3 & & & 1 & & & & & & & & & & & 2 & & & 6 \\
\hline 491 & & & & & & & & & & & & & & & & & & & & 2 & 2 \\
\hline 492 & & 2 & & 1 & & & & & & 1 & & & & & & & & & & 1 & 5 \\
\hline 495 & & & & & & & 1 & & & & & & & & & & & 1 & & 2 & 4 \\
\hline 498 & & & & & & & & & & 3 & & & & & & & & & & & 3 \\
\hline 499 & & & & & & & 3 & & & 1 & & & & 2 & 1 & & & 5 & & & 12 \\
\hline 500 & & & & & & & 7 & & 1 & 3 & 2 & & 3 & 7 & 1 & 1 & 3 & 14 & & 15 & 57 \\
\hline 503 & & & & & & & 2 & & & & & & & & & & & 1 & & & 3 \\
\hline 504 & & & & & & & & 2 & & & & & & & & & & & & & 2 \\
\hline 506 & & & 1 & & 1 & & 8 & & & 2 & 2 & & & 1 & & & & 2 & & & 17 \\
\hline 507 & & & & & & & 2 & & & 1 & 1 & & & 3 & 2 & & 1 & 2 & & 3 & 15 \\
\hline 508 & & & & & & & 1 & & & & & & & & & & & 1 & & & 2 \\
\hline 509 & & 1 & & & & & 7 & & & & & & 3 & 1 & & & & 4 & & & 16 \\
\hline 510 & & & & 13 & & & & & & & & & & & & & & 1 & & & 14 \\
\hline$\underline{511}$ & 1 & & & & & & & & & 2 & & & & & & & & & & & 3 \\
\hline 512 & 1 & & & & & & & & & & & & & & & & & 1 & & & 2 \\
\hline
\end{tabular}




\section{Dated Phases}

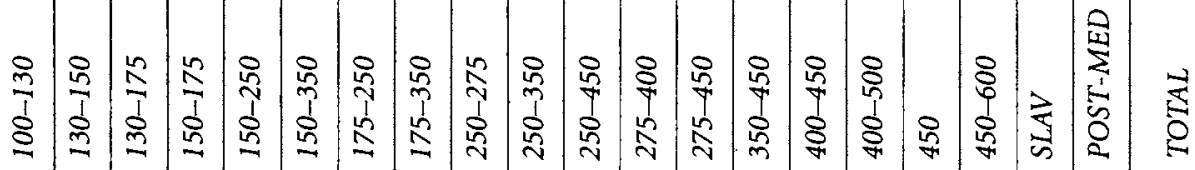

513

515

516

517

518

519

523

524

525

526

528

529

530

532

533

\begin{tabular}{l|l}
534 & 5
\end{tabular}

535

536

537

540

541

544

545

\begin{tabular}{|l|l|l}
\hline 547 & 3 & 24 \\
\hline
\end{tabular}

\begin{tabular}{r|r|r}
\hline 548 & 9 & 8 \\
\hline
\end{tabular}

549

551

552

553

555

556

557

558

564

565

566

567

568

569

576

577

578

579

581

583

584

586

\begin{tabular}{l|l|l|l|l|l|l|l|l} 
& & & & & & & & 2 \\
\hline 1 & 1 & & & & & & 2 & 4 \\
\hline
\end{tabular}

\begin{tabular}{r|r|r|r|r|r|r|r|r}
\hline 2 & & & & & 2 & & 1 & 5 \\
\hline
\end{tabular}

\begin{tabular}{r|r|r|r|r|r|r|r|r|r|r|r|r|r|r}
2 & 3 & & & & & 2 & & & & & & 1 & 10 \\
\hline 15 & & & 8 & & & & 4 & 1 & 1 & 3 & 3 & & 3 & 39 \\
\hline
\end{tabular}

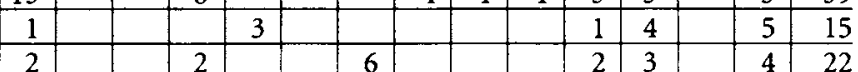

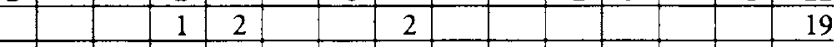

\begin{tabular}{|l|l|l|l|l|r|r|r|r|r|r|r|r|r}
15 & & & 3 & 4 & & 11 & 2 & & 5 & 12 & & 6 & 58 \\
\hline
\end{tabular}

\begin{tabular}{|l|l|l|l|l|l|l|l|l|l|l|l|l|l|l|l|l|l|l|r|r|r|r|}
4 & 17 & 1 & & & & 9 & 1 & & 3 & 3 & & 24 & 10 & & & & 15 & 28 & & 115 \\
\hline
\end{tabular}

\begin{tabular}{r|r|rrr|r|r|r|r|r|r|r|r|r|r}
9 & 1 & & 3 & 3 & & 24 & 10 & & & & 15 & 28 & & 115 \\
\hline & & & 2 & 1 & & & & & & 1 & & & 3 & 7 \\
\hline
\end{tabular}

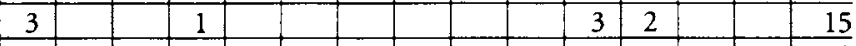

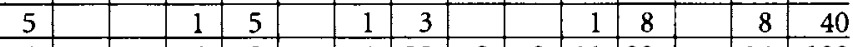

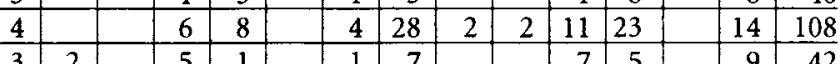

\begin{tabular}{l|l|l|l|l|l|l|l|l|l|l|l|l|l|l}
9 & 1 & 1 & & & 7 & & & 5 & & 9 & 42 \\
\hline
\end{tabular}

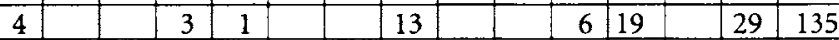

\begin{tabular}{|r|r|r|r|r|l|l|r|r|l|r|r|l|l|r|r|r|r|r|}
59 & 1 & 1 & & 4 & & & 3 & 1 & & & 13 & & & 6 & 19 & & 29 & 135 \\
\hline
\end{tabular}

\begin{tabular}{|l|l|l|l|l|l|l|l|l|l|l|l|l|l|l|l|l|r|r}
\hline & & 1 & & & & & & 2 & & & & & & 1 & 1 & & 3 & 8 \\
\hline
\end{tabular}

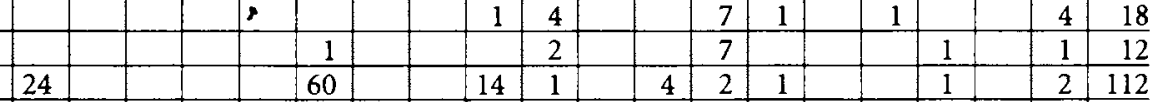

\begin{tabular}{rl|l|l|l|l|r|r|r|r|r|r|r|r|r|r|r|r|r|}
\hline 8 & & & & & & 1 & & & 1 & & & & 1 & 1 & & & 21 \\
\hline
\end{tabular}

\begin{tabular}{|r|r|l|l|l|l|l|l|l|l|l|l|l|l|l|l|l|l|l|l}
12 & 1 & & & & 1 & & & 3 & & & 3 & 1 & & & & 1 & & & 22 \\
\hline 1 & & & & & 4 & & & 4 & 1 & 1 & 1 & 4 & & & 1 & 11 & & 4 & 32 \\
\hline
\end{tabular}

\begin{tabular}{|l|l|l|l|l|l|l|l|l|l|l|l|l|l|l|l|l|l|r} 
\\
\hline
\end{tabular}

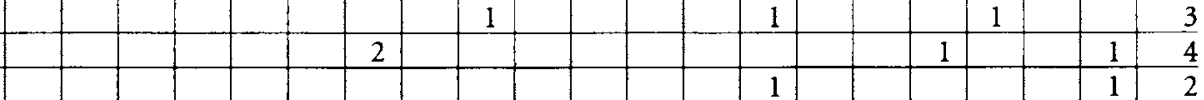

\begin{tabular}{|l|l|l|l|l|l|l|l|l|l|l|l|l|l|l|l|l|l|l|} 
& 1 & & & \\
\hline
\end{tabular}

\begin{tabular}{|l|l|l|l|l|l|l|l|l|l|l|l|l|l|l|l|l|l|r|r} 
& & & & & & & & & 1 & & & & 1 & & & & & & 2 \\
\hline
\end{tabular}

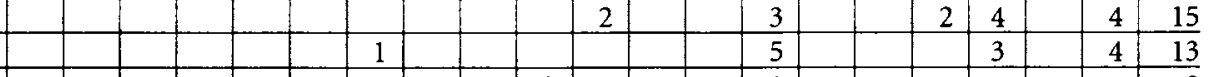

\begin{tabular}{|l|l|l|l|l|l|l|l|l|l|l|l|l|l|l|r|r} 
& \\
\hline
\end{tabular}

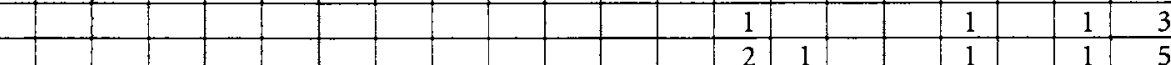

\begin{tabular}{rl|l|l|l|l|l|l|l|l|l|l|l|l|l|l|l|l|l|r|r} 
\\
\hline
\end{tabular}

\begin{tabular}{|l|l|l|l|l|l|l|l|l|l|l|l|l|l|l|l|l|l|l|r|r|r|r|r|r|r|}
\hline \\
\hline
\end{tabular}

\begin{tabular}{ll|l|l|l|l|l|l|l|l|l|l|l|l|l|l|l|l|}
\hline & \\
\hline
\end{tabular} 


\section{Dated Phases}

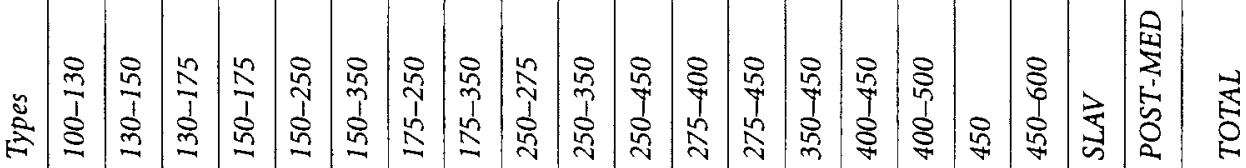

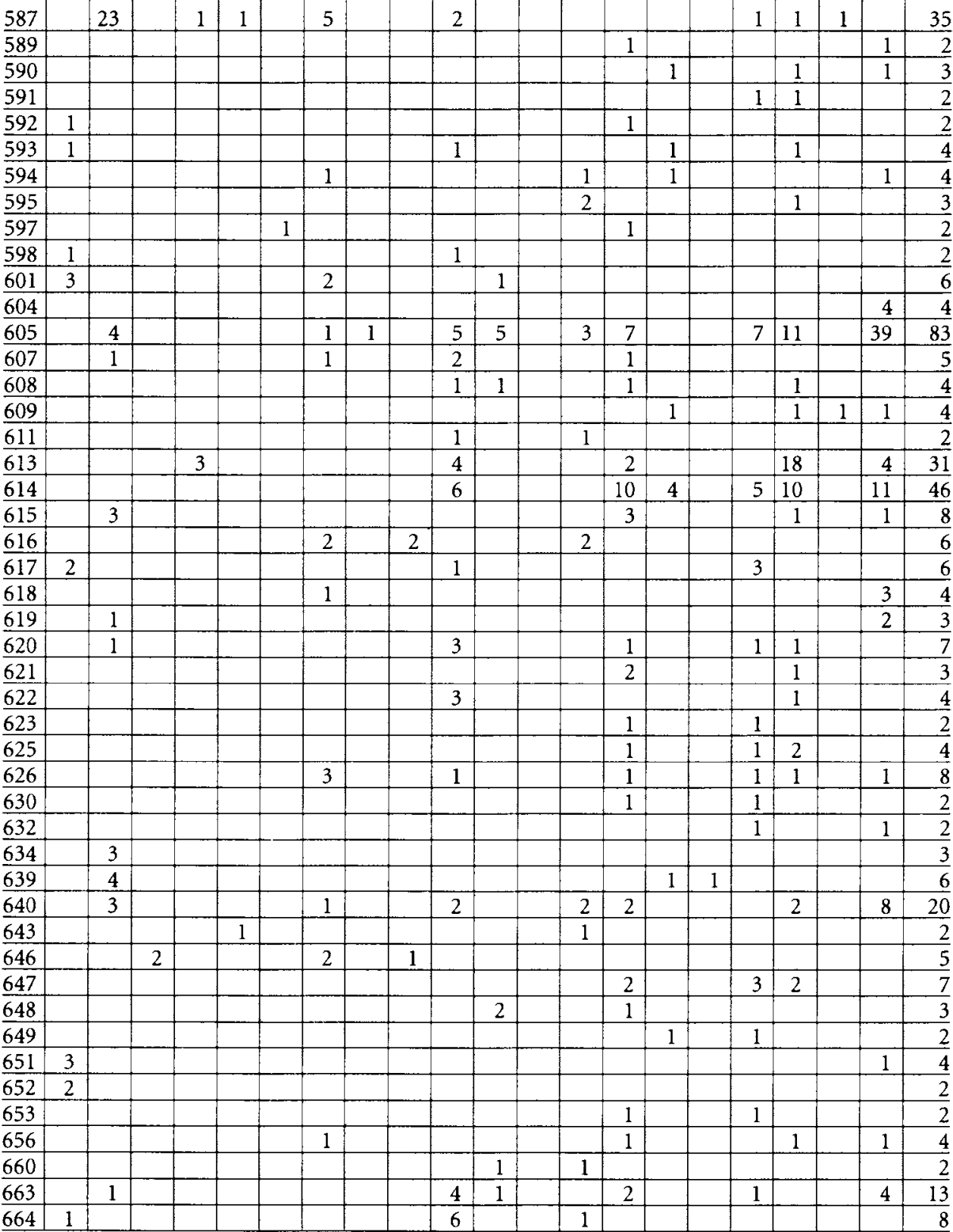




\section{Dated Phases}

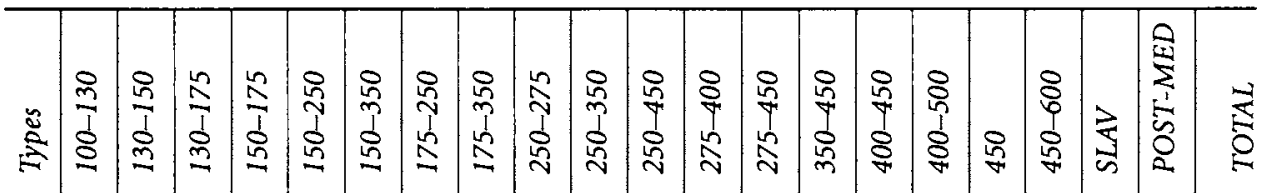

665

668

4

670

671

672

$\frac{673}{674}$

$\frac{674}{675}$

676

678

682

684

685

686

687

688

689

690

692

694

697

698

70

702

704

$\frac{707}{708}$

708

$\frac{709}{710}$

711

712

$\frac{713}{71}$

714

$\frac{715}{716}$

718

719

723

724

725

728

732

733

734

735

736

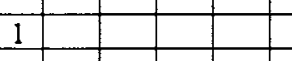

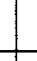

$$
\begin{array}{ll|l|l|l|l|l|l|l|l|l} 
& & & & 1 & & & & & & 5 \\
\hline
\end{array}
$$

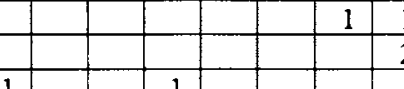

1

2

2

7

2

\begin{tabular}{|l|l|l|l|l|l|l|l|l|}
\hline & & & & 1 & & 1 & 2 \\
\hline & & & & & & 1 & 5 \\
\hline
\end{tabular}

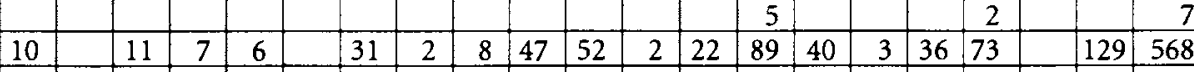

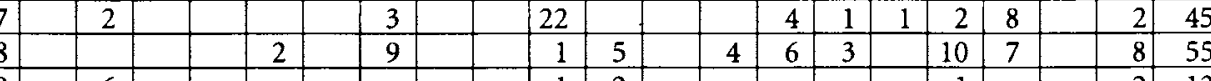

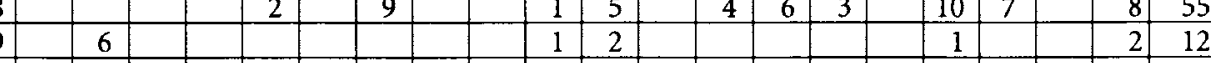

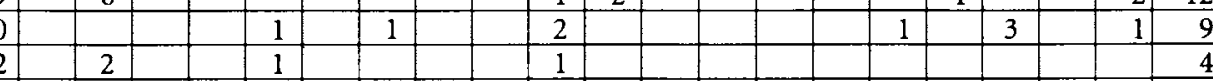

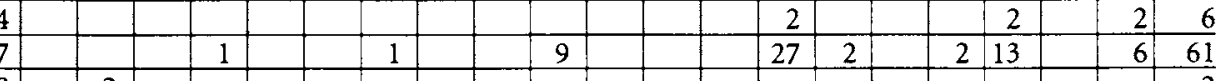

\begin{tabular}{|l|l|l|lllllllll|l|l|l|l|l|l|l|l|l}
2 & & & & & & & & & & & & & & & & & & 2 \\
\hline
\end{tabular}

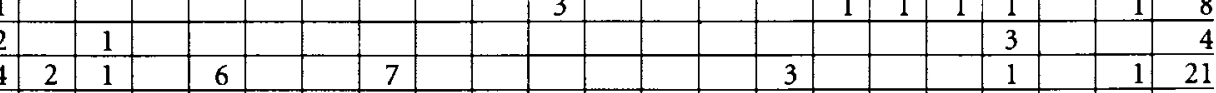

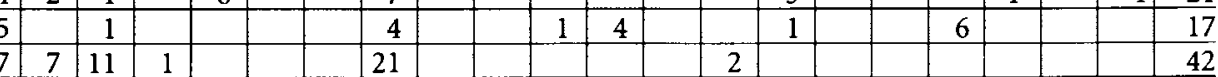

\begin{tabular}{|c|c|c|c|c|c|c|c|c|c|c|c|c|c|c|c|}
\hline & & & & & 42 \\
\hline
\end{tabular}

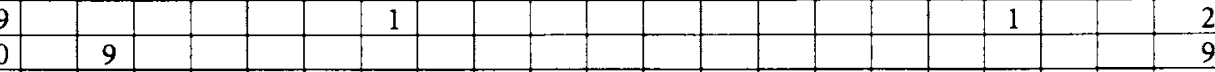

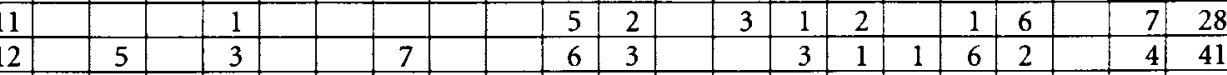

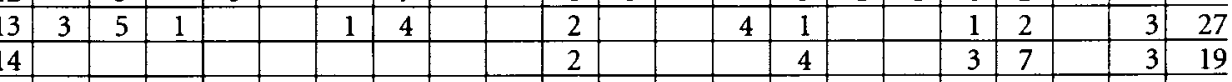

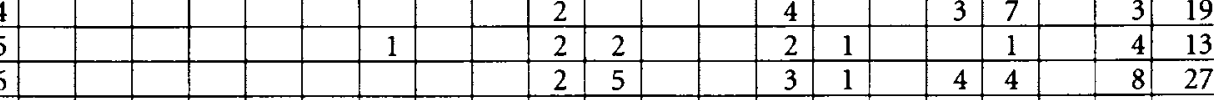

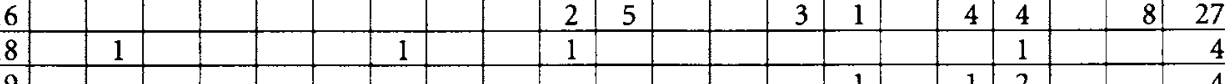

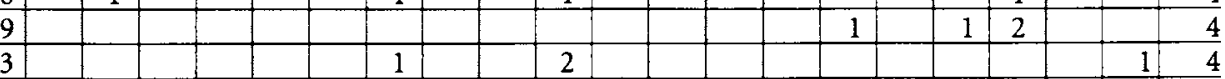

\begin{tabular}{l|l|l|l|l|l|l|l|l|l|l|l|l|l|l|l|l|l|l|r|r}
24 & 1 & & 1 & & & & & & & & & & & & & & & & & 2 \\
\hline
\end{tabular}

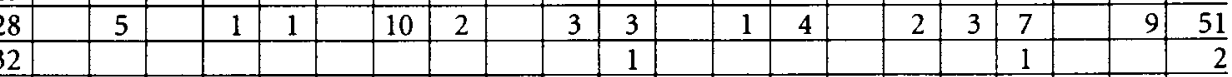

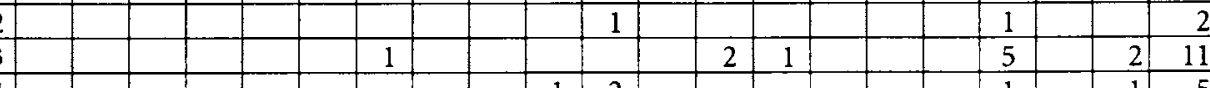

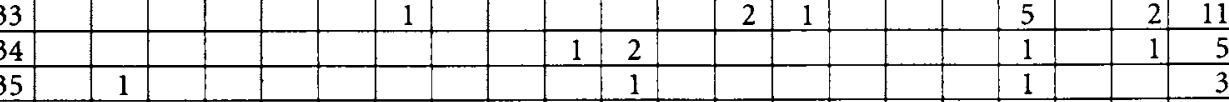




\section{Dated Phases}

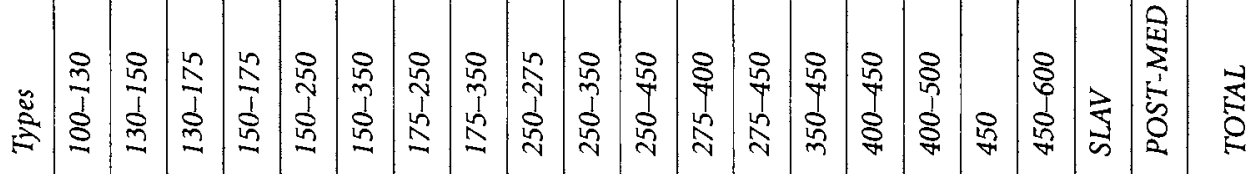
\begin{tabular}{l|l}
739 & 1 \\
\hline 740 &
\end{tabular} 1

741

742

745

\begin{tabular}{l|l|l|}
\hline 746 & 1 \\
\hline 748 & & \\
\hline
\end{tabular}

748

749

750

751

753

756

758

761

\begin{tabular}{l|l|l|}
762 & 1 & 5 \\
\hline 764 & 4 & 5
\end{tabular}

\begin{tabular}{r|r|r|r}
\hline 764 & 4 & 5 & 1
\end{tabular}

\begin{tabular}{r|r|r}
\hline 766 & & 3 \\
\hline 767 & 6 & 18
\end{tabular}

\begin{tabular}{l|l|l|}
\hline 768 & 1 & \\
\hline
\end{tabular}

\begin{tabular}{l|l|l|}
\hline 769 & & 2 \\
\hline 770 & 1 & 9
\end{tabular}

\begin{tabular}{l|l|l|}
\hline 770 & 1 & 9 \\
\hline
\end{tabular}

771

772

774

775

776

777

779

780

783

784

786

794

796

797

799

802

803

804

805

807

809

812

813

815

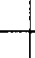

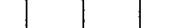




\section{Dated Phases}

\begin{tabular}{|c|c|c|c|c|c|c|c|c|c|c|c|c|c|c|c|c|c|c|c|c|c|}
\hline 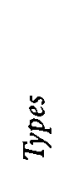 & $\begin{array}{l}8 \\
\frac{1}{1} \\
8 \\
0\end{array}$ & $\begin{array}{l}\frac{8}{5} \\
\frac{1}{2} \\
\frac{7}{2}\end{array}$ & $\frac{n}{2}$ & $\frac{n}{\stackrel{n}{b}}$ & 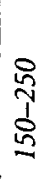 & $\begin{array}{l}8 \\
\frac{b}{b} \\
0\end{array}$ & $\mid \begin{array}{l}8 \\
5 \\
b \\
5 \\
-1\end{array}$ & $\mid \begin{array}{c}0 \\
n \\
b \\
n \\
\end{array}$ & 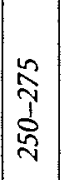 & $\left|\begin{array}{l}0 \\
n \\
\hat{b} \\
0 \\
n\end{array}\right|$ & $\begin{array}{l}0 \\
7 \\
0 \\
0 \\
2\end{array} \mid$ & 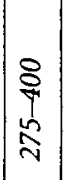 & $\begin{array}{l}8 \\
5 \\
n \\
2 \\
2\end{array}$ & $\left|\begin{array}{l}8 \\
7 \\
7 \\
0 \\
m\end{array}\right|$ & $\begin{array}{l}8 \\
7 \\
8 \\
8\end{array}$ & $\begin{array}{l}8 \\
8 \\
1 \\
8 \\
0\end{array}$ & $\frac{8}{7}$ & $\begin{array}{l}8 \\
8 \\
0 \\
0 \\
7\end{array}$ & $\vec{s}$ & 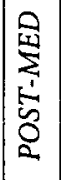 & $\underset{R}{\stackrel{4}{s}}$ \\
\hline$\underline{818}$ & & & & & & & & & & & & & & & & & 1 & 2 & & 1 & 4 \\
\hline 820 & & & & & & & & & & & & & & & & & 1 & & & 1 & 2 \\
\hline 821 & & 4 & & & & & 2 & & & & & & & & & & & & & & 6 \\
\hline 825 & & & & & & & & & & & & & 1 & & & & 1 & & & & 2 \\
\hline 826 & & 1 & & 1 & & & 3 & & & & & & & 4 & & & & & & & 9 \\
\hline 827 & & & & & & & 1 & & & & & & & & & & & 1 & & & 2 \\
\hline 828 & & & & & & & & & & & & & & & & & & & & 2 & 2 \\
\hline 829 & & & & 1 & & & & & & 1 & & & & & & & & & & & 2 \\
\hline 830 & & & & & & & & & & & 1 & & & & 1 & & & & & 2 & 4 \\
\hline 831 & & & & & & & & & & & 2 & & & 2 & & & & 1 & & 2 & 7 \\
\hline 832 & & & & & & & 1 & & & & & & & & & & & & & 1 & 2 \\
\hline 834 & & & & & & & & & & & & & & & & & 1 & 4 & & & 5 \\
\hline 835 & 2 & 1 & & & & & & & & & & & & & & & & & & 1 & 4 \\
\hline 837 & & & & & & & & & & & & & & 1 & & & & & & 1 & 2 \\
\hline 842 & & & & & & & & & & & & & & & 1 & & 3 & & & 2 & 6 \\
\hline 843 & & & & & & & & & & & & & 1 & & & & 1 & & & 2 & 4 \\
\hline 846 & & & & & & & & & & & & & & 1 & & & & & & 1 & 2 \\
\hline 847 & & & & & & & & & & 1 & & & & & & & & & & 1 & 2 \\
\hline 848 & & & & & & & & & & & & & & & & & & 1 & & 1 & 2 \\
\hline$\underline{851}$ & & & & & & & & & & & & & & & & 1 & 1 & & & & 2 \\
\hline 854 & & & & & & & & & & & & & & & & & 2 & & & & 2 \\
\hline 859 & 2 & 2 & & & & & & & & 1 & & & & & & & & & & & 5 \\
\hline 860 & & & & & & & & & & & & & & 1 & & & & & & 1 & 2 \\
\hline 861 & 2 & & & & & & & & & & & & & & & & & & & & 2 \\
\hline 868 & & & & & & & & & & & & & & & & & 1 & & & 1 & 2 \\
\hline 872 & & & & 1 & & & & & & & & & & & & & & & & 1 & 2 \\
\hline 877 & & & & & & & & & & 1 & & & & & & & 1 & 2 & & & 4 \\
\hline 878 & 1 & 19 & & & 1 & & 9 & 1 & & 6 & & 1 & 3 & 7 & 3 & & 2 & 12 & & 6 & 71 \\
\hline 882 & & 1 & & & & & & & & & & & & & 1 & & & & & 1 & 3 \\
\hline 883 & & & & & & & & & & & & & 1 & 2 & & & & & & 3 & 6 \\
\hline 885 & \begin{tabular}{|l|}
16 \\
\end{tabular} & 11 & 5 & 15 & 5 & & 34 & 2 & & \begin{tabular}{|l|}
28 \\
\end{tabular} & 16 & 1 & 24 & 25 & 17 & 9 & 37 & 53 & 1 & \begin{tabular}{|l|}
61 \\
\end{tabular} & 360 \\
\hline 886 & 1 & 2. & & & & & 4 & & & 2 & & & 2 & 4 & & & & 3 & & 1 & 19 \\
\hline 887 & & 4 & 4 & & & & 14 & & 7 & 8 & 8 & & 8 & 17 & 4 & 1 & 5 & 24 & & 23 & 127 \\
\hline 888 & & 4 & & & & & 18 & 12 & 1 & 10 & 7 & & 1 & 7 & 1 & & 3 & 4 & & 6 & 74 \\
\hline 889 & & & & & & & 1 & & & & 1 & & & 2 & & & & 4 & & 1 & 9 \\
\hline 891 & & & & & & & & & & & & & 1 & & & & & & & 1 & 2 \\
\hline 894 & & & & & & & & & & & & & & 1 & & & 1 & 2 & & 5 & 9 \\
\hline 897 & 3 & & & 4 & & & & & & & & & & 1 & & & & & & & 8 \\
\hline 899 & & 1 & & & & & & & & & & & & & & & & & & 2 & 3 \\
\hline 902 & & & & 1 & & & & & & 4 & 1 & & & 1 & 1 & 2 & 1 & 1 & & 2 & 14 \\
\hline 903 & & I & & 1 & & & & & & 2 & & & & & & & & 2 & & 2 & 8 \\
\hline 908 & & 4 & & & & & & & & & & & & & & & & & & & 4 \\
\hline 909 & & & & & & & & & & & & & & & & & & 1 & & 1 & 2 \\
\hline 910 & & & & & & & & & & 1 & 3 & & & & & & 1 & 1 & & 1 & 7 \\
\hline 913 & 2 & 1 & & & & & 5 & & & & 1 & & & 4 & 2 & & 4 & 9 & & & 28 \\
\hline 914 & & & & & & & 2 & & & & & & & & & & & & & & 2 \\
\hline 915 & & & & & 1 & & 2 & & & 1 & & & 3 & & 1 & & & 1 & & & 9 \\
\hline
\end{tabular}




\section{Dated Phases}

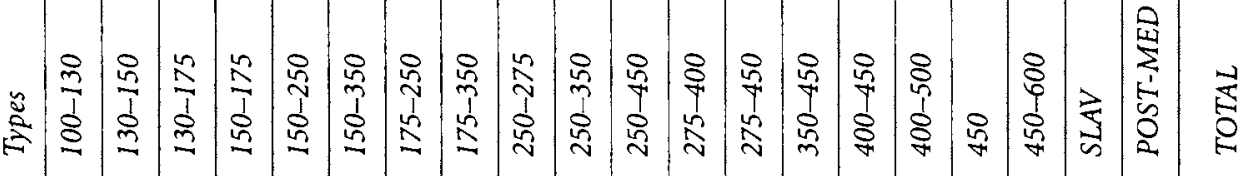

\begin{tabular}{|c|c|c|c|c|c|c|c|c|c|c|c|c|c|c|c|c|c|c|c|c|}
\hline 916 & & 1 & & & & & 1 & & & 1 & & & & & & & & & & \\
\hline 917 & & & & & & & 1 & & & & & & & & 1 & & & & & 2 \\
\hline 918 & 1 & 1 & & 1 & & & & & & 2 & & & 10 & 6 & & & 5 & 6 & 16 & 48 \\
\hline 919 & & & & & & & 1 & & & 3 & 13 & & & 7 & 4 & & 3 & 12 & 10 & 53 \\
\hline 936 & & & & & 1 & & & & & 2 & & & & & & & & & & 3 \\
\hline 937 & & & & & & & 2 & & & 1 & 1 & & & 4 & & & & 2 & 2 & 12 \\
\hline 939 & & & & & 1 & & & & & 1 & & & & & 1 & & & & & $\underline{3}$ \\
\hline 940 & & & & & 2 & & 1 & & & & & & 1 & 1 & & & & & & 5 \\
\hline 941 & & & & & & & 2 & & & & & & & 1 & & & & 3 & 1 & 7 \\
\hline 942 & & 2 & & & & & 1 & & & & & & & & & & 1 & & & 4 \\
\hline 943 & & & & & & & 1 & & & & & & & 2 & & & & & & 3 \\
\hline 944 & & & & & & & & & & 1 & & & & & & 1 & & & & 2 \\
\hline 946 & & & & & & & 1 & & & & & & & & & & 1 & 2 & 2 & 6 \\
\hline 948 & & & & & 1 & & & & & & 1 & & & 2 & 1 & & & 2 & 3 & 10 \\
\hline 949 & & & & & & & 1 & & & & 1 & & & & - & & & 1 & 1 & 4 \\
\hline 950 & & & & & & & & & & & & & 1 & 1 & & & & & & 2 \\
\hline 954 & & & & & & & 1 & & & 1 & & & & & 1 & & & 1 & & 4 \\
\hline 955 & & 1 & & & & & 7 & 1 & & 1 & 1 & & & 3 & & & & 1 & 1 & 16 \\
\hline 956 & & & & & 1 & & & & & & & 1 & & & & & & 1 & & 3 \\
\hline 957 & & 1 & & 2 & & & . & & & . & & & & 1 & & & & 1 & & 5 \\
\hline 958 & & & & 2 & & & 3 & & & 1 & 3 & & & 1 & 1 & & & 4 & 4 & 19 \\
\hline 959 & & & & & & & 2 & & & & & & 1 & & & & & & & 3 \\
\hline 960 & & 2 & & & & & & & & & & & & & & & & & & 2 \\
\hline 961 & & & & . & & & & & & & & & & 1 & & & & & 1 & 2 \\
\hline 970 & & & & & & & 2 & & & 1 & & & & & & & & & 1 & 4 \\
\hline 972 & & & & 1 & & & & & & & & & & & & & & 1 & & 2 \\
\hline 973 & & & & & & & & & & 1 & & & & & & & 1 & & & 2 \\
\hline 974 & & & & & & & & & & & & & & & & & & & 2 & 2 \\
\hline 977 & & & & & & & & & & & & & & & 2 & & & & 2 & 4 \\
\hline 978 & & 1 & 1 & & & & 1 & & & 1 & & & & & & & & & 1 & 2 \\
\hline 980 & & 2 & & 1 & & & 2 & & & 3 & 2 & & 2 & & & & 2 & 3 & 5 & 22 \\
\hline 983 & & & & & & & & & & 3 & & & & & & & 1 & & & 4 \\
\hline 984 & & & & & & & 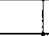 & & & & & & & 2 & & & 1 & & 2 & 5 \\
\hline 987 & & & & & & & & & & & 1 & & & 4 & & & & & & 5 \\
\hline 988 & & & & & & & & & & 2 & & & & & & & & & & 2 \\
\hline 990 & & & & & & & & & & & & & & & & & 1 & 1 & & 2 \\
\hline 991 & & & & & & & 2 & & & & & & & & & & & & & 2 \\
\hline 992 & & 1 & & & & & & & 1 & & & & 3 & & & & & & & 5 \\
\hline 994 & & & & & & & & & & 1 & & & & & & & & & 1 & 2 \\
\hline 1000 & & 5 & & & & & & & & & & & & & & & & & & 5 \\
\hline 1002 & & & & 1 & & & 2 & & & & & & & & & & & & & 3 \\
\hline 1005 & & & & & & & 4 & & & & & & & & & & & & 1 & 5 \\
\hline 1006 & & & & & & & & & & 1 & 2 & & & & & & & & & 3 \\
\hline 1007 & & 1 & & & & & & & & 1 & & & & & & & & & & 2 \\
\hline 1008 & & & & & & & & & & & & & & & & & & 2 & 1 & 3 \\
\hline 1016 & & & & & & & & & & & & & & & & & & 2 & & 2 \\
\hline & & & & & & & & & & & & & & & & & & & & \\
\hline
\end{tabular}




\section{Dated Phases}

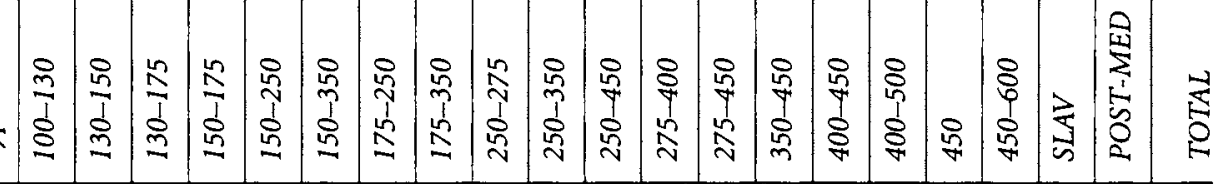

1019

1020

1022

1029

1030

1040

1042

1045

1047

1048

1050

1051

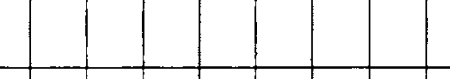

1

1052

1056

1057

1058

1059

1060 1.

1

\begin{tabular}{ll|l|l|l|l|l} 
& & & & 3 & 4 \\
\hline & & 1 & 2 & & & 3 \\
\hline 1 & & & & 1 & 2
\end{tabular}

106

1066

1069

1070

1074

1075

1076

1090

1091

1093

1099 \begin{tabular}{ll|l|l|l|l|l|l|l|l|}
\hline & & & & & & \\
\hline
\end{tabular} \begin{tabular}{l|l|l|l} 
& 1 & & \\
1 & & & 1 \\
\hline
\end{tabular}

\begin{tabular}{llllllll|l|l|l|l}
\hline & & & & & & & & & 2 & 2 \\
\hline
\end{tabular}

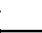

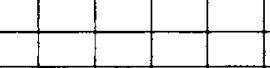

\begin{tabular}{rr|r|r|r|r|r|r|r}
\hline & & 1 & 1 & & 2 & & 1 & 5 \\
\hline & & & & & & & 2 & 2 \\
\hline & & & & 1 & & & 1 & 2 \\
& 1 & & & 1 & & & 3 & 5 \\
& 1 & & & 1 & 2 & & 10 & 22 \\
\hline & 1 & 1 & & & 1 & & 6 & 12 \\
\hline
\end{tabular}

1102

1119

1125

1132

1137

1140

1164

1180

1181

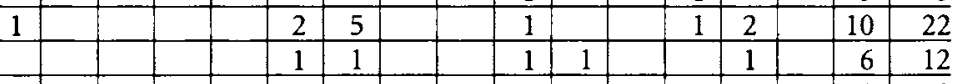

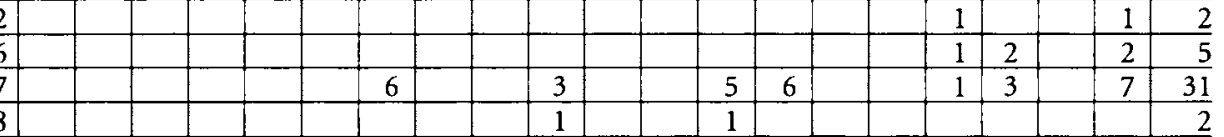

\begin{tabular}{|l|l|l|l|l|l|l|l|l|l|l|l|l|l|l|l|l|l} 
\\
\hline
\end{tabular}

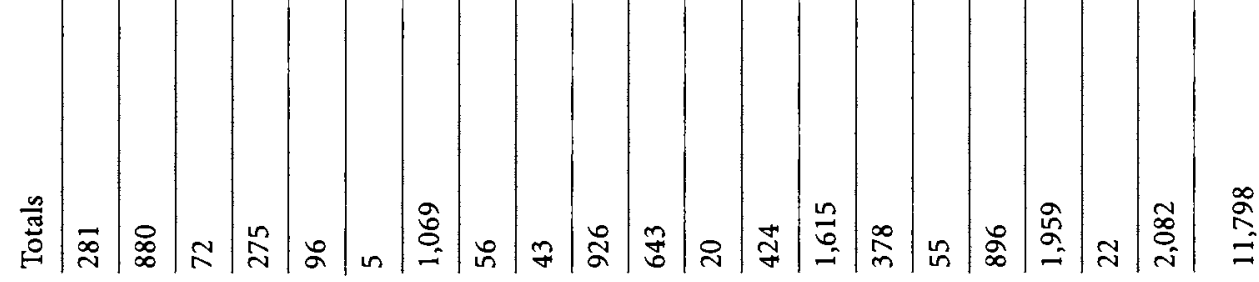




\section{Appendix 3: Relative frequency of wares (total body sherds) by dated phase}

\section{Dated Phases}

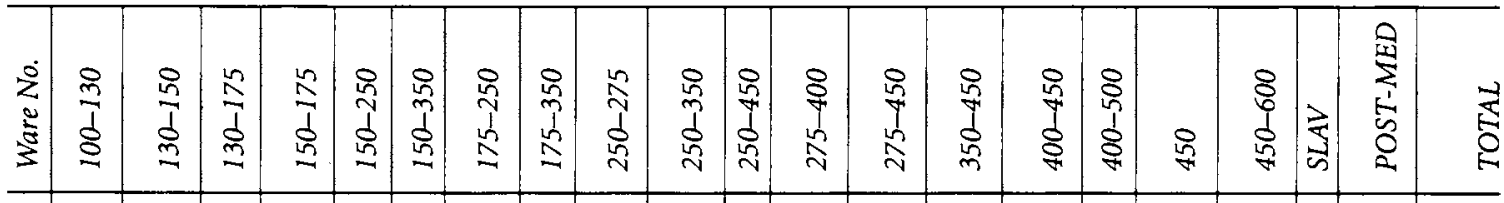

\begin{tabular}{llllllllllllllll|l|l|l|l|l|l|l}
1 & 110 & 1,959 & 151 & 1,239 & 153 & 35 & 2,393 & 164 & 455 & 3,003 & 16 & 1,025 & 1,244 & 946 & 1,648 & 86 & 3,880 & 7,979 & 43 & 5,505 & 32,034 \\
\hline
\end{tabular} \begin{tabular}{l|r|r|r|r|r|r|r|r|r|r|r|r|r|r|r|r|r|r|r|r|r|r|r|}
\hline 4 & 393 & 605 & 89 & 120 & 59 & & 126 & 78 & 482 & 523 & & 612 & 234 & 53 & 62 & 6 & 812 & 2,455 & 6 & 2,227 & 8,942 \\
\hline
\end{tabular}

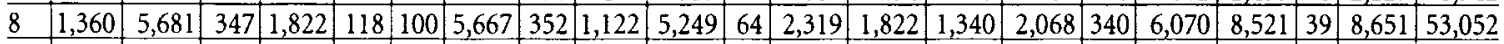

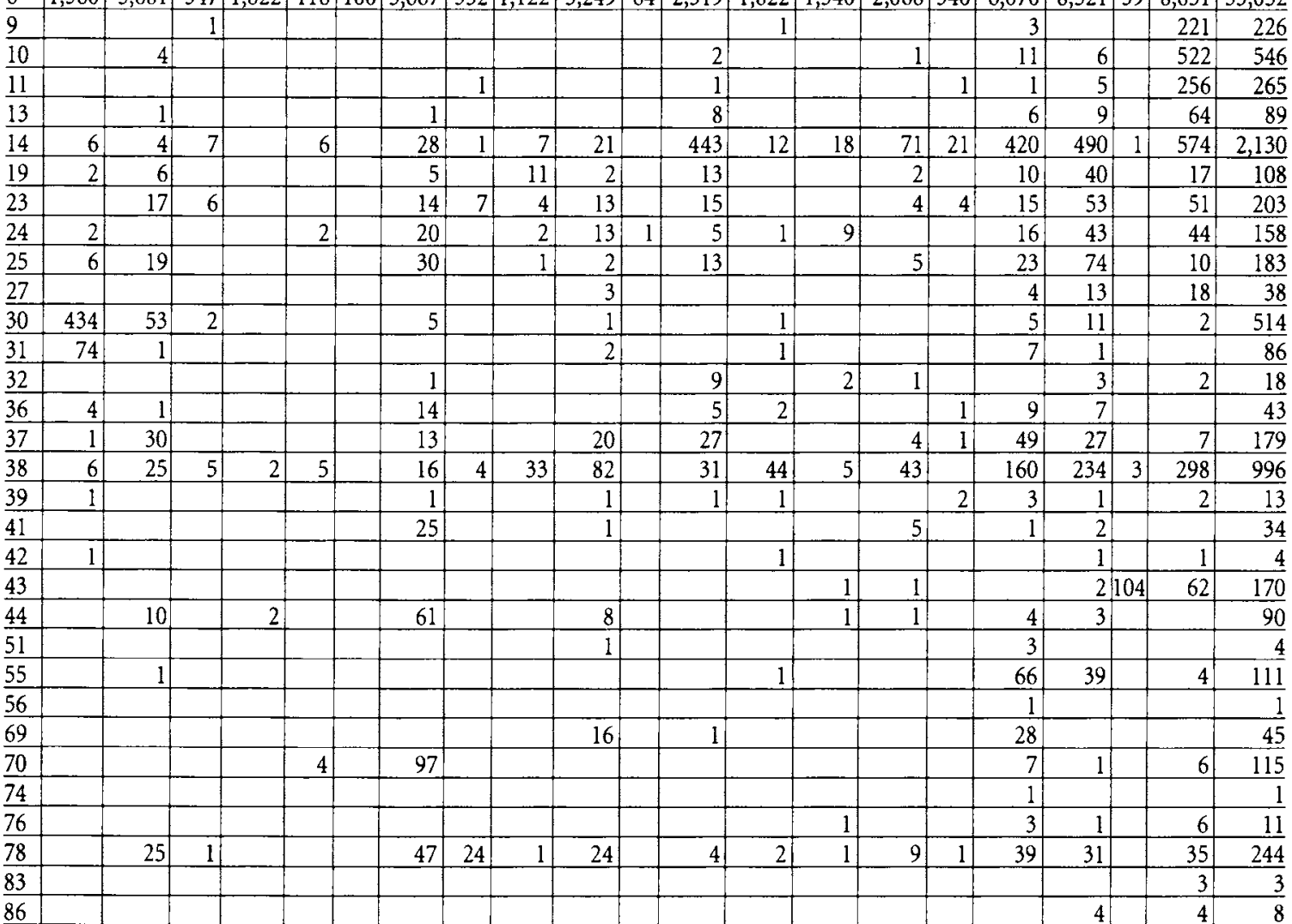




\section{Dated Phases}

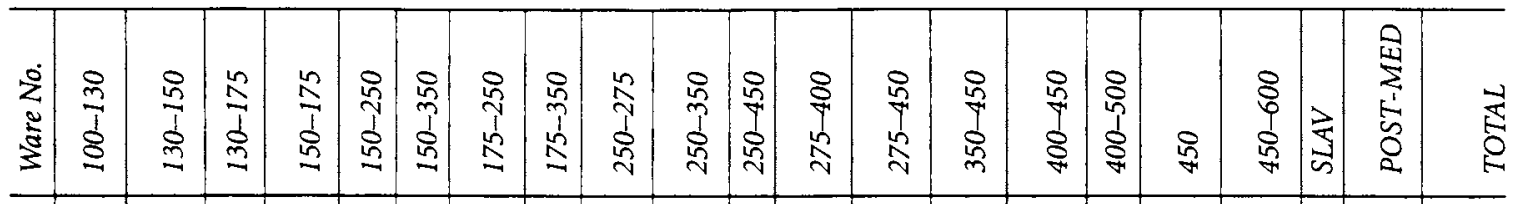

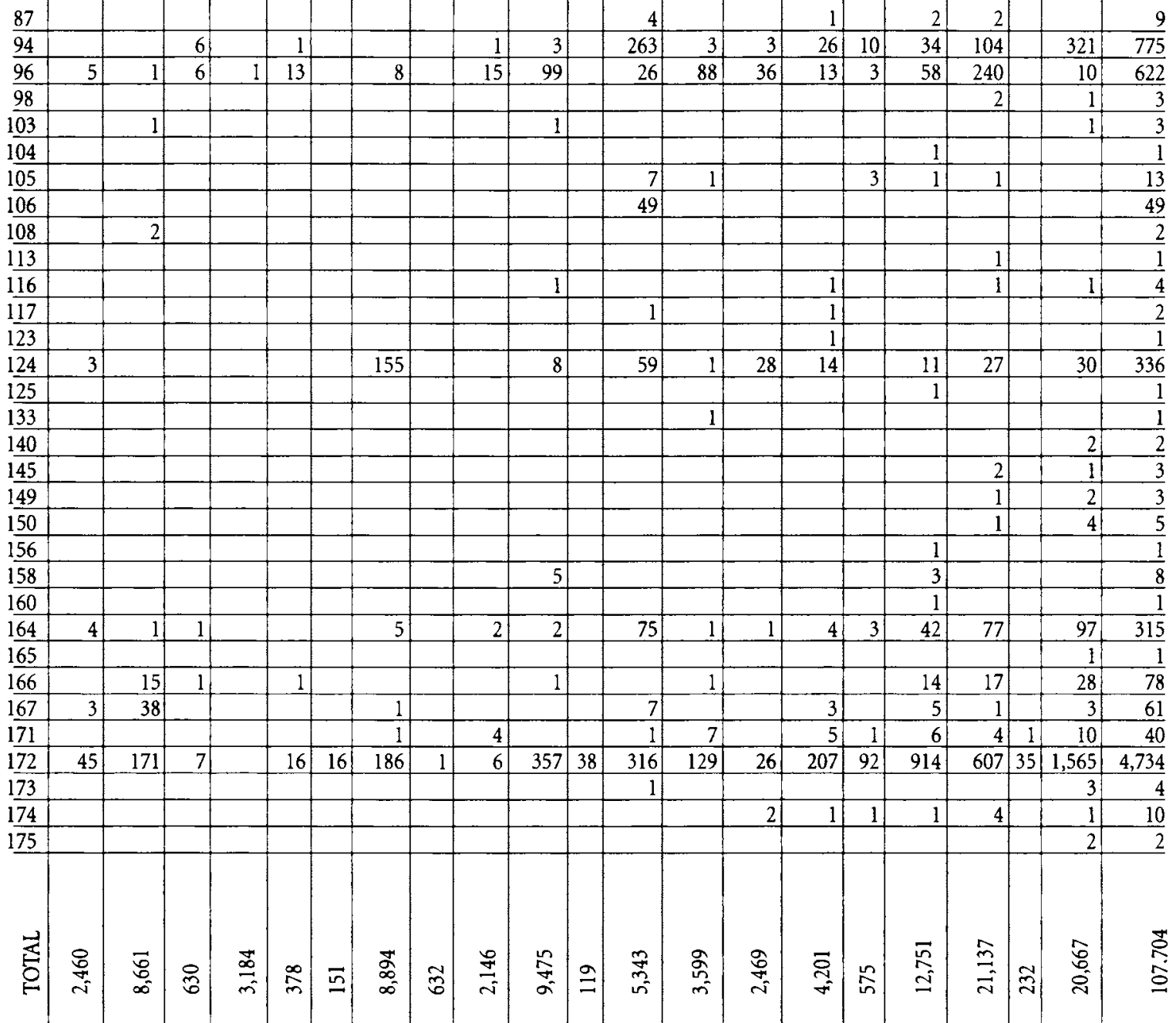




\section{SECTION THREE}

\section{The glass}

J.D. Shepherd 



\section{The glass: methodology and site assemblages}

\section{Preface}

The total glass assemblage from Nicopolis includes a wide range of vessel types dating from the mid first century to the sixth or seventh centuries. To produce a detailed study of every type and form would result in a survey of inordinate length. Here, the catalogue and illustrations are intended to allow the reader to locate parallels for particular forms and types and to make use of the internal dating evidence from the site. For those who wish to gain access to more detailed information, the glass archive can be consulted.' The catalogue discussion should be regarded as complementary notes, giving an indication of external evidence for the incidence and date of certain individual vessel types. This allows the glass to be placed in a wider context but this is not intended to be exhaustive. Furthermore, no rigorous attempt has been made to quantify the material. ${ }^{2}$ Discussion of the glass in relation to other finds and the site is covered elsewhere in this volume. ${ }^{3}$

\section{Introduction}

The site produced a total of 7,299 fragments of glass. Of this overall site total, 1,469 are fragments of window glass (20.12 per cent), 5,107 are indeterminate vessel fragments, which cannot be assigned to any particular form (69.96 per cent), and 723 come from identifiable vessels or the identifiable parts of vessels (9.90 per cent). Objects such as glass-working debris, beads and counters are not included in these totals. ${ }^{4}$

During the earliest seasons of excavation, every piece of glass was treated as a small-find. Each fragment was individually recorded and received three-dimensional coordinates. It was hoped that the distribution of finds across the site might show functional variation between areas and, in the case of window glass, it was considered 
possible that this might help in the architectural reconstruction of individual buildings.

This method was subsequently suspended for the following reasons:

1. The fragmentary nature of the glass.

2. The high proportions of finds which were clearly residual.

3. The failure of the distribution plot of glass fragments from the Large Basilica to produce any positive results, despite the fact that this appeared to present the best chance of relating the distribution of glass to a building's layout. ${ }^{5}$

4. The sheer number of fragments recovered and the inordinate amount of time required to record them.

Considering that a single context system was employed, it seemed justifiable to suspend detailed small-finding of every glass fragment but to record the glass by bulk for each context (as was the case for pottery and animal bone). However, the recording of notable fragments as individual small-finds continued. For this reason, all of the glass fragments from the early seasons have small-find numbers, whereas only the most significant fragments from the later seasons were recorded in this manner. In the catalogue, small-find numbers, where they exist, have been included.

It has to be admitted that the failure of the three-dimensional recording on this site to produce results was a great disappointment, especially in area $\mathrm{F}$ where it was hoped that the large number of window-glass fragments, recovered from the floor of the church, might demonstrate concentrations which might help to reconstruct the appearance of the basilica: especially the position of windows and the parts of the church illuminated by lamps. This disappointment was compounded by the fact that many person hours had been spent in precisely recording the glass fragments. The decision to commence the detailed recording of the glass was worth attempting but it is evident that the usefulness of such a procedure should be constantly monitored so as to ensure that time is not wasted. With hindsight, it would have been better for the glass to have been bulk recorded from the start and detailed recording only carried out as and when circumstances appeared propitious. This, indeed, was the method employed for the greater part of the campaign following suspension of detailed recording.

The following report first examines the distribution of glass across the site by area. This is not intended to be a detailed quantification of the site assemblage as a whole. As described below, the quantification of glass fragments is a notoriously difficult exercise. However, the discussion is intended to highlight such general observations as can be made concerning the variations in the nature and quantity of vessel and window glass from area to area. The catalogue contains an entry for every identifiable vessel fragment from the site arranged by glass metal and vessel 
type for the two main periods: (i) the second to mid fifth century (occupation contemporary with the Roman and late Roman city), and (ii) mid fifth to late sixth century (when the early Byzantine defences were in use). Where a number of similar fragments form a clear group (e.g. standard fire-rounded rims or applied true base rings) a type example is described and other similar examples from that area are catalogued in a group entry below. Indeterminate body fragments are grouped in the archive according to metal colour but are not included in the published catalogue below. $^{6}$

\section{Glass survival}

The majority of the glass from Nicopolis is very fragmentary indeed. Not only are many of the fragments small but the late Roman and early Byzantine metals, which make up by far the greatest part of the entire site assemblage, have degraded quite considerably.

Glass metal colours can be grouped into three main categories:

1. Monochrome: where the intention was to colour the glass by the addition of specific oxides (e.g. deep blue, yellow, emerald green, etc.).

2. Colourless: where the aim was to decolourize the metal by the addition of specific oxides to neutralize iron oxide and other impurities present in the batch.

3. Naturally coloured: where little or no attempt has been made to neutralize the iron oxide in the batch, allowing a green or blue tint to colour the glass.

Naturally coloured metals are by far the most common (green, greenish colourless). Colourless metals are the next most popular. Very few monochrome metals were recorded and, when they were, they tend to have been used as decoration on colourless or naturally coloured vessels (as trails, nos 138-142, or flashing, nos 41-63, the diatretum fragments). As mentioned above, the majority of the glass from the site has weathered badly. The colourless fragments tended to have an opaque white, powdery surface decomposition layer, the naturally coloured metal an enamellike surface decomposition layer. It was not possible to carry out any scientific analysis but it is probable that this condition is due to a combination of metal compositions which are unstable over time and to the soil conditions on the site. The subsequent flaking of much of the surface decomposition layers on many fragments may have been caused by the change in environment following excavation. The thinness of the majority of the vessels, in combination with possibly unstable metals used and soil conditions which caused in situ weathering, contributed to the poor condition of the glass. Furthermore, these problems would have been compounded by 
trampling and redeposition in antiquity. In addition, the collection of glass for recycling could have further distorted the composition of assemblages and is another factor which cannot be overlooked when comparing the character and volume of material recovered from different areas.

Roman writers, such as Martial in his epigram on Caecilius ( $I, 41)$ and Statius (Silv. I, 6,74), imply that broken glass (cullet) was recycled in the Roman period. Both authors mention that people could scrape together a meagre living from collecting broken glass in exchange for other items (sulphur matches). Presumably they then sold this cullet to a nearby glasshouse for recycling. Of course, it is reasonable to presume that broken glass was only collected if it was available in places where it could be easily retrieved. On archaeological sites, it is rare to find complete or substantial portions of glass vessels in contexts other than the following:

(a) Drains, wells, rubbish pits or cess pits. In these circumstances, it was generally either physically impossible or undesirable to recover the glass once it had been lost or discarded.

(b) Graves or ritual deposits. In these cases, the desire to retrieve the glass for recycling would have involved desecration and no doubt occurred only rarely, given the small profit which came from selling glass for recycling.

(c) Sealed deposits following catastrophic events such as volcanic action, fire, earthquake etc. The best known of such sites are the Italian towns of Pompeii and Herculaneum. The collapse of a wall of the forum basilica at Cosa destroyed and sealed the contents of several rooms in an adjacent building which included a large glass assemblage (Grose 1973, 31-52). Following such disasters and 'minor catastrophes', it is reasonable to presume that the most valuable and salvageable material would have been recovered but that a substantial amount of glass would remain in situ. Such a situation may apply to the Large Basilica at Nicopolis which was destroyed by fire. ${ }^{7}$

Table 10.1 The total number of glass fragments expressed as percentages of the assemblage

\begin{tabular}{rrr}
\hline Area & Number of fragments & \% of site total \\
\hline A & 176 & 2.41 \\
B & 277 & 3.80 \\
C & 499 & 6.84 \\
D & 948 & 12.99 \\
E & 395 & 5.41 \\
F & 2,601 & 35.63 \\
K & 886 & 12.14 \\
M & 408 & 5.59 \\
P & 893 & 12.23 \\
R & 159 & 2.18 \\
S & 57 & 0.78 \\
\hline
\end{tabular}


It is interesting to note that, at Nicopolis, the best preserved glass vessels come from the drain in area $B$ (nos 66 and 119) and the most important vessel, the diatretum from area $\mathrm{P}$ (nos 41-63), was found in a dump deposit, probably comprising destruction material brought to the site from the late Roman city. ${ }^{8}$ In the first case, the vessels were most unlikely to have been retrieved and, in the second, the vessel was brought in, probably as part of a load of soil to level up the interior of the early Byzantine tower and was presumably either not noticed by the builders or was already broken.

\section{A breakdown of the site assemblage}

As mentioned above, a grand total of 7,299 fragments of glass was recovered from the eleven areas excavated by the British team. Table 10.1 shows the numbers of finds from each area and the percentage of the overall site total which this represents.

Table 10.2 lists the three main categories of glass from each area. These are:

(I) Identifiable vessel fragments.

(II) Indeterminate vessel fragments.

(III) Window glass fragments.

These totals are expressed as percentages for each area (1) and as percentages of the total site assemblage (2). Hence for area $\mathrm{A}, 33$ fragments of identifiable glass represent 18.75 per cent of the area total and 0.45 per cent of the overall site total. 131 indeterminate fragments represent 74.43 per cent of the area total and 1.79 per

Table 10.2 Identifiable (I), indeterminate (II) and window glass (III) fragments expressed as percentages of the area total (1) and overall site total (2)

\begin{tabular}{rrrrrrrrrr}
\hline Area & $I$ & \multicolumn{1}{c}{1} & \multicolumn{1}{c}{2} & \multicolumn{1}{c}{$I I$} & 1 & \multicolumn{1}{c}{2} & $I I$ & 1 & \multicolumn{1}{c}{} \\
\hline $\mathrm{A}$ & 33 & 18.75 & 0.45 & 131 & 74.43 & 1.79 & 12 & 6.82 & 0.16 \\
$\mathrm{~B}$ & 33 & 11.91 & 0.45 & 239 & 86.28 & 3.28 & 5 & 1.81 & 0.08 \\
$\mathrm{C}$ & 63 & 12.62 & 0.86 & 393 & 78.76 & 5.38 & 43 & 8.62 & 0.59 \\
$\mathrm{D}$ & 120 & 12.66 & 1.64 & 733 & 77.32 & 10.04 & 95 & 10.02 & 1.30 \\
$\mathrm{E}$ & 49 & 12.40 & 0.68 & 310 & 78.48 & 4.24 & 36 & 9.12 & 0.49 \\
$\mathrm{~F}$ & 158 & 6.07 & 2.16 & 1,608 & 61.83 & 22.03 & 835 & 32.10 & 11.44 \\
$\mathrm{~K}$ & 92 & 10.38 & 1.26 & 498 & 56.21 & 6.83 & 296 & 33.41 & 4.06 \\
$\mathrm{M}$ & 30 & 7.35 & 0.41 & 339 & 83.09 & 4.64 & 39 & 9.56 & 0.53 \\
$\mathrm{P}$ & 140 & 15.67 & 1.92 & 709 & 79.40 & 9.72 & 44 & 4.93 & 0.60 \\
$\mathrm{R}$ & 2 & 1.26 & 0.03 & 97 & 60.01 & 1.33 & 60 & 37.73 & 0.05 \\
$\mathrm{~S}$ & 3 & 5.26 & 0.04 & 50 & 87.72 & 0.68 & 4 & 7.02 & 0.05 \\
Total & 723 & & 9.90 & 5,107 & & 69.96 & 1,469 & & 19.35 \\
\hline
\end{tabular}


cent of the overall site total and 12 window glass fragments from this area represent 6.82 per cent of the area total and 0.16 per cent of the overall site total.

Just under 70 per cent of the site assemblage comprises indeterminate body fragments and just under 20 per cent is window glass. Slightly under 10 per cent of the entire site assemblage came from identifiable vessel fragments and other smallfinds of glass. A number of cautionary conclusions can be drawn from these two tables, the most obvious being that no one area assemblage can be described as typical for the site as a whole. Assemblages from the areas range from just 0.78 per cent of the site total (area S) to as much as 35.63 per cent (area F). This is, of course, not simply because there were marked variations in the quantity of glass reaching different parts of the site. It also reflects variations in the volume of soil excavated in different areas. ${ }^{9}$

Moreover, there were also significant variations in the proportion of the three categories of glass found in different areas - identifiable fragments, the indeterminate fragments and the window glass fragments. However, in every case, the indeterminate fragments accounted for more than 55 per cent of the area totals (ranging from 56.21 per cent to 87.72 per cent). This high percentage must, in part, be due to the very fragile nature of many of the vessels. The thin bodies, which formed the major part of vessels, naturally would break up into a greater number of pieces than the distinctive rims and bases - depending upon a variety of factors which are difficult to quantify. The character of the site assemblages is also notable for the considerable variation in the number of window glass fragments recorded from different areas. These vary from as little as 1.81 per cent of the total (area B) to 37.73 per cent (area $\mathrm{R})$. Even if the window glass fragments are set aside, it is still evident from the vessel fragment totals in table 10.2 that there are wide variations in the ratio of identifiable fragments to indeterminate fragments, ranging from approximately $1: 4$ (area A), c. 1:5 (areas K and P), 1:6 (area E) to 1:50 (area R).

It is clear that using glass finds in any discussion of glass supply to Nicopolis, or the nature of the circulation of glass on the site, is fraught with many difficulties and uncertainties. It should be stressed, however, that these figures relate to the total number of fragments from each area, irrespective of their stratigraphic context. It is possible that a seriated analysis of the Nicopolis glass might produce more fruitful results and it is hoped that this will be the subject of future studies.

\section{Dating}

It will be apparent from the above discussion that at Nicopolis, as on all urban sites, the majority of the glass is residual and so the context date of a particular find, though it represents the date of final deposition, does not necessarily mean that the vessel was in use in that period. However, where the special circumstances of 
particular finds do suggest that the period when the glass was in use can be ascertained (e.g. the drain in area B), then this is noted in the discussion and highlighted in the catalogue. Similarly, where a vessel was found in a context clearly earlier than the normally accepted date for the vessel, this is also noted. In the following discussion and catalogue, reference is made to publications from other sites where dating has been proposed. All dates, unless otherwise specified, refer to the accepted chronology for vessels of a particular type, apart, that is, from the first reference to the find in the catalogue where context dates are listed.

\section{Glass supply to the site by area}

Note that, in the following tables, the first percentage in the area column denotes the percentage of the total assemblage from the site and the percentages in the following columns (window glass, identifiable and unidentifiable vessels) refer to the total number of each category compared with the total of finds from the area. Isolated small-finds from each area are listed below the respective tables.

\section{Area A}

\begin{tabular}{lrrrr}
\hline & Area A & Window glass & Identifiable vessels & Unidentifiable vessels \\
\hline Total & 176 & 12 & 33 & 131 \\
$\%$ & 2.41 & 6.82 & 18.75 & 74.43 \\
\hline
\end{tabular}

One counter and two beads were also recorded.

Like area $C$, this area was located on the line of the Roman urban fortifications and excavation here included the investigation of sections of the defensive ditch. ${ }^{10}$ Residuality in this assemblage appears to be high. However, the area also produced the only clear example of intrusive material from the entire site: an optic-blown late Roman/early Byzantine beaker (no. 254) from a mid second century context. "The area assemblage contains just nine fragments which can be dated positively to the first to fourth centuries. The finds come from vessels which were common at Nicopolis and well attested in the Empire as a whole. The later glass from area A is similarly well attested at Nicopolis with few exceptions. As one would expect amongst late Roman/early Byzantine assemblages, drinking vessels and bowls are numerous and together comprise 22 of the 33 identifiable finds. Notable is a jug (no. 670) with a pinched handle (possibly residual and of Roman date) and a small narrow-necked jar (no. 537). 


\section{Area B}

\begin{tabular}{lrrrr}
\hline & Area $B$ & Window glass & Identifiable vessels & Unidentifiable vessels \\
\hline Total & 277 & 5 & 33 & 239 \\
$\%$ & 3.80 & 1.81 & 11.91 & 86.28 \\
\hline
\end{tabular}

Also, one spindle-whorl, one bead, six fragments of glass-working pot metal and two droplets of glass were recorded. The latter eight fragments suggest that glassworking may have been carried out in the vicinity. ${ }^{12}$

It should be stressed that, apart from the fragments from the fill of the Roman road drain (nos 66 and 119 from, respectively, contexts 342 and 341) and the early second century pit (no. 126 from context 261), the assemblage from area B was extremely fragmentary and even those identifiable vessel fragments (e.g. rims and bases) were very small indeed. For this reason, it has not been possible to illustrate many of the fragments which could be identified, especially those of the late Roman period.

The fragmentary state of most of this glass, which is unlike any other assemblage or group from any other area at Nicopolis, must be explained either by the nature of deposition or by the use of the area during the late Roman and early Byzantine periods. It is most likely that the glass had been subject to a great deal of trampling and/or redeposition over a long period of time. ${ }^{13}$

The glass from area B has two striking characteristics. Firstly, the best preserved glassware came from Roman contexts. Although there are only a few examples, they do point to the use of high quality glassware during this period. Secondly, even though the fragmentary nature of the later glass limits discussion of individual items, the condition of the glass has implications for the kinds of activity taking place on the site, namely much trampling, by human or animal action, resulting in secondary breakages, crushing and perhaps including redeposition.

Apart from two small fragments of the late first or second century (nos 8 and 126), the two vessels from the drain referred to above (nos 66 and 119), a wheel-cut beaker fragment of third or fourth century date (no. 15) and a fragment from a prismatic square-sectioned bottle, all of the remaining identifiable fragments can be broadly assigned to the fourth to sixth centuries.

\section{Area C}

\begin{tabular}{lrrrr}
\hline & Area $C$ & Window glass & Identifiable vessels & Unidentifiable vessels \\
\hline Total & 516 & 43 & 63 & 393 \\
$\%$ & 7 & 8.33 & 12.20 & 76.16 \\
\hline
\end{tabular}


Also one bead was recorded.

The glass from this area is a mixed group. Roman glass is reasonably well preserved but the late Roman fragments tend to be small and abraded (although not as severely as was the case for finds from area $B$ ). The majority of both the early and the late vessel types are well attested at Nicopolis.

\section{Area D}

\begin{tabular}{|c|c|c|c|c|}
\hline & Area $D$ & Window glass & Identifiable vessels & Unidentifiable vessels \\
\hline Total & 948 & 95 & 120 & 733 \\
\hline$\%$ & 12.99 & 10.02 & 12.66 & 77.32 \\
\hline
\end{tabular}

Also, two bracelet fragments, one bead and glass-working debris comprising two moils, nine fragments of pot metal and two droplets were recorded.

The 120 identifiable fragments from this area include, in the main, standard bowls and beakers with variations on the fire-rounded rim and ordinary applied true base rings.

\section{Area E}

\begin{tabular}{lrrrr}
\hline & Area $E$ & Window glass & Identifiable vessels & Unidentifiable vessels \\
\hline Total & 395 & 36 & 49 & 310 \\
$\%$ & 5.41 & 9.12 & 12.40 & 78.48 \\
\hline
\end{tabular}

Also, one bead was recorded.

Many of the fragments are very small and abraded which suggests that, as with the area $B$ material, they are redeposited. It should be noted here that a small fragment of millefiori glass of the mid first century AD was discovered during the second season of excavation. Unfortunately, it was not submitted for identification and so does not appear in the catalogue. ${ }^{14}$ Its presence, however, is another indication of the supply of early glass to the city.

The majority of the vessels from this area come from well-attested types which have been found elsewhere on the site. These include early Roman linear wheel-cut colourless bowls and beakers, late Roman outsplayed and cracked-off beakers and bowls, numerous fire-rounded rims of the late Roman and early Byzantine date and bases, probably from these vessels, with applied true base rings. 
Area F

\begin{tabular}{lrrrr}
\hline & Area $F$ & Window glass & Identifiable vessels & Unidentifiable vessels \\
\hline Total & 2,601 & 835 & 158 & 1,608 \\
$\%$ & 35.63 & 32.10 & 6.07 & 61.83 \\
\hline
\end{tabular}

Also, one plain bracelet fragment, and six fragments of glass-working debris comprising three pot metal fragments, two droplets and glass-coated tile fragments were recorded.

The composition of the glass comprises a wide variety of types and represents the largest assemblage from a single area. First of all there is a good Roman assemblage (from the late first century to the late third and fourth centuries) which was well sealed beneath the Large Basilica. Secondly, there is the glass associated with the destruction phase of the basilica itself. Although this material is important, in that it gives some indication of the architectural pretensions of the building, it will be seen that much of it was damaged in the initial destruction of the building, and was then re-sorted and broken by trampling and further disturbed by the postmedieval robbing of the church's walls and foundations.

Area $\mathrm{F}$ produced a remarkable total of 158 fragments of identifiable glass, the majority from the rims and bases of standard, well-attested bowls and beakers.

Area K

\begin{tabular}{lrrrr}
\hline & Area $K$ & Window glass & Identifiable vessels & Unidentifiable vessels \\
\hline Total & 886 & 296 & 92 & 498 \\
$\%$ & 12.14 & 33.41 & 10.38 & 56.21 \\
\hline
\end{tabular}

No other glass finds were recorded.

The area includes a very good Roman assemblage of the second and third centuries and very high quality cut glassware, dating to the late first to third century. The only fragment of snake-thread glass came from this area (no. 120) as well as three identifiable bottle fragments, surprisingly the largest concentration from the entire site. 


\section{Area $M$}

\begin{tabular}{lrrrr}
\hline & Area $M$ & Window glass & Identifiable vessels & Unidentifiable vessels \\
\hline Total & 408 & 39 & 30 & 339 \\
$\%$ & 5.59 & 9.56 & 7.35 & 83.09 \\
\hline
\end{tabular}

No other glass finds were recorded.

The nature of the assemblage from this area can be explained by the fact that excavation here produced a well-stratified sequence of Roman deposits. It includes a very good group of late second or third century wheel-cut bowls and beakers (nos $12,13,19,35,36,25,26,17)$. These vessels range from small cups (nos 12-13), deep, wide bowls (nos 19 and 35) and deep, bag-shaped bowls (nos 17, 25 and 26). The remainder of the glass from this area is all late Roman or early Byzantine in date and conforms well with the standard forms of those periods, well represented at Nicopolis.

\section{Area $P$}

\begin{tabular}{lrrrr}
\hline & Area $P$ & Window glass & Identifiable vessels & Unidentifiable vessels \\
\hline Total & 893 & 44 & 140 & 709 \\
$\%$ & 12.23 & 4.93 & 15.67 & 79.40 \\
\hline
\end{tabular}

Also, three possible tesserae and one droplet of glass were recorded.

A small group of Roman glass is represented here (nos 115, 144, 125, 242) but by far the most important fragments come from a diatretum (nos 41-63).

\section{Area $R$}

\begin{tabular}{lrrrr}
\hline & Area $R$ & Window glass & Identifiable vessels & Unidentifiable vessels \\
\hline Total & 159 & 60 & 2 & 97 \\
$\%$ & 2.18 & 37.73 & 1.26 & 61.01 \\
\hline
\end{tabular}

Also one bracelet fragment was recorded.

Of note is the relatively large proportion of window glass (37.73 per cent of the total assemblage) from this site of an early Byzantine tower, especially when compared with the excavations of two other towers ( $\mathrm{P}$ and $\mathrm{S}$ ) where the proportion of the total area assemblages represented by window glass fragments was, respectively, just 4.9 per cent and 6.89 per cent. Seven fragments came from the make-up deposit for the first earth floor of the tower (5218), 3 from the make-up deposit immediately 
below the second paved floor (5214). These 10 fragments are probably residual and are Roman or late Roman in origin. However, 38 of the total of 60 fragments came from building debris, immediately above the second floor (5205) and 12 from the soil build-up below it and overlying the secondary paved floor (5206). Although, strictly speaking, it is impossible to prove that the accumulation of debris above the second floor dates to the early Byzantine period, it seems most likely that it does represent the weathering and collapse of material immediately following the abandonment of the site in the late sixth century. ${ }^{15}$ Given that it is therefore likely that the windows of this tower were glazed, it is of interest to note that no similar evidence was found during the excavation of the two other towers which were simpler in design and lacked the tiled floor found in this area. ${ }^{16}$

\section{Area $S$}

\begin{tabular}{lrrrr}
\hline & Area S & Window glass & Identifiable vessels & Unidentifiable vessels \\
\hline Total & 57 & 4 & 3 & 50 \\
$\%$ & 0.78 & 7.02 & 5.26 & 87.72 \\
\hline
\end{tabular}

Also, one plain bracelet fragment was found.

Since only three fragments could be identified, it is obvious that this assemblage is too small a sample upon which to base any conclusions concerning the nature of glass supply to this part of the site. However, it is perhaps significant that the proportion of window glass from this gate-tower is notably less than in the case of the tower in area $\mathrm{R}$.

\section{NOTES}

1 This is available in electronic format and is stored in the Department of Archaeology at the University of Nottingham.

2 For the problems of quantification, see above, p. 304.

3 See above, Chapter 3.

4 Beads and counters are to be published in Nicopolis: The Finds, Volume 2 (forthcoming) which contains the small-finds from the excavations.

5 Glass of all categories (window, vessel and lamp fragments) concentrated in the south aisle and east of the apse, outside the building. If this distribution has any significance, it clearly does not relate to the use of the building. It has been tentatively suggested that this might point to areas where fittings were salvaged before the church burnt down: Poulter 1995, 162.

6 On the archive, see above, footnote 1.

7 See above, pp. 24-5.

8 See Poulter 1995, 214-15.

9 See above, pp. 28-9.

10 See above, p. 11.

11 This context (2245), close to the northern baulk in area A, though predating the construction of the Roman defences $c$. AD 175, immediately underlay a mixed deposit, comprising mid fifth 
century pottery and was contaminated by post-medieval robbing. The context in question was examined at the end of the 1987 season and again at the beginning of the following year when it was noted that erosion during the intervening winter introduced the danger of contamination by material falling from the section. This glass fragment was found in 1988 .

12 See below, pp. 376-8.

13 This area contained a road surface which may also have formed part of a market area in the fourth to early fifth centuries $A D$, see above, p. 19.

14 This object was not found in the small-finds archive.

15 These deposits were immediately overlain by post-medieval spoil from the robbing of the defences in the eighteenth/nineteenth century so it could be argued that the glazed windows might have been added after the end of early Byzantine occupation. Even so, this is inherently unlikely given the evidence for abandonment in the post-Byzantine period, see above, p. 25 .

16 For the exceptional size of the tower in area $\mathrm{R}$ and its equally exceptional paving, see above, p. 24. 


\section{The glass catalogue}

Given the residual nature of most of the glass from the site, the dating in the following catalogue is based primarily upon the chronology established for comparable vessels from other parts of the Roman, late Roman and early Byzantine empires. However, where particular contexts provide a precise date for particular finds (e.g. the drain in area B) or where there is an apparent discrepancy between the date of the glass types as found elsewhere and the Nicopolis contexts, the evidence is noted in the catalogue and, where appropriate, in the following discussion. Roman glass, including items found in late Roman and early Byzantine contexts but which are clearly residual, are grouped together with glass from securely dated Roman contexts. Context numbers are in round brackets, followed by the date for that context and small-find numbers (SF) are included where they were assigned. Note that the following terms are used to describe the glass. Sticking part refers to the upper and lower ends of a handle where it is attached to the rim or neck and body of a vessel. Metal refers to the material of the glass itself, the equivalent of 'fabric' in ceramic studies. This catalogue does not include 51 fragments from the site which came from recognizable parts of vessels (e.g. necks, carinations) but which cannot be assigned to specific forms.

\section{COLOURLESS, GROUND, POLISHED AND WHEEL-CUT DECORATED VESSELS, late first to fourth centuries (Figs 11.1-11.3)}

Unless otherwise stated, all of the following fragments (nos 1-64) come from free-blown, colourless vessels with decoration and details executed on the wheel and finished by polishing.

1. $\mathrm{K}(4430), 1750+$. The edge of a rectangular table or coaster with part of a square-sectioned leg. Cast. Late first century.

2. A (2260), 100-130, SF. 5311. A small cup with a slightly swelling body. Flat, ground rim. Ground base ring with a small horizontal rib above. Late first or early second century. 
3. F (3011), 150+, SF. 7341. Fragment from the rim and part of the handle of a skyphos. Cast with a horizontal volute upper sticking part. Late first or third century.

4. K (4512), 250-450. Fragment from the rim of a dish or plate. Cast with a slightly overhanging lip. Late first century.

5. K (4515), 250-450. Two fragments from a shallow bowl or dish. Cast with an overhanging rim. Late first or second century.

6. C (4131), 150-250. Fragment from the side of a small bowl. Cast with an almost horizontal flanged rim. Late first or early second century.

7. A similar rim to no. 6 from area C (4128), 250-350. Not illustrated.

8. B (248), 300-450, SF. 2498. Two fragments from the rim and side of a beaker or bowl with a slight overhanging rim. Late first or early second century.

9. $\mathrm{C}(96), 450-600$, SF. 6048. Fragment from the rim and side of a beaker or bowl with a flat rim and a ridge below the lip. Late first or early second century. Not illustrated.

10. F (3047), 450-600. Fragment from the rim of a beaker with a flat rim and a horizontal rib below the lip. Part of what is possibly the upper sticking part of a handle can be seen at the edge of the fragment. Late first or early second century.

11. F (3151), 800-1000. Fragment from the base of a beaker. The bowl of the beaker is rounded towards the bottom. Applied free-blown, incomplete, splayed foot. Late first or early second century.

12. $\mathrm{M}(4920), 350-450^{\circ}$. Fragment from the side of a small hemispherical bowl. Slightly outsplayed, cracked-off rim. The body is decorated with very faint horizontal wheel-cut lines below the lip. On the body, a zone of vertical rice grain facets has been cut between two rows of two horizontal wheel-cut lines. Below this, and above a single horizontal wheel-cut line, is a zone of circular facets. Late second or third century.

13. $M(4835), 450-600$. Small fragment from the side of a small hemispherical bowl or cup. Decorated with a zone of at least two interlocking rows of vertical rice grain wheel-cut facets, above a single row of similar facets set horizontally. Below this is a zone of circular facets. Late second or third century.

14. K (4480), 1750+. Fragment from the side of a small hemispherical cup or bowl. Decorated with a wheel-cut design consisting of, from the top, a zone 
of rice grain facets, two groups of two horizontal wheel-cut lines, a zone of large oval facets set vertically above a line of horizontal facets, above two horizontal wheel-cut lines above a zone of vertically set oval facets. Third or fourth century.

15. B (260), 300-450. Fragment from the side of a small hemispherical bowl. With wheel-cut decoration comprising, from the top, a single horizontal wheel-cut line, a zone of two rows of narrow vertical rice grain facets, a line of horizontal rice grain facets and a zone of circular facets. Third or fourth century.
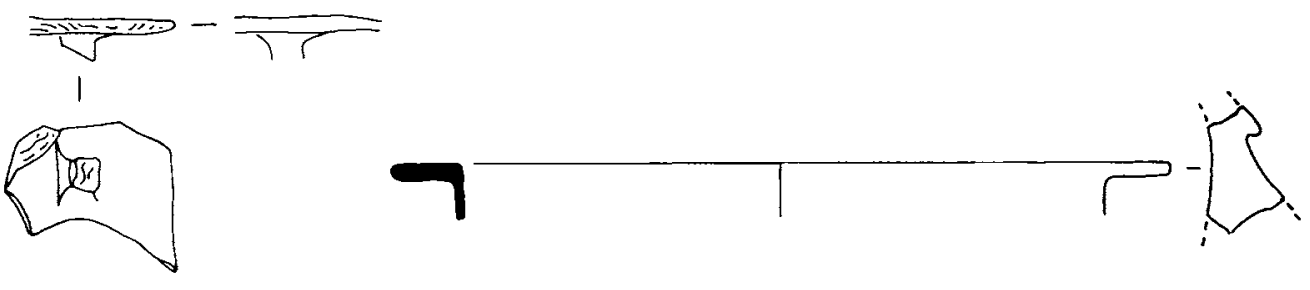

1

3
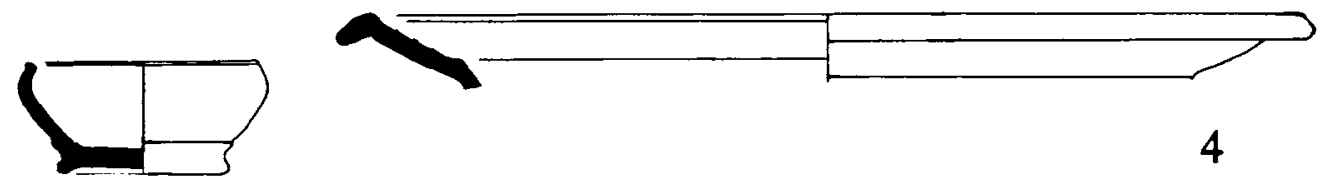

4

2
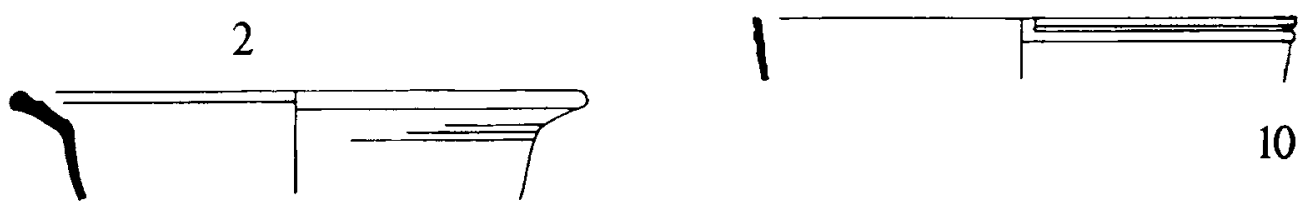

\section{5}
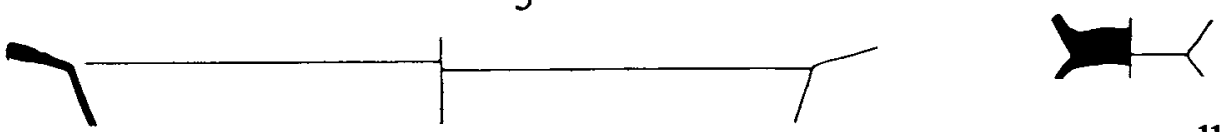

11

6
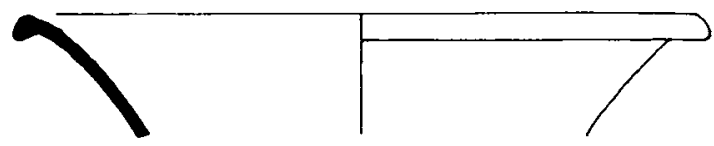

8

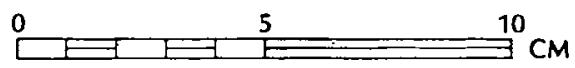

11.1 Decorated colourless, ground, polished and wheel-cut vessels, late first to fourth century 


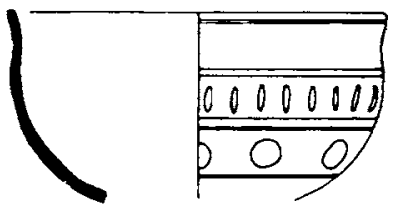

12
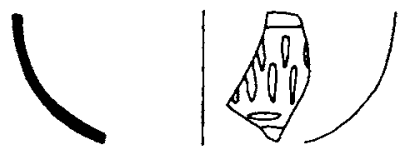

15

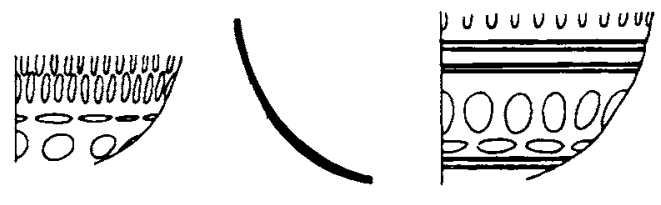

13
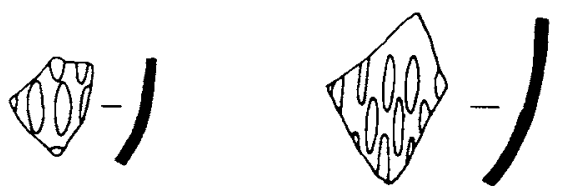

16
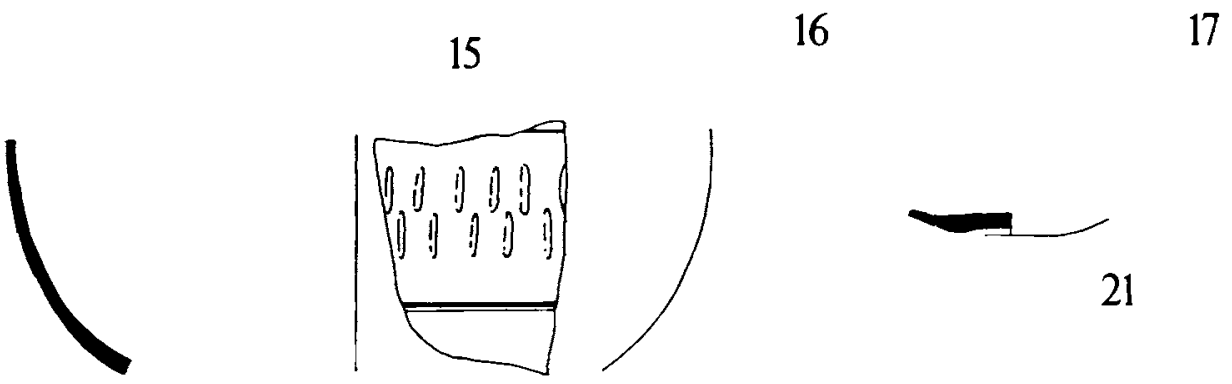

18
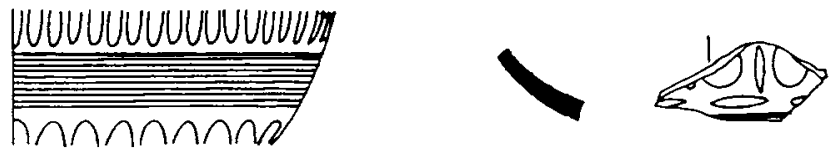

19
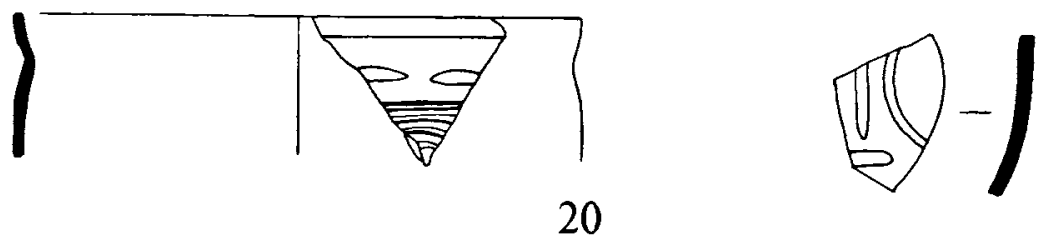

20
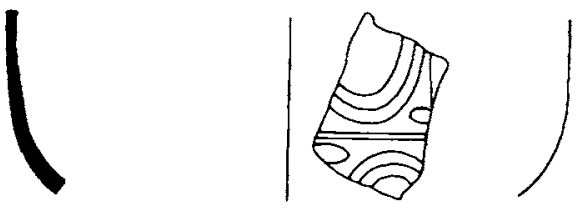

24

22

11.2 Decorated colourless, ground, polished and wheel-cut vessels, late first to fourth century 
16. F (3003), 1750+. Fragment from the side of a beaker. Decorated with wheelcut rice grains set vertically in quincunx. Third or fourth century.

17. $M(-)$. Small fragment from the side of a bowl or beaker. Decorated with three rows of rice grain facets set vertically in quincunx. Late second or third century.

18. C (5306), 250-350. Fragment from the side of a hemispherical bowl.

Decorated with a wheel-cut design consisting of, from the top, a single horizontal wheel-cut line, a zone of two rows of vertical rice grain facets, a single horizontal wheel-cut line, and a zone of circular facets. Third or fourth century.

19. M (4942), 350-450. Small fragment from the side of a bowl or beaker.

Decorated with ten close-set horizontal wheel-cut lines between two zones of vertically cut oval wheel-cut facets. Late second or third century.

20. S (5272), 450-600. Fragment from the rim of a bowl. Rim cracked-off and ground smooth. Lip slightly outsplayed above a slightly swelling body. Body decorated with wheel-cut design consisting of, on the rim, two horizontal wheel-cut lines with, between them, a line of horizontal rice grain facets. A 'random' zone lies below this on the body. This is possibly a zone of crosshatching. Third or fourth century.

21. P (5008), c. 450, SF. 14097. Fragment from the base of a beaker. Base formed by a large wheel-cut circular facet. Third or fourth century.

22. D (434), 1750+, SF. 4100. Fragment from the side of a bowl or beaker. Body decorated with a wheel-cut design consisting of an oval facet within an oval alongside an 'I' element. This zone is separated from a similar zone, with circular elements rather than oval, by a single horizontal line. Third or fourth century.

23. F (3209), 1750+. Fragment from the side of a beaker. Decorated with a wheel-cut design consisting of two oval facets between a vertical rice grain facet with a horizontal rice grain facet beneath each oval. A single horizontal wheel-cut line is discernible below this zone. Third or fourth century.

24. K (4431), 1750+. Fragment from the side of a beaker or bowl. Body decorated with two wheel-cut circles on either side of a vertical line. A horizontally orientated wheel-cut facet is above this line. Third or fourth century.

25. $M(4896), 1750+$. Small fragment from the side of a bowl or beaker. Decorated with two circles, each with a central circular facet, on either side of a vertical wheel-cut groove. Late second or third century. 
26. M (4804), 1750+. Small fragment from the side of a bowl or beaker. Decorated with rice grain facets in a 'wheat sheaf' pattern with circles on either side and an oval facet set horizontally above. Above this is a single horizontal wheel-cut line. Late second or third century.

27. A (2128), c. 450, SF. 5135. Fragment from the side of a beaker. Decorated with at least one zone of circular wheel-cut facets and a horizontal wheel-cut line. Third or fourth century. Not illustrated.

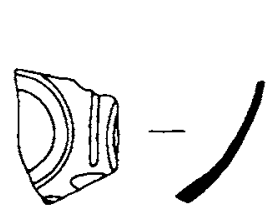

25

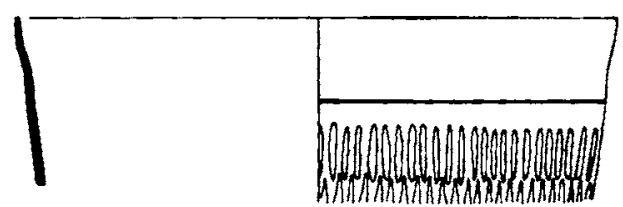

35

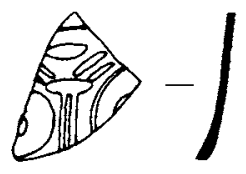

26

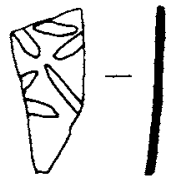

36

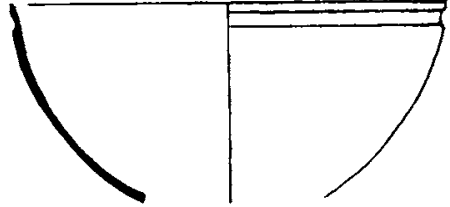

37

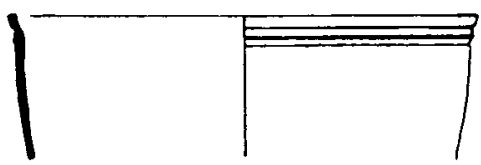

38

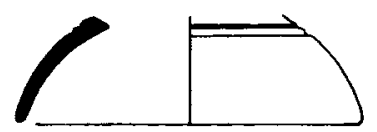

39
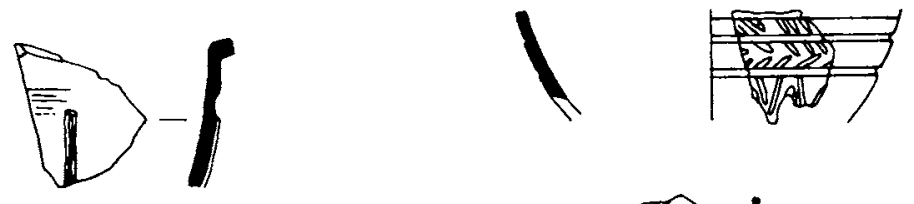

40

64

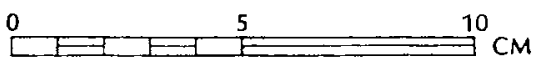

11.3 Decorated colourless and blue (no. 64), ground and polished wheel-cut vessels, late first to fourth century 
28. K (4505), 250-450. Fragment from the side of a beaker. Decorated with an oval wheel-cut facet. Third or fourth century. Not illustrated.

29-34. Fragments with parts of oval or circular wheel-cut facets from area $D$ (402), 1750+, SF. 1063; D (471), 1750+, SF. 4225; F (3193), 450-600; ${ }^{1} \mathrm{~F}$ (3240), 450-600; K (4492), 1750+ ; K (4505), 250-450. Not illustrated.

35. $M$ (4945), 250-350. Fragment from the rim and side of a beaker. Slightly outsplayed, cracked-off rough rim. Body decorated with a zone of at least two rows of thin vertical rice grain facets. Late second or third century.

36. $M(4928), 1750+$. Small fragment from the side of a beaker or bowl. Body decorated with at least six wheel-cut elongated facets, four in the shape of an ' $X$ ' with a facet between the upper and lower arms. Late second to fourth century.

37. $\mathrm{P}$ (5019), c. 450. Three fragments from the rim and side of a hemispherical beaker. Natural greenish-blue glass. Rim cracked-off and ground smooth. Decorated with a broad ground groove below the lip. Rim sloping inwards towards the lip. Third or fourth century.

38. $\mathrm{P}$ (5018), c. 450. Fragment from the rim and side of a hemispherical beaker or small bowl. Square sectioned, ground and polished rim with, below the lip, a thin horizontal ridge above a broad ridge. Third or fourth century.

39. $F(3250), 1750+$, SF. 8256. Fragment from the rim and side of a small hemispherical cup or, more probably, the base of a large indeterminate vessel with flat lip and a single horizontal wheel-cut groove on the body. Third or fourth century.

40. K (4480), 1750+. Fragment from the side of a small hemispherical bowl with a slightly overhanging rim (lip missing). Body decorated with a ground and cut vertical 'I', possibly the letter 'I'. Third or fourth century.

41-63. P (5018), c. 450 (x3); P (5051), c. 450 (x20) (Plates III and IV). Twenty three fragments from the rim and part of the side of a wheel-cut, ground and polished cage cup (diatretum). Free-blown blank of colourless glass with one blue and one emerald green band. The blue band has been cut into plain vertical bars, the emerald band runs around the top of an open network of circles. Small 'bows' exist at the joins of circles. Fourth century. The fragments are as follows:

$\mathrm{P}$ (5018), c. 450

41. SF. 14145a (Plates III,1, III,3 and III,4). Colourless with blue vertical bar.

42. SF. 14145b (Plates III,1 and IV,2). Colourless with connecting spur. 
43. SF. 14167 (Plates III, 1, III,5 and III,6). Colourless with blue vertical bar.

$\mathrm{P}(5051), c .450$

44. SF. 14632. Colourless with blue vertical bar.

45. SF. 14629. Colourless with blue vertical bar.

46. SF. 14640. Rim with part of side including blue vertical bar.

47. SF. 14630 (Plates IV,3 and IV,4). Colourless with connecting spur with green decoration and part of second connecting spur.

48. SF. 14622 (Plate IV,1) Colourless with two connecting spurs (five sided and diamond).

49. SF. 14639 (Plate III,2). Colourless spur with green decoration (curve and horizontal).

50. SF. 14638. Colourless with connecting spur.

51. SF. 14631. Colourless with connecting spur.

52. SF. 14641. Colourless with irregular outer surface.

53. SF. 14636. Colourless with irregular outer surface.

54. SF. 14633. Colourless with irregular outer surface.

55. a. Colourless fragment. Irregular thickness.

56. b. Colourless fragment. Irregular thickness.

57. c. Colourless fragment. Irregular thickness.

58. d. Colourless fragment. Irregular thickness.

59. e. Colourless fragment. Irregular thickness.

60. f. Colourless fragment. Irregular thickness.

61.g. Colourless fragment. Irregular thickness.

62. h. Colourless fragment. Irregular thickness.

63. i. Colourless fragment. Irregular thickness.

64. R (5218), c. 450, SF. $13034+$ SF. 13036 (Plate IV,5). Two fragments from the side of a beaker or bowl (diatretum). Free-blown thick blue glass. Decorated with very deep, coarse geometric wheel-cutting consisting of a herringbone collar with, above, chevrons pierced through by slim oval holes. Fourth or fifth century. 


\section{JUGS, FLAGONS, BOTTLES AND PHIALS, first to fourth century} (Figs 11.4-11.5)

Unless otherwise stated, all of the following fragments (nos 65-112) come from free-blown, naturally coloured vessels (i.e. natural green, blue or green-blue).

65. C (-), SF. 6563. The handle of an aryballos. Dolphin-shaped handle. Late first to third century.

66. B (342), 175-250, SF. 2670. The upper part and lower sticking part of the handle of a trefoil-mouthed jug. Colourless glass with a green tint. Rim firerounded and folded inwards. Handle decorated with three high relief ribs. Second century.

67. D (691), 150-175, SF. 4700. Fragment from the rim of a flask or bottle. Lip folded inwards and outsplayed. Second to fourth century.

68. K (4405), 1750+. Fragment from the rim of a flask or bottle. Colourless glass with a green tint. Fire-rounded, flared rim with a single trail of the same metal below the lip. Late third or fourth century.

69. D (704), 350-450, SF. 4713. Fragment from the rim and neck of a flask or bottle. Colourless glass with a green tint. Fire-rounded, flared rim decorated below with a thick spiral trail of the same metal. Late third or fourth century.

70. D (682), 350-450. A similar rim to no. 69. Not illustrated.

71. C (5306), 250-350. Fragment from the rim of a flask or bottle. Colourless glass with a green tint. Flared, fire-rounded rim with a thick trail of the same metal below the lip. Late third or fourth century.

72. D (451), 1750+, SF. 4159. Fragment from the plain, strap handle of a flask or jug. Second to fourth century.

73. C (4033), c. 450, SF. 6530 . The handle from a small jug. Colourless with a green tint. Plain strap handle. Late third or fourth century.

74. K (4405), 1750+. Fragment from the plain strap handle of a small bottle or flagon. Colourless glass with a green tint. Second to fourth century.

75. K (4515), 250-450. The handle of a flask or jug. Colourless glass. Drawn handle with three high relief vertical ribs. Second to fourth century.

76. B (248), 300-450, SF. 2505. Fragment from the lower sticking part of the handle of a flask or flagon. First to fourth century. Not illustrated. 


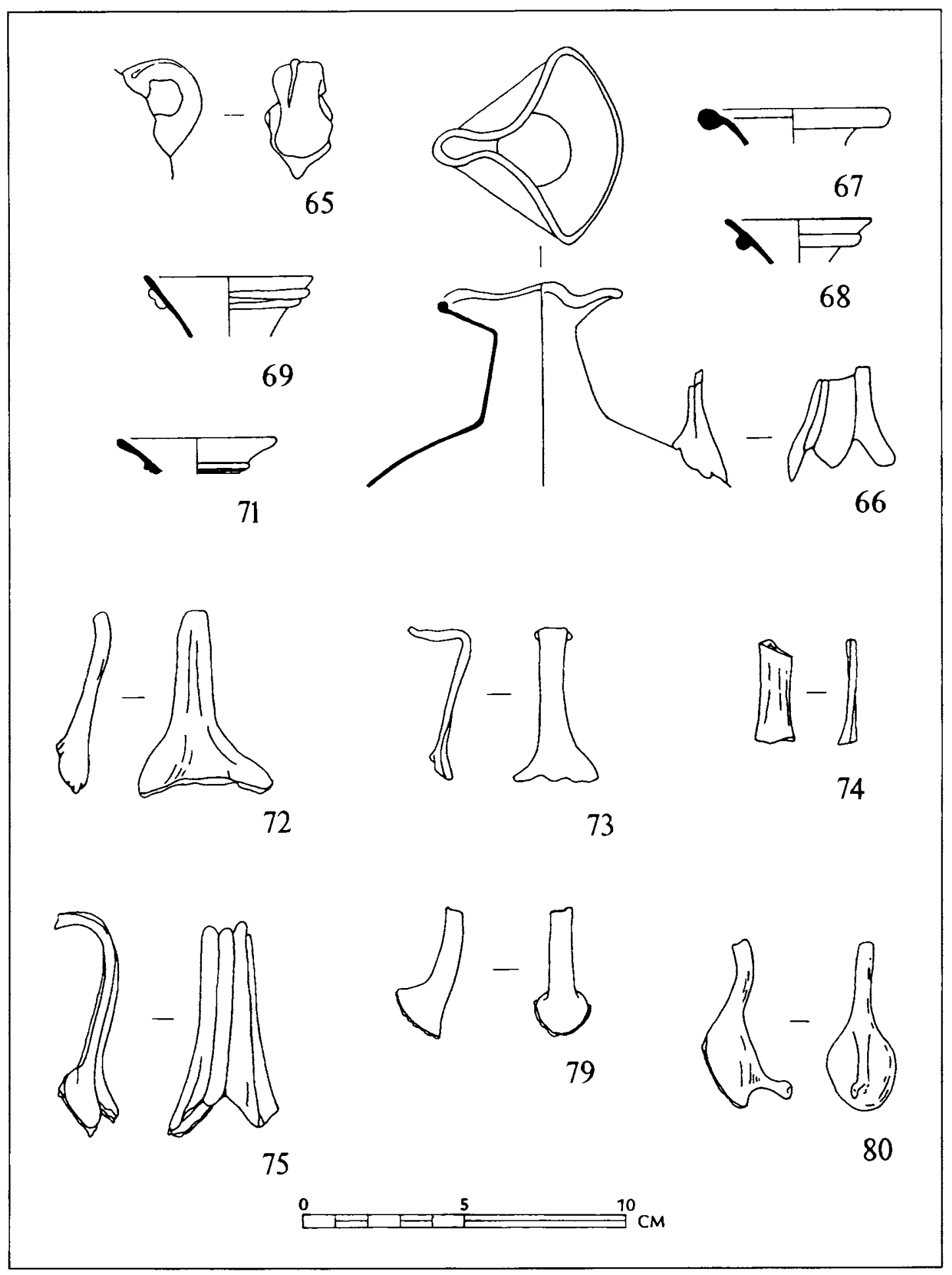

11.4 Jugs, flagons, bottles and phials, first to fourth century 
77. C (4107), 250-350. Small fragment from the handle of a flagon or jug. Late third or fourth century. Not illustrated.

78. C (4132), 150-250. A similar fragment to no. 77. Not illustrated.

79. F (3157), 1750+. Fragment from the plain rod handle of a flagon or jug. Third or fourth century.

80. K (4493), 1750+, SF. 10205. Fragment from the handle of a jug or flask. Colourless glass. Thick lower sticking part with a small pulled spur. Plain rod handle. Second to fourth century.

81. A (2259), 100-130, SF. 5296. Fragment from the lower sticking part of the handle of a jug. Thick sticking part with a single pinched element. Third or fourth century.

82. E (1024), 450-600, SF. 3109. A thick fragment, possibly part of the thumb grip of a large bottle or jug or a thick handle from the side of a vessel. Late first to third century.

83. D (681), 175-250, SF. 4694. Fragment from the rim of a flask or bottle. The rim is of unusual form. The lip has been folded inwards and the whole flattened out and down. After reheating the top of the rim has been flattened. Late first to third century.

84. F (3011), 1750+, SF. 7020. Fragment from the rim of a bottle. Rim folded inwards and flattened down. Late first to third century.

85. $\mathrm{K}(4463), 1750+$. Fragment from the rim of a bottle or flask. The rim has been folded inwards and flattened down. Second to fourth century.

86. K (4516), 250-450. As no. 85 .

87. K (4512), 250-450. As no. 85 .

88-89. K (4515), 250-450; K (4516), 250-450. Similar rims to no. 85. Not illustrated.

90. A (1), 1750+, SF. 1. Fragment from the rim of a flask or bottle. Rim folded in and flattened out. Late first to fourth century. Not illustrated.

91. D (677), 175-250. Nine fragments from the base of a mould-blown, squaresectioned prismatic bottle. Pushed-in base with pontil scar. Base decorated with a single ' $C$ ' or circle in one corner. The other three corners are missing. Late first to third century. Not illustrated. 
92. D (559), 350-450. Fragment from the base of a mould-blown squaresectioned prismatic bottle. Base decorated. Only part of one circle is extant. Late first to third century. Not illustrated.

93-108. Sixteen fragments from the sides of an indeterminate number of mould-blown square-sectioned bottles from areas B (248), 300-450; C (4118), 130-150; D (434), 1750+; D (453), 1750+ (x4); D (667), 175-250; D (676), 175-250 (x4); E (1024), 450-600; K (4504), 450-600; K (4506), $250-450(\mathrm{x} 2)$. Not illustrated.

109. B (255), 300-450, SF. 2495. Fragment from the neck and part of the rim of a phial (unguentarium). First to fourth century.

110. F (3064), 1750+, SF. 7751. Fragment from the rim of a flask or bottle. Rim folded inwards and flattened. First to third century.

111. F (3011), 1750+, SF. 7018. A similar rim to no. 110. Not illustrated.

112. A (19), 450-600, SF. 1048. Fragment from the neck of a small phial (unguentarium). First to fourth century. Not illustrated.

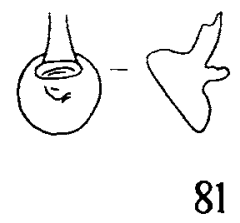

81
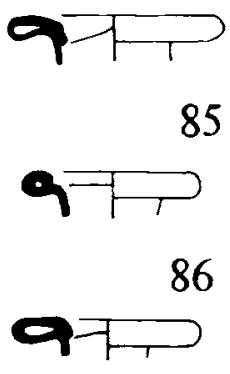

87

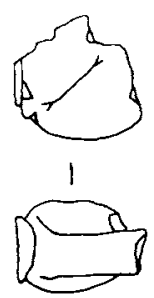

82

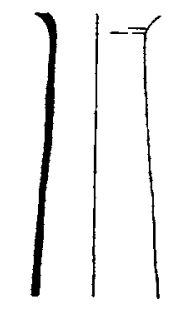

109

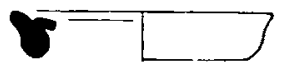

83

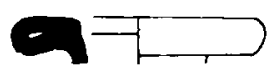

84

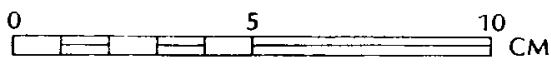

11.5 Jugs, flagons, bottles and phials, first to fourth century 


\section{BOWLS, BEAKERS AND JARS, first to fourth century}

(Figs 11.6-11.10)

\section{Colourless glass}

Unless otherwise stated, all of the fragments below (nos 113-125) come from free-blown colourless vessels.

113. E (1042), 450-600, SF. 3108. Fragment from the rim and side of a beaker. Outsplayed, cracked-off rim. Body decorated with two horizontal wheel-cut lines below the lip and one on the body. Second century.

114. E (1184), 130-175, SF. 3317. Fragment from the rim and side of a thin walled beaker. Outsplayed, cracked-off rim. Late first or second century.

115.P (5017), c. 450. Fragment from the rim and side of a beaker. Outsplayed and cracked-off rim. Body decorated with horizontal wheel-cut lines $2 \mathrm{~mm}$ and $12 \mathrm{~mm}$ below the lip. Late first or second century.

116. D (676) SF. 4664, 175-250. Fragment from the rim of a bowl. Lip of rim folded out and down to form a flattened hollow tubular lip. Second to fourth century.

117.D (661), 250-350, SF. 4604. A similar rim to no. 116. Not illustrated.

118. D (676), 175-250, SF. 4677. Fragment from the rim of a bowl. Lip of rim folded out and down to form a flattened hollow tubular lip. Second to fourth century.

119. B (341), 175-250, SF. 2669. A bulbous-bodied bowl or beaker. Fire-rounded, everted rim. Body decorated with a thin spiral trail of the same metal. Slightly pushed-in base. Mid to late second century.

120. K (4405), 1750+. Fragment from the side of a vessel of indeterminate form. Body decorated with an opaque white milled trail (i.e. rigareed snake-thread). Third or fourth century.

121.D (691), 150-175, SF. 4699. The base of a beaker. Pushed-in base with an outsplayed, flattened hollow tubular base ring. Second to third century.

122. D (661), 250-350, SF. 4614. A similar base to no. 121. Not illustrated.

123. K (4516), 250-450. Fragment from the base of a beaker. High domed kick. Second to fourth century.

124. A (2017), c. 450, SF. 1221. Fragment from the thickened internal base ring of beaker, possibly of the 'Airlie' type (Isings form $85 \mathrm{~b}$ ). This fragment has been 


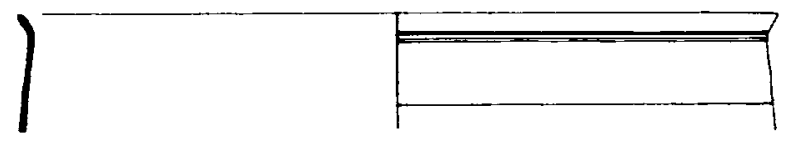

113

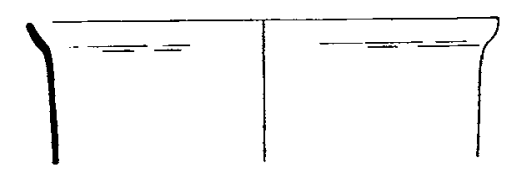

114

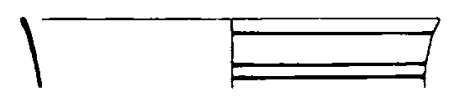

115
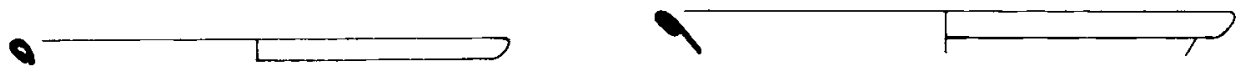

116

118

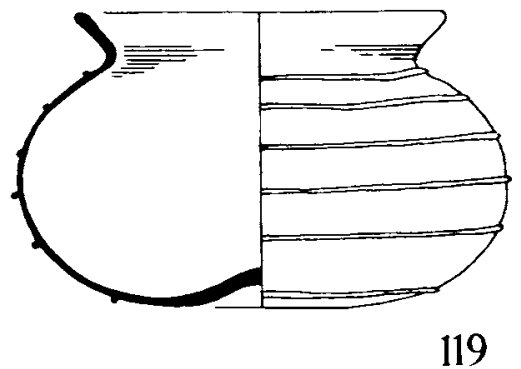

$\sim$

123
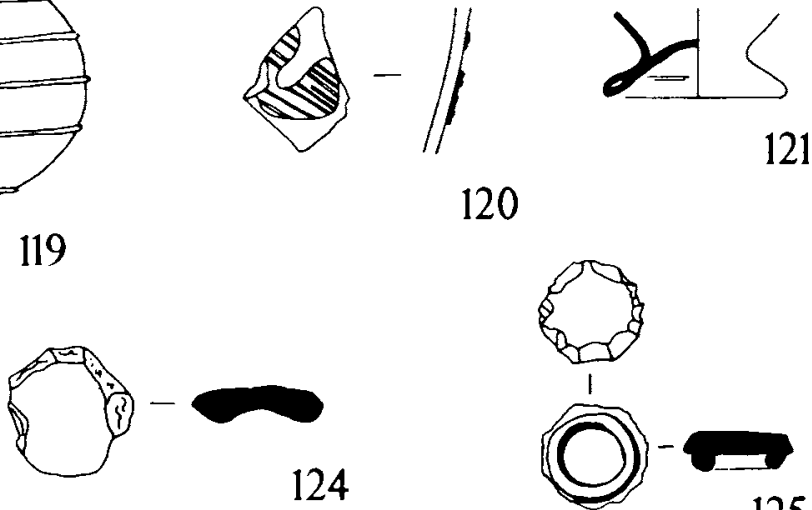

120

121
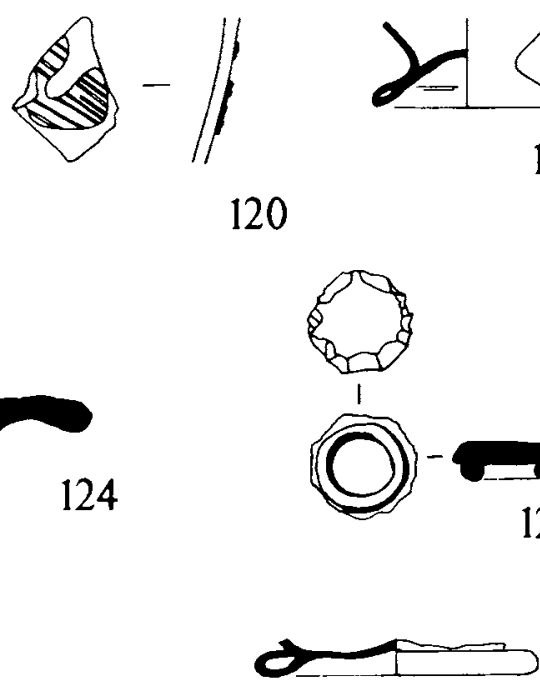

127

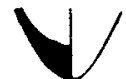

128

$d-1 \Rightarrow$

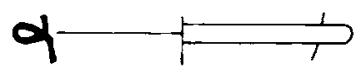

130

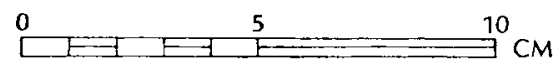

11.6 Beakers, bowls and jars, first to fourth century 
grozed around the edge up to the internal ring to make into a counter. Late second to third century.

125.P (5039), 450-600. Fragment as no. 124.

\section{Naturally coloured glass}

Unless otherwise stated, nos 126-137 come from naturally coloured free-blown vessels.

126. B (261), 100-130, SF. 2510. Fragment from the side of a beaker, cup or chalice (eg. calix or cantharus) with a cut-out horizontal hollow tubular collar. First century.

127. K (4405), 1750+. Fragment from the upper part of a barrel-like vessel. The body of the vessel tapers inwards towards the mouth. Decorated with an edge piece and spiral thread of the same metal. Third or fourth century.

128. A (2017), c. 450, SF. 1218. Fragment from the base of a small beaker. High pushed-in base. First to fourth century.

129. A (2260), 100-130, SF. 5299. The base of a beaker. Pushed-in base with a hollow tubular base ring. Late first to third century.

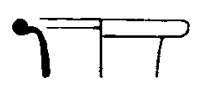

131

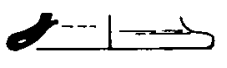

132

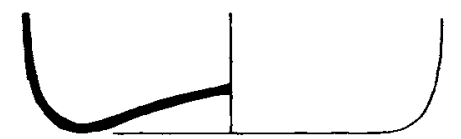

136

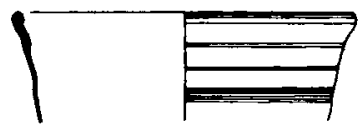

138

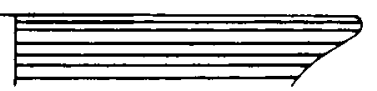

140

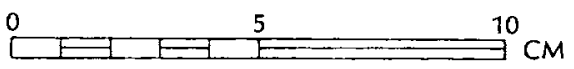

11.7 Beakers, bowls and jars, first to fourth century 
130. D (681), 175-250, SF. 4691. Small fragment from the base of a beaker. Pushed-in base, forming a solid base ring. Second to fourth century.

131. D (699), 130-150, SF. 4717. Six fragments from the rim and neck of a jar. Lip of rim folded inwards and outsplayed. Second to fourth century.

132. D (681), 175-250, SF. 4696. Fragment from the rim of a small jar. Rim firerounded, outsplayed and flattened. Second to fourth century.

133-134. Similar rims to no. 132 from area D (555), undated; D (691), 150-175, SF. 4702. Not illustrated.

135. A (2245), 130-175, SF. 1463. Fragment from the base of a jar. Pushed-in, cutout base. Late first to third century. Not illustrated.

136. K (4507), 250-450. Fragment from the base of a bowl or bottle. Straight sided with a simple pushed-in base. Second to fourth century.

137. C (4110), 250-350. Fragment from the base of a bowl or flagon. Simple pushed-in base. Late third or fourth century. Not illustrated.

\section{Beakers with blue trails}

138. D (657), 250-350, SF. 4609. Fragment from the rim and side of a beaker. Colourless glass. Rim decorated with a fire-rounded edge trail of translucent blue glass. The body of the vessel is decorated with a marvered spiral trail of translucent blue glass. Second to third century.

139. D (449), 1750+. Fragment from the rim of a bowl or beaker. Colourless glass. Flared body and upright fire-rounded rim. Body decorated with a thin spiral trail of translucent blue glass. Second to third century.

140.P (5014), c. 450. Fragment from the rim of a beaker. Natural green glass. Flared body with insplayed rim. Body decorated with an applied and marvered spiral trail of translucent blue glass. Third or fourth century.

141.P (5051), c. 450. Five fragments from the rim and body of a vessel of indeterminate form. Natural greenish colourless glass. Fire-rounded rim. Body decorated with marvered trails of translucent blue glass. Third or fourth century. Not illustrated.

142.P (5018), c. 450. Fragment from the side of the bulbous-bodied beaker or bowl. Natural green glass. Decorated with trail of blue glass. Third or fourth century. 
4. Beakers or bowls with fire-rounded, upright rims, first to fourth century

143. C (4114), 250-350. Fragment from the rim and side of an 'Airlie' type beaker (Isings form $85 \mathrm{~b}$ ). Colourless glass with a green tint. Thickened, fire-rounded upright rim sloping slightly inwards. Late second to fourth century.

144.P (5027), 150-250. Fragment from the rim of an 'Airlie' type beaker (Isings form $85 \mathrm{~b}$ ). Colourless glass. Thickened, fire-rounded rim sloping slightly inwards. Late second or third century.

145-156. Rims similar to nos. 143 and 144 from area C (96), 450-600, SF. 6040 ;C (4013), c. 450. SF. 6496; C (4053), 300-450, SF. 6535; C (4132), 150-250; C (5311) 250-350 (x3); F (3034), 1750+, SF. 7237; F (3250), 1750+; K (4515), 250-450; P (5018), c. 450; P (5036), 1750+. Not illustrated.

5. Beakers or bowls with fire-rounded rims, cut out below the lip, first to fourth century

Nos 157-185 come from free-blown colourless vessels with thickened, fire-rounded rims cut out below the lip.

157.F (3045), 1750+, SF. 7337. Fragment from the rim of a small beaker. Straightsided body. Late second or third century.

158. M (4867), c. 250. Fragment from the rim of a small beaker. Late second or third century.

159. K (4439), 1750+. Fragment from the rim of a beaker or bowl. Late second or third century.

160-166. Rims similar to nos. 157-159 from area C (5311), 250-350 (x6); F (3001), 450-600; ${ }^{2} \mathrm{~F}(3011), 1750+$, SF. 7272; K (4506), 250-450; K (4515), 250-450. Not illustrated.

167. D (667), 175-250. Fragment from the rim of a straight-sided bowl or beaker. Late second to fourth century.

168-177. Rims similar to no. 167 from area D (659), 250-350 SF. 4600; D (658), 250-350, SF. 4590; D (658), 250-350, SF. 4593; D (658), 250-350, SF. 4594; D (657), 250-350, SF. 4582; D (676), 175-250, SF. 4643; D (676), 175-250, SF. 4676; D (559), 350-450 (x2); D (620), undated, SF. 1508. Not illustrated.

178. D (665), 250-350, SF. 4620. Fragment from the rim and side of a small cup. Second to fourth century.

179.D (453), 1750+, SF. 4148. As no. 178 above. 


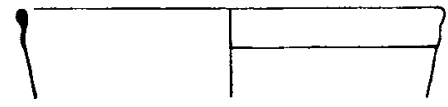

143

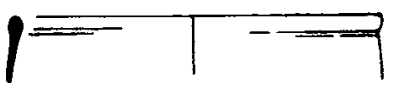

157

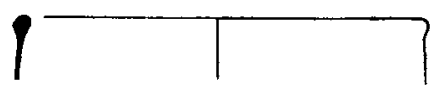

159

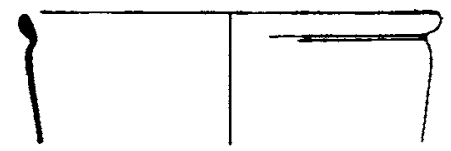

178

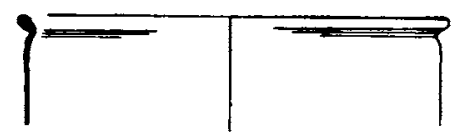

180

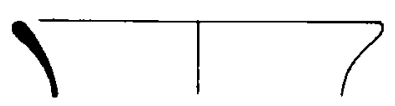

186

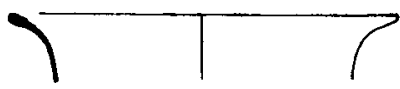

193

$\gamma$

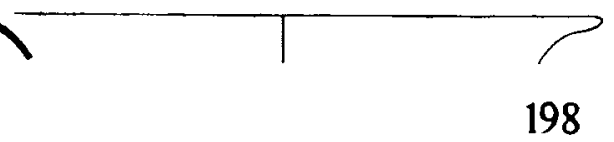

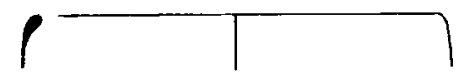

144

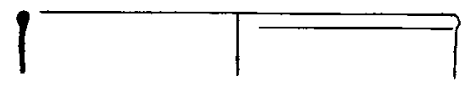

158
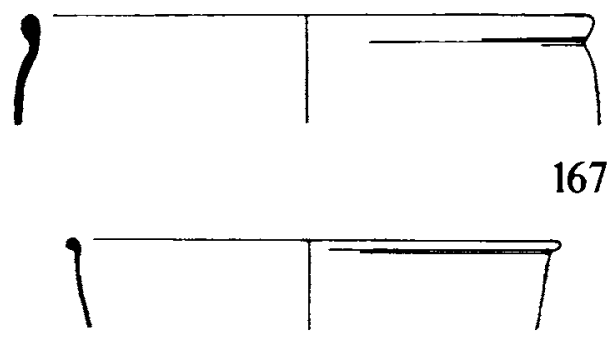

179

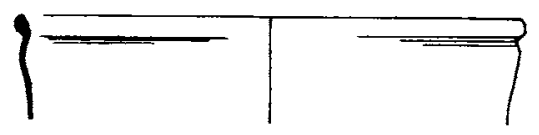

181

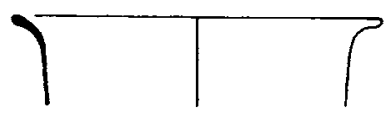

192

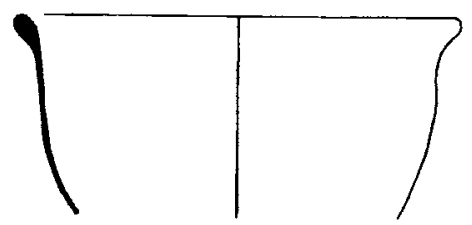

194
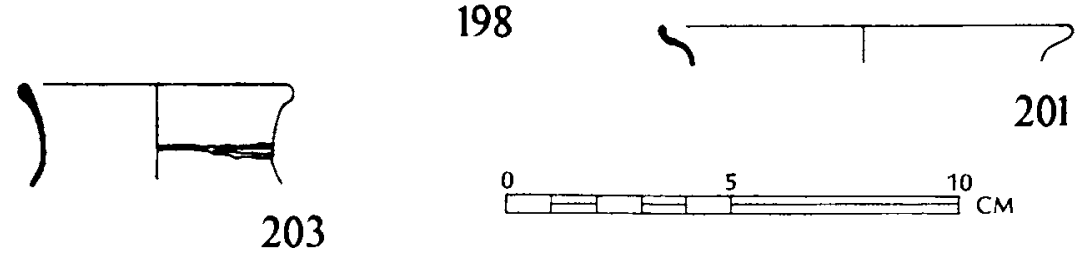

11.8 Beakers and bowls, first to fourth century 
180.D (661), 250-350, SF. 4617. As no. 178 above.

181.D (656), 350-450, SF. 4581. As no. 178 above.

182-185. Rims similar to no. 178 from area D (656), 350-450, SF. 4583 (x2); D (661), 250-350, SF. 4612; D (451), 1750+. Not illustrated.

\section{Beakers or bowls with fire-rounded outsplayed rims, first to fourth century}

Unless otherwise stated, nos 186-200 come from free-blown, colourless vessels with fire-rounded and outsplayed rims.

186. D (676), 175-250, SF. 4659. Fragment from the everted rim of a bowl or beaker. Colourless glass with a green tint. Second to fourth century.

187-191. Rims similar to no. 186 from area D (693), 350-450, SF. 4707; D (676), 175-250, SF. 4675; D (659), 250-350, SF. 4592; D (676), 175-250, SF. 4646; D (453), 1750+. Not illustrated.

192. D (699), 130-150, SF. 4716. Fragment from the everted rim of a bowl or beaker. Colourless glass with a green tint. Second to fourth century.

193. D (676), 175-250, SF. 4668. Fragment from the everted rim of a bowl or beaker. Colourless glass with a green tint. Second to fourth century.

194.D (676), 175-250, SF. 4644. Seven fragments from the rim and side of a small hemispherical cup. Second to fourth century.

195-197. Rims similar to no. 194 from area D (667), 175-250; D (676), 175-250 SF. 4649; D (691), 150-175, SF. 4701. Not illustrated.

198. F (3088), 1750+, SF. 8012. Fragment from the rim of a bowl. Natural green glass. Late second to fourth century.

199-200. Rims similar to no. 198 from area F (-), SF. 7661; F (3128), 450-600, ${ }^{3}$ SF. 7476. Not illustrated.

7. Jars with fire-rounded, outsplayed rims, first to fourth century

Nos 201-203 come from free-blown vessels with fire-rounded, outsplayed rims.

201.D (677), 175-250, SF. 4670. Small fragment from the rim of a jar or beaker. Colourless glass with a green tint. Third or fourth century.

202. D (677), 175-250. A rim similar to no. 201. Not illustrated. 


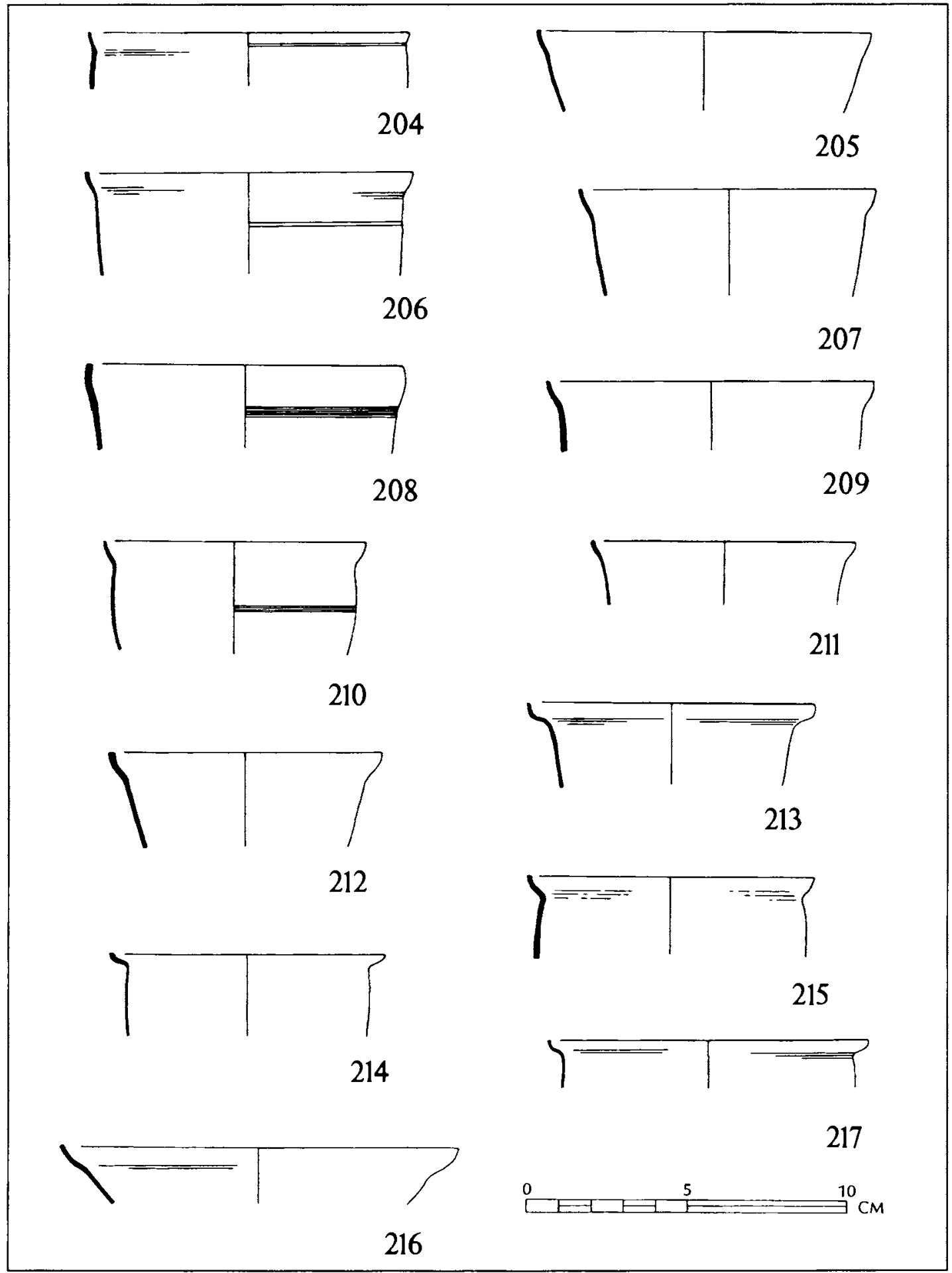

11.9 Beakers and bowls, first to fourth century 
203.P (5014), c. 450. Fragment from the rim of a beaker. Natural green glass.

Body decorated with spiral trail of the same metal. Third or fourth century.

\section{Beakers with cracked-off, outsplayed rims, late third or fourth century}

Unless otherwise stated, the following fragments (nos 204-237) come from free-blown, naturally coloured beakers with cracked-off, outsplayed rims.

204. K (4405), 1750+, SF. 10114. Fragment from the rim of a beaker. Colourless glass. Body decorated with a horizontal wheel-cut line $c .3 \mathrm{~mm}$ below the lip. The body of the vessel swells outwards below this line. Late third or fourth century.
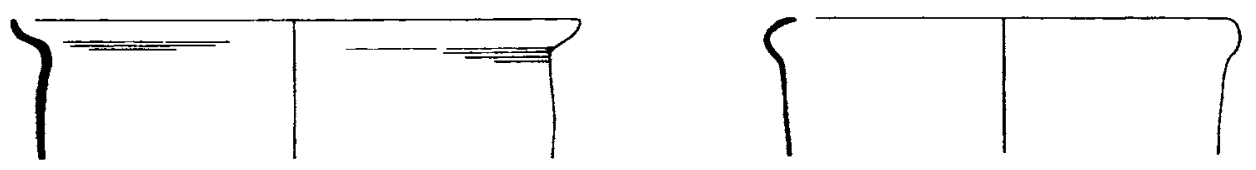

219

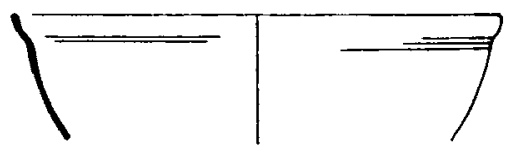

238

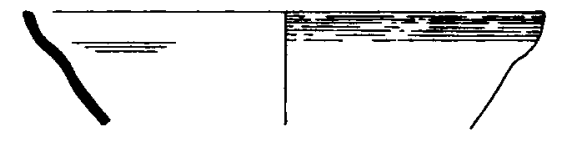

239

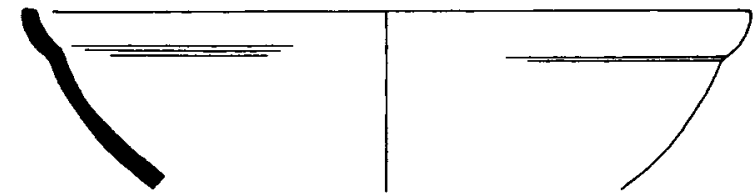

240

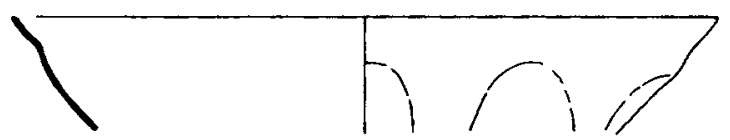

241

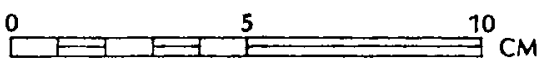

11.10 Beakers and bowls, first to fourth century 
205. C (4007), 1750+. Fragment from the rim and side of a beaker. Late third or fourth century.

206. F (3011), 1750+, SF. 7114 . Fragment from the rim of a beaker. Late third or fourth century.

207.F (3288), 400-450. As no. 206.

208. P (5051), c. 450. As no. 206.

209. P (5051), c. 450. As no. 206.

210.P (5051), c. 450. As no. 206.

211. M (4805), 1750+. As no. 206.

212. C (40), 1750+. As no. 206.

213. P (5051), c. 450. Large fragment from the rim and side of a beaker. Wide, outsplayed and cracked-off rough rim. Third or fourth century.

214.P (5051), c. 450. As no. 213.

215. F (3258), 1750+. As no. 213.

216. E (1190), 400-450. As no. 213.

217.E (1189), 400-450. As no. 213 but thin walled and with almost horizontal lip. Third or fourth century.

218. A similar rim to no. 217 from area E (1190), 400-450. Not illustrated.

219. E (1147), c. 450. Fragment from the rim of a beaker. Third or fourth century.

220.P (5018), c. 450. Fragment from the rim of a beaker. Good quality natural green glass. Outsplayed and cracked-off rim, almost horizontal lip. Third or fourth century.

221. K (4405), 1750+. Fragment from the rim and side of a beaker. Late third or fourth century. Not illustrated.

222-237. Rims similar to no. 206 from area C (96), undated, SF. 6048; E (1031), 450-600, SF. 3060; E (1147), 400-450; F (3011), 1750+, SF. 7326; F (3041), 1750+, SF. 7150; F (3047), 450-600, SF. 7192; F (3182), 800-1000; F (3209), 1750+; F (3219), 450-600; F (3241), 400-450 (x2); F (3255), 1750+; F (3264), $1750+; \mathrm{F}$ (3286), 450-600; F (3349), 400-450; P (5051), c. 450. Not illustrated. 
9. Shallow bowls with cracked-off, outsplayed rims, late third or fourth century

Nos 238-241 come from free-blown, naturally coloured shallow bowls with cracked-off, outsplayed rims.

238. D (451), 1750+. Fragment from the rim and side of a small bowl. Late third or fourth century.

239. F (3349), 400-450, SF. 8326. As no. 238.

240. D (-). As no. 238.

241.P (5051), c. 450 . As no. 238.

\section{BOWLS, BEAKERS AND JARS (BASES), first to fourth century (Fig. 11.11)}

\section{Applied base rings}

The following fragments come from the bases of bowls or beakers, probably those described above in section C. All are colourless and free-blown except for no. 244, and have applied base rings.

242. P (5027), 150-250. Fragment from the side of a bowl or beaker. Late first to third century.

243.P (5024), 150-250. As no. 242.

244.P (5024), 150-250. As no. 242 but in a natural green glass. Not illustrated.

245.P (5051), c. 450. As no. 242. Not illustrated.

\section{Pedestal base rings}

Nos 246-248 are all naturally coloured pedestal base fragments from free-blown vessels, probably bowls.

246. C (4110), 250-350. Fragment from the pedestal base ring of a plate or bowl. Late third or fourth century.

247. B (341), 175-250. Fragment from the base of a large bowl or jar. Pushed-in base forming a wide and high hollow tubular base ring. Late first to third century. Not illustrated but see no. 664 for a similar, later example.

248. C (4131), 150-250. As no. 246. Not illustrated. 


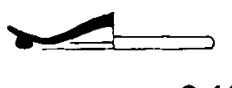

242

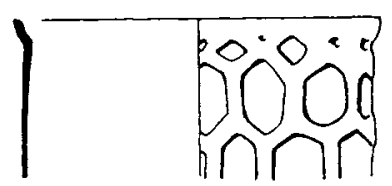

253

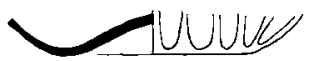

255
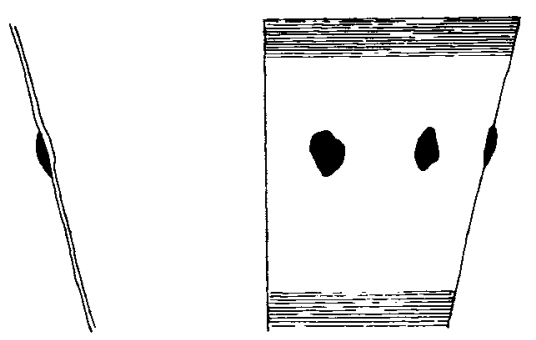

257

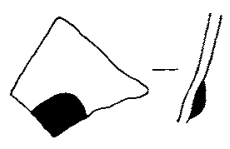

263
243
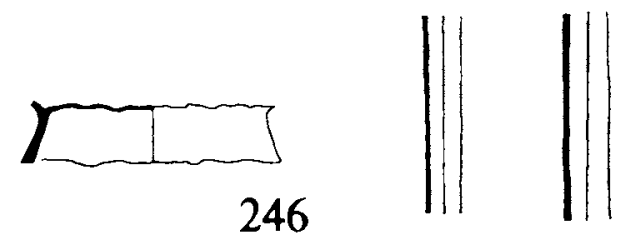

249

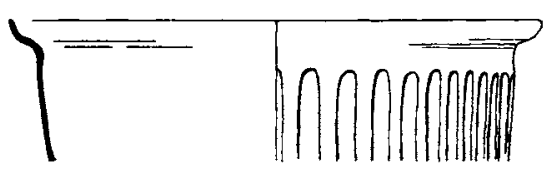

254

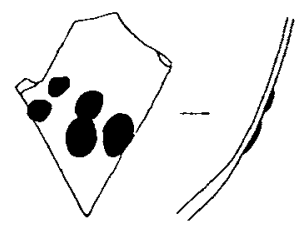

256
(8)

258

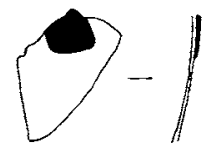

265
... 260 


\section{FUNNELS (Fig. 11.11)}

Fragments from the lower ends of funnels. The upper portions are probably recorded in the bowl fragments described above. All are free-blown colourless glass.

249. D (691), 150-175, SF. 4709. A cylindrical tube of glass, possibly part of a funnel. Length $38 \mathrm{~mm}$; width $6.5 \mathrm{~mm}$. Roman.

250.D (676), 175-250, SF. 4663. Fragment as no. 249. Length 40mm; width tapers slightly from 9 to $8 \mathrm{~mm}$. Roman.

251.C (4118), 130-150. Fragment as no. 249 . Length $21 \mathrm{~mm}$; width tapers slightly from 8 to $7 \mathrm{~mm}$. Second or third century. Not illustrated.

252.P (5024), 150-250. Fragment as no. 249. First to third century. Not illustrated.

\section{MOULD-BLOWN BEAKERS DECORATED WITH RIBS AND HONEYCOMB PATTERNS (Fig. 11.11)}

253. P (5018), c. 450. Eight fragments from the rim and side of a beaker. Mouldblown natural green glass. Outsplayed and cracked-off rim. Body decorated with mould-blown honeycomb design in relief. Third or fourth century.

254.A (2245) SF. 5278, 130-175. Fragment from the rim and part of the side of a beaker. Optic-blown natural green glass. Rim outsplayed, cracked-off and left rough. Decorated with relief vertical ribs. This is a late Roman type which must be intrusive in this context, dated $\mathrm{AD} 130-175 .{ }^{4}$ Fourth to sixth century.

255. D (451), 1750+. Fragment from the base of a bowl or beaker. Mould-blown colourless glass with a green tint. Pushed-in base. Body decorated with a low relief honeycomb pattern. Fourth or fifth century.

\section{BEAKERS AND BOWLS DECORATED WITH APPLIED MONOCHROME BLOBS (Fig. 11.11)}

Nos 256-268 are from free-blown vessels of very good quality natural green glass with a brown tint.

256. F (3054), 1750+, SF. 7261. Fragment from the side of a beaker. Decorated with five green marvered blobs. Fourth or fifth century. 
257. F (3071), 1750+. Fragment from the side of a beaker. Decorated with a line of marvered blue blobs (of which three are extant) with, above, a zone of horizontal wheel-cut lines $c .8 \mathrm{~mm}$ wide and below, a similar zone at least $10 \mathrm{~mm}$ wide. Fourth or fifth century.

258. F (3011), 1750+, SF. 7336 . As no. 257 but decorated with a blue marvered blob. Fourth or fifth century.

259. A fragment similar to no. 258 from area F (3011), 1750+, SF. 7114. Not illustrated.

260.E (1194), 400-450. Fragment from the side of a beaker. Decorated with three marvered blue blobs. Fourth or fifth century.

261-262. Similar fragments to no. 260 from area E (1014), c. 450, SF. 3017 (two marvered blobs); E (1189), 400-450 (one marvered blob). Not illustrated.

263. D (449), 1750+. Fragment from the side of a beaker or cup. Body decorated with marvered blue blobs of which only one is extant on this fragment. Fourth or fifth century.

264-267. P (5051), c. 450. Four fragments from the bodies of an indeterminate number of beakers or bowls. Decorated with applied and marvered blue blobs. Fourth or fifth century. 264 and 265 illustrated.

268.P (5018), c. 450. As nos 264-267.

\section{STEMMED GOBLETS, fourth to sixth century (Fig. 11.12)}

All of the following fragments (nos 269-282) come from free-blown naturally coloured vessels except the optic-blown vessel no. 269.

269. A (2192), c. 450, SF. 5217. The lower part of the bowl and part of the stem of a goblet. Optic-blown on a solid stem of natural green glass. Conical bowl decorated with vertical ribs in low relief. Round ball knop. Fourth to sixth century.

270.D (434), 1750+, SF. 4104. The stem of a goblet. Hollow, cylindrical stem splaying towards the base. A single thin merise wraps around the stem. Fourth to sixth century.

271.F (3032), 450-600, ${ }^{5}$ SF. 7444. The base of a stemmed goblet. One piece. Pushed-in base with a hollow tubular base ring and ball knop. Fourth to sixth century. 

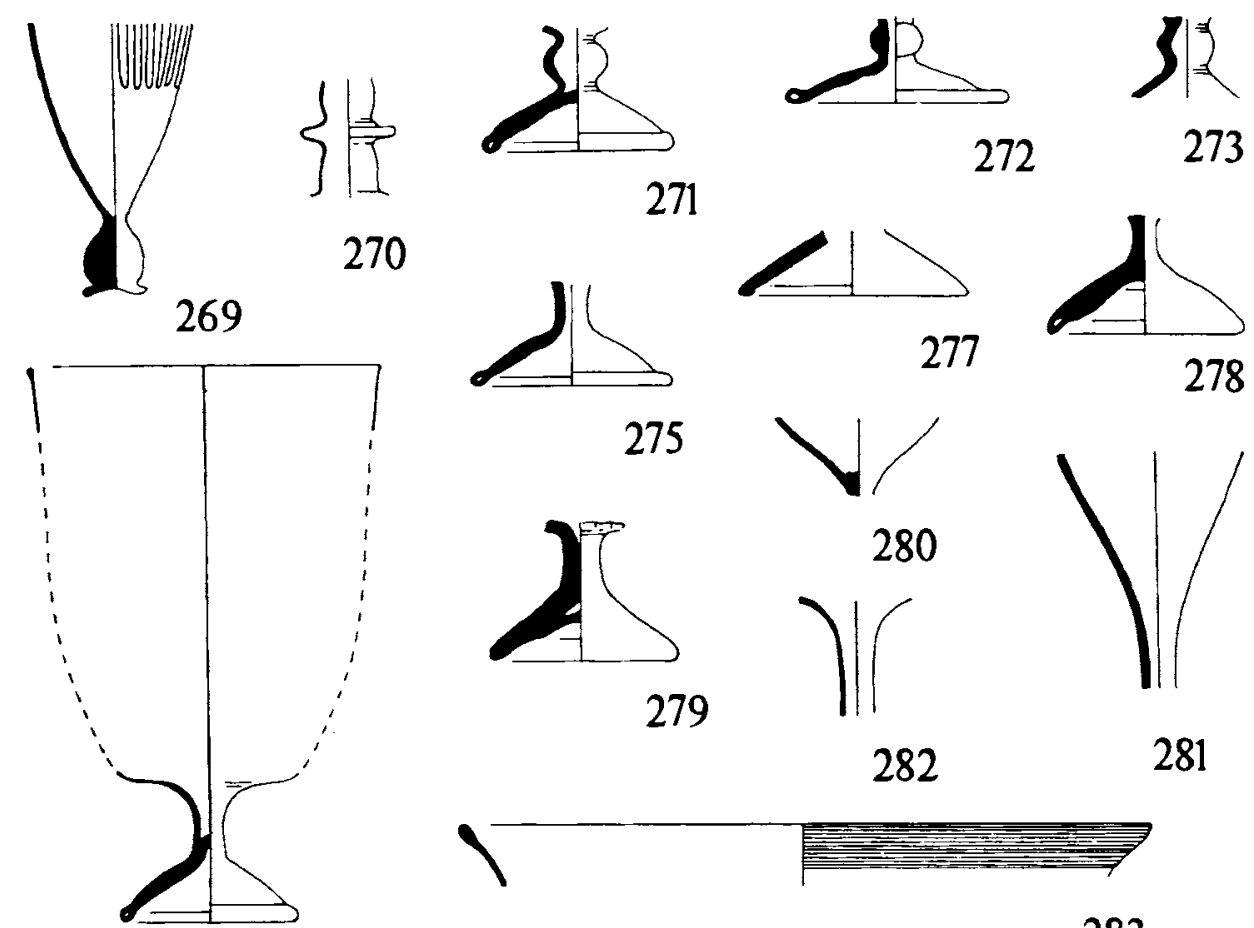

274
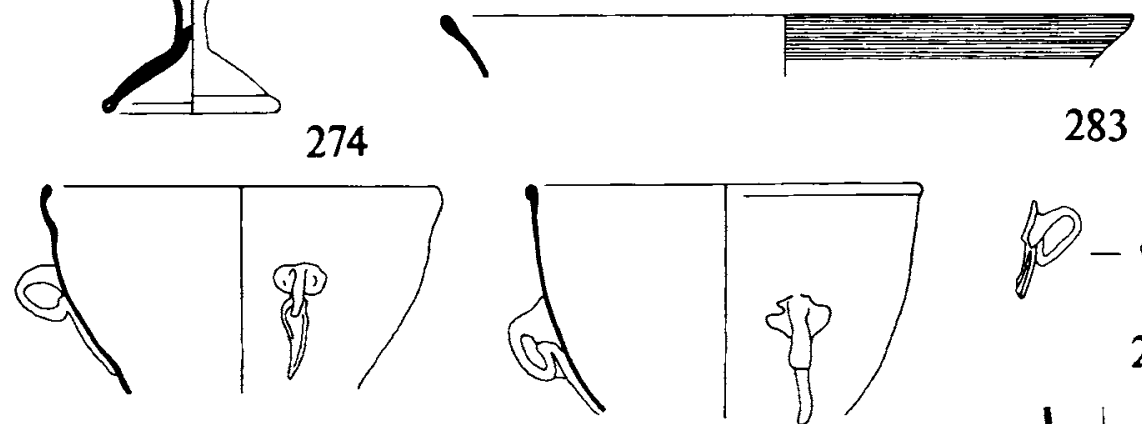

282
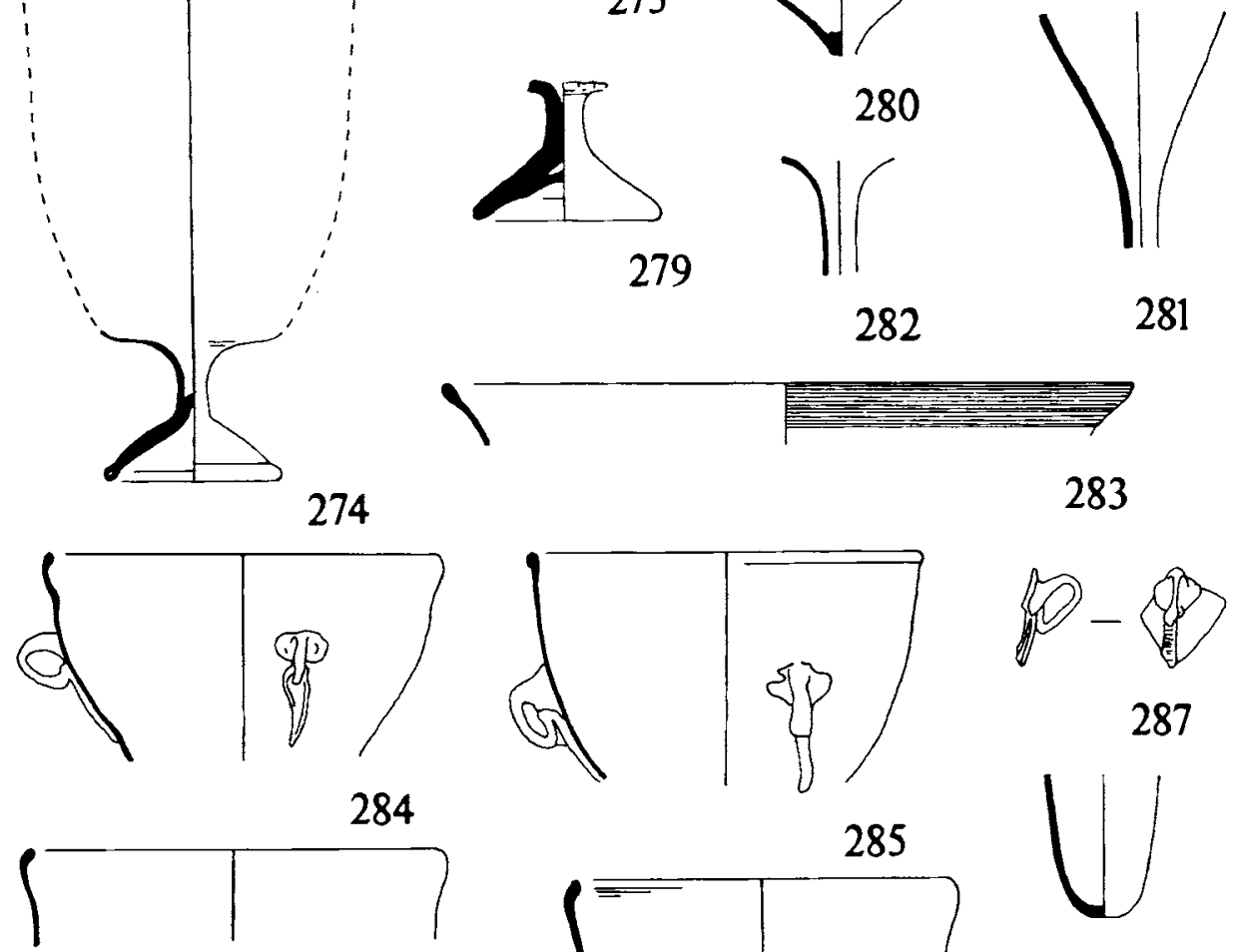

288
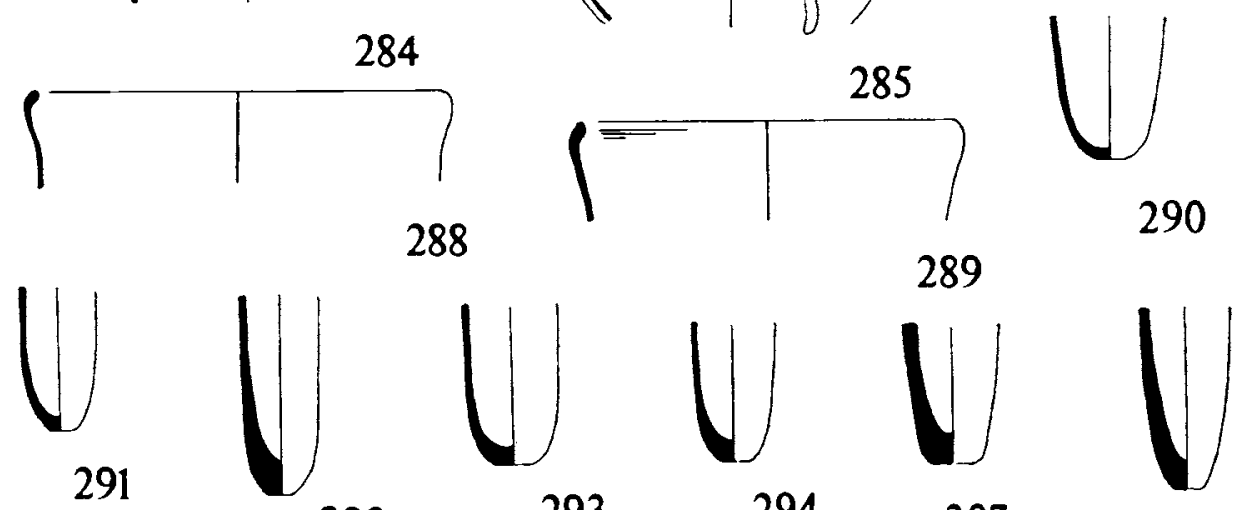

290

289
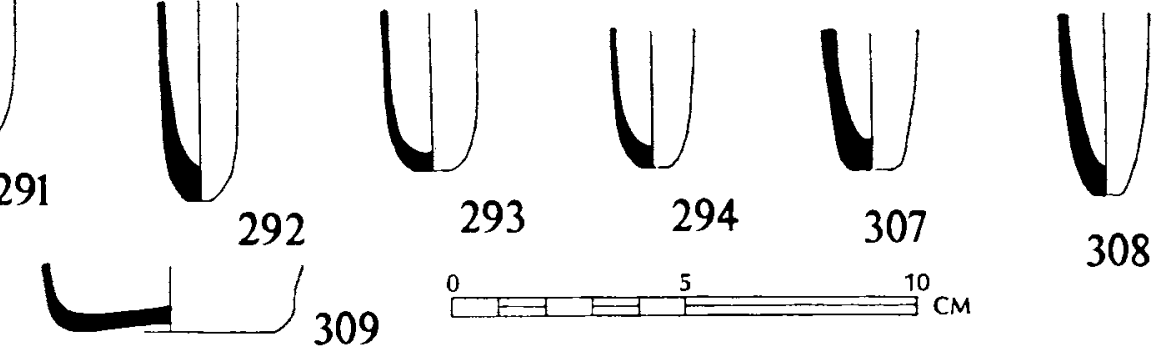

308

11.12 Stemmed goblets and lamps, fourth to sixth century 
272. E (1087), 450-600, SF. 3298. Fragment from the base of a stemmed goblet. One piece pushed-in base with a hollow tubular base ring and ball knop. Fourth or sixth century.

273. F (3132), 1750+. Fragment from the stem of a stemmed goblet. One piece with a round knop. Fourth to sixth century.

274. F (3032), 450-600, ${ }^{6}$ SF. 7438. The rim and the lower part of a stemmed goblet. One piece. Rim fire-rounded and upright. Pushed-in base with a hollow tubular base ring. Plain stem, bowl flat at base. Fourth to sixth century.

275. F (3254), 1750+, SF. 8124. The base of a stemmed goblet. One piece pushedin base with hollow tubular base ring. The stem is incomplete but a slight flaring suggests that there was a round knop. Fourth to sixth century.

276. A base similar to no. 275 from area F (3139), 450-600, ${ }^{7}$ SF. 7764 . Not illustrated.

277. F (3139), 450-600, ${ }^{8}$ SF. 8043. Fragment from the base of a stemmed goblet. One piece pushed-in base with a hollow tubular base ring. Fourth to sixth century.

278. A (2020), 450-600, SF. 5016. Fragment from the base of a stemmed goblet. Pushed-in base with a slight hollow tubular base lip. Fourth to sixth century.

279. A (2035), 450-600, SF. 5053. A base as no. 278. Fourth to sixth century.

280. D (473), 450-600, SF. 4562. The lower part of the bowl of a stemmed goblet. Fourth to sixth century.

281. B (248), 300-450, SF. 2500. The lower part of the bowl of a stemmed goblet. Conical, waisted body with a hollow stem. Fourth to sixth century.

282. M (4915), 400-450. The stem and part of the base of a stemmed goblet. One piece. Hollow stem. Fourth to sixth century.

\section{LAMPS, fourth to sixth century (Fig. 11.12)}

Nos 283-309 come from free-blown naturally coloured vessels.

283. D (445), 450-600, SF. 4125. Fragment from the flared rim of a lamp or beaker. Rim fire-rounded, decorated with a thin, closely set spiral trail of the same metal. Fourth to sixth century.

284. F (3032), 450-600, ${ }^{9}$ SF. 7448. Fragment of the rim and side of a lamp. Firerounded rim. One small applied handle with a flattened spur is extant. Also from this context are two other body fragments each with a similar handle with flattened spurs. Fourth to sixth century. 
285. F (3032), 450-600, ${ }^{10}$ SF. 7391. A rim and handle as no. 284.

286. F (3125), 1750+, SF. 7465. A rim and handle as no. 284. Not illustrated.

287. F (3032), 450-600, ${ }^{11}$ SF. 7433. Fragment from the small handle of a lamp. Fourth to sixth century.

288. F (3250), 1750+. Fragment from the rim of a lamp. Flaring body with a thickened and fire-rounded in-sloping rim. Fourth to sixth century.

289. F (3250), 1750+. As no. 288.

290. E (1110), c. 450, SF. 3291. Fragment from the base of a lamp. Thick, rounded base with pontil scar. Fourth to sixth century.

291. F (-), SF. 7456. The lower part of a lamp. Thickened rounded base with pontil scar. Fourth to sixth century.

292. F (-), SF. 7456a. As no. 291. Burnt.

293. F (-), SF. 7456b. As no. 291. Burnt.

294. F (3009), 450-600, SF. 7012. As no. 291.

295-306. Bases similar to no. 291 from area F (-), SF. 7492 (x2); F (3045), 1750+, SF. 7258 burnt; F (3032), 450-600, ${ }^{12}$ SF. 7424, SF. 7425, SF. 7426 (x2), SF. 7434 (x2) both burnt, SF. 7440 (x2); F (3193). ${ }^{13}$ Not illustrated.

307. K (4426), 1750+. The base of a lamp. The base is rounded with a pontil scar. Fourth to sixth century.

308.S (5251), 1750+. The base of a lamp. Hollow pointed base with a thickened end. Pontil scar visible. Fourth to sixth century.

309. K (4453), 1750+. Fragment from the base of a beaker or lamp. Thick flat base with thin, slightly flared, walls. Fourth to sixth century.

\section{WHEEL-CUT DECORATED VESSELS, fourth to sixth centuries (Fig. 11.13; plate III)}

The following fragments (nos 310-312) come from free-blown naturally coloured vessels.

310.P (5018), c. 450. Fragment from the side of a bowl. Decorated with a shallow wheel-cut and incised design consisting of what appears to be the shoulder of a figure holding a spear or standard. The fragment is badly weathered, so much so that the outer layer of the weathering disintegrated shortly after 


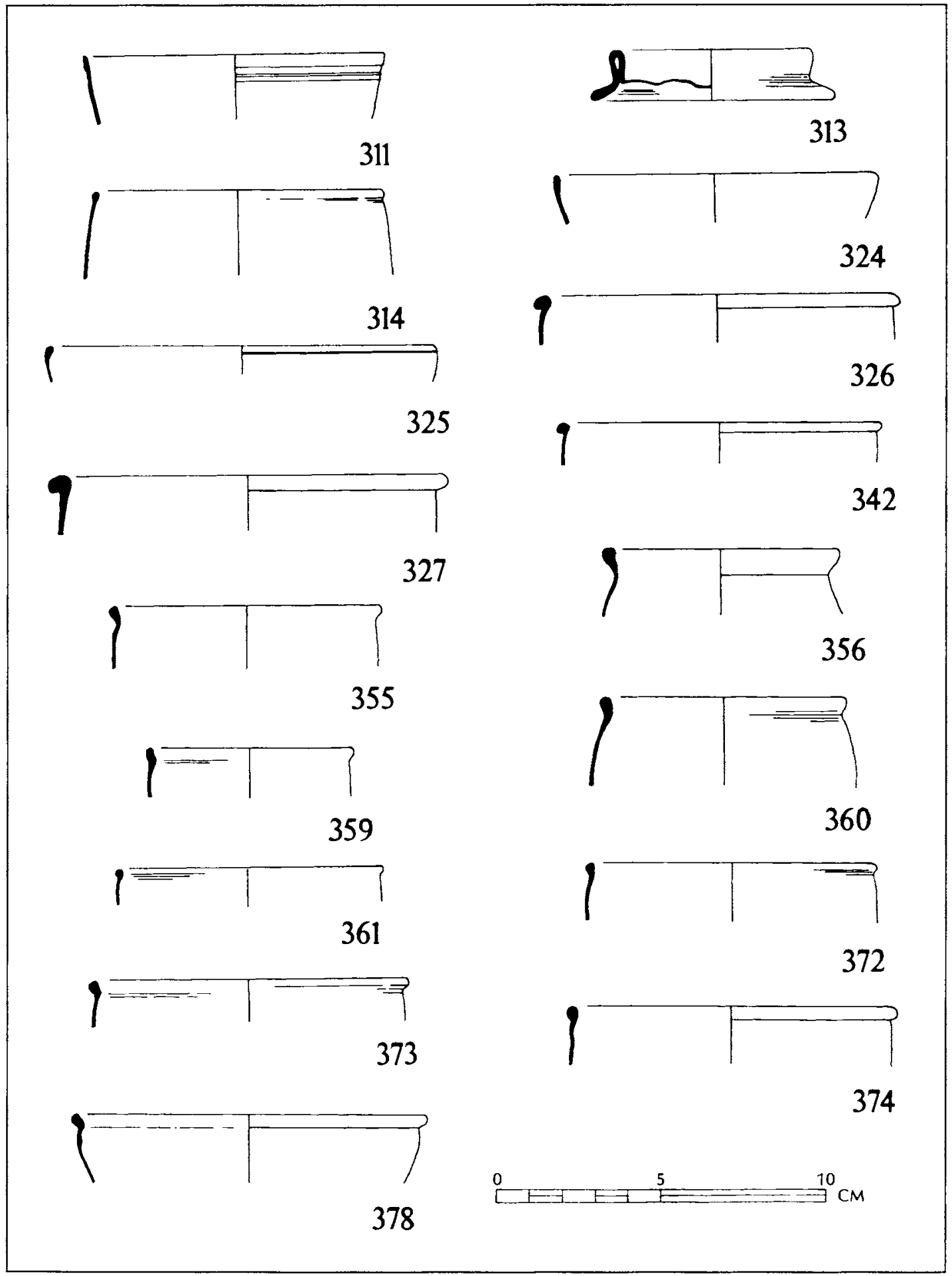

11.13 Wheel-cut decorated vessels, flanged jar (313), beakers and bowls, fourth to sixth century 
discovery, taking with it the shallow decoration. Plate IV,6 is the only record of the design.

311.F (3219), 450-600. Fragment from the rim of a bowl or beaker. Cracked-off rim with two broad wheel-cut lines below the lip. Fourth to sixth century.

312. E (1194), 400-450. Fragment from the side of a bowl. Decorated with horizontal wheel-cut line in three groups on the interior. Fourth to sixth century. Not illustrated.

\section{FLANGED JAR, fourth to sixth century (Fig. 11.13)}

313. A (2054), 1750+, SF. 5075. Fragment from the rim of a jar. Free-blown colourless glass. Rim folded down and horizontally forming a flange to take a lid. Fourth to sixth century.

\section{BOWLS, BEAKERS AND JARS, fourth to} sixth century (Figs 11.13-11.15)

\section{Beakers and bowls with fire-rounded, upright rims}

Nos 314-325 come from free-blown, colourless vessels with a green tint with upright, fire-rounded rims.

314. A (2251), 450-600. Fragment from the rim and part of the side of a beaker. Straight sided vessel. Fourth to sixth century.

315-323. Rims similar to no. 314 from area A (1), 1750+ (x2); A (9), 1750+ (x2); A (11), 1750+; A (2024), c. 450 (x3); A (2216), 450-600. Not illustrated.

324. E (1024), 450-600, SF. 3106. Fragment from the rim of a beaker. Fourth to sixth century.

325. F (3011), 1750+, SF. 7138. Fragment from the rim of a beaker or bowl. Fourth to sixth century.

\section{Beakers or bowls with thickened, overhanging rims}

Unless otherwise stated, nos 326-354 come from free-blown colourless vessels with a green tint with thickened, overhanging bead rims. 
326. F (3011), 1750+, SF. 7344. Fragment from the rim of a bowl or beaker. Fourth to sixth century.

327. F (3209), 1750+, SF. 8182. As no. 326.

328-341. Rims similar to no. 326 from F (3011), 1750+, SF. 7139, SF. 7366; F (3042), 1750+, SF. 7152; F (3045), 1750+, SF. 7275; F (3054), 1750+, SF. 7262 ; F (3139), 450-600, ${ }^{14}$ SF. 7764 (x3), SF. 7811 (x4); F (3209), 1750+; F (3310), $400-450$. Not illustrated.

342. M (4825), 450-600. Fragment from the rim of a beaker. The body of the vessel slopes in towards the rim. Fourth to sixth century.

343-353. Bead rims similar to no. 342 from area $M(-)$ (x3); M (4804), $1750+$ (x3); M (4805), 1750+ (x2); M (4827), 1750+; M (4835), 450-600; M (4945), 250-350. Not illustrated.

354.P (5018), c. 450. Fragment from the rim of a beaker or bowl. Fourth to sixth century. Not illustrated.

3. Beakers or bowls with fire-rounded rims, cut out below the lip, fourth to sixth century

Nos 355-501 come from free-blown beakers or bowls in a variety of metals colourless, colourless with a green tint and naturally coloured. All have fire-rounded rims cut out just below the lip.

355. M (4915), 400-450. Fragment from the rim of a beaker. Colourless glass with a green tint. The body slopes in towards the rim and is decorated with a very thin applied trail, probably spiral, of the same metal. Late third to sixth century.

356. C (4033), c. 450, SF. 6531. Fragment from the rim and side of a bulbous-bodied beaker or jar. Colourless glass with a green tint. Fourth to sixth century.

357-358. Rims similar to no. 356 from area C (5302), 300-450; C (5311), 250-350. Not illustrated.

359. K (4480), 1750+. Fragment from the rim of a beaker. Natural green glass. Fourth to sixth century.

360.E (1110), c. 450, SF. 3290. Fragment from the rim and side of a bulbousbodied beaker. Colourless glass with a green tint. Fourth to sixth century.

361. K (4512), 250-450. Fragment from the rim of a beaker. Natural green glass. Fourth to sixth century. 
362-371. Rims similar to no. 361 from area K (4405), 1750+; K (4439), 1750+; K (4480), 1750+ (x2); K (4499), 250-450; K (4506), 250-450; K (4512), 250-450 (x2); K (4515), 250-450 (x2). Not illustrated.

372. K (4430), 1750+. As no. 361 .

373.F (3297), 400-450. As no. 361.

374. $\mathrm{K}$ (4515), 250-450. Fragment from the rim of a straight-sided beaker. Colourless glass. Fourth to sixth century.

375-377. Rims similar to no. 374 from area K (4515), 250-450 (x3). Not illustrated.

378. C (4033), c. 450, SF. 6532. Fragment from the rim of a beaker. Colourless glass with a green tint. A variant of no. 356 above. Fourth to sixth century.

379-395. Rims similar to no. 378 from area C (91), 1750+, SF. 6038; C (4031), 450-600; C (4033), c. 450, SF. 6533, SF. 6523 (x2), SF. 6534, SF. 6538 (x2); C (4099), 400-500; C (4110), 250-350; C (4113), 250-350; C (4207), 400-600; C (5306), 250-350 (x3); C (5311), 250-350 (x2). Not illustrated.

396. F (3310), 400-450. Fragment from the rim of a beaker or bowl. Colourless with a green tint. Body tapers in towards the rim. Fourth to sixth century.

397-412. Rims similar to no. 396 from area F (-), SF. 8255; F (3011), 1750+, SF. 7118; F (3054), 1750+, SF. 7288, SF. 7296; F (3088), 450-600, ${ }^{15}$ SF. 7897; F (3128), 450-600, ${ }^{16}$ SF. 7541; F (3130), 1750+, SF. 7538; F (3132), 1750+; F (3139), 450-600; ${ }^{17} \mathrm{~F}(3139), 450-600 ;{ }^{18}$ SF. 7764; F (3219), 450-600 (x2); F (3254), 1750+; F (3286), 450-600; F (3310), 400-450 (x2). Not illustrated.

413. F (3250), 1750+. Fragment from the rim of a beaker. Colourless glass. Fourth to sixth century.

414-423. Rims similar to no. 413 from area $F(3292), 400-450$ ( $x 4) ; F(3297)$, 400-450; F (3306), 450-600; F (3334), 400-450; F (3355), 450-600; F (3361), $400-450$ (x2). Not illustrated.

424. D (661), 250-350, SF. 4612. Fragment from the rim of a beaker. Natural green glass. Fourth to sixth century.

425-463. Rims similar to no. 424 from areas D (402), 1750+; D (412), 450-600; D (422), 1750+, SF. 4062 (x2); D (424), 1750+, SF. 4054 (x2); D (426), 450-600; D (429), 1750+; D (434), 1750+, SF. 4104 (x2); D (445), 450-600, SF. 4115 (x2); D (449), 1750+, SF. 4143; D (451), 1750+; D (453), 1750+, SF. 4116 (x3); D (656), 1750+, SF. 4583 (x2); E (1004), 450-600, SF. 3042; E (1007), c. 450, SF. 3081; E (1010), 450-600, SF. 3068; E (1018), 1750+, SF. 3025, SF. 3031, SF. 3036; 


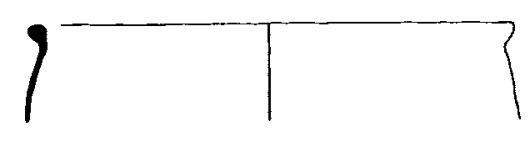

396

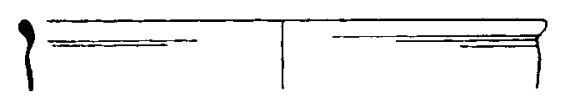

424

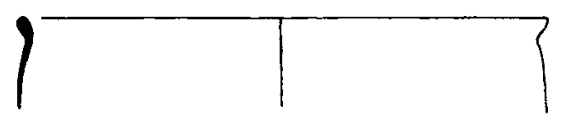

483

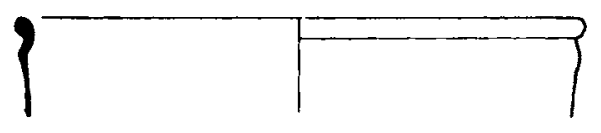

498
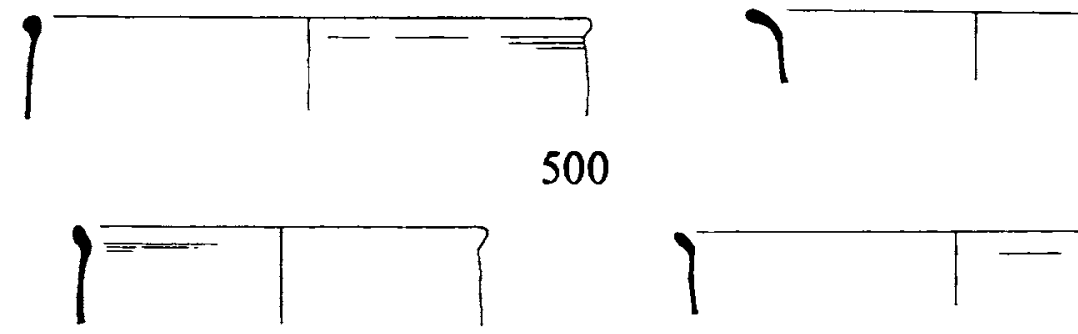

503

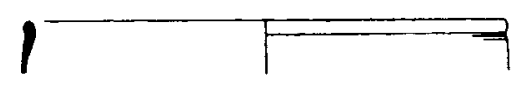

413

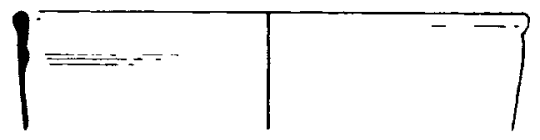

464

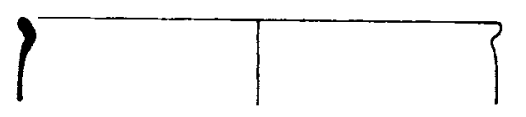

497

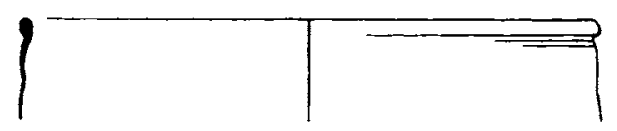

499
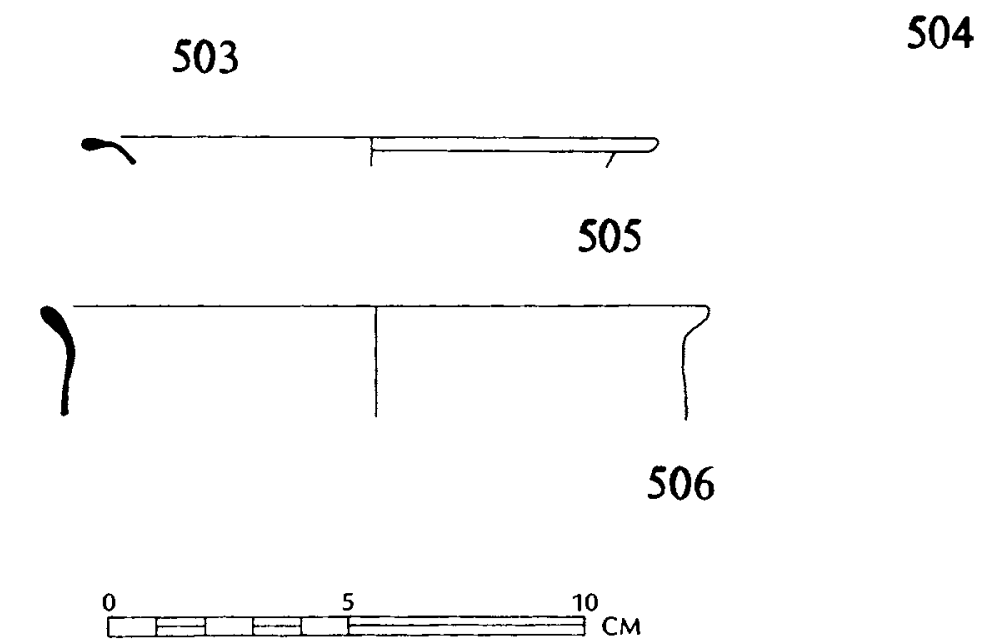

11.14 Beakers or bowls, fourth to sixth century 
E (1024), 450-600, SF. 3111, SF. 3101, SF. 3092; E (1031), 450-600, SF. 3073, SF. 3116, SF. 3061, SF. 3058; E (1040), 450-600, SF. 3083; E (1128), c. 450, SF. 3306; F (3298), 450-600; F (3310), 400-450 (x2). Not illustrated.

464. K (4506), 250-450. Fragment from the rim of a beaker. Colourless glass.

Fourth to sixth century.

465-482. Rims similar to no. 464 from area K (4402), 1750+; K (4415), 1750+; K (4432), 1750+ (x2); K (4479), 1750+ (x3); K (4463), 1750+; K (4493), 1750+; K (4505), 250-450 (x4); K(4506), 250-450 (x2); K (4516), 250-450 (x3). Not illustrated.

483. P (5050), c. 450. Fragment from the rim of a beaker. Colourless glass with a green tint. Body slopes in towards the rim. Fourth or fifth century.

484-496. Rims similar to no. 483 from area $\mathrm{P}$ (5018), c. 450; $\mathrm{P}$ (5019), c. 450; $\mathrm{P}$ (5020), 250-350; P (5021), 250-350 (x2); P (5024), 150-250; P (5030), 150-250; P (5039), 450-600; P (5045), 450-600; P (5051), c. 450 (x4). Not illustrated.

497.P (5022), 250-350. As no. 483.

498. C (4095), 400-500. Fragment from the rim of a small jar or beaker. Greenish blue glass. Fourth to sixth century.

499. R (5218), c. 450. Fragment from the rim of a straight-sided beaker. Colourless glass with a green tint. Fourth to sixth century.

500. F (3003), $450-600^{19}$ SF. 7016. As no. 499.

501. A rim similar to no. 499 from area E (1024), 450-600, SF. 3099. Not illustrated.

\section{Beakers or bowls with fire-rounded, outsplayed rims, fourth to sixth century}

Unless otherwise stated, nos 502-536 come from free-blown beakers or bowls of naturally coloured glass with fire-rounded, outsplayed rims.

502. K (4479), 1750+. Fragment from the rim of a bowl. Fourth to sixth century.

503. K (4507), 250-450. Fragment from the rim of a small bulbous-bodied bowl or beaker. Fourth to sixth century.

504. A (2040), c. 450. Fragment from the rim and part of the side of a beaker. Fourth to sixth century.

505.P (5014), c. 450. Fragment from the rim of a beaker or bowl. Good colourless glass. Fourth to sixth century. 
506. K (4480), 1750+. Fragment from the rim of a bulbous-bodied bowl or beaker. Fourth to sixth century.

507-536. Rims similar to no. 506 from areas A (2141), 450-600, SF. 5165; B (210), 450-600, SF. 2004; B (201), 450-600, SF. 1006; B (207), 1750+, SF. 1031; B (221), 130-150, SF. 2033; B (231), 175-350, SF. 1131; B (240), 1750+, SF. 2081, SF. 2101; B (241), 300-450, SF. 2113, SF. 2111; D (691), 150-175; D (550), 450-600; D (576), 350-450 (x2); D (583), 350-450 (x3); E (1010), 450-600, SF. 3076; E (1031), 450-600, SF. 3053, SF. 3114; K (4402), 1750+ (x2); K (4479), 1750+; K (4480), 1750+ (x2); K (4506), 250-450 (x3); K (4509), 250-450. Not illustrated.

\section{Jars with fire-rounded, outsplayed rims}

Nos 537-544 come from free-blown jars of naturally coloured glass with firerounded, outsplayed rims.

537. A (2023), c. 450, SF. 5059. Fragment from the rim of a jar. Fourth to sixth century.

538. F (3001), 450-600. ${ }^{20}$ Fragment from the rim of a beaker or jar. Fourth to sixth century.

539. C (4095), 400-500. Fragment from the rim and side of a jar or bowl. Fourth to sixth century.

540-544. Rims similar to no. 539 from area C (4007), 1750+; C (4033), c. 450, SF. 6536; C (4107), 250-350; C (5306), 250-350 (x2). Not illustrated.

\section{Beakers with cracked-off and outsplayed rims, fourth to sixth century}

Nos 545-554 come from free-blown beakers in naturally coloured glass with cracked-off, outsplayed rims.

545.D (473), 450-600, SF. 4237. Fragment from the rim of a beaker. Fourth to sixth century.

546. A similar rim to no. 545 from area D (434), 1750+, SF. 4095. Not illustrated.

547.F (3298), 450-600, SF. 8273. As no. 546 but in a good natural green glass, similar to the metal for the vessels with blue blobs (nos. 256-268). Fourth or fifth century.

548.P (5051), c. 450. As no. 547.

549.P (5051), c. 450 . As no. 547. 
550.P (5018), c. 450, SF. 14211 . As no. 547.

551.A (2251), 450-600. Fragment from the rim and side of a beaker. Body decorated with an applied trail of the same metal $25 \mathrm{~mm}$ below the lip. Fourth to sixth century.

552. A (2017), c. 450, SF. 5065. Small fragment from the rim and side of a beaker. Fourth to sixth century.

553. A (2014), 450. As no. 552, 600, SF. 5037. As no. 552. Not illustrated.

554.P (5018), c. 450, SF. 14139. Fragment from the rim of a beaker. Fourth or fifth century. Not illustrated.

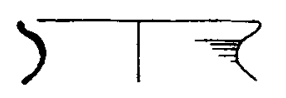

537

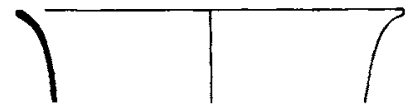

538

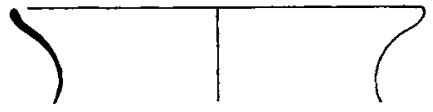

539

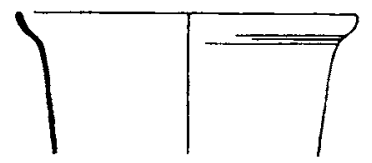

545

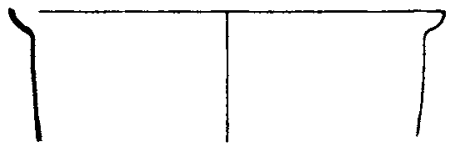

548

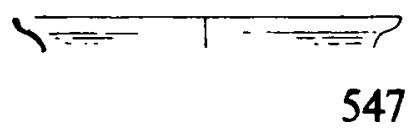

\section{7}

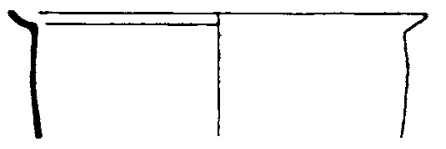

549
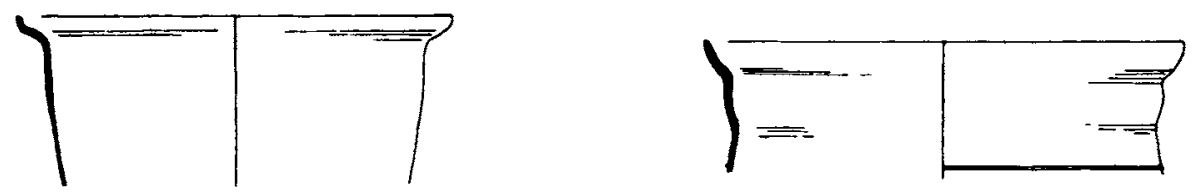

550

551
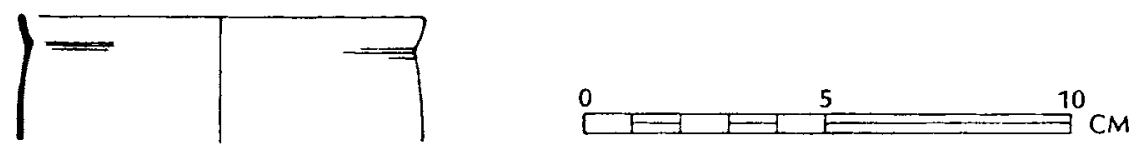

552

11.15 Jars and beakers, fourth to sixth century 


\section{BASES OF BOWLS, BEAKERS AND JARS (Figs 11.16-11.17)}

1. Slightly pushed-in bases with constriction from beakers or bowls, fourth to sixth century

Nos 555-562 come from the bases of free-blown beakers or bowls, probably those represented by the rim fragments above. They are of naturally coloured glass and have a slightly pushed-in base with a slight constriction above.

555. E (1191). 400-450. Fragment from the base of a beaker. Fourth to sixth century.

556-557. Bases similar to no. 555 from area E (1031), 450-600, SF. 3062; E (1190), 400-450. Not illustrated.

558. P (5051), c. 450. The base of a beaker. In a very good quality metal similar to that used for the beakers with coloured blobs (nos 256-268). Fourth or fifth century.

559. A similar base to no. 558 from area $P(5051)$, c. 450. Not illustrated.

560.P (5048), c. 450. Fragment from the base of a beaker. Fourth to sixth century.

561-562. Similar bases to no. 560 from area P (5018), c. 450 (x2). Not illustrated.

\section{Simple, pushed-in bases from beakers}

Nos 563-578 come from free-blown beakers in naturally coloured glass with simple, pushed-in bases.

563. B (247), 300-450, SF. 2243. Fragment from the base of a beaker or phial (unguentarium). Fourth to sixth century.

564. B (241), 300-450, SF. 2116. Fragment from the base of a beaker. Fourth to sixth century.

565-569. Bases similar to no. 564 from area B (213), 300-450, SF. 2017; B (231), 300-450, SF. 2040; B (240), 1750+, SF. 2069, SF. 2074; B (243), 300-450, SF. 2177. Not illustrated.

570. D (488), 1750+, SF. 4561. Fragment from the base of a beaker. Fourth to sixth century.

571. A base similar to no. 570 from area D (402), 1750+. Not illustrated.

572. K (4480), 1750+. Fragment from the base of a beaker. Fourth to sixth century.

573. F (3157), 1750+. Fragment from the base of a beaker. Fourth to sixth century. 


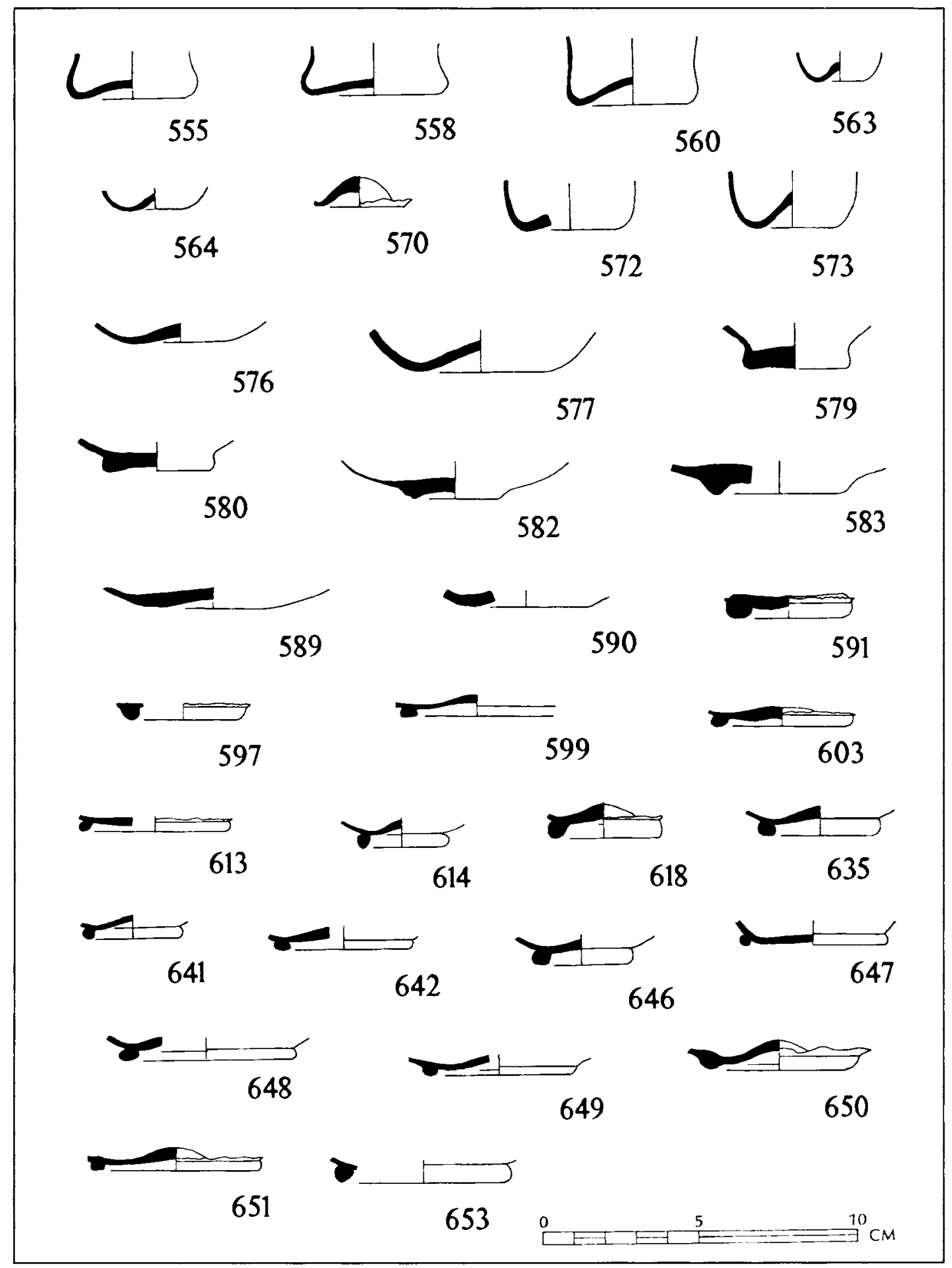

11.16 Beakers, bowls and jars (bases), fourth to sixth century 
$574-575$. Bases similar to no. 573 from area $F(3011), 1750+; F(3078), 450-600 .^{21}$ Not illustrated.

576. P (5051), c. 450. Fragment from the base of a bowl. Fourth to sixth century.

577.F (3034), 1750+, SF. 7186. Fragment from the base of a bowl or flask. Fourth to sixth century.

578. B (293), 300-450. The base of a bowl or jar. Fourth to sixth century. Not illustrated.

\section{Thickened bases from beakers or bowls, fourth to sixth century}

Nos 579-590 come from free-blown bowls or jars with thickened bases and flared walls of colourless glass with a green tint.

579. F (3011), 1750+, SF. 7103. The base of a bowl. Fourth to sixth century.

580. F (3288), 400-450. As no. 579.

581. A base similar to no. 579 from area F (3193), 450-600, ${ }^{22}$ SF. 8116 . Not illustrated. 582. M (4951), 250-350. The base of a wide bowl or dish. Fourth to sixth century. 583. (3250), 1750+. As no. 582 .

584-588. Bases similar to no. 582 from area F (3045), 1750+, SF. 7202; F (3047), 450-600, SF. 7203; F (3233), 450-600; F (3288), 400-450; F (3353), 400-450, SF. 8317 . Not illustrated.

589. D (-). The base of a wide bowl or dish. Fourth to sixth century.

590.P (5049), c. 450. Fragment from the base of a beaker or bowl. Fourth to sixth century.

\section{Applied true base rings from beakers or bowls, fourth to sixth century}

Nos 591-661 come from the bases of beakers or bowls, probably those represented by the rims above. They are all free-blown in a variety of metals, especially colourless with a green tint and natural green. The bases are fashioned with an applied base ring. 591. C (5306), 250-350. The base of a small bowl or beaker. Colourless glass with a green tint. Fourth to sixth century.

592-596. Similar bases to no. 591 from area C (4031), 450-600, SF. 6511; C (4033), c. 450, SF. 6530, SF. 6539, SF. 6540; C (4131), 150-250. Not illustrated. 
597. A (2017), c. 450, SF. 5017. Fragment from the base of a beaker. Natural green glass. Fourth to sixth century.

598. A (2109), 450-600, SF. 5109. A base similar to no. 597. Not illustrated.

599. M (4915), 400-450. Fragment from the base of a bowl or beaker. Colourless glass. Fourth to sixth century.

600-602. Bases similar to no. 599 from area $M(-)(x 2) ; M(4802), 1750+$, SF. 12015. Not illustrated.

603. D (658), 250-350, SF. 4595. The base of a bowl or beaker. Natural green glass. Fourth to sixth century.

604-612. Bases similar to no. 603 from area D (415), 1750+; D (416), 1750+; D (419), 1750+; D (421), 1750+; D (434), 1750+, SF. 4101 (x2); D (453), 1750+; D (665), 250-350; D (682), 350-450. Not illustrated.

613.D (663), 250-350, SF. 4616. Fragment as no. 603 in colourless glass.

614. K (4405), 1750+. The base of a small bowl or beaker. Colourless with a green tint. Fourth to sixth century.

615-617. Bases similar to no. 614 from area K (4479), 1750+; K (4505), 250-450; K (4511), 250-450. Not illustrated.

618. E (1110), c. 450, SF. 3289. The base of a beaker. Natural green glass. Fourth to sixth century.

619-634. Bases similar to no. 618 from area E (1004), 450-600, SF. 3052, SF. 3055; E (1024), 450-600, SF. 3087 (x3); E (1031), 450-600, SF. 3064 (x4); E (1033), 450-600, SF. 3056 (x4); E (1131), 450-600, SF. 3308 (x3). Not illustrated.

635. F (3001), 450-600, ${ }^{23}$ SF. 7007. Fragment from the base of a beaker or bowl. Natural green glass. Fourth to sixth century.

636-640. Bases similar to no. 635 from area F (3011), 1750+, SF. 7137; F (3078), $450-600 ;{ }^{24} \mathrm{~F}(3341), 400-450 ; \mathrm{F}(3241), 400-450 ; \mathrm{F}$ (3361), 400-450. Not illustrated.

641.F (3141), 1750+, SF. 7816. As no. 635.

642.F (3011), 1750+, SF. 7265. As no. 635 but in colourless glass.

643-645. Bases similar to no. 642 from area F (3011), 1750+, SF. 7137; F (3306), 450-600; F (3310), 400-450. Not illustrated.

646. F (3310), 400-450, SF. 8209 . As no. 635 but of natural blue glass. 
647.F (3182), 800-1000, SF. 8106. Fragment from the base of a beaker. Colourless glass with a green tint. Fourth to sixth century.

648. K (4515), 250-450. Fragment from the base of a bowl. Colourless glass.

Fourth to sixth century.

649. K (4431), 1750+. As no. 648 .

650.D (676), 175-250, SF. 4647. As no. 648.

651.D (676), 175-250, SF. 4650. As no. 648.
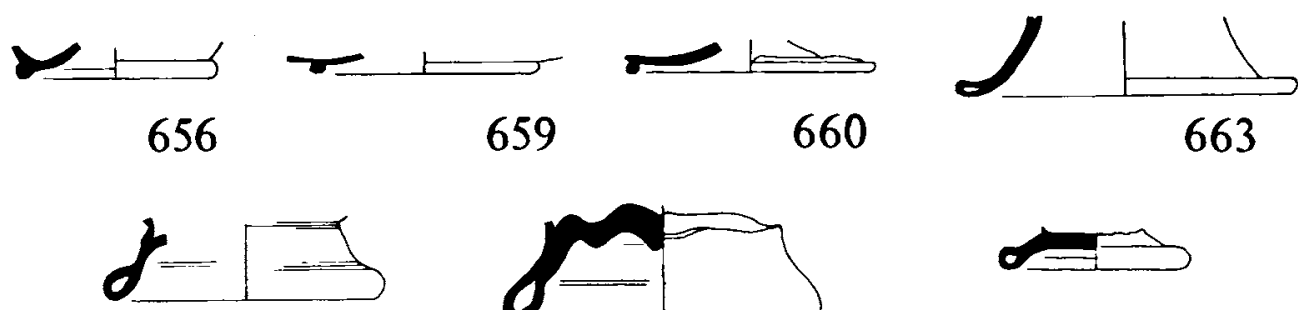

664

659

660

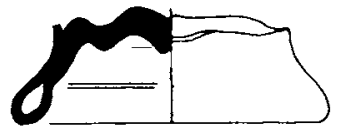

665

662
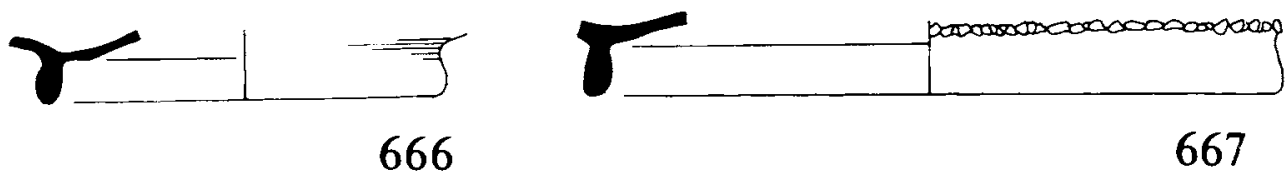

667

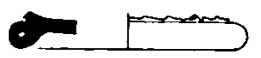

668

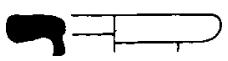

669
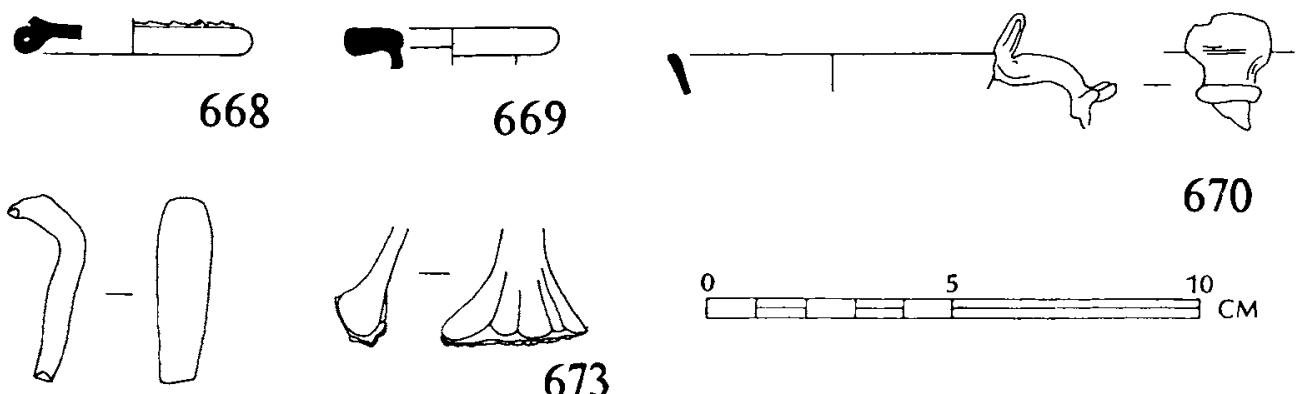

671

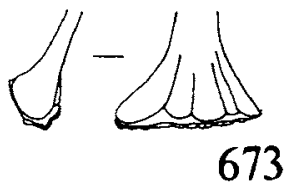

670

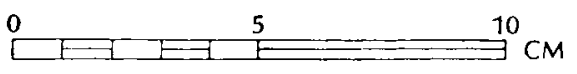

11.17 Beakers, bowls and jars (bases), jugs, flasks and bottles, fifth to sixth century 
652.D (491), 450-600, SF. 4242. A base similar to no. 648. Not illustrated.

653.P (5018), c. 450. Fragment from the base of a bowl or beaker. Natural green glass. Fourth to sixth century.

654-655. Bases similar to no. 653 from area $\mathrm{P}$ (5018), c. 450 (x2). Not illustrated.

656. B (240), 1750+, SF. 2072. Fragment from the base of a beaker or bowl.

Natural green glass. Fourth to sixth century.

657-658. Bases similar to no. 656 from area B (243), 300-450, SF. 2177; B (248), 300-450, SF. 2290. Not illustrated.

659. M (4861), 250-350. Fragment from the base of a bowl. Thin colourless glass. Fourth to sixth century.

660. B (248), 300-450, SF. 2290. Fragment from the base of a bowl. Colourless glass. Fourth to sixth century.

661. B (293), 300-450. A base similar to no. 660. Not illustrated.

5. High applied or pedestal base rings from beakers or bowls, fourth to sixth century

Nos 662-667 come from the high applied or pedestal foot rings of free-blown beakers or bowls of a variety of metals.

662. B (243), 300-450, SF. 2148. Fragment from the base of a beaker. Natural green glass. Pushed-in pedestal base with a hollow tubular base ring. Fourth to sixth century.

663. K (4512), 250-450. Fragment from the base of a beaker or flask. Colourless glass with a blue tint. Pushed-in high pedestal base. Fourth to sixth century.

664. D (682), 350-450. Fragment from the wide base of a bowl or beaker. Natural green glass. Pushed-in base forming a hollow tubular base ring. Fourth to sixth century.

665. D (665), 250-350, SF. 4619. Fragment from the base of a large bowl or jar. Thick natural green glass. Pushed-in base forming a high flattened hollow tubular pedestal foot ring. Fourth to sixth century.

666. E (1224), c. 450. Fragment from the base of a dish or plate. Natural greenishblue glass. Applied solid pedestal base ring. Fourth to sixth century.

667. K (4515), 250-450. Fragment from the base of a large dish or plate. Colourless glass. Large applied base ring. The broken vessel has been grozed 
around the edge of the base ring thus converting it into a shallow dish when inverted. Fourth to sixth century.

\section{A bowl or beaker with a hollow tubular base ring}

668. S (5281), c. 450. Fragment from the base of a beaker or bowl. Natural greenish-blue glass. Pushed-in base with a hollow tubular base ring. Fourth to sixth century.

\section{JUGS, FLASKS and BOTTLES, fourth to sixth century (Fig. 11.17)}

669. P (5014), c. 450. Fragment from the rim of a bottle or flask. Natural green glass. Folded in and flattened down rim. Fourth to sixth century.

670. A (2251), 450-600, SF. 5286. Fragment from the upper sticking part of the handle of a jug. Natural blue glass. Pinched grip on the vessel lip and the angle of the handle. Fourth to sixth century.

671.P (5051), c. 450. Fragment from the handle of a jug or flagon. Natural green glass. Plain strap handle. Fourth to sixth century.

672. P (5018), c. 450. Fragment from the upper sticking part of a jug or flagon. Natural green glass. Handle decorated with four relief ribs. Fourth to sixth century. Not illustrated.

673.P (5018), c. 450. Fragment from the handle of a jug or flagon. Colourless glass with a green tint. Plain strap handle. Fourth to sixth century.

\section{NOTES}

1-3 Destruction level over the floor of the Large Basilica - but contaminated by post-medieval robbing.

4 See above, footnote 11.

5-24 Destruction level over the floor of the Large Basilica. However, this context was contaminated by post-medieval robbing. 


\section{The glass catalogue: discussion}

\section{Introduction}

The list of comparanda for vessels from Nicopolis, discussed in the following section, is intentionally not exhaustive. Although it is likely that much of the imported glass came from the East, from Asia Minor and the eastern Mediterranean, and collections of glass for these regions have been published, very few sites can be regarded as providing securely dated assemblages, notable exceptions being Karanis in Egypt and Dura-Europos on the Euphrates. ${ }^{1}$ Perforce, the majority of secure or relatively secure dates for glass finds are more often in western Europe. This results in an apparent western bias in the literature cited but, until further material is forthcoming from well-stratified deposits in the East, it is here judged inappropriate to include all published examples, especially where the chronology is uncertain, when one of the primary aims of this report is to provide a reliably dated catalogue. ${ }^{2}$ Furthermore, glass finds from other sites on the lower Danube have rarely been published and the reports from Novae and Iatrus provide the only comparable assemblages for the region. ${ }^{3}$

\section{Detailed discussion of the pieces}

The small table or coaster fragment (no. 1) is of particular interest because of its rarity. It comes from a small rectangular stand with four small legs, carved to look like stylized animal legs, in imitation of full-sized tables. They must have functioned in much the same way as coasters or centre plates do today, namely for placing under drinking vessels or serving dishes. Metal examples are well known (see for example two circular silver stands from Pompeii in Ward-Perkins and Claridge 1976, nos 320-321).

Many glass examples have been published, not because the form was common, but because it is easy to distinguish such fragments from other cast forms of the mid to late first century. An almost complete rectangular colourless example 
from Rome, formerly in the Sangiorgi collection and now in the Corning Museum, measures $103 \times 69 \mathrm{~mm}$ and stood 25 to $28 \mathrm{~mm}$ high (Goldstein 1979, 152-3, no. 326, Acc. No. 66.1.211). Both this and the Nicopolis example are comparable with a more highly decorated rectangular stand $(115 \times 66 \mathrm{~mm})$ made from rock crystal in the Vatican Museum (Fremersdorf 1975, 118, no. 1063, pl. 85). This form is also known in coloured metals. An almost dark green example, measuring $143 \times 93 \mathrm{~mm}$, comes from a tomb at Mérida, Spain, associated with medical equipment (Floriano 1940-41, 420, fig. 5.19). This find accounts for the suggestion that such items may have served as palettes for mixing cosmetics and medicinal preparations ( $\mathrm{Cool}$ and Price 1995, 27). A larger, turquoise stand, $208 \times 136 \mathrm{~mm}$, was found in the Casa Dei Due Atri, Herculaneum (Scatozza Horicht 1986, 72, no. 258, tavv 23 and 40). A deep purple or deep blue fragment (the glass is almost black in colour) with part of one leg comes from Winchester Palace, Southwark, London from a late first century context (Brehm and Shepherd forthcoming). At least seven are known from Colchester. Three brown, almost black, examples came from the Sheepen excavations, one in a context dated $c$. AD 43/4 -60/1 and two from a pit dated $\mathrm{AD} 60 / 1-c .65$ (Harden 1947, 298, nos. 39-39a, pl. 87), a dark yellow-brown and a purple example (both almost black) came from Site J at Lion Walk, one in a context dated AD 60/1, the other dated AD 60/c. 75-100/150 (Cool and Price 1995, 26, nos 185-6), a yellowbrown, almost black, example was found in a context dated c. 49-110 at Gilbeard School (Cool and Price 1995, 26, no. 187) and a deep purple fragment came from a late second or third century context at Site G at Culver Street (Cool and Price 1955, 26, no. 188. Other examples are cited there from Carlisle, Fishbourne and Caersws in Britain). A few circular, colourless stands are also known. A fragment from the edge and one leg extant comes from a site adjacent to Winchester Palace in Southwark, at 21-23 Southwark Street (Calverts Buildings) (Shepherd 1992, 136, no. a $<918>$ ). This was a residual piece in a medieval pit. Another is known from Baden-Aquae Helveticae (Fünfschilling 1986, 144 no. 397, taf. 21).

The small cup (no. 2) is another rare type for which exact parallels are lacking and even similar vessels are not easy to find. Made in a thick and very good quality colourless metal with a greenish tint, this small cup has been ground and polished on the interior and exterior to produce the final shape. Close examination reveals slight bevels at the lip and immediately above the base, the fashioning of which must have required a great degree of skill. The cup itself belongs to a well known class of late first century cut and polished beakers and cups in a good quality colourless glass, typified by truncated conical beakers such as Isings form 21 , but it is obviously a purpose-made miniature vessel. So much time and technical effort has been spent on making this object that it must have been a valuable item and was made, perhaps, as a toy or a presentation gift.

Although exact parallels are not known to the author, two similar miniature bowls were found in London. The first is a green, ground and polished miniature 
cup with wheel-cut facets on the side, from the grave of a young girl in the eastern cemetery of Londinium at Mansell Street (Shepherd forthcoming, Museum of London Acc. No. MSL87, [745] <335>). The technique of manufacture of this Mansell Street piece puts it in the same category as the Nicopolis cup, but the monochrome colour of the metal is exceptional. Colourless glass and the use of glass-cutting specifically on cast and free-blown colourless blanks for fashioning shapes and decoration became popular during the Flavian period at a time when the demand for monochrome metals, including green, had long been in decline. It is possible that the London vessel is an early example of this technique but, whatever its function may be, it is sufficient here to stress, once again, that the character and quality of the metal, and the effort needed to fashion and decorate the vessel, suggest that it was not intended to serve a utilitarian function.

It is interesting to note that this London cup was found in a girl's grave, together with a fragment of first century millefiore glass and a coin of Hadrian, pierced for suspension; all may well have been keepsakes or toys ((Barber et al. 1990, 10). The girl was buried during the late second or early third century which suggests, perhaps, that the small cup may well have been a treasured possession, being passed from generation to generation for over a hundred years. Alternatively, it may have been lost and then found. Perhaps, like the millefiori fragment, they were items which so appealed to the young girl that her family determined to place them alongside her body in the grave. The second London cup is also green in colour, a dull emerald green, but is free-blown and undecorated (unpublished, Museum of London Acc. No. A27540). It was found in Lombard Street in 1927 and is without any other associations. Since its find spot is in the centre of the Roman town, it could hardly have come from a grave. Reference can be made here also to a small ceramic cup of the same size as the Nicopolis and London glass cups from London Wall, London and purchased by the London Museum in 1912 (unpublished, Museum of London Acc. No. A8413) which must belong to the same tradition.

No. 3 comes from the wing of a handle of a two-handled cup or skyphos (Isings 1957, form 39). These vessels are known in the Mediterranean region during the Hellenistic period and before the late first century BC but reappear in the colourless glass repertoires of the final quarter of the first century AD (Price 1991, 162). Examples of this date come from St Swithin's House, Walbrook, London (Price 1991, 159, no. 610), Mérida, Spain (Price 1974, 75-6, fig. 2.2), Vindonissa (Berger 1960, 83 , taf. 14.215). Price $(1991,162)$ notes an unpublished fragment from a first century context at the Unexplored Mansion site at Knossos, Crete. This form is also depicted on a wall painting at Pompeii (Maiuri 1957, xxii). It also appears in the catacombs at Rome (Fremersdorf 1975, 82, no. 800, taf. 42) and at Köln (Fremersdorf 1967, 62, taf. 21) but it is probable that these were made during the third century AD. A number of skyphoi, decorated with relief cut foliage and lettered designs, come from late third or fourth century graves at Zülpich-Enzen (Heimberg 1980, 35-6), Rheinbach- 
Flerzheim (Follmann-Schulz 1986, 23-4) and Köln-Lindethal (La Baume and Nüber 1971, 80, taf. 4.16; Harden 1987, 189, no. 99). Unfortunately, this fragment from Nicopolis is too small to permit direct comparisons with other known skyphoi.

The cast, colourless glass bowls (nos 4-8) date from the late first century and the early second century (see Grose 1991 for a recent summary of these forms). Parallels for the bowls with overhanging lips (e.g. nos 4-7) are numerous - for example at Dura-Europos, Syria (Clairmont 1963, 18f., no. 90), Karanis, Egypt (Harden 1936, Class IB I, 49-50, pl. xii, no. 166), four from a second century grave in Nieuwenhagen, Holland (Isings 1971, 77-8, nos 136-139) Conimbriga, Portugal (Alarcão 1965, 76). In Britain examples are known from Lullingstone (Cool and Price 1987, 111, nos 325 and 326), St. Thomas St., Southwark (Townend and Hinton 1978, fig. 176, no. 101), New Market Hall site, Gloucester (Charlesworth 1974, fig. 29, no. 4), Caerwent (Boon 1972-73, fig. 2, no. 19) Fishbourne (Harden and Price 1971, fig. 138, no. 26) and Caerleon (Boon 1972-3, 116).

The cast and wheel-ground and polished colourless bowls (nos 8 and 9) belong to a category of open form contemporary with nos 4-7 described above. Similar bowls, with rim diameters varying from 9 to $12 \mathrm{~cm}$, come from Dura-Europos (Clairmont 1963, 24, nos 90-91) and Karanis in Egypt (Harden 1936, pl. XII, no. 166). No. 10, a rim fragment with a ground horizontal rib below the rim, also belongs to the late first century. It is too small to be certain but there appear to be traces of a cut handle attachment. Possibly, this is another skyphos fragment but here with a plainer handle design.

Wheel-cut faceted vessels are a common feature of the Nicopolis assemblage and include examples dated from the late first to the third century. Many of these come from late Roman or later contexts but there is little doubt that they belong to the earlier Roman glass-working traditions. They must belong to the period of the Roman city, as must be the case for other examples of comparatively early glassware, and must have represented luxury imports. It is probable that they were made in regional centres of glass-working since their production required not only the skills of the glass-worker but also the services of the glass-cutter.

The base fragment, no. 11, is quite distinctive and comes from a class of facetcut conical beakers (Isings 1957, form 12) which are the earliest examples of Roman wheel-cut faceted forms (see Oliver 1984 for a detailed study of this form). This type is Flavian and Trajanic in date and was widely distributed throughout the Empire. Oliver (1984, 46-58) lists 105 examples from places as far apart as Britain and Begram in Afghanistan. The large base fragment, no. 39, with traces of a horizontal wheelcut line, is unparalleled and cannot be related to any known form. It is possible that it belongs to this late first century repertoire of colourless cut and ground vessels but, if so, then the vessel it came from would have been very large indeed.

Late second and third century hemispherical bowls with wheel-cut designs are well represented (nos 12-19 and 35). The most common designs were zones of small 
rice-grain shaped or circular facets, separated by bands of wheel-cut or abraded lines (e.g. York, Harden 1962, 136, fig. 88. HG 205.1) and were widely distributed across the Empire. Other examples from Britain include a vessel from a pit dated to $A D$ 155-165 at Towcester (Price 1980, 63, no. 1, fig. 14) and vessels from Verulamium (Charlesworth 1984a, 145, no. 86, fig. 62.38) Colchester (Cool and Price 1995, 76-8, nos 412-14), and Canterbury (Shepherd 1995, 1231, nos 54-7). They are also well attested throughout the north-western provinces, for example, at Köln (Fremersdorf 1967, 92 taf. 75 and 94, taf. 81), Lillebonne (Sennequier 1985, 55, no. 26), NidaHeddernheim (Welker 1985, 28, nos 86-7, taf. 7 and 19), Strasbourg (ArveillerDulong and Arveiller 1985, 106-8, nos 205 and 206) and Xanten (Charlesworth 1984b, 290, taf. 102.9), at Conimbriga in Portugal (Alarcão 1965, Est 3/84 and 86), Aquileia in Italy (Calvi 1968, 66-7, 72, no. 168, tav 11.3), Karanis, Egypt (Harden 1936, 120, no. 317, pl. 14) and Dura-Europos, Syria (Clairmont 1963, 60ff.). They are also found outside the Empire, such as a cup from a grave at Himlingöje, Denmark and Häven, Kreis Wismar, Germany (Fremersdorf 1967, 92-3, taf.n 76 and 78).

A large number of these vessels was found at Dura-Europos (Clairmont 1963, $60 \mathrm{ff}$.) where it was possibly to subdivide them into stylistic groups. For example, nos $12,14,18$ and 19, with a band of rice-grain facets separated from a zone of round facets by horizontal wheel-cut lines, are variants of Clairmont's Group D. No. 19 which is closely paralleled by an example from Strasbourg-Koenigshoffen (Arveiller-Dulong and Arveiller 1985, 107-8, no. 206). Nos 13 and 15-17, on the other hand, with rows of facets separated by horizontally cut lines of facets, compare with Clairmont's Group C (1963, 65-6, fig. 2). The significance of these groupings, however, is not clear and the fact that so many different groupings of facet and linear designs are known reflects more, perhaps, the virtuosity of the glass cutter than any regional or chronological variation.

A third class of wheel-cut vessel, in this case deep hemispherical cups with more geometric designs (nos 20-36), dates to the third century. These, like those described above, appear throughout the Empire. For example, seven bowls deposited c. $\mathrm{AD} 300 / 310$, which appear to have been a set, even though the decoration on each is different, came from the cellar of Building XIV, 5 at Verulamium (Charlesworth 1972, 208-10 no. 5, fig. 78, 48-50). Others are known from London (Wheeler 1930, 121, fig. 42,1-2), Köln (Fremersdorf 1967, 78, 80-4, tafn. 49, 54-63), Trier (GoethertPolaschek 1977, 54, no. 182, taf. 38) and Dura-Europos (Clairmont 1963, 74-9, nos 275-306, pls 27-9).

The two hemispherical bowls (nos 37-38), both from area P, come from a fourth century class of vessel which is often decorated with elaborated figural and geometric wheel-cut and incised designs (for example, see Harden 1987, 216-7, no. 120). Unfortunately, neither of these two fragments is decorated. A third fragment from area $\mathrm{P}$ retained traces of a wheel-cut figure, probably a man holding a spear or 
standard. This fragment (no. 310) could not be located for study at the end of the excavation although it has been photographed (plate IV, 6).

No. 40 comes from a small hemispherical bowl, wheel-cut and polished, with a ground relief decoration which includes a vertical bar. This is probably part of an inscription, the letter being a Latin 'I' or Greek iota or one bar of the Greek eta. Of course, with just this single letter it is not possible to reconstruct the entire legend but reference should be made here to a vessel from Canterbury, Kent, with a similar profile (Shepherd 1995, 1231-4, nos 66-7). This fragment had the letters 'ZII' which can be confidently regarded as an abbreviated form of ZHCAIC. A number of vessels with the legend PIE ZHCAIC and variations on this theme are well attested (UrnerAstholz 1974).

\section{Nos 41-63-Diatretum (Plates III, IV)}

Twenty-three fragments (nos 41-63) come from a cage cup (vas diatretum) which is, without doubt, the most luxurious vessel among the entire Nicopolis ad Istrum glass assemblage.

Vasa diatreta illustrate well the work of two kinds of artisan in the late antique period, the glass-worker and the glass (and gem) cutter. To produce a vessel such as the Nicopolis diatretum, the glass-worker (vitriarius) would first fashion a free-blown, thick walled beaker of colourless glass on which horizontal bands of coloured glass had been gathered or marvered. This 'blank' was then handed over to the glass-cutter (diatretarius) who would cut the vessel into its final shape. The results, with networks of circles, letters, ovolo collars and even figures standing proud from the surface of the receptacle itself, linked to it by small and well-concealed bridges, were the most expensive of glass vessels produced in late antiquity. Such was the appreciation of the skills involved in making these vessels, and their value, that a statute of $A D 337$ stipulated that both vitriarii and diatretarii were granted exemptions from tax (munera) on the understanding that they continued their craft and that they ensured that their skills were passed on to the next generation (Codex Justinianus 10, 64, 1). Furthermore, there was also a ruling in the Digest of Justinian (Digest 9,2,29) which held diatretarii liable if they, through carelessness, broke the vessels which were entrusted to them but protected those who received flawed blanks. This implies that there had been disputes between vitriarii and diatretarii over vessels which had broken while being cut. The latter could easily disguise his errors by blaming the blank supplied by the former and, no doubt, there must have been instances when many hours of work were lost by a diatretarius when a flaw in a blank caused the vessel to break. There would appear to have been some kind of formal and mutual agreement on the quality of the blanks at the time they were handed over from one artisan to another.

Because of their exceptionally high quality, these vessels have been the subject of a number of studies, especially since the late 1950s and the publication of the 
Rothschild Lycurgus cup (Harden and Toynbee 1959, with addenda and corrigenda in 1963). This study divided diatreta into two main categories, A) with figures and B) with network, sometimes with legends. Doppelfeld (1961) extended the typology for the network vessels, subdividing that group into four further classes. These are:

1. With inscription, ovolo collar and network

2. With inscription and network

3. With network only

4. With ovolo collar and network.

These systems of subdivision are intended, in the first instance, merely as a means of ordering the known examples of diatreta (Harden and Toynbee catalogued 26 examples in 1959, increasing this to 35 in 1963. Subsequent discoveries of vessels and fragments in private and museum collections and from excavated contexts have increased this number to about 50). The significance of the groups and different decorative regimes is still, however, unclear. There may be a chronological difference, although the fact that the vessels were cherished possessions during the late Roman period has no doubt resulted in them being passed on from one generation to another. There may also be regional differences but again, as valuable possessions, the cups could have travelled with their owners. This may account for the discovery of a cup with a Greek inscription in Köln (Doppelfeld 1961). The presence of a figured cup in the Begram hoard, Afghanistan, is an extreme though pertinent example which illustrates this point.

Diatreta with undercut decoration are known as early as the late first century $\mathrm{AD}$ (Harden 1987, 241), for example the beaker with a representation of a lighthouse found at Begram in Afghanistan (Whitehouse 1989). Fragments of another figured cup come from Athens and were recovered from the ruins of a building which was destroyed in $\mathrm{AD} 267$.

It may be no coincidence that both of the earliest known examples are figured vessels and that the majority of the Harden Group B vessels come from fourth century contexts, e.g. Yambol, Bulgaria (first half of the fourth century - Dimitrova and Popov 1977), Daruvar, former Yugoslavia (early fourth century - Sunkowsky 1956, fig. 19), Köln-Braunsfeld, Germany (first half of fourth century - Doppelfeld 1961), Niederemmel an der Mosel, Germany (second third of the fourth centuryBöhme et al. 1981, no. 66), Corinth, Greece (mid fourth century - Weinburg 1964, 51-4), Köln, Germany (two fourth century examples - Fremersdorf 1967, 64, taf. 24-5).

The surviving fragments of the Nicopolis cup come from the upper part of a diatretum. Some join together which allows a tentative reconstruction (fig. 12.1). 
The vessel had a slightly outsplayed rim with a raised ridge below the lip, a feature which is common to many of these vessels (e.g. the 'Trivulzio' and the Köln-Braunsfeld cups - Harden 1987, 238-41, nos 134-5). Below the rim is a band of blue vertical bars, connected to the body of the vessel on small bridges. Below this, a network with the upper part in green glass.

At first sight it would appear that the Nicopolis cup belongs to Doppelfeld's subdivision 2, i.e. inscription with network. However, on closer analysis, it would appear that the Nicopolis cup belongs to a group sui generis, a not surprising conclusion given that so few examples have been found. It is possible that the upper band was not an inscription but a plain zone of vertical bars. None of the five ends of these bars which survive on the fragments (not one bar is complete) has serifs. This contrasts with the serifs on the Greek and Latin legends on many of the surviving examples. However, it is interesting to note that two vessels do have legends without serifs. These are the fragment of a Doppelfeld subdivision 2 cup from Corinth (Weinberg 1964, 51-4 with a fragmentary legend that reads either BIBE VIVAS MVLTIS ANNIS or, possibly, FAVENTIBVS DEIS after other known cups) and a cup from Brigetio, now in the Budapest Museum (Nagy 1930, $111 \mathrm{ff}$. with the legend VIVAS MVLTIS ANNIS). It is surprising, however, that the bars on the Nicopolis cup are simple vertical elements with no indication of them having been parts of more detailed decorative elements or letters. Given the absence of serifs and other letters, it is most reasonable to propose that the vertical elements decorated the entire upper part of the cup and that there were no other letters or elements.

No other vessel survives with a similar decoration but it is interesting to compare the Nicopolis find with the fragment of what Weinberg believes to be an unfinished diatretum in the Benaki Museum, Athens (Weinberg 1964, 54-5). The fragment came from a collection purchased in Egypt and so, unfortunately, the original provenance is not known. It comes from the upper part of a colourless cup with the same profile as the diatretum with a rim diameter of $12 \mathrm{~cm}$. Immediately below the rim is a green band overlaid on the colourless body which has been vertically cut into broad and narrow bands $(0.6$ and $1.5 \mathrm{~cm}$ wide). Although this band is very close to the rim, it would appear that this object belongs to the diatretum class of vessel and is, in all probability, an unfinished example (no attempt has been made to eliminate the traces of cutting around the rim and on the blue band). Although it is possible that the narrower bars were to be cut away to make the spaces between letters (to be provided by the broad bars) the fact that they have been left as they were suggests that they were to be part of the design. If this is so, then it is possible that this vessel was designed to have a simple band of vertical bars, perhaps with stops between them.

Another feature of the Nicopolis cup is the narrow band of green glass around the top of the network. A fragment from the upper part of the network joins another 

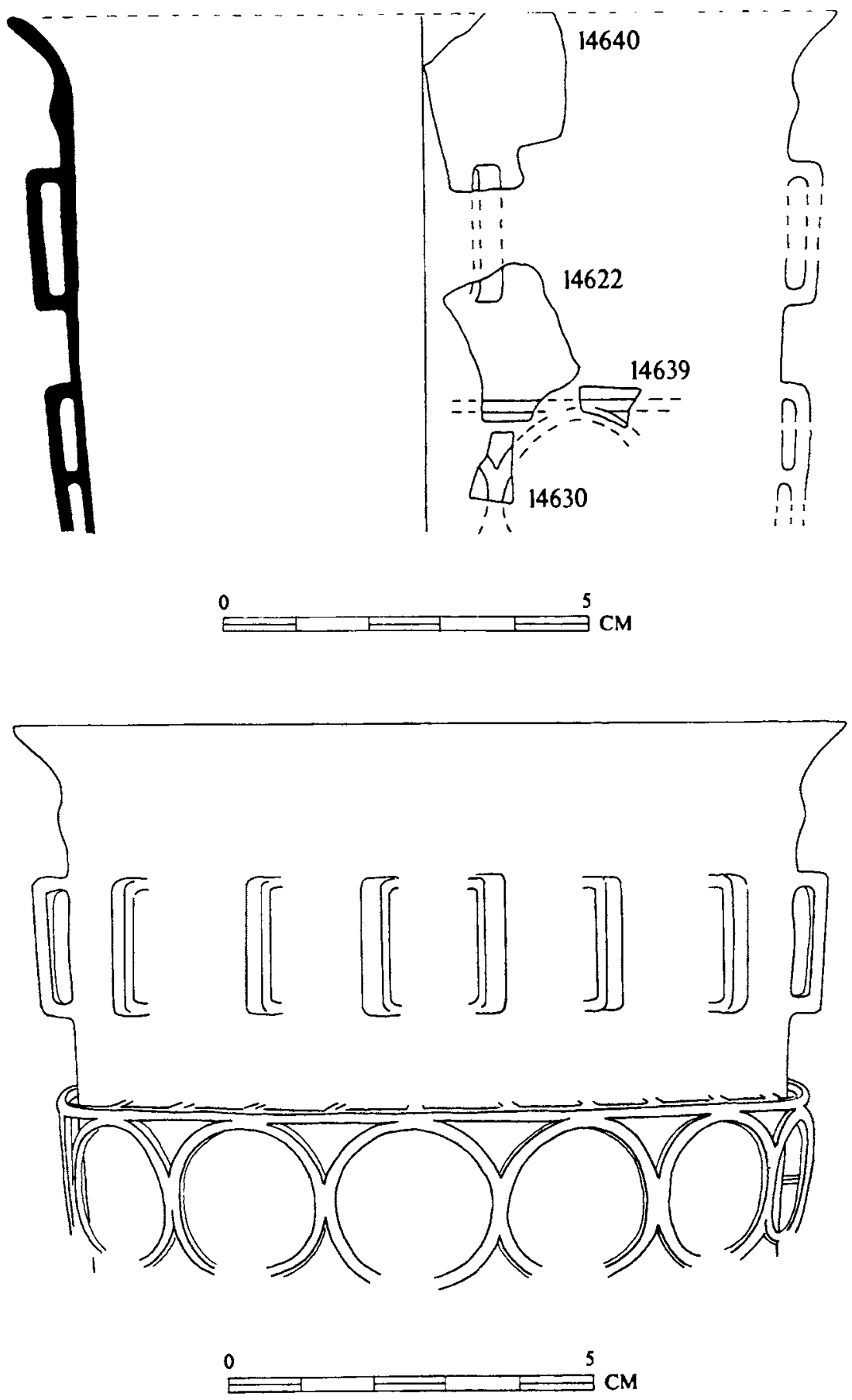

12.1 A. Approximate position of diatretum fragments. B. Tentative reconstruction of the diatretum 
fragment with the lower part of a blue vertical bar so there could not have been an ovolo collar decorated in a similar colour (cf. the Köln-Braunsfeld cup, Doppelfeld 1961. The tip of the ovolo collar and the horizontal bar at the uppermost bows at the top of the network on this cup is in yellow glass.) It would appear, therefore, that only a thin band of green had been applied to the colourless body in, it would appear, the place for the top of the network.

The discovery of the Nicopolis cup adds another example to the growing catalogue of late Roman diatreta. ${ }^{4}$ Unfortunately, it does little to help to resolve some of the questions that still need to be answered regarding these vessels. Because its decoration has no exact parallels, it does not add to our knowledge about the distribution of any particular group. The vessel, in this shattered form, came from a deposit which had been used to backfill the foundations of the early Byzantine tower (area P). This deposit (12.25 cubic metres) contained a large quantity of building materials and objects (including forty-four coins of the late fourth and early fifth century). It would appear that it had been collected from an area rich in building debris and finds, perhaps from the destruction deposit which covered the late Roman city when it was destroyed c. 450 (Poulter 1995, 215). If this is the origin of the deposit, then it would appear likely that the Nicopolis cup was in use during the first quarter of the fifth century.

Another highly decorated vessel type is represented by two small fragments of thick blue glass (no. 64, plate IV,5). This type is one of the very few monochrome coloured vessels from the site assemblage, a point worth noting in itself. But what makes it even more important is the deep cutting of the decoration which covers both fragments. In fact, it is possible to see that the cutting actually pierced right through the glass along a zone of ovals (the ovals being holes, not mere facets). The form of such an oval cut is best illustrated on the fragmentary cup from the Catacombs in Rome, now in the Biblioteca Apostolica and dated to the late third or fourth century (Harden 1987, 244). The gap between the stalks of two leaves and their lowermost parts is executed as a single vertical wheel-cut oval which has passed right through the outer cage of the vessel. It is very difficult to reconstruct the design of this vessel but one of the two fragments (SF. 13036) appears to consist of horizontal grooves with herringbone cutting between above a zone of oval holes, set vertically with oblique slashes between each oval. This general pattern is similar in style to an overlay glass beaker from Evebø, Sogn og Fjordane, Norway (Ekholm 1963, 34, fig. 27). Ekholm states there that this type 'seems to be an imitation of Oriental glasses, which suggests an Eastern origin although very few have been found outside Scandinavia.' The second fragment (SF. 13034) is cut with seemingly random lines which could represent the limbs of animals (Whitehouse 1990). This is not the place to examine in any great detail the possible parallels and importance of these fragments. It is sufficient here to note that it probably belongs to the diatreta class of vessel of the late third and fourth century. It must have been a vessel of some 
rarity and great value which, together with the diatreta from area $\mathrm{P}$, indicate that some of the inhabitants of late Roman Nicopolis were wealthy.

The oil flask or aryballos, represented by the handle fragment (no. 65), would have been used for containing oils and unguents required while bathing and is one of the most common types of toilet vessels. A handle or chain between its two small, dolphin-like handles allowed it to be suspended from the wrist or from a thong around the waist. The type first appears during the Claudian period (at Carnuntum see Isings 1957, form 61) and continues into the third century with some variations e.g. colourless with deep wheel-cutting such as from the legionary bath-house at Caerleon (Allen 1986, 107-8, no. 52). This particular site produced a very large number of these oil flasks dating from the early Flavian period to the mid to late third century. The form is rare in the fourth century. At Karanis, Egypt (Harden 1936,252 ) it is believed that none was made after the Constantinian period. One of the latest finds from the north-western provinces is an oil flask with a bowl-shaped mouth from a fourth century cemetery at Nijmegen (Isings 1957, 80). The form in the Black Sea region has been examined in a recent study by Sorokina (1987).

No. 66 is the upper part of a very thin-walled, trefoiled-mouthed jug. A simple handle has been attached to the shoulder of its bulbous body. Unfortunately, the handle is incomplete and so the upper sticking part of the handle cannot be described. The rim has been simply folded over at that part directly opposite the upper sticking part of the handle and very slightly pinched forming a very delicate spout. The trefoil-mouthed jug is well-known among Roman assemblages (Isings 1957 , form 56 a for first century shapes, Isings form 88 , especially form $88 \mathrm{~b}$, for second and third century shapes) but was not a common feature of late Roman repertoires and had disappeared by the early Byzantine period. Late second or early third century examples, the date of this Nicopolis vessel, come from Maastricht, Holland (Isings 1971, 37, no. 119, fig. 11), Epiais-Rhus, France (Vanpeene 1988, 34, nos 33-35), Trier, Germany (Goethert-Polaschek 1977, 199-200, form 117, nos 1227-1230) and Köln, Germany (Hagen 1906, 405, fig. XXIII, grave 34).

Nos 67-71, bottle or flasks mouths with flared rims and, in the case of nos 68-71, a self-coloured thick trail below the lip, were found in late fourth or early fifth century contexts at Nicopolis. This rim form is very common among assemblages of the late third and fourth centuries. Similar examples from Britain alone come inter alia from Canterbury (Shepherd 1995, 1244, no. 405), Frocester Court (Price 1979, 44, no. 34, fig. 17), Barnsley Park (Price 1982, 181, no. 31, fig. 60), Lankhills (Harden 1979, 219, no. 549, fig. 27), York (Harden 1962, 140, figs 89 and 90), Caerwent (Boon 1974, 114, fig. 2, 15), Shakenoak (Harden 1968, 76, no. 8, fig. 26,6) and Cirencester (Shepherd 1986, 120, nos 619-621). Such rim forms appear on Isings forms 102b, 120, 121, 123 and 126.

The handle fragments, nos 72-81, come from a diverse range of flagons and jugs which cannot be identified precisely. The flat strap handles are more likely to belong 
to bottles such as nos 67-71 above, whereas the smaller, rod handles probably come from small jugs or bottles.

No. 82 is an unusual fragment. It is very thick and has obviously been tooled and has a slight portion of a vessel body adhering to it. However, it is difficult to place on a vessel. It may be simply a thumb grip but, rather than a piece of the vessel body adhering to it, one would expect part of the lip or rim of the vessel. With part of the body present, this might be part of the lower sticking part of a handle. If this is so then this would be a very stout, thick and unorthodox type of handle indeed. A possible parallel may be a beaker, described as a cantharus, from Iatrus (Gomolka 1979,160 , no. 111 , fig. 64). This vessel, conical in profile with a slightly outsplayed rim, is fitted with two elaborate pleated vertical handles which touch the body at six points including the upper and lower sticking parts. It is possible that the Nicopolis fragment comes from a similar handle form, if not from a similar vessel.

The ubiquitous bottle of the mid first to third century AD (Isings 1957, form 50 and 51) is represented by surprisingly few fragments from Nicopolis. Nos 91-108 can definitely be identified as coming from the square-sectioned prismatic form (Isings 1957, form 50) whereas the rims and neck fragments (nos 83-87) could come from either the square or cylindrical form (Isings 1957, form 51). These bottles functioned as in transit and storage containers for liquid and semi-viscous comestibles and cosmetics, used in much the same way as ceramic amphorae though obviously for much smaller quantities.

The bottle rim fragment, no. 83, is particularly interesting. The precise form of this vessel is not certain. It may have come from a bulbous-bodied flask but it is more likely to be part of a square-sectioned bottle such as nos 91-108. The rim form itself is very unusual. It is very similar to Charlesworth's type $2 \mathrm{~b}$ (Charlesworth 1966, 26-7) which she described as being very rare, citing in her 1966 publication only two examples, one from Cyprus (Vessburg 1952) and another from Panticapaeum (Kerch) in the Crimea (British Museum inv. no. 56.3-11, 3-4). Since her study appeared, other eastern Mediterranean and especially Black Sea assemblages have been published. The work of Sorokina has identified this as a common rim form in that region (see Sorokina 1990, fig. 2 for a range of square bottles, bulbous-bodied flasks, bulbous-bodied jugs, cylindrical bottles and ovoid jugs decorated with horizontal wheel-cut lines with this rim form), a distribution extending as far north as Kerch in east Crimea.

Also of interest here is the bottle base fragment (no. 91). This is from a squaresection prismatic bottle and is decorated on the base with an incomplete design (the surviving piece is very fragmentary and could not be illustrated) which includes a letter ' $c$ ' or, as is more likely, an indistinct circle in one corner of the base. The use of circles in the corners of the base designs on such bottles is not a common feature (concentric circles are by far the most common). An unpublished study of over two thousand base designs by the author includes only ten that have circles in the corners 
of the bases. Six are from Kerch (five in Sorokina 1990, 58, fig. 2, nos 10-14 and one in the British Museum Acc. No. 10.56-2,4) and one example from each of the following sites: Jerash (Dussart 1986, 74, fig. 21), Köln (Fremersdorf 1961, 45, no. 82, right), Locarno in Switzerland (Donati 1979, 37, no. 177), and Ptuj in Slovenia (Subic 1974, 41, no. 16, pl. IV, 30). It would be tempting to relate this fragment and the bottle rim (no. 83) with the Kerch material. Possibly, they all came from the same production centre in the Black Sea region or in the eastern Mediterranean.

Nos 109-112 represent the upper parts of phials which, again, cannot be satisfactorily identified by form. In any case, such vessels were manufactured in their thousands throughout the Roman period in every corner of the Empire and so their appearance at Nicopolis is only to be expected.

Nos 113-118 come from a range of bowls and beakers which are long lived types in use throughout the first to third or fourth centuries. It is interesting here to note, however, how few were recorded from this site compared to the wheel-cut fragments of the same date and described above. It should be pointed out, however, that the wheel-cut fragments are easier to identify because of their thickness and decoration. Only rim fragments can be identified for these standard vessels.

The shape of the rim of the bowls nos 116-118 - folded over to form a flattened hollow tubular rim are not common at Nicopolis, where the simple fire-rounded rim predominates. This rim form is very common amongst assemblages of the late first and second centuries, especially in the western Empire. Their thin walls suggest that they were very fine and delicate vessels.

The almost complete vessel from the drain fill in area B (no. 119) is, apart from the small cup from area A (no. 2), one of the most complete vessels from the site. Its deposition at the bottom of the drain no doubt accounts for its survival. (See introduction above for factors which explain the survival of complete glass vessels.) The vessel itself is a small very thin-walled bowl or drinking vessel of the mid to late second century decorated with a thin, self-coloured spiral trail. Precise parallels for the full profile are difficult to find. Numerous fragments from cups and bowls of this date, especially straighter-sided vessels with wheel-cut lines and cracked-off rims, are known throughout the Empire and characteristically are very thin walled. Three examples came from a pit at Felmongers, Harlow dated to AD 160-170 (Price 1987, 189 and 202 nos 8-10, fig. 2) and three virtually complete examples of cups with a trail below the carination come from Housesteads (Charlesworth 1971, 346, figs 1-3) in a deposit dated $A D$ 128-139/42. A jug, decorated with a spiral trail in the same fashion as this Nicopolis vessel, and dating to the late second or third century, comes from the legionary fortress baths at Caerleon (Allen 1986, 108-9, no. 58, fig. 58). No doubt such jugs and the Nicopolis beaker would have come from the same glasshouses, the former being a narrow-necked version of the latter.

No. 120 comes from a vessel of indeterminate shape but which can be classed as a 'snake-thread' glass because of the sinuous design applied to its body. Snake- 
thread glasses were products of the Rhenish glasshouses, but they had originated in the eastern Empire in other forms during the second century (Price 1978, 745; Harden 1987, 105-8). They are extremely common in the Rhineland, the Lowlands and northern France and fragments are known in northern Spain and Italy.

No. 121 comes from a good quality colourless beaker with a pushed-in base forming a flattened hollow tubular base ring. Such vessels are known from the late first century onwards but are not common during the late Roman period (e.g. Isings 1957 form 33, with applied decoration in the form of vertical ovals; form 34 with horizontal wheel-cut lines; form 35 with indented ovals). This example comes from a dump deposit (691) in area $\mathrm{D}$ dated to the third quarter of the second century. No. 130 is a similar base from a floor surface (681), dated c. AD 175-250.

The form of the small fragment with the cut out tubular collar around the body (no. 126) cannot be properly determined. Flanged dishes and bowls, imitating metal vessels and terra sigillata Drag. 38 of the second and early third century, are well known (Morin-Jean 1913, form 85; Trier, Germany, Goethert-Polaschek 1977, 37, form 26, no. 102; Groenstraat, Holland, Isings 1971, 22, no. 61, fig. 3; Brunssum, Holland, Isings 1971, 79, no.142, fig. 15; Köln, Germany, Bonner Jahrbücher 159, $1959,155 f$.). However, this fragment from Nicopolis is too small to come from such a form. It is more likely to come from one of a series of small and delicately wrought drinking vessels, many in imitation of metal vessels, which date from the middle of the first century (similar fragments to the Nicopolis example, all dating from the middle of the first century, were found in the canabae legionis, Nijmegen, Holland, Isings 1980, 321, nos 892-94, fig. 27, 3 and 4; from a deposit sealed between $c$. AD 40 and 45 by the collapse of a wall of the Forum Basilica at Cosa, Italy, Grose 1973, 44, no. 27, fig. 5; and Magdalensburg, Austria, Czurda-Ruth 1979, 62ff.). At first sight the date of this vessel would seem inappropriate for Nicopolis. ${ }^{5}$ However, it came from area B, context 261 , the primary fill of an early pit (264), predating the laying of the paving slabs for the road and supports the presumption, based on the pottery it contained, that this deposit belongs to the earliest years of the Roman city. ${ }^{6}$

The small beaker with applied trails, probably in imitation of a barrel (no. 127), is another type which has few parallels. It compares with Morin-Jean's type 134, a barrel-shaped beaker with a handle attached to the side of the body, a form dated to the third and fourth centuries (Morin-Jean 1913, 176, form 134 with illustrations of vessels from Boulogne, fig. 231, and Köln, fig. 232b). Six examples, three handleless and three with handles, come from Köln dating to the second century and first half of the third century (Fremersdorf 1958, 28, taf. 32; Fremersdorf 1959, 38, taf. 8 and 67-8, tafn. 94-5; Fremersdorf 1961, 31-2, tafn. 32-3 and 32, taf. 34). An example from Amiens is in the Ashmolean Museum, Oxford (Inv. No. 1948-88) and an unprovenanced vessel is in the British Museum (Inv. No. 81 6-26 2).

The most common type of bowl or cup form fashioned with a fire-rounded rim was the 'Airlie' type beaker (Isings 1957, form 85b). This vessel, with a cylindrical 
body, fire-rounded and slightly incurving rim and a double base ring (a hollow tubular base with a concentric internal ring) dates from the late second and third centuries. Some examples are included amongst the Nicopolis material (e.g. no. 144) but identification of this type from just rim fragments is not possible.

The greatest number of fragments from this site, for all periods, comes from the rims and bases of drinking vessels. Two rim types predominate in the late Roman and early Byzantine periods for finishing cups and bowls. These are the fire-rounded rim and the cracked-off, slightly outsplayed rim. Both of these are well attested at Nicopolis and were certainly in use at the same time.

Fire-rounded rims (nos 138-143 and 145-203), slightly everted or upright, especially from contexts dated to the third and fourth centuries, come from standard drinking vessels the exact forms of which cannot be fully determined. Five of these, nos 138-142 are decorated with applied blue spiral trails around their lips. It is most likely that the fragments with applied true base rings are the bases of these vessels. In many cases it is impossible to distinguish these early rims from the later examples (nos 314-536) for they belong, in effect, to the same tradition. The earlier ones do tend to be made from a better metal. A number are colourless with an opaque white decomposition layer and later examples tend to have a more pronounced groove below the lip. No. 356 has a particularly thick rim, flattened on the top, and compares with a small carinated cup from Mezad Tamar, Israel (Erdmann 1977, no. 415) dated to the sixth or seventh century.

Almost as common as fire-rounded rims are rims which have been cracked-off, leaving a rough lip. The evidence from area $\mathrm{P}$, for instance, does suggest that, whereas the fire-rounded rim continued in use until the sixth century or even later, the cracked-off rim, which has its origins in late-first century repertoires but becomes very common during the late third and fourth centuries (nos 204-237) is rarer during the fifth and sixth centuries (nos 545-554).

All types of cup and bowl were finished with cracked-off rims (see Gomolka 1979 passim for vessels of the fourth and fifth century from Iatrus). It is interesting to note that the lamp forms, briefly described below, all have thin fire-rounded rims similar to a number recorded at Nicopolis (see below passim). Apart from Nicopolis, the range of late Roman and early Byzantine rim forms is best illustrated by the late third to seventh century glass assemblage from the late Roman castellum at Mezad Tamar (Kasr Gehainije) (Erdmann 1977, passim).

For the beakers, cups and bowls of the second to third centuries, two main base types are present here: hollow tubular (e.g. no. 132) and true applied base rings (nos 142, 242-243). The former are not common at Nicopolis but might be associated with some of the standard cups and bowls briefly referred to above. The applied true base ring is slightly more common. After the simple pushed-in base, this form of base was one of the easiest to fashion. It is, in effect, a thick trail of glass wrapped around the end of the blown paraison either before or after the end had been slightly 
pushed in. This form of base is not as common in the Roman as it was to become during the late Roman and early Byzantine periods (nos 591-661). Those examples dated to the Roman period here are, in the main, in good colourless glass. Many of the base rings are very thin and well applied, unlike the later examples which become thick and coarsely applied.

Amongst the late Roman fragments dated to the late third and fourth century are a few examples of wide bowls (Isings 1957, form 116, nos 238-40). These vessels were made in the same fashion as the beakers with cracked-off rims, but one example here (no. 241) has been decorated with indentations in the body (Isings 1957, form 117).

Four fragments (249-252) from the tube ends of funnels (Isings 1957, form 74) were found. Examples from Valkenburg in a context dated c. AD 40-47 (van Lith 1978-9, 98, no. 320a, taf. 23), a Claudio-Neronian example from Vindonissa (Berger 1960,225 , no. 225, tafn. 15 and 22.102) and funnels from Pompeii demonstrate that the main period of use of these objects was during the late first century. However, the second century date of the contexts from which these four examples came suggests that this form continued in use beyond the first century.

Other vessels with a cracked-off rims are nos 253 and 254 . These deep bowls or beakers were mould-blown with a honeycomb design in low relief (no. 253) and vertical ribs (no. 254). For the general form, see Goethert-Polaschek 1977, 62, no. 237, form 50 and Isings 1957, form 107a. The mould-blown beaker with vertical ribs (no. 254 ) is an interesting vessel piece. This example, which has numerous late fourth to sixth century parallels, must be intrusive in its Roman context (area A 2245). ${ }^{7}$ For parallels see the two examples from Mezad Tamar cited below in Erdmann 1977; a fourth or fifth century example from Karanis, Egypt, Harden 1936, 156, no. 472, fig. 16; a late fourth century example from Köln, Germany, Fremersdorf 1961, fig. 113 with references there to other examples in the west. The general form is a bag-shaped beaker with only a rudimentary foot or no foot at all (e.g. Isings 1957, form 107a). The body is decorated all over with a low relief pattern of ribs or, as is more frequent, a honeycomb pattern (such as no. 253). Many of the latter have a narrow zone of vertical ribs immediately below the rim (for example Trier, Germany, GoethertPolaschek 1977, 62, no. 237; and Mezad Tamar, Israel, Erdmann 1977, 144. no. 922) but the ribs of the Nicopolis example are much longer. It cannot be proved but it is possible that these ribs extended all over the body. The base of a ribbed mould-blown vessel comes from area $D$ (no. 255). The ribs on a fragmentary beaker from Mezad Tamar, Israel (Erdmann 1977, 144, no. 921) are as long as those on the Nicopolis example. However, it is important to note that this base fragment might have come from a bulbous-bodied flask decorated with vertical ribs (Isings 1957, form 101) such as an example from Paris (Landes 1983, 62, no. 43). Isings cites numerous examples of bottles, plain and ribbed, both vertically and diagonally, from sites in the Rhine/Mosel region such as Strasbourg, Köln, Remagen, Rodenkirchen, 
Andernach with others at Nenquin and Basel. They all date from the second half of the third century or the fourth century. The Nicopolis example is residual; it was found in a post-medieval context.

The site produced a large number of fragments from finely made hemispherical cups and bowls in a distinct green, almost olive green, metal, decorated with applied and marvered blue, green-brown or turquoise blobs of glass (nos 256-268). Such vessels are well known in the eastern Empire, becoming better known in the western Empire, during the fourth century and appear to have continued into the fifth. Those in the east, in bowl, beaker and conical lamp forms, have mainly blue blobs whereas western vessels display a greater variety of colours (see Erdmann 1977, 109, nos 887-91 for Mezad Tamar examples; Harden 1938, 103, nos 331-2 fig. 15, nos 457 and 460, fig. 16, for examples from Karanis; Calvi 1968, 170f for examples from Aquileia; Fremersdorf 1962, 8f, figs 102-12 for examples from the Rhineland).

The stemmed goblet, of which a number of examples were found at Nicopolis (nos 269-282 and including, no doubt, many of the rim fragments described above) is a distinctive late Roman type (Isings form 111). For examples from Carthage and a useful summary of the evidence for the distribution and date of this form see Tatton-Brown (1984, 200-202). All of the Nicopolis examples are single piece glasses with the stem formed by the lower part of the paraison being restricted and then the base pushed in to form a slightly domed foot with a thin hollow, tubular base ring. Some stems have rudimentary round knops on the stems. The majority, however are plain. Depending upon how deeply the base has been pushed in towards the bowl, the stems vary from solid to open and hollow.

One vessel is decorated on the body (no. 269). This goblet, in a good quality natural green metal, has been mould-blown and reinflated (optic-blown) leaving a very faint decoration of vertical ribs. The stem comprises a small ovoid knop. The fragility of the vessel and the size of the extant fragment would seem to exclude any possibility of it being residual in its context (area A 2192), a destruction deposit dated to c. AD 450 . One other smaller fragment from a stemmed goblet (no. 278) comes from another context dated to $c . \mathrm{AD} 450$. Yet another (no. 272) which has a ball knop was found in the primary drain fill beneath the gate in area $\mathrm{E}$, a context dated $\mathrm{AD} 450-600$ and another (no. 279) was found in a rubble spread in area A, dated AD 450-600.

The stem of no. 270 has been very well made with a well defined, angular knop unlike the other stems of this period which are either plain or have a rudimentary ball knop. It comes from a post-medieval context so is clearly residual. Two other examples (nos. 281 and 282) come from the lower part of stemmed goblets with a hollow stem (see also Olczak 1981, fig. 4, no. 2 and fig. 5, nos 1-3 for comparative stems dating from the fourth and fifth centuries from Novae, Bulgaria). No. 282, similar to no. 281, has a bowl with a flatter bottom to it (bucket-bowl). No. 281 comes from a context dated $c$. AD 300-450 and no. 282 from a context dated $c$. AD 250-350. It is more likely that these vessels were deposited towards the end of that date range. 
At Karanis, stemmed goblets date from the fourth century or later (Harden 1936, $167 \mathrm{ff}$. where they are extensively discussed). They appear in fourth or fifth century contexts at Jerash (Baur 1938,517, type F) and fifth to eighth century contexts also at Jerash (Kehrberg 1986, 24-8, fig. 9) and Byzantine and Umayyad contexts from around the church at Pella (Houston Smith 1989, 114-15). Stemmed goblets with three small handles, for use as lamps, are known from Jerash (Baur 1938, 524, no.17). Closer to Nicopolis ad Istrum, numerous examples have been recorded at Iatrus (Gomolka 1979, 161-89, fig. 64 for nos 132 and 188 only). See also Olczak 1981, 58-61 for a brief study of these fourth to sixth century drinking vessels. The fragments from around the church at Pella (Houston Smith 1989, 115) led the excavator there to suggest that these glasses, as well as the lamps, had an ecclesiastical function. But, at Nicopolis, such vessels were found in both ecclesiastical and secular contexts.

Nos 283-309 come from identifiable parts of lamps, in particular large sections of the rim and side, handles and pointed feet. No doubt many of the rims recorded elsewhere in this catalogue belonged to lamps and not drinking vessels. Olczak (1981, 58) records that lamps were the most numerous find from the 1976 and 1978 excavations in the Western Sector at Novae, amounting to 20 per cent of the entire assemblage. Furthermore, the lamp fragments made up almost half of the total assemblage of glass from the recent excavations on the site of the principia (Olczak 1995,32 ). This assemblage contains numerous parallels to the various lamp fragments from Nicopolis. He has identified four types of lamp (fig. 12.2):

a. Narrow cylindrical at the base, wide cylindrical at the rim with an ogee profile at the junction of these two profiles. The base is slightly pushed-in.

b. Pointed, conical base with a slightly flared upper part of the body.

c. Rounded or pointed base with a bowl shaped upper portion, provided with three loops to take a suspension chain.

d. A squat, cup shaped vessel with slightly curving body and three loops to take a suspension chain.

All of the Nicopolis vessels are too fragmentary to attempt a reconstruction of a complete profile. The best preserved fragments, all from area $F(3032$, the destruction level overlying the floor of the Large Basilica) include small looped handles and pointed bases but it is not certain if these come from the same vessels. The profiles of nos 156 and 157 from this context in area $F$ are slightly more conical than the type $c$ and $d$ versions above and could be related to what is interpreted as being two-handled cups with similar profiles from Iatrus (Gomolka 1979, 154, nos 30-35). However, all the examples from Iatrus are fragmentary and it is more likely that they are fragments of three-handled lamps. 

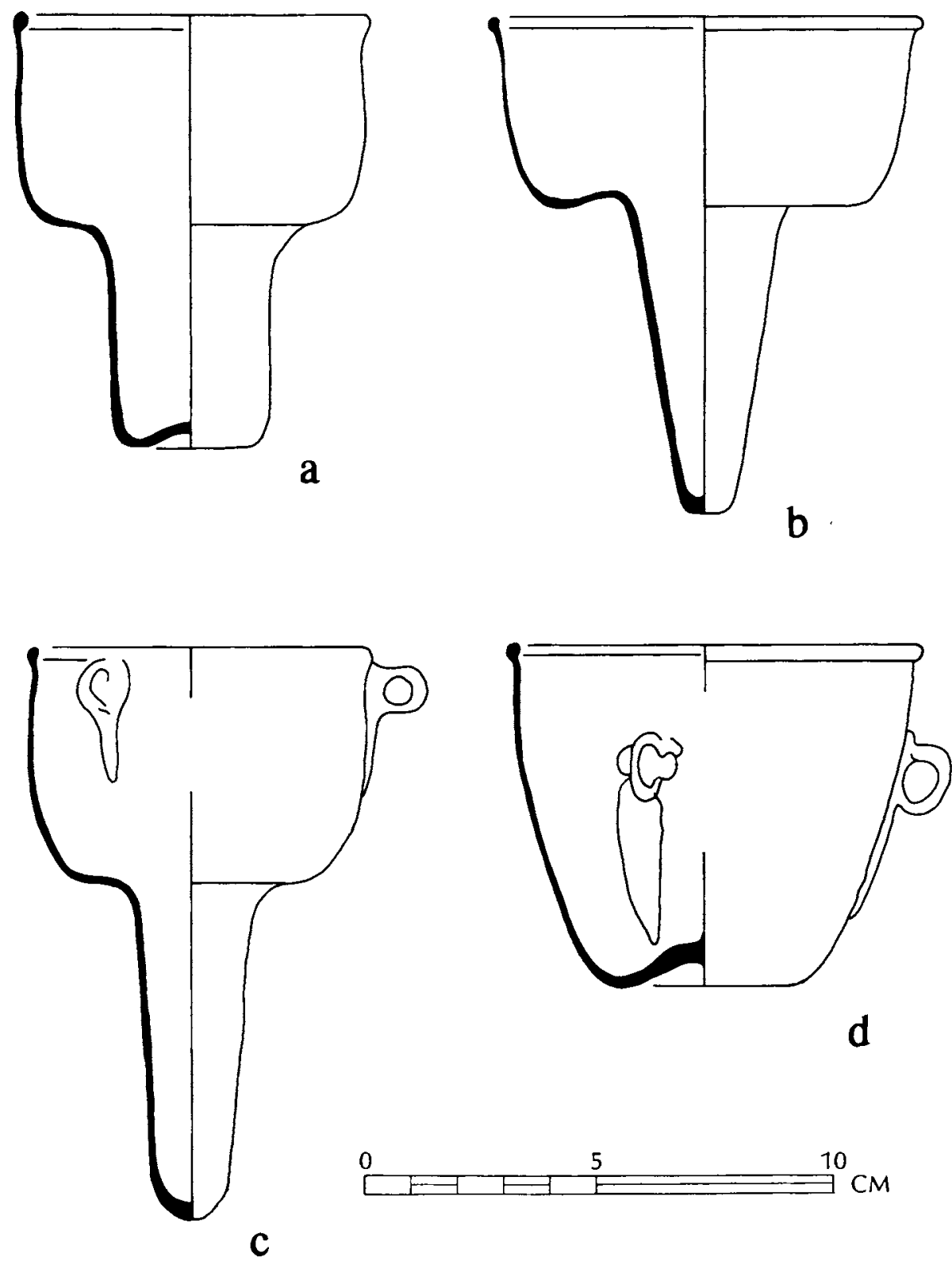

12.2 Reconstruction of lamp types a-d (after Olczak 1995) 
Lamps with three small handles for attachment to a suspension chain are known throughout the Balkans and in the East. Fourth or fifth century examples were recorded at Jerash (Baur 1938, 526ff., types $G, H$ and $K$ ). Jerash also produced fragments from stemmed cups with three small handles which served as lamps (cf. Baur 1938, 524, no. 17).

The lid-seated vessel (no. 313) is another notable find. The lip has been pushed down and then splayed out almost horizontally to take a lid. Unfortunately, no portion of the body of this vessel survives and so the exact form cannot be reconstructed and it has not been possible to find a parallel for this rim shape.

The rim and base fragments from fifth and sixth century contexts have been briefly described above. In addition, there are a number of less common base types. Nos 555-561 come from vessels which are slightly cut out just above the foot of the base and are all in a very good natural green glass. The narrow, and slightly pushed-in, base suggests that it belongs to beakers. However, it is notable that a possible late Roman bottle from Iatrus has the same base form (Gomolka 1979, 153, no. 14, fig. 63). Gomolka equates this example with Isings form 127, a type which is normally more cylindrical in shape and more often much larger in volume.

A number of simple pushed-in bases also occur at Nicopolis (nos 563-578). This method of finishing a base is, perhaps, the simplest to make and could be used for all forms of vessels. These bases, all the same size as the illustrated example (no. 564), could be parts of beakers with truncated conical profiles but some may come from small phials or flasks (cf. no. 563).

Nos. 579-590 come from the bases of very thin-walled bowls with a much thickened base ring. Six come from area F, nos 583-588. Of these, three were found in post-medieval robbing spoil (nos 583-585), one came from the floor of the basilica (no. 586) and two predate the construction of the basilica, one from a make-up deposit, associated with occupation contemporary with the final years of the late Roman city, and the other from the final make-up deposit beneath the brick floor of the basilica (no. 587), both contexts dated $c$. AD 400-450. An example from area $M$ (no. 582) was found in a context dated to the late third or fourth century. The bodies of these vessels were so thin that it is not surprising that only the thickened portions of the bases have survived. It is difficult, therefore, to determine the original profile of this form. Presumably it would have been a simple shallow bowl type with a fire-rounded rim and, if so, may have been $c .150 \mathrm{~mm}$ or more in width. Rim forms of this diameter do occur at Nicopolis but are not common. No. 283 from area D is of this size and, if reconstructed on this base, would produce a bowl with convex sides and a slightly flared, fire-rounded rim.

The beaker (no. 662) with a hollow tubular base ring is more elaborate than the other base types in use during the late Roman and early Byzantine periods (e.g. pushed-in and applied true base rings) and may be Roman. However, its colour is similar to well-dated late metals. 
High pedestal bases, such as nos 664-665, though known in the Roman period, are typical of late Roman assemblages. They are not, however, common amongst the Nicopolis glass (two small fragments from unidentifiable pedestalled vessels come from area $C$, nos 245-456 - one from a Roman context and one from a late third or fourth century deposit. Also, one (no. 663) from area $\mathrm{K}$ came from a late third to fifth century context).

The base fragment from a large bowl, dish or plate (no. 666) is another rare vessel type at Nicopolis. The only other example is from area $\mathrm{K}$ (no. 667), a broad based vessel with applied true base ring which had been grozed around the outside of the base to form a small plate. These vessels have very broad and high true base rings similar to an example from Iatrus (Gomolka 1979, 159, no. 107). The form is Isings form 118 which is described by her as being, essentially, a late Roman eastern type which was not very common. A fragment was published from Karanis (Harden 1938,71 , no. 88 with references there to examples known to him from KölnMungersdorf from the late fourth century Sarcophagus C, associated with other glass of eastern, if not specifically Egyptian, origin; at Jerash from a Byzantine level; and a bowl from Tyre which is, unfortunately, undated).

Fragment no. 668 is from the base of a bowl or beaker with a hollow tubular base ring. This type of base is known at Nicopolis but is not the most common: applied true base rings predominate. One cannot be certain, but it is probable that any vessel with such a base finish was probably of a slightly higher quality than normal, more effort and relatively more skill being employed in making it.

\section{Glass-working debris}

Twenty-seven fragments of waste from the process of making vessels from molten glass, were recovered during the excavations. It is important to stress that there were no fragments of waste associated with glass making - the process of making glass from raw materials. This is typical for the majority of Roman sites where evidence for glass industry has been found and suggests, as also pointed out in the introduction, that glass workers regularly used cullet (broken glass vessels) as their raw material.

Seven main types of glass waste are generated by glass-working:

1. Furnace debris: fragments from the furnace structure itself. Excavated Roman glass furnaces are small and circular with an interior diameter of $c .50-80 \mathrm{~cm}$ 
and with a flue on one side. These probably stood no more than a metre above the ground, even less if partially set in the ground to retain the heat. Two types of furnace may have been used; a pot furnace, where the glass is contained in crucibles within the furnace, and a tank furnace, where the hot chamber in the furnace is, in effect, a reservoir of glass.

2. Crucible debris: ceramic vessels in fabrics with the strength and firing point likely to withstand continuous heating over a considerable period of time. When found, these are coated with a thin skin of glass.

3. Pot or tank metal: small fragments of raw glass from crucibles or tanks with part of the ceramic receptacle still adhering to them.

4. Moils: distinctive cylindrical or slightly conical objects from the ends of blowing irons. ${ }^{8}$

5. Cuttings and threads: distorted fragments from the fashioning and decorating of vessels.

6. Droplets: when found in direct association with any of the above, such droplets could be waste which accidentally dripped from tools passing from the furnace.

7. Distorted scraps: wasters are rare finds amongst glass-working debris since all such material would be recycled. Even so, such items have been found occasionally.

Waste of type 3, pot or tank metal, 4, moils and 6, droplets have been found on the site. These are listed below. No traces of a furnace, which might have been used for glass-working, was identified, although a fragment of tile covered on one surface with a layer of molten glass from area F probably represents furnace debris (type 1$).{ }^{9}$

674-675. D (421), 1750+, SF. 4048 and SF. 4049. Two cylindrical moils in colourless glass.

676-693. B (-), B (243), 300-450 (x2); B (247), 300-450 (x2); B (275), 300-450; D (404), 1750+; D (421), 1750+; D (422), 1750+; D (425), 1750+, SF. 4061; D (426), 450-600, SF. 4074 (x2); D (434), 1750+, SF. 1217; D (514), 450-600; D (558), 350-450; F (3125), 1750+; F (3311), 400-450 (x2). Eighteen fragments of natural green pot or tank metal, some with traces of ceramic adhering.

694-699. B (240), 1750+; B (241), 300-450; D (450), 1750+; D (469), 1750+; F (3034), 1750+, SF. 7187; F (3157), 1750+. Six droplets of natural green glass.

700. F (3045), 1750+, SF. 7224. A fragment of tile, one side covered with a layer of molten glass, probably furnace debris. 
The two moils from area $\mathrm{D}$ (nos 674-675) are direct evidence for glass-blowing on or near to this site. A moil is a cylindrical or conical piece of glass which remains adhering to a blowing iron once a blown vessel has been removed from it. They are quite distinctive in form and have a broken edge, often with clearly conical fracture where it has separated from the blowing iron and a fire-rounded or broken end where the vessel was removed. If the moil is fire-rounded, it is probable that it functioned as a pontil while still on the blowing iron. If it has a broken end it was probably simply struck off when the iron was next needed to gather some glass for the fashioning of a new vessel. They often have many impurities in the body of the glass, such as large air bubbles and 'scale' (flakes of iron oxide from the heat-affected iron blowing irons).

Although this material indicates that the working of glass into vessels did take place at Nicopolis, it is most unlikely that this occurred in the early Byzantine period. The contexts of many of the fragments catalogued above date to the late Roman period or come from post-medieval contexts. Only two pot-metal fragments (from D 426 and D 514) are from contexts contemporary with the early Byzantine city and these, as with those from post-medieval contexts, are probably residual. Even so, these finds, modest as they are in quantity, are significant in that they provide evidence for the manufacture of glass vessels in the provinces of the Roman Empire.

\section{NOTES}

1 For the dominance of eastern imports, see above, p. 30.

2 On the significance of the Nicopolis assemblage and dating, see above, pp. 6-7.

3 On these two sites, see above, pp. 30-1.

4 Scientific analysis of all the glass colours incorporated in the diatretum indicates that the raw materials used were of the highest quality (Henderson and Shepherd, forthcoming).

5 For occupation starting only with the foundation of the city in the early second century, see above, p. 36.

6 See the pottery, pp. 59-60.

7 See above, footnote 2.

8 For discussion of moils, see below, p. 378.

9 An oven, probably for cooking, was found in area A and two others in area F: Poulter 1995, 62, 153. Two other furnaces in area $\mathrm{E}$ were clearly used for working iron and copper-alloy: Poulter 1995, 139, 143. 


\section{BIBLIOGRAPHY}

Alarcão, J. and A. 1965. Vidros romanos de Conimbriga, Ministério da Educação Nacional, Lisbon Allen, D. A. 1986. 'The glass vessels', in The legionary fortress baths at Caerleon, 2: the finds, (ed. J. D. Zienkiewicz), 98-116

Anderson-Stojanović , V. R. 1992. 'Stobi: The Hellenistic and Roman pottery', in Stobi: Results of the Joint American-Yugoslav Archaeological Investigations, 1970-1981 (ed. J. Wiseman) Princeton

Angelov, N. 1973. 'Kulturni plastove predi isgrajdaneto na dvoretsa' in Tsarevgrad Turnov 1, (K. Mijatev), 259-350

Arveiller-Dulong, V. and Arveiller, J. 1985. Le verre d'époque romaine au Musée Archéologique de Strasbourg, Notes et Documents des Musées de France, 10, Paris

As, van A. 1987. 'Towards a corpus of Mesopotamian Pottery', University of Leiden Department of Pottery Technology Newsletter, 5, 29-38

Bakurdjiev, G. 1955. Bulgarian Ceramics, Sofia

Barber, B., Bowsher, D. and Whittaker, K. 1990. 'Recent Excavations of a Cemetery of Londinium', in Britannia, 21, 1-12

Baur, P. V. C. 1938. 'Glassware' in Gerasa. City of the Decapolis (ed. C. H. Kraeling), 504-46, New Haven, $\mathrm{CT}$

Berger, L. 1960. Römische Gläser aus Vindonissa, Basel

Böhme H. W. et al. 1981. A l'aube de la France. La Gaule de Constantin à Childeric, Editions de la Réunion des Musées Nationaux, Paris

Boon, G. C. 1972-73. 'Roman glassware from Caerwent 1855-1925' in Monmouthshire Antiq, 3 (1973), 111-23

Boon, G. C. 1974. Silchester, the Roman town of Calleva, Newton Abbot and London

Böttger, B. 1982. 'Die Gefässkeramik aus dem Kastell Iatrus', Iatrus 2, 33-148

Brehm and Shepherd forthcoming. The glass from Winchester Palace, Southwark

Calvi, M. C. 1968. I vetri romani del Museo di Aquileia. Pubblicazioni dell'Associazone Nazionale per Aquileia, 7, Aquileia

Carswell, J. 1972. Kütahaya Tiles and Pottery from the Armenian Cathedral of St. James, Jerusalem, Oxford

Charlesworth, D. 1966. 'Roman square bottles' in J Glass Stud, 8, 26-40

Charlesworth, D. 1971. 'A group of vessels from the Commandant's house, Housesteads', J Glass Stud, $13,34-7$

Charlesworth, D. 1972. 'The glass' in Verulamium Excavations, vol.1 (ed. S.S. Frere), Report of the Research Committee, Society of Antiquaries of London, 28, 196-215, London

Charlesworth, D. 1974. 'Glass vessels' in 'Excavations at the New Market Hall, Gloucester 1966-7' (M. Hassall and J. Rhodes), Trans Bristol and Gloucestershire Archaeol Soc, 93, 75-6

Charlesworth, D. 1984a. 'The glass' in Verulamium Excavations, vol.3 (ed. S. S. Frere), Oxford University Committee for Archaeology, Monograph 1, 146-73, Oxford

Charlesworth, D. 1984b. 'The Xanten Glass' in Beiträge zur Archäologie des römischen Rheinlands: 4, Rheinische Ausgrabungen, 23, 283-300 
Clairmont, C. W. 1963. The Excavations at Dura-Europos, Final Report IV, Part V: The glass vessels, New Haven, CT

Comşa, M. 1965. 'Zur Romanisierung der Gebiete nördlich der Donau (Muntenien, Südmoldau) im 4.Jh.u.Z', Dacia N.S. 9, 283-93

Cool, H. and Price, J. 1987. 'The glass' in The Roman villa at Lullingstone, Kent: 2, the wall-paintings and finds (G. W. Meates), Kent Archaeol Soc Monograph 3, 110-42

Cool, H. and Price, J. 1995. Roman vessel glass from excavations in Colchester, 1971-85, Colchester Archaeological Report 8, Colchester

Crowfoot, J. W., Crowfoot, G. M. and Kenyon, K. 1957. 'Terra Sigillata General List' in Samaria-Sebaste III, the Objects, 306-57, London

Culică, V. 1975. 'Plumburi commerciale din cetatea Romano-Bizantină de la Izvoarele (Dobrogea), I-III' Pontica, 8, 215-62

Czurda-Ruth, B. 1979. Die römischen Gläser vom Magdalensburg, Kärtner Museumsschriften, 65, Klagenfurt

De Laet, S. J. 1949. Portorium, Étude sur l'organisation douanière chez les Romains, surtout à l'époque du haut-empire, Bruges

Dimitrova A. and Popov Z. 1977. 'Zwei Begräbnisse aus der ersten Hälfte des 4 Jh. aus Yambol', Thracia IV, Sofia, 235-57

Dimitrova-Milcheva, A. 1984. 'Terra Sigillata aus Rheinzabern und Westerndorf in Novae (Moesia Inferior)', Bayerische Vorgeschichtsblätter, 49, 113-24

Donati, P. 1979. Locarno: la necropoli romana di Solduno, Quaderni d'informazione, 3, Locarno

Doppelfeld O. 1961. 'Das Diatretglas aus dem Gräberbezirk des Römischen Gutshofs von Köln-Braunsfeld', Kölner Jahrbücher, 5, 1960-61, 7-35

Dragendorff, H. 1895. 'Terra sigillata', Bonner Jahrbücher, 96

Duncan, G. L. 1983. 'Coin circulation on the Danubian limes of Dacia Ripensis', Ancient Bulgaria, 2, $165-76$

Duncan, G. L. 1993. Coin Circulation in the Danubian and Balkan Provinces of the Roman Empire, London

Dussart, O. 1986. 'Analyse du matériel de verre' in 'Recherches sur le sanctuaire de Zeus à Jerash', Jerash Archaeological Project 1981-1983 (J. Seigne), 74, Amman

Dyczek, P. 1987. 'Uwagi na temat ceramiki odkrytej w Novae w 1979 roku, odcinek IV. Budowla 2 portykami', Novaensia $1,253-88$

Dyczek, P. 1991. 'Ceramika z odcinka IV/1981, 1983', Novaensia, 2, 101-28

Dymaczewska, U. and Kotecki, J. 1981. 'Ceramika Naczyniowa', Novae-Sektor Zahodni 1976, 1978, 73-83, Poznan

Ekholm, G. 1963. 'Scandinavian glass vessels of oriental origin from the first to the sixth century', $J$ Glass Stud, 5, 29-37

Erdmann, E. 1977. 'Die Glasfunde von Mezad Tamar (Kasr Gehainije) in Israel', Saalburg Jahrbuch, 34, $98-146$

Falkner, R.K. 1986. 'The pottery' in 'The Jerash North Theatre: Architecture and Archaeology 1982-1983', Jerash Archaeological Project 1981-83 (ed. F. Zayadine) vol. 1, 247-51

Falkner, R. K. and Strange, P. forthcoming. The Nicopolis Kiln Location Project

Floriano, A. 1940-41. 'Aportaciones arqueologicos a la historia de la medecina romana', in Archivo Español de Arcqueologia, 14, 415-53

Follmann-Schulz, A. B. 1986. Die römischen Gläser aus Bonn, Köln

Franken, H., van As, A. and Jacob, L. Newsletters of the Department of Pottery Technology, University of Leiden

Fremersdorf, F. 1958. Das Naturfarbene sogenannte blaugrüne Glas in Köln, Die Denkmäler des römischen Köln, 4, Köln

Fremersdorf, F. 1959. Römische Gläser mit Fadenauflage in Köln (Schlangenfadengläser und verwandtes), 
Die Denkmäler des römischen Köln, 5, Köln

Fremersdorf, F. 1961. Römisches geformtes Glas in Köln, Die Denkmäler des römischen Köln, 6, Köln

Fremersdorf, F. 1962. Die römischen Gläser mit aufgelegten Nuppen in Köln, Die Denkmäler des römischen Köln, 7, Köln

Fremersdorf, F. 1967. Die römischen Gläser mit Schliff, Bemalung und Goldauflagen aus Köln, Die Denkmäler des römischen Köln, 8, Köln

Fremersdorf, F. 1975. Antikes, islamisches und mittelalterliches Glas: sowie kleinere Arbeiten aus Stein, Tagat (?) und verwandten Stoffen in der vatikanischen Sammlungen Roms, Catalogo del Museo Sacro, 5, Vatican City

Fulford, M. 1978. 'Coin circulation and mint activity in the late Roman empire: some economic implications', Archaeol J, 135, 67-114

Fulford, M. 1991. 'Britain and the Roman Empire: the evidence for regional and long distance trade', in Roman Britain: Recent Trends (ed. R. F. J. Jones) 1991, 35-47

Fünfschilling, S. 1986. 'Römisches Gläser aus Baden-Aquae Helveticae (aus den Grabungen 1892-1911)', in Jahresbericht 1985, Gesellschaft pro Vindonissa, 81-160

Goethert-Polaschek, K. 1977. Katalog der römischen Gläser des Rheinischen Landesmuseums Trier, Mainz am Rhein

Goldstein, S. M. 1979. Pre-Roman and Early Roman Glass in the Corning Museum of Glass, Corning, New York State

Gomolka, G. 1979. 'Die spätantiken und frühmittelalterlichen Gläser aus Iatrus' in Iatrus-Krivina Spätantike Befetigung und frühmittelalterliche Siedlung an der unteren Donau: Band I: Ergebnisse der Ausgrabungen 1966-73, Schriften zur Geschichte und Kultur der Antike, 17, 145-66, Berlin

Grose, D. F. 1973. 'Roman glass of the first century AD: a dated deposit of glassware from Cosa, Italy' in Annales du 6e Congrès de l'Association Internationale pour l'Histoire du Verre, 31-52

Grose, D. F. 1991. 'Early Imperial Roman cast glass: the translucent coloured and colourless fine wares' in Roman Glass: Two Centuries of Art and Invention (M. Newby and K. Painter) vol.13 of Occasional Papers from The Society of Antiquaries of London, 1-18

Hagen, J. 1906. 'Ausgewählte römische Gräber aus Köln' in Bonner Jahrb, 114/5, 379-433

Harden, D. B. 1936. Roman glass from Karanis found by the University of Michigan archaeological expedition in Egypt 1924-29, Univ of Michigan Stud, Humanistic Series, 4

Harden, D. B. 1947. 'The Glass' in Camulodunum: first report on the excavations at Colchester 1930-1939 (C. F. C. Hawkes and M. R. Hull) Report of the Research Committee of the Society of Antiquaries of London, 14, 287-307, Oxford

Harden, D. B. 1962. 'Glass in Roman York' in An inventory of the historical monuments in the City of York: vol 1: Eburacum, Roman York, RCHM, 136-41, London

Harden D. B. 1963. 'The Rothschild Lycurgus Cup: Addenda and Corrigenda', J Glass Stud, 5, 9-17

Harden, D. B. 1968. 'The glass' in Excavations at Shakenoak farm, near Wilcote, Oxfordshire, 1 (A. C. C. Brodribb, A. R. Hands and D. Walker), 74-81, Oxford

Harden, D. B. 1979. 'Glass vessels' in The Roman cemetery at Lankhills (G. Clarke), Winchester Studies: 3: pre-Roman and Roman Winchester 2, 209-20, Oxford

Harden, D. B. 1987. Glass of the Caesars, Milan

Harden, D. B. and Price, J. 1971. 'The glass' in Excavations at Fishbourne, 1961-1969: 2: the finds (B Cunliffe), Report of the Research Committee of the Society of Antiquaries of London, 27, 317-68, London

Harden D. B. and Toynbee J. M. C. 1959. 'The Rothschild Lycurgus Cup', Archaeologia, 97, 179-212

Hayes, J. W. 1972. Late Roman Pottery, London

Hayes, J. W. 1980. A supplement to Late Roman pottery, London

Hayes, J.W. 1985. 'Sigillata Orientale A (Eastern Sigillata A); Sigillata Orientale B (Eastern Sigillata B); Ceramica di Çandarli - Produzione Pergemena; and Sigillata Cipriota' in Enciclopedia dell'arte antica classica e orientale. Atlante delle forme ceramiche 2 (tardo ellenismo e primo impero). Ceramica 
fine romana nel bacino mediterraneo (ed. G. P. Carratelli)

Hayes, J. W. 1992. Excavations at Saraçhane in Istanbul, vol 2: The Pottery, Princeton

Heather, P. and Matthews, J. 1991. The Goths in the Fourth Century, Liverpool

Heimberg, V. 1980. 'Vielleicht heiss sie Nonnula. Ein spätrömischer Sarkopharg aus Zülpich-Enzen',

Das Rheinische Landesmuseums Bonn. Berichte aus der Arbeit des Museums, 24-6

Hodder, I. 1979. 'Pottery Distributions: Service and Tribal Areas' in Pottery and the Archaeologist (ed.

M. Millet), Institute of Archaeology Occasional Paper 4

Hoddinott, R. F. 1975. Bulgaria in Antiquity, London

Houston Smith, R. and Day, L. Preston 1989. Pella of the Decapolis: Vol 2: Final Report on the College of

Wooster Excavations in Area IX, The Civic Complex, 1979-1985, The College of Wooster

Isings, C. 1957. Roman Glass from Dated Finds, Groningen

Isings, C. 1971. Roman Glass in Limburg, Groningen

Isings, C. 1980. 'Glass from the canabae legionis at Nijmegen' in Ber Rijksdienst Oudheidkund Bodenmerz, $30,281-346$

Ivanov, T., Seraphimova, D. and Nikolov, N. 1969. Raskopki v Sandanski prez 1960 IAI, 31, 119-97

Kabakchieva, G. 1983. 'Tipologia i cronologia na glinenite chervenolakovi panitsi ot Trakia (I -IV v.)', Arkeologia, $25(4), 1-12$

Kabakchieva, G. 1986. Keramika ot vilata pri Ivailograd II-IV. v. Raskopki i prouchvania. K. 15, Sofia

Kabakchieva, G. 1990. 'Rotfirniskeramik aus Butovo in Ulpia Oescus', Rei Cretariae Romanae Fautorum Acta $27 / 28,67-76$

Kabakchieva, G. 1994. 'Arheologicheski danni za rannorimskata istoriya na Ulpia Oescus' Settlement Life in Ancient Thrace, 3rd International Symposium 'Cabyle' Jambol, 148-70

Kabakchieva, G., Sultova, S. and Vladkova, P. 1988. Keramichni tsentrove na teritoriyata na Nicopolis ad Istrum, II-IV vek, Veliko Turnovo

Keay, S. J. 1984. Late Roman Amphorae in the Western Mediterranean, 2 vols, British Archaeological Reports International Series 196

Kehrberg, I. 1986. 'Summary report on glass' in 'The North Decumanus and North Tetrapylon at Jerash' (W. Ball, J. Bowsher, I. Kehrberg, A. Walmsley and P. Watson) Jerash Archaeological Project 1981-1983, 375-84, Amman

Kuzmanov, G. 1985. 'Rannovizantinska keramica ot Trakia i Dacia. (IV-nachaloto na VII v.)', Raskopki i Prouchvania 13

La Baume, P. and Nüber, E. 1971. 'Das Achatgefäss von Köln', Kölner Jahrbuch, 12, 80-93

Landes, C. 1983. Verres gallo-romains, Catalogue d'Art et d'Histoire du Musée Carnavalet, 4, Paris

van Lith, S. M. E. 1978-9. 'Römisches Glas aus Valkenburg Z.H' in Oudheidkundige mededelingen uit het Rijksmuseum van Oudhedeh te Leiden, 5960, 1-150

Loeschke, S. 1912. 'Sigillata-Töfereien in Tschandarli', Athenische Mitteilungen 37, 344-407

Ludowici, W. 1908. Urnen-Gräber römischer Töpfer in Rheinzarben: und III Folge dort Gefundener Stempel-Namen und Stempel-Bilder bei meinen Ausgrabungen 1905-1908, Munich

Maiuri.1957.

Majewski, K. et al. 1981. Novae Sektor Zachodni, 1979, Archeologia, 32, 85-163

Millet, M. (ed.) 1979. Pottery and the Archaeologist, Institute of Archaeology Occasional Paper 4

Minchev, A. 1983. 'The Late Roman fine ware imports to the western Black Sea coast' Ancient Bulgaria, $2,194-201$

Mitrea, B. and Preda, C. 1964. 'Nécropoles de type Sinta-Tcherniakhov en Valachie', Dacia N.S. 8, 211-37

Mladenova, J. 1991. Antichnata vila Armira krai Ivailograd, Sofia

Morin-Jean 1913. La verrerie en Gaule sous l'empire Romain, Paris

Muşeţeanu, C. and Elefterescu, D. 1990. 'Céramique sigillée à Durostorum', Dacia N.S. 34, 235-44

Naceva, V. 1984. Étude technologique du vernis rouge sur la céramique fine des ateliers Romains dans les villages de Butovo, Hotnica et Pavlikeni, de la region de Veliko Turnovo, Studien zur Römischen Keramik, vorträge des 13. Internationalen Kongresses der Rei Cretariae Romanae Favtores, 155-61 
Nagy L. 1930. 'Vas diatretum aus Brigetio' Archaeologiai Értesítö 44m $111 \mathrm{ff}$

Olczak, J. 1981. 'Wyroby Szklane' in 'Novae - Sektor Zachodni 1976, 1978' (S. Parnicki-Pudetko),Wyniki Badan Wykopaliskowych Ekspedycji Archeologicznej vam Kierownictwo naukowei i redakcja, 55-73, Poznan

Olczak, J. 1995. 'Szklo rzymskie z terenu komendantury w Novae, Novensia, 8, (ed. L. Press), Warsaw

Oliver, A. 1984. 'Early Roman faceted glass' in J Glass Stud, 26, 35-58

Öney, G. 1971. Türk devri Çanakkale seramikleri/Turkish Period Çanakkale Ceramics, Çanakkale Seramik Fabrikalari, Istanbul

Orton, C., Tyers, P. and Vince, A. 1993. Pottery in Archaeology, Cambridge, 152-65

Orton, C. 1980. Mathematics in Archaeology, Cambridge

Orton, C. 1982. 'Computer Simulation Experiments to Assess the Performance of Measures of Quantity of Pottery', World Archaeology, 14, 1-19

Oswald, F. 1931. Index of Potters' Stamps on Terra Sigillata Samian Ware, Nottingham

Oswald, F. and Pryce, T. D. 1920. An Introduction to the Study of Terra Sigillata, London

Peacock, D. P. S. and Williams, D. F. 1986. Amphorae and the Roman Economy, London and New York

Petrović, P. 1977. 'Forteresse Romaine a l'embouchure de la rivière Porečka dans les Portes de Fer, Akten des Xi. internationalen Limeskongress (ed. J. Fitz), Budapest, 259-75

Pick, B. 1898. Die antiken Münzen Nord-Griechenlands, vol. 1: Dacien und Moesien (gen. ed. F. ImhoofBlumer), Berlin

Popilian, G. 1976. Ceramica Romană din Oltenia, Scrisul Romănesc, Craiova

Popilian, G. and Ciucă, I. 1988. 'Nouvelles informations sur l'importation de terra sigillata en Dacie romaine méridionale', Dacia N.S. 32, 61-78

Poulter, A.G. 1983. 'Town and Country in Moesia Inferior', Ancient Bulgaria 2, 74-118

Poulter, A.G. 1987. 'Townships and Villages', The Roman World (ed. J. Wacher), 1, London, 388-411

Poulter, A.G. 1990. 'Frontier people beyond and behind the limes: the impact of the native population upon the Lower Danubian frontier', Akten des 14. internationalen limeskongresses 1986 in Carnuntum (eds H. Vetters and M. Kandler), Vienna, 143-52

Poulter, A.G. 1992a . 'Nicopolis ad Istrum: the Anatomy of a Graeco-Roman City', Die Römische Stadt im 2. Jahrhundert n. Chr., derFunktionswandel des öffentichen Raumes, Kolloquium in Xanten vom 2. bis 4. Mai 1990, veranstaltet durch Archäologischer Park/Regionalmuseum Xanten, Archäologisches Institut der Universität zu Köln, Bayerische Akademie der Wissenschaften-Kommission zur Erforschung des antiken Städtewesens (eds H.-J. Schalles, Henner von Hesberg and P. Zanker), 69-86, Köln and Bonn

Poulter, A.G. 1992b. 'The use and abuse of urbanism in the Danubian province during the Later Roman Empire' in The City in Late Antiquity (ed. J. Rich), 99-135, London

Poulter, A.G. 1994. 'Churches in space: the early Byzantine city of Nicopolis' in Churches Built in Ancient Times: Recent Studies in Early Christian Archaeology, Occasional Papers from the Society of Antiquaries of London (ed. K. Painter), 249-68, London

Poulter, A.G. 1995. The Roman, Late Roman and Early Byzantine city of Nicopolis ad Istrum: the British excavations 1985-1992, Monograph of The Society for the Promotion of Roman Studies, London

Press, L. and Sarnowski, T. 1990. 'Novae. Römisches Legionslager und frühbyzantinische Stadt an der unteren Donau', Antike Welt, 21, 225-43

Price, J. 1974. 'The glass' in Roman Manchester (G. D. B. Jones), 131-4

Price, J. 1978. 'Trade in Glass' in Roman Shipping and Trade: Britain and the Rhine Provinces (eds J. du Plat Taylor and H. Cleere), CBA Res Rep, 24, 70-78, London

Price, J. 1979. 'The glass' in 'Frocester Court Roman villa: second report 1968-77: the courtyard' (H. S. Gracie and E. G. Price), in Trans Bristol \& Gloucestershire Archaeol Soc, 97, 37-46

Price, J. 1980. 'The Roman glass' in 'Excavations at Park Street, Towcester' (G. Lambrick), Northamptonshire Archaeol, 15, 63-8

Price, J. 1982. 'The glass' in 'The excavation of a Romano-British rural establishment at Barnsley Park, 
Gloucestershire, 1961-1979: part II: c AD 360-400' (G. Webster and L. Smith), in Trans Bristol \& Gloucestershire Archaeol Soc, 100, 174-85

Price, J. 1987. 'Glass from Felmongers, Harlow in Essex: a dated deposit of vessel glass found in an Antonine pit' in Annales du 10e Congrès de l'Association Internationale pour l'Histoire du Verre,185-206, Amsterdam

Price, J. 1991. 'Glass' in Excavations in the Middle Walbrook Valley City of London,1927-1960 (T. Wilmott), London \& Middlesex Archaeol Soc Spec Paper, 13, 153-67, London

Rashev, R. 1983. 'Pliska - the first capital of Bulgaria', Ancient Bulgaria, 2, 255-69

Rice, P. M. 1987. Pottery Analysis, a sourcebook, Chicago

Robinson, H. 1959. The Athenian Agora. Volume 5: Pottery of the Roman Period, Chronology, Princeton Robinson, R. C. W. 1983. 'Clay Tobacco Pipes from the Kerameikos', Mitteilungen des Deutschen Archäologischen Instituts (Athenische Abteilung) 98, 265-84

Robinson, R. C. W. 1985. 'Tobacco pipes of Corinth and of the Athenian Agora', Hesperia 54, 149-203

Scatozza Horicht, L. A. 1986. I vetri romana di Ercolano, Ministero per i beni culturali ed ambientali soprintendenza archeologica di Pompei, Cataloghi 1, Rome

Schönert-Geiss, E. 1979. Die Fundmünzen von Krivina, Iatrus, 1, 167-209

Schutz. H. 1985. The Romans in Central Europe, New Haven and London

Sennequier, G. 1985. Verrerie d'époque romaine, Rouen

Shepard, A. O. 1976. Ceramics for the Archaeologist, Washington

Shepherd, J. D. 1986. 'The glass' in Houses in Roman Cirencester (A. McWhirr), 117-21, Cirencester

Shepherd, J. D. 1992. 'The glass' in 'A possible mansion in Roman Southwark: excavations at 15-23 Southwark Street, 1980-86' (C. Cowan), Trans London and Middlesex Archaeol Soc, 43, 120-36

Shepherd, J. D. 1995. 'The glass vessels', in Excavations in the Marlowe Car Park and Surrounding Areas: Part II: The Finds (K. Blockley, M. Blockley, P. Blockley, S. S. Frere and S. Stow), The Archaeology of Canterbury, 5, 1227-58

Shepherd forthcoming. The glass from the Eastern cemeteries of Londinium

Simpson, St.J. 1990. 'A Brief Introduction to Ottoman Clay Pipes', Society for Clay Pipe Research Newsletter, 27, 6-10

Sorokina, N. P. 1987. 'Glass aryballoi (1st-3rd centuries AD) from the Black Sea region', J Glass Stud, $29,40-46$

Sorokina, N. P. 1990. 'Die kleinasiatische Gruppe von Gläsern des 1.-2. Jh. N.Chr' in Annales du 11e Congrés de l'Association Internationale pour l'Histoire du Verre, 55-60, Amsterdam

Soultov, B. 1962. 'Prinos kum antichnata istoriya na Pavlikenskiya krai', Izvestiya Veliko Turnovo 1, 7-20 Soultov, B. 1976. Centres antiques de poteries en Mésie inférieure, Sofia

Soultov, B. 1977. Pavlikenskiyat krai prez antichnostta, Sbornik Pavlikeni i Pavlikenskiya krai, Sofia

Soultov, B. 1983. 'The typology and chronology of provincial Roman pottery', Ancient Bulgaria, 2, $119-28$

Soultov, B. 1985. 'Ceramic production in the territory of Nicopolis ad Istrum (2nd-4th centuries)', Terra Antiqua Balcanica, 1

Spriggs, M. and Miller, D. 1979. 'Ambon-Lease: A Study of Contemporary Pottery Making and its Archaeological Relevance' in Pottery and the Archaeologist (ed. M. Millet), Institute of Archaeology Occasional Paper, 4

Still, M. 1995. Lead Sealings (unpublished $\mathrm{PhD}$ thesis, University of London)

Subic, Z. 1974. 'Tipoloski in kronoloski pregled rimskega stekla v Poetovioni' in Arheoloski Vestnik, 25, 39-61

Sunkowsky R. 1956. Antike Gläser in Carnuntum und Wien, Kulturreferat des Amtes der Niederösterreichischen Landesregiegung, Wien

Tatton-Brown, V.A. 1984. 'The glass' in Excavations at Carthage: The British Mission. Vol I,1: The Avenue $d u$ President Habib Bourguiba, Salammbo: The site and the finds other than pottery (H. R. Hurst and S. P. Roskams), 194-212, Sheffield 
Townend P. and Hinton, P. 1978. 'Glass' in Southwark Excavations, 1972-1974 (eds ]. Bird, A. H. Graham, H. Sheldon and P. Townend), Surrey Archaeol Soc and London \& Middlesex Archaeol Soc Joint Pub, 1, 151-3, 285, 387-9, 462 and 490-91

Tudor, D. 1968. Oltenia Romană (3rd. edn), Bucharest

Uenze, S. 1992. Die spätantiken Befestigungen von Sadovec: Ergebnisse der Deutsch-BulgarischÖsterreichischen Ausgrabungen 1934-1937, 1-2, Munich

Urner-Astholz, H. 1974. 'Die römische Jagdschale und eine Kugelschliffschale von Skein am Rhein' in Schaffhauser Beiträge zur Geschichte, 51, 7-61

Vanpeene, N. 1993. Verrerie de la Nécropole D'Épiais-Rhus (Val-D’Oise) Guiry-en-Vexin

Vessberg, O. 1952. 'Roman Glass Found in Cyprus', Opuscula Archaeologica, 7, 109-65

Waagé, F. O. 1948. Antioch-on-the-Orontes. 4. part 1. Ceramics and Islamic Coins, Princeton

Ward-Perkins, J. and Claridge, A. 1976. Pompeii AD 79, London

Weinburg, G. Davidson 1964. 'Vasa diatreta in Greece,' J Glass Stud, 6, 47-55

Welker, E. 1985. Die römischen Gläser von Nida-Heddernheim II, Schriften des Frankfurter Museums für Vor-und Frühgeschichte, 8 , Bonn

Wendel, M. 1986. 'Die Keramik' in Iatrus-Krivina III, 114-46

Wheeler, R. E. M. 1930. London in Roman Times, London Museum Catalogue, 3, London

Whitehouse, D. B. 1989. 'Begram reconsidered', Kölner Jahrbuch für Vor-und Frühgeschichte, 22, 152

Whitehouse, D. B. 1990. 'Late Roman cameo glass', Annales du 11e Congrès de l'Association Internationale pour l'Histoire du Verre, Basel 1988, Amsterdam, 193-8

Wiseman, J.R. 1984. 'The city in Macedonia Secunda', Villes et Peuplement dans l'Illyricum protobyzantin, actes du colloque organisé par l'École française de Rome (Rome, 12-14 mai 1982), Collection de l'École française de Rome 77, 309-13 



\section{INDEX}

Page numbers in bold refer to illustrations.

In the entries for 'pottery' and 'pottery forms' the ware numbers are in square brackets to avoid confusion with page numbers, e.g. ware [8] 83-4.

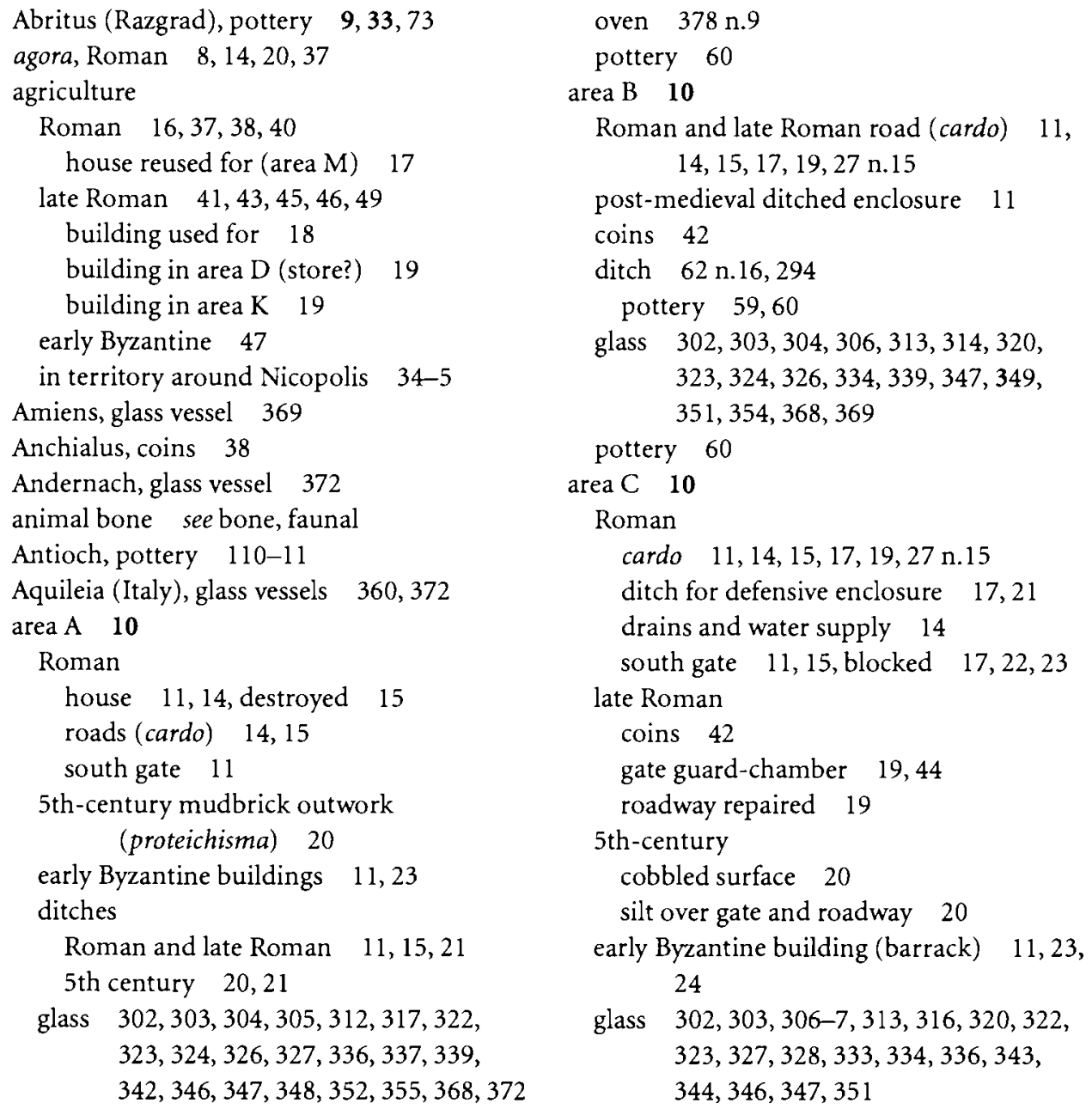




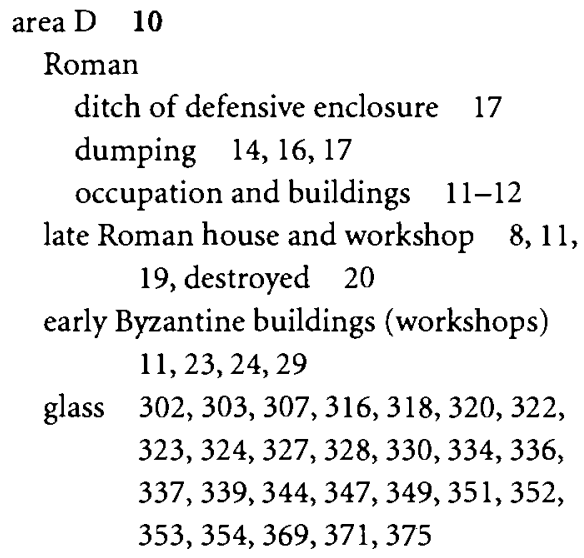

area $\mathrm{K}$

agricultural building, late Roman 10,11 , 19

glass $302,303,304,308,312,313,316$, $318,320,322,323,324,326,327$, $328,332,333,340,343-4,346,347$, $349,352,353,354,376$

$$
\text { pottery } 61
$$

Slav 25

see also Small Basilica under basilicas (churches)

area $\mathrm{L}$

amphorae 251-2

early Byzantine building $10,12,23,24$ area $\mathrm{M}$

Roman

Antonine hypocaust 14

Severan house with frescoes (villa suburbana) on plateau $12,16-17$

Roman and late Roman dumping 17,19 early Byzantine foundations of range of buildings (store buildings or barracks(?)) 12, 22-3

glass $302,303,309,313,316-17,318,328$, $333,339,343,351,352,354,375$

area $\mathrm{N}$, early Byzantine building $10,12,23$, 24

area $\mathrm{P} \quad 10$

Roman 16

building burnt and debris 17

column-base 14

road 14,15

rubbish dumping 17

late Roman soil over cardo maximus 19

early Byzantine

defences 21

tower [1] 10, 1, 22, 24, 25, 74, 309-10, 365

coins 365

glass $302,303,304,309,316,318,324$, $326,327,328,332,333,334,336$, $337,340,343,346,347-8,349,351$, $354,355,360,365,370$

pottery $60,62 \mathrm{n} .20,74$ 
area $\mathrm{R} \quad 10$

early Byzantine defences 21

pentagonal tower [8] 10, 11,22, 24

glass $302,303,304,309-10,319,346$

pottery 62 n. 20

area $\mathrm{S} 10$

5 th-century cemetery 20

early Byzantine

cobbled surface 23

east gate $8,10,11,22,23$

converted into tower and fire 23,24 309

glass $302,303,310,316,340,355$

pottery $62 \mathrm{n} .20$

Slav 25

Armira villa, pottery $52 \mathrm{n} .86,66,67,69,70$, $71,75,76,77,78,79,81,82,83,85$

Asia Minor 14,47

glass from 356

immigrants from 37

lead sealings 43

mortaria 114

pottery from $41,45,113$

see also pottery, amphorae

Athens

diatretum in Benaki Museum 363

glass vessel 362

pottery from agora 86

Attila 20,21

Augusta Traiana (Stara Zagora) 9, 34, 35, 50 n.26

Baden-Aquae Helveticae, glass stand 357

Barnsley Park, glass vessel 366

barracks, early Byzantine

area $\mathrm{C} \quad 11,23,24$

area $M$, foundations $12,22-3$

at Iatrus 46

Basel, glass vessel 372

basilicas (churches)

glass lamps used in 48

Large Basilica (area F) 11, 22, 25

glass $300,302,308,373,375$

roof tiles 25

Small Basilica (church; area K) 11,22, 25 roof tiles 25 baths, Roman 8

beads 306, 307

Begram (Afghanistan), glass cup in hoard 362

bird bone see bone, faunal

Black Sea (coast)

glass oil flask, from region 366

inscriptions $51 \mathrm{n} .58,52 \mathrm{n} .79$

pottery 44,115

trade routes $35,37,38,41$

bone, faunal

Roman 37

late Roman 19, 41

bone-working, late Roman 19

Boulogne, glass vessels 369

bracelets $307,308,309,310$

Brigetio, glass cup 363

British Museum, glass vessels 368,369

Brunssum (Holland), glass vessel 369

building construction

Roman and late Roman 19,35

early Byzantine

of basilica 22

of buildings 23

of defences 21

building materials (limestone, mudbrick)

$19,35,38$

Bulgars 24, 25

Butovo

funerary inscription 37

pottery production $33,34,36,38-9,66$, $70,71,74,76,79,80,82,83,84,85$, $108-10,116-17$

Byzantine see early Byzantine city; glass; pottery

Cabyle 9,35

Caerleon, glass vessels $359,366,368$

Caerwent, glass vessels 359,366

cannon-balls, post-medieval 26

Canterbury, glass vessels $360,361,366$

Carnuntum, glass vessel 366

Carthage, glass vessels 372

castellum aquae, late Roman military

annexe $8-9 ; \mathrm{pl} . \mathrm{V}$

causeway $10,13 \mathrm{n} .9,19,22$ 


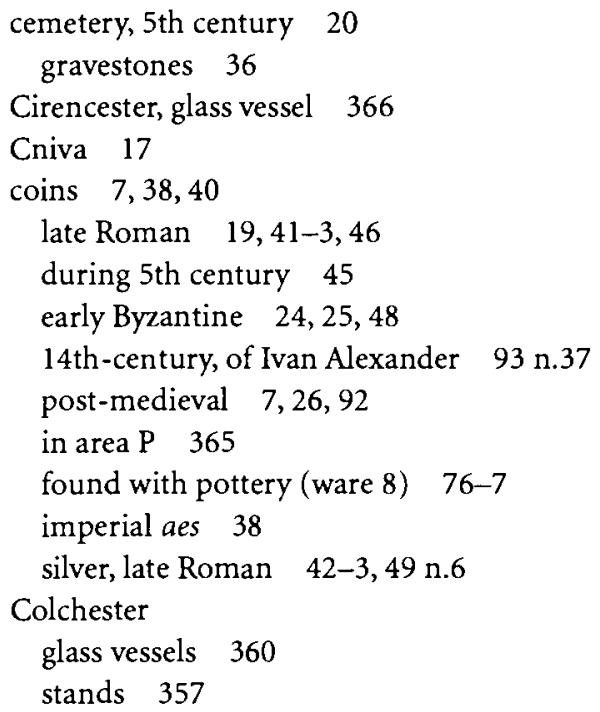

dating, of site and finds $6-7$
Decius 17

diatreta see under glass forms

Dichin, coins $53 \mathrm{n} .112$

Discoduraterae, emporium $33,34,35$, $50 \mathrm{n} .26$

Dura-Europos (Syria), glass vessels 356, 359,360

Durostorum 9,33

lead sealings $52 \mathrm{n} .76$

early Byzantine city (c.450-c.600) 3, 5, 5, 6, $10,21-5,47-8,49 ;$ pl.VI

dating 6,7

location plan 3,5

amphorae (area C) 23

buildings 10

area $\mathrm{A} \quad 11,23$

area $C$, barrack $11,23,24$

area $\mathrm{D}$, workshops $11,23,24,29$

area $\mathrm{H} 23,24$

area $\mathrm{L} \quad 12,23,24$

area $\mathrm{M}$, foundations of range of buildings, store buildings or barracks(?) 12, 22-3

area $\mathrm{N} 12,23,24$

coins $24,25,48$

finds 29

fortifications $10,11,22,21,25-6,27 ; \mathrm{pl} . \mathrm{V}$

gates 11,22

east (area S), later converted into tower $22,23,24$

south (area E) 22, 23-4

western 22

geophysical survey 10,11

Roman curtain-wall reused (area E) 8, $10,11,21$

towers (areas P and R) 11,21-2,24, 25, 29

destruction 24-5

abandoned in late 6th or early 7 th century 10,25

see also basilicas (churches); pottery

Egypt, diatretum from 363

emporia 33, 34, 35

environmental evidence 3,45 ; see also agriculture; bone, faunal 
Ephesos, stamps on lead sealings 43 Epiais-Rhus (France), glass vessel 366 Evebø (Norway), glass beaker 365 extramural settlements

Roman, on plateau $16,17,48$ abandoned 17,40

late Roman $12,19,20,43-4,45$

4 th-century material 29

market 19,44

abandonment 45

legionary settlements on the Danube 39

First Bulgarian Kingdom $91,110,112,118$

flooring, brick in basilicas 22

floor tiles, tower in area $\mathrm{R} \quad 22,24$

forts and fortresses

possible auxiliary fort under Roman city 12

pottery supplies 44

see also Iatrus; military sites; Novae

frescoes, in Roman extramural house (area M) 12,16

Frocester Court, glass vessel 366

gates

\section{Roman}

east and north 8

south (area C) 11,15,17,22

portcullis 15

late Roman outer guard-chamber 19,44

blocked $11,17,22,23$

demolished 20

5th-century fire-place 21

early Byzantine 11,22

east (area S) 8, 10, 11, 22, 23, 24

converted into tower 23

no north gate 22

south (area E) 10,11,22

rebuilt $23-4$

west (main gate) $10,13 \mathrm{n} .9,22$

geophysical survey $9,10,11,12,22$

Geto-Thracian tribes $35-6$

glass $3,5-6,32,41,299-378$

archive 7,32

comparisons $30-1$ dating $30,304-5$

economic and social implications of 28-30

survival of $45,301-3$

Roman 37, 40, 306, 307, 308, 309-10

recycling 302

late Roman $41,45,305,307,370,372,376$

Byzantine/early Byzantine $48,307,309$, 310,370

from Large Basilica (area F) 300, 302, $308,373,375$

see also window glass

glass forms (and types) 30

aryballos handle (oil flask) $320,321,366$

beakers $41,313,314,315,316-17,317$, $318,359,368-9$

applied base-rings $334,335,370-1$

applied monochrome blobs $335,336-7$

bases $349,350,351-4,353,355,375$, 376

with blue trails $326,327,370$

colourless $324,325,368,369$

cracked-off rims $331,332-3,332$, $347-8,348,370,371$

fire-rounded rims $324,325,328,329$, $330,332,341,342,343-4,345$, $346-7,368,369-70$

mould-blown $335,336,371$

naturally coloured $325,326-7,369$

thickened rims $341,342-3$

wheel-cut $45,341,342,368$

bottles $320,321,322-3,323,353,355$, $366,367-8$

naturally coloured 326,327

bowls $41,313-14,314,315,316-17,317$, $318,359-61,368,369$

applied monochrome blobs 335, 337, 372

applied and pedestal base rings 334 , $335,370-1$

bases $350,351,352,353,353,354,355$, 375,376

with blue trails $326,327,370$

colourless $324,325,359,368$

cracked-off rims $332,334,368,370$, 371 
fire-rounded rims $324,325,328,329$, $330,341,342,344,345,346-7,368$, $369,370,375$

mould-blown $335,336,371$

naturally coloured $\quad 326,327$

thickened rims $\mathbf{3 4 1}, 342-3,375$

wheel-cut $340,342,368$; pl.IV

cantharus 326,367

chalice $325,326,369$

colourless (bowls/beakers/jars) 324-6, 358,359

cups $312,313, \mathbf{3 1 4}, \mathbf{3 1 5}, \mathbf{3 1 7}, 318,357-8$, 360,370

fire-rounded rims $328,329,330,369$, 370

monochrome blobs $335,337,372$

naturally coloured $\mathbf{3 2 5}, 326$

diatreta 45-6

beaker or bowl $318,319,365-6$; pl.IV

cage cup 309, 318-19, 361-6, 364; pls III and IV

dishes $45,313,314,369$

bases $350,351,353,354-5,376$

flagons $320,321,322,353,355,366$

naturally coloured 327

flasks $320,321,322,323,323,353,355$, 366

bases $\mathbf{3 5 0}, 351, \mathbf{3 5 3}, 354,375,376$

funnels $335,336,371$

goblets (stemmed) 41, 45, 337, 338, 339, 372-3

inscription (No.40) 361, 362-3

jars

base rings 334

bases $351,353,354,375,376$

fire-rounded rims $329,330,341,343$, 347,348

flanged $341,342,375$

naturally coloured 326,327

jugs $320,321,322,323,353,355,366-7$

lamps $41,45,48,338,339-40,370,373$, 374, 375

millefiori 307,358

naturally coloured (bowls/beakers/jars) 326-7

phials (unguentarium) 323, 323, 349, 350, 368,375

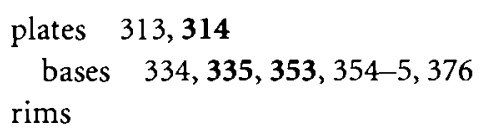

Gloucester, glass bowl from New Market Hall site 359

Golemanovo Kale 31

coins 48, 53 n. 112

Goths

city besieged by (270) 17

garrison and local foederati 17

in extramural settlement $19,44,48$

pottery associated with ('foederati ware')

19,111-12 (and see pottery, ware [14])

rebellion by and invasions of 20,40

trade with 43

grain stores

Slav grubenhaus as 25

at Iatrus 46

granaries 46

Groenstraat (Holland), glass vessel 369

grubenhaüser

early medieval (area F), Slav 12-13

as grain store 25

Slav pottery 12,$91 ;$ pl.VII

post-medieval $13,26,91$

Haemus (Stara Planina) 9, 17, 31, 34, 35

Harlow, glass vessels at Felmongers 368

Häven (Germany), glass vessel 360

Heddernheim, glass vessel 360

Herculaneum, turquoise stand from Casa Dei Due Atri 357

Himlingöje (Denmark), glass vessel 360

Hotnitsa 33

building stone 35 
pottery kiln 118

pottery production $34,36,38,66,67$, $69-70,71,74,76,79,80,83,84,85$, 108-10, 116-17

Housesteads, glass vessels 368

Huns 9, 20, 21, 25, 45, 46

hypocaust, Roman (M) 14

Iatrus (Krivina) 9

amphora type 257

coins $42,45,46,48$

fort $31,33,35,46$

glass $356,367,370,373,375,376$

pottery $44,46,48,66,68,69,71,73-4,75$,

$77,78,80,81,85,90,91,96,112,117$

workshop and millstones 46

immigrants, of Eastern origin 36,37

inscriptions

Roman $8,16,34,35,36,37,38,40$

of Agathodoros from Nicaea, from

Butovo 37

late Roman, from a tomb 18

4 th-century public and private $52 \mathrm{n} .79$

Italy, snake-thread glass 369

Izvoarele (Sucidava?), late Roman lead sealings 9,43

jars see under glass forms; pottery forms

Jerash, glass vessels 50 n.24, 368, 373, 375, 376

jugs see under glass forms; pottery forms

Karanis (Egypt), glass vessels $356,359,360$, $366,371,372,373,376$

Kerch (Panticapaeum), Crimea, glass vessels 367,368

kilns, for pottery production $34,36-7,39$, $40-1,108-10$

north of Nicopolis 108,110

at Novae 112 n.6

see also Butovo; Hotnitsa; Pavlikeni

Knossos, glass cup or skyphos from Unexplored Mansion 358

Köln (Germany), glass vessels $358,360,362$, $366,367,368,371$

Köln-Braunsfeld (Germany), glass vessels $362,363,365$
Köln-Lindethal (Germany), skyphoi 359

Köln-Mungersdorf (Germany), glass vessel 376

lamps

clay $37,41,96$

moulds for 35

see also glass forms

Lankhills, glass vessel 366

Large Basilica see under basilicas

lead sealings, late Roman 43

Lillebonne, glass vessel 360

Locarno (Switzerland), glass vessel 368

London

glass vessels $\quad 357-8,360$

London Wall, ceramic cup 358

St Swithin's House, Walbrook, glass cup 358

see also British Museum; Southwark

Lullingstone, glass bowl 359

Maastricht (Holland), glass vessel 366

Magdalensburg (Austria), glass vessel 369

magnate's palace, in late medieval period(?) 26

magnetometer (magnetic) survey 11,24

makers' marks see under pottery

Marcianopolis 9,21, 34, 35

coins 38

medieval, early 5,25

grubenhaus (area F) 12-13, 25, 91

see also pottery; Slav period

medieval, late $25-6,31$

magnate's palace(?) 26

sgraffito ware 26

Mediterranean, trading links with $41,42-3$; see also pottery

Mérida (Spain)

glass cup or skyphos 358

stand from tomb 357

metal ingots, imported 35

metalwork

Roman, in Walachia 43

late Roman 43-4

post-medieval 26 


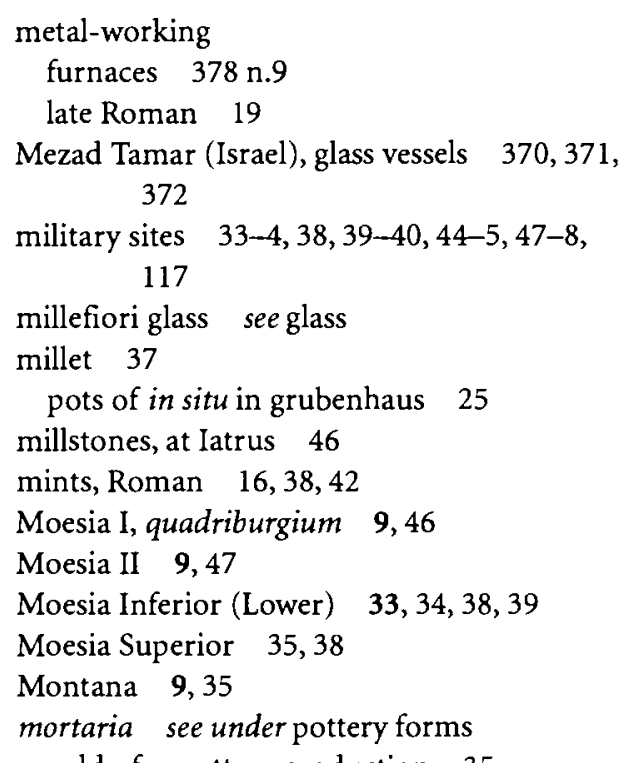

Naissus 9,35

Nenquin, glass vessel 372

Nicaea 14,37

Nicomedia 14,37

Niederemmel an der Mosel (Germany), glass vessel 362

Nieuwenhagen (Holland), glass bowl 359

Nijmegen (Holland)

glass oil flask 366

glass vessel 369

Nikiup (modern village) $8,10,27$

itinerant pottery salesmen 92

Old Nikiup see Stari Nikiup

Novae (Svishtov) 9

glass $31,356,372,373$

lead sealings $52 \mathrm{n} .76$

legionary fortress $31,33, \mathbf{3 3}, 35$

pottery $31,38,44,66-77$ passim, $81-5$

passim, 96, 117

pottery kiln $112 \mathrm{n} .6$

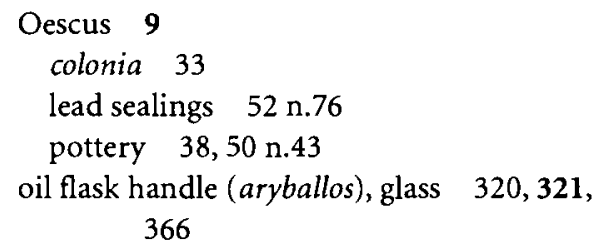

Old Nikiup see Stari Nikiup

olive cultivation 35

olive oil $34,35,37,41,114$ (table 8.1)

Olt, river 35,38

ovens

for cooking $378 \mathrm{n} .9$

early Byzantine 23

Oxford, Ashmolean Museum, glass beaker 369

\section{palaestra 8 \\ Pannonia \\ imports from 35 \\ lead-glazed ware 41 \\ mortaria 38,114}

Panticapaeum see Kerch

Paris, glass vessel 371

Pavlikeni

pottery production $33,34-5,36,38,66$, $70,71,74,76,77,79,80,81,83,84$, $85,108-10,116-17$

pottery production in northern suburbs (unexcavated) 108

villa 40,110

Pella, glass vessels 373

Piretensium, emporium 33, 34, 35, 50 n.26

plaster, from Roman house 12

plateau

pre-Roman occupation 12

Roman 16

cardines $8,14,15$

extramural house (villa suburbana) and frescoes (area M) 16-17

abandoned 17

late Roman extramural settlement 19-20, $29,43-4$

in 5 th century 20

see also extramural settlements

Pompeii

glass funnels 371

silver stands 356

wall painting 358

Porechka, river 46

post-medieval (c.1750-c.1850) $5,10,26-7$

dating 6,7

ditched enclosure (area B) 11 
houses and grubenhaüser $13,26,91$

metalwork 26

robbing $17,23,27$

see also coins; pottery

pottery $3,5-6,32,113-18$

archive $7,32,58-9$

collection and recording $58-9$

comparison with other sites on the lower

Danube 30-2

dating 59-61

economic and social implications 28,30

local production 29-30

relative frequency of types by dated phase 61,281-94

relative frequency of wares (total body sherds) by dated phase 295-6

residuality $94,96,113$

site-based chronology $\quad 6-7$

terminology $\quad 63-4$

type series 58

wares and their associated types 63-93

(and see pottery forms)

pottery, by date:

Roman (c.117-250) 7, 30, 36-40,44, 59, 60-1, 65-91 passim, 113-18, 281-96

in use $c .100-130 \quad 95,96,110-11$, 281-96

in use $c .130-250 \quad 96-9,97,98,111$, 281-96

late Roman (c.250-450) 7,21, 40-6, $113-14,115-16,281-96$

in use $c .250-350 \quad 100,101,115,281-96$

in use $c .350-450 \quad 102-4,102,103,115$, 281-96

early Byzantine $\quad 7,21,30,47-8,60,65-91$ passim, 105, 106, 113,114

Slav (ware [43]) 12, 25, 64, 91, 107, 112,

$115,118,260-3,276,281-96 ;$ pl.VII

makers' marks $260,261,262,263$; pl.VIII

post-medieval $7,26,64,91-2,94,107$, $112,115,264-73,281-96$

sgraffito $92,271,272,273$

ware [9] $64,91,94,107,274,295$

ware [10] $64,91,94,107,112,275,295$

ware [11] 64, 91, 94, 107, 275, 295 pottery, by ware/fabric.

African Red Slip Ware (wares [149] and [150]) 41, 47, 87, 101, 104, $105,111,116,249,250,279,296$

amphorae $41,43,44-5,47,73,104,105$, 114 (table 8.1), 115, 116-17 (and graphs), 251-60, 277-80, 296

African 37, 41, 47, 89-90, 115, 254-7

(and see wares [19], [37] and [38])

Asia Minor see ware [167]

Cyprus/N. Syria? 114 (table 8.1)

Eastern Mediterranean (Aegean) 64, 87-9, 115, 251-7 (and see wares

[76], [94], [96], [164] and [167])

Gaza see ware [76]

miscellaneous $90-1,254-60$

Nile Valley fabric 88,114 (table 8.1), $252,277,296$

Spain 114 (table 8.1)

Tunisian see ware [38]

ware [8] 83-4, 229-33

ware [14] 159

ware [19], African $64,90,105,114$

(table 8.1), 275, 295

ware [23] 64, 114, 275, 295

ware [24] 156 (and see ware [24] below)

ware [27] 114, 275, 295

ware [37], African $64,89,99,101,104$, 105,114 (table 8.1), 115, 276, 295

ware [38], Tunisian (African) 37, 64,

$89,96,99,101,104,105,114$

(table 8.1), 115, 255, 276, 295

ware [69] 114, 277, 295

ware [76], Gaza $47,87-8,104,105,114$

(table 8.1), 277, 295

ware [87] 277

ware [94] $88,101,104,105,114$

(table 8.1), 115

ware [96] $64,88,99,101,104,105,114$

(table 8.1), 115, 278, 296

wares [98-104] 278

ware [105] 114, 278, 296

ware [106] 114, 278, 296

wares [108-123] 278-9

ware [124], brown $64,99,114$

(table 8.1), 279, 296 


$$
\begin{aligned}
& \text { wares }[125-145,156-160] \quad 279-80 \\
& \text { ware }[164] \quad 64,89,104,105,114 \\
& \quad(\text { table } 8.1), 280,296 \\
& \text { ware }[165] \quad 280 \\
& \text { ware }[166] \quad 114,280,296 \\
& \text { ware [167], Asia Minor } 45,89,99,114 \\
& \text { (table 8.1), 280, } 296
\end{aligned}
$$

Bulgar 25

Candarli ware 110,111

Cypriot Red Slip Ware (ware [175]) 47, $87,105,116,250,251,280,296$

Cypriot Sigillata 111

Eastern Sigillata A 49 n.7, 79, 110-11

Eastern Sigillata $B \quad 111$

fine wares 40,43, 45, 47 (and see below: ware $[8]$; ware $[78])$

'foederati ware' see below: ware [14]

Gaulish wares see below: Samian

Green-glazed ware (ware [32]) 87, 104, 276,295

imports, Roman $7,86-7,101,104,105$, 115-16, 248-51

industrial see ware [44]

Kütahaya ware (degenerate form of) 92

Late Roman C Ware (ware [174]) 41, 44, $47,87,104,105,115,116,249,250$, 280,296

Macedonian t.s. grise $\quad 85,86,93$ n.26

miscellaneous wares (ware [172] and others) $86,244-8,274,280$ (and see crucibles)

Samian (ware $[171]$ ) 86-7, 99, 115, 280, 296

Central Gaulish $\quad 38,50-1$ n.43, 86, 96

East Gaulish $38,86,248-9,250$

Gaulish terra sigillata 38, 110

Gaulish wares $110-11$

South Gaulish $50 \mathrm{n} .43$

Slavv see above: pottery, by date

Thracian, local $36,65,108,113$ (and see below: ware [25])

ware [1], grey ware $36,44,45,47,60,64$, $65,66-72,96,98-9,101,102,104$, $105,108,114,115$ (graph), 123-54, 274,295 ware [4], local fine ware $64,84-5,99$, 239-41, 274, 295

white-slipped censers $\quad 236-9$

ware [7] 274

ware [8], local red-slipped fine ware $36-7,64,74-84,96,99,101,102$, $104,105,108-11,113-14,115$ (graph), 161-236, 274, 295; pls I-II origins of 110-11

stamped 109,109

ware [13] 275, 295

ware [14], micaceous grey 'foederati ware' $\quad 19,44,45,47,64,73-4,102$, $104,105,111-12,114,118,156-61$, 275,295

ware [24], coarse yellow-buff ware 64 , $72-3,101,102,104,154,155,156$, 275,295

ware [25], local Thracian early coarse ware $36,64,65,96,119,120,121$, 275,295

ware [30/31], early Roman red-brown coarseware $36-7,60,64,65,96$, $108,120,121,122,123,275,295$

ware [32] see above: Green-glazed ware ware [36] 276, 295

ware [39], misc fine ware $86,244,247$, 276, 295

ware [41] 276, 295

ware [43] see Slav above, under. pottery, by date

ware [44], reddish-brown coarse ware 86 , $99,244,245,276,295$

ware [51] 276, 295

ware [55] $64,246,247,276,295$

ware [56] 277, 295

ware [70] $64,277,295$

ware [74] 277, 295

ware [78], black slip (grey-slipped) fine ware $64,85-6,101,102,104,105$, $242,243,277,295$

ware [83], sgraffito ware 277,295

ware [86] 277, 295

ware [96], [105], [106] and [124] see above amphorae

ware [149] see above. African Red Slip ware 


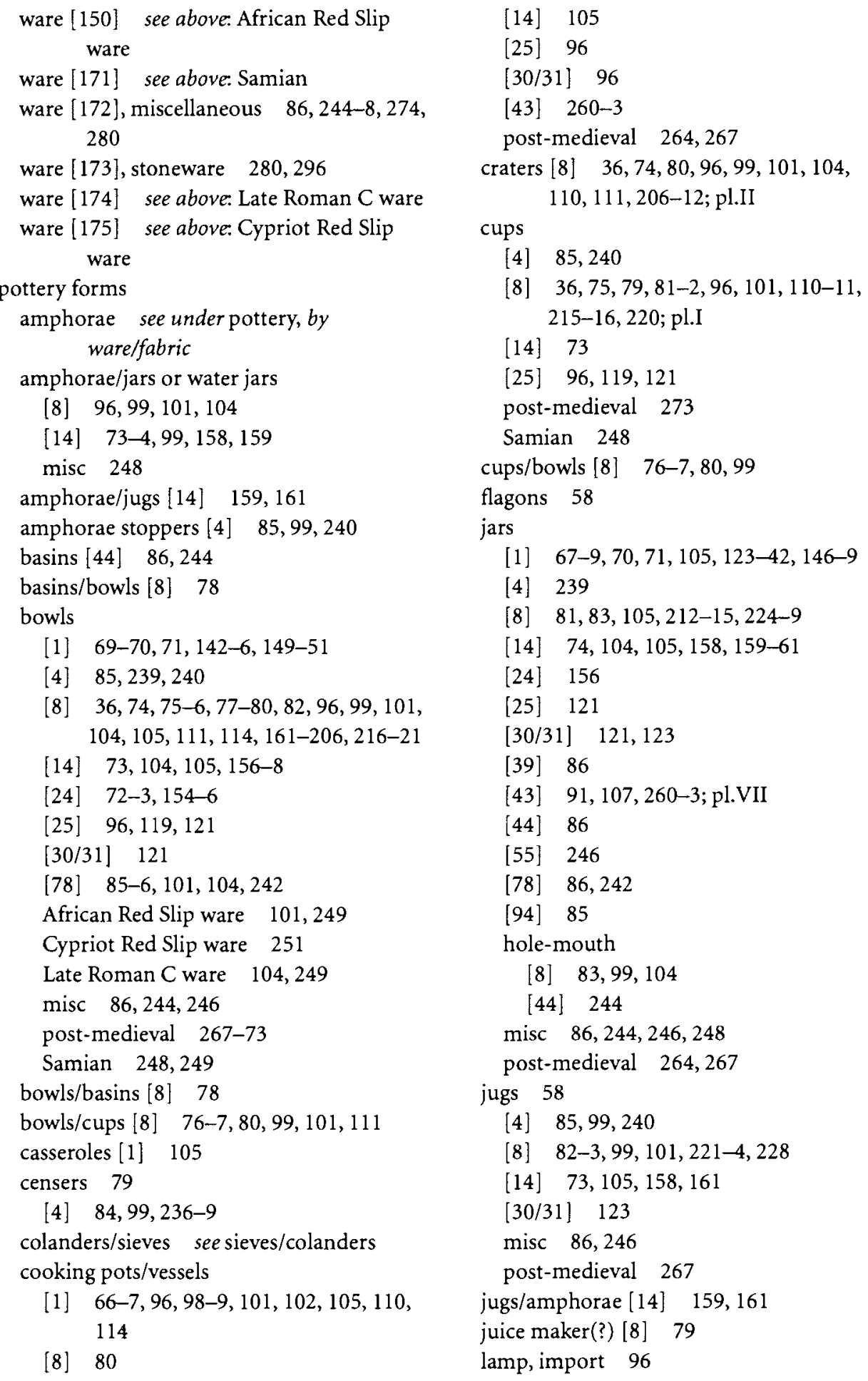


lids

[1] $71-2,98,101,104,151-4$

[8] $83,226-8$

[14] $74,104,161$

[30/31] 96, 123

mortaria $38,86,87,244,245$

Samian (East Gaulish?) 248

pitchers (stomni) 85

plate/bowl, Samian 249

'Rakia jug', post-medieval 267

saucers [8] 79, 202-4

sieves/colanders

[1] 71

[8] 79

[14] $73,104,105$

sifters 79

trays [8] 84, 101, 104, 233-6

vessels with out-turned rims [1] 67

water jars

[8] $96,99,101,104$

[14] $73-4,99,104,105,114$

see also crucibles

Propontis mints 42

propyleion 14

proteichisma (mudbrick outwork) (area A) 20

Ptuj (Slovenia), glass vessel 368

public buildings

Roman $8,14,48$

late Roman 18

quadriburgium 46

Quaestura Exercitus 47

quarries, for stone 35,38

recycling, of glass, Roman 302

Remagen, glass vessel 371

residuality 300,304

resistivity survey $11,12,22$

Rheinbach-Flerzheim, skyphoi 358-9

Rhineland

glass vessels 372

snake-thread glass 369

Rilski, St Ivan 26

roads (and streets)

Roman $8,12,14,15,60$

area $\mathrm{A} \quad 14,15$ area $B$ and $C 11,14,15,17,19,27$ n.15, 42,60

area $\mathrm{P} 14,15$

cardines on plateau $8,14,15$

cardo maximus $8,14,19$

streets and street-grid $8,11,14,15$

late Roman, area F 19, 20, 21

early Byzantine, abandoned or absent in 23

in Danubian Plain 35

Rodenkirchen, glass vessel 371

Roman city $3,5,6,8-9,12,14-17,15,16$, $36-40,48 ; \mathrm{pl} . \mathrm{V}$

dating 6,7

plans 4,5

column-base (area P) 14

defences $8,11,15$

annexe see under late Roman city

curtain-wall 15 (reused, see early

Byzantine city)

foundation of city $62 \mathrm{n} .19,94$

houses 11,14-15

hypocaust from Antonine residence (area M) 14

Severan, with frescoes (area M) 12, 16-17

town house (area A) $14,15,40$

possible auxiliary fort under 12

public buildings $8,14,48$

late Roman city (c.296-c.450) 3,5, 6, 12, $17-20,18,29,40-6$; pl.V

animal bone 19

annexe, military (castellum) $8-9$

building (area D) 8,11, 19, 20

building (area K) 11, 19

coins 19,41-3

defences $8-9,10,11,43$

finds 12,29

inscriptions 18

public building 18

tomb, brick-built 18

town houses $17-18$

destruction and abandonment (c.450)

$3,7,9,20-1,45,46,47,60,365$

see also gates; glass; inscriptions; mint; pottery; roads; see also buildings by name 


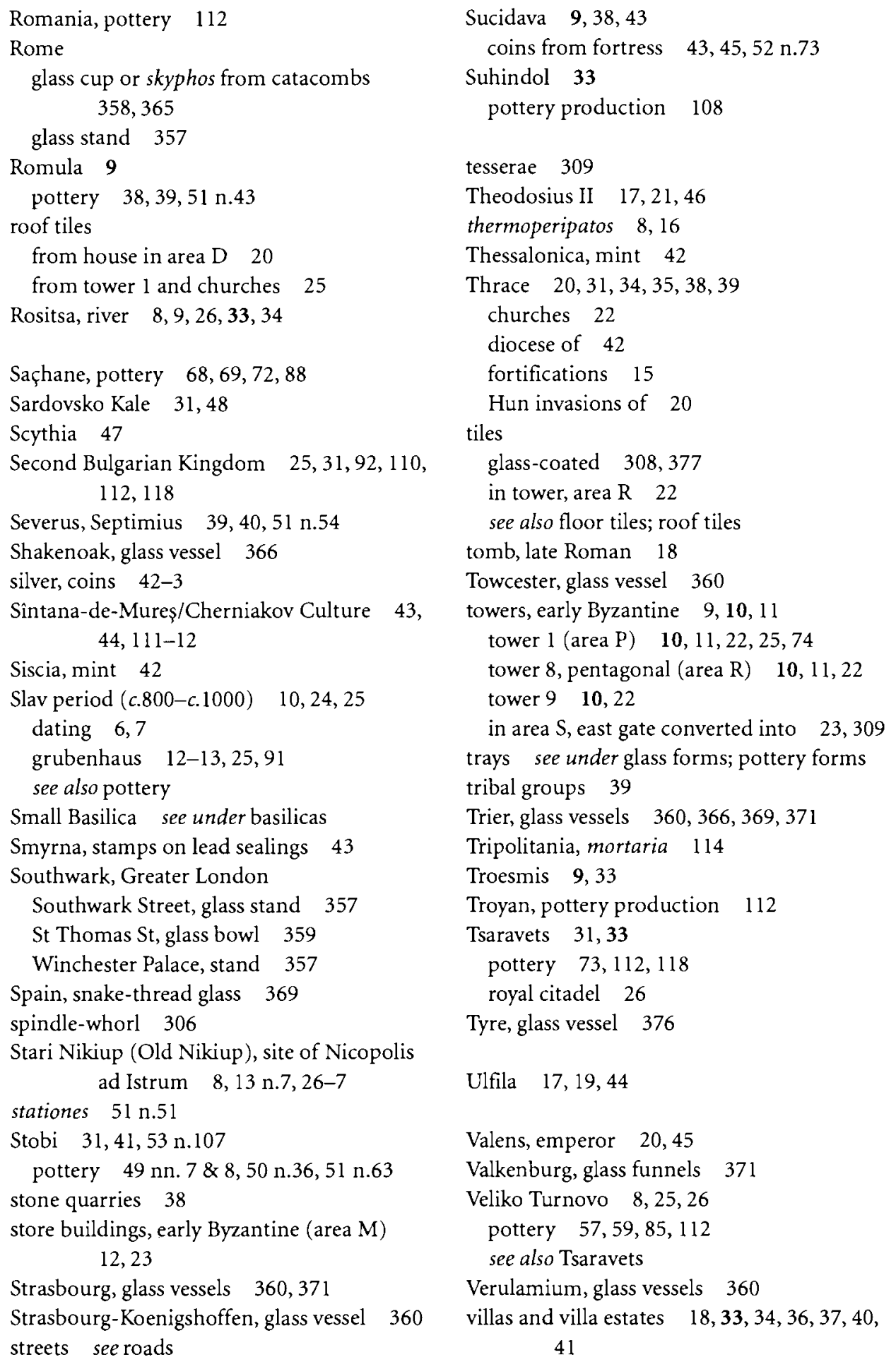


400 Nicopolis ad Istrum: The Finds

at Pavlikeni 110

villa suburbana see area $M$

Vindonissa

glass funnel 371

glass skyphos 358

Walachia 33,43

water supply, Roman 14

window glass $22,24,299-300,303,304$, 305-10 passim

wine $50 \mathrm{n} .26,114$ (table 8.1 ) workshops, area D late Roman 11, 19

early Byzantine $11,23,24,29$

Xanten, glass vessel 360

Yambol (Bulgaria), glass vessel 362

Yantra, river $8,31,33,34,35,38,46$

York, glass vessel 366

Zülpich-Enzen, skyphoi 35 